\title{
Collaboration and the Use of
}

\section{Online Collaborative Toolsets in the}

\section{Project Management Environment}

A thesis submitted in fulfilment of the requirements for the degree of Doctor of Philosophy

\section{James J. Harley \\ B.A., G. Dip. (App. Sc. Museum Studies), M.App.Sc. (Museum Studies), M.App.Sc (Project Management)}

School of Property, Construction and Project Management College of Design and Social Context

RMIT University

February 2009 


\section{DECLARATION}

I certify that except where due acknowledgement has been made, the work is that of the author alone; the work has not been submitted previously, in whole or in part, to qualify for any other academic award; the content of the thesis is the result of work which has been carried out since the official commencement date of the approved research program; any editorial work, paid or unpaid, carried out by a third party is acknowledged; and, ethics procedures and guidelines have been followed.

James J. Harley

25 February 2009 


\section{ACKNOWLEDGEMENTS}

The following people and organisations deserve my thanks and appreciation for their assistance in this research.

- To Nick Blismas, my senior supervisor, for our long discussions about everything, as well as the research. His assistance with the thesis layout and development of the drafts is much appreciated;

- To Ron Wakefield, Head of School and co-supervisor, for continual support for the project and assistance with the final drafts and weekend readings;

- To RMIT for its assistance with the project and in supporting me through the Australian Postgraduate Award;

- To the staff of the Case organisations who were so generous with their time and forthcoming with their views. Without them, this research could not have occurred. They continually demonstrated support for the project and passion for project management;

- To my family - Louise my partner, without whom, little in life makes any sense. She provided overwhelming support to me, especially in the proofing of the final document. To my son Hector, for being forever understanding; to my daughter Harriet, for the gifts of artwork that I would find on my work table; and to everyone at the Bluehouse - thank you for your generous hospitality amid the many other activities happening in our lives. 


\section{TABLE OF CONTENTS}

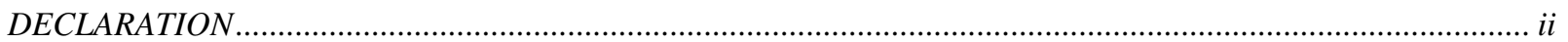

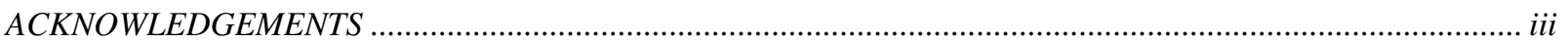

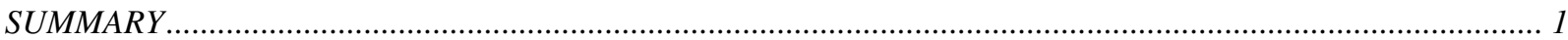

SECTION ONE

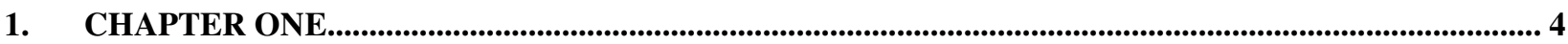

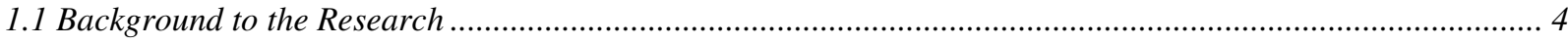

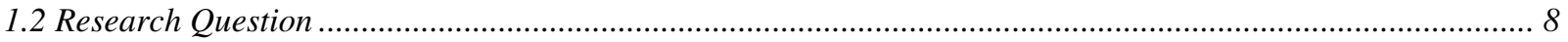

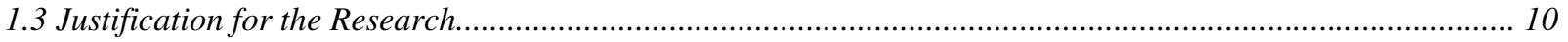

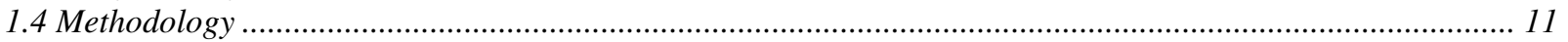

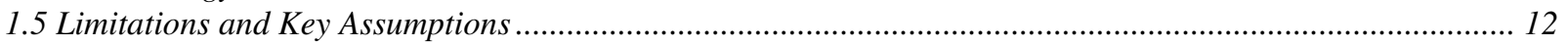

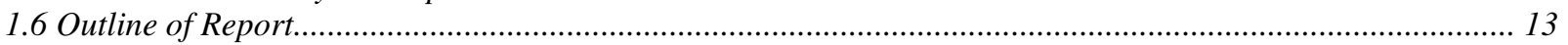

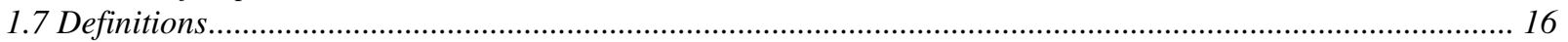

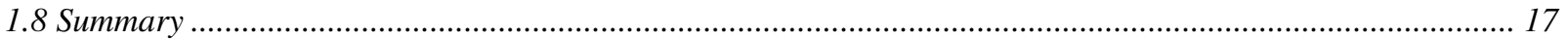

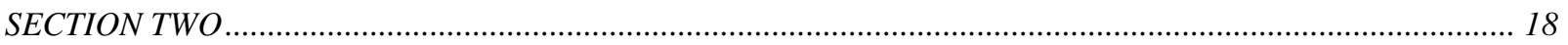

2. CHAPTER TWO - Online Collaborative Toolsets ............................................................................ 18

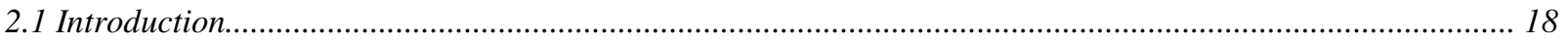

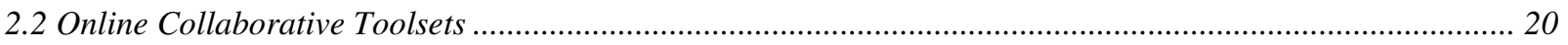

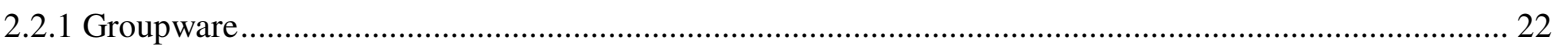

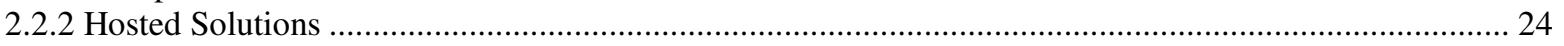

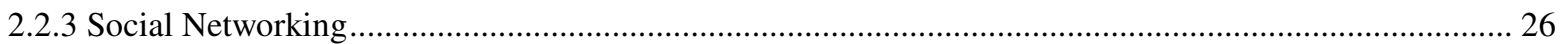

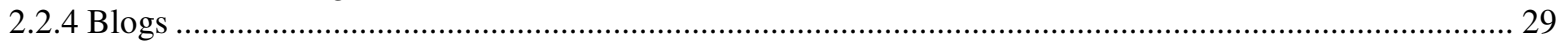

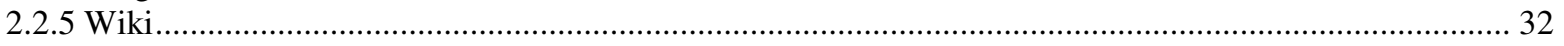

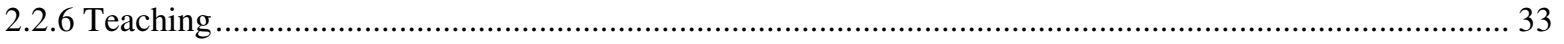

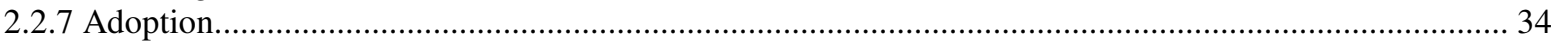

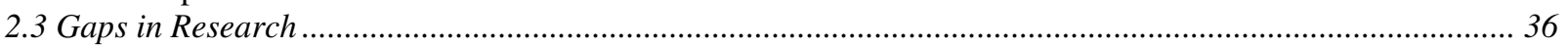

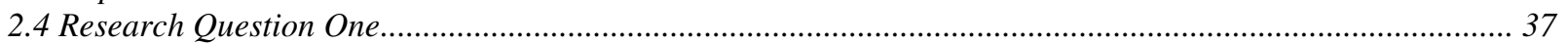

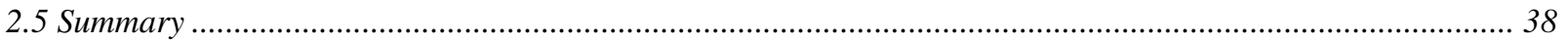

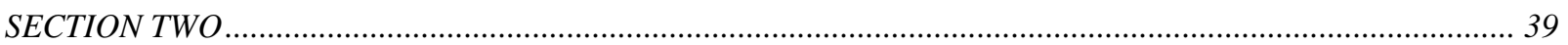

3. CHAPTER THREE - Project Management Environment ........................................................................... 39

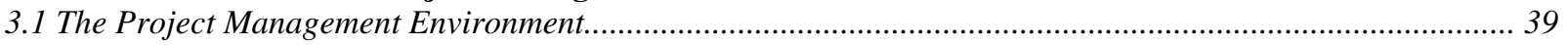

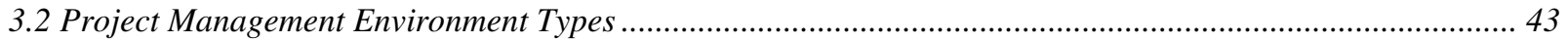

3.3 Project Management Environment Organisation Structure ................................................................... 49

3.4 Online Collaborative Toolsets and Project Websites................................................................................. 52

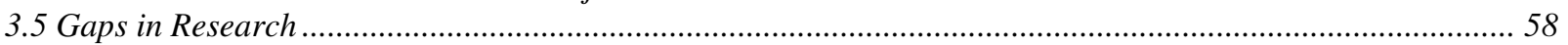

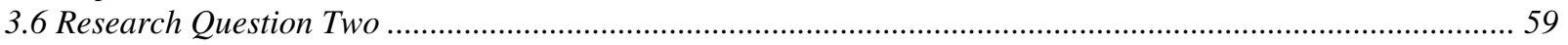

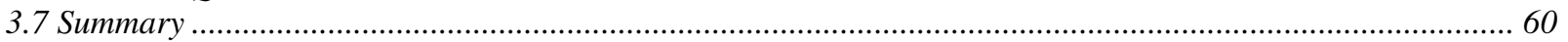

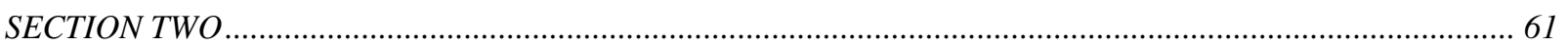

4. CHAPTER FOUR - Collaboration ..................................................................................................61

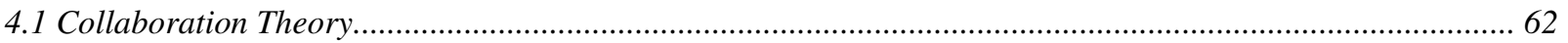

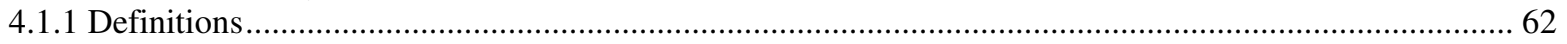

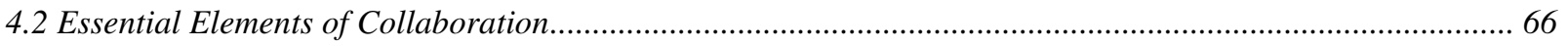

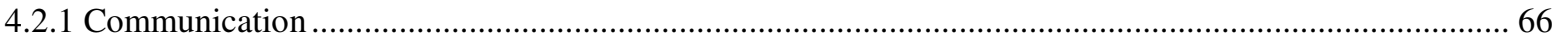

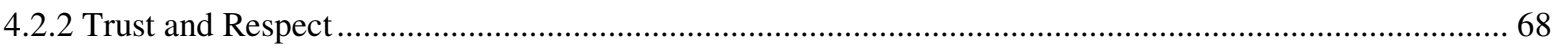

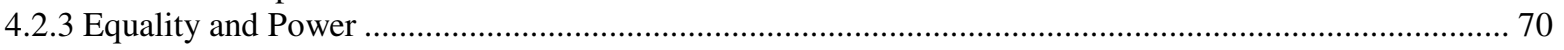

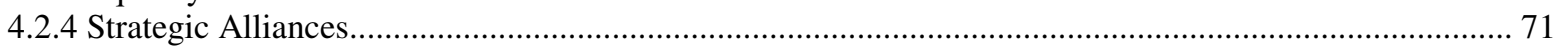

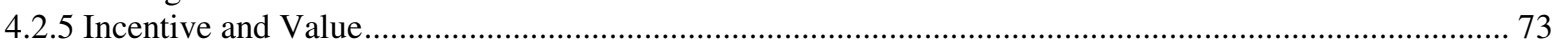

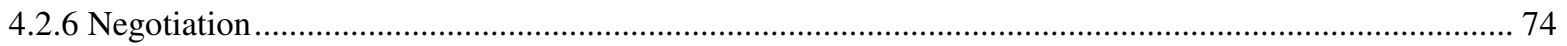

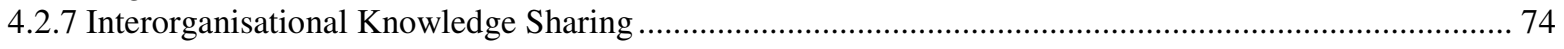

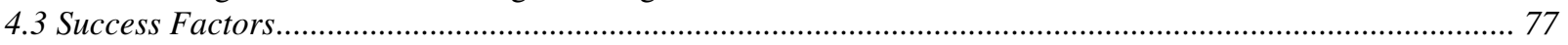

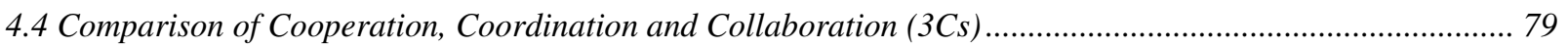

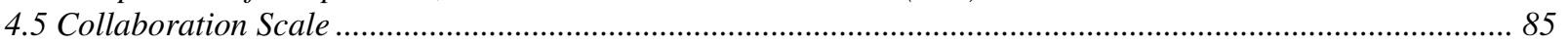

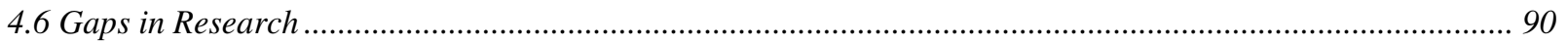

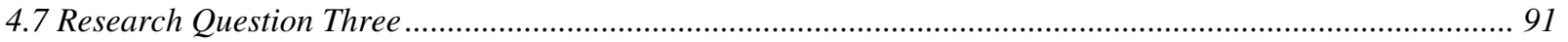

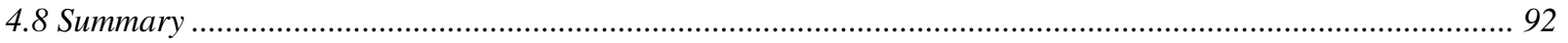




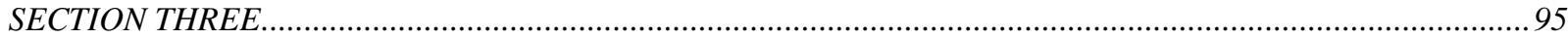

5. CHAPTER FIVE - Methodology ................................................................................................................95

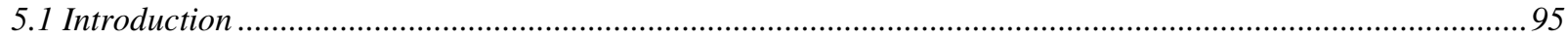

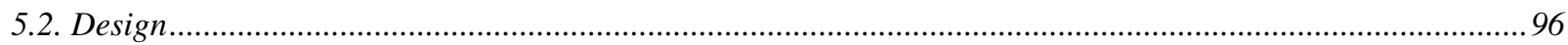

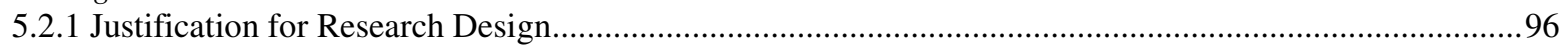

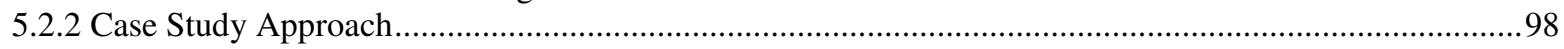

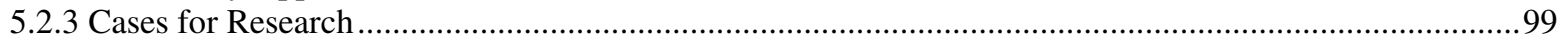

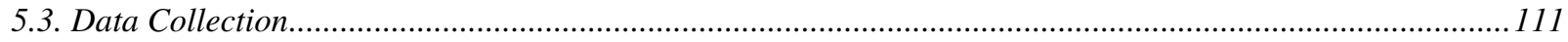

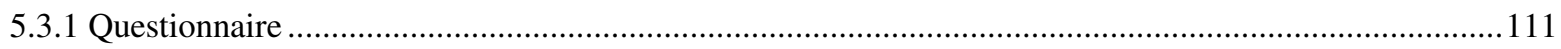

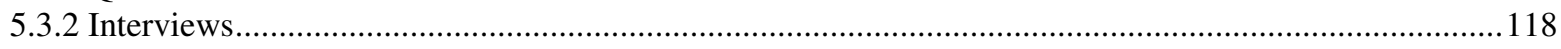

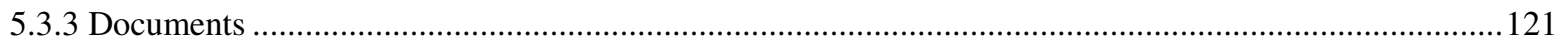

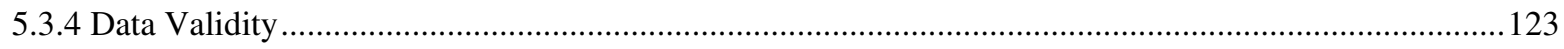

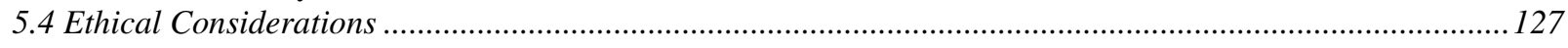

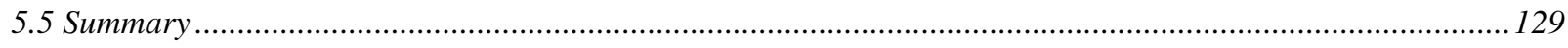

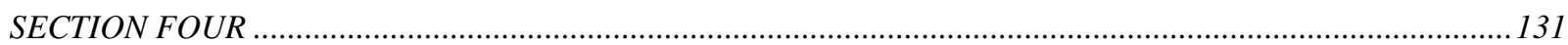

6. CHAPTER SIX - Characteristics of Online Collaborative Toolsets............................................................131

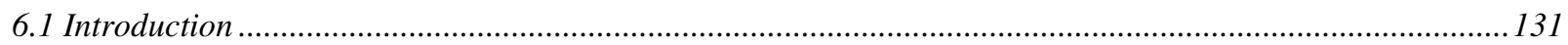

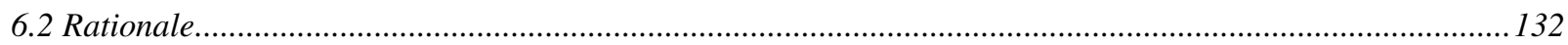

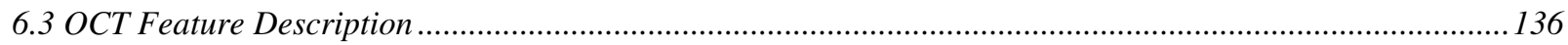

6.3.1 Central File Repository (document management) .................................................................136

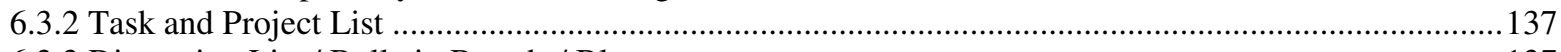

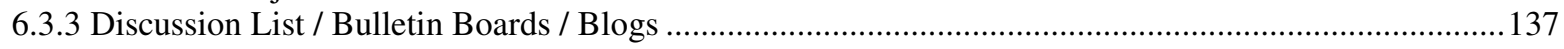

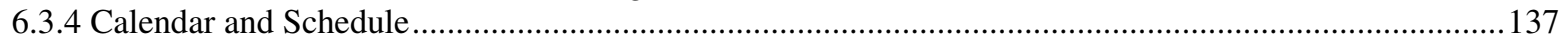

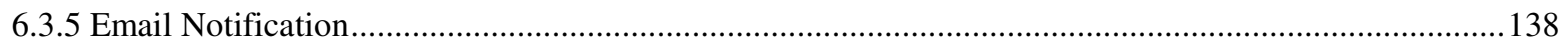

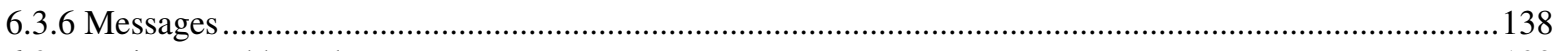

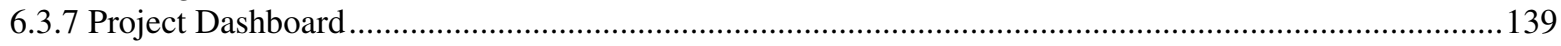

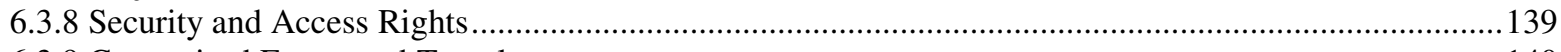

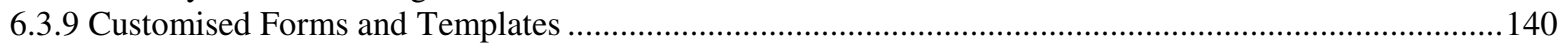

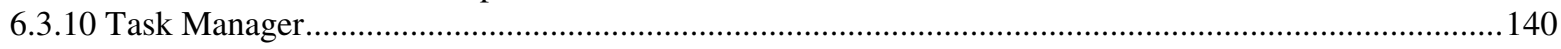

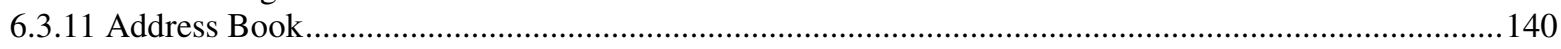

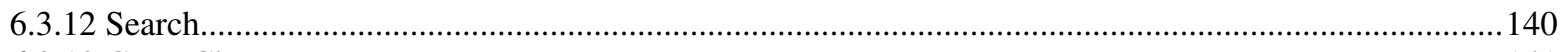

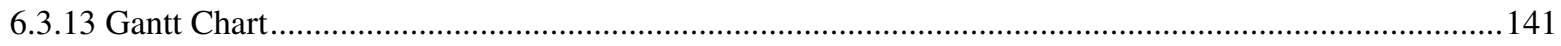

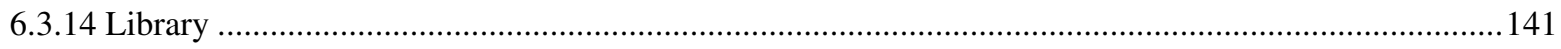

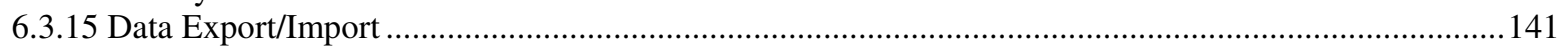

6.3.16 Collaboration Space / Central Ideas Area / Wiki ........................................................................ 142

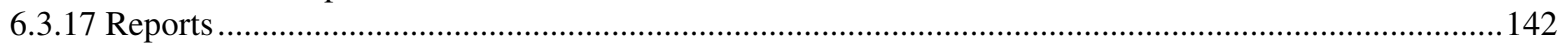

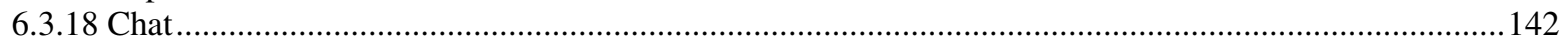

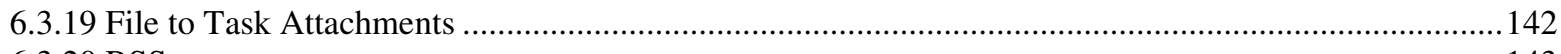

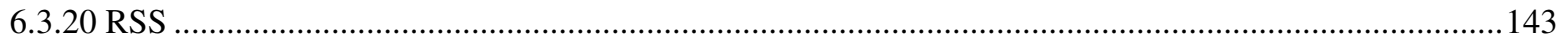

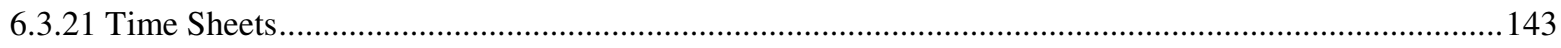

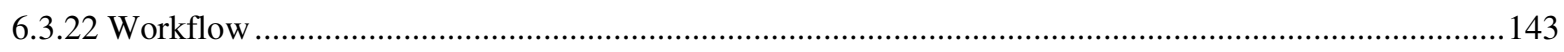

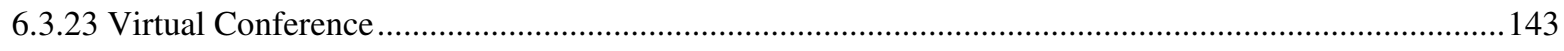

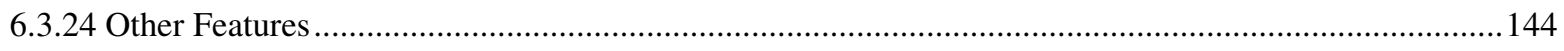

6.4 Analysis of Case Online Collaborative Toolsets............................................................................ 145

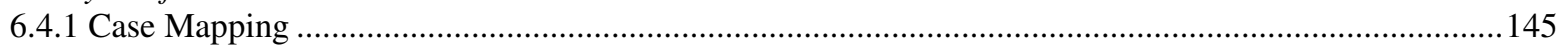

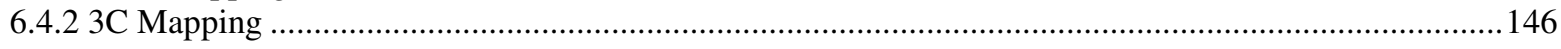

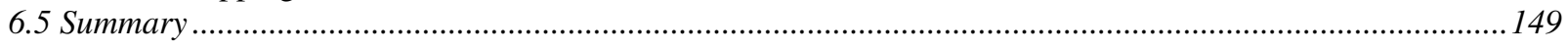


7. CHAPTER SEVEN - How are Online Collaborative Toolsets used in the Project Management

Environment?

152

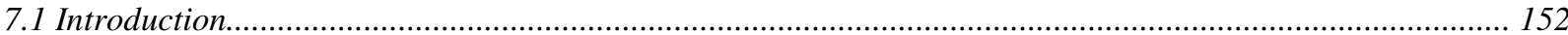

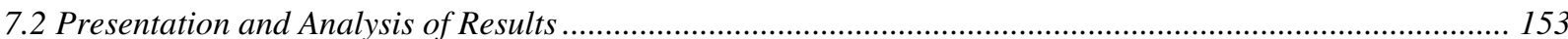

7.2.1 PART ONE, Section One: Shared Calendar .............................................................................. 155

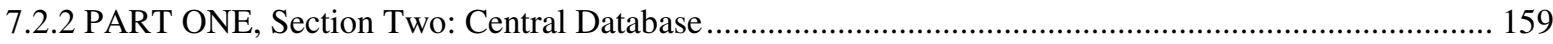

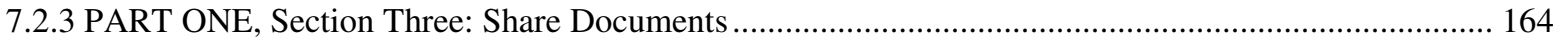

7.2.4 PART ONE, Section Four: Store Documents ............................................................................... 169

7.2.5 PART ONE, Section Five: Announcement Board ….................................................................. 175

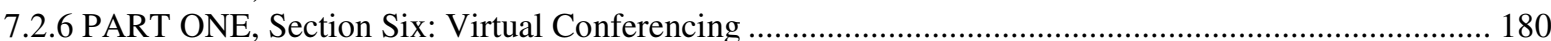

7.2.7 PART ONE, Section Seven: The OCT in General ....................................................................... 184

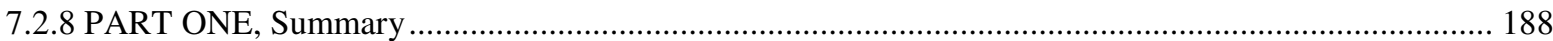

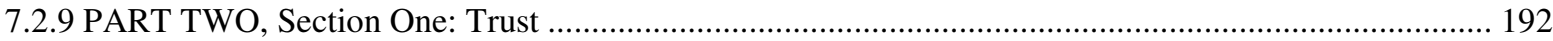

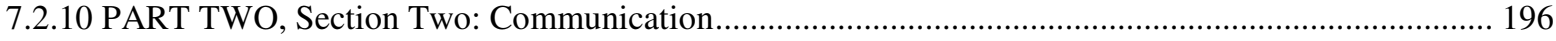

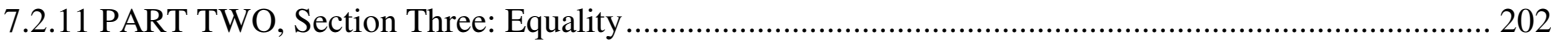

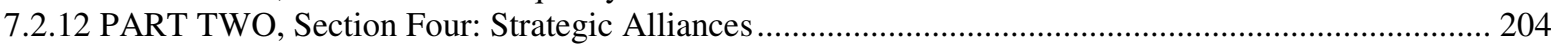

7.2.13 PART TWO, Section Five: (Project) Knowledge Distribution .......................................................... 207

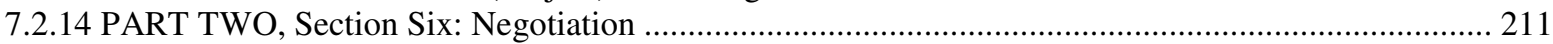

7.2.15 PART TWO, Section Seven: Incentives ................................................................................... 213

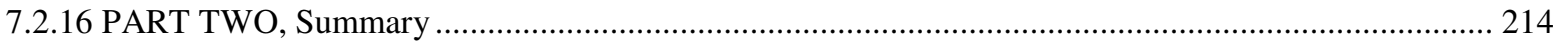

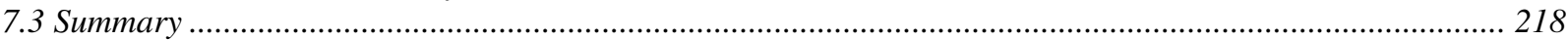

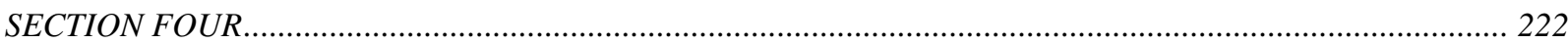

8. CHAPTER EIGHT - What is the Level of Collaboration when using Online Collaborative Toolsets in

the Project Management Environment? ..............................................................................................222

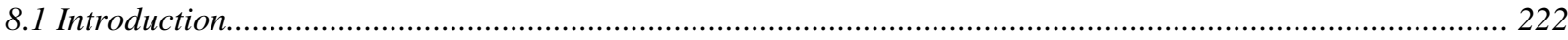

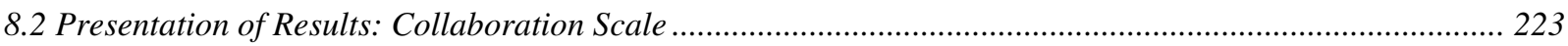

8.2.1 Organisation D (State Government Organisation) ....................................................................... 224

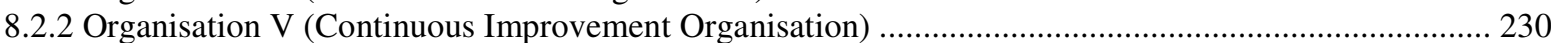

8.2.3 Organisation M (Government Construction Organisation) ............................................................... 236

8.2.4 Organisation C (Commercial Construction Project) ...................................................................... 242

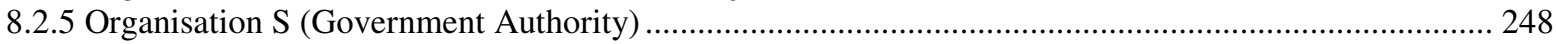

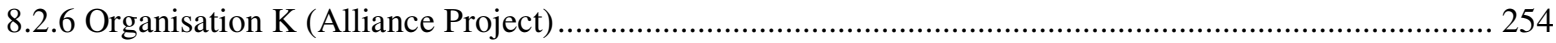

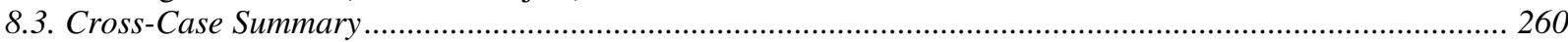

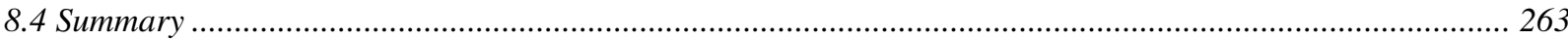

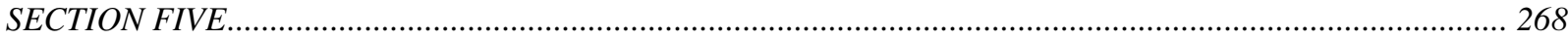

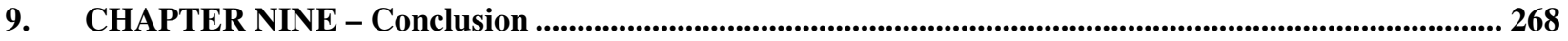

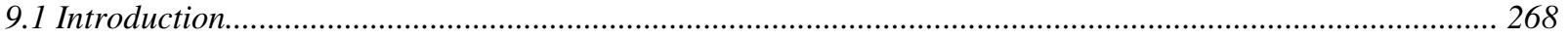

9.2 Conclusions about the Research Question and Propositions.............................................................. 268

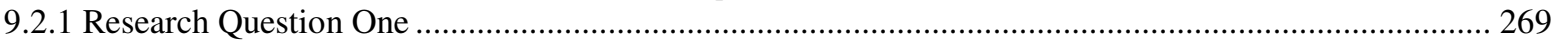

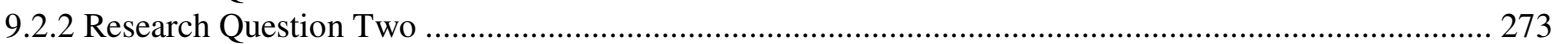

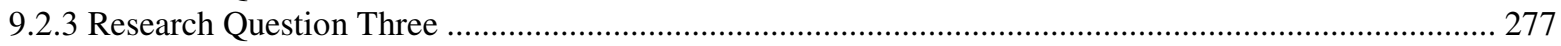

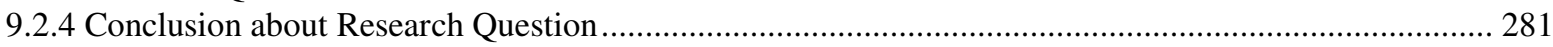

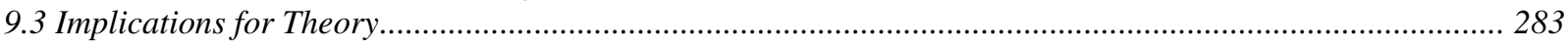

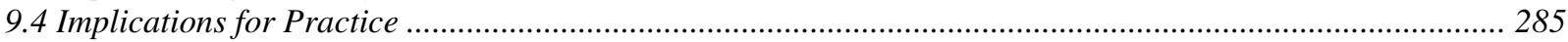

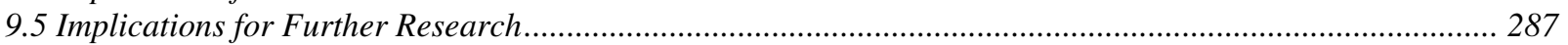

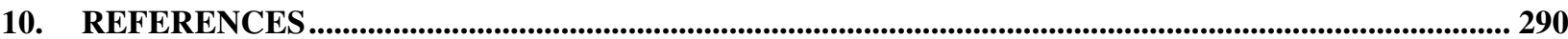


11. APPENDICES

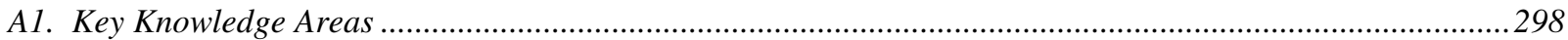

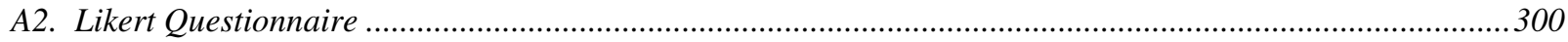

A3. Part One Statements set against the PME Knowledge Areas and Collaboration Characteristics..................304

A4. Likert Statements set against Collaboration scale and Collaboration Characteristics ..................................307

A5. Likert questionnaire coded for the Collaboration scale .......................................................................... 312

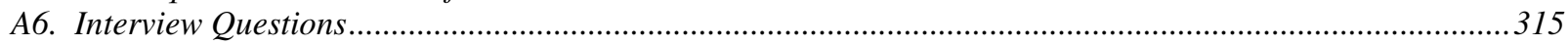

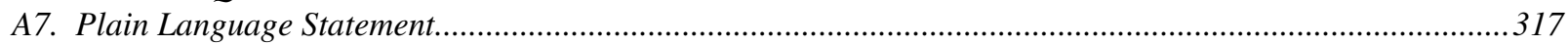

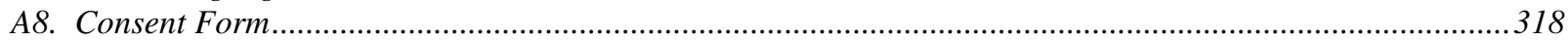

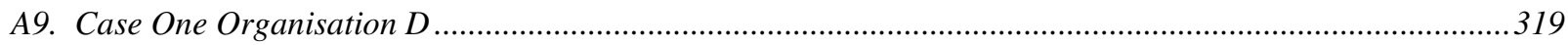

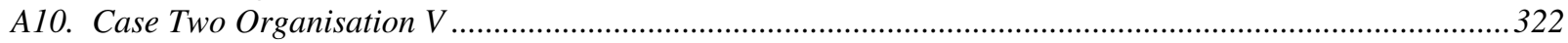

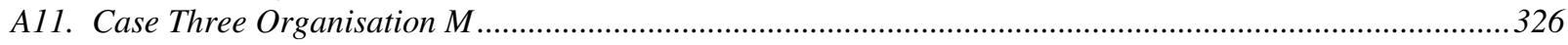

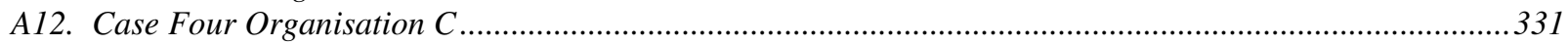

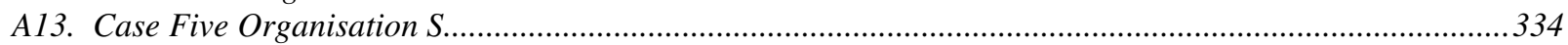

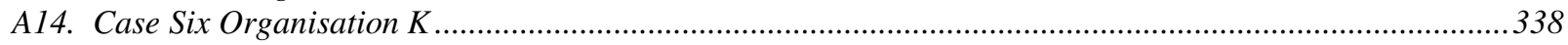

A15. Cross-case summary of total aggregate sorted against Collaboration scale .............................................345

A16. Organisation D comparative overview of the Prince2 and Departmental Project Management Methodology

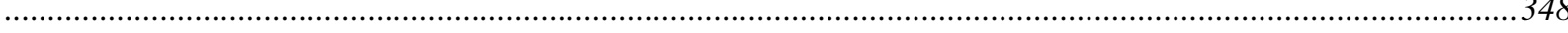

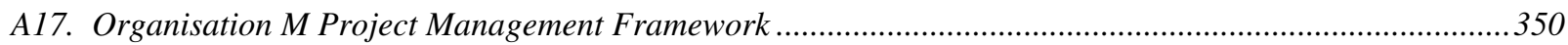

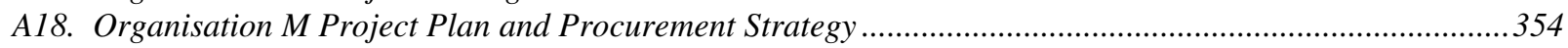

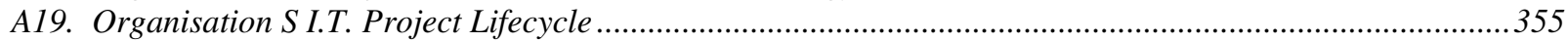

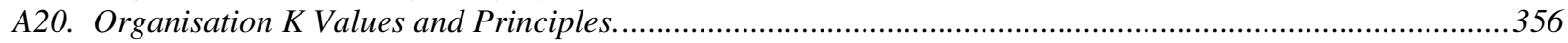

\section{LIST OF TABLES}

Table 2-1: Features of Asynchronous and Synchronous groupware___ 24

Table 2-2: Networked Tools Features___ 27

Table 2-3: Comparison of Web 1.0 and 2.0_ 28

Table 3-1: Basic Project Management Lifecycle__ 42

Table 3-2: Metrics Knowledge Areas __ 43

Table 3-3: Project Types__ 45

Table 3-4: Typology of projects__ 46

Table 3-5: Matrix description _ 51

Table 3-6: Issues affecting implementation of the project website ___ 56

Table 4-1: Sample of literature dealing with collaboration __ 65

Table 4-2: Management Success Factors __ 79

Table 4-3: Vision and Relationships___ 80

Table 4-4: Structure, Responsibilities and Communication __ 80

Table 4-5: Authority and Accountability___ 80

Table 4-6: Resources and Rewards___ 80

Table 4-7: Cooperation and Coordination criteria___ 82

Table 4-8: Summary of Cooperation, Coordination and Collaboration (3Cs). ___ 86

Table 4-9: Elements linked to Collaboration scale___ 87

Table 4-10: Collaboration Scale___ 88

Table 4-11: Research Questions and Propositions___ 92

Table 5-1: Research design types __ 97

Table 5-2: Case study matrix ___ 101

Table 5-3: Case One Organisation D Details__ 103

Table 5-4: Case Two Organisation V Details__ 104

Table 5-5: Case Three Organisation M Details__ 105

Table 5-6: Case Four Organisation C Details __ 106

Table 5-7: Case Five Organisation S Details__ 108

Table 5-8: Case Six Organisation K Details__ 109

Table 5-9: Case study details comparatively summarised ___ 110

Table 5-10: Part One Questionnaire Section Headings ___ 113

Table 5-11: Part Two Questionnaire Section Headings _ 114

Table 5-12: Excerpt from comparative case analysis - The use of OCTs in general ___ 115

Table 5-13: Likert coding for consistency ___ 115 
Table 5-14: Collaboration characteristics

Table 5-15: Likert section ID

Table 5-16: Key to percent response for Likert statement ___ 117

Table 5-17: Likert questionnaire coded for collaboration ___ 117

Table 5-18: Excerpt of sorted Likert against collaboration scale - Aggregate sample ___ 118

Table 5-19: Interview areas ___ 121

Table 5-20: Project documentation __ 121

Table 5-21: Data treatment___ 122

Table 5-22: Validity Matrix __ 125

Table 5-23: Type of triangulation___ 126

Table 5-24: General theories of ethics___ 127

Table 6-1: OCT Vendor List___ 134

Table 6-2: OCT features________ 135

Table 6-3: Feature list of OCTS against Cases and 3Cs__ 148

Table 7-1: Case study details comparatively summarised___ 154

Table 7-2: The use of a SHARED CALENDAR in the OCT__ 155

Table 7-3: The use of a CENTRAL DATABASE in the OCT _ 159

Table 7-4: The capacity to SHARE DOCUMENTS in the OCT__ 164

Table 7-5: The capacity to STORE DOCUMENTS in the OCT 169

Table 7-6: The use of an ANNOUNCEMENT BOARD in the OCT _ 175

Table 7-7: Organisation M email load___ 179

Table 7-8: The use of VIRTUAL CONFERENCING in the OCT _ 180

Table 7-9: The use of OCTs in general___ 184

Table 7-10: Cross-case summary against Collaboration scale ___ 191

Table 7-11: Trust ___ 192

Table 7-12: Communication____ 196

Table 7-13: Equality___ 202

Table 7-14: Strategic Alliances __ 204

Table 7-15: Knowledge Distribution ___ 207

Table 7-16: Negotiation ___ 211

Table 7-17: Incentives__ 213

Table 7-18: Cross-case summary against Collaboration scale ___ 217

Table 8-1: Organisation D sorted against Collaboration scale___ 225

Table 8-2: Organisation V sorted against Collaboration scale ___ 231

Table 8-3: Organisation M sorted against Collaboration scale___ 237

Table 8-4: Organisation C sorted against Collaboration scale ___ 243

Table 8-5: Organisation S sorted against Collaboration scale __ 249

Table 8-6: Organisation K sorted against Collaboration scale _ 255

Table 8-7: Summary of Mean Case values against Collaboration scale ___ 261

Table 9-1: Research questions and propositions ___ 268

Table 9-2: Case study details comparatively summarised (represented from Table 5-9) __ 269

Table 9-3: Feature list of OCTs rated against Cases and 3Cs (represented from Table 6-3) __ 271

Table 9-4: Re-presented from Chapter 7, Tables 7-10 and 7-18__ 276

Table 9-5: Collaboration scale re-presented from Chapter Four, Table 4-9___ 279

Table 9-6: Summary of mean case values against Collaboration scale ___ 279

Table 11-1: Key Knowledge Area___ 298

Table 11-2: Likert Questionnaire ___ 300

Table 11-3: Part One Statements set against PME Knowledge Areas and Collaboration Characteristics ___ 304

Table 11-5: Likert questionnaire coded for the Collaboration scale ___ 312

Table 11-6: Interview Questions____ 315

Table 11-7: Organisation K project partner table____ 338

Table 11-8: P3 eResource Knowledge Areas ___ 344

Table 11-9: Cross-case summary of total aggregate sorted against Collaboration scale___ 345

Table 11-10: Organisation D comparative overview of the Prince2 and Departmental Project Management

Methodology 348 


\section{LIST OF FIGURES}

Figure 1-1: Chapter Guide to Thesis with reference to Perry (1998)___ 14

Figure 2-1: Groupware matrix ___ 23

Figure 3-1: Basic Four Stage Lifecycle ___ 41

Figure 3-2: Composite organisation__ 50

Figure 4-1: Juxtaposition of outcomes ___ 83

Figure 4-2: Juxtaposition of outcomes as described by Rogers and Whetten (1982)__ 89

Figure 4-3: Expanded explanation of juxtaposition of outcomes with reference to Rogers and Whetten (1982) __ 89

Figure 5-1: Age of Respondents across cases $(n=42)$

Figure 5-2: Sex of Respondents across cases $(n=42)$

Figure 7-1: Pt.1. Qu.8: The use of Shared Calendars in the OCT supports equality amongst team members__ 157

Figure 7-2: Organisation V home page __ 158

Figure 7-3: Pt.1 Qu.15: The use of a CENTRAL DATABASE in the OCT centralises reporting of data___

Figure 7-4: INCITE screen shot - correspondence functionality ___ 162

Figure 7-5: INCITE project records and sub-files___ 162

Figure 7-6: Pt.1 Qu.18: The use of a CENTRAL DATABASE in the OCT requires a level of trust between team

members

Figure 7-7: Organisation S Library Dashboard. ___ 166

Figure 7-8: Pt.1 Qu.22: The capacity to SHARE DOCUMENTS in the OCT requires a level of trust between team members

Figure 7-9: Pt.1 Qu.28: The capacity to SHARE DOCUMENTS in the OCT adds time and cost to managing the shared documents

Figure 7-10: Display of AutoCAD files inside AutoDesk Buzzsaw 169

Figure 7-11: Pt1. Qu.33: The capacity to Store Documents in the OCT increases ease of retrieving documents _ 172

Figure 7-12: ACONEX Document Register function ___ 172

Figure 7-13: INCITE screen shot - technical records library ___ 174

Figure 7-14: Pt.1 Qu.44: The use of an Announcement Board in the OCT manages the use of email more efficiently

Figure 7-15: Display of email notification within AutoDesk Buzzsaw

Figure 7-16: Pt1. Qu.57: The use of VIRTUAL CONFERENCING in the OCT enables more effective control over schedule and project issues

Figure 7-17: Pt1. Qu.61: The use of VIRTUAL CONFERENCING in the OCT replaces the need to meet physically

Figure 7-18: Pt.1 Qu.64: The use of OCTs in general ensures all documents are easily found

Figure 7-19: Organisation S QuickPlace Taskbar ___ 187

Figure 7-20: Pt.1 Qu.66: The use of OCTs in general ensures all project related information is kept up to date and in one place ___ 187

Figure 7-21: Pt.2 Qu.3: The project team requires a level of trust in order to successfully operate ___ 194

Figure 7-22: Pt2 Qu.5: Negotiations depend on the presence of trust____ 194

Figure 7-23: INCITE screen shot - creating new INCITE Note document___ 198

Figure 7-24: INCITE Technical Library screen shot.____ 199

Figure 7-25: Pt.2 Qu.19: Team members communicate more effectively when using OCT__ 200

Figure 7-26: ACONEX Mail reporting/searching___ 201

Figure 7-27: Pt.2 Qu.25: Knowledge distribution is not important for team members___ 203

Figure 7-28: Pt.2 Qu.30: Knowledge sharing is a critical component of managing alliances___ 205

Figure 7-29: Pt.2 Qu.34: OCT delivers the incentives needed to manage strategic alliances___ 206

Figure 7-30: Pt.2 Qu.35: The distribution of knowledge regarding the project is important to team members_209

Figure 7-31: Pt.2 Qu.42: Knowledge distribution should be managed by the project manager___ 210

Figure 7-32: Pt.2 Qu.47: Negotiations between stakeholders is aided when parties trust each other___ 212

Figure 8-1: OrgD responses to Likert expressed as mean values, sorted against Collaboration scale___ 229

Figure 8-2: OrgV responses to Likert expressed as mean values, sorted against Collaboration scale ___ 235

Figure 8-3: OrgM responses to Likert expressed as mean values, sorted against Collaboration scale___ 241

Figure 8-4: OrgC responses to Likert expressed as mean values, sorted against Collaboration scale ___ 247

Figure 8-5: OrgS responses to Likert expressed as mean values, sorted against Collaboration scale____ 253

Figure 8-6: OrgK responses to Likert expressed as mean values, sorted against Collaboration scale____ 259

Figure 8-7: All organisations responses to Likert expressed as mean values, sorted against Collaboration scale (inc.

Aggregate) 
Figure 9-1: All Organisations expressed as mean values, sorted against Collaboration scale 280

Figure 11-1: Organisation D governance structure

Figure 11-2: Organisation structure

Figure 11-3: Organisation M internal project governance structure

Figure 11-4: Organisation M project governance structure 329

Figure 11-5: Organisation C governance structure

Figure 11-6: Organisation C Project management structure 332

Figure 11-7: Organisation S management structure 335

Figure 11-8: Organisation S project Reference group structure

Figure 11-9: Alliance Leadership Team 339

Figure 11-10: Organisation K management structure 341

Figure 11-11: P3 eResource knowledge areas - interface 344

Figure 11-12: Organisation S I.T. Project Lifecycle 355 


\section{SUMMARY}

This research aims to develop an understanding of the extent to which collaboration occurs through the use of online technologies in the project management environment. Given the breadth of the technological landscape, this research will focus on the use of online collaborative toolsets (or groupware) - internet applications that enable individuals and groups to work together, regardless of where they are or when they choose to work.

The contemporary project management environment requires the delivery of a set of outcomes that often involves the coordination and management of multiple teams, across multiple sites, and in some instances across countries. Increasingly, projects are being managed through internet networks to increase efficiencies and facilitate communication and information distribution. Due to the capabilities of online collaborative toolsets project-related material is available to all project personnel, customized to their role and function in the organisation. According to vendors, these toolsets enable project managers to improve their service delivery mechanisms and develop new operational methods including collaborative practices and strategies.

This research seeks to examine the benefits of using of online collaboration toolsets (OCTs) within the project management environment (PME). To that end, the Research Question can be expressed as:

Does collaboration occur through the use of online collaborative toolsets in the project management environment?

Flowing from the major research question, are the following subsidiary research questions and their associated propositions:

Question One: $\quad$ What are the features of Online Collaborative Toolsets?

Proposition One: Online Collaborative Toolsets contain features that facilitate cooperation, coordination, and collaboration.

Question Two: How are Online Collaborative Toolsets used in the Project Management Environment? Proposition Two: Online Collaborative Toolsets in the Project Management Environment are used for cooperation and coordination, and to a lesser extent collaboration.

Question Three: $\quad$ What is the level of collaboration when using Online Collaborative Toolsets in the Project Management Environment?

Proposition Three: $\quad$ Collaboration can be modelled as a scale ranging from cooperation, through coordination, to collaboration. 
To address the Research Question this research investigates six PMEs and their use of OCTs, and uses a Collaboration scale developed specifically to measure the level of collaboration existing within each PME.

The Collaboration scale presents collaboration not as a single entity, but as a scale ranging from low to high across six elements. Central to this theory is that for collaboration to exist, all elements must rate highly against the scale. The research argues that although all collaborative elements are found within a PME, it is the level of each element that determines the degree to which collaboration is occurring.

The comparative case study approach was chosen for this research as it provides the capacity to develop in-depth analysis of multiple cases. It also caters for the use of multiple sources and methods of data to be used for analysis, including documents, interviews and questionnaires. The multiple case approach enabled the research to gain an understanding of how each case used the OCT within their project environments, whilst also identifying patterns across the cases.

The case study approach incorporated three broad strategies to collect data. The first strategy included a Likert questionnaire using the Dichotomous scale, which was administered to collect data on the operations of the individual projects. The second strategy included interviews that asked the project manager of each case specific questions regarding the PME. The third strategy involved desk research to scan for literature and web artefacts.

Responses to the questionnaire were individually tabulated, tallied and then sorted by case, allowing cases to be viewed comparatively. These findings, in conjunction with the interviews, were then analysed within case and across cases in order to identify trends and patterns. The analysis also included testing for the extent to which collaboration was occurring in the PME. 
The conclusions drawn from this research are:

1. OCTs can contain a variety of features, several of which are common amongst all. The research identified common requirements and use of the OCTs within the cases.

2. Although OCTs are capable of facilitating a high level of collaboration, Project Managers do not use OCTs for this purpose. The different project environments reviewed are not necessarily collaborative, nor do they use OCTs to assist with collaborative exercises.

3. OCTs are used predominantly for cooperation and coordinating activities within the PME.

4. Collaboration in the PMEs reviewed exists in degrees, at times being identified with cooperative functions, and at other times coordinating functions.

5. The findings demonstrate a pattern of collaboration, which is consistent across all cases. This pattern demonstrates a variation in the collaborative elements across the PME, and indicates a priority that may exist in regard to how these elements are prescribed within the actual project environment. 


\section{SECTION ONE}

\section{CHAPTER ONE}

\subsection{Background to the Research}

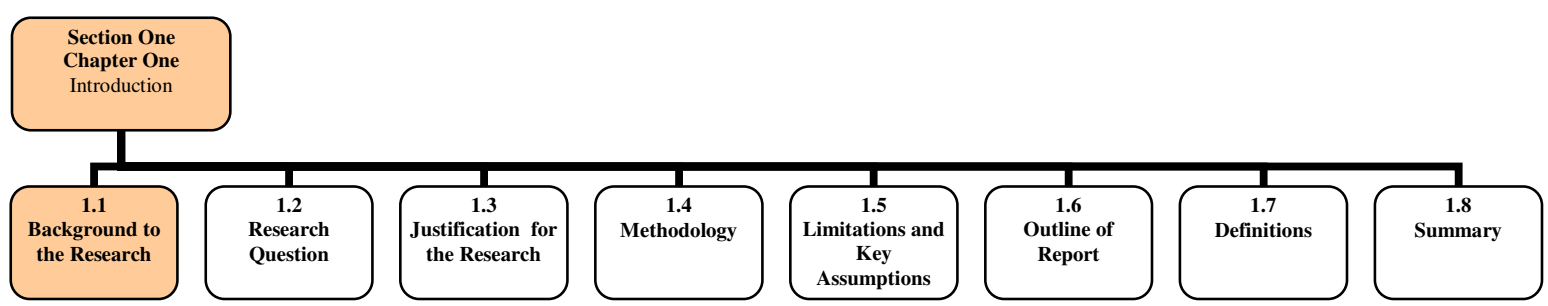

The application of online technologies is a modern phenomenon. From the time that Tim Berners-Lee created the world wide web in 1990, it is estimated there are now more than 180 million websites spread across the world (Netcraft, 2008). In recent years in Australia, the use of the internet as a vehicle for accessing information, communication and undertaking commerce has continued to increase, with news services and 'personal communication such as email, instant messaging and social networking sites increasingly becoming a feature of people's daily lives' (ABS, 2008a).

The Australian Bureau of Statistics notes the following:

- Although the proportion of businesses using a computer appears to have stabilised, the proportion of businesses (in Australia) reporting internet use continues to grow (ABS, 2008b).

- At the end of the June quarter 2008, there were 7.23 million subscribers to the internet in Australia. This comprised 1.02 million business and government subscribers and 6.21 million household subscribers (ABS, 2008c)

- Connections with download speeds of $1.5 \mathrm{Mbps}$ or greater increased to 3.10 million or $43 \%$ of all subscribers, compared to 2.47 million or $36 \%$ of subscribers at the end of December 2007 (ABS, 2008c).

- During the year ended 30 June 2007, 86\% of all (Australian) businesses reported access to the internet (or internet access) and 34\% reported having a web presence (ABS, 2008d). 
The rise of the internet has also seen a change in the way people communicate and relate to each other. Whereas distances were considered a barrier for communication in pre-internet times, now the internet provides not only the opportunity but the technological environment in which transcontinental and intercontinental communication can exist. The internet has long provided a network infrastructure for collaborative technologies that supports how people and groups communicate and relate to each other (Nectar, 2007).

The presence of an always-available communication channel, whether it be internet application, email or a more mobile device, has seen a shift in the way people now communicate with each other. With the increasing connectivity to the internet, the power of the world wide web, and the distributed nature of organisations, multiuse computer systems (groupware) are becoming more common (Gutwin and Greenberg, 2000).

It perpetuates a constant sending and retrieval of messages and visual stimulus - in rich content format, video or voice - to literally any location in the world with an internet connection. In extending the reach of these applications, communication itself has become more complex (Katzy et al., 2000).

The internet, it would seem, is everywhere.

This change in the capacity to communicate has reverberated across corporate, commercial, education and government sectors. A standard work environment in the contemporary workspace would include a computer (desktop or laptop unit), access to the internet/intranet, email application, and myriad desktop programs or applications. A dedicated (and often outsourced) I.T. service provider would manage most of these applications (Hutchins, 2003). This all occurs to ensure that the user can access the technology to participate and contribute in the fullest capacity, with minimal need for training or specialist I.T. skills.

This access can be from work or home, beamed over cable or wirelessly, onto standard or mobile devices. The most important factor being its availability to the user whenever the job requires it; it is the ubiquity that is the crucial element. 
The business imperative of web-enabled technology has flowed through to the project management environment (PME). No longer are projects conceived, controlled and undertaken in a single site. Distributed work environments are becoming more attractive in response to increasing outsourcing strategies (Qureshi et al., 2005). The contemporary PME can extend to multiple sites, several teams and in many circumstances multiple locations, all of which can benefit from a tool that assists with the operational aspects of the job.

Online collaborative toolsets (OCTs) or groupware attempts to achieve this aim. There are different types of OCTs all of which involve programs that help people work together even though they may be remotely located from each groupware (McDonald, 2003, Techtarget, 2007, Forakerdesign, 2007, Gutwin and Greenberg, 2000). The OCT can be as simple as providing an online space for community engagement, through to delivering sophisticated and innovative workflow and I.T. solutions for larger companies. Either way, it will ideally operate with little need for technical interaction by the user (Mack et al., 2001).

With the allure of always-on internet-enabled desktops, OCTs offer multiple users access to common information. This proves attractive to organisations that have team based activity, as OCTs offer a central online teamspace, where shared and common information can be stored and accessed at any time required. Groupware offers additional functionality to teams, providing an electronic solution to many processes and facilitating team dynamics including facilitating communication, forming groups of common interests and saving time and costs in coordinating group work (Forakerdesign, 2007).

The relevance to the PME is obvious. Where traditional project management has struggled to control project documentation, processes and communication across multiple sites, the OCT has introduced a functionality and mechanism that can assist with the operation. It can encourage individual team members to take more control of their access to information, becoming an active player in the business and social interaction of project-related information and tasks.

But is it working? Are OCTs living up to the promise, and is there a change in the way projects are being managed? 
The OCT can be considered a subset of social networking software because it enables groups of people to interact with each other. Social software and social networking tools refer to web applications that enable participants to store information in various formats and share this information with selected individuals or groups. It enables teams or groups of people to coordinate their electronic files and can be applied to a wide range of web-enabled software that facilitates social contact and interaction (Christopher, 2007). The application of blogs and the variety of technological features are all part of the social software revolution.

Project management is the application of knowledge, skills, tools and techniques to project activities to meet project requirements (PMI, 2004). It is accomplished through the application and integration of the project management processes, with the project manager the person responsible for accomplishing the project objectives (PMI, 2004, Gray and Larson, 2000). Given this, there is a likely and functional relationship between the features offered through the OCT and the environment in which project managers operate.

Using OCTs assists organisations to customise an online space for their projects. OCTs are marketed and designed with collaboration in mind, utilising the electronic networks for real-time (synchronous) collaboration and for team-based (asynchronous) activities including threaded discussions and document-based collaboration. They can improve business processes whilst at the same time creating collaborative links between companies (Kontzer, 2002).

The term 'collaboration' appears to be central to the manner in which OCTs are presented to the market. There are promises of increased efficiency in the project (Teamspace, 2004), improvement in the organisation's productivity (Aceproject, 2006), secure online file sharing with other team members regardless of their location (Ike, 2006), sharing, planning and coordinating work (Projectplace, 2006), and collaborating with team members (Webex, 2006). And yet a review of the term collaboration highlights many variations to the definition and application of the term, with some seeing it as being simply equal to participation (Romano et al., 2002) while others consider it to exist when two or more people transfer information online (Breite and Vanharanta, 2003).

This leads to complications when attempting to identify if collaboration exists in the use of OCTs. There are also ambiguities in the practical usage of the term, and it is not uncommon to 
see the term collaboration being used interchangeably with the terms cooperation and coordination (Mattessich et al., 2001, Fitzek and Katz, 2006). Given the manner in which OCTs are described, it would seem that the vendors and developers apply a loose and varied interpretation of the term collaboration, making the task of understanding the role of collaboration in these products, more difficult. It also gives rise to the question about the use of internet-enabled products and the benefits they many bring to the project environment.

Given this background to the research, the following sections of the chapter will outline the central research problem and question to be addressed and subsequent structure of this research.

\subsection{Research Question}

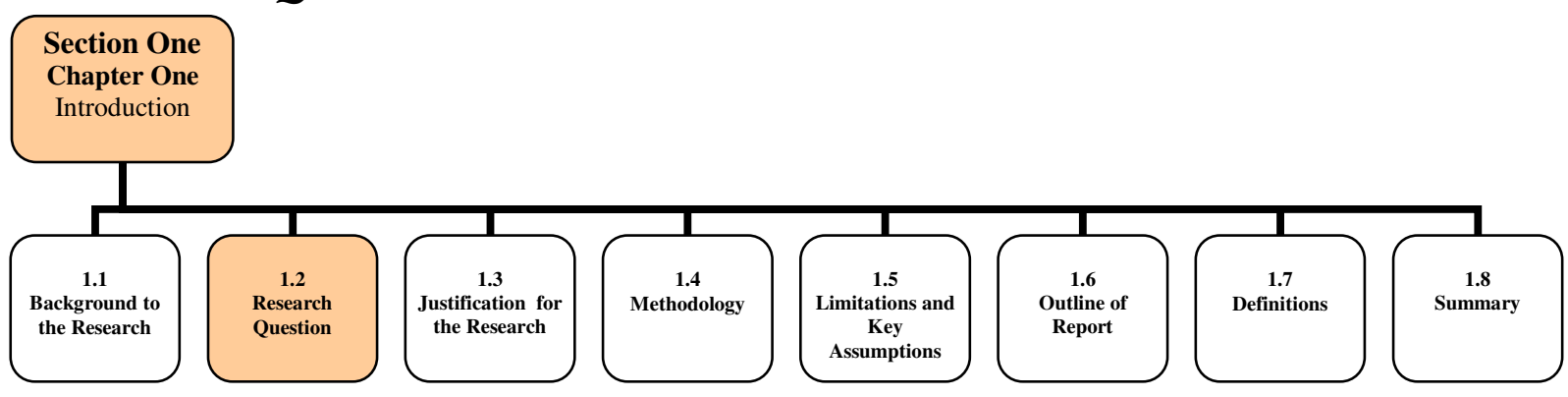

The contemporary PME is the result of complex stakeholder relationships, with the object of the project often being delivered by several teams spread across several sites and possibly involving transcontinental or international consultations. The complexity of the project does not dilute the requirement of the project manager to control and coordinate the many facets of the job, with responsibilities further compounded by the increasing governance and contractual requirements.

The PME now has the internet at its disposal. Increasingly, projects are being managed through electronic transmissions, utilising the availability of internet or intranet networks on which to manage the project-related responsibilities. These responsibilities may include the resourcing of staff and materials, scheduling and monitoring of tasks and timelines, managing communications across teams, and preparing reports and documentation. The online capacity enables projectrelated material to be available to all project personnel, customised and configurable to ensure that staff only has access to material appropriate to their position and role within the PME. 
Internet-based tools provide an opportunity for project managers to improve their service delivery mechanisms and examine different electronic methodologies and processes. Online communications enables new operational methods to be considered, including embracing collaborative strategies and practices.

This research seeks to address these issues by investigating the use of online collaborative toolsets within the project management environment. To this end, the Research Question can be expressed as:

Does collaboration occur through the use of online collaborative toolsets in the project management environment?

From the major research question, the following subsidiary research questions were developed:

Question One: $\quad$ What are the features of online collaborative toolsets?

Question Two: $\quad$ How are online collaborative toolsets used in the project management environment

Question Three: What is the level of collaboration when using online collaborative toolsets in the project management environment? 


\subsection{Justification for the Research}

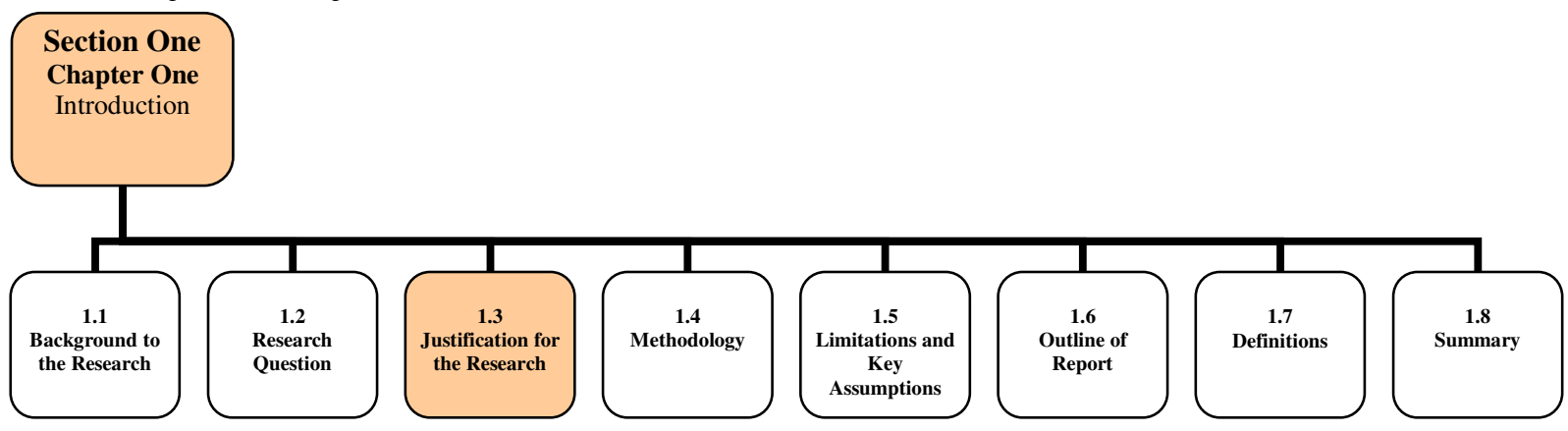

The OCT has the capacity to provide many opportunities for business including improved business processes, aggregating the company's content, delivering increased application functionality whilst at the same time creating collaborative links between companies, their partners and customers (Kontzer, 2002). This technology is suitable for the project management environment application as companies search for more ways to manage the complexities of projects within an increasingly dispersed workforce.

This research seeks to understand this technology in the context of project management, where project managers are expected to coordinate resources in order to complete the project, often to what is referred to as the triple constraint of project scope, time and cost (Gray and Larson, 2000, PMI, 2004). This research will also review the notion of collaboration, given that this term features prominently in the description and application of these tools, with the vendors targeting the use of these tools for the PME.

The breadth of the OCT market highlights the choice available to business, with the PME being but a sub-set. A review of the OCTs available over a two-year period identified more than 30 products that claim to assist with managing projects and providing the necessary technological environment to enhance collaboration. However there is scant academic treatment or quantifiable analysis that reviews these tools to assess if these claims are true, and if their deployment within the project environment provides direct benefit to the customer or client, or to activities associated with project management.

To address this situation, this research will apply a comparative case study approach, seeking to review individual project environments and their use of the OCT. This approach will include detailing the individual organisation's project environment, reviewing the specific OCT and 
undertaking an analysis of collaboration as it may exist within the project. This approach was chosen over other approaches for its ability to compare and contrast the different project environments, and to be able to seek clarification of common attributes and conditions. It also enables several data gathering mechanisms to be undertaken. This approach enables the research to identify patterns of usage and possible trends in the way that the tool is used across the PME.

Given the above, this research is in a position to contribute specific information on the benefits and consequences of the use of OCTs in projects. This knowledge may assist organisations in their decisions regarding deploying an OCT for a project, or in understanding the circumstances in which an OCT may benefit their environment. This is particularly important in those circumstances where it is essential that project members interact with each other over activities such as negotiation of goals, working procedures, task allocation, scheduling, resource allocation and co-working on documents (Romano et al., 2002, Sclater et al., 2001). It will also assist in providing guidance on the role that collaboration will play both in the deployment of these tools, and the PME itself.

\subsection{Methodology}

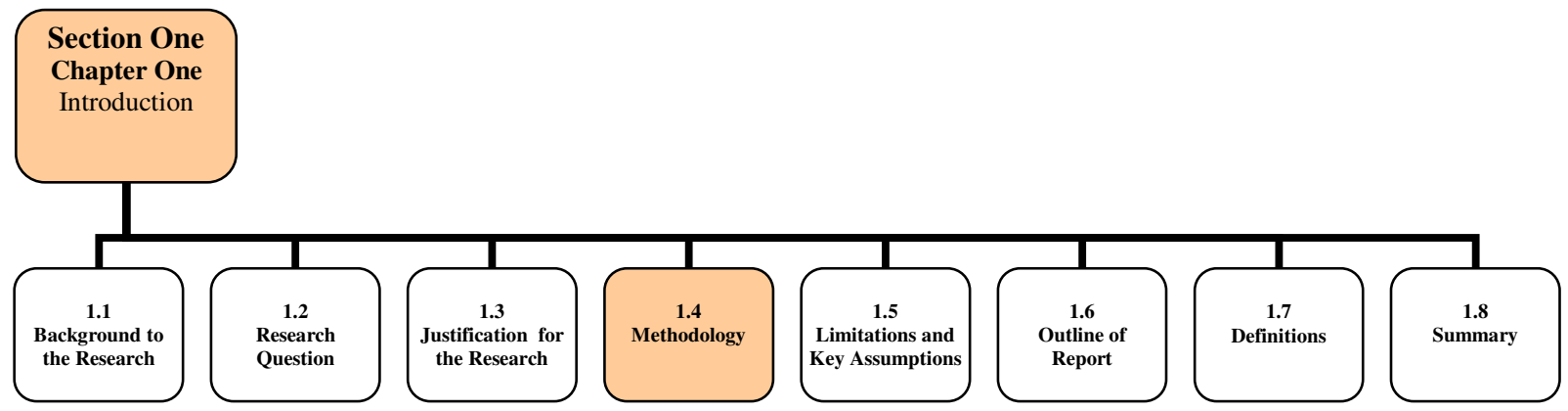

This research uses a comparative case study design as it allows a focus on multiple cases. This approach assists in gaining a greater understanding of the dynamics present within the individual case settings (Eisenhardt, 1989, Creswell, 1998). It uses the combination of a questionnaire, semi structured interviews and desk research, with the findings tested for reliability through methodological triangulation. A Likert questionnaire using the Dichotomous scale is administered to collect data on the operations of the individual projects, whilst the interview addresses specific questions regarding the PME to the project manager of each case. The desk research is used to scan for literature and web artefacts. Responses to each question of the questionnaire are individually tabulated, tallied and then sorted by case, allowing cases to be 
viewed comparatively. These findings, in conjunction with the interviews, are then analysed within case and across cases in order to identify trends and patterns. The analysis also includes testing for the extent to which collaboration was occurring in the PME. The methodology is fully explained and justified in Chapter Five.

\subsection{Limitations and Key Assumptions}

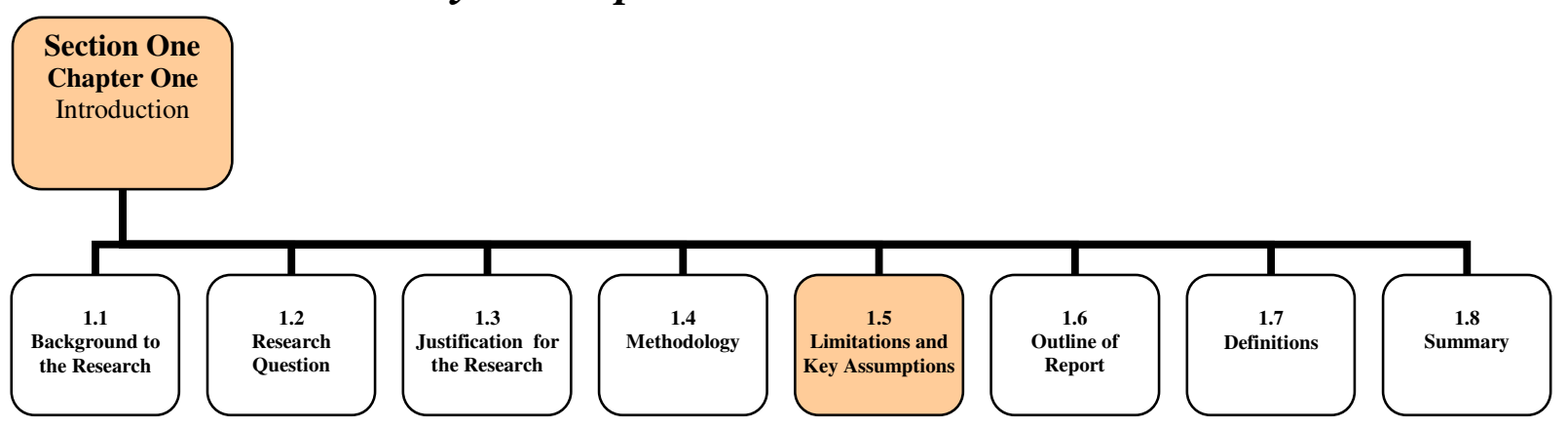

This research is based on those cases that could be identified and approached and which subsequently accepted the invitation to participate. Given this, this research and its findings are restricted to the six cases who chose to participate. As is the case with many large projects, there can be more than one project manager (or project manager role) functioning within the project. Due to the practicalities of research that requires the investigator to travel to a site, and for personnel to be made available at that time, this research is limited by the amount of resources and time that the participating organisation was able to contribute.

Both a limitation and an assumption of this research is that the cases provided assistance to the investigator in the data gathering component, including sourcing respondents for the Likert questionnaire, and in some cases, the collection of these responses. The cases were also not always proactive or supportive of the use of OCTs in the workplace, or of collaborative practices in general, and the researcher was required to manage this tension with delicacy.

This research does not provide an exhaustive overview of the OCTs currently on the market, mainly as this landscape is fluid. Changes in vendors, names of products and ownerships of applications are continually occurring. All products and their respective vendors were located and sourced over the public internet and neither price of the solution nor country of origin were considered barriers for inclusion of the product in the research. So too does this research excuse 
itself from a technical analysis of the OCTs, and the telecommunications and infrastructure setup of each organisation. To do so would treble the size of this research without adding value to the findings.

The research and findings are related to the cases reviewed, but the findings may have implications for other types of organisations or projects. This research does not conclude that the findings could directly apply to other PMEs regardless of their type, without further specific research being undertaken.

\subsection{Outline of Report}

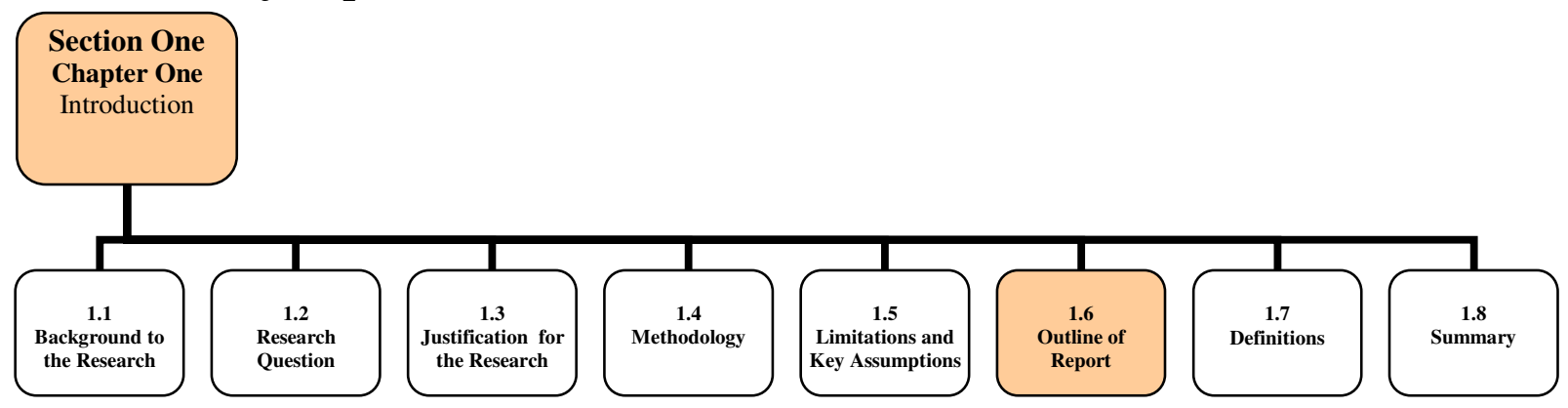

The thesis is divided into five main sections, across nine chapters, with references and appendices at the end.

Figure 1-1 provides an outline of the structure of the thesis. The thesis follows a structured approach for presenting a thesis as recommended by RMIT and outlined by Perry (1998) who proposes that a thesis should follow certain style conventions and include five main sections: Introduction, Literature Review (or Research Issues), Methodology, Analysis of data, and Conclusions and implications (Perry, 1998). The thesis follows this convention, albeit with some modifications to cater for the specifics of the research. This is especially the case where Chapters Two to Four cover the Literature Review section, and Chapters Six to Eight cover the Analysis of data section. A brief summary of these chapters follows. 


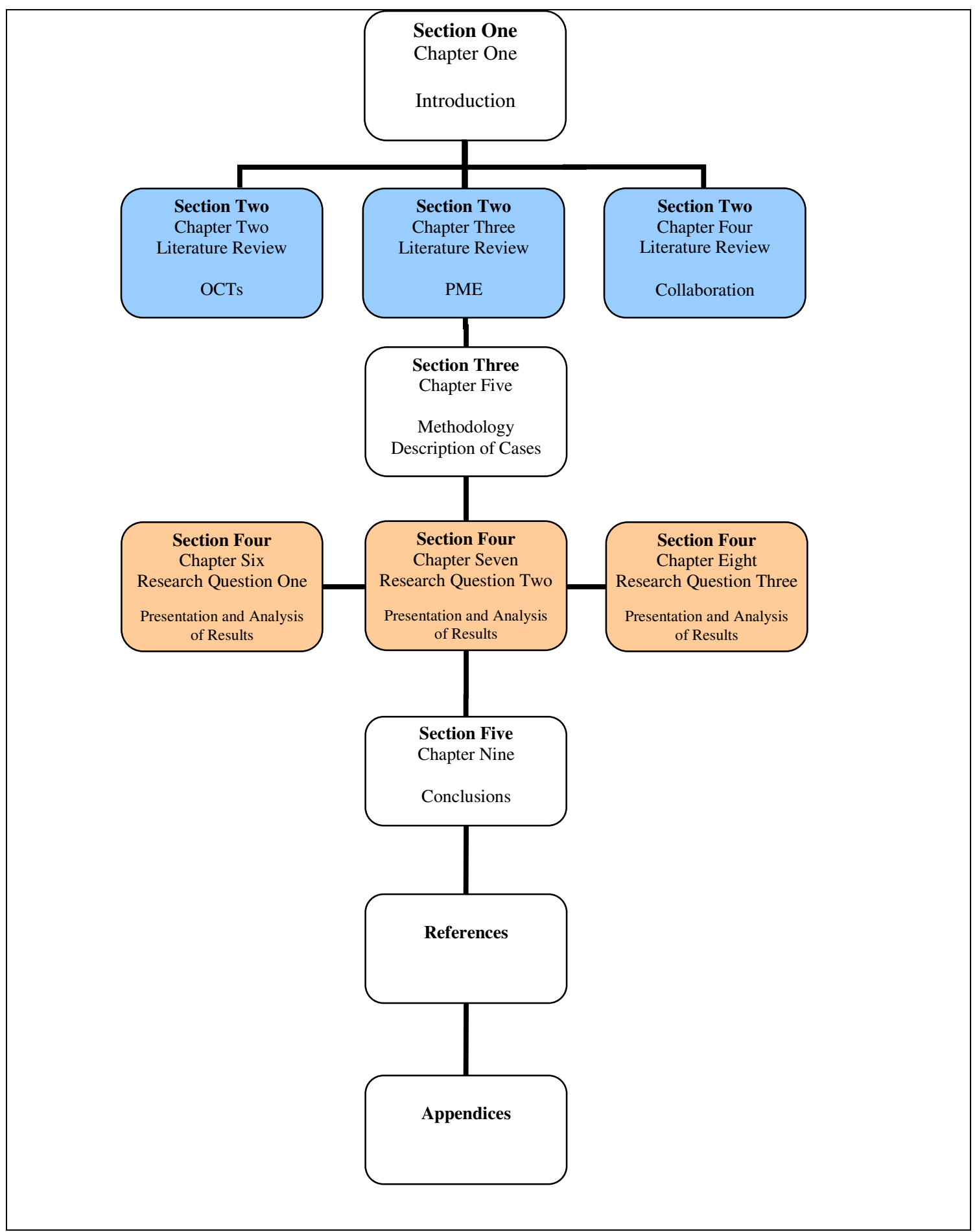

Figure 1-1: Chapter Guide to Thesis with reference to Perry (1998)

Chapter One is an introductory chapter summarising the key points of the thesis. Included in this chapter is some background to the research, the research problem and hypothesis, justification for this research, methodology, outline of definitions and limitations and key assumptions made by the writer. 
Chapters Two to Four provide a comprehensive Literature Review of published research in the topic areas. Due to the breadth of the material covered, this section, which is normally contained to a single chapter, is split into individual chapters, each dealing with a specific area and each detailing any gaps in research. Chapter Two reviews OCTs, Chapter Three the PME, whilst Chapter Four outlines information around collaboration and introduces the Collaboration scale. The order of these three chapters is determined by the research question and provides a logical progression through the literature - that is, a review of OCTs and the PME needs to be covered prior to a discussion on the relevance of collaboration in the context of these two items.

Chapter Five is specifically concerned with the design and methodology of the research. This chapter details the theoretical underpinning of this research design and provides information on the methodological approach taken. It outlines the use of the questionnaire and interviews as a device to gather data and information from the cases. The chapter also details the ethical considerations of this research, and provides a description of the six cases included in the research. The chapter ends with a summary of the main points of the chapter.

Chapters Six through Eight present the findings of the data including details from the Likert instrument and interviews. Each of the three research questions is addressed with a description of common themes drawn from the data gathering stage, and an analysis of these findings provided for each case and across the six cases. It ends with a summary of the main points.

The Nineth and final chapter draws on the outcomes of the previous chapters and develops new thinking from the analysis and the reading material reviewed in the Literature Review chapters. This chapter specifically addresses the research questions, draws together the key points of the research and reading and brings the work that constitutes the thesis and research topic, to an end.

The reference section details all references cited throughout the thesis, using the RMIT-revised Harvard style. The appendices section contains the supporting documentation used in this research, including the interview questions, Likert instrument and ethics form. 


\subsection{Definitions}

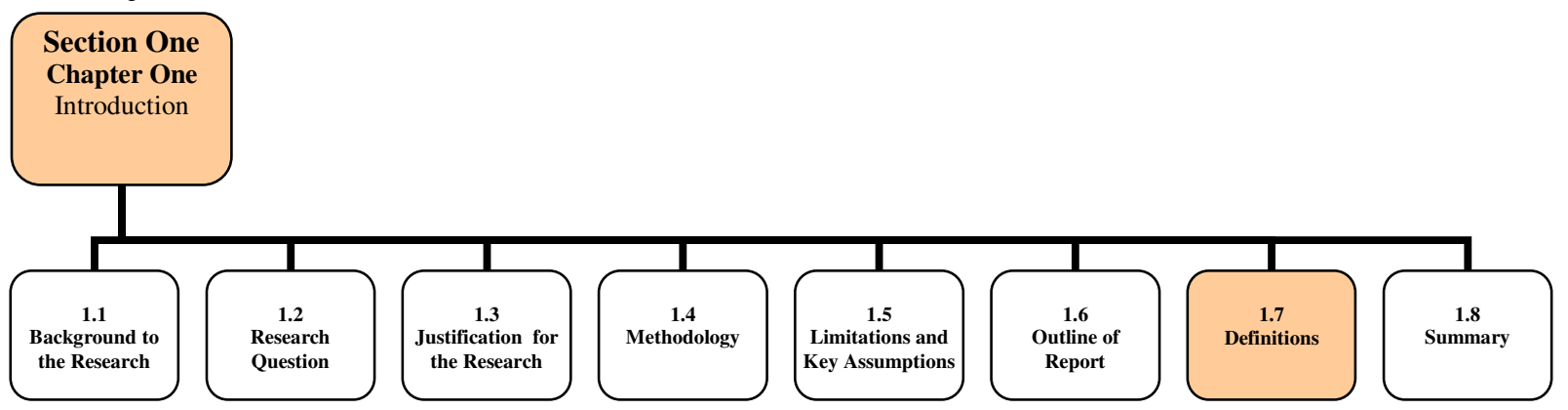

This section briefly sets out a number of acronyms used within the body of the thesis.

$\begin{array}{ll}\mathrm{Cp} & \text { Cooperation } \\ \mathrm{Cd} & \text { Coordination } \\ \mathrm{Cb} & \text { Collaboration } \\ 3 \mathrm{Cs} & \begin{array}{l}\text { Used to collectively refer to Cooperation, } \\ \text { Coordination and Collaboration }\end{array} \\ \mathrm{CIN} & \text { Continuous Improvement Network } \\ \text { I.C.T. } & \text { Information and Communications Technology } \\ \text { I.T. } & \text { Information Technology } \\ \text { OCT / OCTs } & \text { Online Collaborative Toolset(s) } \\ \text { Org } & \text { Organisation } \\ \text { PM (1) } & \text { Project Manager One (from an organisation) } \\ \text { PME / PMEs } & \text { Project Management Environment(s) } \\ \text { RSS } & \text { Really Simple Syndication } \\ \text { SE } & \text { Senior Engineer }\end{array}$




\subsection{Summary}

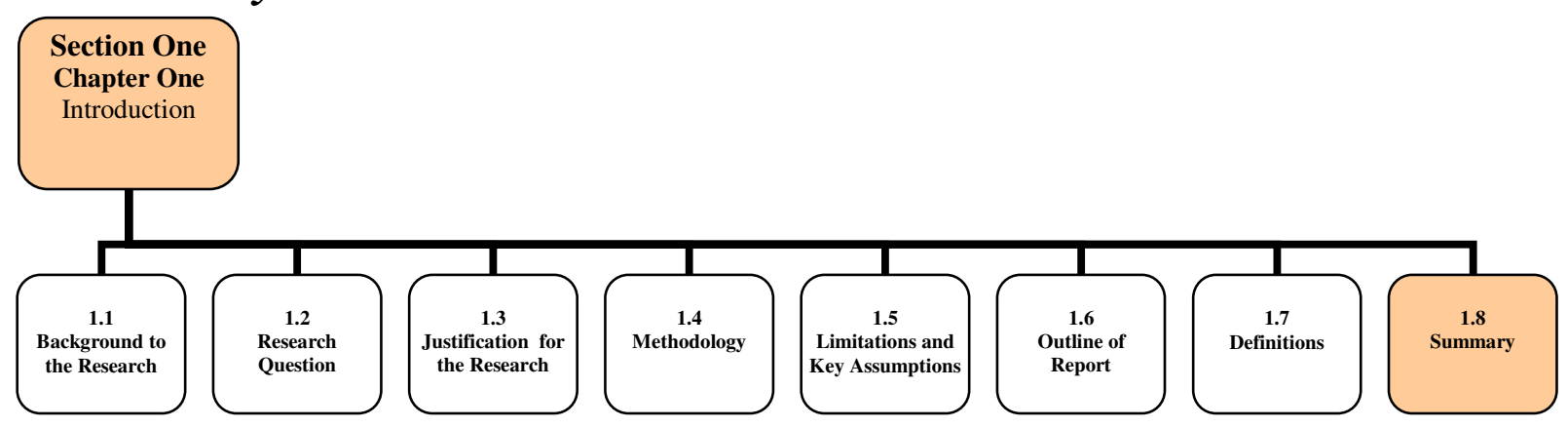

This chapter identified the key elements of the research. It provided a background into the research and the questions that are to guide it. It also detailed justification for the research by briefly discussing the areas of OCTs, the PME and collaboration. It then briefly outlined the methodology that will shape this research, a description of the delimitations of the research, a brief summary of the subsequent chapters, and a list of the definitions that have been applied throughout the research. The following chapter is the first of four chapters that comprise the Literature Review section. These chapters will detail the current state of knowledge in the subject area and will develop a theoretical foundation for the research. 


\section{SECTION TWO}

\section{CHAPTER TWO - Online Collaborative Toolsets}

\subsection{Introduction}

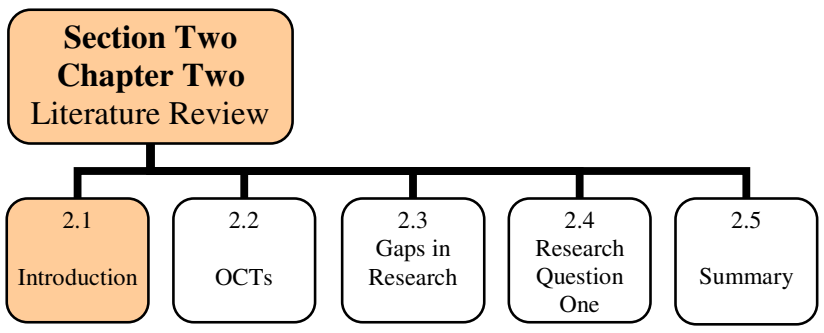

Section Two will review the literature pertaining to three areas. These areas include what is described as Online Collaborative Toolsets (OCTs), the project management environment (PME) and what is understood by the term collaboration. These three areas, which form individual chapters in the section, are selected as they address the key objectives of the research problem. Each of the next three chapters will detail the relevant literature on the area and identify the research issues pertinent to each. Each chapter concludes with a research question and associated proposition, which is linked back to the main research question and problem. Throughout this section, the research propositions will be justified and the questions that shape the research and inform the future chapters on analysis and findings will be refined.

It is important that this research has a thorough understanding of the elements that are contained within the research problem and how they contribute towards answering the research question. As such, the literature covered in this section will necessarily begin in broad areas, progressively narrowing in focus as the sub-research questions emerge. This section is therefore larger than perhaps is normally associated with a literature review due to the number of areas to be covered and their relative size and complexity in relation to the research task at hand.

Section Two has been structured into three chapters, with the first and last including an introduction and conclusion of the material. The chapters cover the three main subject areas, already introduced as OCTs, the PME and collaboration and also cover the gaps in research or literature coming from these areas. Each chapter will commence with a content diagram to help 
the reader track where they are in the specific subsection and in the chapter as a whole. A brief description of these individual chapters follows.

Chapter Two will review the characteristics of OCTs and review the factors that contribute towards their use. The chapter will provide a general introduction to the term and then become more specific in describing and detailing its features. The chapter will develop this information as a way to describe that which forms such a large part of the research at hand, for without knowledge of the application being discussed, the research is placed at risk. This chapter will review what is known as Groupware, and discuss the two main solution configurations made available to clients of the tools - that of hosted and non-hosted solutions. The chapter will then discuss the emerging phenomenon of social networking and Web 2.0, and move to review the use of wikis and blogs within the OCTs. The chapter identifies the gaps in the research or literature for the area. These gaps may inform future research directions, or act as points of divergence for ongoing research. The chapter will conclude by investigating how OCTs can be used in the teaching and learning environment and briefly discuss issues around adoption of OCTs. At the conclusion of this chapter, the first of three research questions and associated propositions will be presented.

Chapter Three covers the PME. It reviews the PME and its nine knowledge areas of project organisation, scope, time, cost, quality, human resources, communication, risk and procurement. It also briefly discusses the different types and cultures of PME that may exist and reviews the PME organisation structure. From there, the chapter reviews the use of the project websites or virtual teams within the field of project management. The chapter also includes a brief section on the gaps in research or literature for the area. It concludes with the second research question and associated proposition, and introduces the final subject area of collaboration.

Chapter Four introduces the term collaboration to the research, and in providing an understanding of its application and identification, introduces the terms of cooperation and coordination. This chapter discusses the difference between these three terms and suggests a new model for understanding and measuring the extent to which collaboration exists within the PME. In undertaking this task, the section includes introductory material on collaboration theory, and the definitions that guide its use. The chapter then proceeds to list the essential elements of collaboration and the factors that may contribute to its successful implementation, culminating in 
a comparison of cooperation, coordination and collaboration (3Cs). In doing this work, it introduces a Collaboration scale to this research. This Collaboration scale, which is created through the distillation of the key elements of the 3Cs, is used as a mechanism for reviewing each case's use of OCTS in the PME, and provides a foundation on which to assess the role that collaboration plays in these circumstances.

The chapter ends with a brief section on the gaps in research or literature for the area, moving on to a conclusion that summarises the main points from the Literature Review. It then introduces the following chapter on research design, methodology and description of cases.

\subsection{Online Collaborative Toolsets}

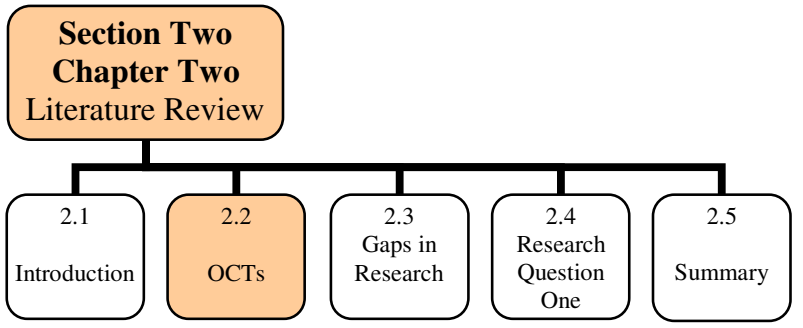

This chapter reviews the characteristics of online collaborative toolsets (OCTs) and discusses both the human elements and I.T. components that deliver an outcome. This discussion will be necessarily broad and general in order to define what might be included in an OCT product. Of interest as well, is the development of commercially generic I.T. applications to suit collaborative activities, and the prevalence of internet environments that provide easy and funnelled access to a variety of information. Such web-enabled software is referred to as Groupware (Forakerdesign, 2007) and it is generally synonymous with sharing information over the internet across a group of dispersed users.

The OCT has the capacity to provide myriad opportunities for business including improved business processes, aggregating the company's content, delivering increased application functionality whilst at the same time creating collaborative links between companies, their partners and customers (Kontzer, 2002). This technology is suitable for PME applications because companies are gradually seeking more ways to manage the complexities of projects, within an increasingly dispersed workforce (Qureshi et al., 2005). 
A common application of an OCT involves creating a shared workspace, which is often shortlived and self-managed, while incorporating resources and online information (Palmer, 2003). This project style approach suits the PME because it allows for the features of project management to be incorporated into a collaborative workspace. Collaboration can be defined as 'to labour (in literary or scientific work) as the associate of another or of others' (Webster's New Twentieth Century Dictionary of the English Language 1947) or 'to work jointly on an activity or project' (Oxford Concise English Dictionary 1999). This serves as a warning about the social nature of collaboration as it can be either ad hoc and chaotic or meticulously planned and coordinated. The organic processes that define some collaborations are in opposition to processes that may be able to be scripted, automated and controlled through structured process management. Collaboration requires facilitation, and as such the OCT is being used more and more by organisations to enable work to be shared, and less to enforce rules and regulations (Palmer, 2003). Organisations that build systems which place the individual user in control (May, 2000), must also be able to respond to the resulting fluid relationships. Alternately, organisations are redesigning their internal structure and external relationships to create knowledge networks that facilitate improved communication of data, information and knowledge, while improving coordination, decision-making and planning (Warkentin et al., 2001).

The use of OCTs allows organisations to customise an online space for their project, which is an advantage for projects that have specific short-term requirements or require the coordination of information across a distributed and often national working environment.

The OCT can be as simple as providing an online space for community engagement, through to delivering sophisticated and innovative workflow and I.T. solutions for larger companies. Either way, it will ideally operate with little need for technical interaction by the user (Mack et al., 2001) and preferably with maintenance outsourced (Hutchins, 2003). Considerations such as services to be offered through the OCT, including for example, systems and data integration or management and security, determine the level of complexity that the software solution will need to accommodate in order to satisfactorily provide the business tools required.

This chapter will now briefly address issues pertinent to a discussion on OCTs, including groupware, hosted solutions, social networking, blogs, wikis, teaching and adoption. 


\subsubsection{Groupware}

The internet has long provided a network infrastructure for collaborative technologies that supports how people and groups communicate and relate to each other (Nectar, 2007). As previously noted, collaborative technologies deployed or operating on the internet are generically referred to as groupware. The increasing availability and bandwidth of broadband internet connections in offices, education institutions and the domestic environment has led to a significant increase in commercial groupware systems. These technologies succeed because they make collaboration possible where it was previously impossible. Yet if the full potential of current collaborative technology is to be realised, including capitalising on innovations to come, researchers must find ways to make all computer-supported collaboration more efficient, productive and natural (Nectar, 2007).

There are different types of OCTs or collaborative software, all of which involve computer programs that help people work together collectively even though they may be remotely located from each groupware (Techtarget, 2007, Forakerdesign, 2007, McDonald, 2003, Gutwin and Greenberg, 2000). Computer-Supported Cooperative Work refers to the field of study that examines the design, adoption, and use of groupware. Despite the name, this field of study is not restricted to issues of cooperation or work but also examines competition, socialization, play and is increasingly called on to facilitate project management methodologies and to make systems more sensitive to social situations, ultimately guiding users toward effective collaborations (McDonald, 2003, Forakerdesign, 2007, Romano et al., 2002).

Groupware can enable project teams to undertake a series of interactions including, but not limited to cooperation, coordination, and collaboration. These functions will be examined later in the chapter when discussing how the OCT can be deployed within the project environment. The term groupware is now generally considered to include those technologies relying on a computer network and using features such as email, newsgroups and videophone or chat (Forakerdesign, 2007, Curtis and Lawson, 2001) and increasingly including access to information, for example online databases (Curtis and Lawson, 2001). 
Groupware, as specifically applied to the internet, has also been described as arising from three distinct, yet interrelated modes of document exchange - the web, email and Usenet conferencing. The confluence of these modes makes the internet the mother of all groupware applications (Udell, 1999).

Groupware technologies are typically categorised into two primary dimensions. The first depends on whether the users of the groupware are working together at the same time - often referred to as real-time or synchronous groupware. The second dimension is whether the users are working at different times - this is referred to as asynchronous. The other variable is the location of the workers at the time of the interaction. Groupware allows workers to be either in the same place, as in co-location, or in a different place, referred to as non co-location. Figure 2-1 highlights the differences between these different modes of groupware.

\begin{tabular}{|c|c|c|}
\hline & $\begin{array}{l}\text { synchronous } \\
\text { (same-time) }\end{array}$ & $\begin{array}{l}\text { asynchronous } \\
\text { (different time) }\end{array}$ \\
\hline $\begin{array}{l}\text { Same Place } \\
\text { (co-located) }\end{array}$ & $\begin{array}{l}\text { voting } \\
\text { presentation } \\
\text { support }\end{array}$ & shared computers \\
\hline $\begin{array}{l}\text { Different Place } \\
\text { (non co-located) }\end{array}$ & $\begin{array}{c}\text { videophone/conference } \\
\text { chat }\end{array}$ & $\begin{array}{c}\text { email } \\
\text { workflow }\end{array}$ \\
\hline
\end{tabular}

Figure 2-1: Groupware matrix

The advantages of asynchronous communication includes the capacity to communicate at a time that suits the worker, and which does not have to occur in real-time with other users or members of the group. Email is an example of asynchronous communication. The advantage of synchronous communication however, is the opposite, whereby the user has the capacity for realtime interaction amongst team members. This would occur when all parties are online and communicating at the same time, such as with virtual conferencing or instant messaging (TechTarget, 2007, ForakerDesign, 2007, Raygan and Green, 2002). Table 2-1 highlights the core features that differentiate the two operating modes. 
Table 2-1: Features of Asynchronous and Synchronous groupware

\begin{tabular}{|l|l|}
\hline Asynchronous & Synchronous \\
\hline email & shared whiteboards \\
\hline newsgroups & video communications \\
\hline mailing lists & chat systems \\
\hline workflow systems & decision support systems \\
\hline hypertext & multi player games \\
\hline group calendars & \\
\hline collaborative writing systems & \\
\hline
\end{tabular}

Groupware offers additional functionality to teams. It can provide an electronic focus or solution to many processes therefore facilitating many aspects of team dynamics and collaboration. Some of the features attributable to groupware include:

- to facilitate communication across team members;

- to enable communication where it wouldn't otherwise be possible;

- to enable telecommuting;

- to cut down on travel costs;

- to bring together multiple perspectives and expertise;

- to form groups with common interests where it wouldn't be possible to gather a sufficient number of people face-to-face;

- to save time and costs in coordinating group work;

- to facilitate group problem-solving; and

- to enable new modes of communication, such as anonymous interchanges or structured interactions (Forakerdesign, 2007).

The deployment of groupware is also distinguished by how the product is distributed to the enduser, often referred to as either a hosted or non-hosted solution.

\subsubsection{Hosted Solutions}

Hosted solutions are where the vendor provides the environment in which the OCT software and technical facilities are to be accessed. The hosted model enables the OCT solution to be distributed easily to many users regardless of the I.T. environment of the business (customer/user). This is particularly important if project teams comprise more than one business unit of a company, or many teams of people from many different companies.

The hosted solution also provides access to the software from anywhere and anyplace; the core requirement being the availability of a suitable internet account and access speeds (broadband now being the norm for effective transfer rates). Hosted solutions allow access from private 
workspaces for online collaboration and virtual teams. They offer a variety of business oriented communication tools, predominantly using asynchronous communication, but some offer realtime conferencing and instant messaging as well (Woolley, 2007) and signal the beginning of the convergence of information workplace platforms (Driver, 2006).

The hosted solution requires that the project information and data be distributed over the internet and stored within the vendor's secure I.T. environment. As such, it is essential that the mechanisms in place for securing the project information are considered by both vendor and customer, so content and commercially sensitive material can be managed within an acceptable threshold and to the business owner's satisfaction (Booch and Brown, 2002).

Non-hosted solutions are those that involve the installation of software on the company's own servers, usually behind firewalls. In a non-hosted environment, the solution must be installed and configured on each user's desktop/workspace to ensure that the software can run from the individual's system. Access to the OCT for the user therefore, is dependent upon having access to the specific computer that has the software installed on it. This computer must also host the appropriate tools to run the software. As such, it is the company's responsibility to manage all issues regarding the application. Issues such as security and Disaster Recovery Policies and associated administrative tasks and mechanisms (Booch and Brown, 2002) would normally be included in the hosted solution's service agreement.

Of the two types of OCT solutions outlined, the hosted solutions offer significantly more flexibility in deployment and administrative levels. They require a low technical requirement by the users, and require little or minimal technical administration by the business customer. Most importantly, the hosted solution provides a distributed deployment of the OCT to the project team that may literally reside in different physical locations throughout the life of the project. As project teams are constantly changing and becoming more complex, especially in the use of contractors, specialist technicians and consultants, the OCT will need to be applied to these types of PMEs. Given these factors, the research will focus primarily on hosted solutions and their features. 


\subsubsection{Social Networking}

OCTs can also be considered a subset of social networking software because they enable groups of people to interact with each other. Social software and social networking tools refer to web applications that enable participants to store information in various formats and share this information with selected individuals or groups if desired. OCTs assist with collecting, organising, managing and sharing information amongst the team members. They introduce a social element that assists these groups to become more organised and efficient in disseminating their information. OCTs play an important role in the social networking aspect of team dynamics (Driver, 2006). The social networking functionality of the software can bring a tension into the PME, or it can lead to increased coordination and contribution by team members (Driver, 2006).

Although aspects of the PME will be reviewed in more detail later in the next chapter, it is noteworthy to consider the role that social networking software may play in the PME. For that purpose, it is useful to gain an introductory understanding of the issues around social networking software and its features.

Social networking software is a term that can be applied to a wide range of web-enabled software that facilitates social contact and interaction, and enables teams or groups of people to coordinate their electronic files (Christopher, 2007). Much of the software allows one to create an instant community that members can join and participate in (Webscribblesolutions, 2007). The use of social networking tools encourages participation, and is an example of how application-based products can evolve and add value as communication and work habits change. The use of social networking software has been particularly prevalent with younger users, however it has been recognised that this application can be spread across other groups of people, for example the company or corporation (Krill, 2007).

The application of blogs and the variety of technological features (including trackback, Really Simple Syndication and podcasting) are all part of the social software revolution. Blogs are increasingly embedded in an infrastructure of social tagging, social bookmarking, picture sharing and other emerging applications of the social software movement (Aschenbrenner and Miksch, 2005). Beyond embedding blogs in their public relations, organisations are increasingly aware of the influence and power of blogs - seeing the importance of employing blogs and other social 
software in their information and communication strategies (Tapscott and Williams, 2006, Aschenbrenner and Miksch, 2005).

Christopher (2007) identifies a number of features attributable to networked tools, presented in

Table 2-2.

Table 2-2: Networked Tools Features

\begin{tabular}{|l|l|}
\hline Networked tools features & Description \\
\hline Browser accessibility & All users should be able to access the software through a login using a web browser. \\
\hline Easily configurable & $\begin{array}{l}\text { Non-technical members should be able to perform a series of configurable tasks } \\
\text { without the need for specific technical expertise. }\end{array}$ \\
\hline Access control & $\begin{array}{l}\text { Ability to assign rights (permission to access certain areas) to individuals and } \\
\text { groups to allow them to access their workspaces. }\end{array}$ \\
\hline Workspaces & $\begin{array}{l}\text { Ability to create web pages to support projects, for individuals and ad hoc teams, } \\
\text { departments and stakeholders. }\end{array}$ \\
\hline File repositories & $\begin{array}{l}\text { Ability to add repositories to the workspaces, for storing, tagging or organising } \\
\text { files. }\end{array}$ \\
\hline Group calendar & $\begin{array}{l}\text { Ability to add calendars and calendar items to the workspaces, to organise } \\
\text { information associated with meetings, milestones and events. }\end{array}$ \\
\hline General communications & Ability to post text and images in a structured way on the workspace's web pages. \\
\hline Wiki & $\begin{array}{l}\text { Ability to create wiki style correspondence, including the ability for the entire team } \\
\text { to see new material, in context, as soon as it is posted. }\end{array}$ \\
\hline Discussion Board & Ability to add a discussion tool which allows users to post topics and messages. \\
\hline Search & $\begin{array}{l}\text { Ability to search both the full text and the metatags of files in repositories, as well } \\
\text { as contents of wikis, calendars and discussion boards. }\end{array}$ \\
\hline Virtual Meeting tools & $\begin{array}{l}\text { Ability to use a variety of different tools, including instant messaging, shared } \\
\text { display and meeting (audio) recording. }\end{array}$ \\
\hline Configurable database & $\begin{array}{l}\text { Ability to create and configure individual databases in workgroups that can be } \\
\text { customised for task-tracking, contact information and issues management. }\end{array}$ \\
\hline Links & $\begin{array}{l}\text { Capability to create a hyperlink to any file, page, or embedded content and post } \\
\text { those hyperlinks on the pages of the workspace. }\end{array}$ \\
\hline
\end{tabular}

Harley (2005) further distilled the core features of networked tools in a review of more than twenty collaborative software applications, to identify the six key features in most applications, including:

- calendar;

- shared documents;

- central database;

- document storage;

- announcement board; and

- virtual conferencing (Harley, 2005).

With an awareness of these features, the research can begin to review commercially available OCTs and to analyse these features for their intended use. In doing so, this approach sets out the task that will influence the development of the first research sub-question. Before formalising 
this sub-question, this section will continue to review the variety of features pertaining to OCTs and their variations.

One such variation is the recent introduction of the term Web 2.0. This relatively new term describes internet technology and applications including blogs, wikis, RSS (Really Simple Syndication) and social bookmarking (Techtarget, 2007). The use of Web 2.0 enhances the user's internet experience by being able to share information more freely and intuitively, develop personal collaboration environments and in general contribute to the online space in a more creative fashion. There is no clear-cut demarcation between Web 2.0 and Web 1.0 technologies, hardware and applications, rather it is the social or interconnected nature of the activity that defines it. A list of Web 2.0 characteristics include the following:

- blogging;

- Ajax and other new technologies;

- Google Base and other free web services;

- RSS-generated syndication;

- social bookmarking;

- mash-ups;

- wikis and other collaborative applications;

- dynamic as opposed to static site content;

- interactive encyclopaedias and dictionaries;

- ease of data creation, modification or deletion by individual users; and

- advanced gaming (Techtarget, 2007).

O'Reilly (2005) set out to define Web 2.0 by comparing it to Web 1.0 , and by showing the different applications used by the different styles of the web. Table 2-3 highlights the two terms and the types of applications that could be used by each:

Table 2-3: Comparison of Web 1.0 and 2.0

\begin{tabular}{|l|l|}
\hline Web 1.0 & Web 2.0 \\
\hline DoubleClick & Google AdSense \\
\hline Ofoto & Flickr \\
\hline mp3.com & Napster \\
\hline Britannica Online & Wikipedia \\
\hline personal websites & Blogging \\
\hline domain name speculation & search engine optimisation \\
\hline page views & cost per click \\
\hline publishing & Participation \\
\hline content management systems & Wikis \\
\hline directories (taxonomy) & tagging ('folksonomy') \\
\hline Stickiness & Syndication \\
\hline
\end{tabular}

Source: O’Reilly, 2005 
The pervasiveness of the internet will usher in an era where companies will lower their proprietary barriers and collaborate to foster greater innovation. Tapscott and Williams (2006) believe that people will employ instant messaging, blogs, wikis and other web-based applications to communicate and develop ideas.

Through the use of social software, the internet becomes a possible vehicle for ongoing, massive collaboration. Blogs, wikis, chat rooms, peer-to-peer networks and personal broadcasting are putting unprecedented power in the hands of individual workers to communicate and collaborate more productively (Lynch, 2007).

\subsubsection{Blogs}

Blogs appear to play an important role as a forum for public debate, with knock on consequences for the media and for politics (Drezner and Farrell, 2004). The blog provides an informal thread of discussion, usually written in a journal style (Techtarget, 2007) which encourages engagement. Given its more informal style, the blog can provide a useful and perhaps more relevant tool for managing fluid or organic communication processes that depend upon or require ad hoc and multiple themes being simultaneously discussed from multiple sources in the one virtual meeting place (Richardson, 2003).

Weblogs are pages consisting of several posts or distinct chunks of information per page. These pages are often arranged in reverse chronology highlighting the most recent post at the top and the oldest post at the bottom (Bar-Llan, 2005). It can also be seen as a form of journal that has been posted on the internet (Enzer, 2006, Internet.Com, 2007).

'A blog is really quite simple. It is nothing more than a personal web site with content displayed in reverse chronological order. New posts are placed at the top of the page instead of the bottom, making it easy to see what has changed. In most cases, site visitors can identify the author and leave comments for others to see. Blogs are loosely joined to each other through hyperlinks. Find one blog and you can probably spend hours clicking links from blog to blog to blog. This linking means that any blogger who has something to say is part of a global network called the blogsphere' (Scoble and Israel, 2006).

Blogging is part of a bigger picture. A blog may simply be seen as a tool. It is becoming however, one of the most powerful components to emerge so far in a communication revolution that has been 'going on for quite some time now and is reaching its tipping point' (Scoble and 
Israel, 2006). Young workers are embracing web-based tools in a way that often confounds older generations but promises real advantages for companies that adapt to their style of working (Lynch, 2007).

Raygan and Green (2002) note three main categorisations of blogs - content, format and authorship. The first categorisation of blogs for the authors includes the different types of content that may be the subject of the blog. The blog may consist of content that is mainly associative, personal and self-expressive, or is perhaps topic oriented in which case the topic can be related to a hobby or to the author's profession or business.

The second issue for the authors relates to various formats deployed to present blogs. These formats range from a blog that consists of a set of lists of sites that for whatever reason may be of interest to the author, to essays that may or may not include links to other sites or blogs. Blogs can alternately be constructed as an announcement mechanism to the author's respective readers. The postings in a blog can range from the traditional monologue presentation, to one that embraces a more interactive nature and which subsequently encourages comments and even questions from its readers/audience (Raygan and Green, 2002).

The third category of a blog is its authorship. A blog can be authored and maintained by a variety of entities ranging from one person to a small or large group or community. Blogs can be initiated by individuals or a company and can serve any number of purposes. However, authors of blogs may often not state the explicit purpose of the blog, with readers noting that the topics and format change and mutate over time (Raygan and Green, 2002). The revolution of the blog highlights a change in the way authors, and subsequently the business communicates to its customers and entire constituencies including business partners, vendors, employers, investors and the media (Scoble and Israel, 2006).

The blog is considered the first technology to enable a simple conversation to go instantly global (Scoble and Israel, 2006). It does this by decentralizing the corporate communications, and removing it from those who have traditionally controlled it. In the process it eliminates many of the physical and geographic barriers that have restricted the development of relationships between those people who may have common or similar interests. 
The blog facilitates a conversation between author and reader. It is conversational in tone and approach. This may prove an important aspect when viewing communications across companies or project teams, because while face-to-face meetings are effective, the realities of distributed project teams and multiple sites of the project (especially in larger projects like construction) make it impossible to have such meetings all the time with all members. Phones, faxes, emails, SMS online forums, bulletin boards, chat rooms and instant messaging all play a role in extending a conversation in the social networking environment (Tapscott and Williams, 2006). The power of the blog however, is that it can allow the author to communicate with many people in multiple locations from many points, providing there is access to an internet enabled computer.

While some OCTs offer features that allow blogging to occur, a basic blogging tool can simply be a web interface that allows one to work in an easy manner. This allows the blogging application to manage all the technical aspects of presenting one's contribution to the web interface in the appropriate format and layout. In other words, the user gets to focus on what to write, and the blogging tool takes care of the rest of the site management (Wordpress, 2007).

Scoble and Isreal (2006) identify what they refer to as six pillars of blogging that distinguish the differences between blogging and any other communications channel. Scoble and Israel argue that one may be able to find these elements elsewhere, but it is only in blogs where they all exist as a set. These pillars are:

- publishable: anyone can publish a blog;

- findable: through search engines, people will find blogs by subject, author or both;

- social: the blogsphere is one big conversation;

- viral: information often spreads faster through blogs than via a news service;

- syndicatable: by clicking on an icon, one can get free 'home delivery' of RSS-enabled blogs; and

- linkable: because each blog can link to all others, every blogger has access to millions of other bloggers (Scoble and Israel, 2006).

The blog may prove to be an important feature in any OCT for a project that has a requirement to distribute information quickly and informally, or where communication to the team members can be exploited through the use of viral mechanisms. As such, the blog has the capacity to provide quick and timely project-critical information to a distributed team structure. 


\subsubsection{Wiki}

Another example of social networking software is the wiki. The wiki has been used to collaboratively create online encyclopaedias (Wikipedia - http://www.wikipedia.org/) and other structured documents. The wiki has the capability to be more than software for enabling multiple people to edit websites and can be seen as a metaphor for a new era of collaboration and participation (Tapscott and Williams, 2006).

A wiki is a server program that allows users to collaborate in forming the content of a website (Techtarget, 2007). A wiki web is formed around a topic or project effort. At its core, the wiki concept allows anyone to edit any page including other users' contributions and thus the division between author and reader is small. New pages are linked to existing pages by means of a WikiWord (Raygan and Green, 2002, Tapscott and Williams, 2006).

The wikiweb is built on the premise that collaboration among users will improve content over time (Tapscott and Williams, 2006). The application of the wiki also heralds the start of peer production, or peering; an activity that happens when masses of people and firms collaborate openly to drive innovation and growth in their industries (Tapscott and Williams, 2006). In order to view how a wiki can be applied in the project/business environment, it is useful to examine an example of how the software can be deployed.

One such product, the TWiki, was developed from the wiki environment and built as an enterprise collaboration platform and knowledge management system. It is a hosted solution and is built as a structured wiki, being deployed across a variety of environments to manage several tasks including a project development space, a document management system, a knowledge base and as a groupware tool (Theony, 2005).

As with all wikis, the product allows users to update content from a web-browser environment, without the need to have any special programming or application development experience. The TWiki looks and feels like a normal intranet or internet site including an edit item hyperlink at the bottom of the page. This item allows users to click on the hyperlink to begin to change a topic or add content on the page (Theony, 2005). The TWiki is a flexible alternative to adapt to different business requirements, depending on the activity or task required. 
The vendors note that the product has been used in several ways including (but not exclusively):

- to replace a static intranet: content is maintained by the employees thereby eliminating the requirement for a single webmaster. It would also alleviate the risk of all content being updated by a single position - it is a form of distributed authoring;

- $\quad$ as a knowledge base and Frequently Asked Questions (FAQ) system;

- to design and document software products;

- to track issues (i.e. bugs) and features of the software development phase;

- as a document management tool;

- to collaborate on common goals or activities; and

- as a company internal message board (Theony, 2005).

How the wiki can be applied to the PME is yet to be determined, but as detailed, its features allow for a different type of structure to be used to disseminate information to team members.

\subsubsection{Teaching}

In the teaching environment, collaboration can also use blogs (O'Connell, 2003) and shared virtual teaching environments (Mcfadzean and Mckenzie, 2001) to encourage participation and interaction amongst students and lecturers. This may also resonate in the PME, especially with knowledge management strategies and HR protocols.

Shared virtual teaching environments can involve computer mediated communications methodologies that attempt to incorporate collaborative learning into a course structure. These methodologies include information retrieval, the use of electronic mail and bulletin boards and participating in computer conferences. This environment encourages anytime/anyplace learning, which enables participants to log on to the system at any time and anywhere in the world (Mcfadzean and Mckenzie, 2001).

OCTs have been applied in the education and science areas as a means to access and use digital technology and to provide participants with a means of research and collaboration (Centie: Centre for Networking Technologies for the Information Economy, 2004, Edna: Education Network of Australia, 2004, TLF: The Learning Federation, 2004). The essence of the process is about distributed communication and information, with the web playing an ever increasing role in this distribution network. 
Collaboration within the electronic mode can also be distinguished by the capacity of the user to access information when required, and to tap into flexible tools of technology (Microsoft Australia Small Business Centre, 2004). At a minimum, the process of collaboration in the online mode should contain the ability to share documents and information (Palmer, 2003). Other collaborative environments use the online space as a communication service. In these instances, members of the network are linked to facilitate the growth of the network and to discuss common interests and practices (Edna: Education Network of Australia, 2004), or to connect disparate groups in order to share information and technical features (Burton, 2001, Centie: Centre for Networking Technologies for the Information Economy, 2004, TLF: The Learning Federation, 2004).

\subsubsection{Adoption}

The subject matter and any mediation used in these environments is critical to adoption rates. Merely providing access to a discussion board will not necessarily create conversation, or exchange knowledge; there must be a mutual desire or understanding of the effort required if a meaningful result is to be achieved. Collaboration proceeds to deeper levels as relationships form and naturally deepen (Fingar and Aronica, 2001). For the PME and its use of collaborative technologies, these relationships can include commercial incentives, in that businesses may be more prone to invest in the act of collaboration if it can be shown to deliver real and/or tangible benefits; for example income or revenue (Mcfadzean and Mckenzie, 2001, Vangen and Huxham, 2003). This has been shown to be the case in the creation of alliances in the project management environment, an area which will be discussed in the PME section of this chapter.

Use of online collaborative technologies, including portals, blogs and email, can be effective using both high end and benign technology i.e. simple, common, everyday applications (Fisher and Dourish, 2004). The more participants in these networks become geographically dispersed, and the higher use of public or commercial infrastructure, the less control users will have over the infrastructure that carries their project information. This can be an issue for the PME given the high levels of secure commercial-in-confidence, or tender material that may become central to their online presence. The capacity of virtual conferencing to engage in discussions and consultations is also becoming increasingly important to remote users or members that are geographically dispersed in the network (Health Share, 2004). As such, success of collaboration 
for the PME may rest with its ability to engage in a discussion that occurs across the many sites over networks that are becoming increasingly out of its control and are externally hosted.

From simple to complex, OCTs are now essential in developing additional value from the online environment and providing an efficient distribution mechanism for project-related information.

The use of social network analysis can also be used as a mechanism for discovering and understanding group structure. Individuals' roles at particular times can be primarily understood by their network positions relative to each other and relative to the others with whom they collaborate (Fisher and Dourish, 2004). This is something to keep in mind when considering how the OCT and its inherent network can be applied to the PME.

The social networking aspect of the OCT (including blogs and wikis) will be important when viewing the role of collaboration within the PME, and the way in which the PME uses OCTs. The nexus between social networking and interorganisational/intra-project information sharing within projects and between project team members will be relevant to this research. 


\subsection{Gaps in Research}

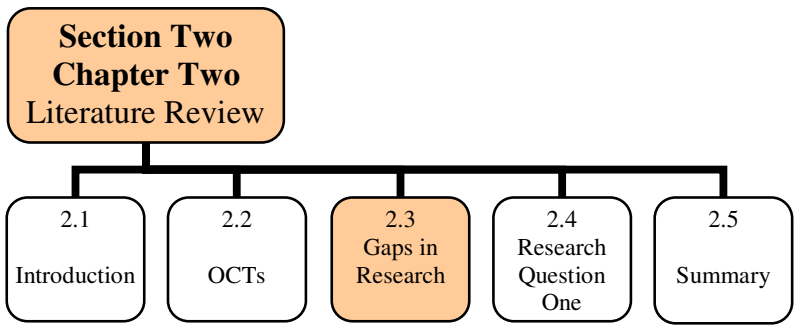

The review of OCTs provided a foundation on which to understand the varying features that are part of the suite of products commercially available. The review sought to distinguish between the different types of OCTs available, including the difference between asynchronous and synchronous groupware, project websites and social networking software. The section briefly touched on the emerging field of Web 2.0, noting that this is an area in its technological and application infancy, and as such, its full benefits are yet to be understood. The research did not uncover literature that analysed the use of these tools in operation, nor assessments of their capabilities or features across the spread of products available at the time of this research.

Of particular interest for this research was the lack of academic material that discussed the theoretical application and/or design of OCTs outside the area of computer-supported cooperative work. Consequently little material could be discovered that discussed the application of commercially available OCTs on the operating environments for which they are intended. This supports the emphasis of this research, which seeks to understand the features of the OCTs and the benefits they bring to the operating environment.

The feature list of the OCTs outlined in this chapter, and as detailed by Christopher (2007) and Harley (2005), also excludes most of the features associated with Web 2.0 capabilities, and as such, the research has identified this as an area where future developments may occur. These developments will have relevance to the research at hand, if and when the features are incorporated into the OCTs used within the PME. 


\subsection{Research Question One}

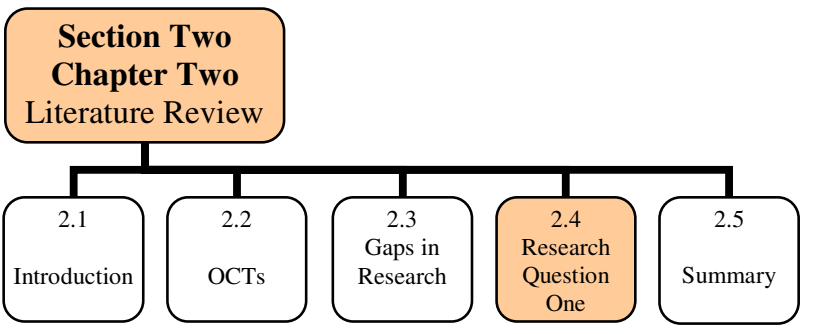

This chapter has detailed several permutations to the OCT and the features that may form part of a collaborative tool. In noting these elements, what is striking is the array of features, uses and environments in which these applications can be deployed. For the purposes of this research however, the investigation of OCTs is restricted to the PME and as such defines the first question of the research:

Research Question One: What are the features of Online Collaborative Toolsets (OCTs)?

In framing this question, the research seeks to identify not only the core features of the OCT to be applied in the PME, but submits a proposition as to its use and effectiveness. The proposition notes the features of the tool and attempts to identify how these features may be deployed within the PME and for what end. It is intentionally pragmatic, rather than theoretical with its approach, allowing for the research to be informed by actual project use, rather than the functional capacity of the specific tool.

Proposition One: $\quad$ OCTs contain features that facilitate coordination, cooperation, and collaboration.

In framing this first research question and proposition in this way, the research highlights the work in this chapter and introduces future work to come in this document. It also serves as a prompt for the following chapter in this Literature Review section; a chapter that reviews the PME in order that the research may understand the environment in which OCTs will be reviewed. In doing so, it keeps an ongoing reference to the overarching research question:

Does collaboration occur through the use of online collaborative toolsets in the project management environment? 


\subsection{Summary}

\section{Section Two}

Chapter Two

Literature Review

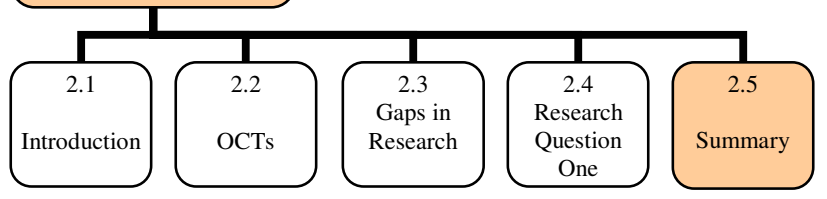

This chapter reviewed the characteristics of OCTs, and posed the first of three research questions for the study. It introduced the concept of the OCT and highlighted some of the issues organisations face when deciding to deploy an OCT into the work place. It discussed general features of OCTs, whilst paying particular attention to groupware and the importance of the distinction between synchronous and asynchronous communication tools. It compared both hosted and non-hosted applications, and concluded that the study would restrict itself to the hosted solutions primarily because the hosted solution provides the capacity to deploy the OCT to a distributed project team regardless of their physical location.

It then reviewed the issues surrounding social networking and its importance in the feature list of the OCT, which served as a precursor to a brief discussion on social networking technology including Web 2.0, blogs and wikis. The section concluded with a brief discussion of the use of OCTs in learning and teaching environments, culminating in the presentation of the first of three research sub-questions and propositions.

The next chapter will review the research issues surrounding the PME, with a view to identifying those constraints that may impact on the use and effectiveness of OCTs in an actual working environment. 


\section{SECTION TWO}

\section{CHAPTER THREE - Project Management Environment}

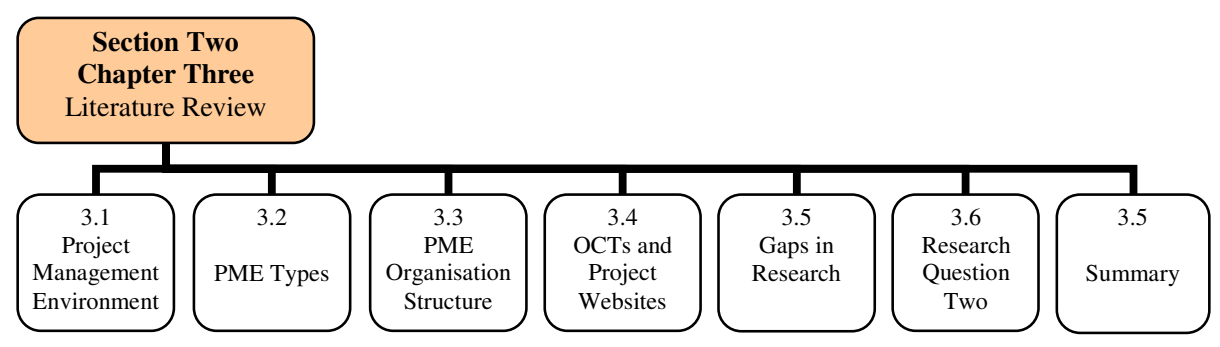

This third chapter extends the work covered in the previous chapter, and builds a greater understanding of the role and impact that the project management environment (PME) has in the application and use of online collaborative toolsets (OCTs).

This chapter of the Literature Review will look at three main areas. It will investigate the broader field of the PME and review the main metrics used for measuring project operations. It will review the different PME types, in order to present an understanding of how organisations are structured to undertake project work. It will review the PME, including the use of virtual project teams, in relation to its use of OCTs and project websites in the day-to-day operation of a project.

\subsection{The Project Management Environment}

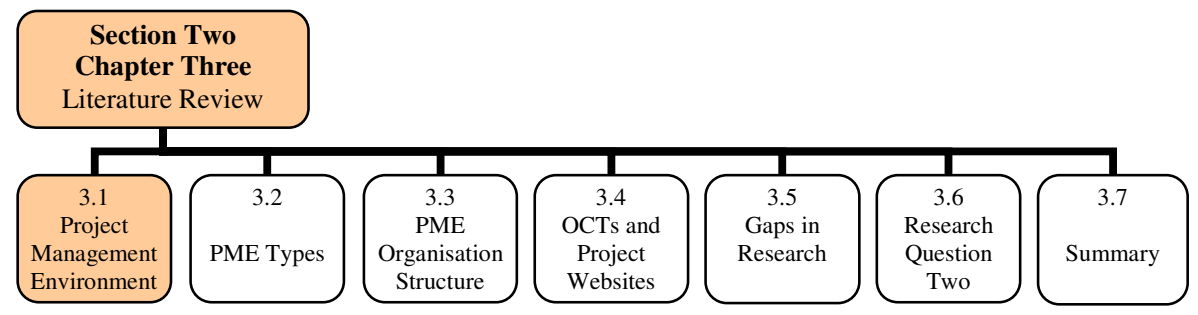

Turner defines a project as 'an endeavour in which human, material and financial resources are organised in a novel way, to undertake a unique scope of work, of given specifications, with constraints of cost and time, so as to achieve beneficial change defined by quantitative and qualitative objectives.' (Turner, 1999) 
The Project Management Institute defines a project as a temporary endeavour undertaken to create a unique product, service or result (PMI, 2004). The term temporary means every project has a definite beginning and end. 'The end is reached when the project's objectives have been achieved, or it becomes clear that the project objectives will not or cannot be met, or the need for the project no longer exists and the project is terminated' (PMI, 2004). The inclusion of the term temporary does not necessarily mean that the project must be short in duration, as some projects may span several years, but rather in every case the duration of a project is finite- that is, projects are not ongoing efforts.

Gray and Larson reinforce this understanding by defining a project as a complex, non-routine, one-time effort limited by time, budget, resources and performance specifications designed to meet customer needs (Gray and Larson, 2000). This is aligned with the definition provided by the PRINCE2 methodology that identifies a project as a management environment created for the purposes of delivering one or more business products according to a specified business plan (Onna et al., 2000).

As noted above, a project creates a set of deliverables for the customer, which the Project Management Body of Knowledge - PMBOK (PMI, 2004) classifies as products, services, or results. The PMBOK notes that a project produces a product or artefact that is quantifiable and can be either an end item in itself or a component item. These deliverables can also include the act of performing a service, such as a business function that supports a production or distribution process or an outcome that may include the development or creation of a document. Combined, these products, services or results form part of the development of a unique entity or deliverable that is the function of the project (PMI, 2004).

Projects however, are not static entities, with their elements shifting and changing in response to developments within the project. Referred to as progressive elaboration, these changes are highlighted through the temporary and unique elements in the project. Progressive elaboration requires a project to develop in stages or components, with each one being developed incrementally as the project progresses. This allows for aspects of the project to become more explicit and detailed as the objectives and deliverables become better understood (PMI, 2004). As such, progressive elaboration is a facet of the dynamic nature of the project environment. 
Project management is the application of knowledge, skills, tools and techniques to project activities to meet project requirements (PMI, 2004). Project management is accomplished through the application and integration of the project management processes of initiating, planning, executing, monitoring and controlling, and closing. The project manager is the person responsible for accomplishing the project objectives (PMI, 2004, Gray and Larson, 2000).

Project managers are expected to coordinate resources in order to complete the project, often to what is called a triple constraint—project scope, time and cost (Gray and Larson, 2000, PMI, 2004) - the three factors that can affect project quality. The relationship between these three factors means if any one of these factors changes, at least one other factor is likely to be affected, or the project risks failing in its budget or schedule (Gray and Larson, 2000, Romano et al., 2002). Project managers also manage projects in response to uncertainty, where an instance of risk or an uncertain event or condition occurring may have a positive or negative effect on at least one project objective. In addition to this, the project manager must also manage the interface between customer expectation and what is feasible and reasonable.

A project exists within a project lifecycle. There are many versions of the project life cycle, however there is growing agreement about a four-step process and its associated functions (Turner, 1999) as shown in Figure 3-1 and Table 3-1.

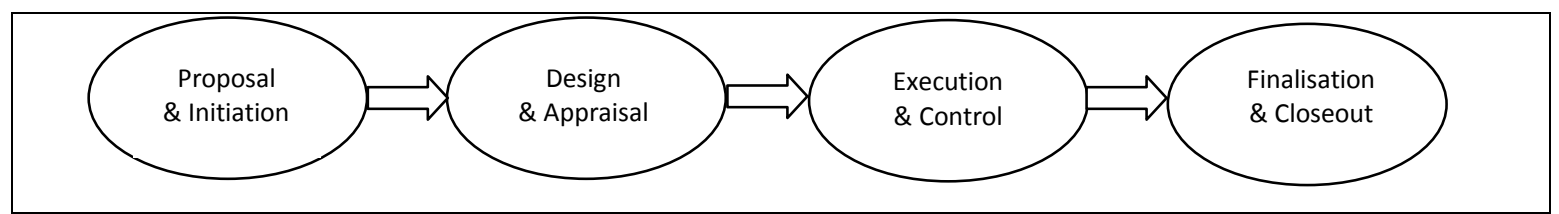

Figure 3-1: Basic Four Stage Lifecycle 
Table 3-1: Basic Project Management Lifecycle

\begin{tabular}{|c|c|c|c|c|}
\hline Stage & Name & Details & Process & Outputs \\
\hline \multirow[t]{2}{*}{ Germination } & \multirow[t]{2}{*}{ Proposal \& initiation } & $\begin{array}{ll}\circ & \text { Initial concept } \\
\circ & \text { Accuracy }-50 \% \\
\circ & \text { Cost }-0 \%\end{array}$ & $\begin{array}{ll}\circ & \text { Develop proposals } \\
\circ & \text { Gather information } \\
\circ & \text { Conduct feasibility } \\
\circ & \text { Estimate design } \\
\end{array}$ & \begin{tabular}{|ll} 
& Functional design \\
$\circ$ & Commitment of resources to \\
& design \\
$\circ$ & Estimates $-20 \%$ \\
\end{tabular} \\
\hline & & $\begin{array}{ll}\circ & \text { Functional requirement } \\
\circ & \text { Accuracy }-20 \% \\
\circ & \text { Cost } 0.2 \% \\
\end{array}$ & & \\
\hline \multirow[t]{2}{*}{ Growth } & \multirow[t]{2}{*}{ Design \& appraisal } & $\begin{array}{ll} & \text { System design } \\
\circ & \text { Accuracy }-10 \% \\
\circ & \text { Cost }-1 \%\end{array}$ & $\begin{array}{ll}\circ & \text { Develop design } \\
\circ & \text { Estimate costs and returns } \\
\circ & \text { Assess viability } \\
\circ & \text { Obtain funding } \\
\end{array}$ & \begin{tabular}{|ll}
$\circ$ & System design \\
$\circ$ & Money and resources for \\
& implementation \\
$\circ$ & Estimates $-10 \%$ \\
\end{tabular} \\
\hline & & $\begin{array}{ll}\circ & \text { Detail design } \\
\circ & \text { Accuracy }-5 \% \\
\circ & \text { Cost }-5 \% \\
\end{array}$ & & \\
\hline Maturity & Execution \& control & $\begin{array}{ll}\circ & \text { Work complete } \\
\circ & \text { Accuracy } \\
\circ & \text { Cost }-95 \%\end{array}$ & $\begin{array}{ll}\circ & \text { Do detailed design } \\
\circ & \text { Baseline estimates } \\
\circ & \text { Do work } \\
\circ & \text { Control progress } \\
\end{array}$ & $\begin{array}{ll}\circ & \text { Effective completion } \\
\circ & \text { Facility ready for commissioning } \\
\circ & \text { Estimates }-5 \%\end{array}$ \\
\hline Metamorphosis & Finalisation \& closeout & $\begin{array}{ll} & \text { Facility commissioned } \\
\circ & \text { Accuracy } \\
\circ & \text { Cost } 100 \%\end{array}$ & $\begin{array}{ll} & \text { Finish work } \\
\circ & \text { Commission facility } \\
\circ & \text { Obtain benefit } \\
\circ & \text { Disband team } \\
\circ & \text { Review achievement }\end{array}$ & $\begin{array}{ll}\circ & \text { Facility delivering benefit } \\
\circ & \text { Satisfied team } \\
\circ & \text { Data for future projects }\end{array}$ \\
\hline
\end{tabular}

Having identified what a project entails and examined its lifecycle, it is now useful to briefly review several key knowledge areas and subsequent project management processes that form the basis for further understanding and classifying the specific operations contained within the PME. An outline of these knowledge areas is included here (in Table 3-2 over) to detail a cross-section of the activities or tasks that may be included in each section and a description of what these activities might involve. A detailed summary of each knowledge area can be found in Appendix A1.

Given these knowledge areas for project management and the roles they each play within the PME, this list highlights the actual work required on projects and introduces the metrics by which the organisation's use of the OCT may be measured. The thesis will return to these metrics in the discussion of research design and the subsequent case study chapters.

The inclusion of these knowledge areas provides fertile ground for investigating how work is performed in the PME and the relationship this has not only to the OCTs, but to the next chapter to be reviewed in this section: collaboration. 
Table 3-2: Metrics Knowledge Areas

\begin{tabular}{|c|c|}
\hline Key Knowledge Area & Outline of knowledge area, process or activity \\
\hline Project organisation & $\begin{array}{l}\text { May include: contract negotiation, assigning roles and responsibilities, adopting } \\
\text { reporting structure, developing project charter, developing preliminary project scope } \\
\text { statement, developing project plans, directing and managing project execution, } \\
\text { monitoring and controlling project work, preparation of a project management } \\
\text { framework, implementing a methodology and associated PM processes, integrated } \\
\text { change control, close project documentation, and an understanding of the organisational } \\
\text { culture. }\end{array}$ \\
\hline Scope & $\begin{array}{l}\text { May include: managing the project through a work breakdown structure (WBS), being } \\
\text { results focussed, balancing objectives and levels of ambition through scope definition, } \\
\text { scope verification, scope planning and control and resource allocation methods. }\end{array}$ \\
\hline Time & $\begin{array}{l}\text { May include: activity definition, activity sequencing, activity resource estimating, } \\
\text { activity duration estimating, schedule development and control. }\end{array}$ \\
\hline Cost & $\begin{array}{l}\text { May include: providing a measure to control costs, assessing project viability, obtaining } \\
\text { funding, managing cash flows, allocating resources, estimating durations, preparing } \\
\text { tenders, budgeting. }\end{array}$ \\
\hline Quality & $\begin{array}{l}\text { May include: meeting specifications, being fit for purpose, meeting requirements, } \\
\text { satisfying the customer, quality planning, quality assurance and quality control. }\end{array}$ \\
\hline Human resources (HR) & $\begin{array}{l}\text { May include: HR planning, acquiring the project team, developing project team, } \\
\text { managing and structuring the project team, ethics and project management, } \\
\text { understanding organisational factors and work cultures. }\end{array}$ \\
\hline Communications & $\begin{array}{l}\text { May include: communications planning, information distribution, performance } \\
\text { reporting, managing stakeholders and customer relations, social network building, } \\
\text { knowledge and information sharing, implementation of virtual teams, building authority. }\end{array}$ \\
\hline Risk & $\begin{array}{l}\text { May include: identification of risks, assessing individual and joint impact of risks, } \\
\text { developing strategies for risk, monitoring and controlling risk and the associated } \\
\text { strategies, risk management planning, qualitative risk analysis, quantitative risk analysis, } \\
\text { risk response planning, establishing contingency reserves, and risk reward trade-offs. }\end{array}$ \\
\hline Procurement & $\begin{array}{l}\text { May include: planning purchases and acquisitions, contracting, requesting seller } \\
\text { response (RFI, RFQ, RFT), selecting sellers, contract administration and measurement } \\
\text { against key performance indicators, contract closure. }\end{array}$ \\
\hline
\end{tabular}

Source: (Rad and Levin, 2006, PMI, 2004, Turner, 1999, Gray and Larson, 2000, Argyris, 1999, Frame, 1994, Romano et al., 2002, Charvat, 2003)

\subsection{Project Management Environment Types}

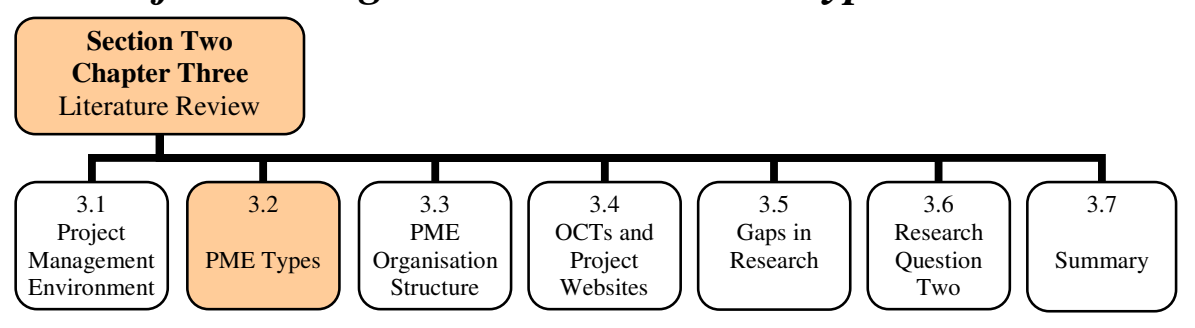

Projects are typically part of an organisation that is larger than the project. Examples of organisations can include corporate bodies, government departments and agencies, international partnerships/alliances and professional associations. This part of the chapter reviews the different structures of organisations managing projects to develop a clearer picture of the way in which the PME is structured and the effect this may have on the operational aspect of the project. The manner in which a project is structured may determine many of its operational mechanisms 
including utilising a project management office, favouring a particular project management methodology, and the administrative and governance systems and procedures that may be instigated. The culture of the organisation will influence the decision to use these operational mechanisms and whether to use joint ventures, partnerships or alliances to manage the operations. In these circumstances, the lead organisation or organisations that initiated it may still continue to play an influential role (PMI, 2004).

Now the research begins to draw together the various components that comprise the project environment in an effort to uncover factors that contribute to effective project management and the presence of collaboration.

For the purposes of this discussion, organisations can be distinguished by how they are structured to deliver the project or its activities. In this instance, organisations are either project-based organisations, or non-project based organisations. The project-based organisations fall into two categories:

1. Organisations that derive their revenue primarily from performing projects for others under contract, for example architectural and engineering firms, consultants, construction, and government contractors. These organisations can also be referred to as clients in some circumstances.

2. Organisations that have adopted management by projects, and which tend to have management systems in place to facilitate the different aspects of project management. For example, their financial systems are often specifically designed for accounting, tracking and reporting on multiple, simultaneous projects (PMI, 2004). These organisations can often be referred to as contractors as they contract many of the services provided by the client organisations.

Non-project-based organisations may lack the management systems specifically designed to support the project needs, which can make project management more difficult or place the project at risk. In some cases, non-project-based organisations will have departments or other sub-units that operate as project-based organisations with systems to support them (PMI, 2004). 
Regardless, the project management team needs to be aware of the organisational make-up and ensure that it comprehends how this may impact on the day-to-day management and processes of the project.

Katzy et al (2000), on the other hand, see the PME in terms of project organisations. They identify four main project types ranging from the traditional to the complex. Table 3-3 details the four main project types including traditional, distributed, interorganisational and virtual, and briefly describes their application.

Table 3-3: Project Types

\begin{tabular}{|l|l|}
\hline Project Type & Description \\
\hline Traditional & $\begin{array}{l}\text { Undertaken in a single location with a relatively homogeneous team, in that the project } \\
\text { team members are all affiliated with the same organisation and often in closely related } \\
\text { departments. }\end{array}$ \\
\hline Distributed & $\begin{array}{l}\text { Features a geographically dispersed project team that subsequently requires an } \\
\text { associated increase in the sophistication of the communication technology. Somewhat } \\
\text { homogeneous team where project members are distributed across multiple sites, but } \\
\text { are still part of the same organisation. }\end{array}$ \\
\hline Interorganisational & $\begin{array}{l}\text { Project teams are closely geographically located but are sourced from a variety of } \\
\text { affiliated organisations, including independent consultants. Examples include } \\
\text { government task-forces and alliances. }\end{array}$ \\
\hline Virtual & $\begin{array}{l}\text { Considered the most complex. Project team members are widely dispersed across both } \\
\text { geographic and organisational boundaries. All the issues mentioned in other types of } \\
\text { projects apply here, with the interaction of these factors increasing the challenge of } \\
\text { virtual project management. Requires appropriate technological infrastructure to } \\
\text { enable the team to function effectively in the project environment. }\end{array}$ \\
\hline
\end{tabular}

Source: Katzy et al (2000)

Evaristo and van Fenema (1999) propose a typology of projects that focuses within organisations based on two dimensions: the number of locations (single versus multiple) and the number of projects (single versus multiple). In these projects, complexity is due to many factors, but in particular to managing multiple interdependencies across time, space and projects (Evaristo and Van Fenema, 1999). Table 3-4 details the range of these projects highlighting the project descriptions for single and multiple location projects in relation to the project type. For example, the traditional project takes place with minimum complexity in a single project in one location, whereas the most complex project is one where there are multiple projects occurring throughout multiple sites. 
Table 3-4: Typology of projects

\begin{tabular}{|l|l|l|}
\hline Project Type & Single Location & Multiple locations \\
\hline Single projects & $\begin{array}{l}\text { Traditional project - minimum complexity } \\
\text { with single project in single location }\end{array}$ & $\begin{array}{l}\text { Distributed project - single } \\
\text { project in multiple locations. }\end{array}$ \\
\hline Multiple projects & $\begin{array}{l}\text { Increasing complexity - multiple projects in a } \\
\text { single location (co-located). }\end{array}$ & $\begin{array}{l}\text { Most complex - multiple projects } \\
\text { in multiple locations. }\end{array}$ \\
\hline
\end{tabular}

A critical difference between distributed projects and traditional projects of various types is related to the focus of the types of collaborative mechanisms utilised (Evaristo and Van Fenema, 1999). Coordination and collaboration mechanisms are fundamental if the management component of projects is to be carried out effectively (Romano et al., 2002). In these instances, coordination is a key activity for managing tasks and resources across the sites of distributed projects. This point resonates with the research at hand, as it links with the previous research question and associated proposition, by questioning the role that cooperation, coordination and collaboration play in the use of OCTs. In doing so, it introduces the second question of the research, one that addresses the connection between the OCTs and the functional elements of the PME.

Given the discussion of the way in which an organisation may structure its operating environment to deliver the project, it is useful to be aware of the role of the primary, lead or principle organisation within the project. These organisations can be drawn from many backgrounds including government projects, commercial, corporate, research, educational to name a few. Each of these types necessarily impacts and determines the role of the eventual project structure and its operational mechanism as it seeks to create its optimum operating environment. The extent of this impact will be addressed in later chapters in this thesis.

In addition to the way in which the organisation may be structured to deliver the project, is the unique personality or culture of the organisation that may impact on, or determine how, it responds or behaves in a given set of circumstances. 
These cultures are reflected in numerous factors, including, but not limited to:

- its shared values, norms, beliefs and expectations;

- the policies and procedures in effect in the organisation;

- its view and interpretation of the authority relationships; and

- its work ethic and approach to what constitutes a full day's work.

The culture of the organisation consequently, will have a direct influence on the project (PMI, 2004). This is evident particularly in the alliance model where partnering organisations come together to create a specific organisation to manage the project for its duration. The alliances are inter-firm cooperative arrangements that span a given economic space and time for the attainment of some strategic objective (Chen, 2003). They create a joint value proposition to the partnering organisations (Monge et al., 1998) whilst distributing the risk across all partnering organisations. It is typically a relationship between two or more suppliers that are servicing the same customer base.

The driving forces behind the formation of the alliance could include cost savings, greater efficiencies, synergy, critical mass, stability, or competitive advantage (Lendrum, 1998). It creates a project organisation comprising staff whose time is completely dedicated to the project and who are drawn from appropriate parts of the partnering organisation.

Partnering is another strategy that determines the organisation of the PME. A working definition of partnering in the PME is the method of transforming contractual relationships into a cohesive, cooperative project team with a single set of goals and established procedures for resolving disputes in a timely manner (Gray and Larson, 2000). Partnering has become an effective mechanism for managing projects and building a foundation for collaboration between potential adversaries before disputes and problems arise (Larson, 1997). It represents more than a set of goals and procedures, and can include a commitment from all the participants working on a project to respect, trust and collaborate with each other (Gray and Larson, 2000).

In addition to these behaviours, a successful partnership could include a common set of values, good communication, cooperation and the ability to resolve conflicts amicably (Lendrum, 1998). 
Partnering is based on the assumption that the traditional adversarial relationship between owner and contractor(s) is ineffective and self-defeating. The advantages of long-term partnerships include:

- reduced administrative costs;

- more efficient utilization of resources;

- improved communication;

- improved innovation; and

- improved performance (Gray and Larson, 2000).

Partnering has the capacity to transform a competitive system into a collaborative project relationship, through the introduction of a common set of goals, and exploiting the benefits that result from a shared working arrangement.

A variation to the partnering principle is the Public Private Partnership. The Private Public Partnership project occurs where the government states its need for capital-intensive, long-lived infrastructure. This infrastructure is then built using a complex combination of government and (mostly) private financing and then operated by a private entity under a long-term franchise, contract, or lease. The Private Public Partnership infrastructure is subsequently managed and operated by a private entity under a long-term contract, franchise or lease with the government. Typical projects would include roads, bridges, and airports to name a few (Savas, 2000).

The culture of the lead, or primary organisation will also play an important role in determining how a project will be managed. Organisation culture refers to a system of shared norms, beliefs, values and assumptions which bind people together, thereby creating shared meanings (Deal and Kennedy, 1982). The culture of the organisation reflects the personality of the organisation and is one of the defining aspects that sets it apart from other organisations even in the same industry.

These features will determine how a project can be implemented. Subsequently the PME organisation structure will be the mechanism and organisational vehicle in which the project deliverables will be enacted and the project team(s) managed. Given this, it is useful to have an understanding of the different structures at the organisation's disposal to deliver the project. 


\subsection{Project Management Environment Organisation Structure}

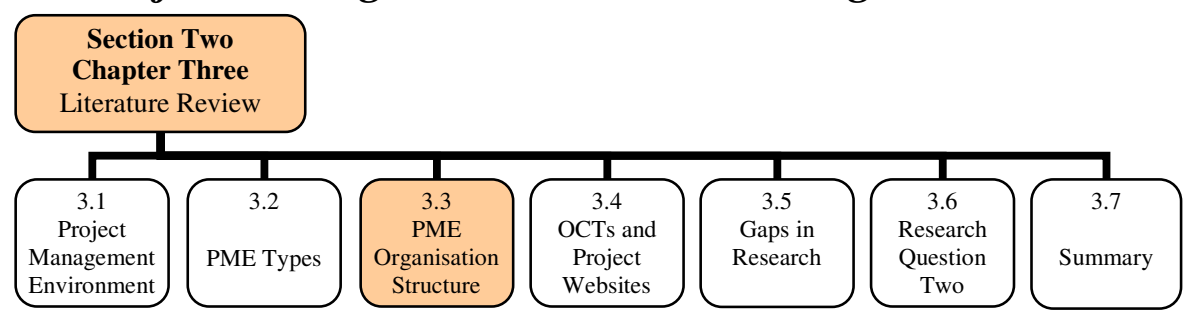

Following on from the discussion in the previous chapter, the type of structure the organisation deploys to manage the project will impact on the delivery and management functions of the project. There are several types of organisational structures relevant to the discussion here. They range from a functional based organisation, to a projectised based organisation, or a blend, involving a series of matrix structures that apply to the particular lead organisational structure (PMI, 2004, Turner, 1999, Goncalves, 2007).

The classic functional organisation is a hierarchy where each employee has one clear superior and staff members are grouped by their speciality. In the functional organisation, the scope of the project is usually limited to the boundaries of the function or speciality (PMI, 2004, Turner, 1999). For example the design department in a functional organisation will do its project work independently of the programming or communications departments.

In the projectised organisation, team members are often co-located, with most of the organisation's resources involved in that project work. In these instances, project managers have a great deal of independence and authority. Projectised, or concurrent organisations may have organisational units that either report directly to the project manager or provide support to the various projects (Goncalves, 2007, PMI, 2004, Turner, 1999).

The matrix organisations are a blend of functional and projectised characteristics (PMI, 2004, Turner, 1999). Organisations that utilise a weak matrix approach maintain many of the characteristics of a functional organisation. In these instances, the project manager functions more in the coordinating or facilitation role. In those organisations where a strong matrix approach is adopted, there are more characteristics of the projectised organisation, including fulltime project managers with considerable authority and dedicated project staff. In the middle of these two types, is the balanced matrix organisation, where the organisation recognises the need 
for a project manager, but does not provide the role with the full authority over the project or its funding circumstances (PMI, 2004).

Most modern organisations will instigate a composite organisation, where all these structures exist at various levels in the organisation as shown in Figure 3-2 (PMI, 2004). An example of this scenario may be where a functional organisation creates a team to manage a dedicated project. This team may include fulltime staff from different functional departments, develop its own set of operating procedures and may operate outside the standard formalised reporting structure. In this sense, it has many of the characteristics of a project team in a projectised organisation.

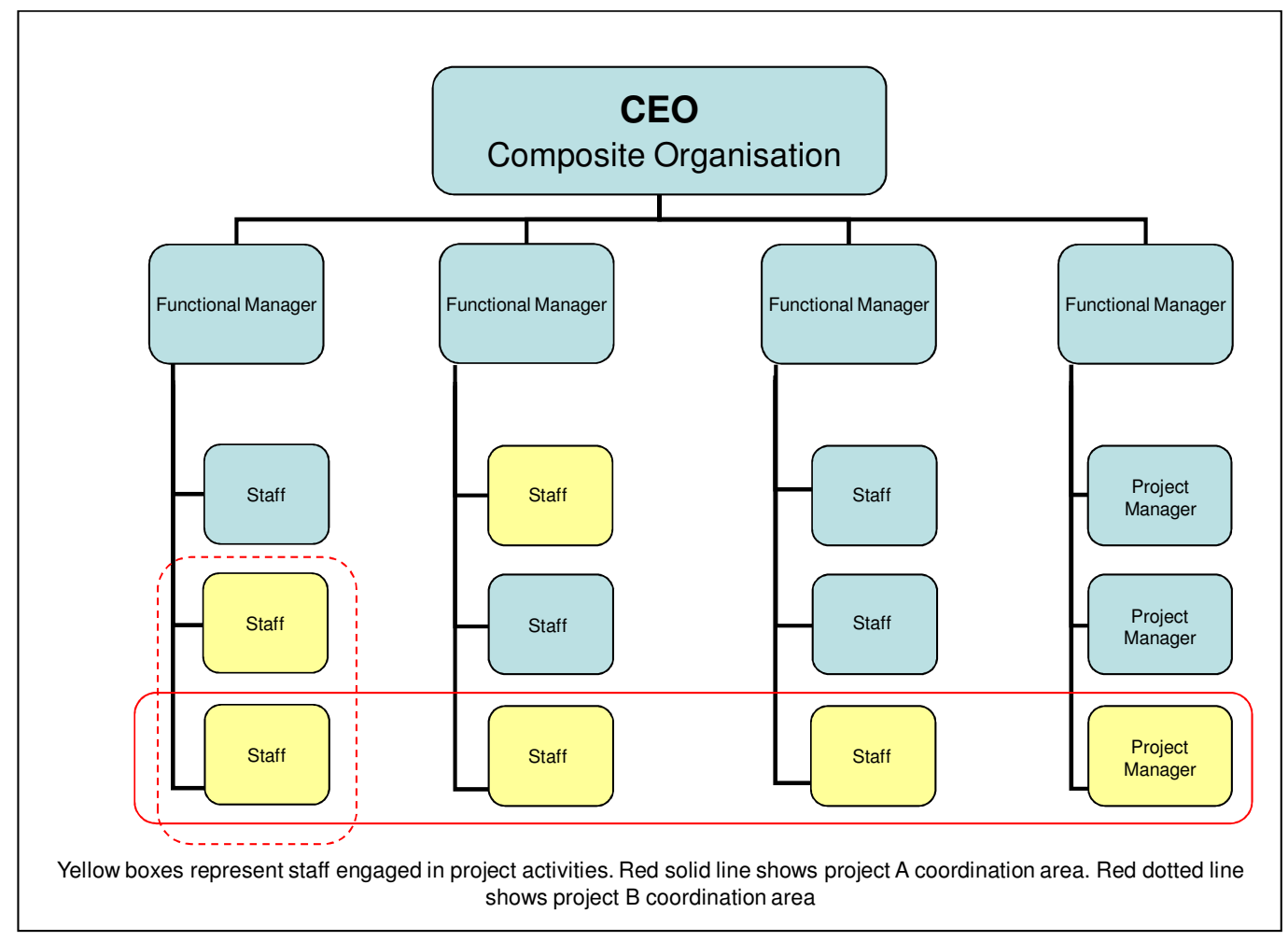

Figure 3-2: Composite organisation

Turner also refers to matrix structures and notes there are a range of five positions across the spectrum (Turner, 1999). These positions are functional hierarchy, coordinated matrix, balanced matrix, secondment matrix and project hierarchy (Table 3-5). 
Table 3-5: Matrix description

\begin{tabular}{|l|l|}
\hline Spectrum & Description \\
\hline Functional Hierarchy & $\begin{array}{l}\text { Project tasks are assigned to relevant operational areas, whose } \\
\text { managers take responsibility for achieving tasks in their area. The } \\
\text { risk in this scenario is if managers disagree on the priorities of the } \\
\text { project, which may result in a lack of resourcing from other areas. }\end{array}$ \\
\hline Coordinated matrix & $\begin{array}{l}\text { Functional managers assign work to people day by day. A project } \\
\text { controller has responsibility for coordinating tasks between the } \\
\text { functions, but has limited authority for ensuring priority is given for } \\
\text { resources. }\end{array}$ \\
\hline Balanced matrix & $\begin{array}{l}\text { A project manager is appointed to oversee the project, and shares } \\
\text { this responsibility with the operational managers. The project } \\
\text { manager is responsible for time and cost, while the operational } \\
\text { managers are responsible for scope and quality. The success of the } \\
\text { matrix is dependent upon the relative strengths of the project and } \\
\text { operational manager and may by default become a functional or } \\
\text { secondment matrix. }\end{array}$ \\
\hline Secondment matrix & $\begin{array}{l}\text { The project manager has primary responsibility for resources, and } \\
\text { assigns their work day by day. The operational managers second } \\
\text { personnel as required, and oversee the quality or the completed } \\
\text { work. In this scenario, the project manager has more effective } \\
\text { control, although the user begins to lose influence. }\end{array}$ \\
\hline Project hierarchy & $\begin{array}{l}\text { The project manager manages a dedicated project team, without the } \\
\text { involvement of the operational managers. In this scenario, the } \\
\text { project manager has total control, the users no longer have any } \\
\text { influence, and the structure is inflexible. }\end{array}$ \\
\hline
\end{tabular}

The different positions provide advantages and disadvantages for the project and the project manager, depending on the organisational particulars and environment of the particular project. For example, in the functional hierarchy, there is a risk of having a lack of resources to undertake the task if resources need to be shared across operational areas. In the coordinated matrix position, there may be resources assigned, but these resources may not be able to be controlled sufficiently to ensure the project is given priority. The seconded matrix attempts to overcome this issue by having an increased control over the resources, but this is at the expense of the involvement of the users. The project hierarchy position is that situation where the project and resources are completely controlled by the project manager within a strict and inflexible project team. The balanced matrix position is considered ideal as it gives the project manager control while maintaining appropriate user involvement levels (Turner, 1999). It also enables involvement from across different sections, with operational managers responsible for scope and quality, while the project manager is responsible for time and cost. The balanced matrix position also provides a suitable position in which the OCT could be deployed, as it could likely require involvement from multiple teams with competing or conflicting priorities, perhaps spread across several sites (or at least business units). 


\subsection{Online Collaborative Toolsets and Project Websites}

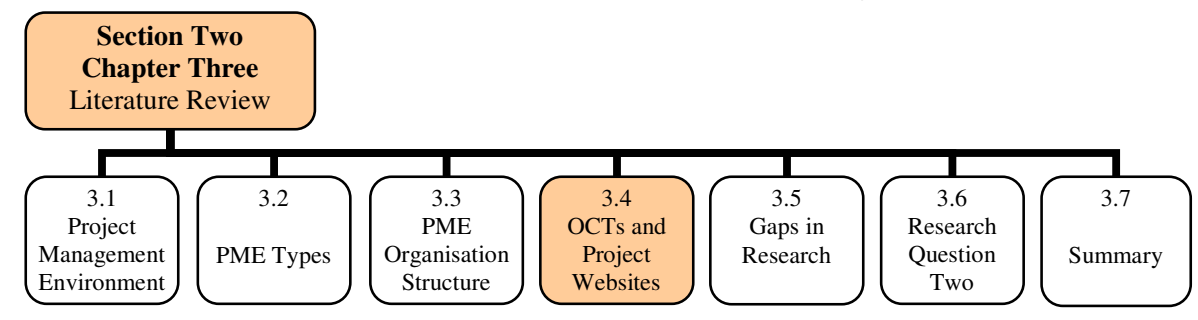

The PME paradigm has begun to shift due to the increasing number of distributed projects involving team members from different sites, organisations and cultures (Romano et al., 2002). Distributed work environments are becoming more active as offshore sourcing and outsourcing strategies are implemented (Qureshi et al., 2005). This has led to the PME taking a different approach - one that utilises the OCTs to manage the teams, to assist in the facilitation of the project deliverables and to support organisational processes reach their potential to increase productivity (Qureshi et al., 2005). Given this, the use of OCTs or project websites within the PME will be discussed briefly in this chapter.

The organisation that hosts the PME can be located in a single physical address, use on-site staff and resources and use an internet-based project management tool (or OCT) to undertake project management related work. The PME in this instance can include staff and distributed project teams from across several floors, buildings, cities or countries. Large scale projects may incorporate input from subject matter experts who are not required to be on-site, and who can undertake their effort from alternate locations. An example of this may be where reports are sent to external companies for analysis, where designs may be drafted, or where legal expertise is provided by an outsourced firm. It is the physical presence of the project, for example a construction or building project, which defines the activity (the product) and the subsequent mechanisms for managing the delivery of this product.

Other projects do not necessarily rely on a physical location in order to deliver the project product, for example the development of software or a piece of government policy. In this instance, the organisation may control a PME that has its members physically distributed across different locations (and possibly countries) and which uses an OCT to undertake its project management related work. 
The distinction here is that the members of the PME may be either physically or virtually present, but regardless of where its team physically exists, it may likely use an internet-based toolkit to undertake project management related tasks. Distributed virtual projects are making an impact in supporting both formal and informal temporary alliances between organisations and groups. In these instances, project team members or enterprises are composed of many different, dynamic and temporary distributed business processes and can contribute to the project in a very similar manner, whilst being dispersed across several physical locations (for example government buildings, academic institutions or countries). These teams also play a significant role in contributing to the organisation's capacity to provide information and knowledge/business intelligence at the required times (Katzy et al., 2000).

Given this, a working definition of a virtual team may be a 'group of individuals who work across time, space and organisational boundaries with links strengthened by webs of communication technology. They have complementary skills and are committed to a common purpose in order to accomplish one or more organisational tasks, have interdependent performance goals, and share an approach to work for which they hold themselves mutually accountable' (Peterson and Stohr, 2008, Qureshi et al., 2005). A simpler definition and one which addresses the use and application of the electronic toolkit is where an electronic project management office system is created to enable virtual teams to collaborate for a finite period of time to achieve a specific goal (Goncalves, 2007). Many organisations realise the benefit of developing and implementing a project management office, especially where the organisation chooses to manage the project through a matrix or projectised organisation structure (PMI, 2004).

This research will not discuss the project management office in detail, but will provide a brief definition. A project management office is an organisational entity established to centralise and coordinate project managers, teams and various management levels on strategic matters and functional entities throughout the organisation to implement project management principles, practices, methodologies, tool and techniques (Dai and Wells, 2004).

However current approaches to project management focus on command and control of distributed processes and not on facilitating distributed networks or collaboration. The OCT presents a logical alternative for monitoring and controlling the progress of the project schedule (Chen et al., 2002), with communication considered the most important factor contributing to the success 
of individuals, project teams and organisational growth. Effective communication is vital for virtual teams that cannot meet in face-to-face settings and which rely on computer mediated technology to share and communicate information (Goncalves, 2007). In these circumstances, it is very important for geographically dispersed members to have a shared understanding of the project deliverables, and a mutual knowledge of the key tasks in order to communicate effectively.

While virtual teams may offer potential benefits to organisations, it comes with a set of challenges peculiar to the virtual environment. The critical factors affecting virtual team development include:

- the team characteristics (size, geographic dispersion and members shared work experience);

- task characteristics (complexity, uncertainty, ambiguity, difficulty);

- information and communication technology choice;

- project management strategies; and

- communication patterns and information sharing and processing (Qureshi et al., 2005).

As discussed in other parts of this thesis, there is significant variation in the understanding people have of the notion of collaboration, and this condition also relates to the way collaboration is understood in the PME and use of OCTs. Collaborative relationships are inherently dynamic in nature (Davenport et al., 1998) however, even if people have varied interpretations of the collaboration in the PME, it does not dilute the premise that collaboration remains a critical component in the contemporary project management paradigm.

If traditional project management is focussed on inputs and outputs of a single project with an emphasis on scheduling, then contemporary project management focuses on managing the work or process of the project through collaborative strategies. In order to achieve the effectiveness and efficiency of these strategies, it is necessary to have a shared understanding of collaboration in the first place and then to agree on the methodology and tools needed to realise these processes. The lower levels of collaboration within the PME focus mainly on information sharing, and while information sharing is important, on its own it is not sufficient (Romano et al., 2002). 
The interaction between project members across sites is essential and requires support in order for collaboration to occur. These interactions include negotiation of goals, working procedures, task allocation, scheduling, resource allocation, and co-working on the same document or task (Romano et al., 2002, Sclater et al., 2001). Without effective interaction support, project members can find that regardless of their effort, they are working towards separate, unaligned or different goals.

The project management system is the set of tools, techniques, methodologies, resources and procedures used to manage a project. It can be formal or informal and aids a project manager in effectively guiding a project to completion. The system is a set of processes and the related control functions that are consolidated and combined into a functioning, unified whole (PMI, 2004). However, using collaboration in the PME is more than putting project management tools on the web so that project management activities can be undertaken at anytime or from anywhere.

As discussed previously, the use of the OCT provides the PME with a suite of tools and resources available from a central and accessible online presence and provides reliable and timely taskrelated information sharing. The OCT within the PME can also be referred to as a project website where the PME and project manager are provided with the opportunity and capability to provide access to information at any time that suits the project worker, through a dedicated website or project portal. This website offers a new approach to communicating project-related material to the project team and can support rapid decision-making.

The use of a project website, and the opportunities it provides, will be dependent on the PME and type of project, its requirements, team makeup and other factors impacting on project dynamics (Katzy et al., 2000). There may also be factors that govern the use of the application aside from the functional characteristics, specifically the approach of the project team to using the tool, and their efforts to introduce it into their daily project-related activities.

O'Brien (2000) lists six key issues that affect the implementation of the project website (Table 3-6). These issues identify non-technical barriers and factors influencing the take-up of the tool, rather than inefficiencies or poor design in the OCT. O'Brien notes that in the construction industry in particular, the level of cooperation within the project team may have little control over the institutional and legal environments in which the project is situated. The project website 
holds the promise of promoting collaborative work approaches, and may provide an open and non-hierarchical approach to managing project information. This becomes problematic however, as even the most collaborative teams typically follow the traditional communications pattern wherein gatekeepers in the owner, architecture (design) and construction firms limit access to communication and information (O'Brien, 2000). As previously discussed, this may also be compounded by an adversarial approach by project partners, which extenuates the restriction of information across the PME.

Table 3-6: Issues affecting implementation of the project website

\begin{tabular}{|l|l|}
\hline Key Issues & Description \\
\hline Resistance to change & $\begin{array}{l}\text { A successful implementation of a project website would ideally involve those } \\
\text { team members who belong to the core operational group to ensure the site is } \\
\text { utilised by the critical users. }\end{array}$ \\
\hline Password barrier & $\begin{array}{l}\text { Website administrators must ensure that the right people have the appropriate } \\
\text { access to the website, including developing different levels of security for } \\
\text { different roles of team members within the PME. It also includes efforts by } \\
\text { people who must use alternate methods to communicate and manage those } \\
\text { stakeholders or team members who may not be given access to the site. }\end{array}$ \\
\hline Communication density & $\begin{array}{l}\text { The project team must ensure it has the necessary discipline and motivation to } \\
\text { commit to using the website as a communication channel. This is especially } \\
\text { important to ensure communication remains effective and is not diluted by other } \\
\text { (pre-existing) communication channels. }\end{array}$ \\
\hline Team tools & $\begin{array}{l}\text { Project websites offer a list of features that must be generic in nature to minimise } \\
\text { effort for users to adopt its features. This results in the tool offering a variety of } \\
\text { features to cover as many different users as possible, rather than specific features } \\
\text { that can be successfully deployed by the entire team. This contributes to a } \\
\text { dilution in its use and a conservative approach to the tool. }\end{array}$ \\
\hline Collaborative maturity & $\begin{array}{l}\text { The project website suggests a collaborative work approach, including an open } \\
\text { and non-hierarchical method for the distribution of information across the PME. } \\
\text { In a collaborative environment however, people may remain uncomfortable in } \\
\text { giving power away, and may also view the existence of the project website as a } \\
\text { threat to this power. }\end{array}$ \\
\hline Related legal issues & $\begin{array}{l}\text { The project website can hold many different types of information, and as such the } \\
\text { status of the record/document/entry kept within the website should be considered } \\
\text { to form part of the project's official records management system. }\end{array}$ \\
\hline
\end{tabular}

Clearly communication plays a central role in the performance of the virtual team. Effective communication entails not only ensuring the information reaches the receiver but that the receiver understands its messages and the action required. A team operating in the virtual environment faces greater obstacles to orderly and efficient transmission of information across the team, as they have greater reliance on their I.T. network and subsequent OCT (Qureshi et al., 2005, Goncalves, 2007).

There are factors other than communication that play an important role in the effective use of virtual teams and /or distributed PMEs. Trust plays an important role if cooperative information 
sharing is to exist (Barua et al., 1997). Qureshi (2005) also notes that trust can be especially elusive and fleeting in virtual teams especially if there are issues with communication or appreciating the cultural differences of the team members. And although virtual teams have the characteristic to sustain communication in order to maintain a shared understanding, a lack of trust also tends to discourage communication amongst team members. Coordination itself poses a significant and constant challenge in the distributed and virtual PME, because when multiple time zones are in play, the context of distributed project management can become difficult if underappreciated. In these instances, the use of video to audio-based communication can assist in improving the decision-making process especially when compared to other collaborative technologies (Qureshi et al., 2005).

Work adaption is seen to present many opportunities and challenges for distributed projects. Adaption provides a catalyst to lateral thinking that can prove to be a crucial input in creative problem solving. In these instances, technology can play a vital role in supporting distributed project management and assist in lowering barriers and providing increased freedom (Qureshi et al., 2005). The actual presence of teamwork will also impact on the level of information sharing and team member interaction within the OCT (Barua et al., 1997). There is an interrelationship between the above factors which suggests that distributed project management requires a high degree of communication and coordination (Qureshi et al., 2005, Romano et al., 2002).

As such, having an understanding of the way in which the OCT is used within the PME becomes important. The organisation must determine if these tools provide functionality which contributes to the useful and effective management of projects, or rather proposing an(other) electronic avenue in which to undertake tasks, without regard for collaborative conditions or improving the project management functions. The risk is that OCTs 'have been designed to combine a centralised and unified way of sharing information with technology that lends itself to the creation of a central data repository' (O'Brien, 2000). 


\subsection{Gaps in Research}

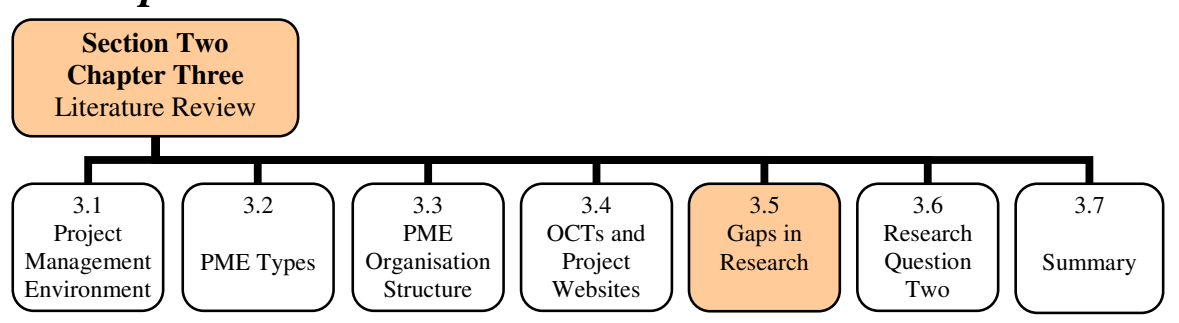

Chapter Two on OCTs showed that the use of Web 2.0 may provide opportunities for the PME to develop more flexible and social networking orientation to its communication and information dissemination regime. Given this, the use of Web 2.0 within the OCTs used in operational PMEs may herald a change in the way information is managed and communication is controlled. The literature search did not uncover any examples where a social network-enabled OCT was deployed across a sophisticated project environment, therefore the value or relevance of this technological promise is yet to be fully understood or measured.

This chapter has covered the well known areas of project management knowledge and project types, and noted the varying matrix structures identified with the different organisational types. This is a well understood area, with the Literature Review uncovering the necessary documents to enable an informed approach for the subsequent investigation. The area where some gaps may occur is within the realm of the virtual project teams and how this may impact on the use of online collaboration. The literature uncovered examples where the virtual teams were reviewed, however their use of an OCT or specific use of project websites was not forthcoming; a result that not only supports the approach of the research, but identifies an area where further research may be warranted. The review found the discussion of virtual teams often focussed on the manner of transmittal and the subsequent results, rather than on the operational or functional aspects of this net-enabled shared space.

Within the discussion of the features and application of the OCTs, and the manner in which the PME can be structured, the literature was scant on the direct linkage between these two environments. As previously noted, the research at hand amounts to a search for an understanding of the relationship and conditions under which the PME can utilise the OCTs, and the direct benefit that this deployment provides to the users, extended team and management groups. Significant bodies of data did not exist, or were elusive to the researcher, supporting the quest of the research, and highlighting the situation where software deployment can continue in 
an organisation without a post implementation review being conducted. Notwithstanding these assessments may exist in commercial-in-confidence or corporate repositories, this research sought, unsuccessfully, to identify information that supported the premise that a tool designed for online collaboration had been evaluated for (collaborative) activity in an actual working PME.

\subsection{Research Question Two}

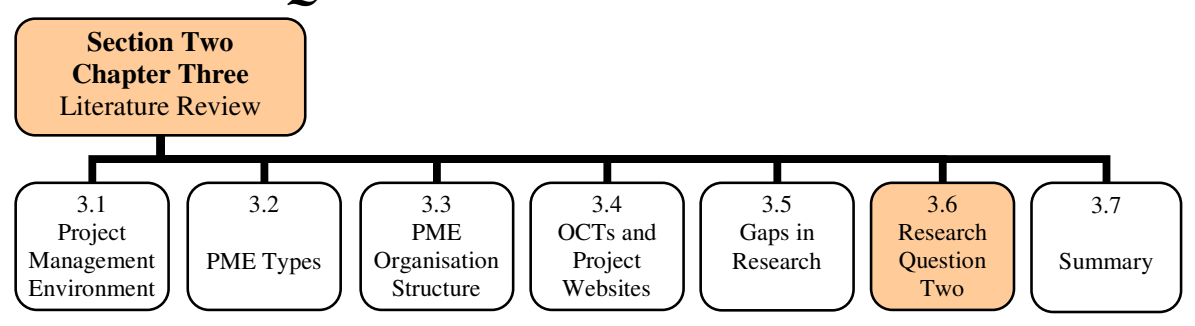

This chapter has detailed the different environments that can be utilised to deliver a project and the associated conditions under which an OCT or project website can be deployed. In reviewing these conditions, it noted that the PME can have several forms and deploy several mechanisms in order to manage the project environment. The use of the OCT within this environment is not simply a matter of selecting a product and then applying it to the working environment. Rather it is a matter of customising and managing the tool to meet the needs of the project type and the project participants.

\section{Research Question Two: How are OCTs used in the PME?}

In framing this question, the research carries on the theoretical work introduced in the first research question, and places the features of the OCTS into a specific operational context - i.e. the PME. Its takes the information gathered from the first question and applies it to the second, thereby narrowing the review of the OCT to a specific operational use. The proposition below references the different types of organisation structures and environments and reviews the actual manner in which the OCT will be deployed in the working environment. It proposes that there may be some ground between the capabilities of the OCT and the way in which the team environment actually uses the OCTs in its work.

Proposition Two: $\quad$ OCTs in the PME are used for cooperation and coordination, and to a lesser extent, collaboration. 
In framing the second research question and proposition in this way, the research highlights the work in this section and introduces future work to come in this thesis. It also serves as a prompt for the following section in this Literature Review chapter; a section that reviews the concept of collaboration. This second research question and associated proposition also maintains a direct link to the overarching research question:

Does collaboration occur through the use of online collaborative toolsets in the project management environment?

\subsection{Summary}

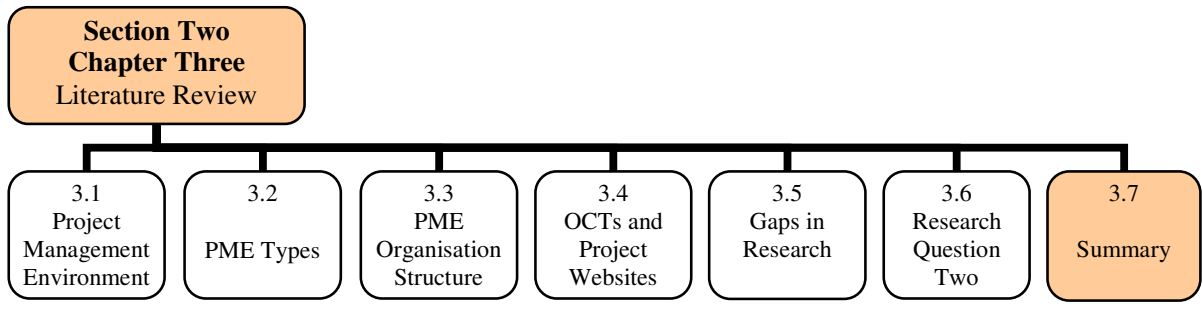

This chapter reviewed issues associated with project management, and in doing so set up the second research question for the study. It reviewed the PME and sought to apply some definitions or descriptions to these and outline the key knowledge areas. The chapter also discussed the different types of PME. It identified that for the purposes of this research, organisations are either project-based or non-project based and outlined the four main project types. The chapter then discussed matrix organisation structures and concluded with a discussion of OCTs and project websites within the PME. It highlighted that members of the PME are either physically or virtually present, and given this, the PME is likely to use an internet-based toolkit to undertake project management related tasks. As with the previous section, the section concluded with a research question and associated proposition.

The next chapter in this section will review the research issues surrounding the concept of collaboration, and look in some detail at the associated terms of cooperation and coordination. This work will conclude the review of the literature and identification of the issues relevant to the research as a whole. 


\section{SECTION TWO}

\section{CHAPTER FOUR - Collaboration}

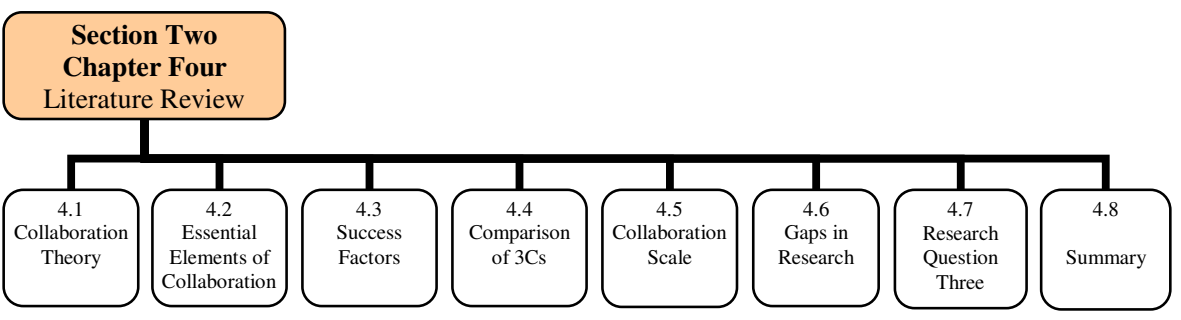

This chapter extends the work covered in the previous two chapters, and introduces the final element of the research; that of collaboration. By reviewing what is understood by the term collaboration and how it can be applied within the project management environment (PME), the research further confines the scope of this review and identifies the instances in which collaboration can be said to exist.

The previous two chapters highlighted the features of the OCTs and how these may apply to the PME. It identified the nexus of these two areas, and noted the common ground on which they can be applied. This third chapter reviews the literature and research issues concerned with the term collaboration, in an effort to further concentrate the research at hand, and to investigate the role of collaboration in the application of the OCT. Given that the term collaboration features heavily in the description and application of these tools, and that the vendors target the use of these tools for the PME, it is pertinent that the research understand the role that collaboration plays in the deployment of these tools, and the degree to which it is required by the organisation.

This chapter will begin by reviewing collaboration theory and providing some useful definitions. It will then discuss the essential elements of collaboration, and report on the success factors that may apply to the successful deployment of collaboration. The chapter will then compare three terms - cooperation, coordination and collaboration - in an effort to clarify the distinguishing features of these three terms, and how this may be applied to the research at hand. It will then present a Collaboration scale that has been developed by this research as a result of the findings from the literature search. The Collaboration scale is a mechanism to measure the level of collaboration occurring within the cases. The chapter then outlines the gaps in research and concludes with the introduction of the third and final research question. 


\subsection{Collaboration Theory}

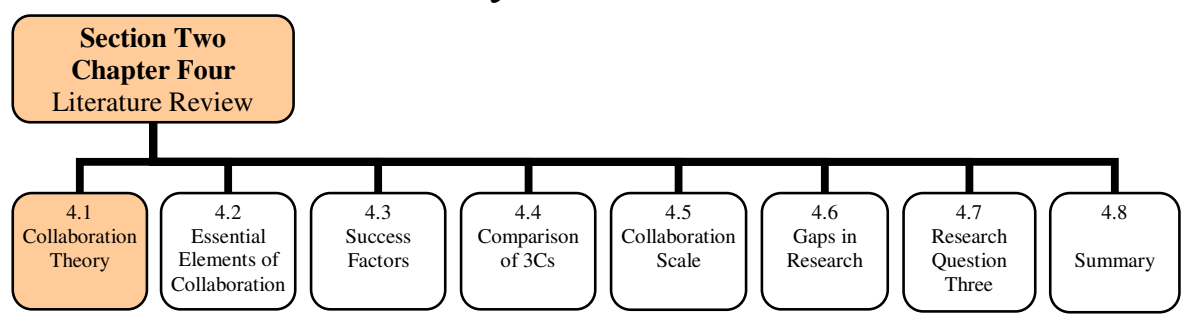

This third and final chapter of Section Two deals with the three terms of cooperation, coordination and collaboration, and seeks to uncover the elements of each in order to develop a scale of differentiation for the terms. This scale details an ingredient list against which each concept can be associated. In detailing these, this research provides an understanding of the instances and environments in which these terms can be found operating within the PME and their relative applicability to OCTs.

It may prove useful to begin this chapter with some working definitions of these three key terms: cooperation, coordination and collaboration.

\subsubsection{Definitions}

Defining collaboration is made complex by ambiguities in practical usage and general disagreement or flexibility in the way in which the term is applied. It is not uncommon to see in practical use, the term 'collaboration' being used interchangeably with 'cooperation' and 'coordination' (Mattessich et al., 2001, Fitzek and Katz, 2006). However, cooperation, coordination and collaboration have distinct meanings within the PME and it is these meanings that this section clarifies.

\section{Cooperation}

Cooperation is characterised by informal relationships that exist without any commonly defined mission, structure, or planning effort. Information is shared as needed, and authority is retained by each organisation so there is virtually no risk. Resources are separate as are rewards (Mattessich et al., 2001). It has also been described as the action or process of working jointly towards the same end (The Concise Oxford Dictionary, 10th Edition 1999). Argyle (1991) defines cooperation as acting together in a coordinated way at work, leisure, or in social relationships, in the pursuit of shared goals, the enjoyment of joint activity, or simply furthering the relationship. Cooperation can also be understood as joint action for mutual benefit, and is the 
strategy of a group of entities working together to achieve a common or individual goal (Fitzek and Katz, 2006). This is in contrast with Schermerhorn's definition of cooperation, where he sees it as deliberate relations between otherwise autonomous organisations for the joint accomplishment of individual operating goals (Schermerhorn, 1975). There is thus complexity over the definition of cooperation, where it can also be seen to be taking place at a small or large scale with few or many collaborating entities (Fitzek and Katz, 2006). The use of one term to describe another supports the quest of this research to provide some clarity around the different terms.

\section{Coordination}

There are also many definitions for coordination with an associated lack of consistency in these definitions (Rogers and Whetten, 1982). Rogers and Whetten propose that coordination can mean different things for different people, and due to the many ways in which its elements can be used or incorporated into processes and strategies, the term has been used synonymously with or confused with a variety of related concepts including cooperation. This lack of agreement about meaning has led the authors to note that propositions about coordination are tenuous at best whilst cautioning practitioners to be wary of applications developed for this use (Rogers and Whetten, 1982).

Coordination can be seen to be the action or process of bringing different elements of a complex activity or organisation into a harmonious or efficient relationship (The Concise Oxford Dictionary, 10th Edition 1999). Coordination is also characterised by relationships that are more formal and which have an understanding of compatible missions. Mattessich et al (2001) note that some planning and division of roles are required, and communication channels are established. Authority still rests with the individual organisations, but there is some increased risk to all participants. Resources are available to participants and rewards are mutually acknowledged (Mattessich et al., 2001).

As coordination often exists across two or more organisations, the term has also been linked with intra and inter-organisation coordination. Rogers and Whetten (1982) define interorganisational coordination as the process whereby two or more organisations create and/or use existing decision rules that have been established to deal collectively with their shared task environment. 
Other authors who also acknowledge the connection with the interorganisational condition. Hall et al (1977) define coordination as the extent to which organisations attempt to ensure that their activities take into account those of other organisations. Warren et al (1974) also conceptualise coordination within the interorganisational domain and note its relevance to decision-making. They define it as a structure or process of concerted decision-making or action wherein the decisions or action of two or more organisations are made simultaneously in part or in whole with some deliberate degree of adjustment to each other.

\section{Collaboration}

There are many variations to the definition or application of collaboration, with some seeing it as being simply equal to participation (Romano et al., 2002) while others consider it to embrace an ability of two or more people or groups to transfer data and information online (Breite and Vanharanta, 2003). Collaboration can however, connote a more durable and pervasive relationship other than this rudimentary level of interaction. Mattessich et al (2001) consider that collaborations have the capacity to bring previously separated organisations into a new structure with full commitment to a common mission. Such relationships require comprehensive planning and well-defined communication channels operating on many levels.

In these new relationships, authority is determined by the collaborative structure and risk is much greater because each member of the collaboration contributes its own resources and reputation. Resources are pooled or jointly secured, and the products are shared (Mattessich et al., 2001) in the collaborative relationship.

The definition provided by The Concise Oxford Dictionary, 10th Edition (1999) does not provide a significant difference between its definition of cooperation and collaboration, by noting that collaboration is also an act of working jointly on an activity or project, while Schrage (1990) notes that collaboration is the act of constructing relevant meanings that are shared by all parties involved to achieve congruent goals. For Gricar (1981) however, collaboration refers to the interaction between two or more organisations in which they identify and acknowledge the ways in which they are mutually interdependent with regard to a particular issue or set of issues.

This is consistent with the definition that collaboration includes two or more people sharing complex information on an ongoing basis for a specific goal or purpose or to achieve common 
goals (Coleman and Antila, 2004, Mattessich et al., 2001). Mattessich et al (2001) also note that the collaborative environment includes a commitment to mutual relationships and goals; a jointly developed structure and shared responsibility; mutual authority and accountability for success; and sharing of resources and rewards.

Given the above definitions for the three terms, it would seem clear that they are closely aligned, and yet are being used in different settings and without clarification when they are used. The melding of the three terms is a constant reminder of not only the various manners in which words are applied in common or everyday use, but also strike a chord when one word in particular, 'collaboration', is applied consistently to a suite of software products or project environments.

This issue will be revisited at a later stage, and begs the question about which definition is being applied in these instances and the different definitions that are being applied to products, and/or the rationale for describing the occurrence of collaboration (Romano et al., 2002).

A review of the literature around collaboration reveals several essential elements that contribute to collaboration being present in a specific environment. These elements include communication, trust and respect, equality and power, strategic alliances or partnerships, incentives, negotiation, and interorganisational knowledge sharing. Table 4-1 highlights a sample of the literature against these elements, while the next section of this chapter will discuss each of these elements.

Table 4-1: Sample of literature dealing with collaboration

\begin{tabular}{|l|l|}
\hline Collaboration element & References \\
\hline Communication & $\begin{array}{l}\text { Davenport et al., 1998, Austin, 2000, Batt and Purchase, 2004, Bharadwaj et al., } \\
\text { 2004, Mattessich et al., 2001, Sclater et al., 2001, Qureshi et al., 2005. }\end{array}$ \\
\hline Trust and respect & Vangen and Huxham, 2003, Austin, 2000, Barnes et al., 2000, Batt and Purchase, \\
& 2004, Davenport et al., 1998, Mattessich et al., 2001, Reina and Reina, 2006, \\
& Black et al., 2002, Herzog, 2001, Qureshi et al., 2005. \\
\hline Equality and power & Vangen and Huxham, 2003, Austin, 2000, Walker, 2003, Batt and Purchase, 2004 \\
\hline Strategic alliances or & Austin, 2000, Batt and Purchase, 2004, Kamensky and Burlin, 2004, Mattessich et \\
partnerships & al., 2001, Yoshino and Rangan, 1995, Black et al., 2002, Lendrum, 1998. \\
\hline Incentives & Austin, 2000, Mattessich et al., 2001, Barua et al., 1997. \\
\hline Negotiation & Davenport et al., 1998, Mattessich et al., 2001, Romano et al., 2002, Phillips et al., \\
\hline Interorganisational & Romano et al., 2002, Austin, 2000, Binz-Scharf, 2005, Black et al., 2002, Gricar, \\
knowledge sharing & 1981, Vangen and Huxham, 2003, Coleman and Antila, 2004, Davenport et al., \\
& 1998, Phillips et al., 1998, Katzy et al., 2000. \\
\hline
\end{tabular}


Other elements identified as contributing to the instance of collaboration within the PME include

- commitment to the project, and to the collaborative environment;

- flexibility on behalf of the team members and partners;

- continuity;

- learning environment;

- leadership;

- good personal relationships;

- an element of risk, which would increase and be shared amongst partners as the collaborative process increased;

- the presence of a 'Collaboration Champion' to drive the collaborative effort and to push the mechanisms and procedures that support a collaboration;

- project members connecting with a sense of purpose and a clarity of purpose; and

- congruency of the mission of the project environment.

\subsection{Essential Elements of Collaboration}

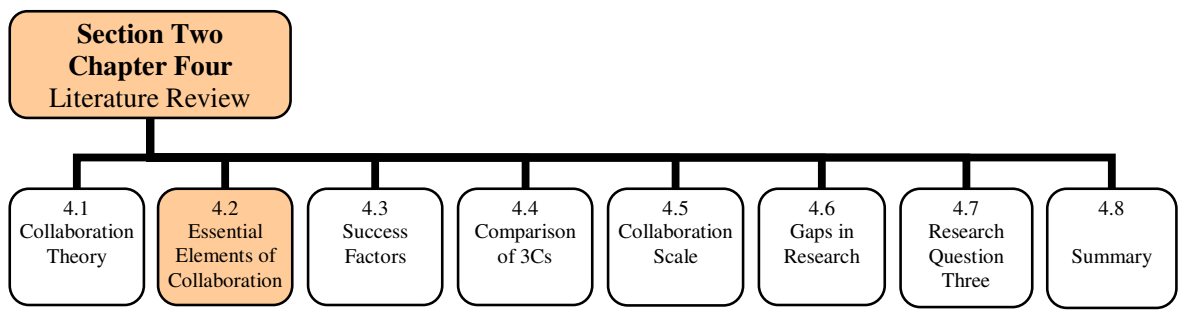

It is not the intention here to contribute to the development of the theoretical understanding of cooperation, coordination and collaboration, but rather to provide a general overview of the issues related to collaboration's essential elements, as outlined by Harley (2005) and the manner in which it manifests within the PME. This enables the research to review the role these elements occupy within the PME, and to increase the understanding of the inter-relationships amongst them. As such, the material presented here provides a general understanding of the position of each of these seven Collaborative elements in the context of this research. Each element will now be reviewed individually.

\subsubsection{Communication}

Collaboration does not occur in a vacuum, and as such, communication plays an important role (Sclater et al., 2001). This is especially the case in virtual teams and consequently distributed project management (Qureshi et al., 2005). It is also essential in the PME and in the use of any type of collaborative tool. Communication can be considered essential for any group-undertaking 
as without it (in whichever format or medium it may occur), the message cannot be delivered with any accuracy.

The ability to communicate effectively is critical if information is to be shared and/or distributed. It has been described as the key that holds together a channel of distribution (Batt and Purchase, 2004). It is not coincidental that communication appears as the primary element for collaboration (and is also implicit in the understanding of other terms - coordination and cooperation). Open and frequent communication is considered to be a critical factor that can influence the success of collaboration, as is the importance of establishing informal relationships and communication links (Mattessich et al., 2001).

Communication between partners of an alliance or PME is also critical, with Austin (2000) drafting several questions that he proposes should be considered when reviewing the effectiveness of the collaboration. These questions seek to understand the culture and level of communication between partners including;

- What level of trust and respect exists between the partners?

- Is communication open and frank and is critical communication constructive?

- How is communication between the partners managed?

- Does each partner have a relationship manager?

- What channels and vehicles are used to communicate internally?

- Are there potential dissenters, and can they be converted?

- How does the alliance communicate externally?

- Do the partners have a coordinated external communication strategy and program?

- Is the partnership underpublicised? (Austin, 2000)

However the number of channel options available to the project team may affect the quality of the communication. The variety of channels include telephone (land line and mobile), fax, voice mail and email - add the OCT to this suite, and the PME requires discipline to ensure the most suitable medium is used at the most suitable time, even to the extent of project managers foregoing communication by other media for specific types of information (O'Brien, 2000).

Communication is also crucial in associated channels of the project, where it can serve as an ideal process by which persuasive information is transmitted, participative decision-making is fostered, programs are coordinated, power is exercised and commitment and loyalty are encouraged (Batt and Purchase, 2004). 
There are instances that can lead to problems occurring with communication, for example social barriers, where the lack of experience working within a collective environment can present other problems (Sclater et al., 2001), or where there is a lack of communication skills which affects the manner and effectiveness of collaboration (Bharadwaj et al., 2004). These problems are barriers to communication and can be due to issues such as not knowing the collaborators in advance, not having clearly defined roles and responsibilities, misunderstandings between members and conflicting institutional or organisational cultures (Sclater et al., 2001).

The ability to effectively communicate across the PME is inextricably linked not only to the content and motivation behind the desire to disseminate the information, but to the management of the collaborative environment itself (Davenport et al., 1998). Without the capability to communicate, it is difficult to manage the expectations of others, and the collaborative environment. This has a flow-on effect to the fulfilment of trust and respect, and the sharing of information within and across the PME.

\subsubsection{Trust and Respect}

It is important to understand or gauge the level of trust and respect that may exist between the partners within the PME (Austin, 2000). The notion of trust occupies a central position for practitioners involved in collaborative initiatives (Vangen and Huxham, 2003). Trust is seen to be the essential intangible asset of collective alliances, the interpersonal webbing that knits organisations together and facilitates concerted effort. Trust is reciprocal, in that one has to give it, in order to receive it, and is built step by step over time (Reina and Reina, 2006). It is also one of the key areas of concern in maintaining a good relationship (Austin, 2000, Batt and Purchase, 2004) and effective communication (Qureshi et al., 2005).

Barnes et al (2000) see trust as being an integral success factor of collaboration. Trust develops through active engagement and participation with others and the delicate fabric of human relationships (Reina and Reina, 2006). The development of trust is an important characteristic that a strategic alliance/partnership requires, although it may not necessarily be required for cooperation to occur (Kadefors, 2004). When creating an alliance, consideration needs to be given for the implications of setting up a collaborative environment where there is no history of relationships between (at least some of) the participating organisations or where previous 
relationships have not engendered mutual trust (Vangen and Huxham, 2003). The PME provides an excellent situation in which these tensions can be tested, as it draws on various team members from different business units, partnering organisations or affiliated companies. The effective operation of the PME will require an understanding of trust and respect, and the factors that may impact on its presence, including the collaborative team member's perception of themselves, of other collaborative team members, and of other collaborative stakeholders involved with the project (Herzog, 2001).

As has been noted for collaboration in general, there are also many different forms of trust that can exist in the PME. Four types of trust are of interest here - contractual, competitive, goodwill and communicative.

- Contractual trust relates to adherence to agreements and promises. It implies there is a mutual understanding that the people in the relationship will do what they say they will do. It deals with keeping agreements, honouring intentions and behaving consistently. Contractual trust forms the basis of most interactions in the workplace (Reina and Reina, 2006, Davenport et al., 1998).

- Competence trust involves acknowledging people's performance, skills and abilities, allowing people to make decisions, involving others and seeking their input, and helping people learn skills (Davenport et al., 1998, Reina and Reina, 2006, Hartman and Romahn, 1999).

- Goodwill trust exists where a mutual commitment is given by the partners in a relationship (Davenport et al., 1998).

- Communication trust is the willingness to share information, tell the truth, admit mistakes, maintain confidentiality, give and receive constructive feedback and speak with good purpose (Reina and Reina, 2006). A breakdown in communication trust can result in a decrease in the amount of risk or collaboration being undertaken in a project, and a reduction of information sharing and overall decreased performance.

Other forms of trust include emotional trust and ethical trust, both of which can be found to exist in the collaboration environment (Hartman and Romahn, 1999). It is also the combination of the different types of trust that influence collaborative levels of trust (Reina and Reina, 2006). 
Trust features in many frameworks for organisations. This is because effective inter-firm links and associated learning between partners depend on high levels of trust (Davenport et al., 1998). In an interorganisational environment, trust can become a major governance mechanism in that it facilitates coordination and collaboration and assists with knowledge sharing (Black et al., 2002).

Notions of trust, knowledge sharing and collaboration become central elements of interorganisational relationships (Black et al., 2002, Vangen and Huxham, 2003). These elements are particularly important for the PME if interorganisational relationships are to involve the mutual participation of people, and an element of cooperation, coordination or collaboration. Trust in this instance, is best understood in terms of the ability to form expectations about the aims and the partner's future behaviour in relation to these aims. A necessary condition for trust is that expectations can be formed on the one hand, and fulfilled on the other (Vangen and Huxham, 2003). Trust has been shown to play a major role in the effectiveness of information sharing and organisational learning, and in knowledge and information sharing in interorganisational relationships (Black et al., 2002).

Of note however, is that cooperation does not necessarily require trust; and it may be induced by coercion. However trust is considered vital to bringing about farther reaching cooperative processes.

Much has been written about the development of trust building and the mechanisms for maintaining trust, however for the purposes of this research it is sufficient to say that trust remains a core element within the application of the three terms of cooperation, coordination and collaboration (3Cs).

\subsubsection{Equality and Power}

Even when attention is paid to the project environment and the management of trust within relationships, the inherent fragility of the trust loop is evident. Alongside the issues relating to the dynamic nature of collaboration, power issues in particular have the capacity to affect this loop (Vangen and Huxham, 2003). Power in collaboration lies not in directly controlling the behaviour of individuals, but rather in defining/creating a situation that constrains and/or enables individuals (Walker, 2003). 
Collaboration involves both aligning the economic goals and aims of the network and the development of the social dimensions. Power is an essential characteristic of social organisations and an inevitable instrument for organisational coordination (Batt and Purchase, 2004). It entails parties being able to understand the relationship so that its own interests can be articulated clearly in order to function within the operating environment (Walker, 2003).

A paradox of collaboration is whilst the process of collaboration creates dependency between the partners, inevitably some will be more central to the enactment of the collaborative agenda than others. This frequently leads to perceptions about power imbalances between those viewed as 'principal' versus those viewed as 'subsidiary' members (Vangen and Huxham, 2003).

Power in collaboration is typically fragmented, yet can achieve collaborative advantage by finding ways to ensure shared power is maximised. The way in which parties negotiate their positions of power and equality within the operating environment leads to the fulfilment of an effective partnership and strategic alliance. And while it is inevitable that the collaborative partners may have unequal power bases, the assumption is that all collaborative participants will be, and should be, equal within the confines of the collaborative project (Walker, 2003).

Technology has the capacity to enable information sharing, but it is dependent upon people in teams wanting to share their information with others. One reason given for people's unwillingness to share information is that information is linked to power and money (Barua et al., 1997), while another suggests that even in collaborative environments, people are uncomfortable giving power away (O'Brien, 2000).

\subsubsection{Strategic Alliances}

Firms do not operate in isolation but must seek to collaborate with other organisations and within other networks in order to achieve their goals and desired outcomes. Networks have risen to prominence due to industrial restructuring, large scale downsizing, vertical disaggregation and outsourcing, and the elimination of management layers. Replacing them are leaner, more flexible firms focused on core technology and processes. 
These firms are closely aligned in a network of strategic alliances and partnerships with customers, suppliers, distributors and competitors (Batt and Purchase, 2004). This network is evident across the contemporary project environment, which shows input from several specialist firms or affiliated suppliers.

The strategic alliance encapsulates relationships between two or more suppliers that are servicing the same customer base, and are thus partners in a horizontal association. The driving forces initially behind the alliance includes cost savings, greater efficiencies, synergy, critical mass, stability, and/or competitive advantage (Lendrum, 1998).

Collaboration is closely tied with the key characteristics of strategic alliances (Yoshino and Rangan, 1995). The first characteristic of strategic alliances is that the participating organisations are pursuing a set of common goals, and that they remain independent subsequent to the formation of the alliances. The second characteristic is that the partnering organisations share the benefits of the alliances and control over the performance of the tasks or activities. The third characteristic is that the partnering organisations contribute on an ongoing basis in one or more key strategic areas.

A firm's position in the alliance or network will depend on the nature of the direct and indirect relationships it has with other players in the network. It will also be determined by the nature of the project, and the associated structures that contribute to the delivery of the outputs. This is exemplified by the different types of project environments that are possible within a collaborative network and the organisational structures that are in place to manage these. Each of these environments, including construction, research, government and interorganisational to name a few, would have a different requirement for their project relationships and subsequent role of their strategic alliance partners.

The commitment given to the partnership by the members is also crucial in ensuring that the relationship can sustain the project timelines. Other factors to consider when reviewing the strategic alliance are whether there is an understanding by the partners of the level of commitment required, the expectations of the partners, whether these are commensurate with execution capabilities and the partner's competency in the area, and if the alliance is considered to be managed properly (Austin, 2000, Davenport et al., 1998). 
Ultimately however, the players or partners within these projects are contributing to a shared or common business objective, or have an incentive for their participation. They share a stake in both the process and the outcome, have multiple layers of participation, and are flexible in regards to the process and structure of the collaboration (Mattessich et al., 2001).

\subsubsection{Incentive and Value}

For the collaborative partnership to work, there needs to be a requisite amount of investment or buy-in by the partners. It is important for members to perceive the collaboration as in their selfinterest (Mattessich et al., 2001), even though the purpose of the partnership is to have a shared vision with attainable goals and objectives.

The creation of value is an element that facilitates the return of effort or investment for the participating partners. Partners may be looking at the PME to identify certain areas where value can be achieved as an incentive to participate, an example being team-based rewards provided in anticipation of a return in better teamwork (Barua et al., 1997). Partners may choose to identify specific benefits that may flow out of the collaboration, weigh up the issue of cost and risk of participation, consider whether social value can be generated from it, and if there are new resources, capabilities or benefits that are being created as a result of the collaboration. When considering these issues, it may also be that the participating organisation should review whether or not to continue with the collaboration (Austin, 2000).

Reciprocal behaviour within the relationship also emerges from a perceived self-interest in a world of permanence and trust, where a team provides information needed by another in anticipation of receiving a similar favour in the future (Barua et al., 1997). This prompts the notion that concepts of incentive and value are closely associated with the type of partnerships or 3C environments that can occur, as well as the expected returns for this engagement. A shared incentive may also decrease the number or severity of disputes, as there is a mutual financial imperative to complete the project. 


\subsubsection{Negotiation}

Collaboration requires a degree of negotiation to occur between the participating partners so they can come to an understanding of the terms of conditions and rules of engagement of their relationship. These negotiations assist in drafting and creating a consensus on operating factors such as the roles and responsibilities of the partners. These negotiations can however be made complex when there is no legitimate authority present to manage the situation and where power and politics become mission critical elements. Participants can remain relatively autonomous within the network, and may need to be convinced to act on their own volition, as there is no legitimate authority that can demand cooperation (Phillips et al., 1998). This approach may not be available to partners who are engaged in significant partnerships, or as stated earlier, strategic alliances. Negotiations can be undertaken in a variety of ways. They can be fluid and loose or in a structured environment, be influenced by market and authority based relationships, or can be based on autonomous participation (Phillips et al., 1998, Walker, 2003).

Ultimately, in order for the PME to survive, partners must embrace a notion of collaboration, one that includes a collective strategy in which organisations cooperate rather than compete, and can compromise when required (Phillips et al., 1998, Mattessich et al., 2001).

\subsubsection{Interorganisational Knowledge Sharing}

Knowledge is a vital resource in project-based industries. In order for collaboration strategies to occur, partners should be able and willing to both distribute knowledge to other members and integrate knowledge made available to them (Halme, 2001). Although this can be realized by managers, it is not easy to find a starting point for managing knowledge in an organisation. The task presents new and challenging processes for the PME (Van Donk and Reizebos, 2005).

Advanced I.T. has prompted many organisations to invest in distributed computing systems and to decentralize the management of information. Yet while decentralised and distributed information management may result in high-quality information being gathered and maintained, there is a risk that islands of high quality information may emerge rather than being shared across the PME. 
For this reason, the role of the information system within a collaborative environment can be to create linkages among sub-units through the development of appropriate policies, guidelines and standards. Today's project organisation requires an effective information-exchange to bridge costly information gaps between different decision-makers or teams controlling specific information or data sets, and to share resources to achieve optimum project deliverables (Romano et al., 2002).

Interorganisational collaboration has the capacity to improve strategic performance in a number of areas within the PME, by helping to spread risk, share resources, enhance flexibility, increase access to technological know-how and information, and provide formal and informal communication links (Phillips et al., 1998, Mattessich et al., 2001).

Knowledge developed in projects and subsequently distributed among project participants provides a vital mechanism for the PME, allowing multi-project organisations to support decisions on a variety of fronts including resourcing and skills development (Van Donk and Reizebos, 2005). Knowledge can be imitated, copied or transferred through various communication channels. The resulting effects depend on the different makeup of the partners, in particular if it includes an individual, group, or entire entity (Binz-Scharf, 2005).

Knowledge sharing in projects will include explicit (to know about facts) as well as tacit and embedded forms, the latter expressed in actions, procedures and/or artefacts, that is, the knowhow of something (Katzy et al., 2000). These are likely to vary considerably across different project environments or work scenarios and are much more difficult to transfer. Tacit or embedded knowledge cannot be separated from the work culture and the social construction of the work processes in each organisation, and as such is inextricably linked to the culture of the PME and the associated relationships. Explicit knowledge transferral can be understood by reviewing and analysing communication patterns within the organisation, while implicit knowledge transfer needs to be judged by how the knowledge is applied (Katzy et al., 2000). In light of the Research Question, this is an important issue to keep in mind, as the research continues to review the manner in which OCTs are used in the operations of actual PME and the degree to which collaboration plays a part in this use. 
Knowledge can be distinguished as something that is either possessed by an individual or a group. It may also be viewed as an organisational-level phenomenon, embedded in organisational forms, social expertise, and as 'knowledge-in-practice' situated in the historical, socio-material and cultural context in which it occurs (Black et al., 2002). The factors that influence whether and how effectively knowledge is shared may also include experience, trust, motivation and the level of difficulty experienced when actually engaging in the knowledge transfer (Binz-Scharf, 2005).

Van Donk and Reizeboz (2005) identify three main aspects of knowledge in project-based organisations. The first is entrepreneurial, and includes the knowledge that pertains to acquisitions within the PME. The second aspect is technical, which is limited to the technology applied to the project, which includes the technical sense of the project. The third aspect embraces the project management knowledge. This aspect combines the theoretical knowledge on project management, which may include associated techniques, with the real experience in conducting and managing the project (Van Donk and Reizebos, 2005). Given that much of the information contained within these three aspects is also distributed amongst several project teams within the PME, it is critical that these types of knowledges are effectively distributed and shared across the environment. Failure to do so could result in risking the delivery of the key result areas or outcomes of the project. This can also lead to tension within the project environment, where problems with information sharing can be attributed partly to the divergence in goals and objectives of different teams or units within the PME, or a symptom of an ineffective partnership (Barua et al., 1997, Binz-Scharf, 2005).

It has also been found that teams engaging in vertical communications do so in order to mould the views of top management, whereas those that are engaged in horizontal communication are attempting to coordinate work and obtain feedback (Binz-Scharf, 2005). This is closely linked to the mechanisms of collaboration environments and stakeholder management, and starts to detail how the practical connections within the PME and the use of the OCT will not only influence the type of information, but the manner and mechanisms by which it is shared.

The project team or collaborative environment also requires a consistency of members and partners to ensure strong interpersonal bonds are maintained and information sharing continues across the environment (Austin, 2000). This sharing environment can be threatened by outside 
forces, including the perception of non-permanence or permanence of interactions between the teams, disparities in information processing capabilities and rewards systems, and inefficient information-sharing behaviour from both the individual and organisational perspective (Barua et al., 1997).

Within the PME however, there is always a possibility of team members of associated organisations using project specific information or employee knowledge for purposes other than intended by the project. In this instance, mutual trust is a necessary condition for any successful knowledge sharing environment (Van Donk and Reizebos, 2005).

\subsection{Success Factors}
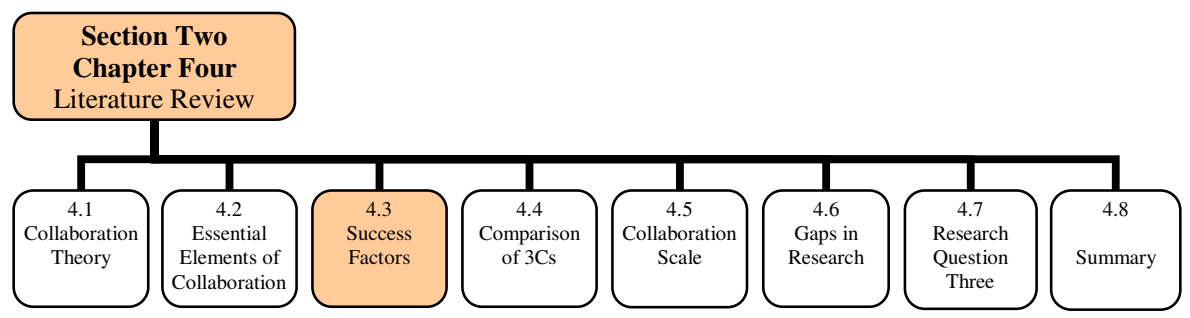

Research has been undertaken in identifying the management success factors, which if present enhance the probability that a collaboration will be successful (Barnes et al., 2000). Barnes et al have identified several core areas that contribute to the successful collaboration framework, and may well point to future considerations of any collaborative environment.

Firstly, choice of partner is considered essential to provide a compatible culture and mode of operation. The selection of the partner will encourage a mutual understanding of the PME, bringing together complementary expertise and strengths. The inclusion of high quality staff and a shared vision contributes to the development of complementary aims and an operating environment where there are no hidden agendas.

The second area concentrates on the cultural environment of the project. Issues that may affect the relationship include whether tensions may develop over conflicting priorities or timescales. The degree of comfort the contributing partners have with publishing material in the public domain (i.e. the internet) may also determine how widely information and knowledge can be shared. The approach specific participants may have to the collaborative environment or to other 
partners and their intellectual or professional rigour will also play a role in whether a collaborative relationship can be sustained. Lastly, the level of flexibility between the partners and their procedures, and whether they trust each other over confidential matters, will ultimately determine if the relationship can survive the collaborative environment.

The third area identified by Barnes et al (2000) is project management. The PME will determine the degree to which collaboration can be successfully implemented. Areas that will impact on this implementation include the presence of clearly defined outcomes and member responsibilities. A mutually agreed project plan will also assist to develop realistic aims and set project milestones, whilst also assisting with the provision of adequate resources across the project environment. The authors note that a simple agreement between the parties/members/organisations that describes the conditions of the collaboration is useful in ensuring that the collaborators deliver, and that internal process issues such as progress monitoring and communication, are understood by everyone.

The fourth area that contributes to a successful collaboration framework is that of the relationships within the collaboration, with a focus on the capacity to monitor and support the presence of a mutual environment; one that has equality of power and dependency, and which has an equality of contributions by all members.

The fifth and final area reviews the broader environmental influences of the project and checks if there is a market need for the relationship and if the entities are stable. This reinforces the notion that collaboration is a complex interweaving of components and elements that must be present for collaboration to occur.

Table 4-2 summarises these five main points and demonstrates that this approach notes the importance of the role of the project manager in ensuring the collaborative environment is as it should be. It provides a focus for the project manager, and suggests that for any review to be undertaken of a project, the input of the project manager will be crucial to gaining a picture of the working PME and the conditions under which any collaborative effort can function. This theme will be followed through to the design phase of this thesis and the subsequent analysis section where several PMEs will be reviewed. 
Table 4-2: Management Success Factors

\begin{tabular}{|l|l|}
\hline Factor & Description \\
\hline Choice of partner & $\begin{array}{l}\text { Mutual understanding of project environment that brings together } \\
\text { complementary expertise and strengths. No hidden agendas by staff. }\end{array}$ \\
\hline Cultural environment & $\begin{array}{l}\text { Sharing information within the public domain (internet), appreciation of } \\
\text { intellectual and professional rigour of team members to sustain } \\
\text { relationships, trust between members. }\end{array}$ \\
\hline Project management & $\begin{array}{l}\text { Determines the degree to which collaboration can be successfully } \\
\text { implemented through the presence of clearly articulated outcomes, project } \\
\text { plans, realistic aims and objectives, and set project milestones. An } \\
\text { agreement between members assists with understanding processes and } \\
\text { deliverables. }\end{array}$ \\
\hline Relationships & $\begin{array}{l}\text { Sustaining a mutual environment that engenders an equality of power and } \\
\text { contributions by team members. }\end{array}$ \\
\hline Environmental influences & Provides the market incentive for a stable relationship to be maintained. \\
\hline
\end{tabular}

Many of these factors have been covered in previous sections of this Literature Review, albeit under different terminology at times, essentially describing similar characteristics required for a successful collaborative experience to occur. These factors will be revisited in future sections of this research, in particular when reviewing the use of the OCTs within the PME.

\subsection{Comparison of Cooperation, Coordination and Collaboration (3Cs)}

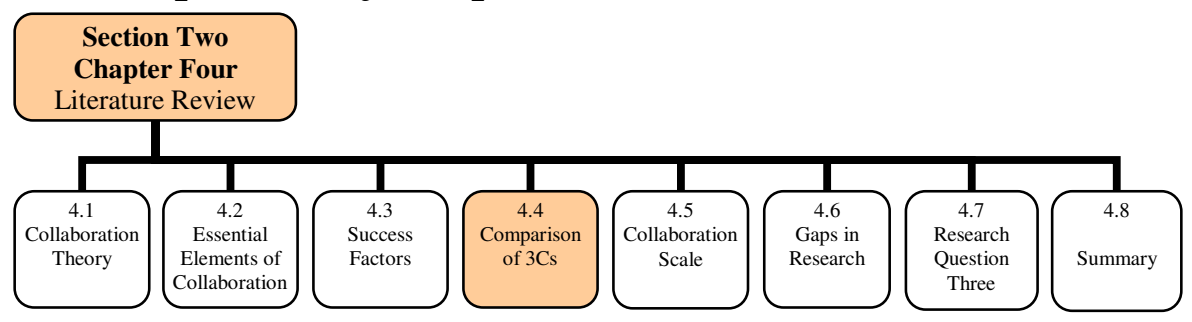

Mattessich et al (2001) propose four key categories to understand and compare the differences between the terms cooperation, coordination and collaboration. These categories present a series of elements that have a varying or gradated relevance to the three terms. In most instances, the element applies less to cooperation and more to collaboration, with coordination occupying the middle ground. This gradation is a theme that will be revisited later in this chapter. These categories are

- Vision and Relationships: includes relationships, missions and goals and interactions

- Structure, Responsibilities and Communication: includes roles, planning and communication

- Authority and Accountability: includes authority, leadership and risk

- Resources and Rewards. 
Table 4-3, Table 4-4, Table 4-5 and Table 4-6 provide an overview of the elements within these

four categories as they apply to cooperation, coordination and collaboration.

Table 4-3: Vision and Relationships

\begin{tabular}{|l|l|l|l|}
\hline Element & Cooperation & Coordination & Collaboration \\
\hline Relationships & $\begin{array}{l}\text { Basis for cooperation is } \\
\text { usually between } \\
\text { individuals but may be } \\
\text { mandated by a third } \\
\text { party. }\end{array}$ & $\begin{array}{l}\text { Individual relationships are } \\
\text { supported by the organisations } \\
\text { they represent. }\end{array}$ & $\begin{array}{l}\text { Commitment of the organisation and } \\
\text { their leaders is fully behind their } \\
\text { representative. }\end{array}$ \\
\hline $\begin{array}{l}\text { Missions and } \\
\text { goals }\end{array}$ & $\begin{array}{l}\text { Organisational missions } \\
\text { and goals are not taken } \\
\text { into account. }\end{array}$ & $\begin{array}{l}\text { Missions and goals of the } \\
\text { individual organisations are } \\
\text { reviewed for compatibility. }\end{array}$ & $\begin{array}{l}\text { Common, new missions and goals } \\
\text { created. }\end{array}$ \\
\hline Interaction & $\begin{array}{l}\text { Interaction is on an as } \\
\text { needed basis and may } \\
\text { last indefinitely. }\end{array}$ & $\begin{array}{l}\text { Interaction is usually around } \\
\text { one specific project or task of } \\
\text { definable length. }\end{array}$ & $\begin{array}{l}\text { One or more projects are undertaken for } \\
\text { longer term results. }\end{array}$ \\
\hline
\end{tabular}

Table 4-4: Structure, Responsibilities and Communication

\begin{tabular}{|l|l|l|l|}
\hline Element & Cooperation & Coordination & Collaboration \\
\hline Roles & $\begin{array}{l}\text { Relationships are } \\
\text { informal, and each } \\
\text { organisation functions } \\
\text { separately. }\end{array}$ & $\begin{array}{l}\text { Organisations take on needed } \\
\text { roles, but function relatively } \\
\text { independently of each other. }\end{array}$ & $\begin{array}{l}\text { Creation of new organisation structure } \\
\text { and/or clearly defined and interrelated } \\
\text { roles that constitute formal division of } \\
\text { labour. }\end{array}$ \\
\hline Planning & $\begin{array}{l}\text { No joint planning is } \\
\text { required. }\end{array}$ & $\begin{array}{l}\text { Some project-specific } \\
\text { planning is required. }\end{array}$ & $\begin{array}{l}\text { More comprehensive planning is required } \\
\text { that includes developing joint strategies } \\
\text { and measuring success in terms of impact } \\
\text { on needs of those served. }\end{array}$ \\
\hline Communication & $\begin{array}{l}\text { Information is } \\
\text { conveyed as needed. }\end{array}$ & $\begin{array}{l}\text { Communication roles are } \\
\text { established and definite } \\
\text { channels are created for } \\
\text { interaction. }\end{array}$ & $\begin{array}{l}\text { Many levels of communication roles are } \\
\text { created as clear information is a keystone } \\
\text { of success. }\end{array}$ \\
\hline
\end{tabular}

Table 4-5: Authority and Accountability

\begin{tabular}{|l|l|l|l|}
\hline Element & Cooperation & Coordination & Collaboration \\
\hline Authority & $\begin{array}{l}\text { Authority rests solely } \\
\text { with the individual } \\
\text { organisation. }\end{array}$ & $\begin{array}{l}\text { Authority rests with the } \\
\text { individual organisation but } \\
\text { there is consultation among } \\
\text { participants. }\end{array}$ & $\begin{array}{l}\text { Authority is determined by the } \\
\text { collaboration to balance ownership by the } \\
\text { individual organisation with expediency to } \\
\text { accomplish purpose. }\end{array}$ \\
\hline Leadership & $\begin{array}{l}\text { Leadership is unilateral } \\
\text { and control is central. }\end{array}$ & $\begin{array}{l}\text { Some sharing of leadership } \\
\text { and control. }\end{array}$ & $\begin{array}{l}\text { Leadership is dispersed, and control is } \\
\text { shared and mutual. }\end{array}$ \\
\hline $\begin{array}{l}\text { All authority and } \\
\text { accountability rests } \\
\text { with the individual } \\
\text { organisation which acts } \\
\text { independently. }\end{array}$ & $\begin{array}{l}\text { Some shared risk, but most of } \\
\text { the authority and } \\
\text { accountability falls to the } \\
\text { individual organisation. }\end{array}$ & $\begin{array}{l}\text { Equal risk is shared by all organions in } \\
\text { the collaboration. }\end{array}$ \\
\hline
\end{tabular}

Table 4-6: Resources and Rewards

\begin{tabular}{|l|l|l|l|}
\hline Element & Cooperation & Coordination & Collaboration \\
\hline Resources & $\begin{array}{l}\text { Resources are } \\
\text { separately serving the } \\
\text { individual } \\
\text { organisation's needs. }\end{array}$ & $\begin{array}{l}\text { Resources are acknowledged } \\
\text { and can be made available to } \\
\text { others for a specific project. }\end{array}$ & $\begin{array}{l}\text { Resources are pooled or jointly secured for } \\
\text { a longer-term effort that is managed by the } \\
\text { collaborative structure. }\end{array}$ \\
\hline Rewards & Nil. & $\begin{array}{l}\text { Rewards are mutually } \\
\text { acknowledged. }\end{array}$ & $\begin{array}{l}\text { Organisations share in the products: more } \\
\text { is accomplished jointly than could have } \\
\text { been individually. }\end{array}$ \\
\hline
\end{tabular}


Furthermore, Rogers and Whetten (1982) provide a list of five criteria with which to explore the distinctions between cooperation and coordination. Their criteria are:

- rules and formality;

- goals and activities;

- implications for vertical or horizontal linkages;

- personal resources; and

- threat to autonomy.

In this matrix, cooperation and coordination are differentiated by the degree to which the terms are relevant to the specific criteria. In the first of the criterion, the two terms are differentiated by how formal rules are managed, with cooperation having very few formal rules, whilst coordination entailing a greater use of decision rules. In the second criterion the individual organisation's goals and activities determine the type of goals that are emphasised, whilst joint goals and activities are aligned closer to coordination. The third criterion entails the extent to which interorganisational linkages occur. In this criterion, cooperation is contained within its own organisational domain, whilst coordination has the capacity to spread and link to other organisation structures. The fourth criterion reviews the type of personnel that are involved, with cooperation having relatively few members drawn from subordinate or lower position within the organisation, whilst coordination may necessitate an increase in resources, commitment and involvement from more senior members of the organisation. The fifth criterion refers to the autonomy of the organisations and notes that the cooperative organisation will engage with little threat to its autonomy, whilst the threat to autonomy increases within the coordinative organisation.

As such, coordination requires a larger commitment to a variety of organisational resources, including personnel and money, and is likely to be more difficult to instigate than cooperation because of these costs (Rogers and Whetten, 1982). This may prove an important factor later in this research when reviewing the manner in which organisations operate within the PME. Table 4-7 details these five criteria and their relevance to cooperation and coordination. 
Table 4-7: Cooperation and Coordination criteria

\begin{tabular}{|l|l|l|}
\hline Criteria & Cooperation & Coordination \\
\hline Rules and formality & no formal rules & formal rules \\
\hline Goals and activities emphasised & $\begin{array}{l}\text { individual organisation's goals } \\
\text { and activities }\end{array}$ & joint goals and activities \\
\hline $\begin{array}{l}\text { Implications for vertical and } \\
\text { horizontal linkages }\end{array}$ & none, only domain agreements & $\begin{array}{l}\text { vertical or horizontal linkages } \\
\text { can be affected }\end{array}$ \\
\hline Personal resources involved & $\begin{array}{l}\text { relatively few - around the lower } \\
\text { ranking members }\end{array}$ & $\begin{array}{l}\text { more resources involved - } \\
\text { higher ranking members }\end{array}$ \\
\hline Threat to autonomy & little threat & more threat to autonomy \\
\hline
\end{tabular}

Cooperation does not necessarily require a contribution in every instance from the entity, as each entity will evaluate the specific situation and make a determination if cooperation is warranted (Fitzek and Katz, 2006). This ad hoc or informal approach is consistent with the operating method outlined by Rogers and Whetten (1982) above.

Argyle (1991) notes that cooperation is required to perform tasks within the material world and to sustain the basic social relationships for life, which includes familial, domestic, social and working environments. Argyle also notes that in order for cooperation to be successful, it requires communication and interaction, and that even though the basic social signals are innate, the cooperative skills for doing it are acquired (Argyle, 1991).

Cooperation within the working environment can also take several forms. The first form is consistent with the performance of a task as noted above, where a worker may undertake a task independently or in partnership with other workers (e.g. in manufacturing on an assembly plant). The second entails a supervisory relationship where the person may not actually do the work, but instead be responsible for ensuring that other people have performed the work correctly and to a pre-set or agreed standard. The third form includes other social relationships that may be found within the work environment such as sharing information, discussions, negotiating and providing expert advice (Argyle, 1991).

Cooperation can be used to describe any relationship where all participants contribute and this action exists in order for the participant to obtain an advantage by giving, sharing or allowing something to happen (Fitzek and Katz, 2006). Cooperation can also lead to or encourage the division of labour between individuals who may specialise in different parts of the job, have differing competencies, or where tasks are interdependent (Argyle, 1991). Rewards and 
incentives can be used to assist the enforcement of rules within the cooperation environment. The reverse is also true, where failing to cooperate can result in punishment, especially where cooperation is socially valued (Argyle, 1991).

The condition of cooperation in this instance is based on the premise that each participating entity is gaining more by cooperating, regardless of the extent to which they cooperate, than they would normally have to gain if they operated alone or independently. Cooperation is therefore dependent upon the interests of the cooperating person or group, and as such may take different forms depending on the circumstance to which it is applied (Fitzek and Katz, 2006). There may also be varying motivating factors for cooperation to occur, including the gain of external rewards such as profit, to further a relationship or to participate in shared activities (Argyle, 1991, Fitzek and Katz, 2006).

Coordination similarly can be for individual or independent purposes, but has the added condition of being a mechanism for planning, action or joint activity between organisations. In these circumstances, organisations can be both independent and share coalitions of activity that may influence joint decisions and actions (White, 1968). An example of this can be expressed in Figure 4-1, where the outcomes of cooperation and coordination are juxtaposed. In the figure, organisation A and B can be shown to relate with each other (in a cooperative fashion) in order to accomplish their respective goals, some of which impact on each other. In a coordinative scenario, this may result in the creation of outcomes that may be different from their initial preferred outcomes (Rogers and Whetten, 1982).
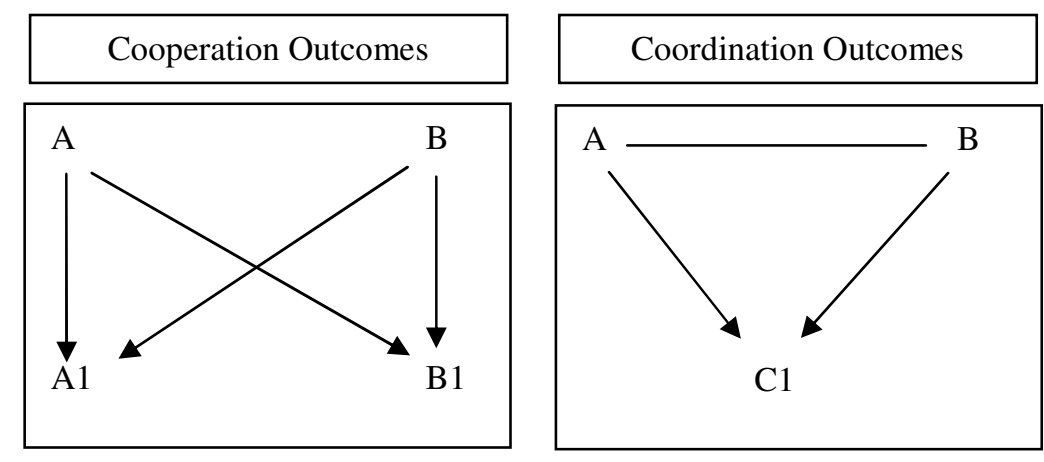

Figure 4-1: Juxtaposition of outcomes 
As the application of coordination across organisations increases, emphasis has shifted from reviewing the issues around controlling internal activities and managing external constraints, to discussions around resource control (Thompson, 1967). Of interest for the research is the identification of those activities that are most suited to coordination. Aitken and colleagues (1975) have specified several including programs and program development, resources, clients or recipients and information. The authors note that coordination can be impeded by institutional barriers including:

- the tendency of organisations to maximize their own autonomy;

- the ideological commitments of professionals;

- the varying concerns of client representatives; and

- the division of interests of resource controllers (Aitken et al., 1975).

Although the authors were referencing the human services arena, these barriers resonate with the research at hand and the project environment, where organisations and companies are brought together for a specific time and outcome.

Coordination is also based upon the undertaking of tasks within the shared or interorganisational environment. In these situations, tasks are spread across multiple organisations, divisions, or business units, with each organisation interacting at these different levels depending on the requirements. In these situations, the task environments of these organisations are pluralistic (Thompson, 1967) and operate without an overarching authority structure in place between the participating organisations. In these circumstances, establishing and maintaining a successful interorganisational coordination program is much more difficult than managing a similar interdepartmental or intra-organisational program, and is more about managing uncertainty (Rogers and Whetten, 1982).

Organisations may choose to use competitive or cooperative strategies to help reduce the uncertainty caused by the task environment. If the organisation has sufficient power or authority, it may choose to follow competitive strategies, but if the acquisition of power is difficult, the organisation is more likely to chose cooperative strategies, including contracting for services, coopting and coalescing, or entering into a combination or joint ventures with other organisations. As previously noted, as the environment becomes increasingly complex, organisations become more specialised, leading to a greater need for increased interorganisational coordination (Rogers and Whetten, 1982). 


\subsection{Collaboration Scale}

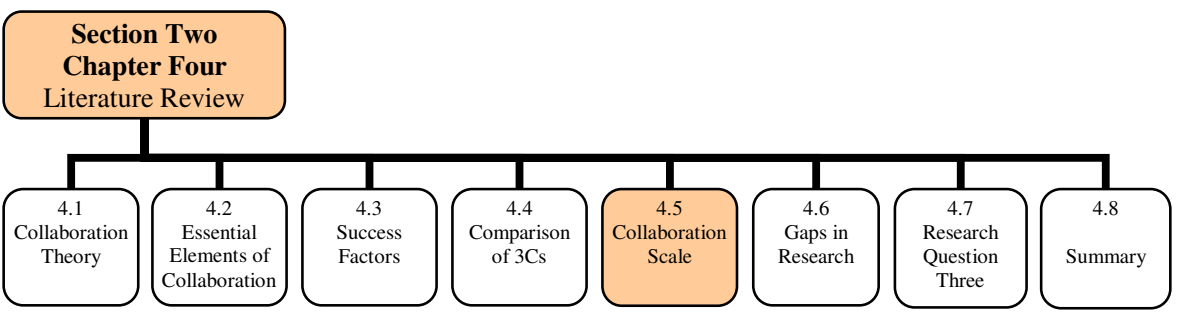

As the previous sections have demonstrated, there are many models and applications for the terms cooperation, coordination, and collaboration, with each one varying slightly depending on the environment or circumstances for which it is intended. The Literature Review has not been able to uncover suitably clear definitions or operating models for each that can be applied to the project management discipline and therefore to the research at hand. In light of this, this research must develop a Collaboration scale that can be applied when analysing data in the future chapters. This scale contributes new knowledge to the body of literature in the area, and provides a mechanism by which to understand the presence of the $3 \mathrm{Cs}$ in the research, as well as providing a mechanism by which to measure the level of collaboration that occurs through the use of the OCTs within the PME.

In developing this scale, the research has distilled the key elements of the $3 \mathrm{Cs}$ identified in the literature in order to compare and contrast all three terms. There are 13 elements, with each being understood as they relate to the 3Cs (Table 4-8). What becomes evident in presenting the elements in this fashion is that each can be understood differently depending on whether it is being applied to cooperation, coordination or collaboration. Furthermore, the description against each term can be understood relative to each other - that is to say, that each element can be understood as existing along a progression or scale with cooperation at the start of the scale, coordination and the middle ground and collaboration being described as high or complex involvement of the particular element. 
Table 4-8: Summary of Cooperation, Coordination and Collaboration (3Cs).

\begin{tabular}{|c|c|c|c|c|}
\hline No. & Element & Cooperation & Coordination & Collaboration \\
\hline 1 & Rules and formality & nil & formal & $\begin{array}{l}\text { formal and shared } \\
\text { processes }\end{array}$ \\
\hline 2 & Goals and activities & $\begin{array}{l}\text { individual organisation } \\
\text { goals and activities }\end{array}$ & $\begin{array}{l}\text { joint goals and } \\
\text { activities }\end{array}$ & $\begin{array}{l}\text { project goals and } \\
\text { activities }\end{array}$ \\
\hline 3 & $\begin{array}{l}\text { Vertical and horizontal } \\
\text { linkages }\end{array}$ & temporary or none & $\begin{array}{l}\text { vertical and } \\
\text { horizontal may be } \\
\text { affected }\end{array}$ & $\begin{array}{l}\text { vertical and horizontal } \\
\text { mandated }\end{array}$ \\
\hline 4 & $\begin{array}{l}\text { Personnel / Resources } \\
\text { Involved }\end{array}$ & $\begin{array}{l}\text { relatively few, drawing } \\
\text { from lower ranking } \\
\text { members }\end{array}$ & $\begin{array}{l}\text { more resources } \\
\text { involved from higher } \\
\text { ranking members }\end{array}$ & $\begin{array}{l}\text { - increased due to } \\
\text { sharing of resources } \\
\text { across tasks } \\
\text { - interdependence } \\
\text { high }\end{array}$ \\
\hline 5 & Autonomy & $\begin{array}{l}\text { - little threat } \\
\text { - proprietary strategies } \\
\text { that maintain } \\
\text { possession and } \\
\text { control over } \\
\text { resources and protect } \\
\text { boundaries }\end{array}$ & $\begin{array}{l}\text { more threat to } \\
\text { autonomy } \\
\text { - strategies require } \\
\text { negotiation with } \\
\text { other organisations }\end{array}$ & $\begin{array}{l}\text { - } \text { authority implicated } \\
\text { with organisation } \\
\text { structure } \\
\text { - Strategies require } \\
\text { participation form } \\
\text { many organisations }\end{array}$ \\
\hline 6 & $\begin{array}{l}\text { Relationships and } \\
\text { strategic alliances }\end{array}$ & informal & more formal & complex \\
\hline 7 & Communication & nil / ad hoc & $\begin{array}{l}\text { communications } \\
\text { channels established }\end{array}$ & complex \\
\hline 8 & $\begin{array}{l}\text { Information sharing and } \\
\text { knowledge distribution }\end{array}$ & shared as needed & shared & complex \\
\hline 9 & Rewards and incentives & separate & $\begin{array}{l}\text { mutually } \\
\text { acknowledged }\end{array}$ & $\begin{array}{l}\text { shared (from a } \\
\text { unifying action) }\end{array}$ \\
\hline 10 & Risk & nil & increased & spread and reduced \\
\hline 11 & $\begin{array}{l}\text { Defined mission, } \\
\text { structure or planning } \\
\text { effort }\end{array}$ & nil & $\begin{array}{l}\text { - understanding of } \\
\text { some compatible } \\
\text { missions } \\
\text { - Some planning and } \\
\text { division of role } \\
\text { required } \\
\end{array}$ & interdependence \\
\hline 12 & Decision making & $\begin{array}{l}\text { for the sake of the } \\
\text { organisation }\end{array}$ & inclusive & concerted \\
\hline 13 & Tasks / interdependence & low & $\begin{array}{l}\text { increased but still } \\
\text { separated }\end{array}$ & complete \\
\hline
\end{tabular}

Source: Austin (2000), Aitken et al (1975), Argyle (1991), Baura et al. (1997), Davenport et al. (1998), Fitzek and Katz (2006), Katzey et al. (2000), Mattessich et al. (2001), Phillips et al. (1998), Rogers and Whetten (1982), Romano et al. (2002), Thompson (1967), Vangen and Huxham (2003), Walker (2003), White (1968).

Table 4-9 reviews these elements and seeks to describe them in an effort to develop a simplified Collaboration scale. In doing so, the 13 broad elements are reduced to 7 central elements, and as such become the core metrics for the scale as outlined in Table 4.10. 
Table 4-9: Elements linked to Collaboration Scale

\begin{tabular}{|c|c|c|c|}
\hline Element & Description / justification & $\begin{array}{l}\text { Aligns } \\
\text { to scale }\end{array}$ & $\begin{array}{l}\text { Element in } \mathbf{C b} \\
\text { scale }\end{array}$ \\
\hline $\begin{array}{l}\text { Personnel / Resources } \\
\text { Involved }\end{array}$ & $\begin{array}{l}\text { Starting from a base of relatively few, and } \\
\text { involving more resources as coordination } \\
\text { develops. Collaboration involves increased } \\
\text { sharing of resources and high interdependence. }\end{array}$ & Yes & Resources \\
\hline $\begin{array}{l}\text { Tasks / } \\
\text { interdependence }\end{array}$ & $\begin{array}{l}\text { Tasks and interdependence have a low } \\
\text { frequency with cooperation, which increases as } \\
\text { it moves to coordination. Tasks are shared } \\
\text { across a collaborative environment. }\end{array}$ & Yes & $\begin{array}{l}\text { Tasks / Activities } \\
\text { scheduling }\end{array}$ \\
\hline Communication & $\begin{array}{l}\text { Communication is at the low end for } \\
\text { cooperation, and increases with the onset of } \\
\text { coordination activities. It becomes complex } \\
\text { and is highly desirable when collaborating. }\end{array}$ & Yes & Communication \\
\hline $\begin{array}{l}\text { Information sharing } \\
\text { and knowledge } \\
\text { distribution }\end{array}$ & $\begin{array}{l}\text { Information sharing occurs as required in } \\
\text { cooperation, becomes shared as part of } \\
\text { coordination, and develops as complex in order } \\
\text { for collaboration to occur. }\end{array}$ & Yes & Information sharing \\
\hline $\begin{array}{l}\text { Relationships and } \\
\text { strategic alliances }\end{array}$ & $\begin{array}{l}\text { Relationships occur on an informal basis for } \\
\text { cooperation, becoming more formal and present } \\
\text { as coordination occurs. Becomes complex in } \\
\text { order for collaboration to occur. }\end{array}$ & Yes & Relationships \\
\hline $\begin{array}{l}\text { Rewards and } \\
\text { incentives }\end{array}$ & $\begin{array}{l}\text { Rewards and incentives are separate or non } \\
\text { existent in cooperation, and become mutually } \\
\text { acknowledged in coordination. These become a } \\
\text { core feature of collaborative environments as } \\
\text { all parties share from a unifying action. }\end{array}$ & Yes & Rewards \\
\hline $\begin{array}{l}\text { Negotiation and } \\
\text { Autonomy }\end{array}$ & $\begin{array}{l}\text { Negotiation is not required within cooperative } \\
\text { relationships, but is as coordination activities } \\
\text { emerge. Collaboration requires strategies that } \\
\text { include participation from many organisations } \\
\text { and stakeholders. }\end{array}$ & Yes & Negotiation \\
\hline Rules and formality & $\begin{array}{l}\text { Rules and processes are not shared in } \\
\text { cooperative environments, but become } \\
\text { increasingly formal and shared moving from } \\
\text { coordination to collaboration. }\end{array}$ & Yes & $\begin{array}{l}\text { Tasks / } \\
\text { Communication / } \\
\text { Relationships }\end{array}$ \\
\hline Goals and activities & $\begin{array}{l}\text { Goals remain on the individual level in } \\
\text { cooperation, and become joint goals through } \\
\text { coordination, and shared project goals when } \\
\text { collaboration is required. }\end{array}$ & Yes & $\begin{array}{l}\text { Information sharing } \\
\text { / Tasks }\end{array}$ \\
\hline $\begin{array}{l}\text { Vertical and } \\
\text { horizontal linkages }\end{array}$ & $\begin{array}{l}\text { No specific linkages required across a } \\
\text { cooperative relationship, whilst both vertical } \\
\text { and horizontal linkages commence in } \\
\text { coordinating activities. These linkages become } \\
\text { critical in collaborative environments. }\end{array}$ & Yes & Relationships \\
\hline Risk & $\begin{array}{l}\text { Risk works in reverse across the } 3 \mathrm{Cs} \text {, where it } \\
\text { is high when working in isolation or in a } \\
\text { cooperative relationship, but can decrease as } \\
\text { coordination develops. In collaboration, the } \\
\text { risk is spread and can be significantly reduced. }\end{array}$ & Yes & $\begin{array}{l}\text { Relationships / } \\
\text { Information sharing } \\
\text { / Incentives }\end{array}$ \\
\hline $\begin{array}{l}\text { Defined mission, } \\
\text { structure or planning } \\
\text { effort }\end{array}$ & $\begin{array}{l}\text { Does not exist in cooperation, but develops in } \\
\text { coordination. Collaboration requires an } \\
\text { interdependency of mission and planning effort. }\end{array}$ & Yes & $\begin{array}{l}\text { Collaboration / } \\
\text { Resources }\end{array}$ \\
\hline Decision making & $\begin{array}{l}\text { Moves from organisational specific in } \\
\text { cooperative environments, to inclusive in } \\
\text { coordination relationships and concerted in } \\
\text { collaborative relationships. }\end{array}$ & Yes & $\begin{array}{l}\text { Communication / } \\
\text { Relationships / } \\
\text { Incentives }\end{array}$ \\
\hline
\end{tabular}


From this revised table, a simplified table has been developed to outline and present the Collaboration scale (Table 4-10). This Collaboration scale is applied to the research at hand in an effort to gauge the level to which collaboration occurs within the PME. Further discussion of this scale will be detailed in the proceeding chapter on Methodology Design, however in this instance, a justification of this scale in relation to the literature reviewed to date is warranted.

Table 4-10: Collaboration Scale

\begin{tabular}{|c|c|c|c|c|}
\hline & Element & Cooperation & Coordination & Collaboration \\
\hline 1 & Resources & low & moderate & high \\
\hline 2 & Tasks / Activities/ Scheduling & low & moderate & high \\
\hline 3 & Communication & low & moderate & high \\
\hline 4 & Information Sharing (including K.D.) & low & moderate & high \\
\hline 5 & Relationships (including Trust, S.A.) & low & moderate & high \\
\hline 6 & Rewards (including Incentives) & low & moderate & high \\
\hline 7 & Negotiations & low & moderate & high \\
\hline
\end{tabular}

In this table, collaboration is viewed on a scale ranging from cooperation through coordination to collaboration. Each of the seven key elements of resources, tasks, communications, information, relationship, rewards and negotiation are rated according to this scale to provide an indication of the level of collaboration occurring for that element. In posing this scale, this research argues that although collaborative elements are found within the PME, it is the level of each element that determines the degree to which collaboration is occurring. Cooperation is viewed on the first scale and has the lowest response rate to the scale's elements. Coordination is placed on the second scale, has a middle response rate to the scale's elements, while Collaboration is the third scale, and is indicated with the highest response rate to the seven key elements. Table 4-10 details this scale and demonstrates how a PME could deliver results that could include a spread across the three scales.

An example of this would be where an environment rates on the low scale (or cooperatively) against the elements of resources and relationships, yet rates on the high scale (collaboratively) against the tasks elements, and on the middle scale for the remaining elements of communication, information sharing and rewards.

Using this scale, the research argues that although all of the collaborative elements are found to be present within the PME, the extent to which they exist is the factor that determines if collaboration is occurring. A factor that may provide an understanding of the level of 
collaboration within the PME is the relative level of importance the PME places on the seven individual collaborative elements and the relationship of these elements to each other within the particular PME. The usage of the Collaboration scale will be reviewed again in the following chapters titled Methodology and Research Findings.

Another way of viewing this approach and the degree to which collaboration occurs within the PME, is to revisit the explanation of the outcomes of the $3 \mathrm{Cs}$ based on the literature previously discussed. Whilst the authors Rogers and Whetten argue that cooperation begins with a relationship in order to accomplish respective goals, and that coordination outcomes may result in the creation of outcomes that may be different from their initial expectations (Rogers and Whetten, 1982), this research proposes an amendment to this model. In this reworking of the authors diagram (previously presented in 4.4 of this chapter) the Collaboration scale can be shown to propose a gradation or scale of interaction and interorganisational linkages and notes a separated process for cooperation and a more reciprocal process of collaboration as the end point (Figure 4-2 and Figure 4-3).

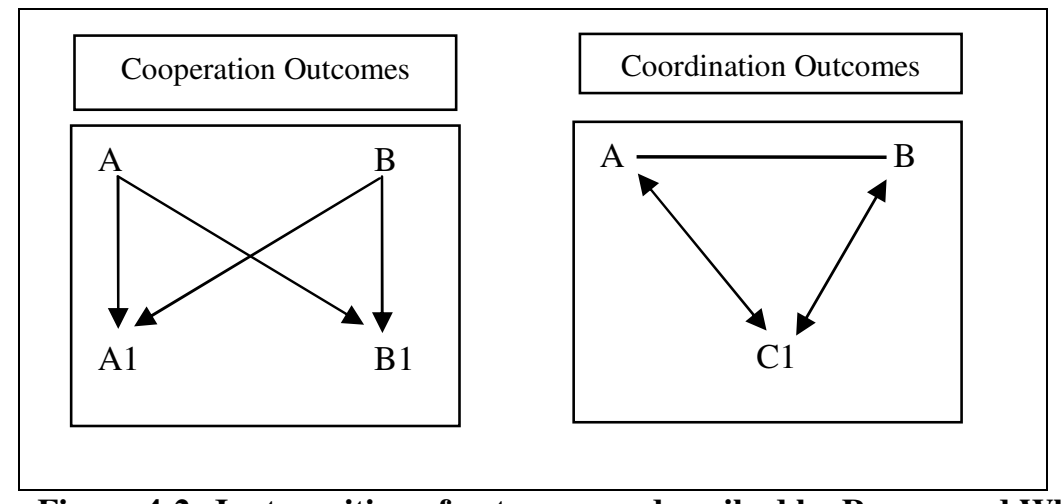

Figure 4-2: Juxtaposition of outcomes as described by Rogers and Whetten (1982)

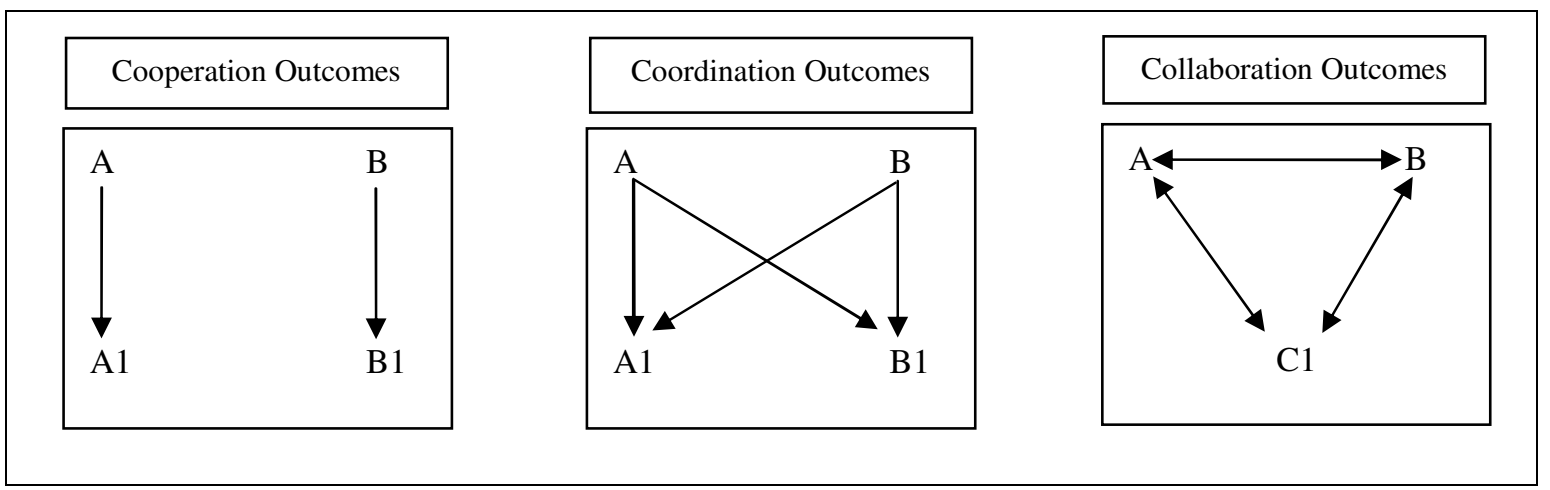

Figure 4-3: Expanded explanation of juxtaposition of outcomes with reference to Rogers and Whetten (1982) 
This is relevant to the research as it demonstrates how collaboration can be understood as an amalgam of the 3Cs; and that when viewed separately, each can play a role in the PME, without necessarily being attached to the concept of collaboration. What is central to the Collaboration scale, is that it is the combination of, and degree to which these components are exploited within the single environment, which gives rise to the definition and subsequent identification of collaboration.

\subsection{Gaps in Research}

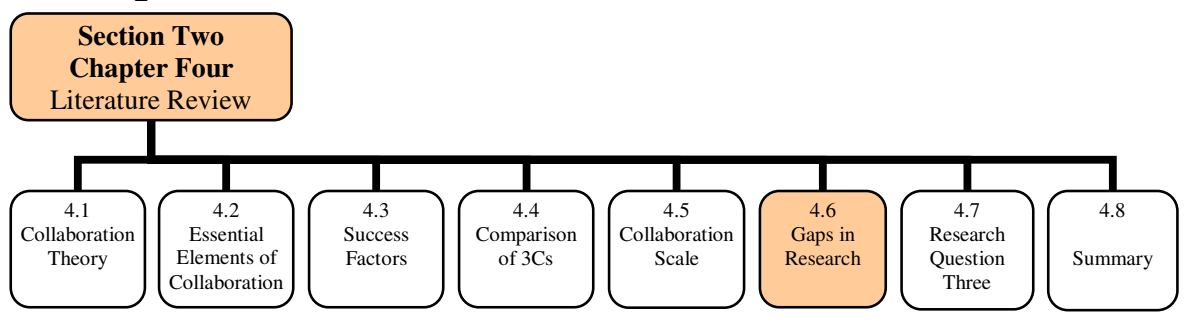

The clarification of the terms of cooperation, coordination and collaboration and their relationship to OCTS and the PME was problematic for this review. As noted in this chapter, the terms are often interchanged, whilst a review of their applicability to the area of OCTs failed to identify any literature. Information on these three terms, mostly in the form of definitions, was available, however literature that detailed a comparative study of the three terms was lacking, as was the way in which the terms can be applied to the PME. The search also failed to uncover the availability of any substantial data sets that can be applied to this research which would provide an existing base from which to draw further conclusions of the terms. This was particularly the case when referencing cooperation and coordination, whilst the body of knowledge on collaboration and its applicability to the PME was more forthcoming. This lack of authoritative texts clearly articulating the difference between the three terms once again supported the premise of the research, that is, that these terms are often interchangeable. It also highlighted the relevance of the Collaboration scale as a mechanism for measuring the degree to which collaboration may occur within a PME or through the use of OCTs. 


\subsection{Research Question Three}

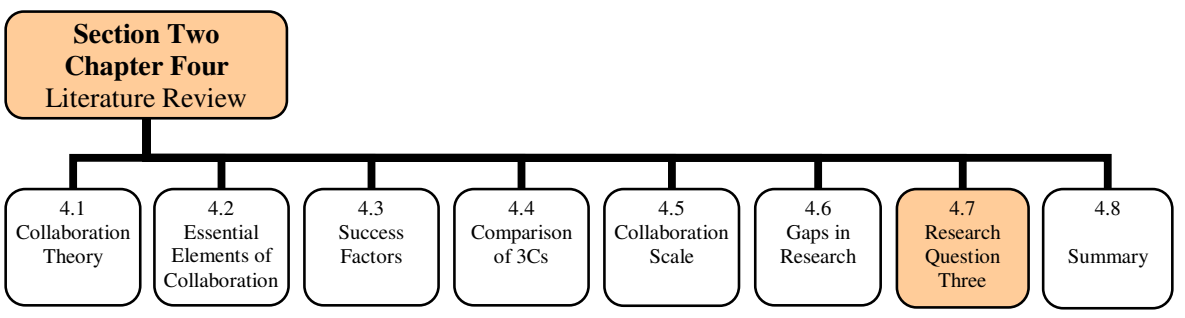

This chapter has investigated the three terms of cooperation, coordination and collaboration and sought to describe the various ways these terms are used and applied in different circumstances. The chapter identified the degrees to which the three terms can be applied to the project environment with a view to posing the third and final research question. This research question references the two preceding research areas, namely OCTs and the PME. Given what is known about the OCTs and their features, and the different structures of the PME, this research seeks to review the actual use and application of the OCT against the 3Cs.

Research Question Three: What is the level of collaboration when using OCTs in the PME?

In framing this question, the research draws out the linkages between the three areas. It sets out to track and record the use of the OCT within the PME to identify if this use is identified with a collaborative environment; or with coordinative or cooperative actions; i.e. those actions that are part of the everyday toolkit of project managers. This search is important, as it allows the research to identify the operational usage of the OCT within a working project environment, and in doing so provides a clearer understanding of the prerequisites required and the benefits offered through the use of an OCT within the PME.

Proposition Three: $\quad$ Collaboration can be modelled as a scale ranging from cooperation through coordination to collaboration.

In framing the final research question and proposition in this way, the research draws together previous questions. This final proposition also points to the overriding research question, by posing alternatives or scales with which collaboration may occur within the PME. It proposes that the OCTs can be used within the PME through several different operating modes or collaborative scales, which progress from cooperation, through to coordination and upwards to collaboration. Research question three presents the proposition that these three elements can 
occur within the PME at different stages of the project lifecycle, and that this impacts and determines the subsequent use of the resident OCT.

In framing the third research question and proposition in this way, the research highlights the work in this chapter and concludes the three significant research areas covered by the literature review, whilst reaffirming the overarching research problem:

Does collaboration occur through the use of Online Collaborative Toolsets in the Project Management Environment?

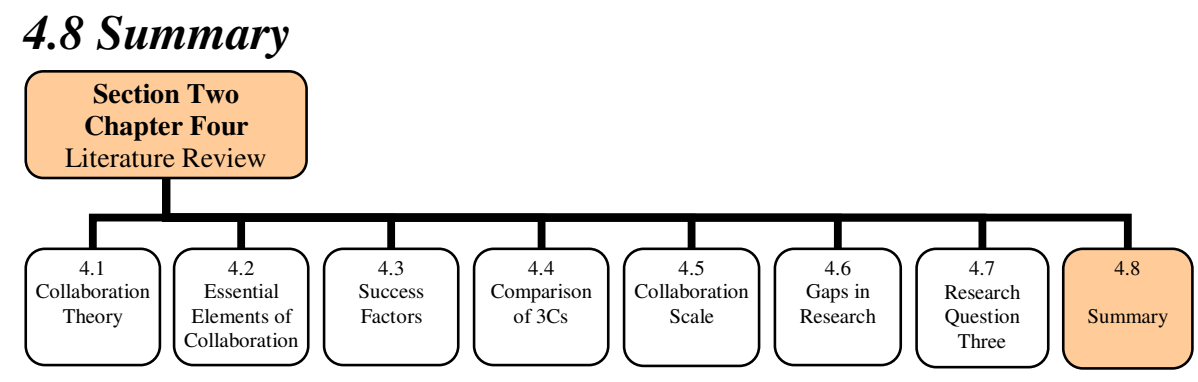

Given the Literature Review was spread over three chapters, it may be helpful to briefly summarise these three chapters before moving on to the next section. Each of the first three chapters concluded with a Research Question and associated Proposition, which combined, address the main Research Question (Table 4-11).

Main Research Question: Does collaboration occur through the use of online collaborative toolsets in the project management environment?

Table 4-11: Research Questions and Propositions

\section{Research Question}

1. What are the features of online collaborative toolsets?

2. How are online collaborative toolsets used in the project management environment?

3. What is the level of collaboration when using online collaborative toolsets in the project management environment?

\section{Proposition}

1. Online collaborative toolsets contain features that facilitate coordination, cooperation, and collaboration.

2. Online collaborative toolsets in the project management environment are used for cooperation and coordination, and to a lesser extent collaboration.

3. Collaboration can be modelled as a scale ranging from cooperation through coordination to collaboration. 
This main Research Question seeks to uncover the presence of collaboration when using an OCT within a PME. In doing so, it questions how the OCT is utilised within the working environment and seeks to map this usage against what we understand collaboration to be. This section therefore provides the necessary identification of issues and literature that will inform the research approach, design and subsequent data gathering stages outlined in the proceeding chapters.

The Literature Review therefore investigated three broad areas - OCTs, PME and Collaboration (chapters 2, 3, and 4).

Chapter Two reviewed the characteristics of online collaborative toolsets, and introduced the concept of OCTs to the reader. It proceeded to highlight some of the issues organisations must manage when using OCTs in an operational environment. This chapter outlined the concept of groupware and identified the distinction between synchronous and asynchronous communication methods and hosted and non-hosted solutions for an OCT. It reviewed the development of social networking and the impact this phenomenon may have on OCTs or virtual/electronic communication in the future. The chapter included a discussion of the role of OCTs in learning and teaching environments and discussed gaps in the literature. It concluded with the first research question and proposition.

Chapter Three reviewed issues associated with project management and provided a working description for the different project environments, while outlining its primary knowledge areas. The chapter outlined the different types of PME in practice, briefly discussing matrix organisation structures. It ended with a discussion of project websites within the project environment and a brief discussion of the gaps in the literature. As with the previous chapters, it concluded with a research question and associated proposition.

Chapter Four sought to describe the three concepts of cooperation, coordination and collaboration, to uncover the elements of each in order to develop a scale of differentiation for the terms. It introduced several definitions of collaboration and concluded that the three terms are closely aligned but are used in different settings without clarification of this difference in their usage. It introduced several key elements of collaboration including communication, trust and respect, equality and power, strategic alliances, incentive and value, negotiation and 
interorganisational knowledge sharing. The chapter also outlined success factors for collaboration and a useful comparison of the three terms.

The chapter then introduced the Collaboration scale. This scale is developed from the literature and is new knowledge that will be used in this research to subsequently analyse the level of collaboration occurring through the use of the OCTs in the case studies. The chapter concluded with a discussion of the gaps in the literature, and as with the previous chapters, introduced a research question and an associated proposition.

The work in this Literature Review scanned available literature and identified the research issues. The following chapter reviews the methodology and research design in order to develop a rigorous process with which to tackle the main Research Question and its sub questions and propositions. 


\section{SECTION THREE}

\section{CHAPTER FIVE - Methodology}

\subsection{Introduction}

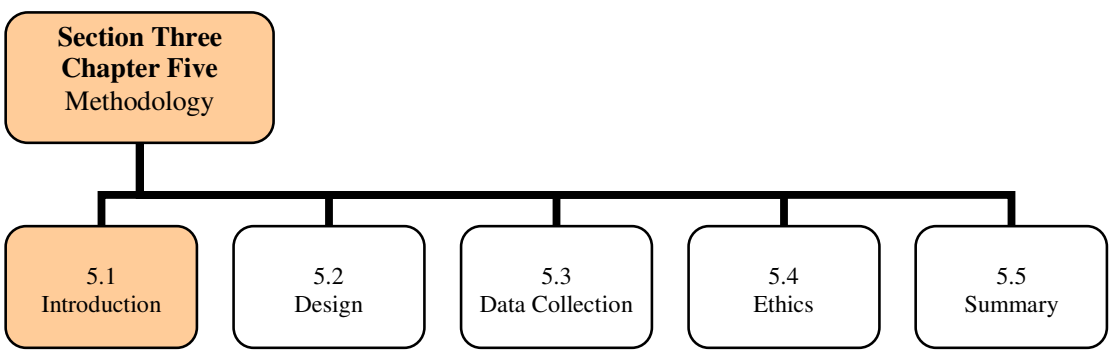

This chapter reviews the methodological considerations of the research and describes the factors that influenced the design, administration and data analysis of the research. In doing so, the chapter outlines the necessary methodological requirements and research designs required to answer each of the research questions and associated propositions. It is the third main section of the thesis and comprises one chapter. The chapter is structured into five separate sections. With the exception of the introduction and conclusion, a brief description of each follows.

Section 5.2 reviews the theoretical considerations pertinent when determining the methodological approach for the research. It outlines different research design types that can be considered when choosing the correct research approach and argues for a comparative case study approach. The section then discusses the case study approach, and introduces each of the six cases with a general description of their project management environment (PME).

Section 5.3 outlines the data collection methods, including the Likert questionnaire, semistructured interviews and supporting documentation. It also details the manner in which data was collected, collated and analysed and supports this with numerous tables on the components of these analytical devices. The section concludes with a discussion of the validation process of the data collection methods.

Section 5.4 outlines the necessary ethical considerations relevant to the research on a theoretical basis, and as it relates to the requirements of the University. 


\subsection{Design}

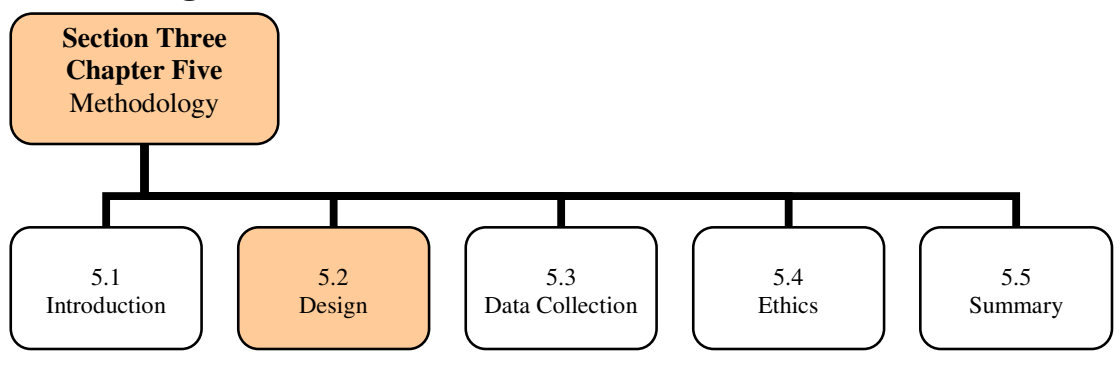

\subsubsection{Justification for Research Design}

This section reviews the different types of design that can be applied to the research questions. Given that the research design provides a framework for the collection and analysis of the data (Bryman, 2001), and will reflect the driving priorities of the research, justification of the approach used in the research is warranted. The research methodology, described later in this chapter, outlines the technique for collecting and subsequently analysing the data that is used to address the three research questions.

There are several types of design that can applied to the research. These types include experimental, cross-sectional, longitudinal, the case study or multiple case study (Bryman, 2001). In Table 5-1 (over page), a brief discussion of each is included, alongside a justification for its inclusion or exclusion from the research. From the choice of design types, the comparative case study approach was selected, as it allows comparison and contrast between different project environments, in order to identify common attributes and conditions.

The comparative case study provides the investigator with the opportunity to select a variety of cases from which to test the research propositions. In this scenario, the comparative case study offers multiple sources of evidence, well suited to the triangulating of data used to develop stronger substantiation of the constructs and hypothesis of the research (Eisenhardt, 1989, Yin, 2003, Garson, 2008). It also enables a combination of qualitative and quantitative data collecting methods to be used, including participant observation, structured and unstructured interviewing, and questionnaires. The use of qualitative data collection methods enables the research to gain a broader understanding of the rationale or theory that may emerge, whilst the quantitative evidence assists in identifying relationships or correlations that may not be obvious to the researcher and which can bolster findings from the qualitative evidence (Eisenhardt, 1989). 
Testing the same propositions through data gathered by multiple methods also improves the rigour of the research approach and helps address validation issues (Garson, 2008).

Table 5-1: Research design types

\begin{tabular}{|c|c|c|}
\hline $\begin{array}{l}\text { Research } \\
\text { Design }\end{array}$ & Description & Justification / comment \\
\hline Experimental & $\begin{array}{l}\text { - Uses an experimental design to } \\
\text { undertake quantitative comparisons } \\
\text { between experimental groups and } \\
\text { control groups } \\
\text { - Two types - laboratory and field } \\
\text { experiment }\end{array}$ & $\begin{array}{l}\text { Not used in the research as the experimental } \\
\text { approach was not required, and due to its } \\
\text { application within the research environment, } \\
\text { considered inappropriate for the collection of data } \\
\text { in this instance. Difficult to be applied in } \\
\text { organisations as requires intervention that is } \\
\text { difficult to obtain. }\end{array}$ \\
\hline $\begin{array}{l}\text { Cross- } \\
\text { sectional }\end{array}$ & $\begin{array}{l}\text { - Uses a survey research or structured } \\
\text { observation on a sample at a single } \\
\text { point in time } \\
\text { - These variables are then examined for } \\
\text { the presence of patterns } \\
\text { - Closely associated with questionnaires } \\
\text { and structured interviews }\end{array}$ & $\begin{array}{l}\text { The research is informed by this design, but as the } \\
\text { research proposes both qualitative and quantitative } \\
\text { research over a short period of time concentrating } \\
\text { solely on project management, this design was } \\
\text { excluded. This design benefits from larger sample } \\
\text { sizes, which is not achievable in this study. }\end{array}$ \\
\hline Longitudinal & $\begin{array}{l}\text { - Survey research on a sample on more } \\
\text { than one occasion } \\
\text { - Uses content analysis of documents } \\
\text { relating to different time periods }\end{array}$ & $\begin{array}{l}\text { The characteristics of this design excluded it from } \\
\text { consideration, as the research seeks to collect data } \\
\text { in a short period of time and does not require } \\
\text { mapping or charting changing behaviours in the } \\
\text { project management environment over time. }\end{array}$ \\
\hline Case study & $\begin{array}{l}\text { - Survey research on a single case with } \\
\text { a view to revealing important features } \\
\text { about its nature. } \\
\text { - Most commonly associated with the } \\
\text { location of the study such as } \\
\text { community or organisation } \\
\text { - Three types - critical, unique and } \\
\text { revelatory (and exemplifying) }\end{array}$ & $\begin{array}{l}\text { This design suits an intensive examination of a } \\
\text { single community of practice, whilst deploying } \\
\text { both quantitative and qualitative research } \\
\text { methodology structures. As the research is } \\
\text { primarily concerned with revealing important } \\
\text { features of the application of OCTs within the } \\
\text { project management area, this design does not } \\
\text { necessarily cater for the examination of patterns } \\
\text { and characteristics across multiple case studies. }\end{array}$ \\
\hline $\begin{array}{l}\text { Comparative } \\
\text { case study }\end{array}$ & $\begin{array}{l}\text { - Survey research in which there is a } \\
\text { direct comparison between two or } \\
\text { more cases, as in cross-cultural } \\
\text { research }\end{array}$ & $\begin{array}{l}\text { This design uses more or less identical methods of } \\
\text { two or more contrasting cases or situations, in } \\
\text { order to compare and better understand the social } \\
\text { phenomena. This approach is considered most } \\
\text { beneficial to the study, as it allows comparison and } \\
\text { contrast between different project environments, } \\
\text { seeking the identification of common attributes and } \\
\text { conditions. Provides several mechanisms in order } \\
\text { to gather data from multiple cases, without need for } \\
\text { going into the field. }\end{array}$ \\
\hline
\end{tabular}

Source: Byrman (2001), Cavana et al. (2001), Yin (2003)

The case study approach for this research developed three broad strategies to collect data on the selected cases. The first strategy was the use of a questionnaire administered to each of the cases, in order to collect data regarding the operations of the project. The second strategy utilised a semi-structured interview to ask specific questions about the PME of each case. The case study 
approach also allowed for additional material or documents to be collected throughout the interview processes if deemed relevant to the research. These approaches will be discussed in detail further in this chapter.

\subsubsection{Case Study Approach}

The case study tradition was chosen as it provided the capacity to develop an in-depth analysis of multiple cases. The approach catered for the use of multiple sources of data to be used for analysis, including documents, interviews and surveys. It also enabled the research to capture material on the expected variations of the use of the OCTs within the different project environments and the impact these differences would have in the deployment of the OCTs within each case. The case study approach is considered the most suitable tradition to identify these differences and use these differences in the subsequent analysis.

By clearly defining the target for the research as the specific cases, as distinct from the total operations of each participating organisation, the research increases its chances of containing the propositions and staying within feasible limits (Yin, 2003). The research questions outlined in the previous section, pose questions of the case studies that are 'how' and 'why' in nature, and as such, the case study design is the best method of understanding the unit of analysis. This design provides a strategy that supports the formulation of propositions, in addition to reflecting on important theoretical issues (Yin, 2003, Garson, 2008) and assists with identifying evidence related to the main research question. The case study is a research strategy that allows the investigator to focus on a single setting or case (or multiple cases), over time, thereby gaining a greater understanding of the dynamics present within that setting (Eisenhardt, 1989, Creswell, 1998). The case study, whether single environment or across multiple cases, can have numerous levels of analysis applied if required. It will typically involve a multi-method approach to data collection combining multiple sources of information rich in context such as archives, interviews, questionnaires and observations, as well as being assisted by the use of qualitative and/or quantitative methodologies (Garson, 2008, Creswell, 1998). In case studies, the aim is to provide a description, test a theory or generate a theory (Eisenhardt, 1989).

The use of multiple cases for the research involved multiple project environments. As the unit of analysis of this research is concerned with the application of OCTs within the PME, only those cases that used an OCT for their project management functions were included in the research. 
The specific I.T. infrastructure of the organisations, or their parent companies were excluded from the project, as were discussions of the general use of technology across the PME. In doing this, the research could clearly focus on the individual case's PME and its subsequent use of the OCTs. This is consistent with the main Research Question that seeks to constrain the research to the use of OCTS in the PME.

In keeping with the case approach, multiple methods of data collection were used. These methods were administered in a consistent approach across all the cases, to ensure that each case was being examined using consistent methodologies and strategies. In applying the multiple case approach, this research sought not only to gather an understanding of how each case used the OCT within the PME, but also to identify patterns and linkages that may be important to the research on the whole (Eisenhardt, 1989, Yin, 2003, Garson, 2008).

In order to test for different uses of OCTs within the PMEs, it was essential that each case be distinguished either by the type of OCT deployed, or by the type or scale of the project. Elements that were considered important for selecting each case and their projects are detailed below.

\subsubsection{Cases for Research}

The following reviews the recruitment selection of the case and provides a description of each.

\section{Case selection}

Selection of the cases to be studied was based on a number of the project characteristics including type, location, size, complexity, and organisation structure. This spread of possibilities allowed for a standardised research approach (in terms of questionnaires and interviews) to be applied to different project environments, whilst also comparing projects of varying dimensions against each other (Eisenhardt, 1989). Given this, cases were not randomly selected, but targeted not only because of their environments and organisation structures, but in relation to their project activity and the diversity of these activities in comparison to each other. It was mandatory that each case study used collaborative software within their PME, and that team members were 
available to complete the questionnaire and project managers were available and freely consented to be interviewed.

Not all cases approached participated in the final research. Table 5-2 details the variety of case study environments targeted, the rationale for their inclusion, and outcome as it pertains to the research.

As previously mentioned, the research design entailed using more or less identical methods against several contrasting cases or situations, in order to compare and better understand the PME and its relationship to OCTs and collaboration. This approach provides the research with the added benefit of being able to compare and analyse the different cases across common research components and identify common attributes and conditions. The matrix shows that the research was able to approach ten organisations, eight of which agreed to participate in the interview, resulting in the final six organisations being included.

The eventual six cases included in the research cover state government department, commercial construction, continuous improvement, government construction and infrastructure development projects. The cases highlight a variety of project types, varying project team sizes and different organisational and operating environments. They afford the research opportunity to review the use of OCTs from within a range of situations, whilst also developing a cross-case analysis consistent with the comparative case study research design. Across the six cases, five separate OCTs were used, with two cases using the same OCT. 
Table 5-2: Case study matrix

\begin{tabular}{|c|c|c|c|c|c|}
\hline & ID & Case study & Type/characteristics & Rationale for inclusion & Outcome \\
\hline 1 & $\operatorname{Org} \mathrm{S}$ & $\begin{array}{l}\text { State Government } \\
\text { Authority }\end{array}$ & $\begin{array}{l}\text { administrative, } \\
\text { technical }\end{array}$ & $\begin{array}{l}\text { High profile interorganisational project } \\
\text { with team members drawn from within } \\
\text { the organisation. }\end{array}$ & participation (as pilot) \\
\hline 2 & Org D & $\begin{array}{l}\text { State Government } \\
\text { Department }\end{array}$ & $\begin{array}{l}\text { administrative, } \\
\text { coordinating }\end{array}$ & $\begin{array}{l}\text { State Government Central Agency with } \\
\text { high profile cross government } \\
\text { administrative project, with team } \\
\text { members drawn from top level of all state } \\
\text { departments. }\end{array}$ & participation \\
\hline 3 & & $\begin{array}{l}\text { State Government } \\
\text { Department }\end{array}$ & $\begin{array}{l}\text { administrative, } \\
\text { consultative }\end{array}$ & $\begin{array}{l}\text { State Government Central Agency with } \\
\text { high profile Information Technology } \\
\text { project. High level of cross-government } \\
\text { consultation with team members drawn } \\
\text { from across all state departments. }\end{array}$ & $\begin{array}{l}\text { included, but later } \\
\text { withdrawn from } \\
\text { research due to poor } \\
\text { response to } \\
\text { questionnaire }\end{array}$ \\
\hline 4 & Org C & $\begin{array}{l}\text { Multinational } \\
\text { company }\end{array}$ & construction & $\begin{array}{l}\text { Multinational company operating as } \\
\text { owner and client organisation undertaking } \\
\text { its first large scale construction project in } \\
\text { Australia. }\end{array}$ & participation \\
\hline 5 & Org M & $\begin{array}{l}\text { State Government } \\
\text { owner }\end{array}$ & construction & $\begin{array}{l}\text { State government department requesting } \\
\text { construction of major civic building with } \\
\text { technical considerations. Includes large } \\
\text { stakeholders and public tender contractor } \\
\text { for construction phase }\end{array}$ & participation \\
\hline 6 & & $\begin{array}{l}\text { Independent } \\
\text { company }\end{array}$ & software development & $\begin{array}{l}\text { Niche software company. Use of subject } \\
\text { matter experts to develop customised } \\
\text { software. }\end{array}$ & $\begin{array}{l}\text { included, but later } \\
\text { withdrawn from } \\
\text { research due to poor } \\
\text { response to } \\
\text { questionnaire }\end{array}$ \\
\hline 7 & & $\begin{array}{l}\text { Independent } \\
\text { manufacturing } \\
\text { company }\end{array}$ & $\begin{array}{l}\text { automobile } \\
\text { manufacturing }\end{array}$ & $\begin{array}{l}\text { National truck company using OCT for } \\
\text { warehousing and customer order tracking. }\end{array}$ & declined to participate \\
\hline 8 & & University & $\begin{array}{l}\text { I.T./academic } \\
\text { collaborative research }\end{array}$ & $\begin{array}{l}\text { Research team distributed across several } \\
\text { Australian universities coordinated by a } \\
\text { national research initiative. }\end{array}$ & $\begin{array}{l}\text { included, but later } \\
\text { withdrawn from } \\
\text { research due to poor } \\
\text { response to } \\
\text { questionnaire } \\
\end{array}$ \\
\hline 9 & Org V & $\begin{array}{l}\text { Networked } \\
\text { organisation }\end{array}$ & $\begin{array}{l}\text { membership based } \\
\text { networking } \\
\text { organisation }\end{array}$ & $\begin{array}{l}\text { Social networking organisation with a } \\
\text { state-wide membership. }\end{array}$ & participation \\
\hline 10 & Org K & $\begin{array}{l}\text { State Government } \\
\text { Client }\end{array}$ & $\begin{array}{l}\text { infrastructure } \\
\text { development }\end{array}$ & $\begin{array}{l}\text { State government client requesting } \\
\text { construction of a large } \$ 500 \mathrm{~m} \text { civil } \\
\text { infrastructure project, with significant } \\
\text { time based constraints and stakeholder } \\
\text { management issues. }\end{array}$ & participation \\
\hline 11 & & $\begin{array}{l}\text { State / Federal } \\
\text { Government } \\
\text { Client }\end{array}$ & construction & $\begin{array}{l}\text { Government entity requesting } \\
\text { construction of hospital. Includes large } \\
\text { stakeholders and public tender contractor } \\
\text { for construction phase. }\end{array}$ & declined to participate \\
\hline
\end{tabular}

All of the case study participants worked for organisations in the public domain. Information was gathered through direct one-on-one communication with the participants and obtained through publicly available sources (e.g. websites and organisational literature). Participation was voluntary and the investigator recruited the interview subjects from each organisation. The study sought to interview people who held specific positions in the organisation structure, rather than people with specific characteristics or attributes. 
The next section of this chapter provides a brief description of each of the six cases that formed part of the research, and ends with a summary table that includes the main section headings of the interviews. This section therefore provides an introduction to the cases and provides the reader with an understanding on which to approach the following chapter. For a more detailed description of each of the cases, see Appendices A8 - 13.

\section{Case One Description Organisation D}

Case One reviews the operations of a specific business unit within a state government department. The unit is responsible for the coordination and preparation of the budget process that has, as its end outcome, the presentation of annual budget papers to the State Parliament. The project is of interest as it has no dollar cost attributed to it (except for the printing of the final papers). It is also unique in terms of government projects because it has an immoveable deadline; one that can not and will never fail, 'that is to say, it will be achieved regardless of the conditions, one way or another' (OrgD PM1). The project is considered to be high risk, primarily because of the political nature of the document and the fact that it must be delivered. The project maintains a fully documented set of risks and issues associated with the project. The project is further complicated by the risk of a security breach prior to the Treasurer's handing down of the announcement causing embarrassment to the Government (OrgD PM1).

The project occurs annually, and therefore has a known set of constraints and drivers. However, each project is considered unique, offering a different set of issues that need to be managed and coordinated, and a different set of political influences impacting on the deliverables. The project is a core piece of work for the department. There is only one full time resource assigned to the project; however, at any one time, over 100 people can be working on the project. Given this, the project is reliant on, and concerned with, coordinating people's time from across all arms of state government (OrgD PM1). It is a complex project due to the logistics and number of people involved in drafting and writing the documents. There are no contractors allowed on the job and there are many stakeholders from a wide variety of government environments including the bureaucratic and political. The project manager's primary role can be characterised as issue resolution (OrgD PM1). 
The project's main deliverables are the completion of a set of four Budget Papers presented to Parliament, and to provide support to the related activities associated with the handing down of that year's budget (OrgD PM1). The main activity of the project occurs between January and May of each year.

Details of the case are summarised below in Table 5-3.

Table 5-3: Case One Organisation D Details

\begin{tabular}{|l|l|}
\hline Case Particulars & \multicolumn{1}{|c|}{ Case Study Details Org D } \\
\hline Type & Government \\
\hline Risk & High \\
\hline Complexity & Medium - due to logistic of coordinating input \\
\hline Organisation & Government department managing the project \\
\hline Management Structure & Balanced Matrix Structure \\
\hline Environment & Distributed \\
\hline Size & 100 people in total: distributed teams \\
\hline Process & Departmental Project Management Methodology \\
\hline OCT & IBM Lotus Notes QuickPlace \\
\hline Stakeholders & $\begin{array}{l}\text { Varied - Government Ministers, Private Offices of Ministers, Departmental } \\
\text { Executive, media }\end{array}$ \\
\hline Cost & Approximately \$200,000 $(\$ 0.2 \mathrm{~m})$ plus in-kind \\
\hline
\end{tabular}

\section{Case Two Description Organisation $V$}

Case Two is a continuous improvement network for a statewide government organisation. Its role is to promote and encourage improvement across the whole of government (OrgV PM). It has about 2000 members and is sponsored by the Departmental Secretaries of each respective government department. The use of the OCT in this case study is different to other case studies in the research due to Organisation V using a blog to manage its project, which involves high levels of logistics and coordination of its members.

The Organisation commenced in July 2006 and had been given until June 2008 to demonstrate its purpose and capacity to deliver to its targeted audience group. In this sense, the organisation is itself a pilot project, with a predefined time period in which to present its outcomes.

The project's main deliverables expressed through its terms of reference, include four key areas:

- To promote an understanding of the business benefits of Continuous Improvement (CI);

- To identify and champion opportunities for continuous improvement across the organisation;

- To empower staff and build capability; and

- To monitor and evaluate the impact of the network. 
The project involves a self-evaluation of the network, plus an ongoing series of seminars, events, workshops and forums, designed specifically for the network and the Organisation's audience base (OrgV PM).

As Organisation V encompasses participation from across government, each government department contributes financially to the operation. The project is medium risk due to its political sensitivities and the possibility that the media may report activities in a negative light. The project is not considered complex, however as it is a relatively fluid organisation, there are no conditions placed on what it can or cannot attempt within its physical boundaries (OrgV PM). The main barrier to achieving tasks however is that the coordinator is the only paid staff of the organisation, and as such, is highly dependent on volunteers and in-kind contributions from the membership. The coordinator has a level of influence over the project and the types of activities to be developed, however he has neither control nor authority over the membership or its departments. As such, any sub-project proposal will require support from the respective department in order for it to be realised.

Details of the case are summarised below in Table 5-4.

Table 5-4: Case Two Organisation V Details

\begin{tabular}{|l|l|}
\hline Case Particulars & \multicolumn{1}{c|}{ Case Study Details Org V } \\
\hline Type & Continuous Improvement \\
\hline Risk & Medium \\
\hline Complexity & Low - use of established technology \\
\hline Organisation & Government department managing the project \\
\hline Management Structure & Weak Matrix Structure \\
\hline Environment & Distributed \\
\hline Size & 2000 people in total: 7-8 sub-project teams \\
\hline Process & Information distribution \\
\hline OCT & WordPress \\
\hline Stakeholders & State Coordination and Management Council (SC\&MC), membership \\
\hline Cost & Approximately \$70,000 $(\$ 0.07 \mathrm{~m})$ \\
\hline
\end{tabular}

\section{Case Three Description Organisation $M$}

This Three reviews a construction project undertaken by a state government department. It is of interest to this research due to its client and stakeholder base. The project has two separate clients, who will co-exist on the finished product. Client 1 is a state-based music recital company, and Client 2 is a state-based theatre company owned by a large and prestigious University. It is a Design and Construct project, with a practical completion date of December 2008, scheduled to open early 2009.

The main deliverables include: 
- 1000 -seat Hall - a purpose built centre for small ensemble performance from chamber music to jazz, chamber opera to world music;

- Smaller flexible 150-seat salon for more intimate musical performances - from cabaret and soirees to recording and educational programs;

- 500-seat theatre;

- Rehearsal studio, and administration facility for Client 2; and a

- Car park (OrgM PM1).

The cost of the project is $\$ 122 \mathrm{~m}$ funded entirely by the State Government. The land is owned by Client 2.

The project is considered 'hugely complex' (OrgM PM1) due to the presence of two main clients and the associated stakeholder considerations. The two clients are differentiated by the degree to which they understand the scope and deliverables of their particular requirements of the project (OrgM PM1). Given the nature of Client 1, there were also very strict acoustic criteria set in place for the facility, with the associated acoustic consultants providing complex advice and testing to ensure the facility was fit for purpose (OrgM PM1). Other factors such as a technical team distributed across several countries, and the presence of a major tram rail line running adjacent to two sides of the building further increased the complexity of the project. There were also external factors that influenced the technical considerations of the building. These resulted in the specification of the facility not being 'as ready for construction as it might have been' (OrgM SE1), including many atypical factors present, that resulted in 'many refreshed drawings and documents' (OrgM SE1). The level of risk attached to the project is however considered relatively low, due to the strong governance strategy in place.

Details of the case are summarised below in Table 5-5.

Table 5-5: Case Three Organisation M Details

\begin{tabular}{|l|l|}
\hline Case Particulars & \multicolumn{1}{|c|}{ Case Study Details Org M } \\
\hline Type & Construction \\
\hline Risk & Low - medium \\
\hline Complexity & High - dual clients, varying scope \\
\hline Organisation & Government organisation managing the project \\
\hline Management Structure & Balanced Matrix Structure \\
\hline Environment & Interorganisational \\
\hline Size & 400+ people: approx 15 teams \\
\hline Process & Administrative and contractual \\
\hline OCT & ACONEX \\
\hline Stakeholders & Complex including two main clients, two Government Ministers, associated \\
& technical and user groups \\
\hline Cost & \$122,000,000 (\$122m) \\
\hline
\end{tabular}




\section{Case Four Description Organisation $C$}

This case reviews a commercial in-house construction project undertaken by a large multinational beverage company based in Sydney. The case is of interest to this research as it is the only 'pure' commercial project, being entirely funded and managed for its own profit.

Organisation C is an Australian owned company, with 30\% owned by the parent company in the USA. Organisation $\mathrm{C}$ has two construction projects in progress, however this case study only refers to one: the construction of the first pure rack-cladding building in Australia. The total cost for the two projects is approximately $\$ 145$ million, with the case study building accounting for about half of this total. The project is considered by Orgc PM1 to have a medium level of risk attached to it.

Organisation $\mathrm{C}$ undertook considerable work through the development of the business case component, a process that was undertaken prior to the project receiving approval, and this provided the necessary assurance for the organisation's executive team to give its endorsement of the project (OrgC PM1). The project uses established technology and is considered by the Owner/Client to be 'a relatively straight forward construction project' (OrgC PM1).

The project's main deliverables include the construction of the two facilities and its associated requirements. The project seeks to:

- rationalise storage for the client;

- increase its pallet throughput;

- increase its pick-rate (i.e. the rate at which assorted products can be picked and packed into pallets of assorted products);

- deliver environmental benefits to limit double handling, and

- co-locate the distribution function of the business with the manufacturing component in order to reduce doubling of facilities and processes.

Details of the case are summarised below in Table 5-6.

Table 5-6: Case Four Organisation C Details

\begin{tabular}{|l|l|}
\hline Case Particulars & \multicolumn{1}{c|}{ Case Study Details Org C } \\
\hline Type & Construction \\
\hline Risk & Medium \\
\hline Complexity & Low - use of established technology \\
\hline Organisation & Commercial organisation managing the project \\
\hline Management Structure & Balanced Matrix Structure \\
\hline Environment & Interorganisational \\
\hline Size & 100 people in total: 10 teams \\
\hline Process & Administrative and contractual \\
\hline OCT & Autodesk Buzzsaw \\
\hline Stakeholders & Varied - Board of Directors, shareholders, State Government \\
\hline Cost & Approximately \$73,000,000 $(\$ 73 \mathrm{~m})$ \\
\hline
\end{tabular}




\section{Case Five Description Organisation $S$}

This case reviews a single project within a state based government authority. The project entails the redevelopment of its corporate website and is necessary to this research for two reasons; its relatively small organisational structure and being an in-house project. Organisation $\mathrm{S}$ is established by a Public Administration Act and comprises a Chair, a Public Sector Standards Commissioner and as many Commissioners as the Premier may appoint. The Public Sector Standards Commissioner has an extended range of responsibilities to ensure the public sector values and employment principles are followed.

The Authority's Chief Executive Officer and staff support the Chair and the Commissioners. The Authority has four major roles, outlined in the Act, which support delivery of the broader objectives of this legislation (OrgS PM1).

The Government has vested Organisation S with functions designed to foster the development of an efficient, integrated and responsive public sector that is highly ethical, accountable and professional in the ways it delivers services to the community (OrgS PM1).

The key functions of the Authority are to:

- identify opportunities to improve the delivery and integration of government services and report on service delivery outcomes and standards;

- promote high standards of integrity and conduct in the public sector;

- strengthen the professionalism and adaptability of the public sector; and

- promote high standards of governance, accountability and performance for public entities (OrgS PM1).

The Authority seeks to achieve its charter by working closely and collaboratively with public sector departments and agencies. The Authority reports directly to the Premier and operates separately from the daily activities of departments and agencies, and has no regulatory or audit role (OrgS PM1). The project's main deliverables are to create a working and efficient website to the Executive of the Authority and its stakeholders and audience groups (OrgS PM1). The total cost for the project is $\$ 70,000$.

The project is not complex, however the process and 'journey for the Executive is the issue that will impact on the outcomes and the methodology for determining that outcome' (OrgS PM1). Although the project is not considered complicated, the 'delicacies' involved with managing the various Executive stakeholders is time consuming and at times unpredictable (OrgS PM1). 
The project is low risk due to the existence of strong governance mechanisms and the level from which the project is being directed (i.e. the Authority's Executive team). This can provide challenges in itself, as priorities for projects at this level can very quickly be transferred to other more immediate projects if the "mood of the Executive turn or they do not see satisfactory progress" (OrgS PM1).

Details of the case are summarised below in Table 5-7.

Table 5-7: Case Five Organisation $S$ Details

\begin{tabular}{|l|l|}
\hline Case Particulars & \multicolumn{1}{|c|}{ Case Study Details Org S } \\
\hline Type & Government Authority \\
\hline Risk & Low \\
\hline Complexity & Low - use of established technology \\
\hline Organisation & Internal project \\
\hline Management Structure & Balanced Matrix Structure \\
\hline Environment & Traditional \\
\hline Size & Approximately 10 people in total: 3 sub projects \\
\hline Process & administrative and corporate \\
\hline OCT & IBM Lotus Notes QuickPlace \\
\hline Stakeholders & Varied - Executive, State Government, target audiences \\
\hline Cost & \$70,000 $(\$ 0.07 m)$ \\
\hline
\end{tabular}

\section{Case Six Description Organisation $K$}

This case reviews a state government initiative to improve a metropolitan railway system. The organisation that is the subject of the case study has responsibility for managing the construction component of the project, which involves laying $14 \mathrm{~km}$ of rail track in a densely populated urban area within an Australia capital city. The project managers interviewed for the case study are responsible for one component of the project. The project is one of fifteen similar rail projects being undertaken by the State government. It is being managed using an Alliance organisation structure consisting of five partner organisations and one client organisation. It has a 6-year timeframe (2007 - 2012), with an estimated cost of $\$ 500 \mathrm{~m}$.

The main deliverables of the project involve the laying of the $14 \mathrm{~km}$ rail track within the time allotted. The list of works is broken down into two categories - the railway station and miscellaneous works. The railway works include:

- the extension of an existing footbridge;

- overhead concourse including booking office, station staff amenities and public toilet;

- a lift, stairs, communications, lighting and power, security and fencing;

- associated suburban side street realigned and landscape works carried out;

- associated infrastructure including rail and station systems/services;

- a suite of signalling and electrical works. 
Miscellaneous works include:

- commuter car parking adjustments;

- landscape works;

- temporary works;

- demolition works;

- road works;

- noise walls;

- signal depot relocation.

The project is a relatively simple construction project from an engineering aspect (OrgK PM1). The complexity however is borne from three distinct areas. The first is that the project must be undertaken from within the rail corridor. This represents an increased level of physical risk of which all team members must be cognisant. The second issue is the existence of an Ethane gas pipeline directly below the construction zone; a matter that escalates the risk attached to workers onsite, and creates another level of complexity to the project. The third risk is the limited period in which to undertake the work. Although the project spans 6 years, the Rail authority has allocated a total of 13 weekends as officially designated maintenance days. This makes the project exceptionally time based in that only 26 days of on-site construction activity are allowed, with no opportunity for extensions (OrgK PM1).

The project is subsequently considered high risk. The pipeline provides risk from both an industrial and safety perspective, resulting in the development and implementation of strict procedures for its management (OrgK PM1). The risk and complexity factors, as well as the fact that it uses an Alliance organisational structure make the case of interest to this research.

Details of the case are summarised below in Table 5-8.

Table 5-8: Case Six Organisation K Details

\begin{tabular}{|l|l|}
\hline Case Particulars & \multicolumn{1}{|c|}{ Case Study Details Org K } \\
\hline Type & Construction \\
\hline Risk & High \\
\hline Complexity & medium to high - ethane pipeline \\
\hline Organisation & Alliance organisation managing the project \\
\hline Management Structure & Projectised \\
\hline Environment & Interorganisational \\
\hline Size & 150 people in total: 8 functional areas, up to 6 sites \\
\hline Process & administrative and contractual \\
\hline OCT & Nexus Point INCITE \\
\hline Stakeholders & Varied - Board of Directors, shareholders, State Government \\
\hline Cost & $\$ 500,000,000(\$ 500 \mathrm{~m})$ \\
\hline
\end{tabular}




\section{Summary of Cases}

Table 5-9 below provides a comparative summary of the ten key project descriptors presented in the individual case studies. The table highlights the breadth of cases selected and notes that these cases range in project types, include a mixture of low, medium and high risk projects, are of varying complexity and size, use five different OCTs and range in cost from $\$ 70,000$ to $\$ 500 \mathrm{~m}$.

The cases have different management structures and environments in place and have to report to different stakeholder groups, making the final six cases sufficiently varied to answer the main Research Question.

Table 5-9: Case study details comparatively summarised

\begin{tabular}{|c|c|c|c|c|c|c|}
\hline $\begin{array}{l}\text { Case } \\
\text { Particulars }\end{array}$ & $\begin{array}{c}\text { Case Study } \\
\text { Details } \\
\text { Org D }\end{array}$ & $\begin{array}{c}\text { Case Study } \\
\text { Details } \\
\text { Org V }\end{array}$ & $\begin{array}{l}\text { Case Study } \\
\text { Details } \\
\text { Org M }\end{array}$ & $\begin{array}{c}\text { Case Study } \\
\text { Details } \\
\text { Org C }\end{array}$ & $\begin{array}{c}\text { Case Study } \\
\text { Details } \\
\text { Org S }\end{array}$ & $\begin{array}{c}\text { Case Study } \\
\text { Details } \\
\text { Org K }\end{array}$ \\
\hline Type & $\begin{array}{l}\text { State } \\
\text { Government }\end{array}$ & $\begin{array}{l}\text { Continuous } \\
\text { Improvement }\end{array}$ & $\begin{array}{l}\text { Government } \\
\text { Construction } \\
\end{array}$ & $\begin{array}{l}\text { Commercial } \\
\text { Construction } \\
\end{array}$ & $\begin{array}{l}\text { Government } \\
\text { Authority }\end{array}$ & $\begin{array}{l}\text { Alliance } \\
\text { Construction } \\
\end{array}$ \\
\hline Risk & High & Medium & Low - medium & Medium & Low & High \\
\hline Complexity & $\begin{array}{l}\text { Medium - due } \\
\text { to logistic of } \\
\text { coordinating } \\
\text { many authors } \\
\text { across multiple } \\
\text { sites }\end{array}$ & $\begin{array}{l}\text { Low - use of } \\
\text { established } \\
\text { technology }\end{array}$ & $\begin{array}{l}\text { High - dual clients, } \\
\text { varying scope }\end{array}$ & $\begin{array}{l}\text { Low - use of } \\
\text { established } \\
\text { technology }\end{array}$ & $\begin{array}{l}\text { Low - use of } \\
\text { established } \\
\text { technology }\end{array}$ & $\begin{array}{l}\text { Medium to high - } \\
\text { ethane pipeline }\end{array}$ \\
\hline Organisation & $\begin{array}{l}\text { Government } \\
\text { department } \\
\text { managing the } \\
\text { project }\end{array}$ & $\begin{array}{l}\text { Government } \\
\text { department } \\
\text { managing the } \\
\text { project }\end{array}$ & $\begin{array}{l}\text { Government } \\
\text { organisation } \\
\text { managing the } \\
\text { project }\end{array}$ & $\begin{array}{l}\text { Commercial } \\
\text { organisation } \\
\text { managing the } \\
\text { project }\end{array}$ & Internal project & $\begin{array}{l}\text { Alliance } \\
\text { organisation } \\
\text { managing the } \\
\text { project }\end{array}$ \\
\hline $\begin{array}{l}\text { Management } \\
\text { Structure }\end{array}$ & $\begin{array}{l}\text { Balanced Matrix } \\
\text { Structure }\end{array}$ & $\begin{array}{l}\text { Weak Matrix } \\
\text { Structure }\end{array}$ & $\begin{array}{l}\text { Balanced Matrix } \\
\text { Structure }\end{array}$ & $\begin{array}{l}\text { Balanced Matrix } \\
\text { Structure }\end{array}$ & $\begin{array}{l}\text { Balanced Matrix } \\
\text { Structure }\end{array}$ & Projectised \\
\hline Environment & Distributed & Distributed & Interorganisational & Interorganisational & Traditional & Interorganisational \\
\hline Size & $\begin{array}{l}100 \text { people in } \\
\text { total: distributed } \\
\text { teams }\end{array}$ & $\begin{array}{l}2000 \text { people in } \\
\text { total: } 7-8 \text { sub- } \\
\text { project teams }\end{array}$ & $\begin{array}{l}400+\text { people: approx } \\
15 \text { teams }\end{array}$ & $\begin{array}{l}100 \text { people in total: } \\
10 \text { teams }\end{array}$ & $\begin{array}{l}\text { Approximately } \\
10 \text { people in } \\
\text { total: } 3 \mathrm{sub} \\
\text { projects }\end{array}$ & $\begin{array}{l}150 \text { people in total: } \\
8 \text { functional areas }\end{array}$ \\
\hline Process & $\begin{array}{l}\text { Departmental } \\
\text { Project } \\
\text { Management } \\
\text { Methodology }\end{array}$ & $\begin{array}{l}\text { Information } \\
\text { distribution }\end{array}$ & $\begin{array}{l}\text { Administrative and } \\
\text { contractual }\end{array}$ & $\begin{array}{l}\text { Administrative and } \\
\text { contractual }\end{array}$ & $\begin{array}{l}\text { Administrative } \\
\text { and corporate }\end{array}$ & $\begin{array}{l}\text { Administrative and } \\
\text { contractual }\end{array}$ \\
\hline OCT & $\begin{array}{l}\text { IBM Lotus } \\
\text { Notes } \\
\text { QuickPlace }\end{array}$ & WordPress & ACONEX & Autodesk Buzzsaw & $\begin{array}{l}\text { IBM Lotus } \\
\text { Notes } \\
\text { QuickPlace }\end{array}$ & $\begin{array}{l}\text { Nexus Point } \\
\text { INCITE }\end{array}$ \\
\hline Stakeholders & $\begin{array}{l}\text { Varied - } \\
\text { Government } \\
\text { Ministers, } \\
\text { Private Offices } \\
\text { of Ministers, } \\
\text { Departmental } \\
\text { Executive, } \\
\text { media } \\
\end{array}$ & $\begin{array}{l}\text { SC\&MC, } \\
\text { membership }\end{array}$ & $\begin{array}{l}\text { Complex including } \\
\text { two main clients, } \\
\text { two Government } \\
\text { Ministers, associated } \\
\text { technical and user } \\
\text { groups }\end{array}$ & $\begin{array}{l}\text { Varied - Board of } \\
\text { Directors, } \\
\text { shareholders, State } \\
\text { Government }\end{array}$ & $\begin{array}{l}\text { Varied - } \\
\text { Executive, State } \\
\text { Government, } \\
\text { target audiences }\end{array}$ & $\begin{array}{l}\text { Varied - Board of } \\
\text { Directors, } \\
\text { shareholders, State } \\
\text { Government }\end{array}$ \\
\hline Cost & $\begin{array}{l}\text { Approximately } \\
\$ 200,000 \\
(\$ 0.2 \mathrm{~m}) \text { plus in- } \\
\text { kind }\end{array}$ & $\begin{array}{l}\text { Approximately } \\
\$ 70,000 \\
(\$ 0.07 \mathrm{~m})\end{array}$ & $\begin{array}{l}\$ 122,000,000 \\
(\$ 122 \mathrm{~m})\end{array}$ & $\begin{array}{l}\text { Approximately } \\
\$ 73,000,000 \\
(\$ 73 \mathrm{~m})\end{array}$ & $\begin{array}{l}\$ 70,000 \\
(\$ 0.07 \mathrm{~m})\end{array}$ & $\begin{array}{l}\$ 500,000,000 \\
(\$ 500 \mathrm{~m})\end{array}$ \\
\hline
\end{tabular}




\subsection{Data Collection}

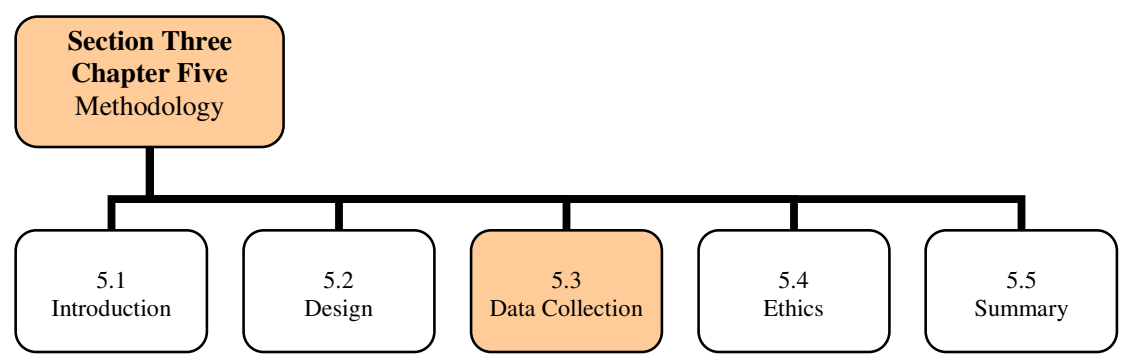

As noted earlier in this chapter, the case study approach selected for this research developed two broad strategies to collect data. The first strategy was the use of a questionnaire administered to each of the cases, whilst the second strategy utilised a semi-structured interview to address specific questions to the project PME of each case. The case study approach also allowed for additional material or documents to be collected throughout the interview and desk research processes. These three approaches will now be discussed in detail.

\subsubsection{Questionnaire}

A questionnaire was designed to be administered to the project managers of the selected case studies to collect data over a range of areas.

The data collected from the questionnaire was contained in three parts, with the first two covering 14 areas or subsections with a total of 123 individual statements. An additional part at the end of the questionnaire was included to gather demographic information about each respondent:

Part One: $\quad$ The use of OCTs including shared calendars, central databases, sharing documents, storing documents, announcement boards, virtual conferencing and general use of OCTs.

Part Two: Elements of collaboration including trust, communication, equality, strategic alliances, (project) knowledge distribution, negotiation and incentives.

Part Three: Demographic details including age, sex, years in project management and position in project.

A Likert scale was used to quickly and quantitatively rate the respondent's reaction to a series of given statements (Cavana et al., 2001) across Parts One and Two. These statements provided a point from which comparisons could be made and from which measures could be charted regarding the use of OCTs, the PME and the extent to which collaboration existed in the PME. 
The Likert scale was chosen over other scales such as the 'category', 'numerical', 'semantic differential', and 'stapel', as it was best suited to examine how strongly respondents agreed or disagreed with statements pertaining to the PME and associated notions of collaboration and use of OCTs. The five point scales of the Likert were selected as they allowed the investigator to pose specific statements in order to measure and compare attitudes amongst the project team members (the respondents).

Part Three of the questionnaire also sought to collect basic demographic information from the respondents. This information was general in nature and sought to confirm the ages of the respondent, their sex, the number of years in project management and their position in the project. Given that each question was mutually exclusive with non-overlapping categories, the nominal scale was applied for the first three questions in Part Three (Cavana et al., 2001). This measurement scale was considered against the other measurement scales of 'ordinal', 'interval' and 'ratio'. It was selected due to information required from the questionnaire being classified as basic, categorical and gross information (Cavana et al., 2001) and which could be expanded upon at the time of the interviews with the project managers if required. A short free-text field was provided to respondents for the fourth and final question regarding their position in the project.

The questionnaires were distributed to the team members prior to the interview, and were collected either at the time of the interview or post interview. They were sent to a total of 56 people and completed by 42, (across six cases), which represented a response rate of $75 \%$. The project manager for each case completed the Likert questionnaire as did the team members that were associated with the project manager role. In this sense, the questionnaire was seeking multiple responses to the same list of questions from each case.

The Likert scales were:

- strongly disagree

- disagree

- agree

- neither agree or disagree

- strongly agree

There were 73 questions in Part One and 50 questions in Part Two. Refer to Appendix A2 for a copy of the Likert questionnaire. 
The questionnaire was emailed to all respondents and the completed questionnaire emailed back to the interviewer to be transferred into a Microsoft Excel spreadsheet (Version 2000). A brief outline of the three parts follows.

Part One of the questionnaire was designed to test responses to the OCT features as they related to project management principles, the PME and general collaboration characteristics as detailed in the Literature Review. To that end it was split into seven subsections detailed in Table 5-10.

Table 5-10: Part One Questionnaire Section Headings

\begin{tabular}{|l|l|}
\hline Part One Subsections & Explanation \\
\hline 1. the use of shared calendars & $\begin{array}{l}\text { This subsection sought to identify how the calendar functionality was } \\
\text { used, and what benefits it brought to the PME. It also sought responses } \\
\text { to whether the use of the tool assisted with managing certain elements of } \\
\text { collaboration. }\end{array}$ \\
\hline 2. central databases & $\begin{array}{l}\text { This subsection asked the respondents questions about the use of the } \\
\text { central database function in the OCT and the effects that the application } \\
\text { of the database can have on managing components of the project. }\end{array}$ \\
\hline 3. sharing documents & $\begin{array}{l}\text { This subsection entailed reviewing the capacity to share documents, and } \\
\text { understanding the advantages and benefits to be realised through this } \\
\text { functionality. It also sought to understand the role that sharing } \\
\text { documents played with managing specific elements of collaboration } \\
\text { including risk, trust and communication. }\end{array}$ \\
\hline 4. storing documents & $\begin{array}{l}\text { This subsection presented questions regarding the capacity to store } \\
\text { documents within the OCT, and the impact or value-adding effect this } \\
\text { functionality provided the team members. }\end{array}$ \\
\hline $5 . \quad$ announcement boards & $\begin{array}{l}\text { This subsection reviewed the use of the announcement board in the OCT, } \\
\text { posing questions regarding the role of this functionality and the flow on } \\
\text { effects to the PME. }\end{array}$ \\
\hline 6. virtual conferencing & $\begin{array}{l}\text { This subsection addressed the use of virtual conferencing in the PME, in } \\
\text { a bid to review alternate communication mechanism of the OCT. }\end{array}$ \\
\hline 7. general use of OCTs & $\begin{array}{l}\text { This subsection posed general questions about the use of the OCT, in } \\
\text { order to collect other relevant applications of the product that did not } \\
\text { necessarily fit within the previous categorisations. This final subsection } \\
\text { also sought to pose previously asked questions in an alternate fashion to } \\
\text { check for consistency in responses. }\end{array}$ \\
\hline
\end{tabular}

The Part One statements were matched against the project management knowledge areas and collaboration characteristics for future cross referencing if required. Refer to Appendix A3 for this coding.

Part Two of the questionnaire was used to examine the concept of collaboration, and was designed to test responses to themes and the extent of collaboration as it related to both the PME and general collaboration characteristics. Part Two also included seven subsections which are outlined in Table 5-11 below. 
Table 5-11: Part Two Questionnaire Section Headings

\begin{tabular}{|ll|l|}
\hline Part Two subsections & Explanation \\
\hline 1. $\quad$ Trust & $\begin{array}{l}\text { The first subsection asked the respondents about trust and the role it played } \\
\text { amongst the team members and the role of the OCT. }\end{array}$ \\
\hline 2. $\quad$ Communication & $\begin{array}{l}\text { The second subsection reviewed communication and the associated role of } \\
\text { communication within their PME and the factors that impact on its delivery. }\end{array}$ \\
\hline 3. $\quad$ Equality & The third subsection addressed equality and its level of importance. \\
\hline 4. Strategic alliances & $\begin{array}{l}\text { The fourth subsection posed questions relating to strategic alliances and its } \\
\text { function within the PME. }\end{array}$ \\
\hline 5. $\quad$ distribution & $\begin{array}{l}\text { The fifth subsection addressed the issue of distribution of project based } \\
\text { knowledge and linked these questions to other areas including the use of the } \\
\text { OCT, central repositories and the role of the project manager. }\end{array}$ \\
\hline 6. $\quad$ Negotiation & The sixth subsection questioned the role that negotiations play in the PME. \\
\hline 7. $\quad$ Incentives & The seventh subsection questioned the role that incentives play in the PME. \\
\hline
\end{tabular}

In all of the 123 questions, the respondents were asked to select the number between 1 and 5 that best described the extent to which they agreed with the statement. The questionnaire posed and re-posed questions to the respondents around the same issues as a way of confirming and internally validating their responses.

Part Three gathered brief information about the respondents. It requested basic details about the respondent and their project management experience in order to gain a clear picture of the different PMEs, and their demographic composition; information that may prove meaningful at the future analysis stage. There were four questions in total, with the first asking the respondents to select their age from one of three scales - under 30 years old, 31-50 years old or over 50 years old. The second question asked them to choose whether they were female or male, with the third question requesting the length of time they had been in project management - this question provided three scales of under five years, 6-15 years, or over 15 years. The fourth and final question provided a small free text field for respondents to note their main role in the project team.

\section{Questionnaire Analysis of Data}

Each question was allocated a unique number in an Excel spreadsheet, and each of the scales was allocated a number or value in order to chart the responses to the questions. For Parts One and Two, (questions 1 - 73, 1 - 50) the scale of 'strongly disagree', 'disagree', 'neither agree nor disagree', 'agree' and 'strongly agree' were identified in the spreadsheet as 1,2,3,4,5 respectively. 
For Part Three the numbers 1, 2, and 3 were used to represent the scales applied in the questions relating to age, sex and years in project management.

Formulas applied to each question enabled graphs to be generated from these results, providing a comparative visual representation of the spread of the responses. The formulas were based on the frequency that a scale was received for the specific question, expressed as a percentage of the total number of responses received for that question. Charts were generated for each question within each case study and then reviewed comparatively across all the cases, which was used as a reference point for later analysis or comparison. Table 5-12 is an example of this comparative analysis - future sections of this thesis will present the full suite of these tables.

Table 5-12: Excerpt from comparative case analysis - The use of OCTs in general

\begin{tabular}{|c|c|c|c|c|c|c|c|c|}
\hline \multirow[t]{2}{*}{$\begin{array}{l}\text { 63. is the most effective tool for } \\
\text { distributing information to the } \\
\text { project team }\end{array}$} & Agg. & OrgD & OrgV & OrgM & OrgC & OrgS & OrgK & \multirow[t]{2}{*}{ Comment } \\
\hline & \multicolumn{7}{|c|}{ Case responses \% } & \\
\hline strongly disagree & $\mathbf{0}$ & 0 & 0 & 0 & 0 & 0 & 0 & \multirow{5}{*}{$\begin{array}{l}\text { Approximately two thirds of } \\
\text { respondents }(67 \%) \text { 'agree' to } \\
\text { 'strongly agree' the use of the OCT } \\
\text { in general is the most effective tool } \\
\text { for distributing information to the } \\
\text { project team. }\end{array}$} \\
\hline disagree & 12 & 25 & 22 & 0 & 0 & 20 & 17 & \\
\hline neither & 21 & 50 & 22 & 8 & 33 & 20 & 17 & \\
\hline agree & 57 & 25 & 56 & 75 & 67 & 40 & 50 & \\
\hline strongly agree & 10 & 0 & 0 & 17 & 0 & 20 & 17 & \\
\hline
\end{tabular}

In addition, and to supplement this analysis, the Likert instrument was also interpreted through the use of aggregated tallies. This approach entailed totalling the responses for each statement per respondent in the case, and then expressing this total as a percentage of the total scale score. This percentage is then interpreted as the case's degree of acceptance (or agreement) to the statement. Statements that were worded to elicit a negative response were coded in the reverse order to allow for consistency of interpretation and for all percentages to be read in the positive (De Vaus, 1995). Table 5-13 provides an example of this coding.

Table 5-13: Likert coding for consistency

\begin{tabular}{|c|l|c|c|c|c|c|c|c|c|}
\hline $\mathbf{A}$ & \multicolumn{1}{|c|}{ B } & C & D & E & F & G & H & I & J \\
\hline & The use of a CENTRAL DATABASE in the OCT: & & & & & & & & \\
\hline 10 & improves the quality of data in the database & 2 & 4 & 2 & 4 & 2 & 4 & 18 & $60 \%$ \\
\hline 11 & manages data from a central environment & 5 & 4 & 4 & 5 & 3 & 4 & 25 & $83 \%$ \\
\hline 12 & decreases confidence in the data & $\mathbf{4}$ & $\mathbf{4}$ & $\mathbf{4}$ & $\mathbf{3}$ & $\mathbf{4}$ & $\mathbf{4}$ & $\mathbf{2 3}$ & $\mathbf{7 7 \%}$ \\
\hline 13 & increases possibility of data corruption & $\mathbf{4}$ & $\mathbf{4}$ & $\mathbf{4}$ & $\mathbf{2}$ & $\mathbf{4}$ & $\mathbf{4}$ & $\mathbf{2 2}$ & $\mathbf{7 3 \%}$ \\
\hline
\end{tabular}


where:

- Column A refers to the Likert statement number;

- Column B refers to the Likert statement;

- Columns $\mathrm{C}-\mathrm{H}$ refer to individual team member responses, ranging from 1 (low) to 5 (high), correlating with 1 (strongly disagree) to 5 (strongly agree);

- Column I refers to aggregated total;

- Column J refers to total expressed as a percent of scale score.

The scale score is calculated by multiplying the number of respondents in the case (n) by best possible score (5). In this example, $n=6$, making the scale score calculation $6 \times 5=30$.

Statements number $12 \& 13$ have their calculations reversed in order to comply with consistency for statements that have negative responses. In these statements, columns are coded 1 (high) to 5 (low), correlating with 1 (strongly disagree) to 5 (strongly agree). From these percentage scores, interpretation on the degree of acceptance to the statement can be made, in association with results from the graphs.

\section{Collaboration Scale}

The data from each case was also sorted for its applicability to collaboration using the Collaboration scale described in Chapter Two (refer to Appendix A4 for this coding). The seven collaboration characteristics were allocated a numerical identification code (Table 5-14), and then applied to one statement in the questionnaire that most related to the characteristic. Parts Three of the questionnaire (demographics) was not tested for collaboration. The responses to these statements (from Part One and Two) were then sorted from highest to lowest responses into the collaboration characteristic groups. In this way, the questionnaire statement is analysed for both its reference to its use or functional attribute, as well as its connection or relevance to collaboration (Research Question Three). This allowed the research to undertake future analysis of the OCTs for both functional and collaborative features and in doing so was able to provide a significant body of data from which to address research questions 2 and 3.

Table 5-14 provides a list of the seven collaboration characteristics and their associated ID code. Table 5-15 provides the ID coding for the 14 Likert sections, and includes $1.1-1.7$ for Part One, and 2.1 - 2.7 for Part Two of the questionnaire. Table 5-16 provides details of the rating codes used in the subsequent coding. Table 5-17 is an excerpt from the entire table that shows the Likert questionnaire coded for the Collaboration scale using the collaboration characteristics and Likert section ID presented in the previous tables. In Table 5-17, questions 1-9 are, for example, 
part of Likert section 1.1, but are given different collaboration characteristic IDs, ranging from Tasks/Scheduling - 2, Communication - 3, and Relationships -5, depending on the individual statement. The full table can be found in Appendix A4.

Table 5-14: Collaboration characteristics

\begin{tabular}{|l|c|}
\hline Collaboration characteristic & ID \\
\hline Resources & $\mathbf{1}$ \\
\hline Tasks/scheduling & $\mathbf{2}$ \\
\hline Communication & $\mathbf{3}$ \\
\hline Information & $\mathbf{4}$ \\
\hline Relationships & $\mathbf{5}$ \\
\hline Rewards & $\mathbf{6}$ \\
\hline Negotiation & $\mathbf{7}$ \\
\hline
\end{tabular}

Table 5-16: Key to percent response for Likert statement

\begin{tabular}{|c|c|}
\hline Percent response & Rating \\
\hline $0-20 \%$ & Low \\
\hline $21-40 \%$ & Low - Moderate \\
\hline $41-60 \%$ & Moderate \\
\hline $61-80 \%$ & Moderate - High \\
\hline $81-100 \%$ & High \\
\hline
\end{tabular}

Table 5-15: Likert section ID

\begin{tabular}{|l|l|}
\hline Likert section Part number & ID \\
\hline Shared calendars & 1.1 \\
\hline Central db & 1.2 \\
\hline Share doc & 1.3 \\
\hline Store docs & 1.4 \\
\hline Announcement Boards & 1.5 \\
\hline Virtual Conferencing & 1.6 \\
\hline OCTs in general & 1.7 \\
\hline Trust & 2.1 \\
\hline Communication & 2.2 \\
\hline Equality & 2.3 \\
\hline Strategic Alliances & 2.4 \\
\hline Project Knowledge Distribution. & 2.5 \\
\hline Negotiation & 2.6 \\
\hline Incentives & 2.7 \\
\hline
\end{tabular}

Table 5-17: Likert questionnaire coded for collaboration

\begin{tabular}{|l|l|l|c|}
\hline $\begin{array}{l}\text { Pt } \\
\text { No. }\end{array}$ & $\begin{array}{l}\text { Qu } \\
\text { no. }\end{array}$ & PART ONE & $\begin{array}{c}\text { Cb } \\
\text { Scale } \\
\text { CODE }\end{array}$ \\
\hline & & $\begin{array}{l}\text { The use of SHARED CALENDARS in the Online Collaborative Toolsets } \\
\text { (OCT): }\end{array}$ & \\
\hline 1.1 & 1 & increases chances of meeting project schedules & $\mathbf{2}$ \\
\hline 1.1 & 2 & improves planning activities & $\mathbf{2}$ \\
\hline 1.1 & 3 & improves prioritising tasks & $\mathbf{2}$ \\
\hline 1.1 & 4 & complicates coordinating activities across the project environment & $\mathbf{2}$ \\
\hline 1.1 & 7 & communicates the availability of team members and resources & $\mathbf{3}$ \\
\hline 1.1 & 8 & supports equality amongst team members & $\mathbf{5}$ \\
\hline 1.1 & 9 & detracts from managing Strategic alliances within the project team & $\mathbf{5}$ \\
\hline & & & \\
\hline & & The use of a CENTRAL DATABASE in the OCT: & $\mathbf{4}$ \\
\hline 1.2 & 10 & improves the quality of data in the database & $\mathbf{4}$ \\
\hline 1.2 & 11 & manages data from a central environment & $\mathbf{4}$ \\
\hline 1.2 & 12 & decreases confidence in the data & $\mathbf{4}$ \\
\hline 1.2 & 15 & centralises reporting of data & $\mathbf{1}$ \\
\hline 1.2 & 16 & detracts from organisational planning & $\mathbf{4}$ \\
\hline 1.2 & 17 & reduces the complexity of maintaining data & $\mathbf{5}$ \\
\hline 1.2 & 18 & requires a level of trust between team members & $\mathbf{3}$ \\
\hline 1.2 & 19 & hampers communication across the project team & \\
\hline
\end{tabular}

Table 5-18 draws together these codes to detail how each statement can be reviewed against the Collaboration Scale. The table is a selective excerpt from the aggregate table for all responses across all six cases. It serves as an example of sorting the highest ranked statement for each of the collaborative characteristics, referencing its specific question number and relevant placement in the questionnaire. 
Table 5-18: Excerpt of sorted Likert against collaboration scale - Aggregate sample

\begin{tabular}{|c|c|c|c|c|c|c|}
\hline Pt No. & $\begin{array}{l}\text { Qu. } \\
\text { No. }\end{array}$ & $\begin{array}{l}\text { PART ONE } \\
\text { Aggregate }\end{array}$ & $\begin{array}{l}\text { Cb Scale } \\
\text { CODE }\end{array}$ & tallies & $\%$ & rating \\
\hline 1.3 & 29 & assists with project planning & 1 & 153 & $73 \%$ & mod-high \\
\hline 1.7 & 73 & complicates managing staff and resources & 1 & 147 & $70 \%$ & mod-high \\
\hline 1.4 & 31 & reduces the number of users accessing files & 1 & 117 & $56 \%$ & moderate \\
\hline 1.6 & 55 & does not replace the number of meetings required & 1 & 115 & $55 \%$ & moderate \\
\hline 1.6 & 61 & replaces the need to meet physically & 1 & 102 & $49 \%$ & moderate \\
\hline 1.1 & 2 & improves planning activities & 2 & 162 & $77 \%$ & mod-high \\
\hline 1.4 & 40 & decreases the quality controls of the document & 2 & 154 & $73 \%$ & mod-high \\
\hline 1.1 & 1 & increases chances of meeting project schedules & 2 & 152 & $72 \%$ & mod-high \\
\hline 1.5 & 52 & increases the capacity to manage risk & 2 & 132 & $63 \%$ & mod-high \\
\hline 1.4 & 39 & increases the time and effort required to manage documents & 2 & 127 & $60 \%$ & moderate \\
\hline 1.6 & 57 & enables more effective control over schedule and project issues & 2 & 125 & $60 \%$ & moderate \\
\hline 1.7 & 65 & increases the amount of administration for the project & 2 & 117 & $56 \%$ & moderate \\
\hline 2.2 & 85 & effective communication benefits project management & 3 & 189 & $90 \%$ & high \\
\hline 2.2 & 89 & managing team members requires communication & 3 & 187 & $89 \%$ & high \\
\hline
\end{tabular}

In this way, the questionnaire can be viewed and analysed for collaboration both by organisation findings specifically, and by its aggregate.

\subsubsection{Interviews}

The methodology used in the multiple case study approach included conducting semi-structured interviews at the workplace of the case study, in order to gain an understanding of specific elements of the PME, the level of use of the OCT, and the extent to which collaboration occurs within the PME. As such, the interviews were no longer neutral tools of data gathering (Fontana and Frey, 2000) but were active interactions applied to gather information and to contextualise comments from across the cases included in the research.

As the research targeted the use of OCTs within the PME, the interview focussed on identifying the circumstances and conditions under which the OCTs were employed, rather than an open and general exploratory-based research on the use of OCTs in general. The interview questions were designed to elicit responses to issues, procedures and dependencies of the central subject (OCTs) within the PME, from the participants. Placed in juxtaposition with the questionnaire, this methodology attempts to further understand and validate the account of the use of the OCT, not by its functional aspects, but in its operation and use of the OCT. In doing this, the interviews provide a mechanism to check the validity of the instruments relative to the purpose and circumstances being investigated (Maxwell, 1992) and enables the research through use of the interviews, to review the data collected through the questionnaire for consistency whilst also 
checking the inferences that may be drawn from them (Hammersley and Atkinson, 1983). The questionnaire was pilot tested for validity to review the suitability of language, logic, issues to be covered and relevance to the PME. This pilot test was undertaken prior to the questionnaire being finalised, and was conducted with a prospective respondent to ensure that the feedback was pertinent to both the questionnaire format and target audience.

\section{Interview Protocol}

A total of nine interviews were conducted (over the six cases) over an 18-month period between 2006 and 2008. Four cases were in Melbourne and two in Sydney. The interviews were tape recorded and the interviewer took notes during the interview. The interviews were semistructured, and presented informally in the offices of the interviewee. The ensuing discussion responded to particular issues raised as part of the information gathering process, so that the discussion could cover ground not necessarily identified in the list of questions. However, all set questions were either asked by the interviewer, or were answered by the interviewee through general discussion or direct response to the question being posed - this included those instances where the interviewee did not know the answers to the questions posed. A copy of associated material (where available or appropriate) was also requested as part of the interview process. In some cases the interviewee took it upon themselves to follow up on some outstanding issues and forward material to the interviewer.

The notes from the interviews were analysed for common themes or issues that resonated with a particular question or group of questions, and were read in context with the findings of the questionnaire. The identity of the interviewees was removed from analysis, which was consistent with the consent form, whilst also complying with confidentiality of respondents (Walter, 2002). Supporting material in the form of computer screen shots, internal documents and organisational procedures, were used to elucidate key themes or to describe individual case study organisation structures. Each case study was subsequently reported against the key themes of the study incorporating all relevant sources.

Content analysis was not used in the study, as the interviews were not transcribed, opting instead to interpret and analyse the comments from the structured component of the interviews and investigator's notes. Content analysis is the manual or automated coding of documents, transcripts, newspapers, audio or video media to obtain counts of words, phrases, or word-phrase 
clusters for purposes of statistical analysis. Typically the researcher, when using content analysis, creates a dictionary which clusters words and phrases into conceptual categories for purposes of counting (Garson, 2008).

The participants were required to answer a series of questions about the nature of their organisation as it related to the project under review and the OCT in use. Each interviewee was asked to comment only on their area of expertise or work environment. The interview structure and question lists were predetermined prior to commencing this stage of the research, with each participant being asked the same set of questions. The interview lasted approximately $1-1 \frac{1}{2}$ hours.

The interviews and completed questionnaires (and the subsequent compilation) constituted the total of the data gathering and provided the source for analysis, along with any additional material provided by the participants or their agents, especially where a third party software was deployed.

\section{Outline of Questions Posed}

The interview methodology was used to gain an understanding of the environment in which the OCT is deployed, and to investigate the environment developed or instigated to deliver the project (the PME) and the impact or role this may have in the use of the OCT. The extent to which collaboration exists within the PME was also investigated. The interviews therefore needed to address issues relevant to not only the parent or host organisation, but to those associated with it - the contractors and sub contractors who form part of the project team, especially where they are geographically distributed and/or play an important role in providing goods and services.

The project managers of each organisation were interviewed to gather an overall commentary on the project environment as it related to the research. The project manager selected the team members with as many as possible offered the opportunity to complete the Likert questionnaire. The questions put to the project managers concentrated on eight broad areas or topics selected to develop a snapshot of the context in which the case operates. Table 5-19 details these topics. 
Table 5-19: Interview areas

\begin{tabular}{|l|l|}
\hline Interview areas & Explanation \\
\hline Type of project & $\begin{array}{l}\text { This topic gained a picture of the type of project being undertaken, its timeframes, deliverables, } \\
\text { estimated cost, level of complexity and associated risk. }\end{array}$ \\
\hline Organisation details & $\begin{array}{l}\text { This topic gathered information regarding the organisation managing the project. Information } \\
\text { including organisation type, organisation and management structure, use of sub-contractors and the } \\
\text { sharing of information were all covered in order to develop a picture of how the organisation is } \\
\text { configured. }\end{array}$ \\
\hline Management structure & $\begin{array}{l}\text { This topic gathered specific information regarding the environment in which the project manager } \\
\text { operates, the presence of team leaders and the way in which sub-contractors are deployed. }\end{array}$ \\
\hline Environment & $\begin{array}{l}\text { This topic reviewed the environment in which the project operated. It included gaining an } \\
\text { understanding of the culture of the organisation, whether it is collaborative by nature and if it has a } \\
\text { history of successfully deploying collaborative strategies. }\end{array}$ \\
\hline Size & $\begin{array}{l}\text { This topic requested information on the size of the project, including the number of people and } \\
\text { teams involved and where they are located in relation to the main activity of the project. }\end{array}$ \\
\hline Process & $\begin{array}{l}\text { This topic reviewed the processes of the organisation, requesting information on any mandated } \\
\text { project related processes, project methodology, flow of information and an introduction to the } \\
\text { OCT. }\end{array}$ \\
\hline Software & $\begin{array}{l}\text { This topic concentrated specifically on the OCT - what it is, why it was chosen, and by whom, the } \\
\text { level of technical support, operating requirements, and how it works. This topic also tries to } \\
\text { separate native software from project related software. }\end{array}$ \\
\hline Stakeholders & $\begin{array}{l}\text { This topic reviews the stakeholders of the project - who they are, what role they play, and what } \\
\text { processes (if any) are in place to manage them. }\end{array}$ \\
\hline
\end{tabular}

For a full listing of the questions used in the interviews, refer to Appendix A5.

\subsubsection{Documents}

The research approach also included the collection and subsequent analysis of supporting

material. This material was additional to the material covered in the interviews and

questionnaires, and fell into two distinct areas: project documentation and publicly available

documents or assets discovered through desk research. Table 5-20 details these two sources.

Table 5-20: Project documentation

\begin{tabular}{|c|c|}
\hline Documentation & Description \\
\hline $\begin{array}{l}\text { Project (case) } \\
\text { documentation }\end{array}$ & $\begin{array}{l}\text { This material was provided as part of the case study approach and was not necessarily in the } \\
\text { public domain. Material provided by the cases included: } \\
\text { - } \text { project artefacts } \\
\text { - } \text { screen shots of the OCT and other electronic document repositories } \\
\text { - } \text { OCT usage reports } \\
\text { - } \text { stakeholder management documentation } \\
\text { - } \text { organisation charts } \\
\text { - Project management process documentation }\end{array}$ \\
\hline Desk research & $\begin{array}{l}\text { The material that was sourced over the internet included: } \\
\text { - Information on the range of OCTs commercially available over the internet. This } \\
\text { source was used to respond to research Question One, 'What are the features of } \\
\text { OCTs?' } \\
\text { - access to OCT vendor sites }\end{array}$ \\
\hline
\end{tabular}




\section{Data Treatment}

The table below details each data source against the approach used, whilst also noting the relevance to the research questions. It notes that the data from the questionnaire is used to enable reporting against individual statements and sections groups, whilst also being used to interpret against the summary of individual or aggregate findings for each case and across cases. The interview data is used to report against key themes for each case. Both the questionnaire and the interviews provide relevant data sources to assist in answering research questions 2 and 3. The supporting material provides additional evidence or documentation raised during the interviews and is used to triangulate and validate data sets as well as describing individual PME processes and organisational structures. This material is also used to answer research question 1. Table 5-21 provides a summary of these data collection strategies.

Table 5-21: Data treatment

\begin{tabular}{|c|c|}
\hline Data source & Approach to evidence / data source \\
\hline Questionnaire & 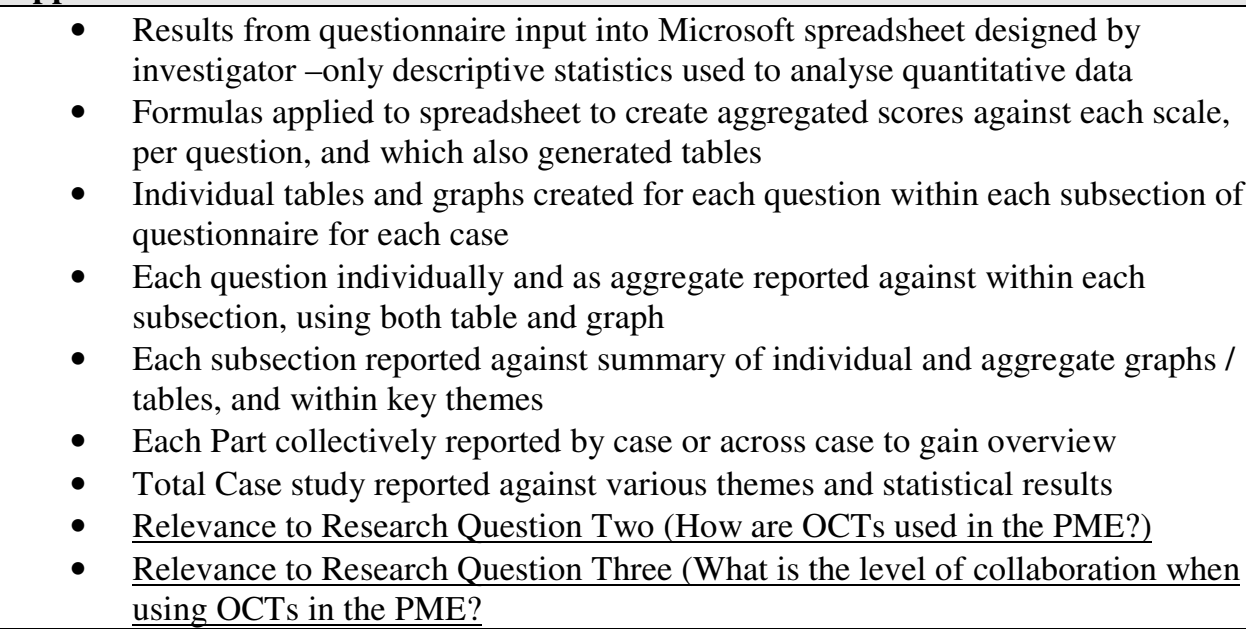 \\
\hline Interview & $\begin{array}{l}\text { - Each section reported using interview notes against interview structure } \\
\text { - } \text { Individual identification coding provided for each case } \\
\text { - } \text { Each interview reported against key themes } \\
\text { - } \text { Relevance to Research Question One (What are the features of OCTs?) } \\
\text { - } \quad \text { Relevance to Research Question Two (How are OCTs used in the PME?) } \\
\text { Relevance to Research Question Three (What is the level of collaboration when } \\
\text { using OCTs in the PME? }\end{array}$ \\
\hline $\begin{array}{l}\text { Supporting } \\
\text { material }\end{array}$ & $\begin{array}{l}\text { - Reports, internal documentation, user statistics, screen shots of OCT - reviewed } \\
\text { and analysed against information received through other data sources } \\
\text { - } \text { Desk research involving checking and scanning publicly available internet sites } \\
\text { for commercially available OCTs. } \\
\text { - } \quad \text { used to triangulate, verify and validate data sets } \\
\text { - } \quad \text { used to describe and document processes and organisational structures } \\
\text { - } \quad \text { Relevance to Research Question One (What are the features of OCTs?) }\end{array}$ \\
\hline
\end{tabular}




\section{Demographics}

The respondents can be grouped according to their age and sex. Figure 5-1 highlights the age of the respondents and notes that more than $60 \%$ fell in the $31-50$ age group. The other two age groups (under 30 years, and over 51 years) were equally represented.

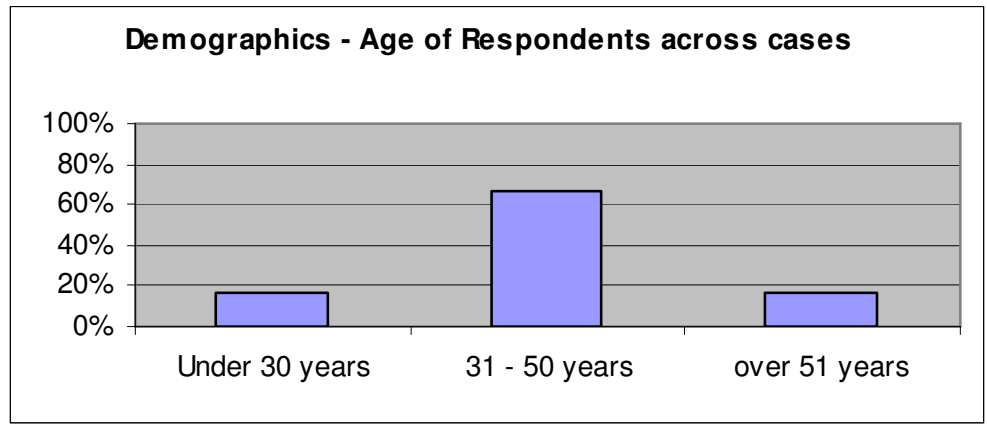

Figure 5-1: Age of Respondents across cases $(n=42)$

Figure 5-2 highlights the sex of the respondents across the cases and notes that two thirds are male, and one third female.

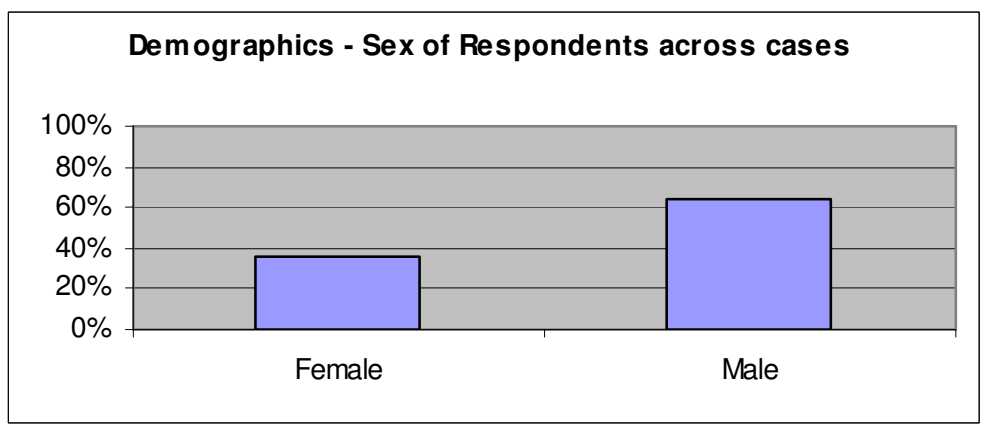

Figure 5-2: Sex of Respondents across cases $(n=42)$

These findings suggest that the make-up of the sample is broadly reflecting the general nature of the economy, in that the majority of respondents were between 31-50 years old, with approximately two thirds male, a finding that is not altogether surprising given that of the six cases selected for the research, half involved construction projects.

\subsubsection{Data Validity}

Both the questionnaire and interview were pilot tested. The interview was pilot tested for validity including suitability of language, logic, issues to be covered and relevance to the PME. This pilot test was conducted with a prospective respondent and was undertaken prior to interviews commencing and sought to ensure that the approach, focus and structure of the 
interview and its questions would best suit the interviewees. The pilot also tested duration to ensure the interviews were kept to a set timeframe.

There are a series of procedures or tests that can be undertaken to test the validity or 'goodness' in the measure of the instrument being applied in the research (Cavana et al., 2001). These tests are applied in order to check prior to its use, the ability and suitability of the instrument to measure the concept (De Vaus, 1995).

A study is valid if its measures actually measure what they claim to, and if there are no logical errors in drawing conclusions from the data (Garson, 2008). It also allows for a rounded and credible picture to be developed through the analysis of the data (Bryman and Burgess, 1994). There are a variety of types of validity tests, with researchers disagreeing on their definitions, types and whether they subsequently overlap (Garson, 2008). To that end, validity is treated as a series of tests used to identify the existence of any threats and biases that may undermine the meaningfulness of the research. Table 5-22 reviews the main concepts of validity, and locates these within the research approach.

The use of face validity was used to gauge responses to the format and flow of the questionnaire, whilst the test of content validity was also undertaken to ensure that the measures and main items contained within the questionnaire were adequate and representative of a set of items that tested the issue (Cavana et al., 2001, Bryman, 2001, Mason, 1996). It also provided an understanding of the concepts or situational factors that the interviews attempted to uncover as part of the theory-building style of the research. As a result of the pilot study and validity testing, the questionnaire was amended to reflect a closer link between the three core research areas - that is OCT use, the PME and the characteristics of collaboration. The use of some terms within the questionnaire were also tightened to make the meanings clearer. 
Table 5-22: Validity Matrix

\begin{tabular}{|c|c|c|c|}
\hline Tests & Suggested Case Study Tactics & Description & $\begin{array}{l}\text { Specific Measures of this } \\
\text { Design }\end{array}$ \\
\hline $\begin{array}{l}\text { Construct } \\
\text { Validity }\end{array}$ & $\begin{array}{ll} & \text { use multiple sources of } \\
\text { evidence } \\
\text { - } \\
\text { - } \text { establish chain of evidence } \\
\text { draft case informants review } \\
\text { - does the instrument tap the } \\
\text { concept as theorised? }\end{array}$ & $\begin{array}{l}\text { refers to the } \\
\text { establishment of } \\
\text { appropriate operational } \\
\text { measures for the } \\
\text { concepts being } \\
\text { measured }\end{array}$ & $\begin{array}{l}\text { multiple sources of } \\
\text { evidence used } \\
\text { document } \\
\text { supplementation provided } \\
\text { by cases }\end{array}$ \\
\hline $\begin{array}{l}\text { Internal } \\
\text { Validity }\end{array}$ & $\begin{array}{ll} & \text { undertake case comparisons } \\
\text { - } & \text { pattern-matching } \\
\text { - } & \text { explanation-building } \\
\text { - } & \text { addresses rival explanations } \\
& \text { use tabulations and } \\
& \text { quantification if possible }\end{array}$ & $\begin{array}{l}\text { - } \text { required for causal (or } \\
\text { explanatory) case } \\
\text { studies, in which an } \\
\text { investigator is trying to } \\
\text { determine whether } \\
\text { event X led to event } Y \text {. }\end{array}$ & $\begin{array}{l}\text { - } \text { cases theoretically } \\
\text { sampled } \\
\text { case comparisons } \\
\text { undertaken using graphs } \\
\text { and tables } \\
\text { triangulation of evidence } \\
\text { and forms of analysis }\end{array}$ \\
\hline $\begin{array}{l}\text { External } \\
\text { Validity }\end{array}$ & $\begin{array}{ll}- & \text { use replication logic in } \\
& \text { multiple cases studies } \\
\text { - } & \text { use theory in single case } \\
& \text { studies } \\
\text { - } & \text { generalization } \\
\text { - } & \text { replication logic } \\
\end{array}$ & $\begin{array}{l}\text { the degree to which the } \\
\text { findings can be } \\
\text { generalised outside the } \\
\text { study }\end{array}$ & $\begin{array}{l}\text { - } \quad \text { replication logic design } \\
\text { case comparisons } \\
\text { undertaken at the } \\
\text { common theoretical level }\end{array}$ \\
\hline Reliability & $\begin{array}{l}\text { - use case study protocol } \\
\text { - triangulation }\end{array}$ & $\begin{array}{l}\text { important consideration } \\
\text { at the data collection } \\
\text { phase }\end{array}$ & $\begin{array}{ll}- & \text { triangulation of evidence } \\
\text { and forms of analysis } \\
\text { explicit case study } \\
\text { protocol established and } \\
\text { adhered to throughout }\end{array}$ \\
\hline
\end{tabular}

Source: Cavana et al. (2001), Eisenhardt (1989), Maxwell (1992), Miles and Huberman (1994) Garson (2008), Silverman (2005), Yin (2003).

Triangulation is a term used to describe a combination of different methods, study groups, local and temporal settings, and different theoretical perspectives in dealing with the phenomenon that is central to the qualitative study (Flick, 2002, Walter, 2002, Silverman, 2005). It is the attempt to increase reliability by reducing systematic (method) error, through a strategy by which the investigator employs multiple methods of measurement (Garson, 2008). It has been used as a strategy for validating results, but is now used more often as a method for further enriching and completing knowledge of the phenomenon (Flick, 2002).

Triangulation works as a reliability tester and for internal validity by comparing methods of data collection. If the alternate methods do not share the same source of systematic error, examination of data from the alternative methods gives insight into how individual scores may be adjusted to come closer to reflecting true scores, thereby increasing reliability (Garson, 2008). 
Denzin (1989) notes four types of triangulation, including data, investigator, theory and methodological triangulation. The following Table 5-23 describes these different types while also providing a justification or comments as to its suitability to this research.

Table 5-23: Type of triangulation

\begin{tabular}{|l|l|l|}
\hline Type & Description & Justification / Comment \\
\hline Data triangulation & $\begin{array}{l}\text { Refers to the use of different data sources as } \\
\text { distinguished from different methods of } \\
\text { producing data. The starting point is to } \\
\text { systematically involve persons, study groups, } \\
\text { and local and temporal settings in the study. }\end{array}$ & $\begin{array}{l}\text { Not considered relevant to the case } \\
\text { study design of the research } \\
\text { design. }\end{array}$ \\
\hline $\begin{array}{l}\text { Investigator } \\
\text { triangulation }\end{array}$ & $\begin{array}{l}\text { The use of different observers of interviewers } \\
\text { within the study to detect or minimise biases } \\
\text { resulting from the researcher as a person. } \\
\text { Involves a systematic comparison of different } \\
\text { researchers' influences on the issue and the } \\
\text { results of the study. }\end{array}$ & $\begin{array}{l}\text { Not considered relevant to the } \\
\text { research design, or the intent of the } \\
\text { study: that is the investigator } \\
\text { should conduct all research. }\end{array}$ \\
\hline Theory triangulation & $\begin{array}{l}\text { Used to extend the possibilities for producing } \\
\text { knowledge, where various theoretical points of } \\
\text { view are placed side by side to assess their } \\
\text { utility and power. Approaches the data with } \\
\text { multiple perspectives and hypotheses in mind. }\end{array}$ & $\begin{array}{l}\text { Not considered relevant to the } \\
\text { research design, however may } \\
\text { have an application to parts of the } \\
\text { research. }\end{array}$ \\
\hline $\begin{array}{l}\text { Mype sub types differentiated - within method } \\
\text { (e.g. the use of different sub scales for } \\
\text { measuring an item in the questionnaire) and } \\
\text { between method (the combination of } \\
\text { questionnaire with a semi structured } \\
\text { questionnaire) triangulation. } \\
\text { Flation }\end{array}$ & $\begin{array}{l}\text { Between Method considered } \\
\text { suitable for the research in that it } \\
\text { allows for a variety of data sources } \\
\text { to be applied to each case. }\end{array}$ \\
\hline
\end{tabular}

Source: Denzin (1989), Flick (2002), Silverman (2005)

The triangulation method in this research was used to test for reliability in the data, and as a methodology to increase knowledge about the cases and broader research question. The value of this approach is that the investigator can make use of multiple and different sources from each method used while also reducing the limitation of a single method (Walter, 2002). It also provides multiple points for the researcher to corroborate evidence from the different sources used within the study (Creswell, 1998). Triangulation is less a strategy for validating results and procedures than it is an alternative to validation (Flick, 2002) with the intent to increase the scope, depth and consistency in methodological proceedings. As such, the triangulation of method, investigator, theory and data is considered one of the soundest strategies of theory construction (Denzin, 1989).

Validity provides constructs within the methodology and design that will assist the investigator to have increasing confidence in the interpretation and analysis of the case study data. These tests 
however, should not replace the importance of the investigator understanding the issues within the case (Maxwell, 1992). To that end, the methodology for the research involved collecting relevant information from a variety of sources including project managers, team and group leaders, and a variety of stakeholders. The information sought is a combination of qualitative and quantitative information, with the subsequent analysis the result of a convergence of all these different source points (Yin, 2003).

\subsection{Ethical Considerations}

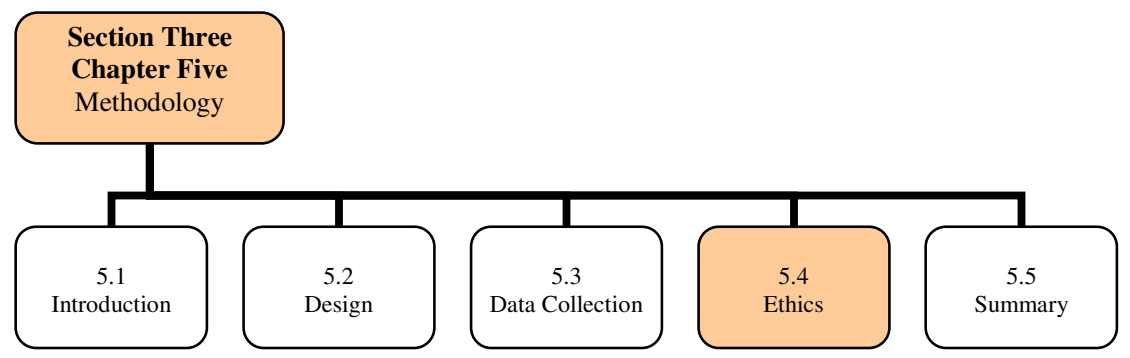

Ethical considerations regarding the study were informed by two processes - the first by an understanding of the ethical consideration of undertaking the research, and the second, a process that was determined by the RMIT Design and Social Context Human Research Ethics Subcommittee.

Specific ethical issues are explicitly or not, related to larger theories of how it is decided that an action is right, correct, or appropriate (Miles and Huberman, 1994). Five general theories put forward by Deyhle, Hess and LeCompte in Miles and Huberman expand these issues and are briefly detailed in Table 5-24.

Table 5-24: General theories of ethics

\begin{tabular}{|l|l|}
\hline Theory & Description \\
\hline Teleological & One that judges actions according to primary ends, good in themselves. \\
\hline Utilitarian & $\begin{array}{l}\text { One that judges actions according to their specific consequences - benefits } \\
\text { and costs - for various audiences: the researcher, the researched, colleagues, } \\
\text { and the public. }\end{array}$ \\
\hline $\begin{array}{l}\text { A view that invokes one or more universal rules derived from Kant's } \\
\text { categorical and practical imperatives of: } \\
\text { would I like this action to be applied to everyone - including me? } \\
\text { and } \\
\text { will I treat every person I encounter as an end, and not as a means to } \\
\text { something I want? }\end{array}$ \\
\hline Critical theory & $\begin{array}{l}\text { One that judges actions according to whether one provides direct benefits to } \\
\text { the researched and/or becomes an advocate for them. }\end{array}$ \\
\hline Conventional view & $\begin{array}{l}\text { According to whether they are congruent with specific agreements made with } \\
\text { others in trusted relationships. }\end{array}$ \\
\hline
\end{tabular}


Flinders (1992) notes that the utilitarian approach addresses the recruitment of respondents through a process of informed consent, that any fieldwork should ensure that respondents are not put at risk, and any subsequent reporting of the data ensure that respondent's confidentiality is maintained (Flinders, 1992). This approach is supported by the investigator and the RMIT Human Research Ethics Sub-committee, as it stipulates that the process for interacting with respondents (through the interviews mechanism) follow ethical approaches including ensuring that participants would not be placed in a vulnerable position with the researcher, or put at risk by taking part in the research (Kellahear, 1989). Care was taken to ensure that the respondents understood they were interacting with the researcher 'personality' and not someone who they may have had contact with in a professional capacity.

Furthermore, as the research required the respondents to engage in an open and safe manner without fear of repercussions for being involved in the study, the identity of the respondents was protected at all times and confidentiality was guaranteed both as a matter of process, and to ensure their involvement in the process (Homan, 1991, Walter, 2002).

As the research involved seeking information directly from participants, approval from the RMIT Design and Social Context Human Research Ethics Sub-committee was required prior to the commencement of field work and data gathering.

This process involved submitting substantial details to the RMIT Design and Social Context Human Research Ethics Sub-committee outlining:

- project particulars;

- details of participants (including the identification of any vulnerable participants);

- estimation of potential risk to participants and subsequent project classification;

- informed consent forms;

- confidentiality of research records;

- details on the location of the interviews; and

- an overview of the types of questions to be asked of the participants.

The application to the Sub-committee was used to assess the risk level category and ethical considerations that may be involved in the research. The outcome of the application to the Subcommittee resulted in the research being approved at a Category Risk Level 2. Risk Level 2 is applied for those research projects where there is a possibility that participants in the study could be identified as being involved in the study. The application noted however that the individual or 
specific responses to the interview questions would not be detailed or made public through the research, and that no comment would be directly attributed to any specific person or detailed in the final research.

For a copy of the Invitation to Participate - Plain Language Statement, and the Consent form refer to Appendices A6 and A7 respectively.

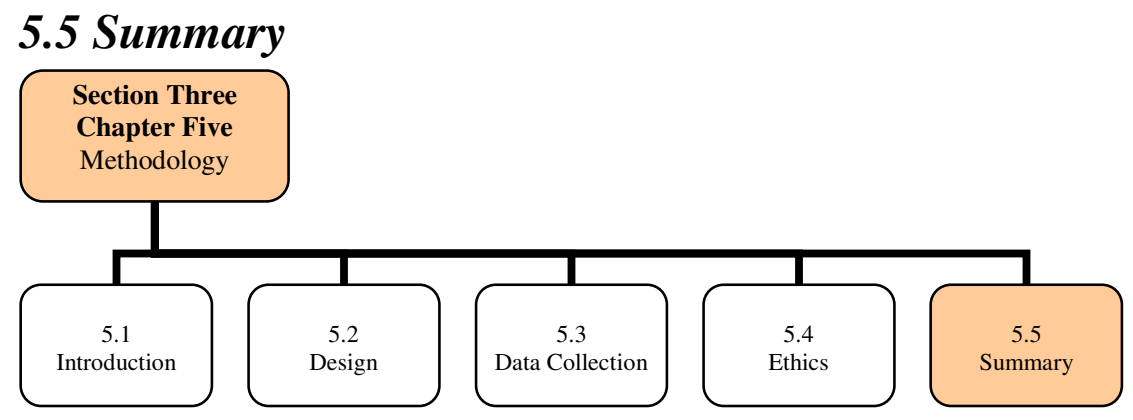

The chapter was divided into five sections (including this conclusion) and can be summarised as follows.

Section 5.1 provided an introduction to the chapter and outlined the path that the chapter would take in presenting the information on Research Methodology.

Section 5.2 introduced the theoretical considerations pertinent when determining which methodological approach should be taken for the research. It provided a summary of the research design types to be considered when choosing the correct research approach. These design types included experimental, cross-sectional, longitudinal, case study and multiple case study, and argued that the approach should follow that of a case study, and more specifically a comparative case study, as it allows comparison and contrast between different project environments. The section then discussed the case study approach, reiterating that the unit of analysis was OCT use in the PME, and introduced each of the six cases with a general description of their PME. This discussion was kept intentionally brief, serving to focus attention on a general description of the project's purpose and objective, however significant additional descriptive material is provided in the Appendices A8-A13. 
The subsequent section (5.3), reviewed the data collection methodology, detailing the three main data collections methods, including the Likert questionnaire, semi-structured interviews and supporting documentation. It also detailed the manner in which the data was to be collected, collated and analysed and supported this with numerous tables on the components of these analytical devices. The section concluded with a discussion of the validation process of the research methods and the pilot study including some comments on triangulation theory.

Section 5.4 outlined the necessary ethical consideration relevant not only to the research on a theoretical basis, but as it relates to the University supporting this research.

This chapter concludes the discussion of research design and methodology and sets the scene for the findings to be discussed. The following thesis section is introduced in light of the issues outlined in this chapter, making reference to, and expanding on the methodological mechanisms introduced. It draws from the literature uncovered in Chapters Two through Four, addressing the research question and its subordinated research questions and associated propositions. To that end, the next three chapters will deal with each of the three research questions in turn, returning to the main Research Question:

Does collaboration occur through the use of online collaborative toolsets in the project management environment? 


\section{SECTION FOUR}

\section{CHAPTER SIX - Characteristics of Online Collaborative Toolsets}

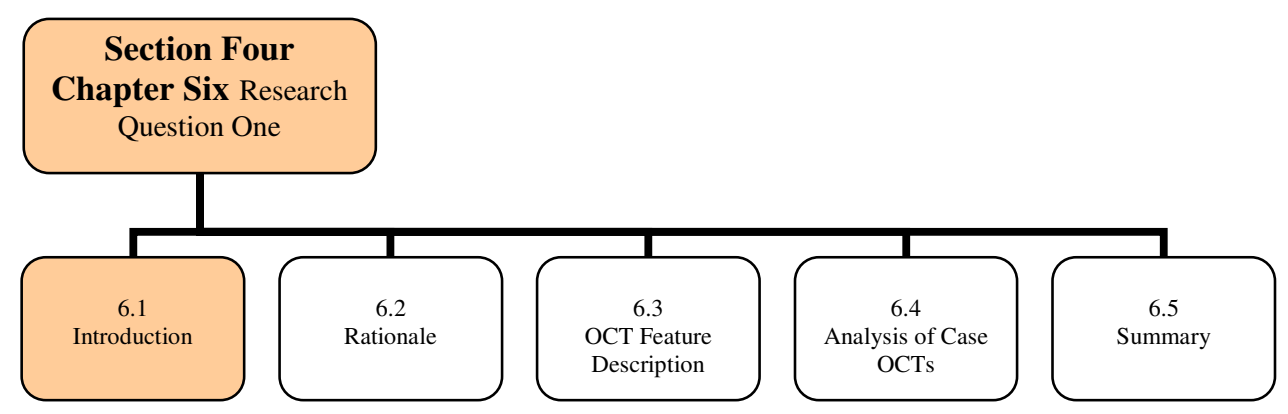

\subsection{Introduction}

This chapter addresses the work of Research Question One introduced in Chapter Two, where several features and permutations of the online collaborative toolsets (OCTs) were noted. The Literature Review revealed a significant array of features, uses and environments in which the OCT can be implemented. This lead to the introduction of the first research question:

Research Question One: What are the features of online collaborative toolsets?

The question enables the research to review and identify core features of OCTs, whilst providing an understanding into how these features are deployed within the project management environment (PME) and the role that collaboration may play. To that end, Research Question One has an associated proposition that is pragmatic in its approach to the feature list:

Proposition One: $\quad$ OCTs contain features that facilitate coordination and cooperation, and collaboration.

In framing this first research question and proposition in this way, this chapter adopts a taxonomic approach to the features. The methodology used to address this question, and outlined in the previous chapter, is primarily informed by desk research of vendors publicly available on the internet, as well as from information discovered through the interviews and the literature search. 
This chapter has the following section structure. Section 6.2 reviews the rationale for including an OCT into the review. This section includes a list of vendors from which the OCT features list was drawn. OCTs offered by these vendors are then reviewed, culminating in a table presenting the common features across 32 OCTs. Section 6.3 provides an analysis of the majority of these features, with Section 6.4 providing this summary specifically across the OCTs identified in the case studies.

\subsection{Rationale}

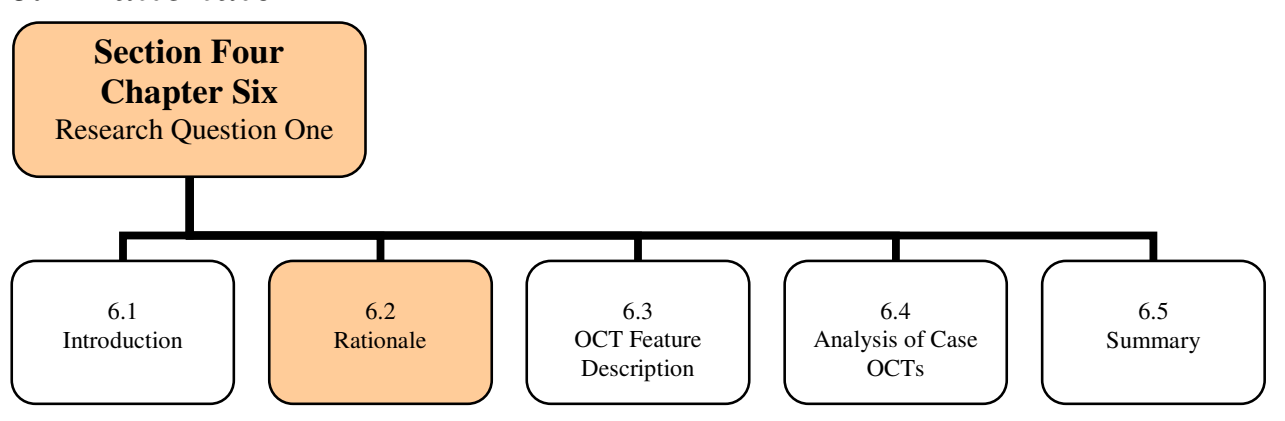

The range of OCTs included in this review were all sourced over the internet. This seemed fitting to the study at hand, as well as consistent with the characteristics of a web-enabled solution. The selection criteria used to identify OCTs for inclusion in the research ranged across a number of elements, with the key selection criterion being that vendors described their products as a collaborative tool that is used over the internet. Examples of these descriptions include, 'more than a portal, it's a tooled up virtual space with everything your group needs to become a truly 24/7 collaborative enterprise' (Communitycrossings, 2006), or 'the world's easiest collaborative workspace' (Pringle, 2006) show not just the way in which the products are described, but the hyperbole attached to them.

A further criterion was to include only those products that were fully supported by the vendor and which were available as a fully hosted solution. As mentioned in Chapter Two, the hosted solution condition is considered the most suitable model to support the widest configuration of project teams, as well as widening the scope of the prospective users of the OCTs to include small companies/organisations, one-off projects or not-for-profit organisations or small teams. 
All products and their respective vendors were located and sourced over the public internet over an 18-month period from July 2006 to February 2008. Neither price of the solution nor country of origin were considered barriers for inclusion of the product in the research.

The characteristics of OCTs currently available in the market place are many and varied, and highlights the differences between not only the myriad products currently on the market, but the different uses or applications of these products. The inclusion or not of particular functional objects or characteristics in an OCT will often be determined by the sector for which it is recommended, or the particular use for which the tool may most effectively be deployed. This chapter therefore reviews OCT product specifications to gain an understanding of the suite of elements or ingredients that can be included in the OCT, and to begin to map the most common features that are offered by the vendors in the marketplace today.

The review involved a list of vendors located through the search during the period (Table 6-1) and the creation of a matrix to document the features of the OCTs (Table 6-2). The review identified 32 separate vendors who were promoting some type of OCT on the internet. These vendors ranged from small internet software companies, to large internationally recognised brands including IBM and Google. 
Table 6-1: OCT Vendor List

\begin{tabular}{|c|c|}
\hline OCT Name & URL \\
\hline QuickPlace & www.ibm.com/software/lotus/products/quickplace/ \\
\hline TeamSpace & www.teramspace.com \\
\hline AceProject & www.aceproject.com \\
\hline Central Desktop & www.centraldesktop.com \\
\hline Collaboration Gateway & www.communitycrossings.com/gateway.asp \\
\hline Collaborative Workspace & www.collaborativeworkspaces.com \\
\hline $\begin{array}{l}\text { Commotiv Collaboration } \\
\text { Workspace }\end{array}$ & WwW.comotivsystems.com \\
\hline eStudio (Samepage) & www.same-page.com/studio \\
\hline GroveSite & www.grovesite.com \\
\hline Hyper Office & www.hyperoffice.com \\
\hline $\mathrm{iKE}$ & www.ike.com \\
\hline Near-Time & www.near-time.net \\
\hline NetSharer & www.netsharer.com \\
\hline TaskComplete & www.taskcomplete.com \\
\hline WebCrossing & www.webcrossing.com \\
\hline Webex WebOffice & www.weboffice.com \\
\hline Autodesk BuzzSaw & usa.autodesk.com \\
\hline Project Coordinator & www.projectcoordinator.net \\
\hline Project Place & wwW.projectplace.com \\
\hline Qmind & www.qmind.com \\
\hline Groove (Team direction) & www.teamdirection.com \\
\hline ProjectSpace (Forum One) & www.forumone.com \\
\hline ContactOffice & www.contactoffice.com \\
\hline Group Jazz & groupjazz.com \\
\hline GroupMind Express & www.groupmindexpress.com \\
\hline iCohere & www.icohere.com \\
\hline EasyProjects.NET & www.easyprojects.net \\
\hline Aconex & www.aconex.com \\
\hline Base Camp & www.basecampphq.com \\
\hline WordPress & wordpress.org \\
\hline Google Docs & Www.google.com \\
\hline inCITE & www.incite.com.au \\
\hline
\end{tabular}

Source: desk audit July 2006 - February 2008 (Some URLs may have changed)

The features list presented in Table 6-2 is ranked from the most common to least common as a result of this review. This list is indicative of what was promoted by the vendors and available at the time. Given this, some features may no longer be available, and new features may have been added to the products. This review does not comment on the usability or effectiveness of the features, but rather provides a general description of their functionality. 
Table 6-2: OCT features

\begin{tabular}{|c|c|c|}
\hline Characteristics & Tally & $\begin{array}{c}\% \text { of OCTs } \\
(n=32)\end{array}$ \\
\hline $\begin{array}{l}\text { central file repository } \\
\text { (document management) }\end{array}$ & 25 & $78 \%$ \\
\hline $\begin{array}{l}\text { task and project list } \\
\text { (project management) }\end{array}$ & 24 & $75 \%$ \\
\hline discussions / bulletin boards / blogs & 21 & $66 \%$ \\
\hline calendar \& schedule & 19 & $59 \%$ \\
\hline email notification & 18 & $56 \%$ \\
\hline messages & 16 & $\mathbf{5 0 \%}$ \\
\hline project dashboard & 14 & $44 \%$ \\
\hline security and access rights & 14 & $44 \%$ \\
\hline customised forms \& templates & 12 & $38 \%$ \\
\hline task manager & 10 & $31 \%$ \\
\hline address book & 10 & $31 \%$ \\
\hline search & 10 & $31 \%$ \\
\hline Gantt chart & 9 & $28 \%$ \\
\hline library & 9 & $28 \%$ \\
\hline data export/import & 9 & $28 \%$ \\
\hline collaboration space / central ideas area / wiki & 8 & $25 \%$ \\
\hline reports & 8 & $25 \%$ \\
\hline chat & 6 & $19 \%$ \\
\hline file to task attachments & 6 & $19 \%$ \\
\hline rss & 5 & $16 \%$ \\
\hline time sheets & 4 & $13 \%$ \\
\hline workflow & 4 & $13 \%$ \\
\hline workload report & 3 & $9 \%$ \\
\hline change tracking & 3 & $9 \%$ \\
\hline issue tracking & 3 & $9 \%$ \\
\hline event registration and calendar & 3 & $9 \%$ \\
\hline user manager & 2 & $6 \%$ \\
\hline user specification & 2 & $6 \%$ \\
\hline newsletters & 2 & $6 \%$ \\
\hline CAD integration & 2 & $6 \%$ \\
\hline virtual conference & 2 & $6 \%$ \\
\hline eCommerce & 1 & $3 \%$ \\
\hline database & 1 & $3 \%$ \\
\hline sms & 1 & $3 \%$ \\
\hline
\end{tabular}

Source: desk audit July 2006 - February 2008 


\subsection{OCT Feature Description}

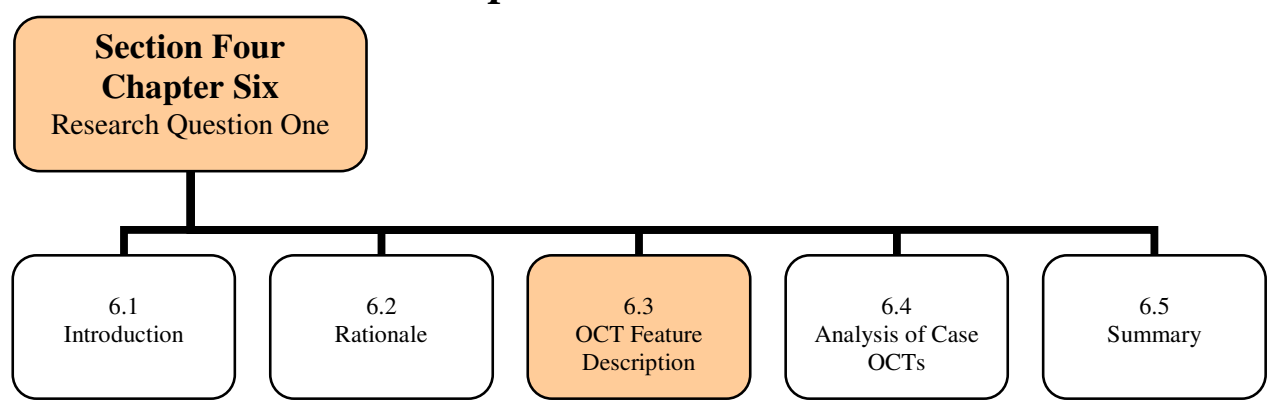

This section describes the common features of OCTs identified in the Section 6.2 and detailed in Table 6-2.

\subsubsection{Central File Repository (document management)}

Rated as the most common feature of the OCT, and often a main feature of the software's screen based interface or dashboard, this functionality provides the capacity to upload and download work from the OCT to the local desktop/workspace of the user. As one of the crucial elements of an OCT, the Central File Repository provides users with a central (and secure) location for files, which subsequently allows users to be working in many different (physical) locations across the life cycle of the project. It also provides a central underpinning of the OCT in that it has the capacity to distribute files over the internet, thus theoretically embracing (internet enabled) workspaces located anywhere in the world.

The list of file types that can be uploaded to the Central File Repository ranges from the full suite of Microsoft Office programs, to industry specific formats including CAD drawings, Portable Document Formats (PDF), HTML, and graphic, music and video files. The uploading functionality is often linked with other characteristics including email notification, send to review, authorisation and comment fields.

The useability of this feature is also varied, ranging from being presented in Windows Explorer style folder directory, to other ordered (and sortable) lists. 


\subsubsection{Task and Project List}

The second most common feature, the Task and Project List, is designed to be the central activity space for the project. The Task and Project List feature can include task summaries, task duration, notes fields, dependencies, staff and resources assigned to the task, file attachment capability to enable full task documentation, and percentage of completion, to name a few characteristics. This feature can have assorted security controls enabled, to allow for some or all project personnel (including customers and sub-contractors) to view and/or access information. These security settings contribute to greater transparency of information, whilst centralising the distribution of project tasks. This feature is often closely related to the useability of the Dashboard feature.

\subsubsection{Discussion List / Bulletin Boards / Blogs}

The capacity to create and/or manage a discussion forum in an online collaborative environment allows for a variety of main and sub-topics to be discussed in an asynchronous fashion. The Discussion / Bulletin Board / Blogs feature allows for multiple topics to be covered in a single OCT and can target multiple respondents/co-authors/readers/recipients depending on the nature of the communiqué. Discussion Boards minimise emails occurring outside the OCT and have the effect of containing discussions within the confines of the project space. Responses to the postings occur within the OCT in the context of the original topic heading. The Discussion feature enables an online discussion to take place, highlighting the user's comments, opinions and positions on the subject matter. This feature can include sorting options to aid with navigation through the issues, a useful function, especially as the discussion list becomes larger, or start to expand the subject.

\subsubsection{Calendar and Schedule}

The Calendar and Schedule feature is another central function of the OCT. Rating at fourth highest, this feature enables project members to view project information in a variety of calendar views or schedules. This functionality includes the option to see entries by a variety of views, including days, weeks and months. It can also be expanded to show all the calendar entries of a single team member (or project team) in one view, with some products also providing an option to export this data to other calendaring tools such as Microsoft Outlook and IBM Lotus Notes. The calendaring feature has value-adding functionality in providing the capacity to show a range 
of project and team member schedules, important dates and project milestones. Some products include the functionality to display these dates in Gantt style, or provide an export facility to other scheduling programs like MS Project.

\subsubsection{Email Notification}

The capacity to notify team members by email rated as the fifth highest feature amongst the surveyed OCTs. The Email Notification feature provides the capacity for the distributed membership of the OCT to be pro-active. Without email notification, team members are not only unaware of changes occurring within the OCT, but it reduces the OCT to a static environment, one that only functions when members engage (i.e. online), rather than as an electronic network of users. The email notification functionality is central to the OCTs role in 'pushing' alerts and items of interest or importance to either all members or specifically targeted members. In order for this to occur, the OCT enables the same message to be sent to one person or a group(s), and in some instances, for this message to be time delayed, or automated as a result of other events occurring.

The Email Notification feature includes the ability to send notifications attached to tasks (and the schedule function discussed above); thereby notifying the user that the task is ready to commence or that it has been completed. Other examples of the feature include being notified when a new posting is placed on the discussion board; when there are general messages to be received or bulletins regarding the project (or a specific activity); or notifications of changes in workflow, for example when a process or document has been completed or approved. The rising use of RSS (Really Simple Syndication), which is discussed later in this section, may impact on the use of this feature in the future versions that incorporate this feature.

\subsubsection{Messages}

The Messages feature enables an immediacy in communication to occur within the project space that can only be achieved through a networked environment. The capacity for members to send or post messages to a central notice board enables transparency of communication and coordination of information between individuals, project team members and stakeholders. It also reduces the generation of the number of external emails (i.e. those existing outside the OCT) used in daily messaging, the volume of which is verging on business spam for larger organisations. 
This feature can incorporate a variety of options to ensure that the message is sent in a timely, strategic and effective manner, including:

- $\quad$ sending messages to a single user of group of users;

- a common posting area;

- capacity to sort by subject or file in project sub-folders;

- determining security access levels for different members of the project team;

- adding attachments;

- adding to a pre-existing posting; and

- creating an email notification from a posting at a later time.

\subsubsection{Project Dashboard}

The Project Dashboard is the screen based interface that orders and presents the features of the OCT to the user. The Project Dashboard sets the style and graphic layout or interface in which users interact both with the product, and ultimately with each other. Given this, the on-screen interface is essential for effective and comfortable communication. The purpose of the Project Dashboard is to show the different functional characteristics of the tool, whilst providing a graphical navigation device in which these characteristics can be located and selected. The more intuitive the dashboard is for team members and miscellaneous users, the easier it is to find individual features of the tool. This in turn leads to greater take-up of the tool, and consequently it is hoped, more effective project management.

\subsubsection{Security and Access Rights}

Security of project information is essential, especially as the information is on the internet and is hosted by the vendor. Security falls into two categories - security of the information contained within the applications/product, and the capacity to configure different access rights to individuals depending on their role and position in the project team. The use of encryption technology (128 bit being the current standard) can be deployed to safeguard the material posted on the site, with initial access to the project space achieved through a combination of usernames and randomly generated passwords. The OCT may also provide managers with the capacity to include or invite members into the OCT and set their level of access (through an ACL - Access Control List) to the different sections of the OCT. This function is particularly relevant where multiple projects are included in the one tool, or where the project has a variety of different phases for either commercial or confidential reasons, and is subsequently not widely 
disseminated throughout the project. Another use is when the composition of team members alters or changes during stages of the lifecycle of the project.

\subsubsection{Customised Forms and Templates}

Customisable forms allow the user to create and design forms and templates specific to the business requirements. It enables the user to build forms for workflow or design templates that can be used for different purposes. This can save time and develop consistency of practices on recurring or repetitive actions, for example, minutes and agenda, weekly reporting, technical reports, task lists and risk assessment reports.

\subsubsection{Task Manager}

The task manager functionality enables individual tasks to be assigned resources, tracked and placed into a schedule. The tasks can then be viewed on a holistic or individual level and can be interlinked with the calendar function.

\subsubsection{Address Book}

The Address Book feature enables contact details to be centrally located on the OCT rather than on individual's desktop systems of other sources. The address book feature assists in providing contact information on project team members, suppliers or contractors (to name a few) in a central web-enabled location, facilitating more efficient dissemination of contact information, as well as reducing the need for each team member to manage local address books. Contact details can be extended to include notes fields as well as multiple telephone and email contact options. Some OCTs enable the contact lists to be exportable to other contact tools like MS Office or IBM Lotus Notes.

\subsubsection{Search}

The Search function is a central feature in OCTs particularly in projects where a significant mass of information/data contained within the OCT is required to be retrieved effectively, efficiently and on demand. The search function in its simplest form could involve a search bar in the dashboard or some other central part of the site real estate, which allows for a full text search capability on all records held in the OCT. More advanced forms of searching may include access 
to specific sections of the OCT for example the discussion threads, correspondence, or report area, with advanced search features on authors, contributors, date submitted to name a few. Some search functions can be saved to create dynamic views that filter and re-mix the space's content based on a custom rule set. Saved searches appear as links within the search tab and are dynamically updated as new matching content is added (Near-Time, 2006).

\subsubsection{Gantt Chart}

Gantt charts are project planning tools used to represent the timing of tasks required to complete a project. The Gantt chart is often used in the PME as it is a combination of graphic and list presentation, which makes project related information more easily understood on a variety of levels. The capacity to print out or export Gantt charts (for example to MS Project format *.mpp) is desirable.

\subsubsection{Library}

The library section of the OCT allows for significant project documentation to be deposited and thereafter made available to members of the team. This function enables key documents of the project to be always available to the team. Documents may include training material, health and safety regulations, standard or commonly used forms, handbooks and guidelines. The documents placed in the library are normally protected from the possibility of being written over or modified by users who access them.

\subsubsection{Data Export/Import}

The Import/Export feature enables data from the OCT to be exported from a native application of the OCT (such as a calendar entry or contact list) into another piece of software in order to read or run reports. The most common form would include exporting data to an MS Excel format (*.xls) or contact list. This functionality allows users to make off-site copies or back-ups of material contained on the OCT. An example of importing data would be something similar but in reverse, where data or a file from a native application on the user's desktop, is migrated to the OCT, in order for the OCT to be able to republish this information in its own style, template or presentation format. Importing data into the OCT may also be achieved using the comma separated values (CSV) files process. 


\subsubsection{Collaboration Space / Central Ideas Area / Wiki}

A Collaborative Space / Central Ideas / wiki feature allows users to collaborate in forming content that will be presented on the webpage. In the collaborative space (or wiki), a user can edit the content, including other users' contributions, using a web browser. The wiki website operates on a principle of collaborative trust. The feature was discussed at some length in the Literature Review (section 2.2.5)

\subsubsection{Reports}

The Reporting feature provides the capacity to generate generic or customised reports relating to the area of the project. Reports can be generated and displayed within the OCT, or exported to another program, typically compatible with the MS Office suite such as Microsoft Excel or Word. Reports can normally be customised and may include items such as resource workloads, timesheets, task or activity progress, milestones, expenditure to name a few.

\subsubsection{Chat}

The Chat feature is an example of the synchronous functionality of the OCT. This feature can be presented in a variety of functions, but normally involves a form of instant messaging. It enables real-time access to other members of the project who are using the OCT at the same time as the user requesting the chat. It has the capacity to have real-time meetings with members of the team who are not physically onsite, and who may be distributed across multiple sites or regions.

\subsubsection{File to Task Attachments}

Linked to the task and project list, this characteristic enables the user to attach files to tasks or project items. It enables users to update a status item or report on the project and support this with the relevant documentation or file. This feature can be used for example to highlight costs against activity, report on task completed, or assessment on action item, to name a few. The file attachments should include the following major file types: DWG, DWF, DXF, PDF and Microsoft Office formats including MPP, DOC and XLS (Autodesk, 2005). 


\subsubsection{RSS}

RSS stands for Really Simple Syndication. It is a way to easily distribute a list of headlines, update notices, and headline content to a wide number of people. It is used by computer programs that organise those headlines and notices for easy reading (Scoble and Israel, 2006).

Prior to RSS, websites used email to notify users of changes to the site, but these email notifications can be suspected as spam. The introduction of RSS creates an alternate method for notification of new and changed content. These notifications can be across multiple sites and are handled automatically by the RSS, presenting the results to the user in a well organised format (Techtarget, 2007).

\subsubsection{Time Sheets}

The Timesheet feature enables the user to manage the time spent on the project by submitting or completing timesheets on the OCT. This functionality allows project managers the opportunity to review resource allocation/use on the project and the associated cost, and plan for future workloads. Timesheet features can include billing functions; for example, where the rates of team members can be specified and associated with effort on task. The billing component of the timesheet enables a report to be generated to retrieve detailed financial information on a project or component of a project (Easyprojects, 2007).

\subsubsection{Workflow}

Workflow enables the PME to create pre-defined processes to ensure that governance mandates are adhered to and structures followed. Workflow would also enable specific routing rules to be set by project role, or individual team members (Autodesk, 2005). Workflow can be particularly useful for gaining and archiving approval milestones, specifically in relation to tender phases or contract processes (Aconex, 2007).

\subsubsection{Virtual Conference}

Although rating comparatively low in the list of features, it is worthwhile to briefly describe the Virtual Conferencing feature. The presence and application of virtual conferencing has been discussed for many years and was often considered to be the core ingredient of interacting in the 
online environment. Virtual conferencing is essentially a live (synchronous) video communication between people in separate locations. At its simplest, videoconferencing provides transmission of static images and text between two locations. At its most sophisticated, it provides transmission of full-motion video images and high-quality audio between multiple locations (Techtarget, 2007).

Videoconferencing software is quickly becoming standard computer equipment, even though the quality of the audio and video signal may not necessarily be very high. The perceived benefits for businesses using videoconferencing include lower travel costs and profits gained from offering videoconferencing as an aspect of customer service. The face-to-face connection when using virtual conferencing adds to the exchange and allows participants to gain an awareness or familiarity with team members they may rarely or never actually meet in the same place (Techtarget, 2007).

Virtual conferencing was found to be offered in only two of the OCTs reviewed. One reason may be because it is related more to the telecommunications network of each user, rather than the hosting environment of the OCT.

\subsubsection{Other Features}

In additional to the features outlined above, there are many new or less common features that are being offered as part of some OCT solutions package. These include:

- Workload report

- Change tracking

- Issue tracking

- Event registration and calendar

- User manager
- User specification

- Newsletters

- CAD integration

- eCommerce functionality

- $\quad$ SMS (short message service) capability 


\subsection{Analysis of Case Online Collaborative Toolsets}

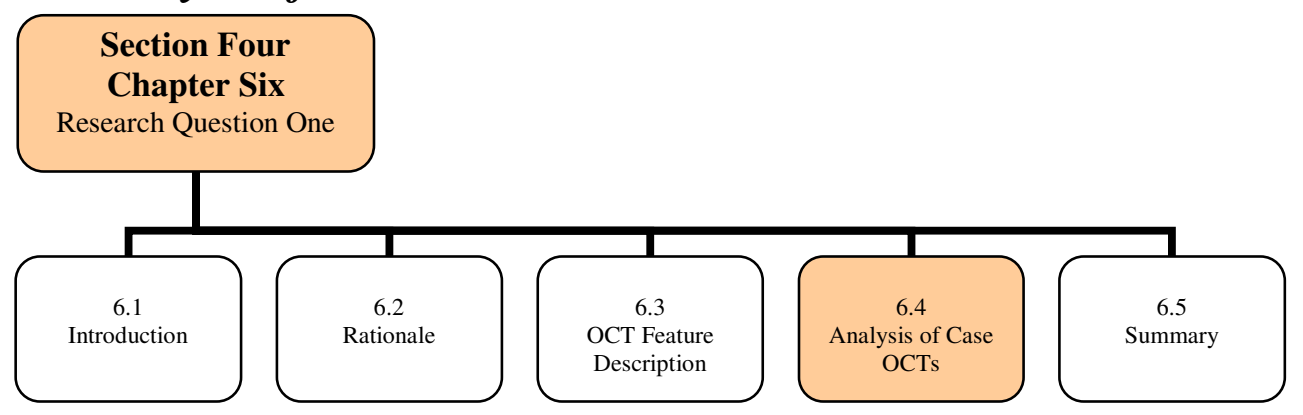

This section of the chapter builds on the information gathered as part of the desk research and begins to relate this information to the research at hand. In doing so, it draws together the feature list of the OCTs with the six individual cases, and then maps these features against the terms cooperation, coordination and collaboration (3Cs). In taking this approach this chapter addresses the Research Question One, and provides a commentary on its associated proposition - one that is informed by material discovered through the desk research and reinforced through the data collection methodologies outlined in Chapter Five (s5.3).

Table 6-3 maps the features discussed in the previous sub section (s6.2, s6.3) against each of the cases in this research. This table now serves to identify the feature list not only as it applies to the cases and their respective OCTs, but against the 3Cs. A discussion of these two mapping exercises now follows.

\subsubsection{Case Mapping}

Table 6-3 highlights that the OCTs used within the cases share many, and contains most of the more popular features. As may be expected, the table shows a high concentration of cross-case commonality in those features that are most common, whilst also indicating a spread or diversity of features across the five OCTs - an occurrence that may be symptomatic of a large international market presence of the OCT application. A discussion of the findings relating to the ten most common features follows.

The first three features, Central file repository, Task and Project List, and Discussion/Bulletin Boards/Blogs were found in two thirds of all the OCTs reviewed. These features were also common in four out of five of the case OCTs. The two most common features, Central File 
Repository, and Task and Project List, were present in all OCTs except WordPress. The third most common, Discussion/Bulletin Boards/Blogs, was found to be present in all except the Incite product.

The next most common feature, Calendar and Schedule, was present in two of the OCTs reviewed. Email Notification was found to exist in some form in all the OCTs, while the Messages functionality was present in all of the OCTs with the exception of Autodesk Buzzsaw. The Project Dashboard was found to be in all OCTs except QuickPlace, while the capacity to Manage Security and Access Rights was present in all OCTs. Customised Forms and Templates were present in $80 \%$ of the OCTs, while Buzzsaw and Quickplace were the only OCTs to demonstrate the presence of a Task Manager. The Address Book feature was present in two of the OCTs, with Search, as previously noted, the third feature to be common across all OCTs.

These findings support the premise that there is not one suite of features common across all the OCTs, although some features are more prevalent than others, and that the final make-up of an OCT may relate to its operational application or client requirements, rather than to its technical functionality. This issue will be explored in the next chapter.

\subsubsection{C Mapping}

All of the OCT features could be seen in one way or another to be useful for the facilitation of collaboration in the PME. However each feature does not necessarily require collaboration to be occurring for it to be functional. Some items are used for cooperation, some for coordinating activities and some are essential if collaboration is to occur. This mapping exercise, as presented in the shaded columns in Table 6-3, highlights the relevance of the 3Cs across the various features and in doing so addresses the first proposition of this research.

Proposition One: $\quad$ OCTs contain features that facilitate cooperation, coordination and collaboration.

Table 6-3 provides a rating of each feature against the three terms drawing on the Literature Review and the desk research of these features. It identifies which of the three terms is essential for each of the feature items, and in doing so proposes that each feature can be seen to assist in delivering against the $3 \mathrm{Cs}$. For example, the Central File Repository feature enables files to be 
shared and centrally located in the OCT, which can be understood to assist with the cooperative and coordinating functions of the PME. As this feature does not require synchronous engagement with other team members, nor require any responding action, it does not relate closely to collaborative functions, even though a collaborative environment would exploit this feature. To that end, a mark is placed against this feature in the cooperation and coordinating column.

Another feature Discussion/Bulletin Boards/Blogs' assists with information dissemination, and as was highlighted in the Literature Review (s2.2.4) can provide a form of discussion that encourages engagement and leads to more complex communication dissemination. Given this, it is seen to relate to all three $\mathrm{Cs}$, and consequently has a mark placed in all three columns. Workflow would be another feature where its function relates closely to cooperative and coordinating activities, but not to collaborative activities. The mapping exercise addresses each of the remaining features in a similar way, highlighting that most features do not require collaboration to be present, but rather facilitates in the main, cooperative and coordinative functions.

These findings are consistent with the Collaboration scale developed as part of this research. To reiterate, the Collaboration scale has been developed to plot the collaborative activity within each case organisation. Its relevance in this research is the argument that although all collaborative elements are found within a PME, it is the level of each element that determines the degree to which collaboration is occurring. This point resonates in viewing the findings of Table 6-3, where across the features, many relate to cooperation and coordination, but only a few are essential for collaboration, supporting the proposition and providing an appreciation of the use of the these tools.

In undertaking this mapping exercise, the first research question and its associated proposition is addressed.

Research Question One: What are the features of online collaborative toolsets?

Proposition One: OCTs contain features that facilitate coordination and cooperation, and collaboration. 
Table 6-3: Feature list of OCTS against Cases and 3Cs

\begin{tabular}{|c|c|c|c|c|c|c|c|c|c|}
\hline & \multirow[b]{2}{*}{$\begin{array}{l}\text { \% of } \\
\text { ALL } \\
\text { (32) } \\
\text { OCTs } \\
\text { (that } \\
\text { offer } \\
\text { these } \\
\text { features) } \\
\end{array}$} & $\begin{array}{l}\text { Org } \\
\text { D,S } \\
\end{array}$ & $\begin{array}{c}\text { Org } \\
\text { v }\end{array}$ & $\begin{array}{c}\text { Org } \\
\text { M }\end{array}$ & $\begin{array}{c}\text { Org } \\
\text { C }\end{array}$ & $\begin{array}{c}\text { Org } \\
\mathbf{K} \\
\end{array}$ & & & \\
\hline Feature & & 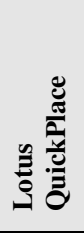 & 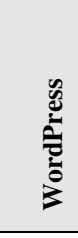 & 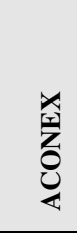 & 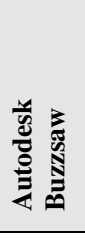 & 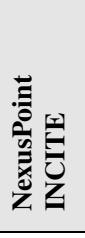 & 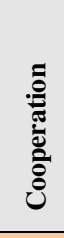 & 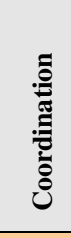 & 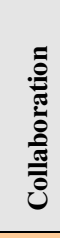 \\
\hline $\begin{array}{l}\text { central file repository } \\
\text { (document management) }\end{array}$ & $78 \%$ & $\checkmark$ & & $\checkmark$ & $\checkmark$ & $\checkmark$ & $\checkmark$ & $\checkmark$ & \\
\hline $\begin{array}{l}\text { task and project list } \\
\text { (project management) }\end{array}$ & $75 \%$ & $\checkmark$ & & $\checkmark$ & $\checkmark$ & $\checkmark$ & $\checkmark$ & $\checkmark$ & \\
\hline $\begin{array}{l}\text { discussions / bulletin boards / } \\
\text { blogs }\end{array}$ & $66 \%$ & $\checkmark$ & $\checkmark$ & $\checkmark$ & $\checkmark$ & & $\checkmark$ & $\checkmark$ & $\checkmark$ \\
\hline calendar and schedule & $59 \%$ & $\checkmark$ & & & & $\checkmark$ & $\checkmark$ & $\checkmark$ & \\
\hline email notification & $56 \%$ & $\checkmark$ & $\checkmark$ & $\checkmark$ & $\checkmark$ & $\checkmark$ & $\checkmark$ & $\checkmark$ & \\
\hline messages & $50 \%$ & $\checkmark$ & $\checkmark$ & $\checkmark$ & & $\checkmark$ & & $\checkmark$ & \\
\hline project dashboard & $44 \%$ & & $\checkmark$ & $\checkmark$ & $\checkmark$ & & $\checkmark$ & $\checkmark$ & \\
\hline security and access rights & $44 \%$ & $\checkmark$ & $\checkmark$ & $\checkmark$ & $\checkmark$ & $\checkmark$ & $\checkmark$ & $\checkmark$ & $\checkmark$ \\
\hline customised forms and templates & $38 \%$ & & $\checkmark$ & $\checkmark$ & $\checkmark$ & $\checkmark$ & $\checkmark$ & $\checkmark$ & \\
\hline task manager & $31 \%$ & $\checkmark$ & & & $\checkmark$ & & $\checkmark$ & & \\
\hline address book & $31 \%$ & $\checkmark$ & & & & $\checkmark$ & $\checkmark$ & & \\
\hline search & $31 \%$ & $\checkmark$ & $\checkmark$ & $\checkmark$ & $\checkmark$ & $\checkmark$ & $\checkmark$ & $\checkmark$ & \\
\hline Gantt chart & $28 \%$ & $\checkmark$ & & & & & $\checkmark$ & $\checkmark$ & \\
\hline library & $28 \%$ & $\checkmark$ & & $\checkmark$ & & $\checkmark$ & $\checkmark$ & & \\
\hline data export/import & $28 \%$ & & $\checkmark$ & $\checkmark$ & & $\checkmark$ & $\checkmark$ & & \\
\hline $\begin{array}{l}\text { collaboration space / central ideas } \\
\text { area / wiki }\end{array}$ & $25 \%$ & & & $\checkmark$ & & & $\checkmark$ & $\checkmark$ & $\checkmark$ \\
\hline reports & $25 \%$ & & & $\checkmark$ & $\checkmark$ & $\checkmark$ & $\checkmark$ & & \\
\hline chat & $19 \%$ & $\checkmark$ & & & & & $\checkmark$ & $\checkmark$ & $\checkmark$ \\
\hline file to task attachments & $19 \%$ & $\checkmark$ & & $\checkmark$ & & $\checkmark$ & & $\checkmark$ & \\
\hline RSS & $16 \%$ & & $\checkmark$ & & & & & $\checkmark$ & $\checkmark$ \\
\hline time sheets & $13 \%$ & & & & & & $\checkmark$ & & \\
\hline workflow & $13 \%$ & & $\checkmark$ & $\checkmark$ & $\checkmark$ & $\checkmark$ & $\checkmark$ & $\checkmark$ & \\
\hline workload report & $9 \%$ & & & & $\checkmark$ & & $\checkmark$ & $\checkmark$ & \\
\hline change tracking & $9 \%$ & & & & $\checkmark$ & $\checkmark$ & & $\checkmark$ & \\
\hline issue tracking & $9 \%$ & & & & & & & $\checkmark$ & \\
\hline event registration and calendar & $9 \%$ & & & & & & & $\checkmark$ & \\
\hline user manager & $6 \%$ & & & & $\checkmark$ & & & $\checkmark$ & \\
\hline user specification & $6 \%$ & $\checkmark$ & & & & & & $\checkmark$ & \\
\hline newsletters & $6 \%$ & & $\checkmark$ & & & & & $\checkmark$ & $\checkmark$ \\
\hline CAD integration & $6 \%$ & & & & $\checkmark$ & $\checkmark$ & $\checkmark$ & $\checkmark$ & \\
\hline virtual conference & $6 \%$ & & & $\checkmark$ & & $\checkmark$ & & & $\checkmark$ \\
\hline eCommerce & $3 \%$ & & & & & & & $\checkmark$ & \\
\hline database & $3 \%$ & & & & & & $\checkmark$ & & \\
\hline SMS & $3 \%$ & & & & & & & $\checkmark$ & \\
\hline
\end{tabular}

Source: Desk research and case studies 


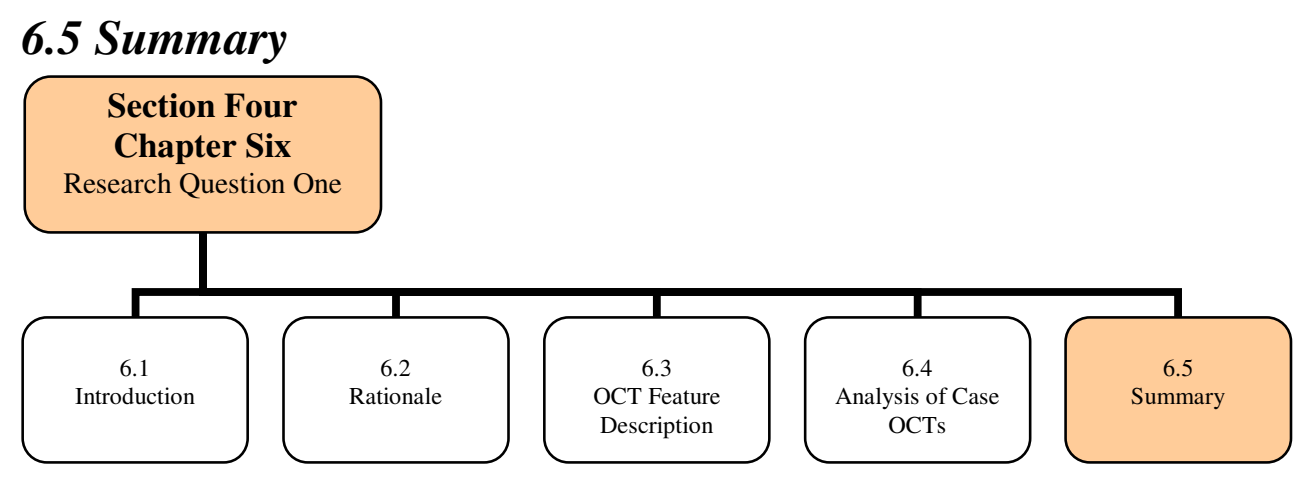

Chapter Six identified and highlighted a range of features found in 32 OCTs reviewed over a period of two years. Section 6.2 described the rationale for including the specific OCT in the research, with the use of key selection criteria that required vendors describe their products, in some manner, to be a collaborative tool used over the internet. These introductory criteria for the research enabled the broadest stroke for including as many OCTs in the collection sample as possible, with one restriction to the criteria - that the vendors must be offering a hosted solution. This enabled the research to draw from a variety of cases, rather than be restricted to those that were technically or operationally advanced to administer and resource a complex internet based application.

Section 6.3 provided a detailed description of the majority of these features, drawn from information available on public websites and vendor information sheets. In combination with the information received through the interviews, section 6.4 compared the features list against the OCTs used in the case organisations, and mapped these features against the $3 \mathrm{Cs}$.

In undertaking this analysis, it was found that the five OCTs have common elements, including the shared workspace, which incorporates the capacity to share information and project-related content (Palmer, 2003). Even though each OCT is a hosted solution, this does not mean that the technical administration is absent, rather team members do not require technical expertise to use the tool, as was noted by the Project Manager for Organisation V (the Networked organisation). Training was also increasingly important to ensure the team members have the necessary induction to the tool to make full use of it (Mack et al., 2001). This was supported by Organisation K (State Government Client) but subsequently lacking for Organisation D (State Government Department). 
The toolsets of these OCTs embrace functionality that can incorporate simple document repository features, or as the table details, the more complex aspects of project management, incorporating human resource elements and varying degrees of interaction required of projects (Romano et al., 2002, McDonald, 2003, Forakerdesign, 2007). All of the case organisations supported the document repositories as one of the more important features of the OCTs.

The OCTs demonstrate a preference for asynchronous, over synchronous activity, enabling the users to communicate and engage at a time that best suits them, rather than engaging in a virtual discussion (Raygan and Green, 2002, Techtarget, 2007, Forakerdesign, 2007). All of the organisations depended on the asynchronous function, but did not acknowledge a strong role for synchronous features or capabilities.

To this end, the relationships are managed within the OCTs through an interchange that makes the OCT the intermediary of the message. That is, it manages the information on behalf of the sender, in order to pass it on to the intended recipient at some later stage. The OCTs are groupware applications that offer additional functionality to members of a team, providing an online, electronic solution for many project management processes, assisting with cooperative, coordinative and collaborative activities (Forakerdesign, 2007), as well as undertaking the social networking functions.

The features of the OCTs included in the research, are consistent with those that are attributable to networked tools, which Christopher (2007) describes as including:

- Owner accessibility

- Configurability

- Access control

- Workspace

- File repositories

- Group calendars
- Linking

- Virtual conferencing

- Discussion boards

- Searching, and

- Databases

This is also evidenced by the presence of blogging tools in four out of five of the OCTs reviewed, which further assists with the project's communication strategies (Tapscott and Williams, 2006, Aschenbrenner and Miksch, 2005). Of the six organisations, only Organisation V (Networked organisation) used an OCT that specifically supported blogging. Interestingly the wiki function is not included in any of the OCTs. 
The features of the OCTs indicate that the degree of compatibility of the tools varies, depending on the intended use and environment, with the presence of both high end and benign technology (Fisher and Dourish, 2004). The feature list amply demonstrates that team members have a suite of toolsets at their disposal and that these can be used to facilitate cooperation, coordination and collaboration. Table 6-3 also highlighted that although there may be many features that are available to the OCT market, there are some consistent features that are likely to be considered 'must haves' for the OCTs to provide a generic use to the PME. These features occupy the top 12 of the features list of the table. Additional features would be incorporated into the OCT where the specifics of the project would require it, for example with the CAD integration feature.

In conclusion, Section 6.4 introduced, discussed and analysed a list of features common to many OCTs, and applied this list to the cases of the research, and to the $3 \mathrm{Cs}$. In doing so, the chapter has responded to the Research Question One, "What are the features of the OCTs?" and its associated proposition, "OCTs contain features that facilitate cooperation, coordination and collaboration."

The conclusion of this chapter now introduces the next stage of the research, where the use and purpose of the OCTs will be reviewed. The following chapter will seek to develop a broader understanding of the OCT used in the PME. It will review the operational processes of the actual PME of each case, and articulate the role that cooperation, coordination and collaboration have in the use of OCTs in the PME. In doing so, it will address the second research question and associated proposition. 


\section{SECTION FOUR}

\section{CHAPTER SEVEN - How are Online Collaborative Toolsets used in the Project Management Environment?}

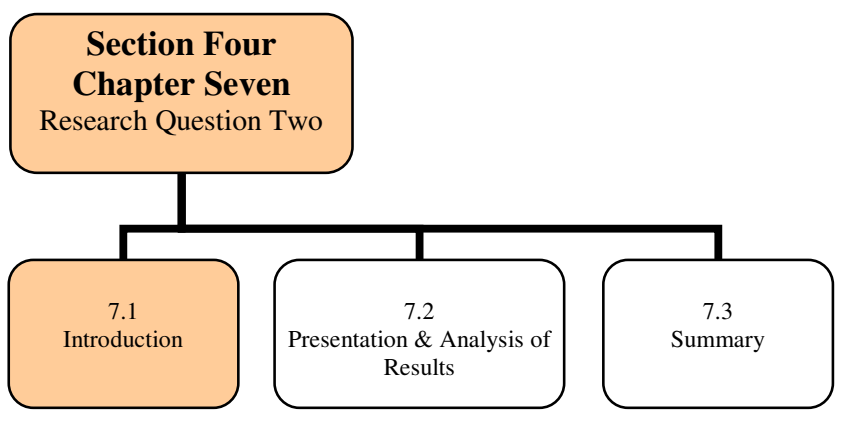

\subsection{Introduction}

This chapter continues the work introduced in Chapter Three, where the project management environment (PME) was reviewed to understand how its different forms and mechanisms may impact on the management of the actual project. It noted that the use of the OCT would need to reflect the cultural and human peculiarities of the PME, in order for it to be utilised to its greatest effect. This lead to the introduction of Research Question Two:

Research Question Two: How are Online Collaborative Toolsets used in the Project Management Environment?

This question is a development of Research Question One and seeks to investigate the features of the OCT in its operational context across several case examples. The research reviews the use of the OCTs in-situ, and seeks to understand the relationship between the functional capabilities of the OCT and its use. Research Question Two has an associated Proposition:

Proposition Two: $\quad$ Online Collaborative Toolsets in the PME are used for cooperation and coordination, and to a lesser extent, collaboration.

In framing the second research question and proposition this way, the research serves to uncover the application of the OCT and prompts the third and final research question dealing with collaboration within the PME. 
The structure of this chapter has three main sections, including an introduction in 7.1. Section 7.2 is in two parts and will follow the structure of the Likert instrument, dealing with the seven general areas of OCTs, and then the six areas of collaboration, making a total of 14 areas for discussion (plus summaries). Each area will present the findings of each individual Likert statement across the six cases, and then discuss these in context of the specific area. In doing this each Likert section will provide information on the general use of the OCT across the cases. A summary will be provided for both parts. The flow of this section can be represented as such:

Part One: - Presentation of Findings: The use of OCTs including shared calendars, central databases, sharing documents, storing documents, announcement boards, virtual conferencing and general use of OCTs

- Summary

Part Two: - Presentation of Findings: Elements of collaboration including trust, communication, equality, strategic alliances, (project) knowledge distribution, negotiation and incentives

- Summary

Section 7.3 will provide a conclusion to the chapter.

\subsection{Presentation and Analysis of Results}

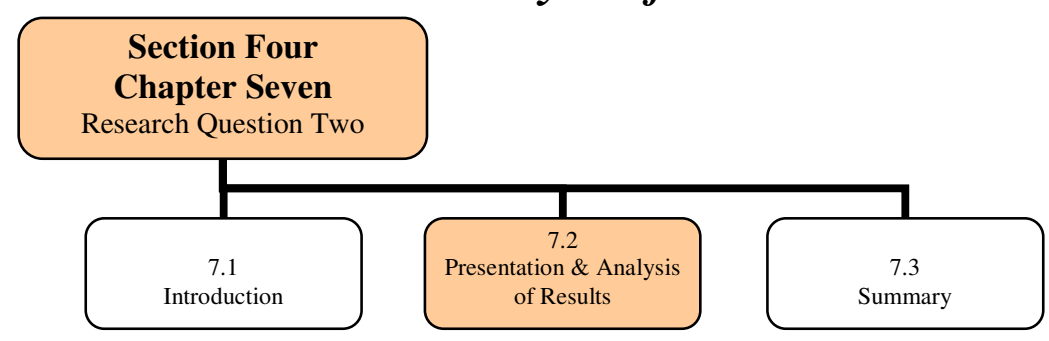

The analysis in this section will follow the structure of the Likert instrument, and will review the use and/or approach of the specific features of the OCT both across the cases, and on an aggregated basis, allowing for comparisons to be made and where possible trends to be observed.

The analysis will reference a summary table that draws its data from the six original case studies. In this way, the analysis can take a comparative approach to the cases, whilst also representing the findings in a summarised format. 
The findings in this section are presented in tables, organised into the separate categories noted above, with the specific commentary included for each statement. The responses to the scales are presented as case percentages (rounded-off), with the highest number from each case shaded. Aggregate tallies may not add to $100 \%$ in some instances due to rounding. A column for the aggregate result is also included and is represented in a different shaded colour. Commentary for each statement is contained to the findings of the cases' overall Likert data, rather than a discussion of each case individually, however each section summary will draw from both the Likert data and material received through the interviews. At the end of each section commentary, a table provides a rating of the aggregated data against the Collaboration scale.

To assist recalling the case details, the summary table from Chapter Five is presented here again (Table 7-1).

Table 7-1: Case study details comparatively summarised

\begin{tabular}{|c|c|c|c|c|c|c|}
\hline Case Particulars & $\begin{array}{c}\text { Case Study } \\
\text { Details } \\
\text { Org D } \\
\end{array}$ & $\begin{array}{c}\text { Case Study } \\
\text { Details } \\
\text { Org V }\end{array}$ & $\begin{array}{c}\text { Case Study } \\
\text { Details } \\
\text { Org M }\end{array}$ & $\begin{array}{c}\text { Case Study } \\
\text { Details } \\
\text { Org C }\end{array}$ & $\begin{array}{c}\text { Case Study } \\
\text { Details } \\
\text { Org S }\end{array}$ & $\begin{array}{c}\text { Case Study Details } \\
\text { Org K }\end{array}$ \\
\hline Type & State Government & $\begin{array}{l}\text { Continuous } \\
\text { Improvement }\end{array}$ & $\begin{array}{l}\text { Government } \\
\text { Construction }\end{array}$ & $\begin{array}{l}\text { Commercial } \\
\text { Construction }\end{array}$ & $\begin{array}{l}\text { Government } \\
\text { Authority }\end{array}$ & $\begin{array}{l}\text { Alliance } \\
\text { Construction }\end{array}$ \\
\hline Risk & High & Medium & Low - medium & Medium & Low & High \\
\hline Complexity & $\begin{array}{l}\text { Medium - due to } \\
\text { logistic of } \\
\text { coordinating many } \\
\text { authors across } \\
\text { multiple sites }\end{array}$ & $\begin{array}{l}\text { Low - use of } \\
\text { established } \\
\text { technology }\end{array}$ & $\begin{array}{l}\text { High - dual } \\
\text { clients, varying } \\
\text { scope }\end{array}$ & $\begin{array}{l}\text { Low - use of } \\
\text { established } \\
\text { technology }\end{array}$ & $\begin{array}{l}\text { Low - use of } \\
\text { established } \\
\text { technology }\end{array}$ & $\begin{array}{l}\text { Medium to high - } \\
\text { ethane pipeline }\end{array}$ \\
\hline Organisation & $\begin{array}{l}\text { Government } \\
\text { department } \\
\text { managing the } \\
\text { project }\end{array}$ & $\begin{array}{l}\text { Government } \\
\text { department } \\
\text { managing the } \\
\text { project }\end{array}$ & $\begin{array}{l}\text { Government } \\
\text { organisation } \\
\text { managing the } \\
\text { project }\end{array}$ & $\begin{array}{l}\text { Commercial } \\
\text { organisation } \\
\text { managing the } \\
\text { project }\end{array}$ & $\begin{array}{l}\text { Internal } \\
\text { project }\end{array}$ & $\begin{array}{l}\text { Alliance } \\
\text { organisation } \\
\text { managing the } \\
\text { project }\end{array}$ \\
\hline $\begin{array}{l}\text { Management } \\
\text { Structure }\end{array}$ & $\begin{array}{l}\text { Balanced Matrix } \\
\text { Structure }\end{array}$ & $\begin{array}{l}\text { Weak Matrix } \\
\text { Structure }\end{array}$ & $\begin{array}{l}\text { Balanced Matrix } \\
\text { Structure }\end{array}$ & $\begin{array}{l}\text { Balanced Matrix } \\
\text { Structure }\end{array}$ & $\begin{array}{l}\text { Balanced } \\
\text { Matrix } \\
\text { Structure }\end{array}$ & Projectised \\
\hline Environment & Distributed & Distributed & Interorganisational & Interorganisational & Traditional & Interorganisational \\
\hline Size & $\begin{array}{l}100 \text { people in } \\
\text { total: distributed } \\
\text { teams }\end{array}$ & $\begin{array}{l}2000 \text { people in } \\
\text { total: } 7-8 \text { sub- } \\
\text { project teams }\end{array}$ & $\begin{array}{l}\text { 400+ people: } \\
\text { approx } 15 \text { teams }\end{array}$ & $\begin{array}{l}100 \text { people in } \\
\text { total: } 10 \text { teams }\end{array}$ & $\begin{array}{l}\text { Approximately } \\
10 \text { people in } \\
\text { total: } 3 \text { sub } \\
\text { projects }\end{array}$ & $\begin{array}{l}150 \text { people in total: } \\
8 \text { functional areas }\end{array}$ \\
\hline Process & $\begin{array}{l}\text { Departmental } \\
\text { Project } \\
\text { Management } \\
\text { Methodology }\end{array}$ & $\begin{array}{l}\text { Information } \\
\text { distribution }\end{array}$ & $\begin{array}{l}\text { Administrative and } \\
\text { contractual }\end{array}$ & $\begin{array}{l}\text { Administrative } \\
\text { and contractual }\end{array}$ & $\begin{array}{l}\text { Administrative } \\
\text { and corporate }\end{array}$ & $\begin{array}{l}\text { Administrative and } \\
\text { contractual }\end{array}$ \\
\hline OCT & $\begin{array}{l}\text { IBM Lotus Notes } \\
\text { QuickPlace }\end{array}$ & WordPress & ACONEX & $\begin{array}{l}\text { Autodesk } \\
\text { Buzzsaw }\end{array}$ & $\begin{array}{l}\text { IBM Lotus } \\
\text { Notes } \\
\text { QuickPlace }\end{array}$ & $\begin{array}{l}\text { Nexus Point } \\
\text { INCITE }\end{array}$ \\
\hline Stakeholders & $\begin{array}{l}\text { Varied - } \\
\text { Government } \\
\text { Ministers, Private } \\
\text { Offices of } \\
\text { Ministers, } \\
\text { Departmental } \\
\text { Executive, media }\end{array}$ & $\begin{array}{l}\text { SC\&MC, } \\
\text { membership }\end{array}$ & $\begin{array}{l}\text { Complex including } \\
\text { two main clients, } \\
\text { two Government } \\
\text { Ministers, } \\
\text { associated } \\
\text { technical and user } \\
\text { groups }\end{array}$ & $\begin{array}{l}\text { Varied - Board of } \\
\text { Directors, } \\
\text { shareholders, State } \\
\text { Government }\end{array}$ & $\begin{array}{l}\text { Varied - } \\
\text { Executive, } \\
\text { State } \\
\text { Government, } \\
\text { target } \\
\text { audiences }\end{array}$ & $\begin{array}{l}\text { Varied - Board of } \\
\text { Directors, } \\
\text { shareholders, State } \\
\text { Government }\end{array}$ \\
\hline Cost & $\begin{array}{l}\text { Approximately } \\
\$ 200,000 \\
(\$ 0.2 \mathrm{~m}) \text { plus in- } \\
\text { kind }\end{array}$ & $\begin{array}{l}\text { Approximately } \\
\$ 70,000 \\
(\$ 0.07 \mathrm{~m})\end{array}$ & $\begin{array}{l}\$ 122,000,000 \\
(\$ 122 \mathrm{~m})\end{array}$ & $\begin{array}{l}\text { Approximately } \\
\$ 73,000,000 \\
(\$ 73 \mathrm{~m})\end{array}$ & $\begin{array}{l}\$ 70,000 \\
(\$ 0.07 \mathrm{~m})\end{array}$ & $\begin{array}{l}\$ 500,000,000 \\
(\$ 500 \mathrm{~m})\end{array}$ \\
\hline
\end{tabular}




\subsubsection{PART ONE, Section One: Shared Calendar}

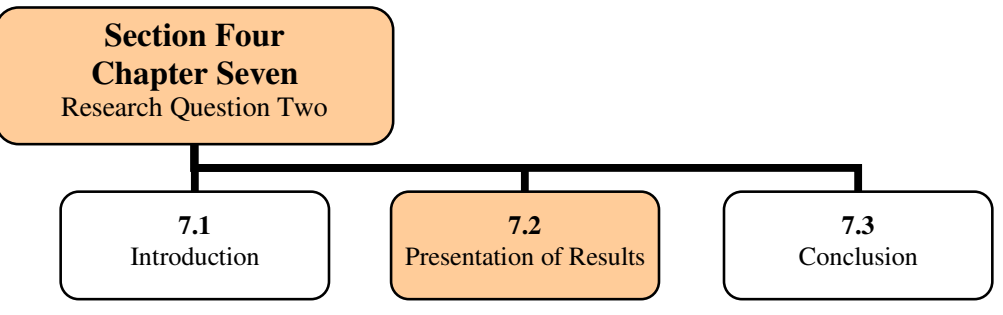

This first section of Part One reviewed the use of shared calendars in the OCT and sought to identify how the calendar functionality was used, and the benefits it brought to the PME.

Table 7-2: The use of a SHARED CALENDAR in the OCT

\begin{tabular}{|c|c|c|c|c|c|c|c|c|}
\hline \multirow[t]{2}{*}{$\begin{array}{l}\text { 1: increases chances of meeting } \\
\text { project schedules }\end{array}$} & $\underset{n=42}{\text { Agg. }}$ & $\underset{n=4}{\operatorname{OrgD}}$ & $\underset{n=9}{\operatorname{OrgV}}$ & $\underset{n=12}{\operatorname{OrgM}}$ & $\underset{n=6}{\operatorname{OrgC}}$ & $\underset{n=5}{\operatorname{OrgS}}$ & $\underset{n=6}{\operatorname{OrgK}}$ & \multirow[t]{2}{*}{ Comment } \\
\hline & \multicolumn{7}{|c|}{ Case responses \% } & \\
\hline strongly disagree & $\mathbf{0}$ & 0 & 0 & 0 & 0 & 0 & 0 & \multirow{5}{*}{$\begin{array}{l}\text { More than half }(58 \%) \text { of respondents } \\
\text { 'agree' or 'strongly agree' that the } \\
\text { use of shared calendars increases the } \\
\text { chances of meeting project schedules }\end{array}$} \\
\hline disagree & 5 & 0 & 0 & 8 & 17 & 0 & 0 & \\
\hline neither & 38 & 50 & 22 & 42 & 67 & 40 & 17 & \\
\hline agree & 48 & 50 & 56 & 50 & 0 & 40 & 83 & \\
\hline strongly agree & 10 & 0 & 22 & 0 & 17 & 20 & 0 & \\
\hline 2: improves planning activities & Agg. & OrgD & OrgV & OrgM & OrgC & OrgS & OrgK & Comment \\
\hline strongly disagree & $\mathbf{0}$ & 0 & 0 & 0 & 0 & 0 & 0 & \multirow{5}{*}{$\begin{array}{l}\text { More than half of respondents (59\%) } \\
\text { 'agree' or 'strongly agree' that the } \\
\text { use of the shared calendars improves } \\
\text { planning activities. }\end{array}$} \\
\hline disagree & 5 & 0 & 0 & 8 & 0 & 20 & 0 & \\
\hline neither & 26 & 50 & 0 & 33 & 67 & 20 & 0 & \\
\hline agree & 48 & 50 & 78 & 50 & 17 & 20 & 50 & \\
\hline strongly agree & 21 & 0 & 22 & 8 & 17 & 40 & 50 & \\
\hline 3: improves prioritising tasks & Agg. & OrgD & OrgV & OrgM & OrgC & OrgS & OrgK & Comment \\
\hline strongly disagree & $\mathbf{0}$ & 0 & 0 & 0 & 0 & 0 & 0 & \multirow{5}{*}{$\begin{array}{l}\text { Respondents are spread between } \\
\text { neutral and 'agree' in response to the } \\
\text { statement that the use of shared } \\
\text { calendars improves prioritising tasks. }\end{array}$} \\
\hline disagree & 2 & 0 & 0 & 0 & 0 & 20 & 0 & \\
\hline neither & 45 & 50 & 11 & 58 & 67 & 60 & 33 & \\
\hline agree & 43 & 50 & 78 & 33 & 17 & 0 & 67 & \\
\hline strongly agree & 10 & 0 & 11 & 8 & 17 & 20 & 0 & \\
\hline $\begin{array}{l}\text { 4: complicates coordinating } \\
\text { activities across the project } \\
\text { environment }\end{array}$ & Agg. & OrgD & OrgV & OrgM & OrgC & OrgS & OrgK & Comment \\
\hline strongly disagree & 12 & 0 & 22 & 8 & 0 & 20 & 17 & \multirow{5}{*}{$\begin{array}{l}\text { Approximately two thirds of } \\
\text { respondents }(64 \%) \text { 'disagree' to } \\
\text { 'strongly disagree' that the use of } \\
\text { shared calendars complicates } \\
\text { coordinating activities across the project } \\
\text { environment. This statement was } \\
\text { worded to elicit a negative response. }\end{array}$} \\
\hline disagree & 52 & 50 & 78 & 42 & 33 & 40 & 67 & \\
\hline neither & 29 & 25 & 0 & 42 & 67 & 40 & 0 & \\
\hline agree & 5 & 25 & 0 & 0 & 0 & 0 & 17 & \\
\hline strongly agree & 2 & 0 & 0 & 8 & 0 & 0 & 0 & \\
\hline $\begin{array}{l}5: \text { improves delivery of } \\
\text { activities in a timely manner }\end{array}$ & Agg. & OrgD & OrgV & OrgM & OrgC & OrgS & OrgK & Comment \\
\hline strongly disagree & $\mathbf{0}$ & 0 & 0 & 0 & 0 & 0 & 0 & \multirow{5}{*}{$\begin{array}{l}\text { Respondents are spread between } \\
\text { neutral and 'agree' in response to the } \\
\text { statement that the use of shared } \\
\text { calendars improves delivery of } \\
\text { activities in a timely manner. }\end{array}$} \\
\hline disagree & 5 & 0 & 0 & 0 & 0 & 20 & 17 & \\
\hline neither & 40 & 50 & 33 & 50 & 67 & 20 & 17 & \\
\hline agree & 48 & 50 & 56 & 42 & 33 & 40 & 67 & \\
\hline strongly agree & 7 & 0 & 11 & 8 & 0 & 20 & 0 & \\
\hline
\end{tabular}




\begin{tabular}{|c|c|c|c|c|c|c|c|c|}
\hline $\begin{array}{l}\text { 6: assists with the development } \\
\text { of trust across the project team }\end{array}$ & Agg. & OrgD & OrgV & OrgM & OrgC & OrgS & OrgK & Comment \\
\hline strongly disagree & $\mathbf{0}$ & 0 & 0 & 0 & 0 & 0 & 0 & \multirow{5}{*}{$\begin{array}{l}\text { The majority of respondents }(57 \%) \\
\text { are neutral in response to the } \\
\text { statement that the use of shared } \\
\text { calendars assists with the } \\
\text { development of trust across the } \\
\text { project team. }\end{array}$} \\
\hline disagree & 2 & 0 & 0 & 8 & 0 & 0 & 0 & \\
\hline neither & 57 & 25 & 33 & 67 & 67 & 80 & 67 & \\
\hline agree & 36 & 75 & 67 & 17 & 33 & 20 & 17 & \\
\hline strongly agree & 5 & 0 & 0 & 8 & 0 & 0 & 17 & \\
\hline $\begin{array}{l}\text { 7: communicates the availability } \\
\text { of team members and resources }\end{array}$ & Agg. & OrgD & OrgV & OrgM & OrgC & OrgS & OrgK & Comment \\
\hline strongly disagree & 2 & 0 & 11 & 0 & 0 & 0 & 0 & \multirow{5}{*}{$\begin{array}{l}\text { The majority of respondents }(69 \%) \\
\text { 'agree' to 'strongly agree' with the } \\
\text { statement that the use of shared } \\
\text { calendars communicates the } \\
\text { availability of team members and } \\
\text { resources. }\end{array}$} \\
\hline disagree & 7 & 0 & 0 & 25 & 0 & 0 & 0 & \\
\hline neither & 21 & 25 & 0 & 17 & 67 & 40 & 0 & \\
\hline agree & 57 & 50 & 67 & 58 & 33 & 20 & 100 & \\
\hline strongly agree & 12 & 25 & 22 & 0 & 0 & 40 & 0 & \\
\hline $\begin{array}{l}\text { 8: supports equality amongst } \\
\text { team members }\end{array}$ & Agg. & OrgD & OrgV & OrgM & OrgC & OrgS & OrgK & Comment \\
\hline strongly disagree & 2 & 0 & 11 & 0 & 0 & 0 & 0 & \multirow{5}{*}{$\begin{array}{l}\text { More than half of the respondents } \\
(57 \%) \text { are neutral in response to the } \\
\text { statement that the use of shared } \\
\text { calendars supports equality amongst } \\
\text { team members. }\end{array}$} \\
\hline disagree & 12 & 25 & 11 & 8 & 17 & 0 & 17 & \\
\hline neither & 57 & 25 & 33 & 58 & 67 & 100 & 67 & \\
\hline agree & 29 & 50 & 44 & 33 & 17 & 0 & 17 & \\
\hline strongly agree & $\mathbf{0}$ & 0 & 0 & 0 & 0 & 0 & 0 & \\
\hline $\begin{array}{l}\text { 9: detracts from managing } \\
\text { strategic alliances within the } \\
\text { project team }\end{array}$ & Agg. & OrgD & OrgV & OrgM & OrgC & OrgS & OrgK & Comment \\
\hline strongly disagree & 7 & 0 & 11 & 0 & 0 & 20 & 17 & \multirow{5}{*}{$\begin{array}{l}\text { The majority of respondents }(55 \%) \\
\text { are neutral in response to the } \\
\text { statement that the use of the shared } \\
\text { calendar detracts from managing } \\
\text { strategic alliances within the project } \\
\text { team. This statement was worded to } \\
\text { elicit a negative response. }\end{array}$} \\
\hline disagree & 33 & 50 & 78 & 8 & 17 & 20 & 33 & \\
\hline neither & 55 & 50 & 0 & 83 & 83 & 60 & 50 & \\
\hline agree & 5 & 0 & 11 & 8 & 0 & 0 & 0 & \\
\hline strongly agree & 0 & 0 & 0 & 0 & 0 & 0 & 0 & \\
\hline
\end{tabular}

\section{Summary}

The use of shared calendars in the OCT is generally supported across the six cases, due to its capacity to increase chances of meeting project schedules (Qu.1), planning, prioritising and coordinating tasks in a timely manner across the PME (Qu.2, 3, 4) and in assisting to communicate the availability of team members and resources $(\mathrm{Qu} .7)$. The responses from the cases suggest that the feature does not assist to develop trust or support equality across the PME (Qu.6, 8, Figure 7-1, OrgS PM1). 


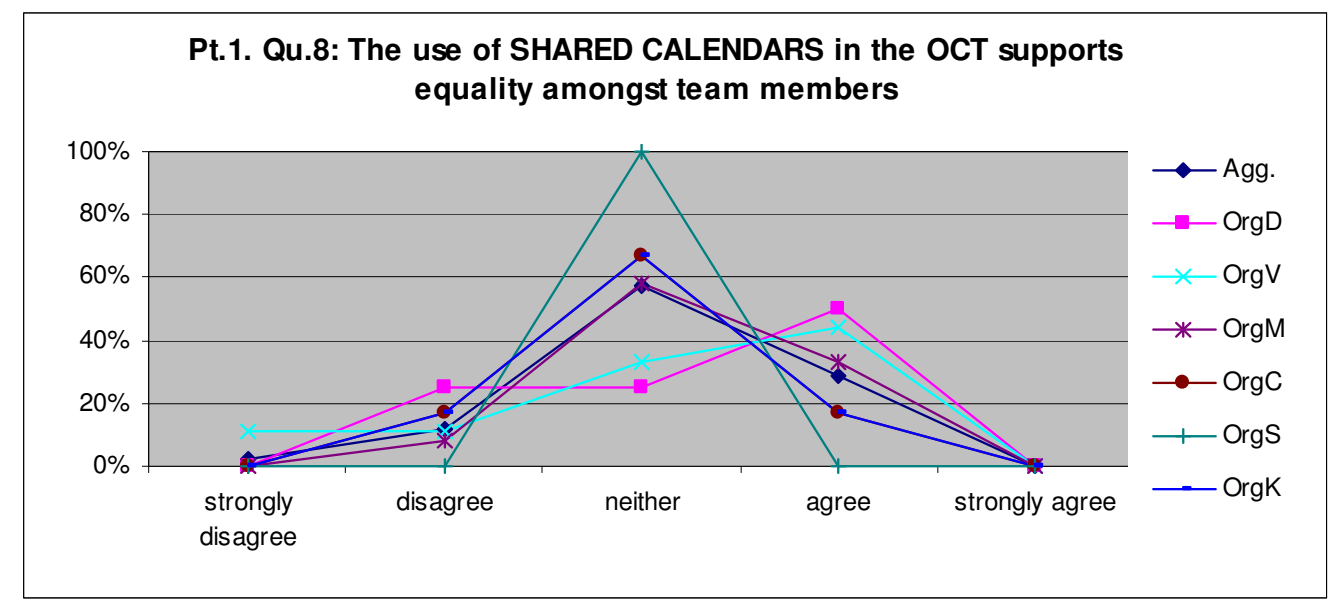

Figure 7-1: Pt.1. Qu.8: The use of Shared Calendars in the OCT supports equality amongst team members

The feature also does not necessarily assist to manage strategic alliances (Qu.9). The use of the shared calendars generally does not assist to develop trust amongst team members (Qu.6), however Org V was supportive of this statement, which is also reinforced by its response to the statement that the feature detracts from managing strategic alliances within the project team.

The Shared Calendar feature assists to communicate the availability of team members and resources across the PME (Qu.7). OrgV (Continuous Improvement org) tended to respond more favourably to the features than other organisations, a finding that may be explained by the virtual and distributed nature of the organisation and its emphasis on coordinating events across its membership (OrgV PM1, Figure 7-2).

The blog is also used to manage Continuous Improvement Network (CIN) events for OrgV, however it does not play a formal role in project management (Figure 7-1). In an example of this, the Project Manager of OrgV cites a circumstance where he was required to coordinate the responses of 30 people. In this instance, the blog was used as a collection tool, with each member contributing their own material through the Comments section of the blog. The Comments section plays an important role in the blog, as it is a 'major part of the mass capture of the narrative' (OrgV PM), a narrative that is essential to the substantiation of the activities and events facilitated by the CIN to the organisation's stakeholders. The reporting and analysis of the comments section of the blog continues to play a part in the formal reporting mechanisms of the CIN. 


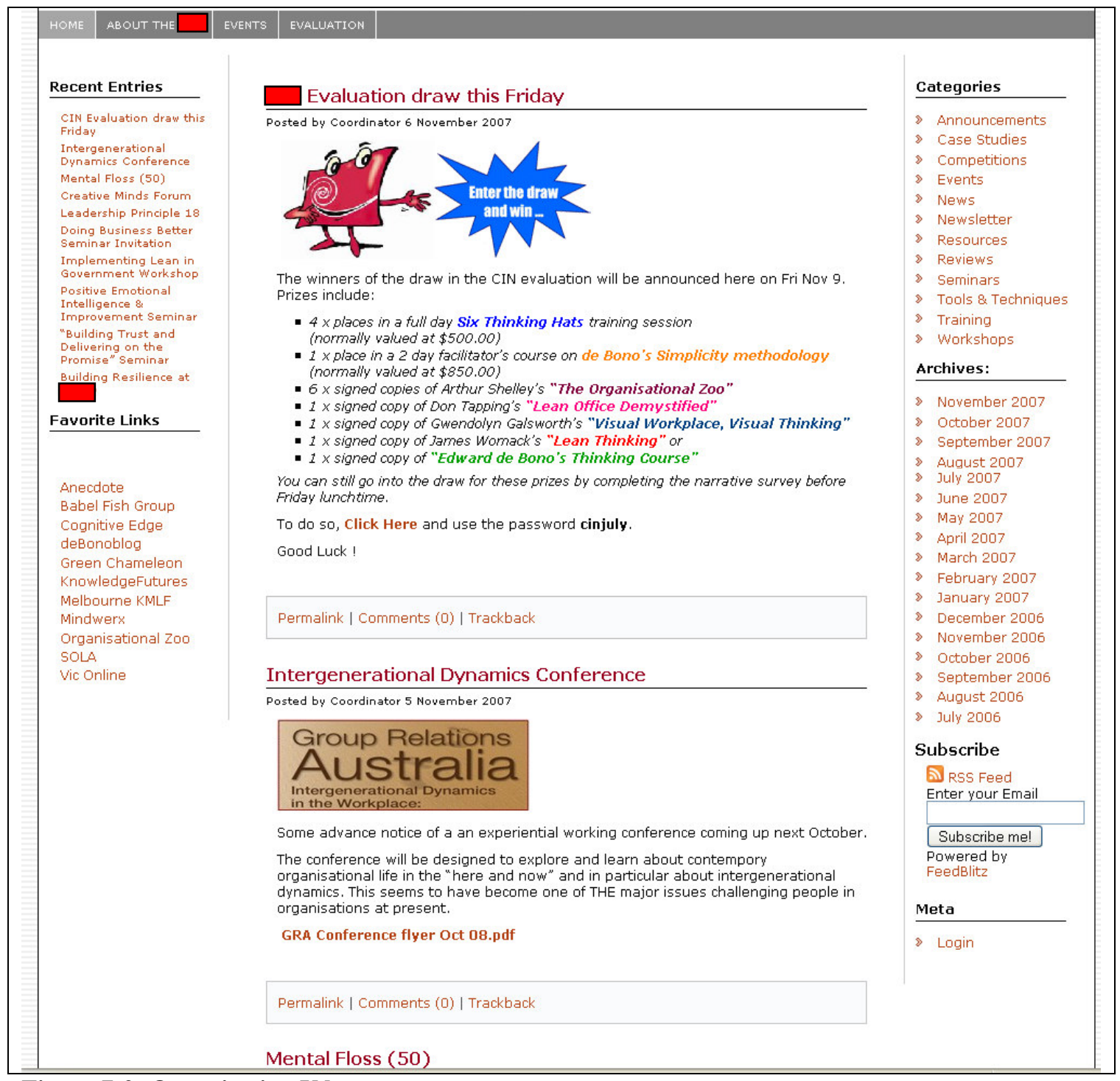

Figure 7-2: Organisation V home page 


\subsubsection{PART ONE, Section Two: Central Database}

The second section, asked the respondents questions about the use of the Central Database function in the OCT and the effects of its application on managing components of the project.

Table 7-3: The use of a CENTRAL DATABASE in the OCT

\begin{tabular}{|c|c|c|c|c|c|c|c|c|}
\hline \multirow[t]{2}{*}{$\begin{array}{l}\text { 10. improves the quality of data } \\
\text { in the database }\end{array}$} & $\underset{n=42}{\text { Agg. }}$ & $\underset{n=4}{\mathrm{OrgD}}$ & $\underset{n=9}{\operatorname{OrgV}}$ & $\underset{n=12}{\operatorname{OrgM}}$ & $\underset{n=6}{\operatorname{OrgC}}$ & $\underset{n=5}{\operatorname{OrgS}}$ & $\underset{n=6}{\operatorname{OrgK}}$ & \multirow[t]{2}{*}{ Comment } \\
\hline & \multicolumn{7}{|c|}{ Case responses \% } & \\
\hline strongly disagree & 0 & 0 & 0 & 0 & 0 & 0 & 0 & \multirow{5}{*}{$\begin{array}{l}\text { Half of the respondents (50\%) 'agree' } \\
\text { with the statement that the use of a central } \\
\text { database in the OCT improves the quality } \\
\text { of data in the database. Half of } \\
\text { respondents from OrgV and C 'disagree' } \\
\text { with this statement. }\end{array}$} \\
\hline disagree & 36 & 25 & 56 & 33 & 50 & 20 & 17 & \\
\hline neither & 12 & 25 & 22 & 0 & 0 & 40 & 0 & \\
\hline agree & 50 & 50 & 22 & 67 & 50 & 40 & 67 & \\
\hline strongly agree & 2 & 0 & 0 & 0 & 0 & 0 & 17 & \\
\hline $\begin{array}{l}\text { 11. manages data from a central } \\
\text { environment }\end{array}$ & Agg. & OrgD & $\operatorname{OrgV}$ & OrgM & $\operatorname{OrgC}$ & OrgS & $\operatorname{OrgK}$ & Comment \\
\hline strongly disagree & $\mathbf{0}$ & 0 & 0 & 0 & 0 & 0 & 0 & \multirow{5}{*}{$\begin{array}{l}\text { Almost two thirds of respondents (64\%) } \\
\text { 'agree' that the use of a central database } \\
\text { manages data from a central location. } \\
\text { This is generally supported by each case, } \\
\text { except OrgD where three quarters of its } \\
\text { respondents were neutral. }\end{array}$} \\
\hline disagree & $\mathbf{0}$ & 0 & 0 & 0 & 0 & 0 & 0 & \\
\hline neither & 14 & 75 & 22 & 0 & 17 & 0 & 0 & \\
\hline agree & 64 & 25 & 78 & 92 & 50 & 40 & 50 & \\
\hline strongly agree & 21 & 0 & 0 & 8 & 33 & 60 & 50 & \\
\hline $\begin{array}{l}\text { 12. decreases confidence in the } \\
\text { data }\end{array}$ & Agg. & OrgD & $\operatorname{OrgV}$ & OrgM & $\operatorname{OrgC}$ & OrgS & $\operatorname{OrgK}$ & Comment \\
\hline strongly disagree & 2 & 0 & 0 & 0 & 0 & 20 & 0 & \multirow{5}{*}{$\begin{array}{l}\text { Approximately two thirds of respondents } \\
(64 \%) \text { 'disagree' with the statement that } \\
\text { the use of a central database decreases } \\
\text { confidence in the data. This finding is } \\
\text { generally supported by all cases. This } \\
\text { statement was worded to elicit a negative } \\
\text { response. }\end{array}$} \\
\hline disagree & 64 & 50 & 78 & 67 & 83 & 40 & 50 & \\
\hline neither & 21 & 50 & 11 & 33 & 17 & 0 & 17 & \\
\hline agree & 10 & 0 & 11 & 0 & 0 & 40 & 17 & \\
\hline strongly agree & 2 & 0 & 0 & 0 & 0 & 0 & 17 & \\
\hline $\begin{array}{l}\text { 13. increases possibility of data } \\
\text { corruption }\end{array}$ & Agg. & OrgD & $\operatorname{OrgV}$ & OrgM & $\operatorname{OrgC}$ & OrgS & OrgK & Comment \\
\hline strongly disagree & 2 & 0 & 0 & 0 & 0 & 20 & 0 & \multirow{5}{*}{$\begin{array}{l}\text { Approximately two thirds of respondents } \\
(62 \%) \text { 'disagree' with the statement that } \\
\text { the use of a central database increases the } \\
\text { possibility of data corruption. This } \\
\text { statement was worded to elicit a negative } \\
\text { response. }\end{array}$} \\
\hline disagree & 62 & 50 & 44 & 58 & 83 & 60 & 83 & \\
\hline neither & 17 & 0 & 22 & 33 & 0 & 0 & 17 & \\
\hline agree & 17 & 50 & 33 & 0 & 17 & 20 & 0 & \\
\hline strongly agree & 2 & 0 & 0 & 8 & 0 & 0 & 0 & \\
\hline $\begin{array}{l}\text { 14. decreases the time it takes to } \\
\text { undertake tasks }\end{array}$ & Agg. & OrgD & $\operatorname{OrgV}$ & OrgM & $\operatorname{OrgC}$ & OrgS & OrgK & Comment \\
\hline strongly disagree & 2 & 0 & 0 & 8 & 0 & 0 & 0 & \multirow{5}{*}{$\begin{array}{l}\text { Responses were spread across the scale in } \\
\text { response to the statement that the use of a } \\
\text { central database decreases the time it takes } \\
\text { to undertake tasks. However there was } \\
\text { general agreement with this statement. }\end{array}$} \\
\hline disagree & 26 & 25 & 0 & 42 & 17 & 40 & 0 & \\
\hline neither & 26 & 25 & 11 & 8 & 33 & 60 & 50 & \\
\hline agree & 43 & 50 & 78 & 42 & 50 & 0 & 33 & \\
\hline strongly agree & 2 & 0 & 11 & 0 & 0 & 0 & 17 & \\
\hline 15. centralises reporting of data & Agg. & OrgD & OrgV & OrgM & OrgC & OrgS & OrgK & Comment \\
\hline strongly disagree & $\mathbf{0}$ & 0 & 0 & 0 & 0 & 0 & 0 & \multirow{5}{*}{$\begin{array}{l}\text { Approximately two thirds of respondents } \\
(67 \%) \text { 'agree' that the use of a central } \\
\text { database centralises reporting of data. } \\
\text { There were no negative responses } \\
\text { recorded to this statement except for OrgS } \\
\text { where } 20 \% \text { 'disagree' with this statement. }\end{array}$} \\
\hline disagree & 2 & 0 & 0 & 0 & 0 & 20 & 0 & \\
\hline neither & 14 & 25 & 11 & 0 & 33 & 0 & 33 & \\
\hline agree & 67 & 75 & 89 & 92 & 33 & 20 & 50 & \\
\hline strongly agree & 17 & 0 & 0 & 8 & 33 & 60 & 17 & \\
\hline
\end{tabular}




\begin{tabular}{|c|c|c|c|c|c|c|c|c|}
\hline $\begin{array}{l}\text { 16. detracts from organisational } \\
\text { planning }\end{array}$ & Agg. & OrgD & $\operatorname{OrgV}$ & OrgM & $\operatorname{OrgC}$ & OrgS & $\operatorname{OrgK}$ & Comment \\
\hline strongly disagree & 0 & 0 & 0 & 0 & 0 & 0 & 0 & \multirow{5}{*}{$\begin{array}{l}\text { Approximately two thirds of respondents } \\
(62 \%) \text { 'disagree' with the statement that } \\
\text { the use of a central database detracts from } \\
\text { organisational planning. This is generally } \\
\text { supported by all cases. This statement } \\
\text { was worded to elicit a negative response. }\end{array}$} \\
\hline disagree & 62 & 50 & 89 & 58 & 50 & 60 & 50 & \\
\hline neither & 24 & 50 & 0 & 25 & 33 & 20 & 33 & \\
\hline agree & 10 & 0 & 11 & 17 & 17 & 0 & 0 & \\
\hline strongly agree & 5 & 0 & 0 & 0 & 0 & 20 & 17 & \\
\hline $\begin{array}{l}\text { 17. reduces the complexity of } \\
\text { maintaining data }\end{array}$ & Agg. & OrgD & OrgV & OrgM & OrgC & OrgS & OrgK & Comment \\
\hline strongly disagree & 2 & 0 & 0 & 8 & 0 & 0 & 0 & \multirow{5}{*}{$\begin{array}{l}\text { Responses were spread across the scale in } \\
\text { response to the statement that the use of a } \\
\text { central database reduces the complexity o } \\
\text { maintaining data. 50\% of respondents } \\
\text { 'agree' to 'strongly agree', while } \\
\text { approximately one quarter ( } 23 \%) \\
\text { 'disagree' to 'strongly disagree'. }\end{array}$} \\
\hline disagree & 21 & 25 & 56 & 17 & 17 & 0 & 0 & \\
\hline neither & 29 & 75 & 0 & 33 & 17 & 60 & 17 & \\
\hline agree & 40 & 0 & 33 & 42 & 67 & 20 & 67 & \\
\hline strongly agree & 7 & 0 & 11 & 0 & 0 & 20 & 17 & \\
\hline $\begin{array}{l}\text { 18. requires a level of trust } \\
\text { between team members }\end{array}$ & Agg. & OrgD & $\operatorname{OrgV}$ & OrgM & $\operatorname{OrgC}$ & OrgS & $\operatorname{OrgK}$ & Comment \\
\hline strongly disagree & 0 & 0 & 0 & 0 & 0 & 0 & 0 & \multirow{5}{*}{$\begin{array}{l}\text { Approximately two thirds of respondents } \\
(67 \%) \text { 'agree' that the use of a central } \\
\text { database requires a level of trust between } \\
\text { team members. }\end{array}$} \\
\hline disagree & 2 & 0 & 0 & 8 & 0 & 0 & 0 & \\
\hline neither & 24 & 0 & 11 & 50 & 33 & 20 & 0 & \\
\hline agree & 67 & 100 & 89 & 33 & 67 & 80 & 67 & \\
\hline strongly agree & 7 & 0 & 0 & 8 & 0 & 0 & 33 & \\
\hline $\begin{array}{l}\text { 19. hampers communication } \\
\text { across the project team }\end{array}$ & Agg. & OrgD & $\operatorname{OrgV}$ & OrgM & $\operatorname{OrgC}$ & OrgS & $\operatorname{OrgK}$ & Comment \\
\hline strongly disagree & 5 & 0 & 0 & 0 & 0 & 20 & 17 & \multirow{5}{*}{$\begin{array}{l}\text { Approximately two thirds of respondents } \\
(64 \%) \text { 'disagree' that the use of a central } \\
\text { database hampers communication across } \\
\text { the project team. Three quarters of } \\
\text { respondents }(75 \%) \text { from OrgD were } \\
\text { neutral. This statement was worded to } \\
\text { elicit a negative response. }\end{array}$} \\
\hline disagree & 64 & 25 & 78 & 67 & 67 & 60 & 67 & \\
\hline neither & 21 & 75 & 11 & 17 & 33 & 20 & 0 & \\
\hline agree & 10 & 0 & 11 & 17 & 0 & 0 & 17 & \\
\hline strongly agree & $\mathbf{0}$ & 0 & 0 & 0 & 0 & 0 & 0 & \\
\hline
\end{tabular}

\section{Summary}

There is general support for the use of a central database in the OCT by all the cases, although some features are more strongly supported than others. The Central Database feature improves the quality of data (Qu.10), managing it from a central environment (Qu.11). There is an increase in the confidence in the data (Qu.12), and a reduction of both the possibility of data corruption (Qu.13) and complexity of maintaining it (Qu.17). The feature centralises the reporting functions (Qu.15, Figure 7-3) and assists with organisational planning and communication across the project team (Qu.16, 19). A level of trust between team members is considered a requirement when using the feature (Qu.18). 


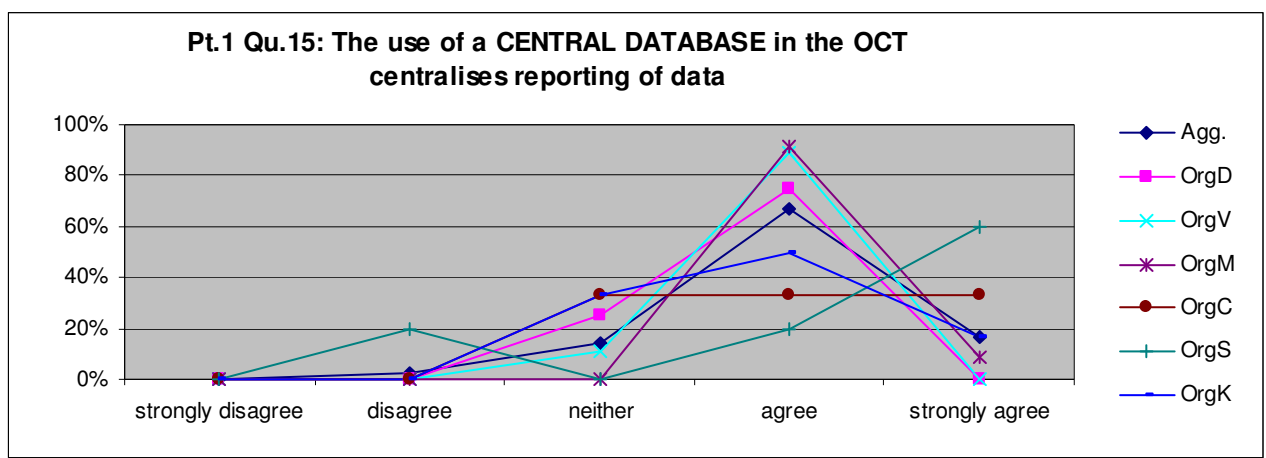

Figure 7-3: Pt.1 Qu.15: The use of a CENTRAL DATABASE in the OCT centralises reporting of data

Responses to the statement that the use of a central database decreases the time it takes to undertake tasks (Qu.14), are spread across the scale. This indicates that although data can be centrally located and available from the one source, this doesn't necessarily impact on the time it takes to undertake tasks or produce efficiencies for team members. However, approximately two thirds of respondents 'agree' that the use of a central database in the OCT centralises reporting of data (Qu.15), indicating that the function of the OCT acting as a central repository is well supported and useful for the PME. This was supported through the interviews, where this feature was well regarded.

In the case of Organisation K (the Alliance project), the INCITE application is used primarily for document storage which is managed through a single entry point by the organisation's Document Controller. The INCITE product is used as 'a very big database capturing all project related information' (OrgK PM2) and is the alliance mandated way to correspond about official projectrelated information, relegating the use of other mail programs such as MS Outlook to nonproject-related transmissions (OrgK PM2).

Figure 7-4 shows the use of the INCITE OCT for managing mail messages within the project environment, while Figure 7-5 provides an example of the project records and sub-files structure in place in the PME. This structure is similar in many OCTs, where it follows a Windows Explorer type layout.

The INCITE product is available in the shared electronic distribution network, which allows all staff and external consultants access to it when required. This is the case even though the majority of staff are co-located on a single office site (OrgK PM2). 
Responses to the statement that the use of a central database reduces the complexity of maintaining data (Qu.17), are spread across the scale, even though almost half 'agree to strongly agree' with this statement. While Organisation V (Continuous Improvement Org) disagrees with this statement, those organisations involved with construction tended to agree. This is in contrast to the finding that the database did not assist with organisational planning (Qu.16).

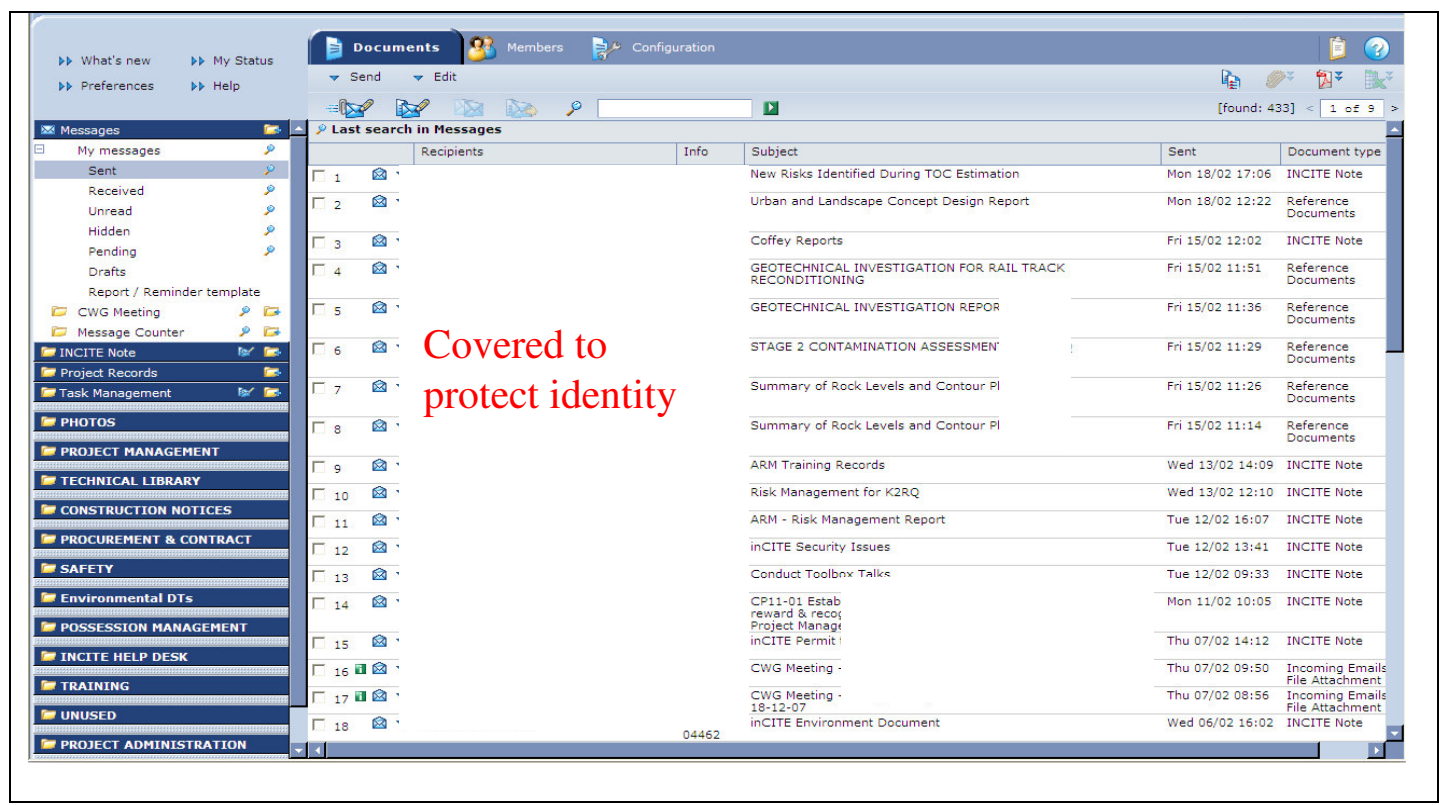

Figure 7-4: INCITE screen shot - correspondence functionality

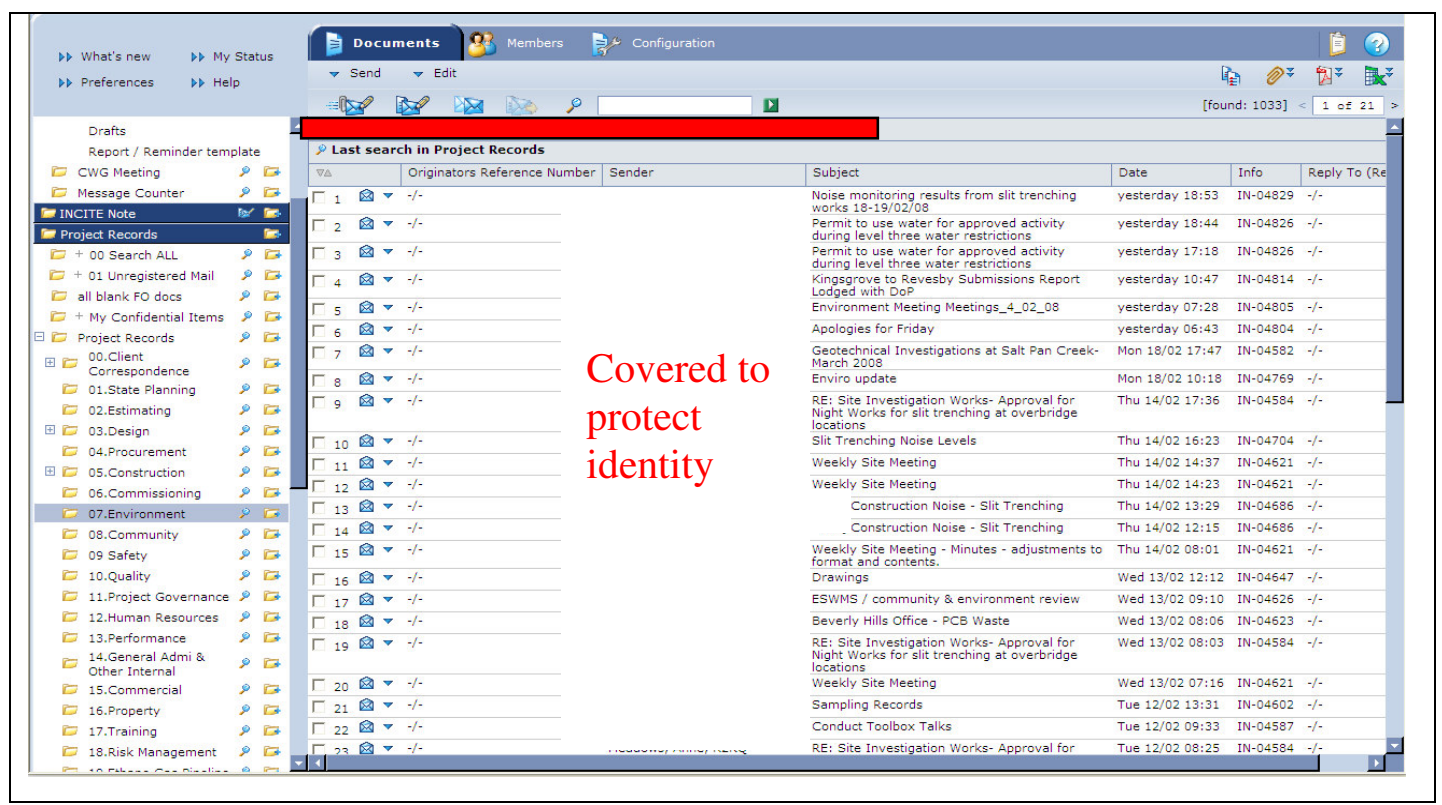

Figure 7-5: INCITE project records and sub-files

There is strong support for the statement that the use of a central database requires a level of trust between team members (Qu.18), in that approximately two thirds of respondents 'agree to 
strongly agree' with this statement. This statement returned a low negative response (Qu.18) as shown in Figure 7-6.

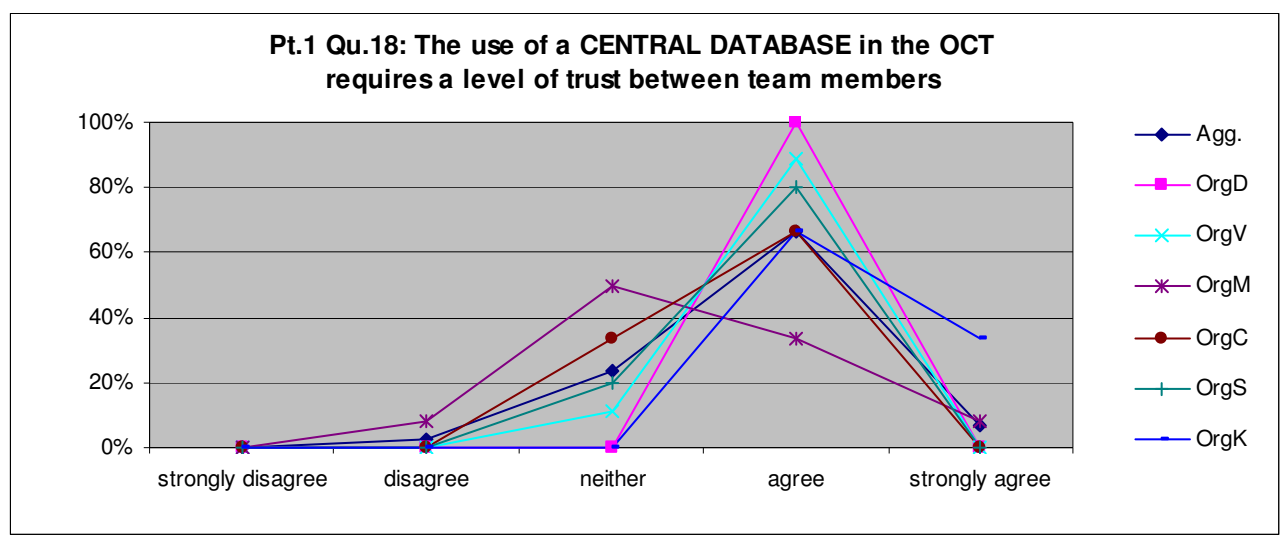

Figure 7-6: Pt.1 Qu.18: The use of a CENTRAL DATABASE in the OCT requires a level of trust between team members

Approximately two thirds of respondents 'disagree' that the use of a central database hampers communication across the project team (Qu.19). This indicates that the OCT assists with communication across the project team, and is a trend that will be reviewed throughout the analysis of the cases. Three quarters of respondents from Organisation D (State Government Org) however were neutral in respect to this statement, suggesting that either the particulars of the PME contributed to the effectiveness of the OCT in communicating to the team members, or that the tool itself was sub-standard. This is supported through the interviews with OrgD PM1, where criticism of the tool was attributed to a perceived lack of its functionality (OrgD PM1). 


\subsubsection{PART ONE, Section Three: Share Documents}

The third section reviewed the capacity to share documents and the benefits of this functionality.

Table 7-4: The capacity to SHARE DOCUMENTS in the OCT

\begin{tabular}{|c|c|c|c|c|c|c|c|c|}
\hline \multirow[t]{2}{*}{$\begin{array}{l}\text { 20. increases the number of } \\
\text { versions of documents }\end{array}$} & $\underset{n=42}{\text { Agg. }}$ & $\underset{n=4}{\operatorname{OrgD}}$ & $\underset{n=9}{\operatorname{OrgV}}$ & $\underset{n=12}{\operatorname{OrgM}}$ & $\underset{n=6}{\operatorname{OrgC}}$ & $\underset{n=5}{\operatorname{OrgS}}$ & $\underset{n=6}{\operatorname{OrgK}}$ & \multirow[t]{2}{*}{ Comment } \\
\hline & \multicolumn{7}{|c|}{ Case responses \% } & \\
\hline strongly disagree & 2 & 0 & 0 & 0 & 0 & 0 & 17 & \multirow{5}{*}{$\begin{array}{l}\text { Responses were spread over the scale } \\
\text { in respect to the statement that the } \\
\text { capacity to share documents in the } \\
\text { OCT increases the number of versions } \\
\text { of documents. This statement was } \\
\text { worded to elicit a negative response. }\end{array}$} \\
\hline disagree & 38 & 25 & 56 & 17 & 67 & 40 & 33 & \\
\hline neither & 19 & 25 & 22 & 8 & 33 & 20 & 17 & \\
\hline agree & 31 & 50 & 22 & 58 & 0 & 20 & 17 & \\
\hline strongly agree & 10 & 0 & 0 & 17 & 0 & 20 & 17 & \\
\hline $\begin{array}{l}\text { 21. increases efficiencies in } \\
\text { distribution of documents }\end{array}$ & Agg. & OrgD & OrgV & OrgM & OrgC & OrgS & OrgK & Comment \\
\hline strongly disagree & $\mathbf{0}$ & 0 & 0 & 0 & 0 & 0 & 0 & \multirow{5}{*}{$\begin{array}{l}\text { Sixty percent of respondents }(60 \%) \\
\text { 'agree' that the capacity to share } \\
\text { documents increases the efficiencies in } \\
\text { the distribution of documents. }\end{array}$} \\
\hline disagree & 12 & 25 & 0 & 17 & 17 & 20 & 0 & \\
\hline neither & 10 & 50 & 0 & 0 & 0 & 0 & 33 & \\
\hline agree & 60 & 25 & 78 & 67 & 83 & 40 & 33 & \\
\hline strongly agree & 19 & 0 & 22 & 17 & 0 & 40 & 33 & \\
\hline $\begin{array}{l}\text { 22. requires a level of trust } \\
\text { between team members }\end{array}$ & Agg. & OrgD & OrgV & OrgM & OrgC & OrgS & OrgK & Comment \\
\hline strongly disagree & $\mathbf{0}$ & 0 & 0 & 0 & 0 & 0 & 0 & \multirow{5}{*}{$\begin{array}{l}\text { Sixty percent of respondents }(60 \%) \\
\text { 'agree' that the capacity to share } \\
\text { documents requires a level of trust } \\
\text { between team members. There is } \\
\text { strong support for this statement } \\
\text { across the cases. }\end{array}$} \\
\hline disagree & 5 & 0 & 0 & 8 & 17 & 0 & 0 & \\
\hline neither & 24 & 0 & 11 & 50 & 17 & 40 & 0 & \\
\hline agree & 60 & 100 & 78 & 42 & 67 & 20 & 67 & \\
\hline strongly agree & 12 & 0 & 11 & 0 & 0 & 40 & 33 & \\
\hline $\begin{array}{l}\text { 23. risks quality control within } \\
\text { the project }\end{array}$ & Agg. & OrgD & OrgV & OrgM & OrgC & OrgS & OrgK & Comment \\
\hline strongly disagree & 5 & 0 & 0 & 0 & 17 & 20 & 0 & \multirow{5}{*}{$\begin{array}{l}50 \% \text { of respondents 'disagree' to } \\
\text { 'strongly disagree' that the capacity to } \\
\text { share documents risks quality control } \\
\text { within the project. This statement was } \\
\text { worded to elicit a negative response. }\end{array}$} \\
\hline disagree & 45 & 0 & 56 & 58 & 67 & 40 & 17 & \\
\hline neither & 19 & 50 & 11 & 25 & 0 & 0 & 33 & \\
\hline agree & 26 & 50 & 33 & 17 & 17 & 20 & 33 & \\
\hline strongly agree & 5 & 0 & 0 & 0 & 0 & 20 & 17 & \\
\hline $\begin{array}{l}\text { 24. improves communication } \\
\text { regarding essential information }\end{array}$ & Agg. & OrgD & OrgV & OrgM & OrgC & OrgS & OrgK & Comment \\
\hline strongly disagree & $\mathbf{0}$ & 0 & 0 & 0 & 0 & 0 & 0 & \multirow{5}{*}{$\begin{array}{l}\text { Almost three quarters of respondents } \\
(74 \%) \text { 'agree' to 'strongly agree' that } \\
\text { the capacity to share documents } \\
\text { improves communication regarding } \\
\text { essential information. }\end{array}$} \\
\hline disagree & 12 & 25 & 0 & 17 & 17 & 20 & 0 & \\
\hline neither & 14 & 50 & 0 & 8 & 17 & 20 & 17 & \\
\hline agree & 62 & 25 & 100 & 50 & 67 & 20 & 83 & \\
\hline strongly agree & 12 & 0 & 0 & 25 & 0 & 40 & 0 & \\
\hline $\begin{array}{l}25 . \text { produces inefficiencies in } \\
\text { retrieval of information }\end{array}$ & Agg. & OrgD & OrgV & OrgM & OrgC & OrgS & OrgK & Comment \\
\hline strongly disagree & 10 & 0 & 0 & 17 & 0 & 20 & 17 & \multirow{5}{*}{$\begin{array}{l}\text { Approximately two thirds of } \\
\text { respondents }(62 \%) \text { 'disagree' to } \\
\text { 'strongly disagree' that the capacity to } \\
\text { share documents produces } \\
\text { inefficiencies in retrieval of } \\
\text { information. This statement was } \\
\text { worded to elicit a negative response. }\end{array}$} \\
\hline disagree & 52 & 25 & 67 & 25 & 100 & 60 & 50 & \\
\hline neither & 24 & 50 & 33 & 25 & 0 & 20 & 17 & \\
\hline agree & 12 & 25 & 0 & 25 & 0 & 0 & 17 & \\
\hline strongly agree & 2 & 0 & 0 & 8 & 0 & 0 & 0 & \\
\hline
\end{tabular}




\begin{tabular}{|c|c|c|c|c|c|c|c|c|}
\hline $\begin{array}{l}\text { 26. develops an equality } \\
\text { amongst the team members }\end{array}$ & Agg. & OrgD & OrgV & OrgM & OrgC & OrgS & OrgK & Comment \\
\hline strongly disagree & 2 & 0 & 0 & 8 & 0 & 0 & 0 & \multirow{5}{*}{$\begin{array}{l}60 \% \text { of respondents are neutral in } \\
\text { respect to the statement that the } \\
\text { capacity to share documents develops } \\
\text { equality amongst the team members. }\end{array}$} \\
\hline disagree & 5 & 0 & 11 & 0 & 17 & 0 & 0 & \\
\hline neither & 60 & 75 & 33 & 58 & 50 & 80 & 83 & \\
\hline agree & 29 & 25 & 56 & 25 & 33 & 0 & 17 & \\
\hline strongly agree & 5 & 0 & 0 & 8 & 0 & 20 & 0 & \\
\hline $\begin{array}{l}\text { 27. assists in managing change } \\
\text { controls in the project }\end{array}$ & Agg. & OrgD & OrgV & OrgM & OrgC & OrgS & OrgK & Comment \\
\hline strongly disagree & $\mathbf{0}$ & 0 & 0 & 0 & 0 & 0 & 0 & \multirow{5}{*}{$\begin{array}{l}60 \% \text { of respondents 'agree' to } \\
\text { 'strongly agree' that the capacity to } \\
\text { share documents assists in managing } \\
\text { change controls in the project. }\end{array}$} \\
\hline disagree & 7 & 0 & 11 & 8 & 17 & 0 & 0 & \\
\hline neither & 33 & 75 & 33 & 42 & 0 & 20 & 33 & \\
\hline agree & 50 & 25 & 56 & 33 & 83 & 40 & 67 & \\
\hline strongly agree & 10 & 0 & 0 & 17 & 0 & 40 & 0 & \\
\hline $\begin{array}{l}\text { 28. adds time and cost to } \\
\text { managing the shared documents }\end{array}$ & Agg. & OrgD & OrgV & OrgM & OrgC & OrgS & OrgK & Comment \\
\hline strongly disagree & 10 & 0 & 11 & 8 & 0 & 20 & 17 & \multirow{5}{*}{$\begin{array}{l}\text { Responses are spread across the scales } \\
\text { in respect to the statement that the } \\
\text { capacity to share documents adds time } \\
\text { and cost to managing shared } \\
\text { documents. This statement was } \\
\text { worded to elicit a negative response. }\end{array}$} \\
\hline disagree & 31 & 25 & 44 & 8 & 50 & 40 & 33 & \\
\hline neither & 21 & 0 & 22 & 33 & 17 & 20 & 17 & \\
\hline agree & 31 & 75 & 22 & 25 & 33 & 20 & 33 & \\
\hline strongly agree & 7 & 0 & 0 & 25 & 0 & 0 & 0 & \\
\hline 29. assists with project planning & Agg. & OrgD & OrgV & OrgM & OrgC & OrgS & OrgK & Comment \\
\hline strongly disagree & $\mathbf{0}$ & 0 & 0 & 0 & 0 & 0 & 0 & \multirow{5}{*}{$\begin{array}{l}\text { Approximately three quarters of } \\
\text { respondents }(72 \%) \text { 'agree' to 'strongly } \\
\text { agree' with the statement that the } \\
\text { capacity to share documents assists } \\
\text { with project planning. }\end{array}$} \\
\hline disagree & 12 & 25 & 0 & 25 & 0 & 20 & 0 & \\
\hline neither & 17 & 50 & 0 & 17 & 50 & 0 & 0 & \\
\hline agree & 67 & 25 & 100 & 50 & 50 & 60 & 100 & \\
\hline strongly agree & 5 & 0 & 0 & 8 & 0 & 20 & 0 & \\
\hline
\end{tabular}

\section{Summary}

Responses to this section range across the scale. The use of shared documents in the OCT does not assist with managing version control of documents (Qu.20), although it does increase efficiencies in the distribution of documents (Qu.21). The sharing of documents does not necessarily assist with quality controls (Qu.23), although it is useful in communicating essential information and retrieving information $(\mathrm{Qu} .24,25)$. There is a time and cost factor however in managing these shared documents (Qu.28). There is support for the use of shared documents to assist with project planning (Qu.29).

Responses to the statement that the capacity to share documents in the OCT increases the number of versions of documents ( $\mathrm{Qu}$. 20) are spread across the scale. This is of interest to the research, as document control is an important component of the PME and a stated feature of the OCTs. There is a functional link between the capacity to manage documents and the operational environment, in that the PME requires a level of confidence in the version of the documents especially when these documents are being shared across multiple sites/members 
(Orgs S, D, M, C \&K). This is especially the case if collaboration on documents is to occur.

This was reinforced by OrgS PM1, who noted the existence of document version confusion and multiple sources of documents across the I.T. network. Similarly, responses to Qu.25 regarding efficiencies to be gained in the distribution and retrieval of documents are at the lower end of the scale.

In the case of Organisation S (State Authority Org), project-related information is placed on the OCT, rather than on its shared drives. However, given the nature of uploading content to the OCT, an initial copy of the document must exist before it can be placed on the OCT document library (OrgS PM1). This has been identified by the organisation as a problem with the OCT, in that it has the potential to cause 'version confusion' with documents, as each document needs to be saved at least twice - once on a local drive, and once on the OCT (OrgS PM1). Organisation $\mathrm{S}$ was also planning to move to a corporate record keeping system, which would see additional requirements placed on staff to save and archive formal organisation documents, including emails (OrgS PM1). Figure 7-7 provides a screen shot of the Library function of the QuickPlace OCT.

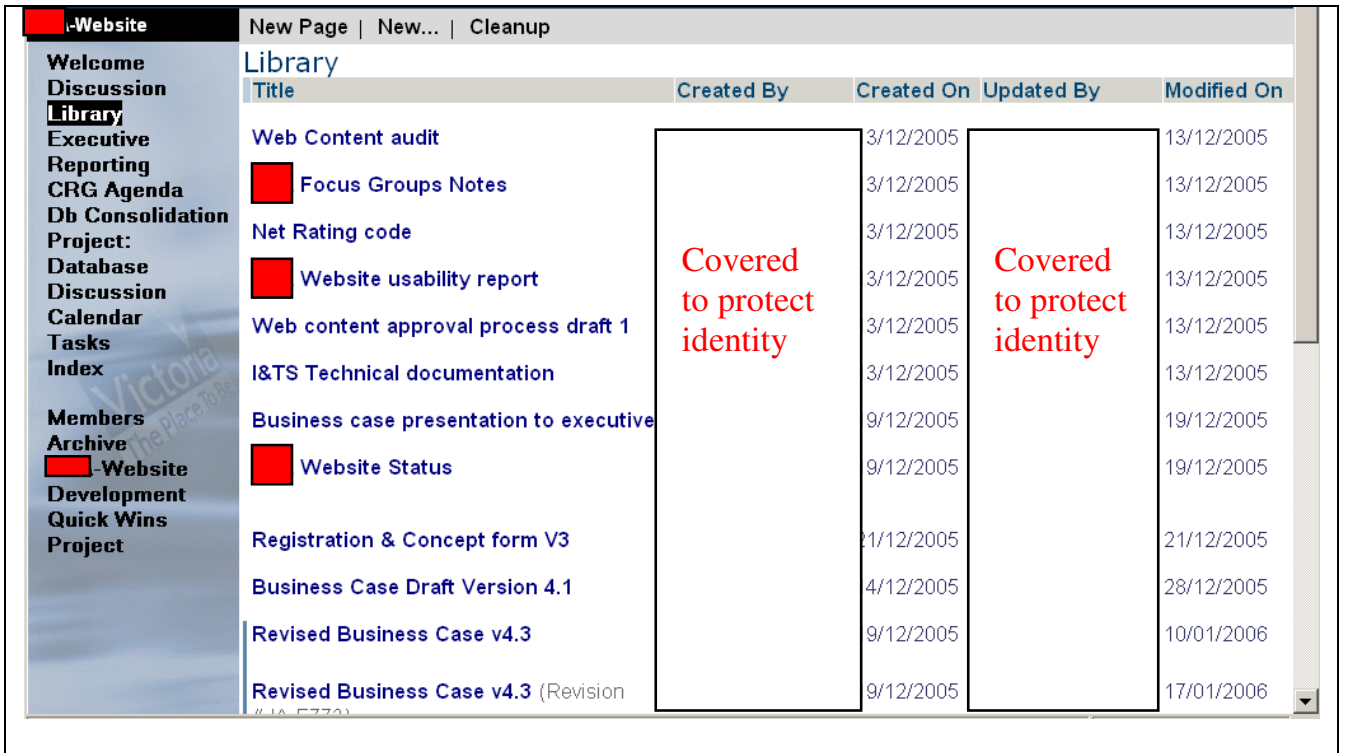

Figure 7-7: Organisation S Library Dashboard.

Sixty percent of respondents 'agree' that the capacity to share documents requires a level of trust between team members (Qu.22, Figure 7-8). There is support for this statement across the cases, which is consistent with the findings from Qu.18 in the previous section. Interestingly, the presence of trust within the PME does not necessarily translate to equality amongst team members (Qu.26). 


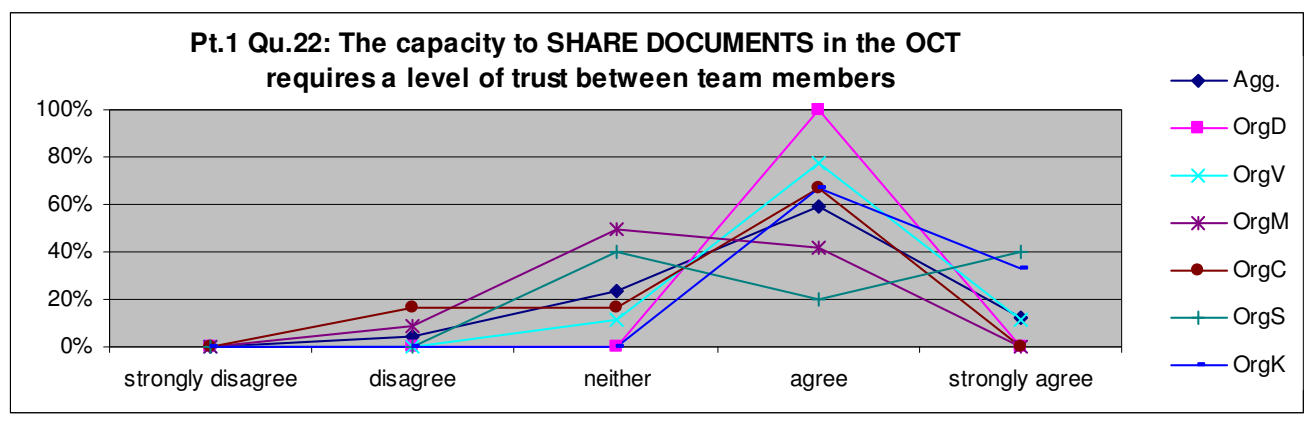

Figure 7-8: Pt.1 Qu.22: The capacity to SHARE DOCUMENTS in the OCT requires a level of trust between team members

Almost three quarters of respondents 'agree' to 'strongly agree' that the capacity to share documents improves communication regarding essential information $(\mathrm{Qu} 24)$. This finding is generally supported across the cases with the exception of $\operatorname{OrgD}$, which had noted that the PME shared the wrong sort of information (OrgD PM1). This highlights that a feature within the OCT does not equate to implementation or exploitation by the PME (of that feature):

'The organisation doesn't necessarily talk about the important details, and they assume that everyone knows what is happening, but in reality no one is sharing information about the important details.' (OrgD PM1).

The use of the OCT to manage change controls in the project (Qu.27) is supported by the construction organisations and Organisation $\mathrm{S}$, which has a strong focus on governance and procedures (OrgS PM1).

Responses are spread across the scale in respect to the statement that the capacity to share documents adds time and cost to managing shared documents (Qu.28, Figure 7-9). There is consistency in responses across the cases, except for Organisation D, which has a heightened negative response. In contrast, almost three quarters of respondents 'agree' to 'strongly agree' that the capacity to share documents within the OCT assists with project planning (Qu.29).

Organisation C (Commercial Construction Project) supports the use of its OCT in the way it handles shared documents (Qu.21, 23, 24, 25). Autodesk Buzzsaw is used primarily to cover-off on project management related processes, such as minutes, meeting schedules, superintendent instructions, price variations and design changes; rather than project related activities (OrgC 
PM1). As such, it is used as the online equivalent of the Project Centre (OrgC PM2). The workflow component of the product and its email functionality is not used.

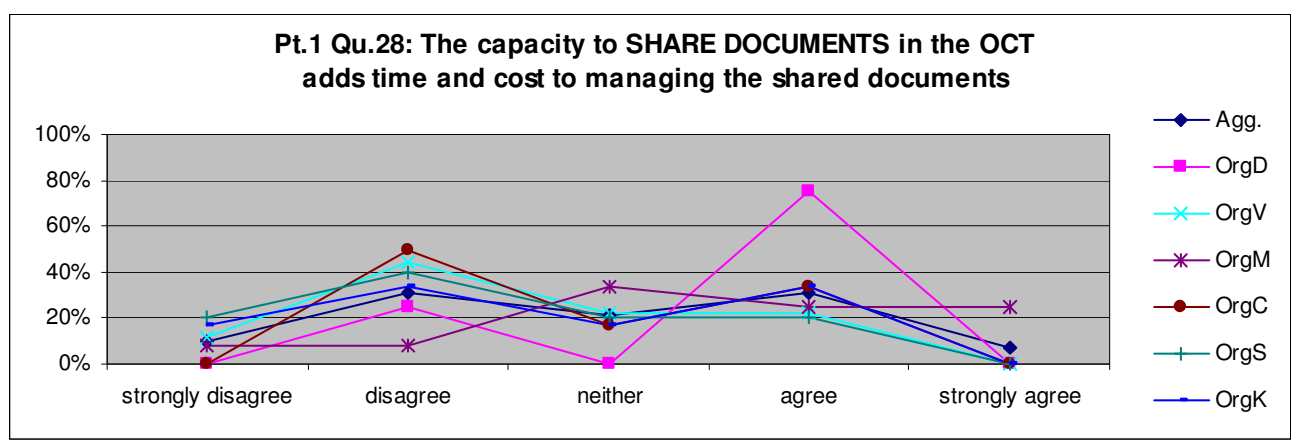

Figure 7-9: Pt.1 Qu.28: The capacity to SHARE DOCUMENTS in the OCT adds time and cost to managing the shared documents

The product is well regarded in the way that it manages architectural drawings, particularly AutoCAD's electronic file formats (*.dwg) and the graphic formats of *.dwf and *.pdf extension files. The use of the tool for distributing electronic drawings to project team members is considered 'really the only way to do it, especially as file sizes can be 6-8 megabytes each' (OrgC PM2, Figure 7-10). It also greatly assists team members dealing with large numbers of drawing files, with Organisation $\mathrm{C}$ noting that it has up to 80 drawings, 30-40 of which may have the same files contained within them (OrgC PM2). This interoperability is a key feature of the product, however it is not surprising given Autodesk is the software developer for both AutoCAD and Buzzsaw products. OrgC PM1, 2 noted that this capability was central to the selection of the OCT in the first instance. 


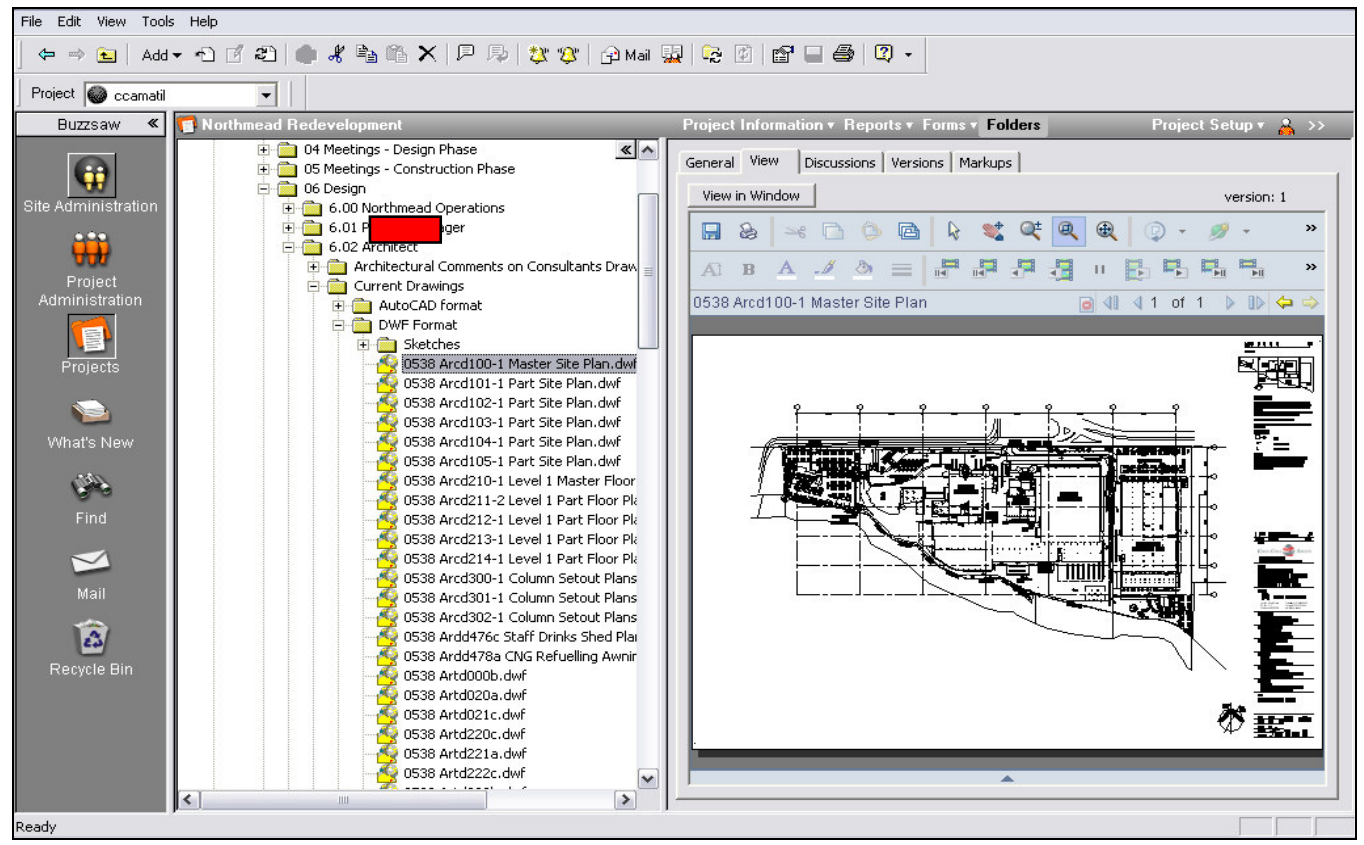

Figure 7-10: Display of AutoCAD files inside AutoDesk Buzzsaw

\subsubsection{PART ONE, Section Four: Store Documents}

The fourth section presented questions about the capacity to store documents within the OCT, and the impact or value-adding effect this functionality provided the team members.

Table 7-5: The capacity to STORE DOCUMENTS in the OCT

\begin{tabular}{|c|c|c|c|c|c|c|c|c|}
\hline \multirow[t]{2}{*}{$\begin{array}{l}\text { 30. enables easy access to all } \\
\text { documents in the central repository }\end{array}$} & $\underset{n=42}{\text { Agg. }}$ & $\underset{n=4}{\operatorname{OrgD}}$ & $\underset{n=9}{\operatorname{OrgV}}$ & $\underset{n=12}{\mathrm{OrgM}}$ & $\underset{n=6}{\operatorname{OrgC}}$ & $\underset{n=5}{\operatorname{OrgS}}$ & $\underset{n=6}{\operatorname{OrgK}}$ & \multirow[t]{2}{*}{ Comment } \\
\hline & \multicolumn{7}{|c|}{ Case responses \% } & \\
\hline strongly disagree & $\mathbf{0}$ & 0 & 0 & 0 & 0 & 0 & 0 & \multirow{5}{*}{$\begin{array}{l}\text { A large majority of respondents }(95 \%) \\
\text { 'agree' or 'strongly agree' that the } \\
\text { capacity to store documents in the } \\
\text { OCT enables easy access to all } \\
\text { documents within the central } \\
\text { repository. }\end{array}$} \\
\hline Disagree & $\mathbf{0}$ & 0 & 0 & 0 & 0 & 0 & 0 & \\
\hline Neither & 5 & 25 & 0 & 8 & 0 & 0 & 0 & \\
\hline Agree & 71 & 75 & 56 & 83 & 100 & 40 & 67 & \\
\hline strongly agree & 24 & 0 & 44 & 8 & 0 & 60 & 33 & \\
\hline $\begin{array}{l}\text { 31. reduces the number of users } \\
\text { accessing files }\end{array}$ & Agg. & OrgD & OrgV & OrgM & OrgC & OrgS & OrgK & Comment \\
\hline strongly disagree & $\mathbf{0}$ & 0 & 0 & 0 & 0 & 0 & 0 & \multirow{5}{*}{$\begin{array}{l}\text { Responses are spread across the scales } \\
\text { in respect to the statement that the } \\
\text { capacity to store documents in the } \\
\text { OCT reduces the number of users } \\
\text { accessing files. }\end{array}$} \\
\hline Disagree & 43 & 25 & 67 & 33 & 50 & 20 & 50 & \\
\hline Neither & 38 & 75 & 11 & 50 & 17 & 60 & 33 & \\
\hline Agree & 17 & 0 & 22 & 17 & 33 & 20 & 0 & \\
\hline strongly agree & 2 & 0 & 0 & 0 & 0 & 0 & 17 & \\
\hline $\begin{array}{l}\text { 32. develops trust between team } \\
\text { members }\end{array}$ & Agg. & OrgD & OrgV & OrgM & OrgC & OrgS & OrgK & Comment \\
\hline strongly disagree & $\mathbf{0}$ & 0 & 0 & 0 & 0 & 0 & 0 & \multirow{5}{*}{$\begin{array}{l}\text { More than half of the respondents } \\
(57 \%) \text { are neutral regarding the } \\
\text { statement that the capacity to store } \\
\text { documents in the OCT develops trust } \\
\text { between team members. }\end{array}$} \\
\hline Disagree & 7 & 0 & 11 & 0 & 17 & 0 & 17 & \\
\hline Neither & 57 & 50 & 33 & 58 & 67 & 100 & 50 & \\
\hline Agree & 33 & 50 & 56 & 42 & 17 & 0 & 17 & \\
\hline strongly agree & 2 & 0 & 0 & 0 & 0 & 0 & 17 & \\
\hline
\end{tabular}




\begin{tabular}{|c|c|c|c|c|c|c|c|c|}
\hline $\begin{array}{l}\text { 33. increases ease of retrieving } \\
\text { documents }\end{array}$ & Agg. & OrgD & $\operatorname{OrgV}$ & OrgM & OrgC & OrgS & OrgK & Comment \\
\hline strongly disagree & $\mathbf{0}$ & 0 & 0 & 0 & 0 & 0 & 0 & \multirow{5}{*}{$\begin{array}{l}\text { More than three quarters of } \\
\text { respondents }(86 \%) \text { 'agree' or 'strongly } \\
\text { agree' that the capacity to store } \\
\text { documents in the OCT increases ease } \\
\text { of retrieving documents. }\end{array}$} \\
\hline disagree & 7 & 0 & 0 & 8 & 0 & 20 & 17 & \\
\hline neither & 7 & 25 & 0 & 0 & 33 & 0 & 0 & \\
\hline agree & 74 & 75 & 89 & 83 & 67 & 40 & 67 & \\
\hline strongly agree & 12 & 0 & 11 & 8 & 0 & 40 & 17 & \\
\hline $\begin{array}{l}\text { 34. discourages communication } \\
\text { across the project team }\end{array}$ & Agg. & OrgD & $\operatorname{OrgV}$ & OrgM & OrgC & OrgS & OrgK & Comment \\
\hline strongly disagree & $\mathbf{0}$ & 0 & 0 & 0 & 0 & 0 & 0 & \multirow{5}{*}{$\begin{array}{l}\text { Two thirds of respondents }(67 \%) \\
\text { 'disagree' that the capacity to store } \\
\text { documents in the OCT discourages } \\
\text { communication across the project } \\
\text { team. This statement was worded to } \\
\text { elicit a negative response. }\end{array}$} \\
\hline disagree & 67 & 75 & 89 & 67 & 67 & 60 & 33 & \\
\hline neither & 17 & 25 & 0 & 0 & 33 & 0 & 67 & \\
\hline agree & 10 & 0 & 11 & 17 & 0 & 20 & 0 & \\
\hline strongly agree & 7 & 0 & 0 & 17 & 0 & 20 & 0 & \\
\hline $\begin{array}{l}\text { 35. provides an incentive to share } \\
\text { information amongst team members }\end{array}$ & Agg. & OrgD & OrgV & OrgM & OrgC & OrgS & OrgK & Comment \\
\hline strongly disagree & $\mathbf{0}$ & 0 & 0 & 0 & 0 & 0 & 0 & \multirow{5}{*}{$\begin{array}{l}\text { More than half of the respondents } \\
(52 \%) \text { 'agree' or 'strongly agree' that } \\
\text { the capacity to store documents in the } \\
\text { OCT provides an incentive to share } \\
\text { information amongst team members. }\end{array}$} \\
\hline disagree & 12 & 0 & 11 & 0 & 33 & 40 & 0 & \\
\hline neither & 36 & 25 & 22 & 50 & 50 & 0 & 50 & \\
\hline agree & 45 & 75 & 67 & 42 & 17 & 40 & 33 & \\
\hline strongly agree & 7 & 0 & 0 & 8 & 0 & 20 & 17 & \\
\hline $\begin{array}{l}\text { 36. increases the effort required to } \\
\text { monitor and control risk }\end{array}$ & Agg. & OrgD & OrgV & OrgM & OrgC & OrgS & OrgK & Comment \\
\hline strongly disagree & 7 & 0 & 0 & 8 & 0 & 20 & 17 & \multirow{5}{*}{$\begin{array}{l}\text { Responses are spread across the scales } \\
\text { in respect to the statement that the } \\
\text { capacity to store documents in the } \\
\text { OCT increases the effort required to } \\
\text { monitor and control risk. This } \\
\text { statement was worded to elicit a } \\
\text { negative response. }\end{array}$} \\
\hline disagree & 24 & 25 & 44 & 17 & 17 & 20 & 17 & \\
\hline neither & 36 & 25 & 33 & 42 & 50 & 20 & 33 & \\
\hline agree & 33 & 50 & 22 & 33 & 33 & 40 & 33 & \\
\hline strongly agree & $\mathbf{0}$ & 0 & 0 & 0 & 0 & 0 & 0 & \\
\hline $\begin{array}{l}\text { 37. reduces the need for } \\
\text { alliances/relationships across the } \\
\text { project environment }\end{array}$ & Agg. & OrgD & OrgV & OrgM & OrgC & OrgS & OrgK & Comment \\
\hline strongly disagree & 7 & 0 & 11 & 0 & 0 & 20 & 17 & \multirow{5}{*}{$\begin{array}{l}\text { More than half of the respondents } \\
(59 \%) \text { 'disagree' or 'strongly disagree' } \\
\text { that the capacity to store documents in } \\
\text { the OCT reduces the need for } \\
\text { relationships across the project } \\
\text { environment. This statement was } \\
\text { worded to elicit a negative response. }\end{array}$} \\
\hline disagree & 52 & 25 & 89 & 33 & 50 & 60 & 50 & \\
\hline neither & 26 & 50 & 0 & 42 & 33 & 0 & 33 & \\
\hline agree & 14 & 25 & 0 & 25 & 17 & 20 & 0 & \\
\hline strongly agree & $\mathbf{0}$ & 0 & 0 & 0 & 0 & 0 & 0 & \\
\hline $\begin{array}{l}\text { 38. increases difficulty in accessing } \\
\text { files remotely }\end{array}$ & Agg. & OrgD & OrgV & OrgM & OrgC & OrgS & OrgK & Comment \\
\hline strongly disagree & 7 & 0 & 0 & 8 & 0 & 20 & 17 & \multirow{5}{*}{$\begin{array}{l}\text { More than half of the respondents } \\
(57 \%) \text { 'disagree' or 'strongly disagree' } \\
\text { that the capacity to store documents in } \\
\text { the OCT increases difficulty in } \\
\text { accessing files remotely. This } \\
\text { statement was worded to elicit a } \\
\text { negative response. }\end{array}$} \\
\hline disagree & 48 & 50 & 56 & 50 & 67 & 20 & 33 & \\
\hline neither & 19 & 25 & 11 & 25 & 17 & 20 & 17 & \\
\hline agree & 21 & 25 & 33 & 8 & 0 & 40 & 33 & \\
\hline strongly agree & 5 & 0 & 0 & 8 & 17 & 0 & 0 & \\
\hline $\begin{array}{l}\text { 39. increases the time and effort } \\
\text { required to manage documents }\end{array}$ & Agg. & OrgD & OrgV & OrgM & OrgC & OrgS & OrgK & Comment \\
\hline strongly disagree & 5 & 0 & 0 & 0 & 0 & 20 & 17 & \multirow{5}{*}{$\begin{array}{l}\text { Responses are spread across the scales } \\
\text { in respect to the statement that the } \\
\text { capacity to store documents in the } \\
\text { OCT increase the time and effort } \\
\text { required to manage documents. } \\
\text { This statement was worded to elicit a } \\
\text { negative response. }\end{array}$} \\
\hline disagree & 40 & 50 & 78 & 33 & 33 & 20 & 17 & \\
\hline neither & 14 & 50 & 11 & 17 & 17 & 0 & 0 & \\
\hline agree & 33 & 0 & 11 & 33 & 33 & 60 & 67 & \\
\hline strongly agree & 7 & 0 & 0 & 17 & 17 & 0 & 0 & \\
\hline
\end{tabular}




\begin{tabular}{|c|c|c|c|c|c|c|c|c|}
\hline $\begin{array}{l}\text { 40. decreases the quality controls of } \\
\text { the document }\end{array}$ & Agg. & OrgD & OrgV & OrgM & OrgC & OrgS & OrgK & Comment \\
\hline strongly disagree & 5 & 0 & 0 & 0 & 0 & 20 & 17 & \multirow{5}{*}{$\begin{array}{l}\text { Approximately three quarters of } \\
\text { respondents (74\%) 'disagree' to } \\
\text { 'strongly disagree' that the capacity to } \\
\text { store documents in the OCT decreases } \\
\text { the quality controls of the document. } \\
\text { This statement was worded to elicit a } \\
\text { negative response. }\end{array}$} \\
\hline disagree & 69 & 50 & 67 & 83 & 83 & 40 & 67 & \\
\hline neither & 14 & 50 & 11 & 17 & 17 & 0 & 0 & \\
\hline agree & 12 & 0 & 22 & 0 & 0 & 40 & 17 & \\
\hline strongly agree & 0 & 0 & 0 & 0 & 0 & 0 & 0 & \\
\hline $\begin{array}{l}\text { 41. enhances contract management } \\
\text { processes }\end{array}$ & Agg. & OrgD & OrgV & OrgM & OrgC & OrgS & OrgK & Comment \\
\hline strongly disagree & $\mathbf{0}$ & 0 & 0 & 0 & 0 & 0 & 0 & \multirow{5}{*}{$\begin{array}{l}\text { Responses are spread between } \\
\text { 'neither' and 'agree' in respect to the } \\
\text { statement that the capacity to store } \\
\text { documents in the OCT enhances } \\
\text { contract management processes. }\end{array}$} \\
\hline disagree & $\mathbf{0}$ & 0 & 0 & 0 & 0 & 0 & 0 & \\
\hline neither & 45 & 100 & 44 & 33 & 33 & 60 & 33 & \\
\hline agree & 52 & 0 & 56 & 67 & 67 & 40 & 50 & \\
\hline strongly agree & 2 & 0 & 0 & 0 & 0 & 0 & 17 & \\
\hline $\begin{array}{l}\text { 42. assists with negotiations within } \\
\text { the project management environment }\end{array}$ & Agg. & OrgD & OrgV & OrgM & OrgC & OrgS & OrgK & Comment \\
\hline strongly disagree & $\mathbf{0}$ & 0 & 0 & 0 & 0 & 0 & 0 & \multirow{5}{*}{$\begin{array}{l}\text { Responses are spread across the scales } \\
\text { in respect to the statement that the } \\
\text { capacity to store documents in the } \\
\text { OCT assists with negotiations within } \\
\text { the project management environment. }\end{array}$} \\
\hline disagree & 17 & 0 & 11 & 25 & 17 & 20 & 17 & \\
\hline neither & 48 & 50 & 22 & 33 & 83 & 60 & 67 & \\
\hline agree & 33 & 50 & 56 & 42 & 0 & 20 & 17 & \\
\hline strongly agree & 2 & 0 & 11 & 0 & 0 & 0 & 0 & \\
\hline $\begin{array}{l}\text { 43. increases difficulty in managing } \\
\text { resources across the project }\end{array}$ & Agg. & OrgD & OrgV & OrgM & OrgC & OrgS & OrgK & Comment \\
\hline strongly disagree & 5 & 0 & 11 & 0 & 0 & 20 & 0 & \multirow{5}{*}{$\begin{array}{l}\text { Responses are spread across the scales } \\
\text { in respect to the statement that the } \\
\text { capacity to store documents in the } \\
\text { OCT increases difficulty in managing } \\
\text { resources across the project. This } \\
\text { statement was worded to elicit a } \\
\text { negative response. }\end{array}$} \\
\hline disagree & 48 & 50 & 78 & 33 & 33 & 40 & 50 & \\
\hline neither & 36 & 50 & 0 & 33 & 67 & 40 & 50 & \\
\hline agree & 12 & 0 & 11 & 33 & 0 & 0 & 0 & \\
\hline strongly agree & $\mathbf{0}$ & 0 & 0 & 0 & 0 & 0 & 0 & \\
\hline
\end{tabular}

\section{Summary}

Respondents show strong support for the capacity of the OCT to store and enable easy access to all documents within the central repository (Qu.30), and with accessing files and documents remotely $(\mathrm{Qu} .33,38)$. This indicates strong support for a main function of the OCT - its ability to provide (asynchronous) access to material from a central location regardless of the physical location of the team member.

For Organisation M (Government Construction Project), the OCT is effective at handling documentation and communication (Qu.30, 33, 40 Figure 7-11). 


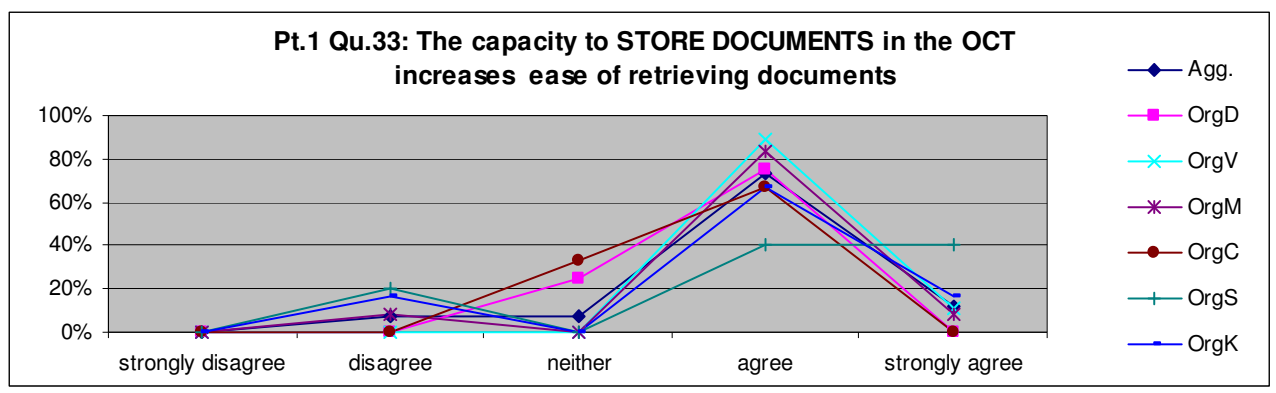

Figure 7-11: Pt1. Qu.33: The capacity to Store Documents in the OCT increases ease of retrieving documents

The system operates as an electronic version of a hardcopy document workflow. User 1 has a document, and will upload it to ACONEX in order to share it with User 2. If User 3 is not sent the document, they will not be able to see it. No information is ever deleted from the network, and strong archiving and version control is in place to ensure that users are aware which version of a document is being reviewed (OrgM PM1). The document register function of the ACONEX is shown in Figure 7-12.

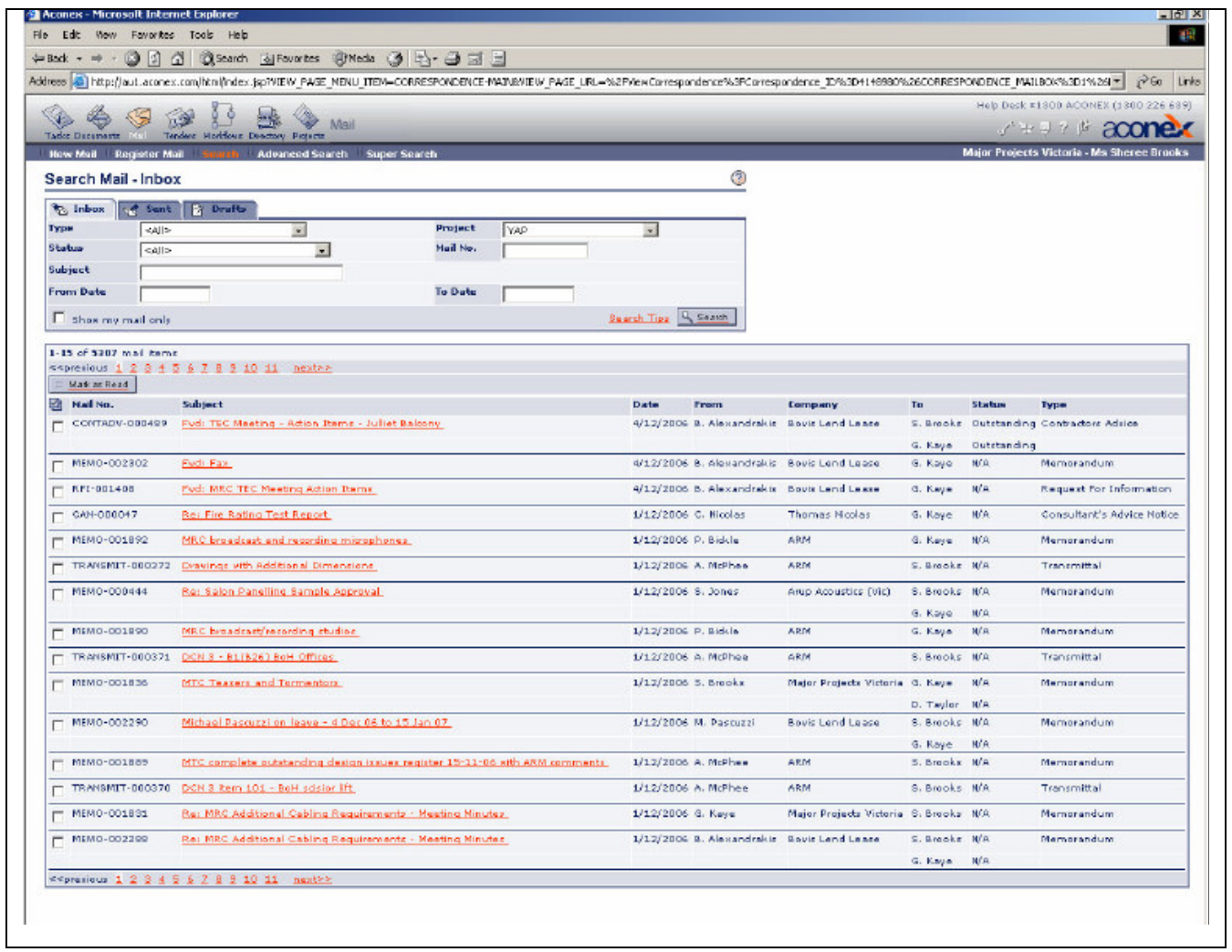

Figure 7-12: ACONEX Document Register function

In the case of Organisation D (State Government Org), the Project Manager's lack of awareness and subsequent use of the OCT was reduced to document management and the delivery of some processes. Of note in this case, is that this use can be viewed in stark contrast with the guidelines 
developed by the Department when deciding on the availability of this tool. These guidelines note, among other items, that:

"QuickPlaces are to be used as a collaborative tool. Their primary purpose is not as document repositories - QuickPlace users will still need to adhere to normal document storage practices utilising network drives to ensure documents can be accessed after a QuickPlace has been archived."

The use of the OCT by Organisation D, and reinforced by OrgD PM1, highlights how the functionality of the tool can be all but ignored through the intuitive use of the tool - which in this case was less than the tool's functionality. The project manager's preference was for a webstyle notice board where he could place all information for the project team to see, including major plans and other important files (OrgD PM1). In this sense, the welcome screen (quasi dashboard) of the OCT was not suitable for the Project Manager's use.

With the exception of Organisation K (Alliance Project), all cases support the statement that the OCT encourages communication across the project team (Qu.34). Organisation $\mathrm{K}$ does not use the OCT for communication due to the OCT's poor link with email, opting instead to use it as a receptacle for governance material (OrgK PM1).

More than half of the respondents (57\%) are neutral regarding the statement that the capacity to store documents in the OCT develops trust between team members (Qu.32). This is of interest given responses to previous questions which indicated shared documents require a level of trust between members (Qu.22), but do not necessarily develop an equality between team members (Qu.26).

The capacity to store documents in the OCT doesn't contribute or lessen the effort required to control risk (Qu.36), nor does it reduce the need for strategic relationships across the PME (Qu.37). The feature supports quality controls (Qu.40), but doesn't necessarily help with negotiations (Qu.42) or managing resources across the PME (Qu.43).

All members within the team of Organisation S (Government Authority) are provided with access rights to upload any material, but in practice, this task is normally left to the project manager and contractors (OrgS PM1). In this sense, the OCT is used as a receptacle for the reference group to access material if and when it required a piece of project related information, rather than as a 
means of communication (OrgS PM1). The project reference group requests that the flow of information be controlled and managed by the project manager. Among other duties, the project manager's role is to:

- ensure all paperwork is completed to quality levels;

- ensure all appropriate documentation is placed in the QuickPlace; and that

- appropriate people are informed of its presence (OrgS PM1).

In the instance of Organisation K (Alliance Project), document control plays an important part in the use and approach of the tool (Qu.40). Files placed into INCITE is similar to files being placed onto a records management system, in that once received by the OCT, they cannot be deleted or removed. This assists with project archiving functions as well as facilitating future retrieval if required. All records become permanent records. The tool is used to keep correspondence as well as project documentation (OrgK PM2, Figure 7-13). Of note also is that it is used as a form of control by OrgK PM 1,2.

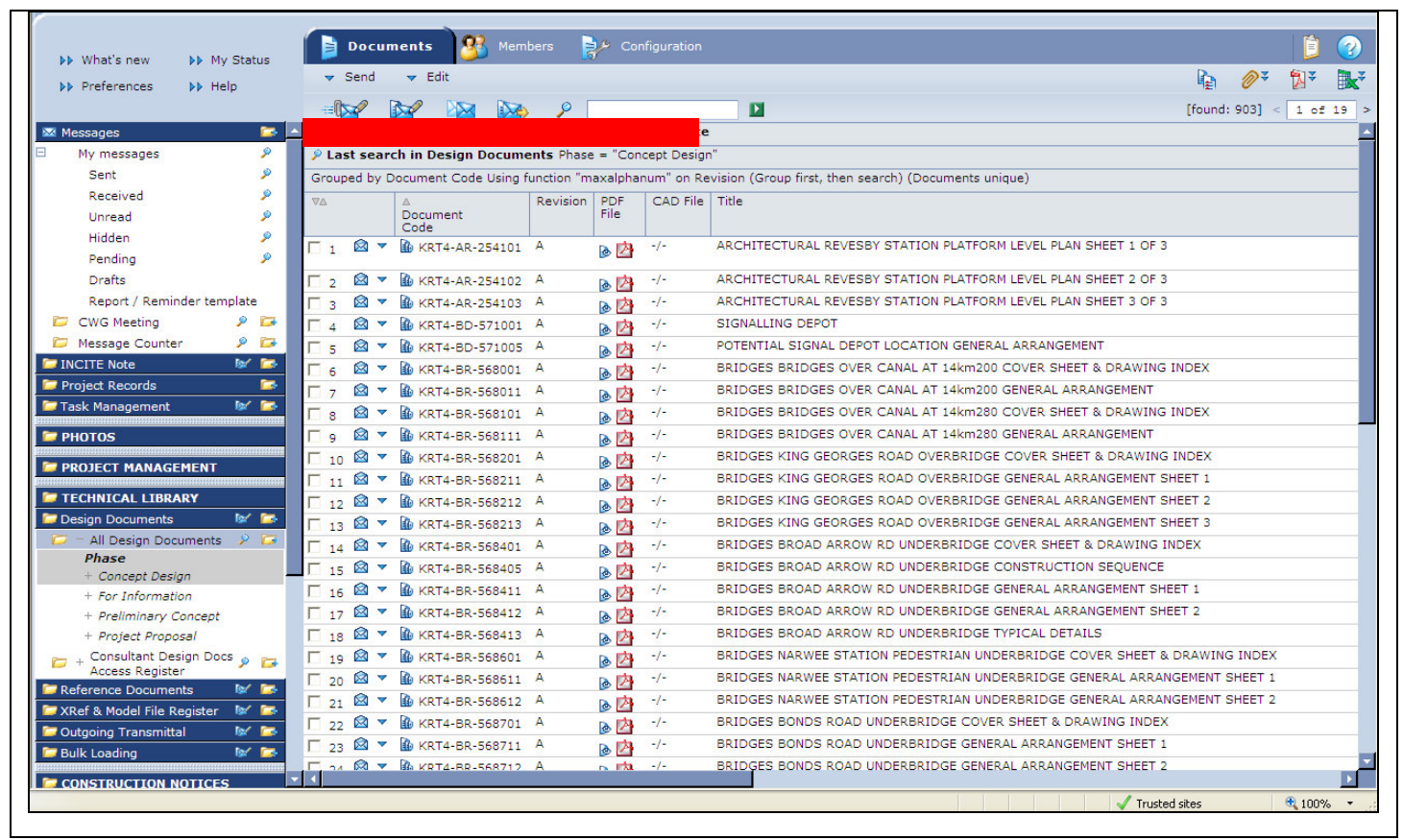

Figure 7-13: INCITE screen shot - technical records library 


\subsubsection{PART ONE, Section Five: Announcement Board}

The fifth section reviewed the use of the Announcement Board in the OCT. It posed questions regarding the role of this functionality and the flow on effects to the PME.

Table 7-6: The use of an ANNOUNCEMENT BOARD in the OCT

\begin{tabular}{|c|c|c|c|c|c|c|c|c|}
\hline \multirow[t]{2}{*}{$\begin{array}{l}\text { 44. manages the use of email } \\
\text { more efficiently }\end{array}$} & $\underset{n=42}{\text { Agg. }}$ & $\underset{n=4}{\operatorname{OrgD}}$ & $\underset{n=9}{\operatorname{OrgV}}$ & $\underset{n=12}{\operatorname{OrgM}}$ & $\underset{n=6}{\operatorname{OrgC}}$ & $\underset{n=5}{\operatorname{OrgS}}$ & $\underset{n=6}{\operatorname{OrgK}}$ & \multirow[t]{2}{*}{ Comment } \\
\hline & \multicolumn{7}{|c|}{ Case responses \% } & \\
\hline strongly disagree & 2 & 0 & 0 & 0 & 0 & 0 & 17 & \multirow{5}{*}{$\begin{array}{l}\text { Responses are spread across the scales } \\
\text { in respect to the statement that the use } \\
\text { of an Announcement Board in the OCT } \\
\text { manages the use of email more } \\
\text { efficiently. }\end{array}$} \\
\hline disagree & 17 & 25 & 0 & 17 & 33 & 20 & 17 & \\
\hline neither & 45 & 50 & 22 & 58 & 50 & 40 & 50 & \\
\hline agree & 31 & 25 & 67 & 25 & 17 & 20 & 17 & \\
\hline strongly agree & 5 & 0 & 11 & 0 & 0 & 20 & 0 & \\
\hline $\begin{array}{l}\text { 45. develops relationships with } \\
\text { team members }\end{array}$ & Agg. & OrgD & $\mathrm{OrgV}$ & OrgM & OrgC & OrgS & OrgK & Comment \\
\hline strongly disagree & $\mathbf{0}$ & 0 & 0 & 0 & 0 & 0 & 0 & \multirow{5}{*}{$\begin{array}{l}\text { Responses are spread across the scales } \\
\text { in respect to the statement that the use } \\
\text { of an Announcement Board in the OCT } \\
\text { develops relationships with team } \\
\text { members. }\end{array}$} \\
\hline disagree & 26 & 25 & 11 & 25 & 50 & 40 & 17 & \\
\hline neither & 45 & 25 & 44 & 75 & 50 & 0 & 33 & \\
\hline agree & 29 & 50 & 44 & 0 & 0 & 60 & 50 & \\
\hline strongly agree & $\mathbf{0}$ & 0 & 0 & 0 & 0 & 0 & 0 & \\
\hline $\begin{array}{l}\text { 46. requires team members to } \\
\text { trust each other }\end{array}$ & Agg. & OrgD & $\mathrm{OrgV}$ & OrgM & OrgC & OrgS & OrgK & Comment \\
\hline strongly disagree & 2 & 0 & 0 & 0 & 0 & 0 & 17 & \multirow{5}{*}{$\begin{array}{l}\text { The majority of respondents }(60 \%) \text { are } \\
\text { neutral in respect to the statement that } \\
\text { that the use of an Announcement } \\
\text { Board in the OCT requires team } \\
\text { members to trust each other. }\end{array}$} \\
\hline disagree & 17 & 0 & 44 & 17 & 0 & 0 & 17 & \\
\hline neither & 60 & 50 & 22 & 67 & 83 & 100 & 50 & \\
\hline agree & 19 & 50 & 33 & 17 & 17 & 0 & 0 & \\
\hline strongly agree & 2 & 0 & 0 & 0 & 0 & 0 & 17 & \\
\hline $\begin{array}{l}\text { 47. is ineffective when } \\
\text { communicating to the project } \\
\text { team }\end{array}$ & Agg. & OrgD & $\mathrm{OrgV}$ & OrgM & OrgC & OrgS & OrgK & Comment \\
\hline strongly disagree & $\mathbf{0}$ & 0 & 0 & 0 & 0 & 0 & 0 & \multirow{5}{*}{$\begin{array}{l}\text { Responses are spread across the scales } \\
\text { in respect to the statement that the use } \\
\text { of an Announcement Board in the OCT } \\
\text { is ineffective when communicating to } \\
\text { the project team. This statement was } \\
\text { worded to elicit a negative response. }\end{array}$} \\
\hline disagree & 40 & 25 & 56 & 17 & 33 & 60 & 67 & \\
\hline neither & 40 & 50 & 33 & 67 & 50 & 0 & 17 & \\
\hline agree & 19 & 25 & 11 & 17 & 17 & 40 & 17 & \\
\hline strongly agree & $\mathbf{0}$ & 0 & 0 & 0 & 0 & 0 & 0 & \\
\hline $\begin{array}{l}\text { 48. contributes to controlling the } \\
\text { project schedule }\end{array}$ & Agg. & OrgD & $\operatorname{OrgV}$ & OrgM & OrgC & OrgS & OrgK & Comment \\
\hline strongly disagree & 2 & 0 & 0 & 0 & 0 & 0 & 17 & \multirow{5}{*}{$\begin{array}{l}\text { Responses are spread across the scales } \\
\text { in respect to the statement that the use } \\
\text { of an Announcement Board in the OCT } \\
\text { contributes to controlling the project } \\
\text { schedule. }\end{array}$} \\
\hline disagree & 12 & 0 & 11 & 17 & 0 & 20 & 17 & \\
\hline neither & 43 & 75 & 11 & 50 & 67 & 40 & 17 & \\
\hline agree & 40 & 25 & 33 & 33 & 33 & 40 & 50 & \\
\hline strongly agree & 2 & 0 & 0 & 0 & 0 & 0 & 0 & \\
\hline $\begin{array}{l}\text { 49. assists with monitoring and } \\
\text { controlling risk in the project } \\
\text { environment }\end{array}$ & Agg. & OrgD & $\operatorname{OrgV}$ & OrgM & OrgC & OrgS & OrgK & Comment \\
\hline strongly disagree & 2 & 0 & 0 & 0 & 0 & 0 & 17 & \multirow{5}{*}{$\begin{array}{l}\text { Responses are spread across the scales } \\
\text { in respect to the statement that the use } \\
\text { of an Announcement Board in the OCT } \\
\text { assists with monitoring and controlling } \\
\text { risk in the project environment. }\end{array}$} \\
\hline disagree & 12 & 0 & 11 & 8 & 17 & 20 & 17 & \\
\hline neither & 50 & 75 & 44 & 58 & 83 & 20 & 17 & \\
\hline agree & 33 & 25 & 44 & 33 & 0 & 60 & 33 & \\
\hline strongly agree & 2 & 0 & 0 & 0 & 0 & 0 & 17 & \\
\hline
\end{tabular}




\begin{tabular}{|c|c|c|c|c|c|c|c|c|}
\hline $\begin{array}{l}\text { 50. provides greater control of } \\
\text { resources planning }\end{array}$ & Agg. & OrgD & $\operatorname{OrgV}$ & OrgM & OrgC & OrgS & OrgK & Comment \\
\hline strongly disagree & 2 & 0 & 0 & 0 & 0 & 0 & 17 & \multirow{5}{*}{$\begin{array}{l}\text { More than half of respondents }(55 \%) \\
\text { are neutral in respect to the statement } \\
\text { that the use of an Announcement } \\
\text { Board in the OCT provides greater } \\
\text { control of resource planning. }\end{array}$} \\
\hline disagree & 19 & 0 & 33 & 17 & 33 & 0 & 17 & \\
\hline neither & 55 & 75 & 22 & 75 & 67 & 60 & 33 & \\
\hline agree & 21 & 25 & 33 & 8 & 0 & 40 & 33 & \\
\hline strongly agree & 2 & 0 & 11 & 0 & 0 & 0 & 0 & \\
\hline $\begin{array}{l}\text { 51. creates difficulty in } \\
\text { distributing information across } \\
\text { the project }\end{array}$ & Agg. & OrgD & OrgV & OrgM & OrgC & OrgS & OrgK & Comment \\
\hline strongly disagree & 7 & 0 & 22 & 0 & 0 & 0 & 17 & \multirow{5}{*}{$\begin{array}{l}\text { More than half of the respondents } \\
(57 \%) \text { 'disagree' to 'strongly disagree' } \\
\text { that the use of an Announcement } \\
\text { Board in the OCT creates difficulty in } \\
\text { distributing information across the } \\
\text { project. This statement was worded to } \\
\text { elicit a negative response. }\end{array}$} \\
\hline disagree & 50 & 50 & 67 & 42 & 17 & 60 & 67 & \\
\hline neither & 33 & 50 & 11 & 42 & 67 & 20 & 17 & \\
\hline agree & 10 & 0 & 0 & 17 & 17 & 20 & 0 & \\
\hline strongly agree & $\mathbf{0}$ & 0 & 0 & 0 & 0 & 0 & 0 & \\
\hline $\begin{array}{l}\text { 52. increases the capacity to } \\
\text { manage risk }\end{array}$ & Agg. & OrgD & $\operatorname{OrgV}$ & OrgM & OrgC & OrgS & OrgK & Comment \\
\hline strongly disagree & 2 & 0 & 0 & 0 & 0 & 0 & 17 & \multirow{5}{*}{$\begin{array}{l}\text { More than half of the respondents } \\
(52 \%) \text { are neutral in respect to the } \\
\text { statement that the use of an } \\
\text { Announcement Board in the OCT } \\
\text { increases the capacity to manage risk. }\end{array}$} \\
\hline disagree & 14 & 0 & 22 & 25 & 0 & 0 & 17 & \\
\hline neither & 52 & 100 & 33 & 58 & 83 & 40 & 17 & \\
\hline agree & 29 & 0 & 33 & 17 & 17 & 60 & 50 & \\
\hline strongly agree & 2 & 0 & 11 & 0 & 0 & 0 & 0 & \\
\hline $\begin{array}{l}\text { 53. assists with the execution of } \\
\text { the project plan }\end{array}$ & Agg. & OrgD & $\operatorname{OrgV}$ & OrgM & OrgC & OrgS & OrgK & Comment \\
\hline strongly disagree & 2 & 0 & 11 & 0 & 0 & 0 & 0 & \multirow{5}{*}{$\begin{array}{l}\text { Respondents are split between 'neither } \\
\text { and 'agree' ( } 45 \% \text { \& } 48 \% \text { respectively) } \\
\text { that the use of an Announcement } \\
\text { Board in the OCT assists with the } \\
\text { execution of the project plan. }\end{array}$} \\
\hline disagree & 2 & 0 & 0 & 0 & 0 & 20 & 0 & \\
\hline neither & 45 & 50 & 11 & 58 & 67 & 20 & 67 & \\
\hline agree & 48 & 50 & 78 & 33 & 33 & 60 & 33 & \\
\hline strongly agree & 2 & 0 & 0 & 8 & 0 & 0 & 0 & \\
\hline
\end{tabular}

\section{Summary}

There is a general neutrality to the way respondents perceive the value and use of the

Announcement Board function. Respondents do not necessarily see the feature as relieving them of email overload (Qu.44, Figure 7-14); a finding supported in the interviews.

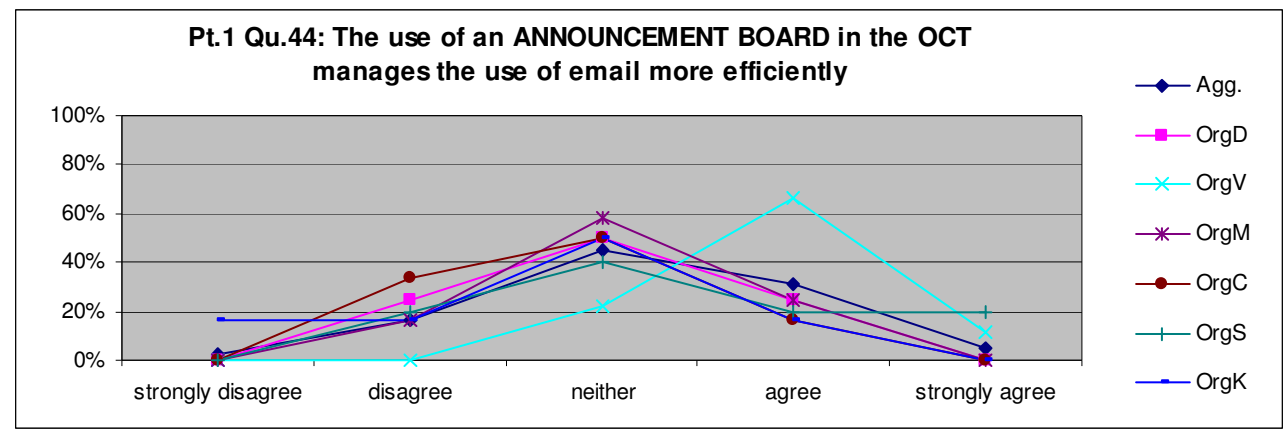

Figure 7-14: Pt.1 Qu.44: The use of an Announcement Board in the OCT manages the use of email more efficiently

The use of the Announcement Board feature in the OCT does not require team members to trust each other (Qu.46) or assist in developing and communicating to the team (Qu.45, Qu.47). 
Responses are spread across the scale in respect to the ability of the feature to contribute to controlling the project schedule (Qu.48), assist with monitoring and controlling risk in the project environment (Qu.49), or provide greater control of resource planning (Qu.50). Respondents were more supportive of the feature's ability to assist with the distribution of information across the PME (Qu.51). However this did not necessarily carry through to assisting to manage risk (Qu.52) or with the execution of the project plan (Qu.53).

The findings are interesting in that the primary function of the feature is to communicate and facilitate efficient dissemination of information across the PME, although the findings suggest that the Announcement Board feature is not considered effective for these functions.

The email notification feature of the OCT is an important feature across all OCTs, however many project managers expressed problems with its application within the PME. In the instance of the use of QuickPlace for Organisation D (State Government Organisation), an email notification functionality was included, however OrgD PM1 found that this simply added to the number of emails people would receive on a daily basis. In response to this, the project team instigated email-free days where staff were encouraged to reduce the number of emails distributed (OrgD PM1) and some staff started using an external Instant Messaging application in place of the email to communicate with one another. Of interest in this situation is that the QuickPlace product states that it can perform instant messaging if required, thus providing an example of where lack of training or awareness of the product has hampered its use and application within the PME.

The use of the OCT did not reduce the number of emails received, and often this specific feature of the tool failed to adequately interface with the in-house email client (OrgM SE1, OrgK PM1, PM2, OrgC PM1). For Organisation K (Alliance Project), the use of the INCITE product is hampered by the lack of an email notification functionality, resulting in an email being sent to the recipient's Outlook folder as an alert that a new item has been posted into the OCT (OrgK PM2).

In the case of Organisation $\mathrm{C}$ (Commercial Construction Project) the email functionality could be applied to individual files, resulting in an email notification, linked to the specific file, being sent to one or more team members. This process does not send the file, but rather provides an email link back to the OCT, thereby managing version control of files, and minimising traffic sent over the network (Figure 7-15). 
However the larger email function of the OCT is not used widely by the project team, as it is considered immature technology and slow to use (OrgC PM1, PM2). This issue is compounded further by the type of email system in use by Organisation $\mathrm{C}$, which is incompatible with the OCT and subsequently cannot be integrated into the workflow features. This is a comment that resonates across many of the organisations reviewed - that the I.T network, or email client is incompatible with the OCT, or that the OCT email functionality is not mandated by the PME. Organisation $\mathrm{C}$ also considers the tool lacking because it is not configured to allow for distributed email groups (OrgC PM1, PM2).

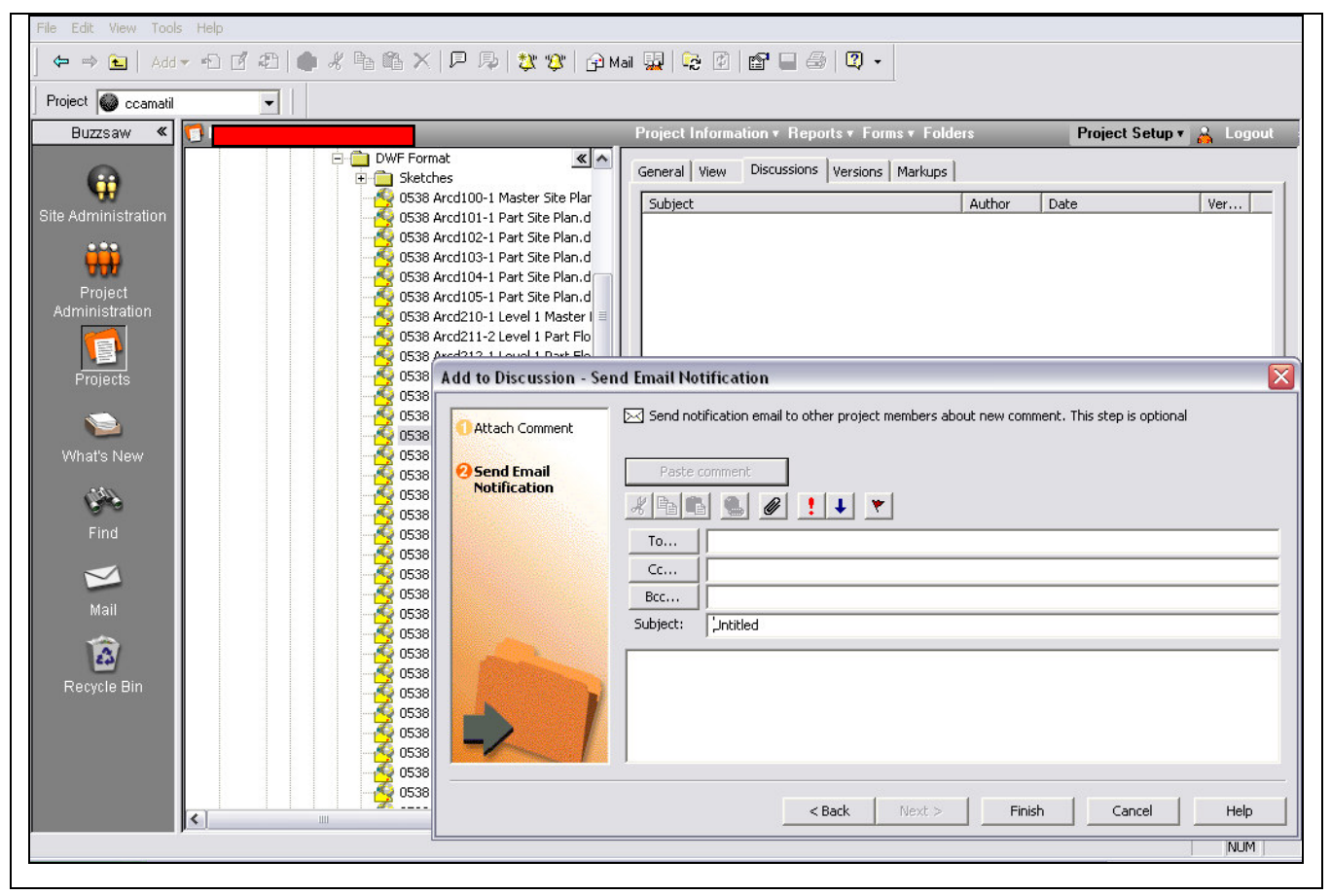

Figure 7-15: Display of email notification within AutoDesk Buzzsaw

Regardless, the use of the tool does not replace existing emails (Qu.44), with the exception of OrgV (the Continuous Improvement Org), which uses the OCT as the primary electronic communication medium (OrgV PM1). The use of the WordPress product was selected by Organisation $\mathrm{V}$ as a means to manage the membership of the CIN (OrgV PM). The primary goal is to provide timely and relevant information to the membership through an effective electronic information distribution mechanism. The blog allows the coordinator to engage in discussions and transmit information on a one-to-many basis, making the task of communication to more than 2000 people manageable. Where and when required, the coordinator will revert to sending an email, containing a link to the blog, to members. This mechanism is used to remind people of the blog and to manage the membership directly. However, this email is rarely more than once or twice per month (OrgV PM). 
In contrast, other organisations noted an increase in email traffic. This is the case in Organisation M (Government Construction project) where the downside of the ease with which to transmit messages and documentation has resulted in email overload, with OrgM SE1 noting that he has been the recipient of most emails through the system since it was introduced onsite. This is due to the practice of copying in (cc) others to emails. The result is that users can be in receipt of the majority of all emails/transmittals generated by ACONEX since the start of the project, which OrgM SE1 estimates to be around 45,000 email transmittals. This type of email overload causes pressures and frustration amongst team members, making it difficult to determine which emails are relevant and important, whilst causing information confusion as the context of the email may not be immediately apparent or known (OrgM SE1). Table 7-7 represents a summary of the email load for the OrgM Project Manager and Senior Engineer. Although the two summaries refer to different time periods, it is useful to see the statistics side by side. The Senior Engineer also notes that January, considered a quite time, would represent a reduced load in traffic and activity (OrgM SE1).

Table 7-7: Organisation M email load

\begin{tabular}{|c|c|c|}
\hline SUMMARY & $\begin{array}{r}\text { OrgM SE1 } \\
\text { Jan } 07\end{array}$ & $\begin{array}{r}\text { OrgM PM1 } \\
\text { April } 07\end{array}$ \\
\hline & Number & Number \\
\hline Total emails sent for the period & 1,388 & 193 \\
\hline total mail received for the period & 5,250 & 494 \\
\hline total drawings / controlled docs transmitted for the period & 1,818 & 83 \\
\hline total mail sent since start of project & 14,131 & 4,558 \\
\hline total mail received since start of project & 45,975 & 14,747 \\
\hline total drawings / controlled docs transmitted since start of project & 33,493 & 13,892 \\
\hline total archive storage & $22 \mathrm{mb}$ & $9.78 \mathrm{mb}$ \\
\hline
\end{tabular}

Source OrgM SE1, OrgM PM1.

The issues this causes for the use of the OCT by the project team seem obvious. If a member of a team is frustrated by the number of emails being received, this could cause them to change their approach to their desktop computer, or impact on the way they communicate to other team members. OrgM SE1 noted that it was difficult to determine which emails were important to his task, and which were 'for information only', relegating that particular feature of the OCT to more of an annoyance, than a project tool. Regardless, the prospect of receiving upwards of 1000 emails per month risks confidence in the system and therefore possibly full use of its capabilities and features, not only by a single team member, but by many. 


\subsubsection{PART ONE, Section Six: Virtual Conferencing}

The sixth section addressed the use of virtual conferencing in the PME in a bid to review an alternate communication mechanism of the OCT.

Table 7-8: The use of VIRTUAL CONFERENCING in the OCT

\begin{tabular}{|c|c|c|c|c|c|c|c|c|}
\hline \multirow[t]{2}{*}{$\begin{array}{l}\text { 54. manages time more } \\
\text { effectively }\end{array}$} & $\underset{n=42}{\text { Agg. }}$ & $\underset{n=4}{\operatorname{OrgD}}$ & $\underset{n=9}{\operatorname{OrgV}}$ & $\underset{n=12}{\operatorname{OrgM}}$ & $\underset{n=6}{\operatorname{OrgC}}$ & $\underset{n=5}{\operatorname{OrgS}}$ & $\underset{n=6}{\operatorname{OrgKK}}$ & \multirow[t]{2}{*}{ Comment } \\
\hline & \multicolumn{7}{|c|}{ Case responses \% } & \\
\hline strongly disagree & $\mathbf{0}$ & 0 & 0 & 0 & 0 & 0 & 0 & \multirow{5}{*}{$\begin{array}{l}\text { Responses are spread across the scales } \\
\text { in respect to the statement that the use of } \\
\text { Virtual Conferencing in the OCT } \\
\text { manages time more effectively. }\end{array}$} \\
\hline disagree & 10 & 25 & 0 & 8 & 17 & 20 & 0 & \\
\hline neither & 49 & 50 & 11 & 75 & 83 & 20 & 50 & \\
\hline agree & 37 & 25 & 78 & 17 & 0 & 60 & 33 & \\
\hline strongly agree & 5 & 0 & 11 & 0 & 0 & 0 & 17 & \\
\hline $\begin{array}{l}\text { 55. does not replace the number } \\
\text { of meetings required }\end{array}$ & Agg. & OrgD & OrgV & OrgM & OrgC & OrgS & OrgK & Comment \\
\hline strongly disagree & 2 & 0 & 11 & 0 & 0 & 0 & 0 & \multirow{5}{*}{$\begin{array}{l}\text { Responses are spread across the scales } \\
\text { in respect to the statement that the use of } \\
\text { Virtual Conferencing in the OCT does } \\
\text { not replace the number of meetings } \\
\text { required. This statement was worded to } \\
\text { elicit a negative response. }\end{array}$} \\
\hline disagree & 17 & 25 & 44 & 0 & 0 & 20 & 17 & \\
\hline neither & 41 & 50 & 0 & 50 & 100 & 20 & 50 & \\
\hline agree & 37 & 25 & 44 & 42 & 0 & 60 & 33 & \\
\hline strongly agree & 2 & 0 & 0 & 8 & 0 & 0 & 0 & \\
\hline $\begin{array}{l}\text { 56. makes it hard to establish } \\
\text { trust between team members }\end{array}$ & Agg. & OrgD & OrgV & OrgM & OrgC & OrgS & OrgK & Comment \\
\hline strongly disagree & 2 & 0 & 0 & 0 & 0 & 20 & 0 & \multirow{5}{*}{$\begin{array}{l}\text { Approximately two thirds of } \\
\text { respondents }(63 \%) \text { are neutral in respect } \\
\text { to the statement that the use of Virtual } \\
\text { Conferencing in the OCT makes it hard } \\
\text { to establish trust between team } \\
\text { members. This statement was worded to } \\
\text { elicit a negative response. }\end{array}$} \\
\hline disagree & 20 & 0 & 56 & 8 & 17 & 20 & 0 & \\
\hline neither & 63 & 50 & 11 & 83 & 83 & 60 & 100 & \\
\hline agree & 12 & 50 & 33 & 0 & 0 & 0 & 0 & \\
\hline strongly agree & 2 & 0 & 0 & 8 & 0 & 0 & 0 & \\
\hline $\begin{array}{l}\text { 57. enables more effective } \\
\text { control over schedule and } \\
\text { project issues }\end{array}$ & Agg. & OrgD & OrgV & OrgM & OrgC & OrgS & OrgK & Comment \\
\hline strongly disagree & $\mathbf{0}$ & 0 & 0 & 0 & 0 & 0 & 0 & \multirow{5}{*}{$\begin{array}{l}\text { Responses are spread across the scales } \\
\text { in respect to the statement that the use of } \\
\text { Virtual Conferencing in the OCT } \\
\text { enables more effective control over } \\
\text { schedule and project issues. }\end{array}$} \\
\hline disagree & 15 & 25 & 22 & 8 & 0 & 20 & 17 & \\
\hline neither & 66 & 50 & 44 & 83 & 83 & 40 & 83 & \\
\hline agree & 20 & 25 & 33 & 8 & 17 & 40 & 0 & \\
\hline strongly agree & 0 & 0 & 0 & 0 & 0 & 0 & 0 & \\
\hline $\begin{array}{l}\text { 58. enhances communication } \\
\text { across the project team }\end{array}$ & Agg. & OrgD & OrgV & OrgM & OrgC & OrgS & OrgK & Comment \\
\hline strongly disagree & 2 & 0 & 0 & 0 & 0 & 0 & 17 & \multirow{5}{*}{$\begin{array}{l}\text { Approximately half of the respondents } \\
(54 \%) \text { are neutral in respect to the } \\
\text { statement that the use of Virtual } \\
\text { Conferencing in the OCT enhances } \\
\text { communication across the project team. }\end{array}$} \\
\hline disagree & 5 & 25 & 0 & 8 & 0 & 0 & 0 & \\
\hline neither & 54 & 25 & 11 & 83 & 100 & 20 & 67 & \\
\hline agree & 37 & 50 & 89 & 8 & 0 & 60 & 17 & \\
\hline strongly agree & 2 & 0 & 0 & 0 & 0 & 20 & 0 & \\
\hline
\end{tabular}




\begin{tabular}{|c|c|c|c|c|c|c|c|c|}
\hline $\begin{array}{l}\text { 59. discourages innovation and } \\
\text { learning across the team }\end{array}$ & Agg. & OrgD & OrgV & OrgM & OrgC & OrgS & OrgK & Comment \\
\hline strongly disagree & 5 & 0 & 0 & 0 & 0 & 20 & 17 & \multirow{4}{*}{$\begin{array}{l}\text { Responses are spread across the scales } \\
\text { in respect to the statement that the use of } \\
\text { Virtual Conferencing in the OCT } \\
\text { discourages innovation and learning } \\
\text { across the team. This statement was } \\
\text { worded to elicit a negative response. }\end{array}$} \\
\hline disagree & 39 & 25 & 89 & 17 & 17 & 60 & 17 & \\
\hline neither & 46 & 50 & 11 & 67 & 83 & 0 & 67 & \\
\hline agree & 10 & 25 & 0 & 17 & 0 & 20 & 0 & \\
\hline strongly agree & 0 & 0 & 0 & 0 & 0 & 0 & 0 & \\
\hline $\begin{array}{l}\text { 60. decreases the ability to } \\
\text { manage and control risk }\end{array}$ & Agg. & OrgD & OrgV & OrgM & OrgC & OrgS & OrgK & Comment \\
\hline strongly disagree & $\mathbf{0}$ & 0 & 0 & 0 & 0 & 0 & 0 & \multirow{5}{*}{$\begin{array}{l}\text { More than half of the respondents }(56 \%) \\
\text { are neutral in respect to the statement } \\
\text { that the use of Virtual Conferencing in } \\
\text { the OCT decreases the ability to manage } \\
\text { and control risk. This statement was } \\
\text { worded to elicit a negative response. }\end{array}$} \\
\hline disagree & 41 & 25 & 89 & 17 & 17 & 60 & 33 & \\
\hline neither & 56 & 75 & 11 & 75 & 83 & 40 & 67 & \\
\hline agree & 2 & 0 & 0 & 8 & 0 & 0 & 0 & \\
\hline strongly agree & $\mathbf{0}$ & 0 & 0 & 0 & 0 & 0 & 0 & \\
\hline $\begin{array}{l}\text { 61. replaces the need to meet } \\
\text { physically }\end{array}$ & Agg. & OrgD & OrgV & OrgM & OrgC & OrgS & OrgK & Comment \\
\hline strongly disagree & 17 & 0 & 56 & 8 & 0 & 0 & 17 & \multirow{5}{*}{$\begin{array}{l}\text { Responses are spread across the scales } \\
\text { in respect to the statement that the use of } \\
\text { Virtual Conferencing in the OCT } \\
\text { replaces the need to meet physically. }\end{array}$} \\
\hline disagree & 32 & 50 & 33 & 8 & 17 & 100 & 17 & \\
\hline neither & 39 & 50 & 0 & 58 & 83 & 0 & 50 & \\
\hline agree & 10 & 0 & 11 & 17 & 0 & 0 & 17 & \\
\hline strongly agree & 2 & 0 & 0 & 8 & 0 & 0 & 0 & \\
\hline $\begin{array}{l}\text { 62. develops relationships with } \\
\text { team members }\end{array}$ & Agg. & OrgD & OrgV & OrgM & OrgC & OrgS & OrgK & Comment \\
\hline strongly disagree & 2 & 0 & 0 & 8 & 0 & 0 & 0 & \multirow{5}{*}{$\begin{array}{l}\text { Approximately two thirds of responses } \\
(68 \%) \text { are neutral in respect to the } \\
\text { statement that the use of Virtual } \\
\text { Conferencing in the OCT develops } \\
\text { relationships with team members. }\end{array}$} \\
\hline disagree & 7 & 25 & 0 & 0 & 0 & 0 & 33 & \\
\hline neither & 68 & 75 & 44 & 92 & 100 & 40 & 50 & \\
\hline agree & 20 & 0 & 56 & 0 & 0 & 40 & 17 & \\
\hline strongly agree & 2 & 0 & 0 & 0 & 0 & 20 & 0 & \\
\hline
\end{tabular}

\section{Summary}

This section has a relative over proportion of neutral responses, suggesting the feature was not well documented or exploited within the PME. The use of a Virtual Conferencing feature within the OCT does not generally contribute to managing time more effectively (Qu.54), or replace the number of meetings required (Qu.55); a significant finding considering this is a primary purpose of the feature. However this finding should also been seen in light that most of the users do not use virtual conferencing functionality within their own PME.

The majority of respondents are neutral on the use of the feature to assist with the development of trust (Qu.56), and on whether it provides more effective control over schedule and project issues (Qu.57, Figure 7-16). 


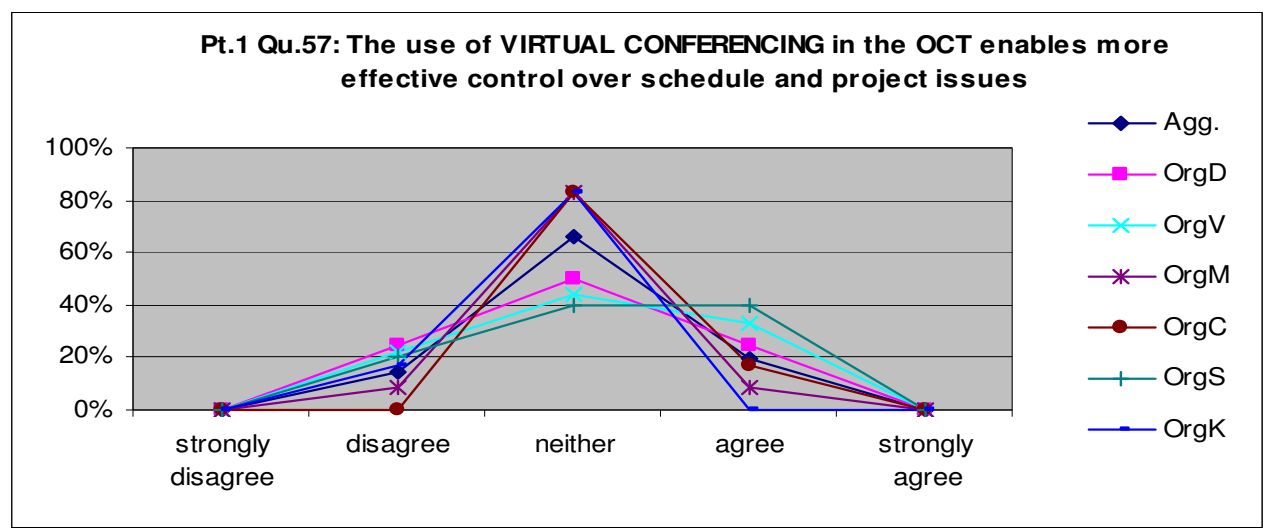

Figure 7-16: Pt1. Qu.57: The use of VIRTUAL CONFERENCING in the OCT enables more effective control over schedule and project issues

The availability of virtual conferencing does not enhance communication (Qu.58), manage team relationships (Qu.62) or necessarily encourage innovation and learning across the team (Qu.59). Virtual conferencing does not assist to manage and control risk (Qu.60), or replace the need to meet physically (Qu.61), although Organisation V (Continuous Improvement Org) strongly disagreed with this statement (Figure 7-17). This finding is consistent with the charter of Organisation V as it is using the OCT as the primary medium to coordinate people across the membership (OrgV PM1), rather than using it as a primary communication medium to manage the membership.

Interaction by the membership with the material contained on Organisation V's blog has also continued to rise during the weekend (OrgV PM), reinforcing the requirement to have the material available outside the government internet environment as well as ensuring the material is available at times other than standard working hours. This provides a set of interesting issues for the coordinator, as he notes the material presented over the blog, and in context of the CIN, is being consumed at times other than traditional working hours, and may provide opportunities in the future (OrgV PM1). However this has not given rise for the Virtual Conferencing feature, and supports the notion that the OCT is primarily being used within an asynchronous fashion, and not requiring same-time interaction. This is also convenient for Organisation V, as the virtual conferencing feature is not included in the Wordpress configuration for Organisation V. This finding can also be understood from the perspective of Organisation S (Government Authority), where it views the adoption of the OCT as playing an integral role in its governance processes (OrgS PM1), rather than in its capacity to communicate virtually to its members. 
The finding that the Virtual Conferencing feature is not widely used across the cases indicates that it is not a feature suited to the project management function of the PME, but may be better suited to other more communication focussed activities, such as presentations or meetings where team members cannot be co-located easily. However, even in those organisations that had significantly distributed teams, for example Organisation M \& K (Government Construction project, and Alliance construction project), this feature although available, was not reported as being used. Both organisations were also neutral in their responses to the statements that the use of the Virtual Conferencing tool in the OCT enhances communication across the project team (Qu. 58) or replaces the need to meet physically (Qu. 61), a finding that was also unanimously rejected by Organisation S (Figure 7-17). From these findings, it would seem that the allure of online visual communication across an I.T. network is not significantly high enough to be incorporated into project management methodologies, even where project teams can be in different countries.

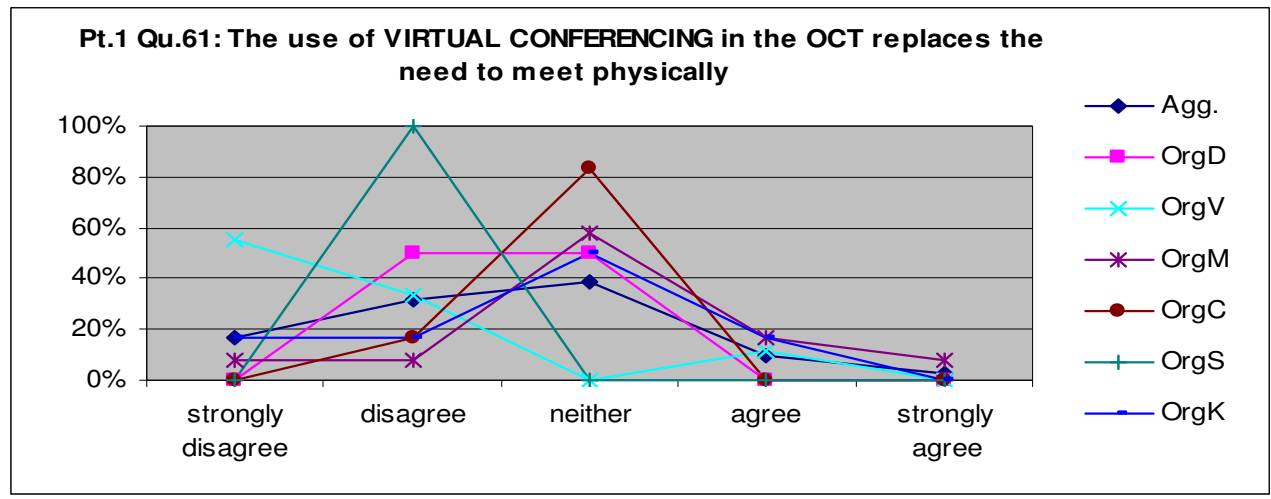

Figure 7-17: Pt1. Qu.61: The use of VIRTUAL CONFERENCING in the OCT replaces the need to meet physically 


\subsubsection{PART ONE, Section Seven: The OCT in General}

The seventh and final section of Part One posed general questions about the use of OCTs, in order to collect other relevant applications of the product that did not necessarily fit within the previous categorisations. This final subsection also sought to pose previously asked questions in an alternate fashion to check for consistency in responses.

Table 7-9: The use of OCTs in general

\begin{tabular}{|c|c|c|c|c|c|c|c|c|}
\hline \multirow{2}{*}{$\begin{array}{l}\text { 63. is the most effective tool for } \\
\text { distributing information to the } \\
\text { project team }\end{array}$} & $\underset{n=42}{\text { Agg. }}$ & $\underset{n=4}{\operatorname{OrgD}}$ & $\underset{n=9}{\operatorname{OrgV}}$ & $\underset{n=12}{\operatorname{OrgM}}$ & $\underset{n=6}{\operatorname{OrgC}}$ & $\underset{n=5}{\operatorname{OrgS}}$ & $\underset{n=6}{\operatorname{OrgK}}$ & \multirow[t]{2}{*}{ Comment } \\
\hline & \multicolumn{7}{|c|}{ Case responses \% } & \\
\hline strongly disagree & 0 & 0 & 0 & 0 & 0 & 0 & 0 & \multirow{5}{*}{$\begin{array}{l}\text { Approximately two thirds of } \\
\text { respondents }(67 \%) \text { 'agree' to } \\
\text { 'strongly agree' that the use of the } \\
\text { OCT in general is the most } \\
\text { effective tool for distributing } \\
\text { information to the project team. }\end{array}$} \\
\hline disagree & 12 & 25 & 22 & 0 & 0 & 20 & 17 & \\
\hline neither & 21 & 50 & 22 & 8 & 33 & 20 & 17 & \\
\hline agree & 57 & 25 & 56 & 75 & 67 & 40 & 50 & \\
\hline strongly agree & 10 & 0 & 0 & 17 & 0 & 20 & 17 & \\
\hline $\begin{array}{l}\text { 64. ensures all documents are } \\
\text { easily found }\end{array}$ & Agg. & OrgD & $\mathrm{OrgV}$ & OrgM & OrgC & OrgS & OrgK & Comment \\
\hline strongly disagree & $\mathbf{0}$ & 0 & 0 & 0 & 0 & 0 & 0 & \multirow{5}{*}{$\begin{array}{l}\text { More than three quarters of } \\
\text { respondents }(81 \%) \text { 'agree' or } \\
\text { 'strongly agree' that the use of the } \\
\text { OCT in general ensures all } \\
\text { documents are easily found. }\end{array}$} \\
\hline disagree & 7 & 25 & 22 & 0 & 0 & 0 & 0 & \\
\hline neither & 12 & 0 & 22 & 25 & 0 & 0 & 0 & \\
\hline agree & 67 & 75 & 56 & 58 & 83 & 60 & 83 & \\
\hline strongly agree & 14 & 0 & 0 & 17 & 17 & 40 & 17 & \\
\hline $\begin{array}{l}\text { 65. increases the amount of } \\
\text { administration for the project }\end{array}$ & Agg. & OrgD & OrgV & OrgM & OrgC & OrgS & OrgK & Comment \\
\hline strongly disagree & 2 & 0 & 11 & 0 & 0 & 0 & 0 & \multirow{5}{*}{$\begin{array}{l}\text { Responses are spread across the } \\
\text { scales in respect to the statement } \\
\text { that the use of the OCT in general } \\
\text { increases the amount of } \\
\text { administration for the project. Thi } \\
\text { statement was worded to elicit a } \\
\text { negative response. }\end{array}$} \\
\hline disagree & 31 & 0 & 56 & 33 & 33 & 20 & 17 & \\
\hline neither & 24 & 50 & 11 & 25 & 33 & 40 & 0 & \\
\hline agree & 29 & 50 & 11 & 8 & 17 & 40 & 83 & \\
\hline strongly agree & 14 & 0 & 11 & 33 & 17 & 0 & 0 & \\
\hline $\begin{array}{l}\text { 66. ensures all project related } \\
\text { information is kept up to date and } \\
\text { in one place }\end{array}$ & Agg. & OrgD & $\mathrm{OrgV}$ & OrgM & OrgC & OrgS & OrgK & Comment \\
\hline strongly disagree & 0 & 0 & 0 & 0 & 0 & 0 & 0 & \multirow{5}{*}{$\begin{array}{l}\text { More than three quarters of } \\
\text { respondents ( } 79 \%) \text { 'agree' or } \\
\text { 'strongly agree' that the use of the } \\
\text { OCT in general ensures all project } \\
\text { related information is kept up to } \\
\text { date and in one place. }\end{array}$} \\
\hline disagree & 14 & 25 & 22 & 0 & 33 & 20 & 0 & \\
\hline neither & 7 & 0 & 22 & 0 & 0 & 0 & 17 & \\
\hline agree & 62 & 75 & 56 & 75 & 50 & 40 & 67 & \\
\hline strongly agree & 17 & 0 & 0 & 25 & 17 & 40 & 17 & \\
\hline $\begin{array}{l}\text { 67. streamlines communication to } \\
\text { the project teams }\end{array}$ & Agg. & OrgD & OrgV & OrgM & OrgC & OrgS & OrgK & Comment \\
\hline strongly disagree & $\mathbf{0}$ & 0 & 0 & 0 & 0 & 0 & 0 & \multirow{5}{*}{$\begin{array}{l}\text { Approximately three quarters of } \\
\text { respondents ( } 74 \%) \text { 'agree' to } \\
\text { 'strongly agree' the use of the OCT } \\
\text { in general streamlines } \\
\text { communication to the project team. }\end{array}$} \\
\hline disagree & 10 & 25 & 0 & 17 & 0 & 20 & 0 & \\
\hline neither & 17 & 0 & 22 & 0 & 17 & 20 & 50 & \\
\hline agree & 64 & 75 & 78 & 67 & 83 & 40 & 33 & \\
\hline strongly agree & 10 & 0 & 0 & 17 & 0 & 20 & 17 & \\
\hline
\end{tabular}




\begin{tabular}{|c|c|c|c|c|c|c|c|c|}
\hline $\begin{array}{l}\text { 68. increases the amount of } \\
\text { paperwork in managing projects }\end{array}$ & Agg. & OrgD & OrgV & OrgM & OrgC & OrgS & OrgK & Comment \\
\hline strongly disagree & 10 & 0 & 11 & 0 & 17 & 20 & 17 & \multirow{5}{*}{$\begin{array}{l}\text { Responses are spread across the } \\
\text { scales in respect to the statement } \\
\text { that the use of the OCT in general } \\
\text { increases the amount of paperwork } \\
\text { in managing projects. This } \\
\text { statement was worded to elicit a } \\
\text { negative response. }\end{array}$} \\
\hline disagree & 40 & 0 & 56 & 50 & 50 & 20 & 33 & \\
\hline neither & 26 & 75 & 11 & 8 & 33 & 40 & 33 & \\
\hline agree & 19 & 25 & 22 & 25 & 0 & 20 & 17 & \\
\hline strongly agree & 5 & 0 & 0 & 17 & 0 & 0 & 0 & \\
\hline $\begin{array}{l}\text { 69. creates an online space which } \\
\text { the team uses as a project meeting } \\
\text { space }\end{array}$ & Agg. & OrgD & OrgV & OrgM & OrgC & OrgS & OrgK & Comment \\
\hline strongly disagree & 2 & 0 & 0 & 0 & 0 & 20 & 0 & \multirow{5}{*}{$\begin{array}{l}\text { Responses are spread across the } \\
\text { scales in respect to the statement } \\
\text { that the use of the OCT in general } \\
\text { creates an online space that the } \\
\text { team uses as a project meeting } \\
\text { space. }\end{array}$} \\
\hline disagree & 21 & 0 & 0 & 42 & 50 & 0 & 17 & \\
\hline neither & 33 & 75 & 33 & 25 & 33 & 0 & 50 & \\
\hline agree & 38 & 25 & 67 & 33 & 17 & 60 & 17 & \\
\hline strongly agree & 5 & 0 & 0 & 0 & 0 & 20 & 17 & \\
\hline $\begin{array}{l}\text { 70. increases the amount of time it } \\
\text { takes to do things }\end{array}$ & Agg. & OrgD & OrgV & OrgM & OrgC & OrgS & OrgK & Comment \\
\hline strongly disagree & 5 & 0 & 11 & 0 & 0 & 0 & 17 & \multirow{5}{*}{$\begin{array}{l}\text { More than half of the respondents } \\
(56 \%) \text { 'disagree' to 'strongly } \\
\text { disagree' that the use of the OCT in } \\
\text { general increases the amount of } \\
\text { time it takes to do things. This } \\
\text { statement was worded to elicit a } \\
\text { negative response. }\end{array}$} \\
\hline disagree & 51 & 25 & 89 & 42 & 33 & 40 & 50 & \\
\hline neither & 22 & 50 & 0 & 25 & 33 & 40 & 17 & \\
\hline agree & 17 & 25 & 0 & 17 & 33 & 20 & 17 & \\
\hline strongly agree & 5 & 0 & 0 & 17 & 0 & 0 & 0 & \\
\hline $\begin{array}{l}\text { 71. assists with managing scope } \\
\text { issues }\end{array}$ & Agg. & OrgD & OrgV & OrgM & OrgC & OrgS & OrgK & Comment \\
\hline strongly disagree & 2 & 0 & 0 & 0 & 0 & 0 & 17 & \multirow{5}{*}{$\begin{array}{l}\text { Responses are spread across the } \\
\text { scales in respect to the statement } \\
\text { that the use of the OCT in general } \\
\text { assists with managing scope issues. }\end{array}$} \\
\hline disagree & 12 & 0 & 0 & 17 & 17 & 40 & 0 & \\
\hline neither & 48 & 75 & 22 & 42 & 67 & 40 & 67 & \\
\hline agree & 36 & 25 & 67 & 42 & 17 & 20 & 17 & \\
\hline strongly agree & 2 & 0 & 11 & 0 & 0 & 0 & 0 & \\
\hline $\begin{array}{l}\text { 72. does not improve quality } \\
\text { control }\end{array}$ & Agg. & OrgD & OrgV & OrgM & OrgC & OrgS & OrgK & Comment \\
\hline strongly disagree & 5 & 0 & 0 & 8 & 0 & 0 & 17 & \multirow{5}{*}{$\begin{array}{l}\text { More than half of respondents } \\
(55 \%) \text { 'disagree' to 'strongly } \\
\text { disagree' that the use of the OCT in } \\
\text { general does not improve quality } \\
\text { control. This statement was worded } \\
\text { to elicit a negative response. }\end{array}$} \\
\hline disagree & 50 & 50 & 33 & 50 & 67 & 60 & 50 & \\
\hline neither & 31 & 25 & 56 & 25 & 33 & 0 & 33 & \\
\hline agree & 14 & 25 & 11 & 17 & 0 & 40 & 0 & \\
\hline strongly agree & $\mathbf{0}$ & 0 & 0 & 0 & 0 & 0 & 0 & \\
\hline $\begin{array}{l}\text { 73. complicates managing staff and } \\
\text { resources }\end{array}$ & Agg. & OrgD & OrgV & OrgM & OrgC & OrgS & OrgK & Comment \\
\hline strongly disagree & 5 & 0 & 0 & 0 & 0 & 20 & 17 & \multirow{5}{*}{$\begin{array}{l}\text { More than half of respondents } \\
(60 \%) \text { 'disagree' to 'strongly } \\
\text { disagree' that the use of the OCT in } \\
\text { general complicates managing staff } \\
\text { and resources. This statement was } \\
\text { worded to elicit a negative } \\
\text { response. }\end{array}$} \\
\hline disagree & 55 & 50 & 78 & 50 & 67 & 20 & 50 & \\
\hline neither & 26 & 25 & 22 & 33 & 33 & 20 & 17 & \\
\hline agree & 14 & 25 & 0 & 17 & 0 & 40 & 17 & \\
\hline strongly agree & $\mathbf{0}$ & 0 & 0 & 0 & 0 & 0 & 0 & \\
\hline
\end{tabular}

\section{Summary}

Respondents across the cases support the statement that the use of the OCT in general is the most effective tool for distributing information to the project team (Qu.63), ensuring that all documents are easily found (Qu.64, Figure 7-18), kept up-to-date and in one place (Qu.66), whilst streamlining communication to the project team (Qu.67). Respondents do not indicate strong support that the use of the OCT reduces administration for the project (Qu.65), creates an online 
meeting space (Qu.69) or assists with managing scope issues (Qu.71). In the instance of Organisation K, deployment issues with the INCITE system support, in association with the fact that the Alliance was in its infancy, contributed to a lower than anticipated use of the tools and subsequent sharing of information (OrgK PM1).

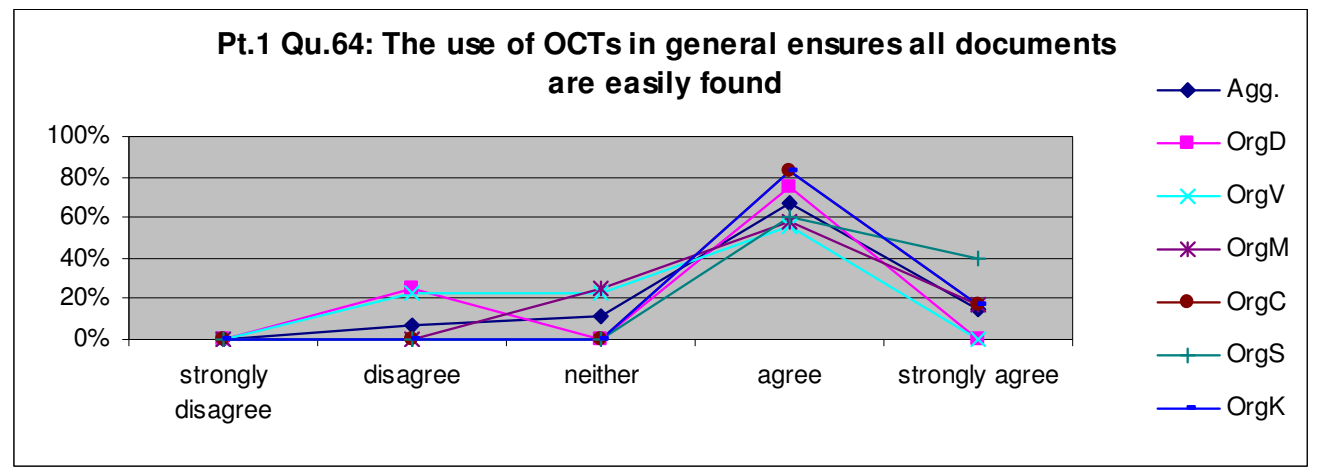

Figure 7-18: Pt.1 Qu.64: The use of OCTs in general ensures all documents are easily found

For Organisation S (State Authority), the additional features of the QuickPlace were not fully utilised within the operations of the project (OrgS PM1). Reasons given for this by the project manager were that 'people are settled in doing things their own way and don't always like to do something differently especially when it is a one-off action' (OrgSPM1), which projects often are. Another observation was that as team members were drawn from relatively senior levels of the organisation, they were disinclined to be strong users of new software, especially if induction or training was required (OrgS PM1). This resulted in an expectation that the project management unit of the Reference group be fully conversant in the OCT and for that role to apply the full capabilities of the tool if and when required (OrgS PM1), for example in the use of the Task feature.

In the Task feature of the QuickPlace OCT, key milestones and task durations were recorded into the OCT (Figure 7-19), however as a project schedule (in the form of a Gantt chart) was included in all briefings to the Executive team and reference group, its online functionality was not exploited (OrgSPM1). Furthermore not all team members had the MS Project software, as it was not part of the Organisation's Standard Operation Environment. This meant that Gantt charts had to be converted to PDF for wider distribution to the team for it to be viewed electronically (OrgS PM1). This is another example of the OCT creating more work for the PME, rather than streamlining its core activities. 


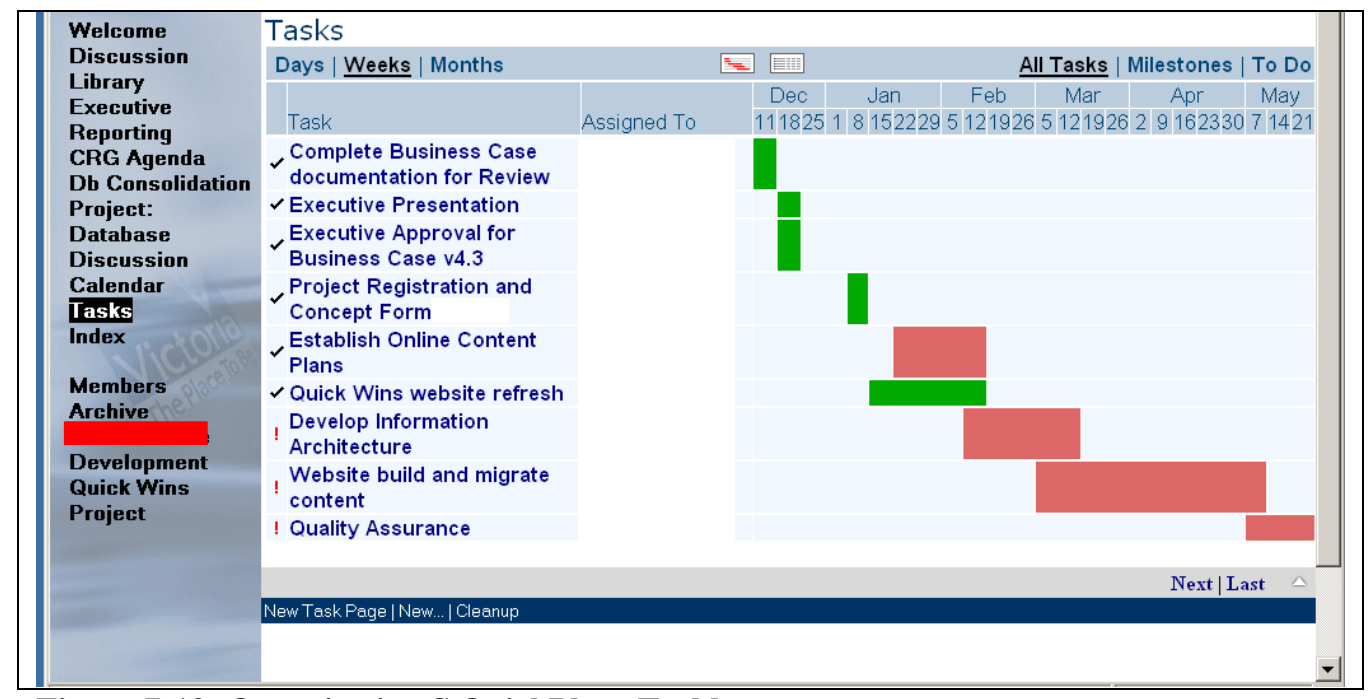

Figure 7-19: Organisation S QuickPlace Taskbar

There is general acceptance across the cases that the use of the OCT in general ensures all documents are easily found, and that project-related information is kept up-to-date and in one place (Qu.66, Figure 7-20). This indicates that the OCT is delivering on the expectation by organisations that the deployment of an OCT will assist the PME and team members with general document management mechanisms and processes.

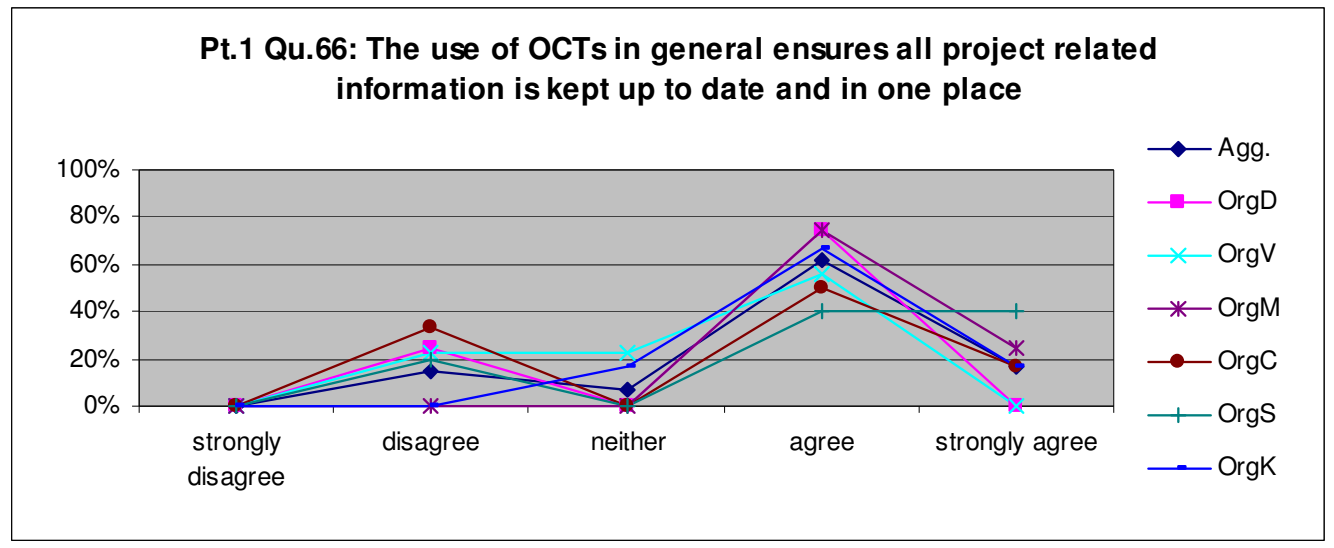

Figure 7-20: Pt.1 Qu.66: The use of OCTs in general ensures all project related information is kept up to date and in one place

Responses are spread across the scale in respect to whether the OCT increases the amount of paperwork in managing projects (Qu.68), whether the use of the OCT contributes to quality controls (Qu.72), and if its use complicates managing staff and resources (Qu.73). Of note is that OrgS PM1 identifies one of the core functions of the OCT as assisting with governance. The latter point is interesting in that five of the six cases show general agreement with this statement, suggesting that there is general support for the use of the OCT in this area. 


\subsubsection{PART ONE, Summary}

The previous seven subsections of Section 7.2 discussed the use of the OCT within the PME, drawing on both the findings from Part One of the Likert instrument, and from the interviews. The discussion was presented in a cross-case fashion, presenting all the findings together and providing commentary and analysis drawn from theses two sources where appropriate.

In reviewing the use of the OCTs through its core functional features, the research is able to summarise and contextualise how the OCTs are used within the PMEs of the case organisations, and to map these against the Collaboration scale. In doing, it addresses the second sub-research question and it associated proposition.

Research Question Two: $\quad H o w$ are Online Collaborative Toolsets used in the Project Management Environment?

Proposition 2: $\quad$ Online Collaborative Toolsets in the Project Management Environment are used for cooperation, and coordination, and to a lesser extent collaboration

The discussion noted that the use of the Shared Calendar feature of the OCT receives general support from across the six cases. The feature provides assistance with the planning and coordinating functions of the PME, and is well used to communicate the availability of team members across the PME. As such, the feature assists in the cooperative and coordinating functions of the cases. The Central Database feature also received general support from across the cases, and was seen to provide the PME with the tools and capabilities to manage and report on project data. By using a central online repository, rather than having multiple sources spread across the PME, cases are able to control data more effectively, with Organisation K (the Alliance project) noting that the OCT fulfilled the role of 'one large database for the project' (OrgK PM2). This feature was seen to assist with the cooperative and coordinating functions of the PME.

The Shared Documents feature is also generally supported across the cases. The capacity to share documents increases efficiencies in the distribution of documents and its associated communication functions, and contributes to compliance with procedural (OrgK PM1), legal 
(OrgC PM1) and governance material (OrgS PM1). The Store Documents feature receives stronger support and is very well regarded by the cases. This feature is hugely important in an online operation, in that it enables files to be uploaded/downloaded from literally any location in the world (with sufficient internet access), making available many different types of documents to members of the team wherever/whenever they are required. This is especially important in the instance of technical drawings, where changes are made regularly and the effort for transporting and updating these drawings can be not only onerous, but costly (OrgM SE1), even when the drawings are being changed in the same city as the construction being undertaken. These two features are seen to assist greatly with cooperation and coordination functions across the cases, however the responses to the Likert instrument and from the interviews did not identify that this use extended to the collaborative functions. This is likely because none of the organisations specifically considered itself a collaborative environment (at the time of the research), and that the focus of the tasks of the PME were requiring at best coordination activities, rather than collaborative engagement.

'I wouldn't say it's collaborative, but it does coordinate a lot of work.' (OrgS PM1)

'The committee is a bit dysfunctional and difficult to work with at the moment.' (OrgV PM1)

'While the organisation wants to be collaborative, it isn't yet.' (OrgD PM1)

'The culture is starting to share, but it is dependent on the project and the personnel' (OrgM PM1)

This culture can be observed in Organisation K's (Alliance project) approach to the OCT. The INCITE OCT provides the capabilities to allow work flow and processes to be built into the application so that certain steps are undertaken in a coordinated fashion (OrgK PM1). In the place of collaboration, OrgK PM1 notes that the nature of the Alliance PME is 'definitely cooperative and coordinative' rather than collaborative, especially given the its shared understanding of delivering project objectives.

There is moderate support for the final two features, Announcement Boards and Virtual Conferencing, with both features being considered with a fair degree of neutrality from the 
respondents. This can be seen in contrast to the way these two features are promoted in miscellaneous vendor material as mechanisms that broadly communicate to team members, with the Announcement Boards especially useful in targeting multiple users with pertinent information. This feature was also considered central in the previous chapter for embracing collaborative elements in the PME. However this has not become apparent in the cases reviewed here. The Announcement Board is not considered effective for communication or information dissemination, and the use of the Virtual Conferencing feature was not well utilised in the PME operations of any of the cases. Importantly, the availability and use of the Announcement Board has not reduced email traffic, especially in those instances where it could cater for generic or basic project-related material. Email overload was also specifically cited as a hindrance in the use of the tool by Organisation M (Government Construction project) and Organisation D (State Government project). However there were instances where the functionality assists in facilitating communication across the PME (Qu. 47), and as such, the two features are seen to assist with cooperation, and to a varying degree, coordination. There are not any instances where either of the features assist or contribute to collaboration.

Overall, there is moderate support for the general use of the OCT across the different organisations. This support is for those features that assist in centrally storing and distributing project-related information, material and data, rather than for joining up team members to facilitate synchronous or same-time communication and collaboration.

'It's more an exchange of email than collaboration.' (OrgK PM1)

This discussion is presented in Table 7-10 with a short summary of the features and its rating against the Collaboration scale. The table highlights that the organisations use the OCTs for cooperative and coordination functions, and do not use the OCTs for collaboration. This is in juxtaposition with the state of most of the organisations, which are not collaborative by nature, even though they see this as something to attain. Of note here also, is that use of the OCTs do not by default create a collaborative environment, even though they may include functionality to support this. This ALSO resonates with the research question proposition, which posits that OCT use in the PME is primarily for cooperation and coordination. 
Table 7-10: Cross-case summary against Collaboration scale

\begin{tabular}{|c|c|c|c|c|}
\hline \multirow[t]{2}{*}{ OCT feature } & \multirow[t]{2}{*}{ Cross case Usage Summary/Comment } & \multicolumn{3}{|c|}{ Cross Case Collaboration Scale } \\
\hline & & Cooperation & Coordination & Collaboration \\
\hline $\begin{array}{l}\text { Use of Shared } \\
\text { Calendars }\end{array}$ & $\begin{array}{l}\text { General support across all cases, where it assisted } \\
\text { with planning and coordinating activities, and } \\
\text { assisted to communicate the availability of team } \\
\text { members. }\end{array}$ & $\checkmark$ & $\checkmark$ & \\
\hline Central Database & $\begin{array}{l}\text { General support across all cases, especially in } \\
\text { being able to manage and report on data from a } \\
\text { central location. }\end{array}$ & $\checkmark$ & $\checkmark$ & \\
\hline Shared Documents & $\begin{array}{l}\text { General support across all cases to increase } \\
\text { efficiencies in distribution of documents and } \\
\text { communicating }\end{array}$ & $\checkmark$ & $\checkmark$ & \\
\hline Store Documents & $\begin{array}{l}\text { Strong support for the capacity of the OCT to } \\
\text { provide (asynchronous) access to material from a } \\
\text { central location regardless of the physical location } \\
\text { of the team member. }\end{array}$ & $\checkmark$ & $\checkmark$ & \\
\hline $\begin{array}{l}\text { Announcement } \\
\text { Boards }\end{array}$ & $\begin{array}{l}\text { Moderate support for the functionality, although } \\
\text { the findings suggest it is not effective in } \\
\text { disseminating information across the PME. }\end{array}$ & $\checkmark$ & $\checkmark$ & \\
\hline Virtual Conferencing & $\begin{array}{l}\text { Moderate support for this feature where it assists } \\
\text { to manage and control risk and time. }\end{array}$ & $\checkmark$ & $\checkmark$ & \\
\hline General use of OCT & $\begin{array}{l}\text { Moderate support of the general use of the OCT in } \\
\text { particular for distributing information to the } \\
\text { project team. }\end{array}$ & $\checkmark$ & $\checkmark$ & \\
\hline
\end{tabular}




\subsubsection{PART TWO, Section One: Trust}

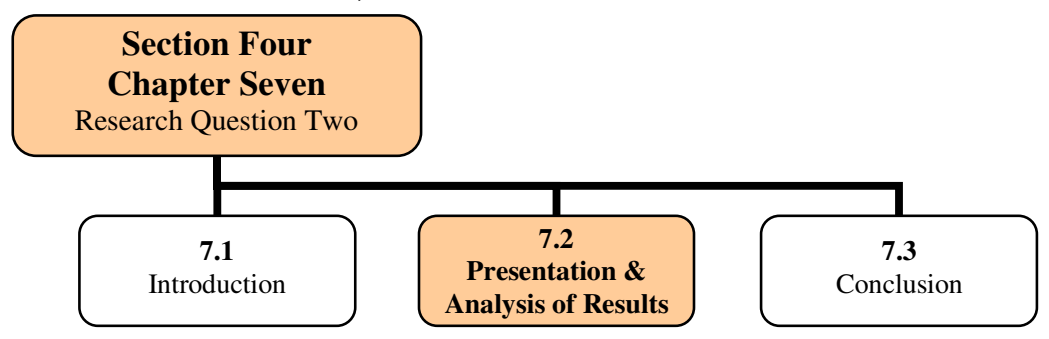

Part two of the Likert instrument sought to obtain responses to characteristics of collaboration.

These characteristics include trust, communication, equality, strategic alliances, knowledge distribution, negotiations and incentives. The Likert statement numbering recommences for Part Two however a continuous number is provided in brackets, for example Pt.2 Qu. 1. (77)

The first section asked the respondents about the role of trust in the PME.

Table 7-11: Trust

\begin{tabular}{|c|c|c|c|c|c|c|c|c|}
\hline \multirow[t]{2}{*}{$\begin{array}{l}1 \text { (74). I trust my team } \\
\text { members }\end{array}$} & $\begin{array}{c}\text { Agg. } \\
n=42\end{array}$ & $\underset{n=4}{\mathrm{OrgD}}$ & $\underset{n=9}{\operatorname{OrgV}}$ & $\underset{n=12}{\mathrm{OrgM}}$ & $\underset{n=6}{\mathrm{OrgC}}$ & $\underset{n=5}{\operatorname{OrgS}}$ & $\underset{n=6}{\mathrm{OrgK}}$ & \multirow[t]{2}{*}{ Comment } \\
\hline & \multicolumn{7}{|c|}{ Case responses \% } & \\
\hline strongly disagree & 0 & 0 & 0 & 0 & 0 & 0 & 0 & \multirow{5}{*}{$\begin{array}{l}\text { More than three quarters of respondents } \\
(84 \%) \text { 'agree' to 'strongly agree' that } \\
\text { they trust their team members. }\end{array}$} \\
\hline disagree & $\mathbf{0}$ & 0 & 0 & 0 & 0 & 0 & 0 & \\
\hline neither & 17 & 0 & 11 & 8 & 33 & 20 & 33 & \\
\hline agree & 74 & 100 & 78 & 83 & 67 & 60 & 50 & \\
\hline strongly agree & 10 & 0 & 11 & 8 & 0 & 20 & 17 & \\
\hline $\begin{array}{l}2(75) . \text { My team members trust } \\
\text { me }\end{array}$ & Agg. & OrgD & OrgV & OrgM & OrgC & OrgS & OrgK & Comment \\
\hline strongly disagree & $\mathbf{0}$ & 0 & 0 & 0 & 0 & 0 & 0 & \multirow{5}{*}{$\begin{array}{l}\text { More than three quarters of respondents } \\
(86 \%) \text { 'agree' to 'strongly agree' that } \\
\text { their team members trust them. }\end{array}$} \\
\hline disagree & $\mathbf{0}$ & 0 & 0 & 0 & 0 & 0 & 0 & \\
\hline neither & 14 & 0 & 11 & 8 & 17 & 20 & 33 & \\
\hline agree & 79 & 100 & 89 & 83 & 83 & 60 & 50 & \\
\hline strongly agree & 7 & 0 & 0 & 8 & 0 & 20 & 17 & \\
\hline $\begin{array}{l}3(76) \text {. The project team } \\
\text { requires a level of trust in order } \\
\text { to successfully operate }\end{array}$ & Agg. & OrgD & OrgV & OrgM & OrgC & OrgS & OrgK & Comment \\
\hline strongly disagree & $\mathbf{0}$ & 0 & 0 & 0 & 0 & 0 & 0 & \multirow{5}{*}{$\begin{array}{l}\text { Respondents unanimously (100\%) } \\
\text { 'agree' or 'strongly agree' that the } \\
\text { project team requires a level of trust in } \\
\text { order to successfully operate. }\end{array}$} \\
\hline disagree & $\mathbf{0}$ & 0 & 0 & 0 & 0 & 0 & 0 & \\
\hline neither & $\mathbf{0}$ & 0 & 0 & 0 & 0 & 0 & 0 & \\
\hline agree & 69 & 100 & 33 & 67 & 100 & 80 & 67 & \\
\hline strongly agree & 31 & 0 & 67 & 33 & 0 & 20 & 33 & \\
\hline $\begin{array}{l}4 \text { (77). Trust is not important in } \\
\text { stakeholder management }\end{array}$ & Agg. & OrgD & OrgV & OrgM & OrgC & OrgS & OrgK & Comment \\
\hline strongly disagree & 38 & 25 & 67 & 25 & 17 & 40 & 50 & \multirow{5}{*}{$\begin{array}{l}\text { Almost all respondents (95\%) 'disagree' } \\
\text { to 'strongly disagree' that trust is not } \\
\text { important in stakeholder management. } \\
\text { This statement was worded to elicit a } \\
\text { negative response. }\end{array}$} \\
\hline disagree & 57 & 75 & 33 & 58 & 83 & 60 & 50 & \\
\hline neither & 2 & 0 & 0 & 8 & 0 & 0 & 0 & \\
\hline agree & 2 & 0 & 0 & 8 & 0 & 0 & 0 & \\
\hline strongly agree & 0 & 0 & 0 & 0 & 0 & 0 & 0 & \\
\hline
\end{tabular}




\begin{tabular}{|c|c|c|c|c|c|c|c|c|}
\hline $\begin{array}{l}5(78) . \text { Negotiations depend on } \\
\text { the presence of trust }\end{array}$ & Agg. & OrgD & OrgV & OrgM & OrgC & OrgS & OrgK & Comment \\
\hline strongly disagree & 2 & 0 & 0 & 0 & 0 & 20 & 0 & \multirow{5}{*}{$\begin{array}{l}\text { More than } 80 \% \text { of respondents }(89 \%) \\
\text { 'agree' to 'strongly agree' that } \\
\text { negotiations depend on the presence of } \\
\text { trust. }\end{array}$} \\
\hline disagree & $\mathbf{0}$ & 0 & 0 & 0 & 0 & 0 & 0 & \\
\hline neither & 10 & 25 & 0 & 0 & 33 & 0 & 17 & \\
\hline agree & 71 & 75 & 56 & 83 & 67 & 60 & 83 & \\
\hline strongly agree & 17 & 0 & 44 & 17 & 0 & 20 & 0 & \\
\hline $\begin{array}{l}6(79) \text {. Trust is important when } \\
\text { sharing knowledge across the } \\
\text { project areas }\end{array}$ & Agg. & OrgD & OrgV & OrgM & OrgC & OrgS & OrgK & Comment \\
\hline strongly disagree & $\mathbf{0}$ & 0 & 0 & 0 & 0 & 0 & 0 & \multirow{5}{*}{$\begin{array}{l}\text { Almost all respondents }(95 \%) \text { 'agree' to } \\
\text { 'strongly agree' that trust is important } \\
\text { when sharing knowledge across the } \\
\text { project areas. }\end{array}$} \\
\hline disagree & 2 & 25 & 0 & 0 & 0 & 0 & 0 & \\
\hline neither & 2 & 0 & 0 & 0 & 0 & 0 & 17 & \\
\hline agree & 71 & 50 & 44 & 83 & 100 & 80 & 67 & \\
\hline strongly agree & 24 & 25 & 56 & 17 & 0 & 20 & 17 & \\
\hline $\begin{array}{l}7(80) \text {. Trust is required } \\
\text { between stakeholders in order } \\
\text { to achieve project objectives / } \\
\text { deliverables }\end{array}$ & Agg. & OrgD & OrgV & OrgM & OrgC & OrgS & OrgK & Comment \\
\hline strongly disagree & $\mathbf{0}$ & 0 & 0 & 0 & 0 & 0 & 0 & \multirow{5}{*}{$\begin{array}{l}\text { More than } 80 \% \text { of respondents }(88 \%) \\
\text { 'agree' to 'strongly agree' that trust is } \\
\text { required between stakeholders in order } \\
\text { to achieve project objectives/ } \\
\text { deliverables. }\end{array}$} \\
\hline disagree & 2 & 0 & 11 & 0 & 0 & 0 & 0 & \\
\hline neither & 10 & 0 & 0 & 17 & 17 & 20 & 0 & \\
\hline agree & 76 & 100 & 67 & 58 & 83 & 80 & 100 & \\
\hline strongly agree & 12 & 0 & 22 & 25 & 0 & 0 & 0 & \\
\hline $\begin{array}{l}8(81) . \text { Documents can be } \\
\text { shared in the project team } \\
\text { without trust }\end{array}$ & Agg. & OrgD & OrgV & OrgM & OrgC & OrgS & OrgK & Comment \\
\hline strongly disagree & 12 & 0 & 11 & 17 & 0 & 0 & 33 & \multirow{5}{*}{$\begin{array}{l}\text { More than half of the respondents }(60 \%) \\
\text { 'disagree' to 'strongly disagree' that } \\
\text { documents can be shared in the project } \\
\text { team without trust. This statement was } \\
\text { worded to elicit a negative response. }\end{array}$} \\
\hline disagree & 48 & 50 & 67 & 50 & 50 & 20 & 33 & \\
\hline neither & 17 & 50 & 0 & 17 & 0 & 40 & 17 & \\
\hline agree & 19 & 0 & 22 & 8 & 50 & 20 & 17 & \\
\hline strongly agree & 5 & 0 & 0 & 8 & 0 & 20 & 0 & \\
\hline $\begin{array}{l}9(82) \text {. Trust is not required in } \\
\text { the project management } \\
\text { environment }\end{array}$ & Agg. & OrgD & OrgV & OrgM & OrgC & OrgS & OrgK & Comment \\
\hline strongly disagree & 26 & 0 & 44 & 17 & 0 & 20 & 67 & \multirow{5}{*}{$\begin{array}{l}\text { More than three quarters of respondents } \\
(83 \%) \text { 'disagree' to 'strongly disagree' } \\
\text { that trust is not required in the project } \\
\text { management environment. This } \\
\text { statement was worded to elicit a } \\
\text { negative response. }\end{array}$} \\
\hline disagree & 57 & 100 & 56 & 50 & 67 & 80 & 17 & \\
\hline neither & 7 & 0 & 0 & 8 & 17 & 0 & 17 & \\
\hline agree & 10 & 0 & 0 & 25 & 17 & 0 & 0 & \\
\hline strongly agree & $\mathbf{0}$ & 0 & 0 & 0 & 0 & 0 & 0 & \\
\hline $\begin{array}{l}10(83) \text {. Collaboration can be } \\
\text { achieved without trust }\end{array}$ & Agg. & OrgD & OrgV & OrgM & OrgC & OrgS & OrgK & Comment \\
\hline strongly disagree & 21 & 0 & 33 & 17 & 0 & 20 & 50 & \multirow{5}{*}{$\begin{array}{l}\text { More than three quarters of respondents } \\
(81 \%) \text { 'disagree' to 'strongly disagree' } \\
\text { that collaboration can be achieved } \\
\text { without trust. }\end{array}$} \\
\hline disagree & 60 & 50 & 67 & 67 & 33 & 80 & 50 & \\
\hline neither & 10 & 25 & 0 & 17 & 17 & 0 & 0 & \\
\hline agree & 10 & 25 & 0 & 0 & 50 & 0 & 0 & \\
\hline strongly agree & $\mathbf{0}$ & 0 & 0 & 0 & 0 & 0 & 0 & \\
\hline $\begin{array}{l}11(84) \text {. OCT facilitates trust } \\
\text { amongst team members }\end{array}$ & Agg. & OrgD & $\operatorname{OrgV}$ & OrgM & OrgC & OrgS & OrgK & Comment \\
\hline strongly disagree & 2 & 0 & 0 & 8 & 0 & 0 & 0 & \multirow{5}{*}{$\begin{array}{l}\text { Approximately half of the respondents } \\
(52 \%) \text { were neutral in respect to the } \\
\text { statement that the OCT facilitates trust } \\
\text { amongst team members. }\end{array}$} \\
\hline disagree & 21 & 0 & 11 & 25 & 17 & 60 & & \\
\hline neither & 52 & 100 & 33 & 50 & 83 & 40 & 33 & \\
\hline agree & 24 & 0 & 56 & 17 & 0 & 0 & 50 & \\
\hline strongly agree & $\mathbf{0}$ & 0 & 0 & 0 & 0 & 0 & 0 & \\
\hline
\end{tabular}




\section{Summary}

This subsection indicates strong support for trust within the PME. Respondents unanimously support the notion that the project team requires a level of trust in order to be successful (Pt.2 Qu.3, Figure 7-21), with 100\% supporting this statement. They also indicated that it is important that they trust their team members (Pt.2 Qu.1) and that team members trust them (Pt.2 Qu.2). Trust is considered important in stakeholder management and the delivery of project objectives (Pt.2 Qu.4, 7) and is required for negotiation (Pt.2 Qu.5, Figure 7-22) and sharing knowledge across the project areas (Pt.2 Qu.6). Trust is required in order for collaboration to be achieved (Pt.2 Qu.10).

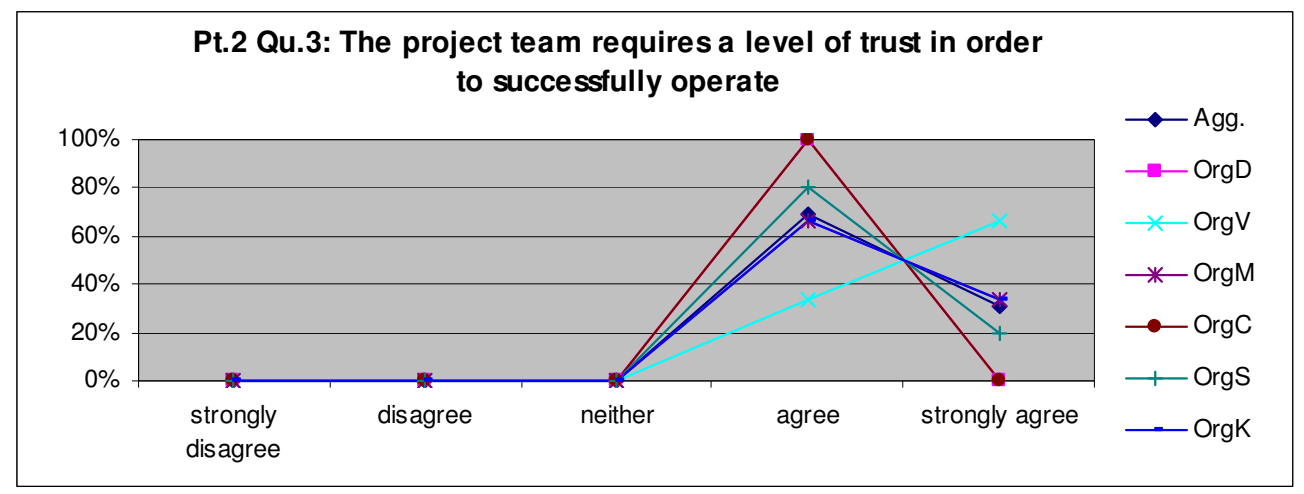

Figure 7-21: Pt.2 Qu.3: The project team requires a level of trust in order to successfully operate

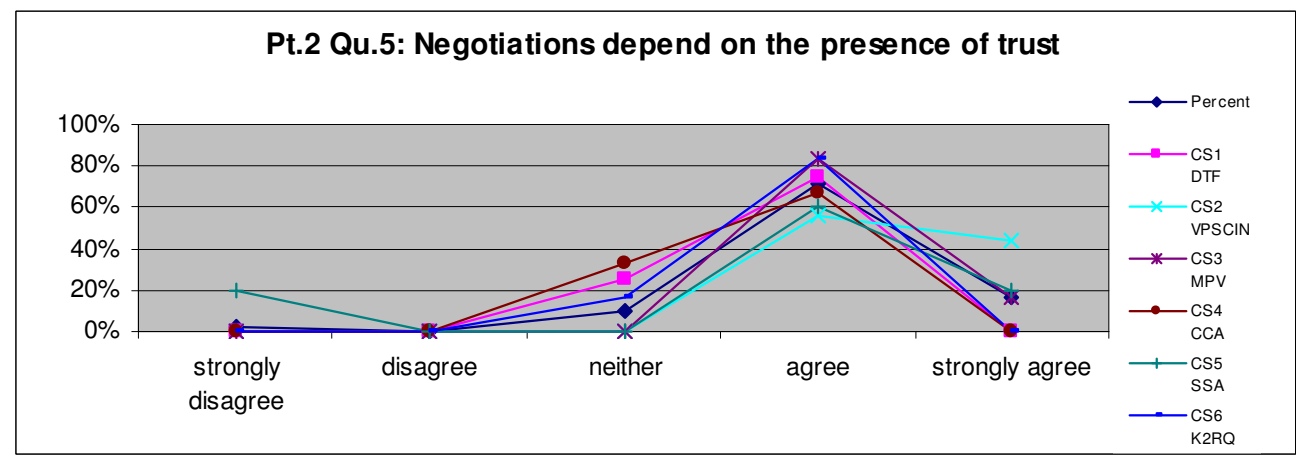

Figure 7-22: Pt2 Qu.5: Negotiations depend on the presence of trust

Organisation S (Government Authority) rates highly across the trust features $(\mathrm{Qu} .1$ - 7, 9, 10), and is of interest here because the organisation is relatively young, having been set up eight months prior to the review commencing. Given this, many business-groups were newly formed and the organisation 'hadn't jelled yet' (OrgS PM1), but it was the wish of the Executive team that the project develop strong corporate knowledge banks (OrgS PM1). The complexity of the project however comes from the status of much of the work of the organisation, which was often Cabinet-in-Confidence and therefore could not be widely shared across the organisation (OrgS 
PM1). This has led to the creation of pockets within the organisation that are 'basically keeping secrets from everyone else' (OrgS PM1). The organisation has a shared drive structure on its I.T. network, however as the organisation is an amalgam of pre-existing government departments, the electronic drives are only accessible to staff in each unit. This 'locking down' of drives is also a requirement for those units undertaking confidential reviews, where material cannot be widely distributed even to other parts of the organisation (OrgS PM1). There is a common drive for all staff which is used for generic information and procedures. The net result of this I.T. structure however is to support an environment where trust does easily flow across different business groups, and where one business group is seen to manage 'more sensitive information' than other units (OrgS PM1).

Of interest in these findings is that Organisation K (the Alliance project) displays strong support for the trust features, but is yet to have this fully realised within the PME $(\mathrm{Qu} .1,2)$. The reasons for this may also relate to the fact that at the time of the research, the organisation would still be considered immature as a project environment, with team members yet to fully integrate with each other (OrgK PM1). The organisation is relatively new at the time of the research, and as such, 'does not have a history of collaboration, however the use of the alliance removes the them and us mentality of the traditional project management dynamics' (OrgK PM1). Of note in this organisation was that the attainment of trust for the team was expanded upon. 


\subsubsection{PART TWO, Section Two: Communication}

The second section of Part Two reviewed communication, its role within the PME and the factors that impact on its delivery.

Table 7-12: Communication

\begin{tabular}{|c|c|c|c|c|c|c|c|c|}
\hline \multirow[t]{2}{*}{$\begin{array}{l}12(85) \text {. Effective communication } \\
\text { benefits project management }\end{array}$} & $\underset{n=42}{\text { Agg. }}$ & $\underset{n=4}{\operatorname{OrgD}}$ & $\underset{n=9}{\operatorname{OrgV}}$ & $\underset{n=12}{\operatorname{OrgM}}$ & $\underset{n=6}{\operatorname{OrgC}}$ & $\underset{n=5}{\operatorname{OrgS}}$ & $\underset{n=6}{\operatorname{OrgK}}$ & \multirow[t]{2}{*}{ Comment } \\
\hline & \multicolumn{7}{|c|}{ Case responses \% } & \\
\hline strongly disagree & 2 & 0 & 0 & 0 & 0 & 20 & 0 & \multirow{5}{*}{$\begin{array}{l}\text { Almost all respondents (96\%)'agree' to } \\
\text { 'strongly agree' that effective } \\
\text { communication benefits project } \\
\text { management. }\end{array}$} \\
\hline Disagree & 0 & 0 & 0 & 0 & 0 & 0 & 0 & \\
\hline Neither & 2 & 0 & 0 & 8 & 0 & 0 & 0 & \\
\hline Agree & 36 & 75 & 22 & 25 & 67 & 40 & 17 & \\
\hline strongly agree & 60 & 25 & 78 & 67 & 33 & 40 & 83 & \\
\hline $\begin{array}{l}13(86) \text {. Communication is not } \\
\text { enhanced by technology }\end{array}$ & Agg. & OrgD & OrgV & OrgM & OrgC & OrgS & OrgK & Comment \\
\hline strongly disagree & 19 & 0 & 22 & 17 & 17 & 20 & 33 & \multirow{5}{*}{$\begin{array}{l}\text { Nearly two thirds of respondents (63\%) } \\
\text { 'disagree' to 'strongly disagree' that } \\
\text { communication is not enhanced by } \\
\text { technology. This statement was worded } \\
\text { to elicit a negative response. }\end{array}$} \\
\hline disagree & 43 & 25 & 44 & 50 & 50 & 40 & 33 & \\
\hline neither & 26 & 50 & 22 & 25 & 33 & 20 & 17 & \\
\hline agree & 7 & 25 & 0 & 8 & 0 & 20 & 0 & \\
\hline strongly agree & 5 & 0 & 11 & 0 & 0 & 0 & 17 & \\
\hline $\begin{array}{l}14(87) \text {. Stakeholder management } \\
\text { relies on communication }\end{array}$ & Agg. & OrgD & OrgV & OrgM & OrgC & OrgS & OrgK & Comment \\
\hline strongly disagree & $\mathbf{0}$ & 0 & 0 & 0 & 0 & 0 & 0 & \multirow{5}{*}{$\begin{array}{l}\text { More than } 90 \% \text { of respondents }(91 \%) \\
\text { 'agree' to 'strongly agree' that } \\
\text { stakeholder management relies on } \\
\text { communication. }\end{array}$} \\
\hline disagree & 7 & 0 & 0 & 8 & 0 & 20 & 17 & \\
\hline neither & 2 & 0 & 0 & 8 & 0 & 0 & 0 & \\
\hline agree & 67 & 75 & 78 & 50 & 100 & 60 & 50 & \\
\hline strongly agree & 24 & 25 & 22 & 33 & 0 & 20 & 33 & \\
\hline $\begin{array}{l}15(88) \text {. Sharing knowledge can } \\
\text { be enhanced using online } \\
\text { technology }\end{array}$ & Agg. & OrgD & OrgV & OrgM & OrgC & OrgS & OrgK & Comment \\
\hline strongly disagree & $\mathbf{0}$ & 0 & 0 & 0 & 0 & 0 & 0 & \multirow{5}{*}{$\begin{array}{l}90 \% \text { of respondents 'agree' to 'strongly } \\
\text { agree' that sharing knowledge can be } \\
\text { enhanced using online technology. }\end{array}$} \\
\hline disagree & 5 & 25 & 0 & 0 & 0 & 20 & 0 & \\
\hline neither & 5 & 0 & 0 & 8 & 0 & 0 & 17 & \\
\hline agree & 64 & 50 & 78 & 58 & 83 & 60 & 50 & \\
\hline strongly agree & 26 & 25 & 22 & 33 & 17 & 20 & 33 & \\
\hline $\begin{array}{l}16(89) \text {. Managing team members } \\
\text { requires communication }\end{array}$ & Agg. & OrgD & $\operatorname{OrgV}$ & OrgM & OrgC & OrgS & OrgK & Comment \\
\hline strongly disagree & $\mathbf{0}$ & 0 & 0 & 0 & 0 & 0 & 0 & \multirow{5}{*}{$\begin{array}{l}95 \% \text { of respondents 'agree' to 'strongly } \\
\text { agree' that managing team members } \\
\text { requires communication. }\end{array}$} \\
\hline disagree & 2 & 0 & 0 & 0 & 0 & 20 & 0 & \\
\hline neither & 2 & 0 & 0 & 8 & 0 & 0 & 0 & \\
\hline agree & 43 & 75 & 56 & 33 & 50 & 40 & 17 & \\
\hline strongly agree & 52 & 25 & 44 & 58 & 50 & 40 & 83 & \\
\hline $\begin{array}{l}17 \text { (90). Communication is not } \\
\text { important when using an OCT }\end{array}$ & Agg. & OrgD & $\operatorname{OrgV}$ & OrgM & OrgC & OrgS & OrgK & Comment \\
\hline strongly disagree & 40 & 25 & 67 & 33 & 33 & 40 & 33 & \multirow{5}{*}{$\begin{array}{l}90 \% \text { of respondents 'disagree' to } \\
\text { 'strongly disagree' that communication } \\
\text { is not important when using an OCT. } \\
\text { This statement was worded to elicit a } \\
\text { negative response. }\end{array}$} \\
\hline disagree & 50 & 75 & 33 & 42 & 67 & 60 & 50 & \\
\hline neither & 5 & 0 & 0 & 8 & 0 & 0 & 17 & \\
\hline agree & 5 & 0 & 0 & 17 & 0 & 0 & 0 & \\
\hline strongly agree & $\mathbf{0}$ & 0 & 0 & 0 & 0 & 0 & 0 & \\
\hline
\end{tabular}




\begin{tabular}{|c|c|c|c|c|c|c|c|c|}
\hline $\begin{array}{l}18(91) . \text { OCT improve } \\
\text { information sharing }\end{array}$ & Agg. & OrgD & OrgV & OrgM & OrgC & OrgS & OrgK & Comment \\
\hline strongly disagree & $\mathbf{0}$ & 0 & 0 & 0 & 0 & 0 & 0 & \multirow{5}{*}{$\begin{array}{l}\text { More than three quarters of respondents } \\
(83 \%) \text { 'agree' to 'strongly agree' that } \\
\text { the OCT improves information sharing. }\end{array}$} \\
\hline disagree & 2 & 25 & 0 & 0 & 0 & 0 & 0 & \\
\hline neither & 14 & 25 & 0 & 17 & 17 & 20 & 17 & \\
\hline agree & 71 & 50 & 78 & 75 & 83 & 60 & 67 & \\
\hline strongly agree & 12 & 0 & 22 & 8 & 0 & 20 & 17 & \\
\hline $\begin{array}{l}19(92) . \text { Team members } \\
\text { communicate more effectively } \\
\text { when using OCT }\end{array}$ & Agg. & OrgD & OrgV & OrgM & OrgC & OrgS & OrgK & Comment \\
\hline strongly disagree & $\mathbf{0}$ & 0 & 0 & 0 & 0 & 0 & 0 & \multirow{5}{*}{$\begin{array}{l}\text { Responses are spread across the scales } \\
\text { in respect to the statement that team } \\
\text { members communicate more effectively } \\
\text { when using OCTs. }\end{array}$} \\
\hline disagree & 17 & 0 & 0 & 17 & 33 & 40 & 17 & \\
\hline neither & 60 & 75 & 56 & 67 & 67 & 40 & 50 & \\
\hline agree & 21 & 25 & 44 & 17 & 0 & 20 & 17 & \\
\hline strongly agree & 2 & 0 & 0 & 0 & 0 & 0 & 17 & \\
\hline $\begin{array}{l}20(93) \text {. Online technology does } \\
\text { not assist with communication in } \\
\text { the project environment }\end{array}$ & Agg. & OrgD & OrgV & OrgM & OrgC & OrgS & OrgK & Comment \\
\hline strongly disagree & 10 & 0 & 11 & 8 & 0 & 20 & 17 & \multirow{5}{*}{$\begin{array}{l}\text { Almost three quarters of respondents } \\
\text { (74\%) 'disagree' to 'strongly disagree' } \\
\text { that online technology does not assist } \\
\text { with communication in the project } \\
\text { environment. This statement was } \\
\text { worded to elicit a negative response. }\end{array}$} \\
\hline disagree & 64 & 25 & 78 & 58 & 83 & 80 & 50 & \\
\hline neither & 17 & 50 & 11 & 8 & 17 & 0 & 33 & \\
\hline agree & 10 & 25 & 0 & 25 & 0 & 0 & 0 & \\
\hline strongly agree & $\mathbf{0}$ & 0 & 0 & 0 & 0 & 0 & 0 & \\
\hline $\begin{array}{l}21 \text { (94). Communication is } \\
\text { essential in achieving project } \\
\text { objectives / deliverables }\end{array}$ & Agg. & OrgD & OrgV & OrgM & OrgC & OrgS & OrgK & Comment \\
\hline strongly disagree & 5 & 0 & 0 & 0 & 0 & 20 & 17 & \multirow{5}{*}{$\begin{array}{l}\text { The vast majority of respondents }(95 \%) \\
\text { 'agree' to 'strongly agree' that } \\
\text { communication is essential in achieving } \\
\text { project objectives / deliverables. }\end{array}$} \\
\hline disagree & $\mathbf{0}$ & 0 & 0 & 0 & 0 & 0 & 0 & \\
\hline neither & $\mathbf{0}$ & 0 & 0 & 0 & 0 & 0 & 0 & \\
\hline agree & 50 & 50 & 56 & 50 & 50 & 40 & 50 & \\
\hline strongly agree & 45 & 50 & 44 & 50 & 50 & 40 & 33 & \\
\hline $\begin{array}{l}22(95) . \text { Communication is not } \\
\text { clearer when using OCT }\end{array}$ & Agg. & OrgD & OrgV & OrgM & OrgC & OrgS & OrgK & Comment \\
\hline strongly disagree & $\mathbf{0}$ & 0 & 0 & 0 & 0 & 0 & 0 & \multirow{5}{*}{$\begin{array}{l}\text { More than half of the respondents }(52 \%) \\
\text { 'disagree' that communication is not } \\
\text { clearer when using OCTs. This } \\
\text { statement was worded to elicit a } \\
\text { negative response. }\end{array}$} \\
\hline disagree & 52 & 25 & 56 & 42 & 67 & 80 & 50 & \\
\hline neither & 33 & 75 & 44 & 25 & 33 & 20 & 17 & \\
\hline agree & 12 & 0 & 0 & 33 & 0 & 0 & 17 & \\
\hline strongly agree & 2 & 0 & 0 & 0 & 0 & 0 & 17 & \\
\hline $\begin{array}{l}23(96) \text {. Communication across } \\
\text { the project environment does not } \\
\text { benefit from using OCT }\end{array}$ & Agg. & OrgD & OrgV & OrgM & OrgC & OrgS & OrgK & Comment \\
\hline strongly disagree & 7 & 0 & 0 & 8 & 0 & 20 & 17 & \multirow{5}{*}{$\begin{array}{l}\text { Almost two thirds of respondents (62\%) } \\
\text { 'disagree' to 'strongly disagree' that } \\
\text { communication across the project } \\
\text { environment does not benefit from using } \\
\text { OCTs. This statement was worded to } \\
\text { elicit a negative response. }\end{array}$} \\
\hline disagree & 55 & 25 & 78 & 67 & 50 & 60 & 17 & \\
\hline neither & 33 & 75 & 22 & 17 & 50 & 20 & 50 & \\
\hline agree & 5 & 0 & 0 & 8 & 0 & 0 & 17 & \\
\hline strongly agree & $\mathbf{0}$ & 0 & 0 & 0 & 0 & 0 & 0 & \\
\hline
\end{tabular}

\section{Summary}

This section returned multiple instances where more than $90 \%$ of respondents indicates support

for various aspects of communication within the PME. Respondents strongly support the role effective communication plays in delivering benefits to project management (Pt.2 Qu.12), assisting with stakeholder management (Pt.2 Qu.14) and managing team members (Pt.2 Qu.16). 
Communication is enhanced by the use of technology (Pt.2 Qu.13, 20) and is important to respondents even when using an OCT (Pt.2 Qu.17). The use of the OCT improves information sharing (Pt.2 Qu.18) and is essential in achieving project objectives / deliverables (Pt.2 Qu.21).

Organisation K uses the Notes feature of the OCT to assist with managing the flow of information across the PME, whilst ensuring each note is linked to a PME function or knowledge area (OrgK PM2). When creating a new document, INCITE prompts several fields to assist with associating the document with the relevant project area; single or multiple recipients can be included. Free text fields are also available with WYSIWYG editors and file attachment options. Figure 7-23 provides a screen shot of this feature in INCITE.

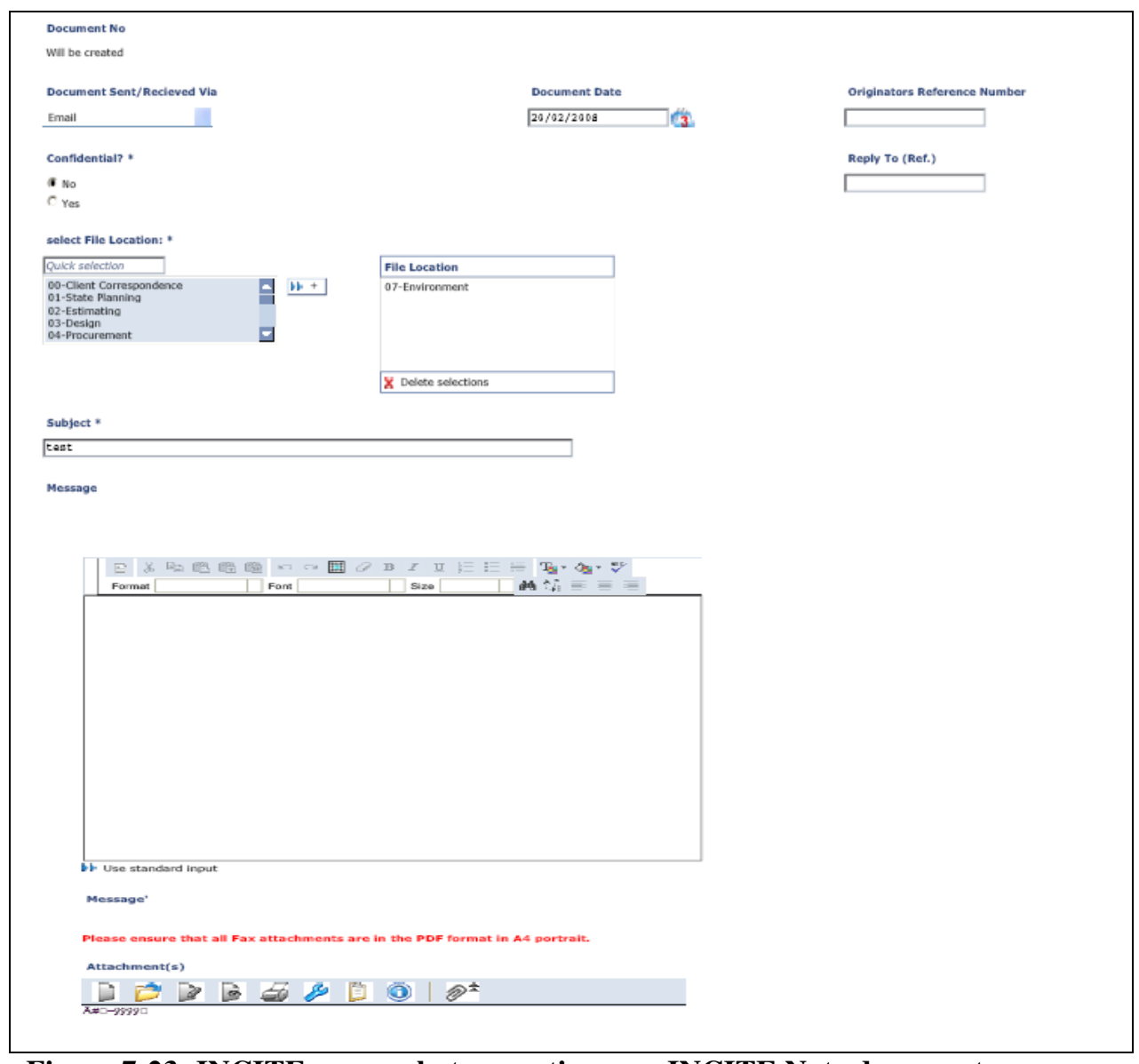

Figure 7-23: INCITE screen shot - creating new INCITE Note document

There has been a change in working conditions onsite for Organisation M (the Government Construction project) since the introduction of the OCT, with the Senior Engineer feeling that the use of the tool has contributed to a lessening of the effectiveness of communication (Qu.19) and commenting that face-to-face communication has subsequently suffered (OrgM SE1). One 
solution he suggests to combat this, has been to refine the Document Controller position to more efficiently manage and control the amount of material distributed to the construction team, thereby reducing both the volume of material transmitted, and the associated effort to manage the information (OrgM SE1).

Of note is that this is consistent to the approach used by Organisation K (the Alliance project), which had a similar case response to the statement that team members communicate more effectively when using an OCT. In the environment of Organisation K, the library is open to all staff, however uploading of documents into the OCT is restricted to a number of people within the Alliance to ensure the material is controlled for quality and useability purposes. Figure 7-24 shows a screen shot of the Technical Records Library of INCITE, highlighting the range and extent of documents that can be stored. The Document Controller and the Quality Manager (that is, OrgK PM2) are the designated people within the Alliance given authority to access all areas of the OCT including the technical library (OrgK PM2).

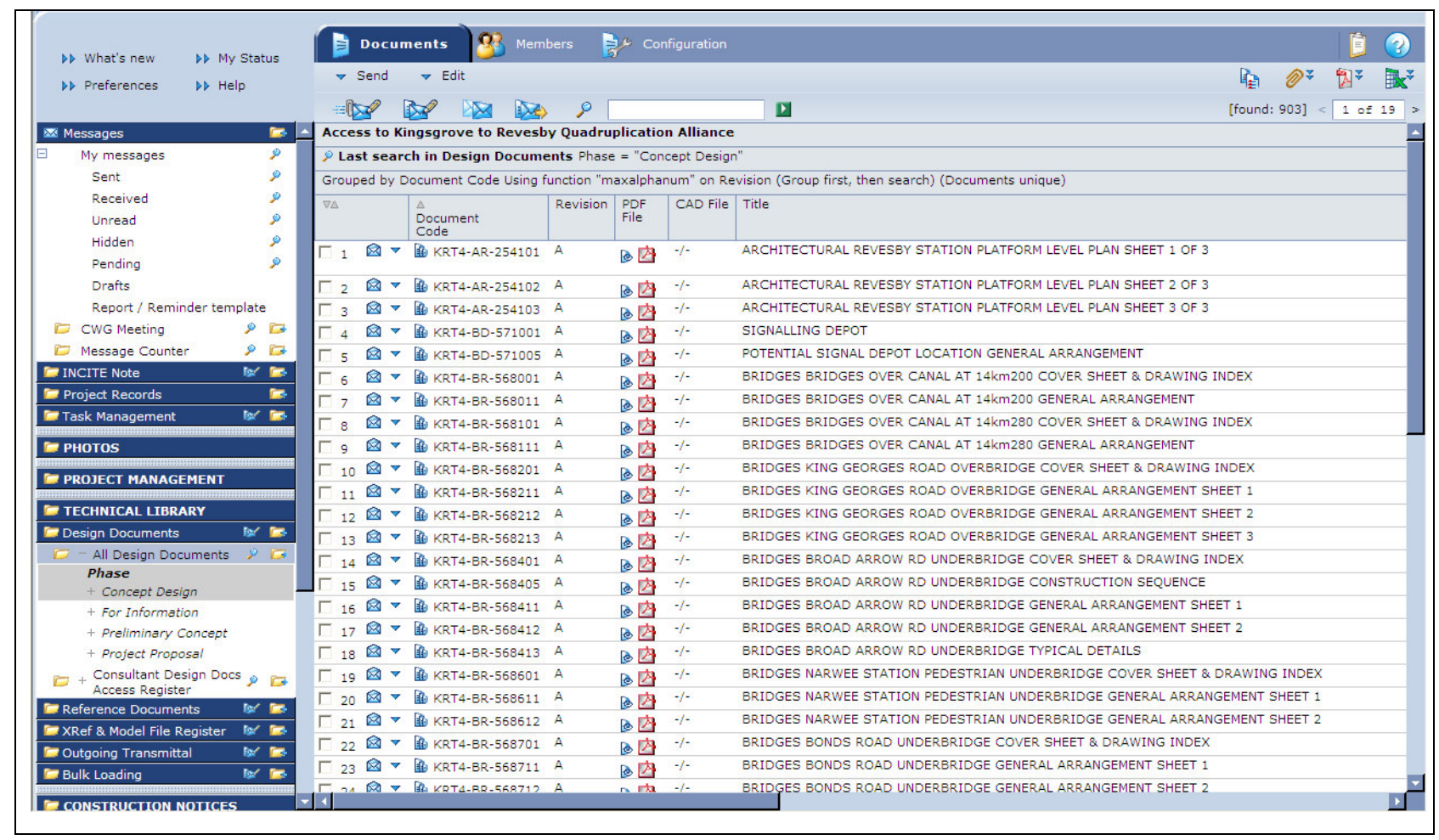

Figure 7-24: INCITE Technical Library screen shot.

In the case of Organisation C (Commercial Construction project), the most often used OCT features include the drawing database, builder's correspondence, submittals to design teams, Requests for Information (RFIs), the majority of official correspondence, and applications for 
delays - features that mostly correlate to communications/correspondence type activities ( $\mathrm{OrgC}$ PM2). The tool is used effectively for transmittals, especially when team members are physically in different sites across Australia (Qu.12, 14 - 18, 20).

Team members do not necessarily communicate more effectively or clearly when using an OCT (Pt.2 Qu.19, Figure 7-25, Pt.2 Qu.22,), with responses spread regarding whether communication overall across the PME benefits from the OCT (Pt.2 Qu.23). This reinforces the findings made elsewhere that the provision of tools do not necessarily translate to a change in behaviour by team members - that is, although the OCTs provide a range of communication functionality, these features must be used and reciprocated by the team members for any difference to be felt.

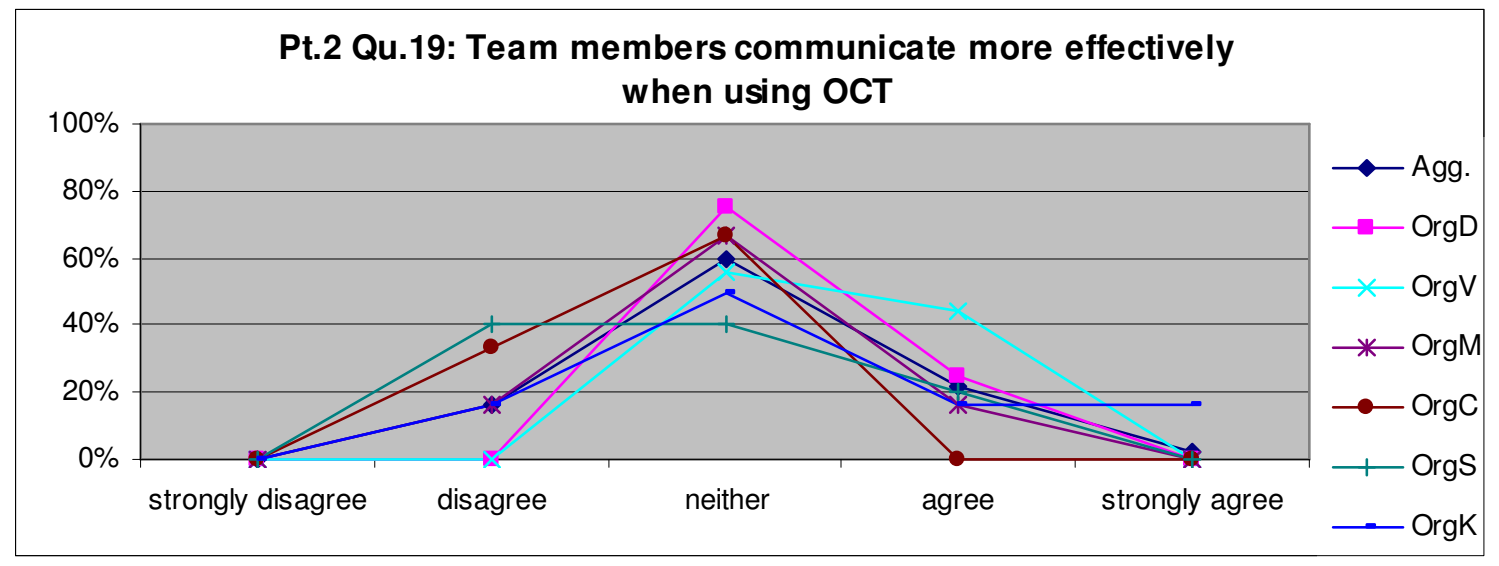

Figure 7-25: Pt.2 Qu.19: Team members communicate more effectively when using OCT

This was demonstrated by OrgM SE1 who observed that his role was to be onsite, rather than at his desk, and that if he wanted to be in front of his computer all day he would have 'become a typist, not a builder' (OrgM SE1). This comment could be seen to be a traditional approach to I.T. in the PME, but it also resonates as a point of tension for team members.

'The tool is used to substantiate and reinforce what is being said at meetings and other discussions.' (OrgM SE1)

The ACONEX tool in Organisation M (the Government Construction project) is a communication mechanism on the construction site and is available to the construction team which includes:

- Construction \& Commercial manager, Engineers x 4

- Site manager, Structure Foreman
- Receptionist/administrator

- Services Manager

- Senior Foreman x 2 (OrgM SE1) 
ACONEX is used to communicate to core teams as well as sub-contractors and consulting contractors, and is often used to substantiate and reinforce what is said at meetings and other discussions (OrgM SE1). It is used to issue notices of delays, RFIs, design change notices from the architect, changes to documents and specifications, transmit drawings and schedules, as well as being the location for meeting minutes and agendas (OrgM SE1).

Everyone has access to the tool onsite, although it is used more by the engineers than the foremen. The foremen are onsite all day and do not have ready access to a computer (OrgM SE1). The engineers are predominately in the office whereas the foreman, many of which 'are ex-carpenters don't always have the time or inclination to be sitting at a computer' (OrgM SE1). The inference being that it is not considered core to their tasks, and usage is estimated at a ratio of 70:30 for engineers:foremen use of the OCT (OrgM SE1). This approach to technology is considered a risk by this research, in that the use of an OCT will not only need to involve a change in the way team members approach project management, but will also impact on the electronic devices that can be utilised to manage electronic project management more effectively. This can include desktop and laptop systems, as well as extending to hand-held mobile devices including phones.

The ACONEX OCT is used for all communications material and has an intuitive and effective interface, allowing for detailed information of the transmittal to be recorded and presented in a summary format. Figure 7-26 provides a screen shot of the ACONEX Mail interface as an example of the clarity and detail of the screen's interface and layout.

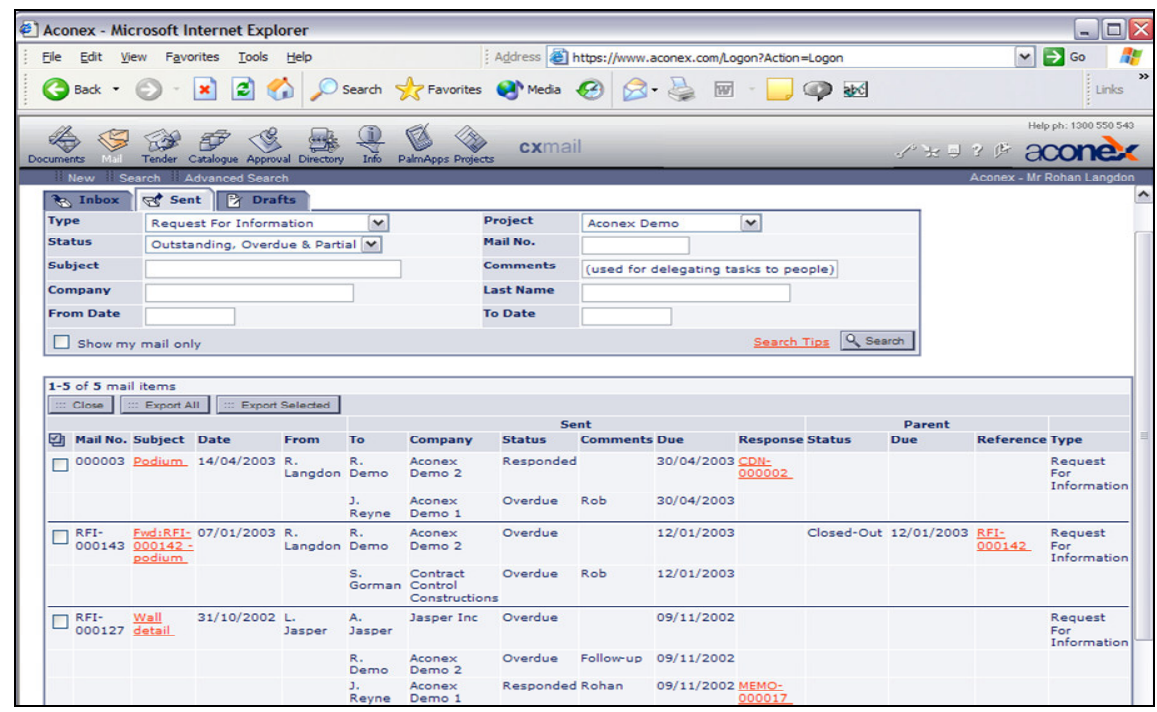

Figure 7-26: ACONEX Mail reporting/searching 


\subsubsection{PART TWO, Section Three: Equality}

The third section addressed equality and its level of importance within the PME.

Table 7-13: Equality

\begin{tabular}{|c|c|c|c|c|c|c|c|c|}
\hline \multirow[t]{2}{*}{$\begin{array}{l}24 \text { (97). Members of the project } \\
\text { team need to feel equal }\end{array}$} & $\begin{array}{c}\text { Agg. } \\
n=42\end{array}$ & $\underset{n=4}{\mathrm{OrgD}}$ & $\begin{array}{c}\mathrm{OrgV} \\
n=9\end{array}$ & $\underset{n=12}{\operatorname{OrgM}}$ & $\begin{array}{c}\mathrm{OrgC} \\
n=6\end{array}$ & $\begin{array}{c}\text { OrgS } \\
n=5\end{array}$ & $\begin{array}{c}\text { OrgK } \\
n=6\end{array}$ & \multirow[t]{2}{*}{ Comment } \\
\hline & \multicolumn{7}{|c|}{ Case responses \% } & \\
\hline strongly disagree & $\mathbf{0}$ & 0 & 0 & 0 & 0 & 0 & 0 & \multirow{5}{*}{$\begin{array}{l}\text { Responses are spread across the scales in } \\
\text { respect to the statement that members of } \\
\text { the project team need to feel equal. }\end{array}$} \\
\hline disagree & 19 & 25 & 11 & 17 & 17 & 40 & 17 & \\
\hline neither & 29 & 25 & 22 & 17 & 50 & 40 & 33 & \\
\hline agree & 45 & 50 & 56 & 58 & 33 & 20 & 33 & \\
\hline strongly agree & 7 & 0 & 11 & 8 & 0 & 0 & 17 & \\
\hline $\begin{array}{l}25 \text { (98). Knowledge distribution is } \\
\text { not important for team members }\end{array}$ & Agg. & OrgD & $\mathrm{OrgV}$ & OrgM & $\operatorname{OrgC}$ & OrgS & OrgK & \\
\hline strongly disagree & 21 & 0 & 33 & 8 & 33 & 20 & 33 & \multirow{5}{*}{$\begin{array}{l}\text { More than three quarters of respondents } \\
(85 \%) \text { 'disagree' to 'strongly disagree' } \\
\text { that knowledge distribution is not } \\
\text { important for team members. This } \\
\text { statement was worded to elicit a negative } \\
\text { response. }\end{array}$} \\
\hline disagree & 64 & 75 & 67 & 67 & 50 & 60 & 67 & \\
\hline neither & 5 & 0 & 0 & 8 & 17 & 0 & 0 & \\
\hline agree & 7 & 25 & 0 & 8 & 0 & 20 & 0 & \\
\hline strongly agree & 2 & 0 & 0 & 8 & 0 & 0 & 0 & \\
\hline $\begin{array}{l}26(99) . \text { Equality is demonstrated } \\
\text { by sharing information between } \\
\text { team members }\end{array}$ & Agg. & OrgD & $\mathrm{OrgV}$ & OrgM & $\operatorname{OrgC}$ & OrgS & OrgK & \\
\hline strongly disagree & $\mathbf{0}$ & 0 & 0 & 0 & 0 & 0 & 0 & \multirow{5}{*}{$\begin{array}{l}\text { Responses are spread across the scales in } \\
\text { respect to the statement that equality is } \\
\text { demonstrated by sharing information } \\
\text { between team members, although over } \\
\text { half of respondents (55\%) 'agree' with } \\
\text { the statement. }\end{array}$} \\
\hline disagree & 14 & 0 & 11 & 0 & 50 & 20 & 17 & \\
\hline neither & 31 & 50 & 22 & 42 & 17 & 40 & 17 & \\
\hline agree & 55 & 50 & 67 & 58 & 33 & 40 & 67 & \\
\hline strongly agree & $\mathbf{0}$ & 0 & 0 & 0 & 0 & 0 & 0 & \\
\hline $\begin{array}{l}27(100) \text {. Team members do not } \\
\text { need to feel equal in order to } \\
\text { contribute }\end{array}$ & Agg. & OrgD & $\mathrm{OrgV}$ & OrgM & OrgC & OrgS & OrgK & \\
\hline strongly disagree & 5 & 0 & 0 & 8 & 0 & 20 & 0 & \multirow{5}{*}{$\begin{array}{l}\text { Responses are spread across the scales in } \\
\text { respect to the statement that team } \\
\text { members do not need to feel equal in } \\
\text { order to contribute. The majority of } \\
\text { respondents ( } 45 \%) \text { 'agree' with this } \\
\text { statement. This statement was worded to } \\
\text { elicit a negative response. }\end{array}$} \\
\hline disagree & 26 & 25 & 33 & 25 & 17 & 0 & 50 & \\
\hline neither & 17 & 50 & 11 & 17 & 17 & 0 & 17 & \\
\hline agree & 45 & 25 & 56 & 42 & 67 & 60 & 17 & \\
\hline strongly agree & 7 & 0 & 0 & 8 & 0 & 20 & 17 & \\
\hline $\begin{array}{l}28 \text { (101). Communication assists } \\
\text { relationship management of } \\
\text { project teams }\end{array}$ & Agg. & OrgD & OrgV & OrgM & $\operatorname{OrgC}$ & OrgS & OrgK & \\
\hline strongly disagree & $\mathbf{0}$ & 0 & 0 & 0 & 0 & 0 & 0 & \multirow{5}{*}{$\begin{array}{l}\text { Almost all respondents }(98 \%) \text { 'agree' to } \\
\text { 'strongly agree' that communication } \\
\text { assists relationship management of } \\
\text { project schedules. }\end{array}$} \\
\hline disagree & 2 & 0 & 0 & 0 & 0 & 20 & 0 & \\
\hline neither & $\mathbf{0}$ & 0 & 0 & 0 & 0 & 0 & & \\
\hline agree & 62 & 75 & 44 & 75 & 100 & 40 & 33 & \\
\hline strongly agree & 36 & 25 & 56 & 25 & 0 & 40 & 67 & \\
\hline
\end{tabular}

\section{Summary}

Responses are spread across the scale in respect to the notion of equality within the PME.

Members do not necessarily need to feel equal in order to contribute (Pt.2 Qu.24, 27), nor is equality demonstrated by team members sharing information (Pt.2 Qu.26). These findings suggest that the presence and maintenance of equality within the PME may not be determined by the harder management structures set in place to deliver the project outcomes, but by softer, HR 
based strategies. These strategies deliver a sense of equality within the workplace, by creating a situation that both constrains and enables individuals within the team (Walker, 2003). This is of particular interest given that the findings do not appear to demonstrate a correlation between the presence of equality and the organisation type, management structure or project environment as discussed in Chapter 5, s5.2.4 (Table 5-9).

Respondents across the cases support the statement that sharing of information and the subsequent process of communication is important for team members and relationship management (Pt.2 Qu.25, Figure 7-27, Pt. 2 Qu.28,). The majority of cases also see this sharing of information across team members as a prerequisite for equality (Pt. $2 \mathrm{Qu} .26)$. This finding is consistent with the literature presented on equality and power in Chapter 4, s4.2.3, where the unwillingness to share information is due to a desire to control or retain power (Barua et al., 1997, O'Brien, 2000).

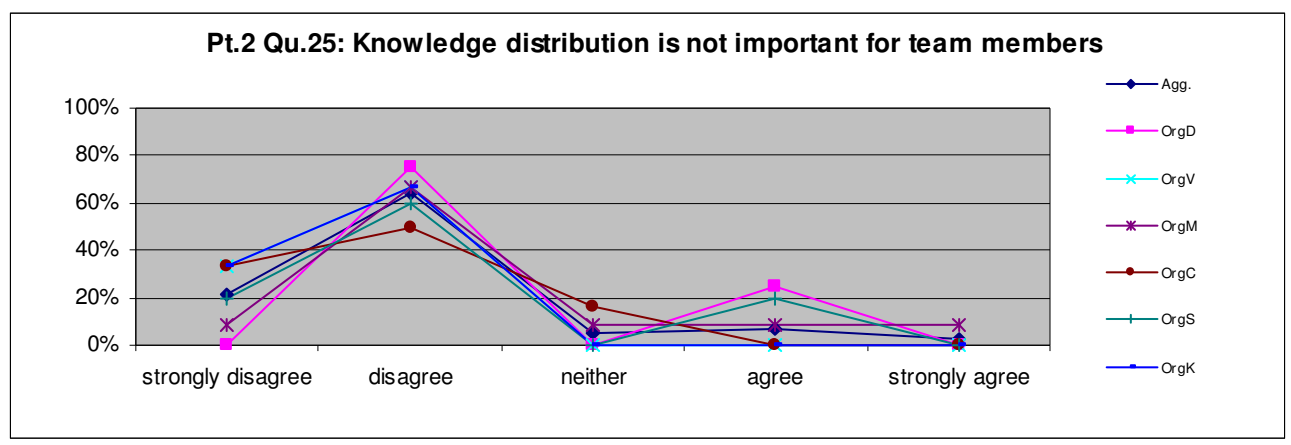

Figure 7-27: Pt.2 Qu.25: Knowledge distribution is not important for team members

One finding that appears to be at odds with the literature on equality discussed in previous chapters, is where responses are spread across the scale in respect to the statement that team members do not need to feel equal in order to contribute (Qu.27). This statement was worded to elicit a negative response, however the majority of respondents in four of the six cases agreed with this statement. This may indicate that equality in the PME may not impact on the sharing and distribution of knowledge especially when using an OCT as the intermediary. Organisation $\mathrm{K}$ was the only organisation where the majority disagreed with this statement in $\mathrm{Qu} 27$, a finding that is consistent with the alliance approach of the organisation. In an alliance environment, team members are encouraged to discard their parent/partner company culture and philosophy, and follow the values and principles of the alliance as defined by the Alliance Leadership Team (OrgKPM1). 


\subsubsection{PART TWO, Section Four: Strategic Alliances}

The fourth section posed questions relating to strategic alliances within the PME.

Table 7-14: Strategic Alliances

\begin{tabular}{|c|c|c|c|c|c|c|c|c|}
\hline \multirow[t]{2}{*}{$\begin{array}{l}29 \text { (102). Strategic alliances can be } \\
\text { strengthened using the OCT }\end{array}$} & $\underset{n=42}{\text { Agg. }}$ & $\underset{n=4}{\operatorname{OrgD}}$ & $\underset{n=9}{\operatorname{OrgV}}$ & $\underset{n=12}{\operatorname{OrgM}}$ & $\underset{n=6}{\operatorname{OrgC}}$ & $\underset{n=5}{\operatorname{OrgS}}$ & $\underset{n=6}{\operatorname{OrgK}}$ & \multirow[t]{2}{*}{ Comment } \\
\hline & \multicolumn{7}{|c|}{ Case responses \% } & \\
\hline strongly disagree & 2 & 0 & 0 & 0 & 0 & 20 & 0 & \multirow{5}{*}{$\begin{array}{l}\text { More than half of the respondents } \\
(54 \%) \text { 'agree' to 'strongly agree' that } \\
\text { strategic alliances can be } \\
\text { strengthened using OCTs. } 40 \% \text { of } \\
\text { respondents were neutral in respect to } \\
\text { this statement. }\end{array}$} \\
\hline disagree & 2 & 0 & 0 & 8 & 0 & 0 & 0 & \\
\hline neither & 40 & 75 & 11 & 50 & 67 & 20 & 33 & \\
\hline agree & 52 & 25 & 78 & 42 & 33 & 60 & 67 & \\
\hline strongly agree & 2 & 0 & 11 & 0 & 0 & 0 & 0 & \\
\hline $\begin{array}{l}30(103) \text {. Knowledge sharing is a } \\
\text { critical component of managing } \\
\text { alliances }\end{array}$ & Agg. & OrgD & OrgV & OrgM & OrgC & OrgS & OrgK & Comment \\
\hline strongly disagree & 0 & 0 & 0 & 0 & 0 & 0 & 0 & \multirow{5}{*}{$\begin{array}{l}90 \% \text { of respondents 'agree' to } \\
\text { 'strongly agree' that knowledge } \\
\text { sharing is a critical component of } \\
\text { managing alliances. }\end{array}$} \\
\hline disagree & $\mathbf{0}$ & 0 & 0 & 0 & 0 & 0 & 0 & \\
\hline neither & 10 & 25 & 0 & 8 & 0 & 40 & 0 & \\
\hline agree & 83 & 75 & 67 & 92 & 100 & 60 & 100 & \\
\hline strongly agree & 7 & 0 & 33 & 0 & 0 & 0 & 0 & \\
\hline $\begin{array}{l}31 \text { (104). Trust is not essential to } \\
\text { developing and maintaining } \\
\text { Strategic Alliances }\end{array}$ & Agg. & OrgD & OrgV & OrgM & OrgC & OrgS & OrgK & Comment \\
\hline strongly disagree & 17 & 0 & 22 & 0 & 17 & 0 & 67 & \multirow{5}{*}{$\begin{array}{l}\text { More than three quarters of } \\
\text { respondents }(84 \%) \text { 'disagree' to } \\
\text { 'strongly disagree' that trust is not } \\
\text { essential to developing and } \\
\text { maintaining strategic alliances. This } \\
\text { statement was worded to elicit a } \\
\text { negative response. }\end{array}$} \\
\hline disagree & 67 & 75 & 78 & 83 & 50 & 80 & 17 & \\
\hline neither & 12 & 25 & 0 & 0 & 33 & 20 & 17 & \\
\hline agree & 5 & 0 & 0 & 17 & 0 & 0 & 0 & \\
\hline strongly agree & $\mathbf{0}$ & 0 & 0 & 0 & 0 & 0 & 0 & \\
\hline $\begin{array}{l}32(105) . \text { Strategic alliances are } \\
\text { managed by open communication }\end{array}$ & Agg. & OrgD & OrgV & OrgM & OrgC & OrgS & OrgK & Comment \\
\hline strongly disagree & $\mathbf{0}$ & 0 & 0 & 0 & 0 & 0 & 0 & \multirow{5}{*}{$\begin{array}{l}\text { A large majority of respondents } \\
(88 \%) \text { 'agree' to 'strongly agree' that } \\
\text { strategic alliances are managed by } \\
\text { open communication. }\end{array}$} \\
\hline disagree & $\mathbf{0}$ & 0 & 0 & 0 & 0 & 0 & 0 & \\
\hline neither & 12 & 25 & 22 & 8 & 17 & 0 & 0 & \\
\hline agree & 81 & 75 & 67 & 92 & 83 & 80 & 83 & \\
\hline strongly agree & 7 & 0 & 11 & 0 & 0 & 20 & 17 & \\
\hline $\begin{array}{l}33 \text { (106). Stakeholder management } \\
\text { is not improved when using OCT }\end{array}$ & Agg. & OrgD & OrgV & OrgM & OrgC & OrgS & OrgK & Comment \\
\hline strongly disagree & 5 & 0 & 11 & 0 & 0 & 0 & 17 & \multirow{5}{*}{$\begin{array}{l}\text { More than half of respondents (57\%) } \\
\text { 'disagree' to 'strongly disagree' that } \\
\text { stakeholder management is not } \\
\text { improved when using OCTs. This } \\
\text { statement was worded to elicit a } \\
\text { negative response. }\end{array}$} \\
\hline disagree & 52 & 25 & 56 & 58 & 33 & 80 & 50 & \\
\hline neither & 38 & 75 & 11 & 42 & 67 & 20 & 33 & \\
\hline agree & 5 & 0 & 22 & 0 & 0 & 0 & & \\
\hline strongly agree & 0 & 0 & 0 & 0 & 0 & 0 & 0 & \\
\hline $\begin{array}{l}34(107) . \text { OCT delivers the } \\
\text { incentives needed to manage } \\
\text { Strategic Alliances }\end{array}$ & Agg. & OrgD & OrgV & OrgM & OrgC & OrgS & OrgK & Comment \\
\hline strongly disagree & 2 & 0 & 0 & 0 & 0 & 0 & 17 & \multirow{5}{*}{$\begin{array}{l}\text { Almost three quarters of respondents } \\
(74 \%) \text { are neutral in respect to the } \\
\text { statement that the OCT delivers the } \\
\text { incentives needed to manage strategic } \\
\text { alliances. }\end{array}$} \\
\hline disagree & 7 & 0 & 11 & 0 & 17 & 20 & 0 & \\
\hline neither & 74 & 100 & 67 & 75 & 67 & 80 & 67 & \\
\hline agree & 17 & 0 & 22 & 25 & 17 & 0 & 17 & \\
\hline strongly agree & $\mathbf{0}$ & 0 & 0 & 0 & 0 & 0 & 0 & \\
\hline
\end{tabular}




\section{Summary}

Responses to this section indicate that knowledge sharing, trust and communication are essential when managing and maintaining strategic alliances (Pt.2 Qu.30, Figure 7-28, Pt.2 Qu. 31, 32). These findings are consistent with the literature discussed previously and reinforce the list of features required for collaboration. Findings to these three statements across the cases range from $84-90 \%$ of respondents indicating very strong support for these themes, regardless of the project environment or organisational structures in place.

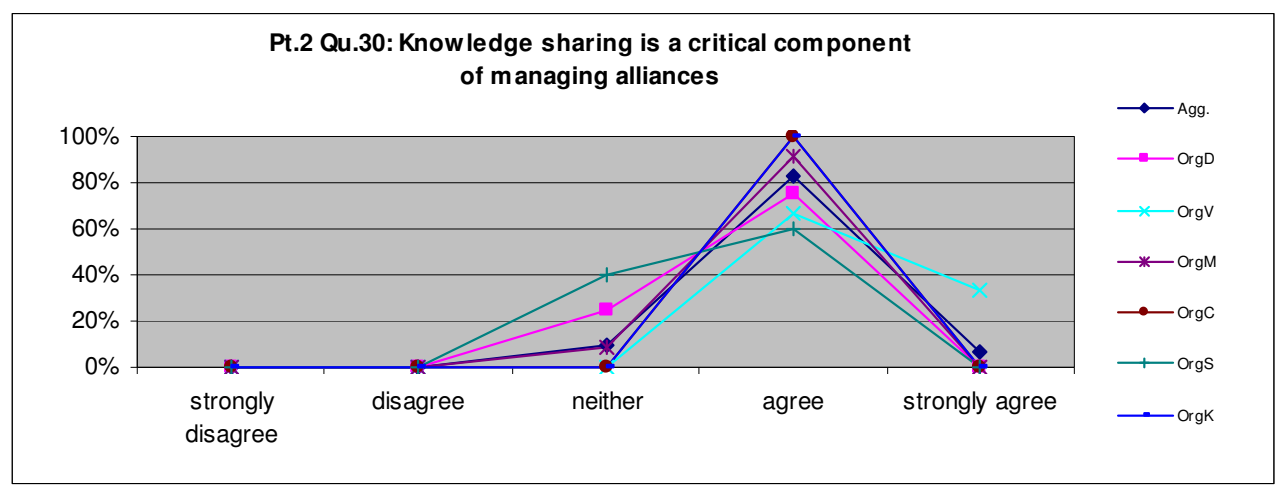

Figure 7-28: Pt.2 Qu.30: Knowledge sharing is a critical component of managing alliances

Organisation $\mathrm{C}$ and $\mathrm{V}$ (the Commercial Construction project and the Continuous Improvement org) unanimously agreed with the statement that knowledge sharing is a critical component of managing alliances, while Organisation $\mathrm{V}$ was also unanimous in its support for the statement that trust is essential to developing and maintaining strategic alliances. This finding is consistent with an organisation that has a large internet distributed audience, and which uses a blog mechanism as its primary communication device.

\section{"The CIN culture is like a gas.” (OrgV PM1)}

The culture of the Continuous Improvement Network managed by Organisation V is 'like a gas' ( OrgV PM), in that it is difficult for the coordinator to discuss in concrete terms (OrgV PM). The coordinator believes the culture to be progressive and forward thinking. It is his opinion that members are determined to change the government's working environment - and as such they are a positive force. This is in contrast to what the coordinator sees as an otherwise general lack of focus towards continuous improvement initiatives within government (OrgV PM). 
In order for Organisation $\mathrm{V}$ to use the blog software, external hosting arrangements were required. This was due to the security protocols in place inside the firewall structures of government, prohibiting the use of blogging software. In the opinion of the coordinator, this demonstrates that the 'government environment is technically too conservative to allow a blog to exist within its internet environment' (OrgV PM). The coordinator noted that this outcome, in hindsight, has improved communication amongst the membership, as the freedom from censorship (or self-censorship) would not have been possible within a government sanctioned internet-based discussion environment.

It is also noteworthy, that the CIN blog is open to anyone on the internet, allowing non-members access to the material and the capacity to contribute to the comments section. Given this open access strategy, publishing has to-date been received primarily from the membership (OrgV PM), suggesting that the internet environment can be used for semi exclusive communication. Formal membership to the CIN involves being listed on a membership database, something that normally happens at CIN functions or as a result of a posting by the coordinator.

The OCT can contribute to strengthening strategic alliances (Pt.2 Qu.29) although the use of the OCT does not necessarily improve stakeholder management (Pt.2 Qu.33). Of interest is that almost three quarters of respondents are neutral on whether the OCT delivers the incentives needed to manage strategic alliances (Pt.2 Qu.34, Figure 7-29). This is telling for the use of the OCTs, especially in the case of Organisation M, which expressly excluded its major stakeholders from the OCT. In this situation, it was a strategic decision to manage the stakeholders outside the OCT, as a means to controlling information flow and project deliverables (OrgM PM1)

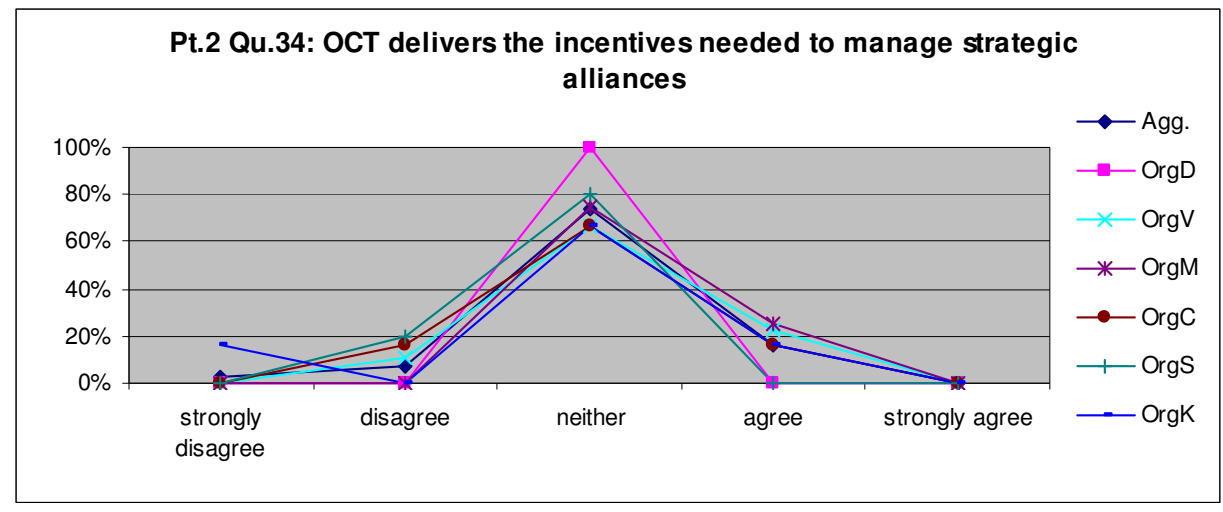

Figure 7-29: Pt.2 Qu.34: OCT delivers the incentives needed to manage strategic alliances 
Responses to this statement support the notion that players and partners within the various projects may have multiple layers of participation, and are flexible about the process and structure of collaboration (Mattessich et al., 2001). That is to say, the OCT may not be the primary or only vehicle through which strategic alliances and relationships can be managed.

\subsubsection{PART TWO, Section Five: (Project) Knowledge Distribution}

The fifth section addresses the issue of distribution of project based knowledge and links these questions to other areas including the use of the OCT, central repositories and the role of the project manager.

Table 7-15: Knowledge Distribution

\begin{tabular}{|c|c|c|c|c|c|c|c|c|}
\hline \multirow[t]{2}{*}{$\begin{array}{l}35(108) \text {. The distribution of } \\
\text { knowledge regarding the project is } \\
\text { important to team members }\end{array}$} & $\underset{n=42}{\text { Agg. }}$ & $\underset{n=4}{\operatorname{OrgD}}$ & $\underset{n=9}{\operatorname{OrgV}}$ & $\underset{n=12}{\operatorname{OrgM}}$ & $\underset{n=6}{\operatorname{OrgC}}$ & $\underset{n=5}{\operatorname{OrgS}}$ & $\underset{n=6}{\operatorname{OrgK}}$ & \multirow[t]{2}{*}{ Comment } \\
\hline & \multicolumn{7}{|c|}{ Case responses \% } & \\
\hline strongly disagree & 0 & 0 & 0 & 0 & 0 & 0 & 0 & \multirow{5}{*}{$\begin{array}{l}\text { Almost all respondents }(98 \%) \text { 'agree' to } \\
\text { 'strongly agree' that the distribution of } \\
\text { knowledge regarding the project is } \\
\text { important. }\end{array}$} \\
\hline disagree & $\mathbf{0}$ & 0 & 0 & 0 & 0 & 0 & 0 & \\
\hline neither & 2 & 25 & 0 & 0 & 0 & 0 & 0 & \\
\hline agree & 74 & 75 & 67 & 83 & 83 & 40 & 83 & \\
\hline strongly agree & 24 & 0 & 33 & 17 & 17 & 60 & 17 & \\
\hline $\begin{array}{l}36(109) . \text { OCT encourage sharing } \\
\text { information amongst team members }\end{array}$ & Agg. & OrgD & OrgV & OrgM & OrgC & OrgS & OrgK & Comment \\
\hline strongly disagree & $\mathbf{0}$ & 0 & 0 & 0 & 0 & 0 & 0 & \multirow{5}{*}{$\begin{array}{l}\text { More than three quarters of respondents } \\
(86 \%) \text { 'agree' to 'strongly agree' that } \\
\text { the OCT encourages sharing of } \\
\text { information amongst team members. }\end{array}$} \\
\hline disagree & 2 & 0 & 0 & 0 & 0 & 20 & 0 & \\
\hline neither & 12 & 25 & 11 & 8 & 17 & 0 & 17 & \\
\hline agree & 79 & 75 & 78 & 92 & 83 & 60 & 67 & \\
\hline strongly agree & 7 & 0 & 11 & 0 & 0 & 20 & 17 & \\
\hline $\begin{array}{l}37(110) \text {. The distribution of } \\
\text { knowledge amongst team members is } \\
\text { central to trust }\end{array}$ & Agg. & OrgD & $\operatorname{OrgV}$ & OrgM & OrgC & OrgS & OrgK & Comment \\
\hline strongly disagree & $\mathbf{0}$ & 0 & 0 & 0 & 0 & 0 & 0 & \multirow{5}{*}{$\begin{array}{l}\text { Approximately three quarters of } \\
\text { respondents ( } 74 \%) \text { 'agree' to 'strongly } \\
\text { agree' that the distribution of knowledge } \\
\text { amongst team members is central to } \\
\text { trust. }\end{array}$} \\
\hline disagree & 2 & 0 & 0 & 8 & 0 & 0 & 0 & \\
\hline neither & 24 & 25 & 22 & 17 & 50 & 20 & 17 & \\
\hline agree & 69 & 75 & 56 & 75 & 50 & 80 & 83 & \\
\hline strongly agree & 5 & 0 & 22 & 0 & 0 & 0 & 0 & \\
\hline $\begin{array}{l}38 \text { (111). Knowledge distribution } \\
\text { should be on an ad hoc basis }\end{array}$ & Agg. & OrgD & OrgV & OrgM & OrgC & OrgS & OrgK & Comment \\
\hline strongly disagree & 14 & 0 & 33 & 0 & 0 & 40 & 17 & \multirow{5}{*}{$\begin{array}{l}\text { Approximately two thirds of } \\
\text { respondents (69\%) 'disagree' to } \\
\text { 'strongly disagree' that knowledge } \\
\text { distribution should be on an ad hoc } \\
\text { basis. This statement was worded to } \\
\text { elicit a negative response. }\end{array}$} \\
\hline disagree & 55 & 50 & 33 & 67 & 67 & 40 & 67 & \\
\hline neither & 24 & 50 & 33 & 25 & 17 & 20 & 0 & \\
\hline agree & 5 & 0 & 0 & 0 & 17 & 0 & 17 & \\
\hline strongly agree & 2 & 0 & 0 & 8 & 0 & 0 & 0 & \\
\hline
\end{tabular}




\begin{tabular}{|c|c|c|c|c|c|c|c|c|}
\hline $\begin{array}{l}39 \text { (112). Knowledge should not be } \\
\text { distributed from a central location }\end{array}$ & Agg. & OrgD & OrgV & OrgM & OrgC & OrgS & OrgK & Comment \\
\hline strongly disagree & 7 & 0 & 11 & 0 & 0 & 20 & 17 & \multirow{5}{*}{$\begin{array}{l}\text { More than half of respondents }(52 \%) \\
\text { 'disagree' to 'strongly disagree' that } \\
\text { knowledge should not be distributed } \\
\text { from a central location. This statement } \\
\text { was worded to elicit a negative } \\
\text { response. }\end{array}$} \\
\hline disagree & 45 & 50 & 44 & 67 & 17 & 40 & 33 & \\
\hline neither & 31 & 50 & 22 & 17 & 67 & 20 & 33 & \\
\hline agree & 14 & 0 & 22 & 17 & 17 & 0 & 17 & \\
\hline strongly agree & 2 & 0 & 0 & 0 & 0 & 20 & 0 & \\
\hline $\begin{array}{l}40(113) . \text { Knowledge distribution is } \\
\text { more than having a central repository } \\
\text { of documents in an OCT }\end{array}$ & Agg. & OrgD & OrgV & OrgM & OrgC & OrgS & OrgK & Comment \\
\hline strongly disagree & $\mathbf{0}$ & 0 & 0 & 0 & 0 & 0 & 0 & \multirow{5}{*}{$\begin{array}{l}\text { Almost all respondents }(95 \%) \text { 'agree' to } \\
\text { 'strongly agree' that knowledge } \\
\text { distribution is more than having a } \\
\text { central repository of documents in an } \\
\text { OCT. }\end{array}$} \\
\hline disagree & $\mathbf{0}$ & 0 & 0 & 0 & 0 & 0 & 0 & \\
\hline neither & 5 & 25 & 0 & 8 & 0 & 0 & 0 & \\
\hline agree & 62 & 50 & 44 & 75 & 50 & 40 & 100 & \\
\hline strongly agree & 33 & 25 & 56 & 17 & 50 & 60 & 0 & \\
\hline $\begin{array}{l}41(114) \text {. Announcement boards in } \\
\text { OCT assist in the distribution of } \\
\text { important information }\end{array}$ & Agg. & OrgD & OrgV & OrgM & OrgC & OrgS & OrgK & Comment \\
\hline strongly disagree & $\mathbf{0}$ & 0 & 0 & 0 & 0 & 0 & 0 & \multirow{5}{*}{$\begin{array}{l}\text { Approximately two thirds of } \\
\text { respondents }(62 \%) \text { 'agree' to 'strongly } \\
\text { agree' that the Announcement Board in } \\
\text { the OCT assists in the distribution of } \\
\text { important imformation. }\end{array}$} \\
\hline disagree & 2 & 0 & 0 & 0 & 0 & 0 & 17 & \\
\hline neither & 36 & 25 & 11 & 58 & 50 & 40 & 17 & \\
\hline agree & 57 & 75 & 89 & 42 & 50 & 40 & 50 & \\
\hline strongly agree & 5 & 0 & 0 & 0 & 0 & 20 & 17 & \\
\hline $\begin{array}{l}42(115) . \text { Knowledge distribution } \\
\text { should be managed by the project } \\
\text { manager }\end{array}$ & Agg. & OrgD & OrgV & OrgM & OrgC & OrgS & OrgK & Comment \\
\hline strongly disagree & $\mathbf{0}$ & 0 & 0 & 0 & 0 & 0 & 0 & \multirow{5}{*}{$\begin{array}{l}\text { Responses are spread across the scales } \\
\text { in respect to the statement that } \\
\text { knowledge distribution should be } \\
\text { managed by the project manager. More } \\
\text { than one third of respondents }(38 \%) \\
\text { 'disagree' with this statement. }\end{array}$} \\
\hline disagree & 38 & 50 & 33 & 33 & 33 & 40 & 50 & \\
\hline neither & 29 & 25 & 33 & 33 & 33 & 20 & 17 & \\
\hline agree & 31 & 25 & 33 & 33 & 33 & 20 & 33 & \\
\hline strongly agree & 2 & 0 & 0 & 0 & 0 & 20 & 0 & \\
\hline
\end{tabular}

\section{Summary}

Almost all respondents consider the distribution of knowledge regarding the project is important to team members (Pt.2 Qu.35, Figure 7-30), with five of the six cases unanimously supporting this statement. This finding is further strengthened by the findings for the statement that the OCT encourages information sharing amongst team members (Pt.2 Qu.36), although it is of interest that respondents indicate that they consider knowledge distribution as being more than having a central repository of documents in an OCT (Pt.2 Qu.40). This may indicate that the flow of information is associated with more organic processes that are linked to knowledge areas, rather than document types and associated formal document filing taxonomies.

Knowledge distribution amongst team members is central to trust (Pt.2 Qu.37), with most agreeing that it should not occur on an ad hoc basis (Pt.2 Qu.38), and should be distributed from a central location (Pt.2 Qu.39). 


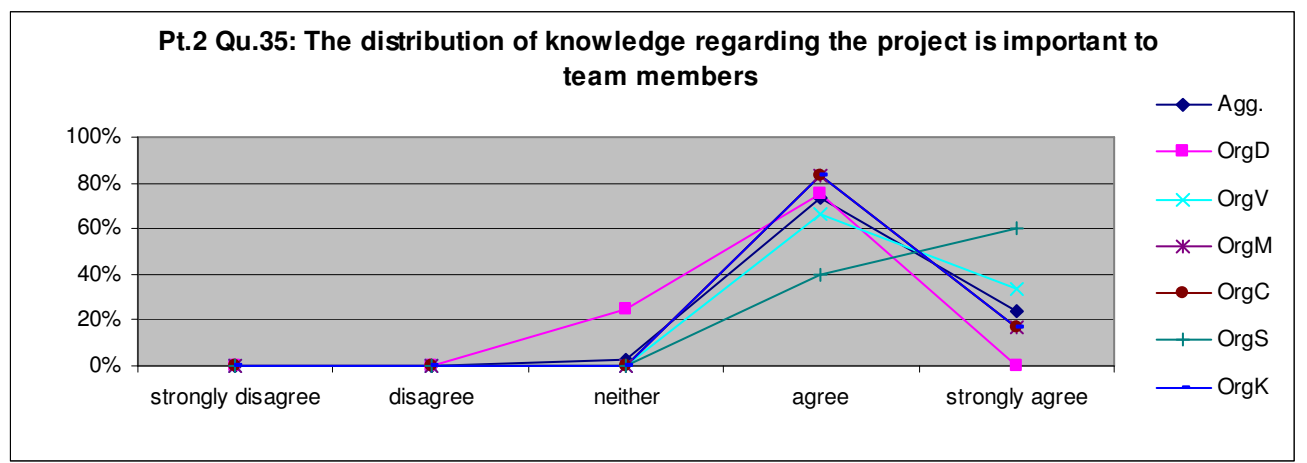

Figure 7-30: Pt.2 Qu.35: The distribution of knowledge regarding the project is important to team members

'It is the job of the project manager to ensure that all members are appropriately informed on project related information.' (OrgS PM1)

The project manager in Organisation S (State Authority) is responsible for managing and coordinating all aspects of the project, including ensuring that all appropriate documentation is available for viewing and that the Executive team is informed as required. Given this, the project manager has the responsibility for ensuring all governance documentation is current and closely followed. Appendix A15 outlines the process to be undertaken for all I.T. projects within Organisation $\mathrm{S}$ and details a suite of eight processes and associated templates that are required to be followed for all for I.T. projects. These processes follow a generic I.T. project lifecycle process, with key milestones identified for documentation completion and business approval.

The role of the OCT within Organisation $\mathrm{S}$ is to provide an electronic distributed central file repository for all appropriate project-related material, with editor access provided to team members, contractors and consultants as required (OrgS PM1). The project manager is the administrator of the OCT and has the highest-level access to the OCT controls. The use of the tool is not specifically part of the formal governance processes noted above, but rather is an implicit component of the project-related process.

However its distributed function is not fully utilised in many of the cases, where it is the project manager who is responsible for distributing information, rather than the OCT facilitating this role. This is in contrast with the findings for Pt.2 Qu. 38, $39 \& 40$ ) and in this regard, the OCT provides a functionality which seems to be supported by the team members, but not necessarily used by them. 
Of note is that responses are spread in respect to whether announcement boards assist with the distribution of important information (Pt.2 Qu.41) and whether the project manager is the most suitable person to distribute knowledge (Pt.2 Qu.42, Figure 7-31). This last finding also supports the distribution nature of projects and the premise behind OCTs, where multiple people can contribute to the posting of information. This is turn provides a tension for project managers who enjoy a level of control of the information flow.

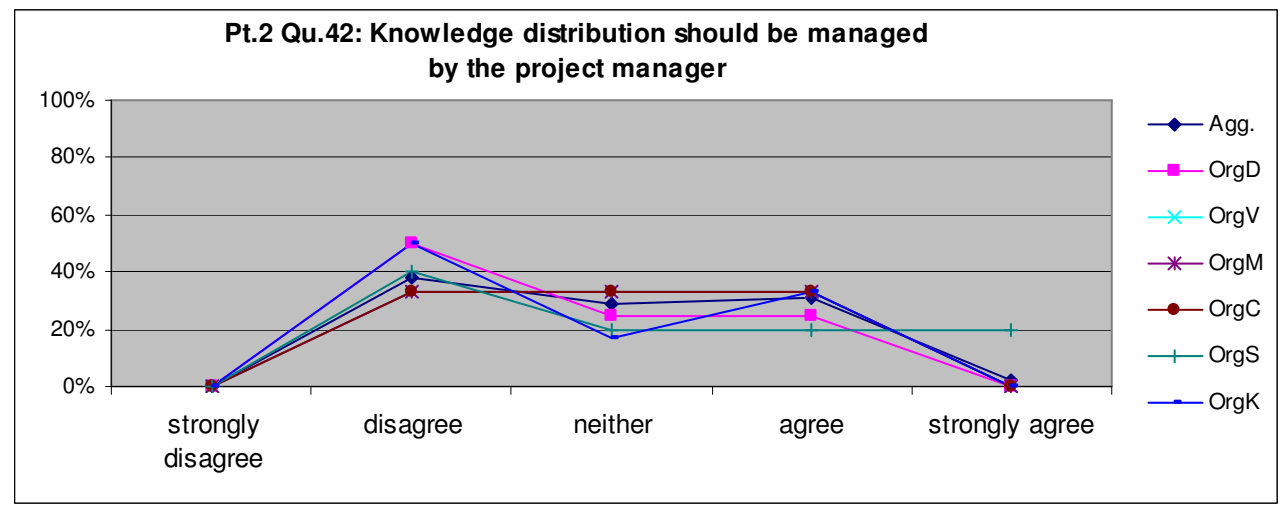

Figure 7-31: Pt.2 Qu.42: Knowledge distribution should be managed by the project manager

The first of these points is consistent with findings from previous statements regarding the use and effectiveness of the Announcement Board functionality (most notably in Part One, Section Five) and as such reaffirms that this feature is not the only tool used to effectively manage information dissemination across the PME. The second point however seems out of place with information received from interviews, where project managers called for greater control of project-related information, especially if this were to result in a lessening of emails received, or greater control of documents or governance processes (Organisation M, K, S). 


\subsubsection{PART TWO, Section Six: Negotiation}

This section reviewed the role of negotiation in the PME.

Table 7-16: Negotiation

\begin{tabular}{|c|c|c|c|c|c|c|c|c|}
\hline \multirow[t]{2}{*}{$\begin{array}{l}43(116) \text {. Negotiation is an integral } \\
\text { part of managing stakeholders }\end{array}$} & $\underset{n=42}{\text { Agg. }}$ & $\underset{n=4}{\operatorname{OrgD}}$ & $\underset{n=9}{\operatorname{OrgV}}$ & $\underset{n=12}{\operatorname{OrgM}}$ & $\underset{n=6}{\operatorname{OrgCC}}$ & $\underset{n=5}{\operatorname{OrgS}}$ & $\underset{n=6}{\operatorname{OrgK}}$ & \multirow[t]{2}{*}{ Comment } \\
\hline & \multicolumn{7}{|c|}{ Case responses \% } & \\
\hline strongly disagree & $\mathbf{0}$ & 0 & 0 & 0 & 0 & 0 & 0 & \multirow{5}{*}{$\begin{array}{l}\text { More than three quarters of } \\
\text { respondents }(86 \%) \text { 'agree' to } \\
\text { 'strongly agree' that negotiation is an } \\
\text { integral part of managing } \\
\text { stakeholders. }\end{array}$} \\
\hline disagree & 2 & 0 & 0 & 0 & 17 & 0 & 0 & \\
\hline neither & 12 & 0 & 11 & 17 & 0 & 0 & 33 & \\
\hline agree & 67 & 100 & 44 & 67 & 83 & 60 & 67 & \\
\hline strongly agree & 19 & 0 & 44 & 17 & 0 & 40 & 0 & \\
\hline $\begin{array}{l}44 \text { (117). Negotiation requires } \\
\text { communication amongst } \\
\text { stakeholders }\end{array}$ & Agg. & OrgD & OrgV & OrgM & OrgC & OrgS & OrgK & Comment \\
\hline strongly disagree & $\mathbf{0}$ & 0 & 0 & 0 & 0 & 0 & 0 & \multirow{5}{*}{$\begin{array}{l}\text { Almost all respondents ( } 96 \%) \text { 'agree' } \\
\text { to 'strongly agree' that negotiation } \\
\text { requires communication amongst } \\
\text { stakeholders. }\end{array}$} \\
\hline disagree & 0 & 0 & 0 & 0 & 0 & 0 & 0 & \\
\hline neither & 2 & 0 & 0 & 8 & 0 & 0 & 0 & \\
\hline agree & 76 & 100 & 67 & 67 & 100 & 60 & 83 & \\
\hline strongly agree & 21 & 0 & 33 & 25 & 0 & 40 & 17 & \\
\hline $\begin{array}{l}45(118) . \text { Incentives are central to } \\
\text { negotiations }\end{array}$ & Agg. & OrgD & OrgV & OrgM & OrgC & OrgS & OrgK & Comment \\
\hline strongly disagree & 2 & 0 & 0 & 0 & 0 & 20 & 0 & \multirow{5}{*}{$\begin{array}{l}\text { Responses are spread across the scales } \\
\text { in respect to the statement that } \\
\text { incentives are central to negotiations. } \\
\text { More than one half of respondents } \\
\text { (52\%) 'agree' to 'strongly agree' with } \\
\text { this statement. }\end{array}$} \\
\hline disagree & 12 & 25 & 11 & 8 & 33 & 0 & 0 & \\
\hline neither & 33 & 50 & 44 & 25 & 17 & 20 & 50 & \\
\hline agree & 45 & 25 & 33 & 58 & 50 & 60 & 33 & \\
\hline strongly agree & 7 & 0 & 11 & 8 & 0 & 0 & 17 & \\
\hline $\begin{array}{l}46(119) . \text { OCT hamper the } \\
\text { negotiation process with } \\
\text { stakeholders }\end{array}$ & Agg. & OrgD & OrgV & OrgM & OrgC & OrgS & OrgK & Comment \\
\hline strongly disagree & 5 & 0 & 0 & 0 & 0 & 20 & 17 & \multirow{5}{*}{$\begin{array}{l}\text { Half of the respondents }(50 \%) \text { were } \\
\text { neutral in response to the statement } \\
\text { that OCTs hamper the negotiation } \\
\text { process with stakeholders, while } 42 \% \\
\text { 'disagree' to 'strongly disagree'. This } \\
\text { statement was worded to elicit a } \\
\text { negative response. }\end{array}$} \\
\hline disagree & 38 & 25 & 67 & 25 & 33 & 40 & 33 & \\
\hline neither & 50 & 75 & 33 & 67 & 50 & 40 & 33 & \\
\hline agree & 7 & 0 & 0 & 8 & 17 & 0 & 17 & \\
\hline strongly agree & $\mathbf{0}$ & 0 & 0 & 0 & 0 & 0 & 0 & \\
\hline $\begin{array}{l}47(120) . \text { Negotiations between } \\
\text { stakeholders is aided when parties } \\
\text { trust each other }\end{array}$ & Agg. & OrgD & OrgV & OrgM & OrgC & OrgS & OrgK & Comment \\
\hline strongly disagree & $\mathbf{0}$ & 0 & 0 & 0 & 0 & 0 & 0 & \multirow{5}{*}{$\begin{array}{l}\text { More than } 90 \% \text { of respondents }(93 \%) \\
\text { 'agree' to 'strongly agree' that } \\
\text { negotiations between stakeholders is } \\
\text { aided when parties trust each other. }\end{array}$} \\
\hline disagree & $\mathbf{0}$ & 0 & 0 & 0 & 0 & 0 & 0 & \\
\hline neither & 7 & 25 & 0 & 8 & 0 & 20 & 0 & \\
\hline agree & 69 & 75 & 44 & 83 & 100 & 40 & 67 & \\
\hline strongly agree & 24 & 0 & 56 & 8 & 0 & 40 & 33 & \\
\hline
\end{tabular}

\section{Summary}

Negotiations are seen to play an important part in managing stakeholders (Pt.2 Qu.43), with

Organisation D (State Government org) unanimously supporting this statement. Five of the six cases were also unanimous in their support for the statement that negotiation requires communication across stakeholders (Pt.2 Qu.44). There was also a strong response to the statement that negotiations between stakeholders are aided when parties trust each other (Pt.2 
Qu.47, Figure 7-32). This is consistent with responses received in the previous section on Trust (Part Two, Section One) and in particular Pt.2 Qu.5 where $89 \%$ of respondents 'agree' to 'strongly agree' that negotiations depend on the presence of trust. The three organisations (Organisations D, M \& S) that did not fully support this statement were from a variety of management structures and project environments, and were all governed by, or had organisational stakeholders drawn from the government / political landscape. The research may infer from this that the management and negotiation of these stakeholders is more about communication and information, than it is about trust. This is supported through statements from the three organisations (D, M \&S) where Executive management personnel are expressly excluded from the OCTs for a variety of reasons. These reasons include their perceived unwillingness to engage in the medium, as a means to control the information flow outside of these groups, and alternately using the OCT as a governance mechanism to demonstrate to Executive that the PME has complied with certain processes.

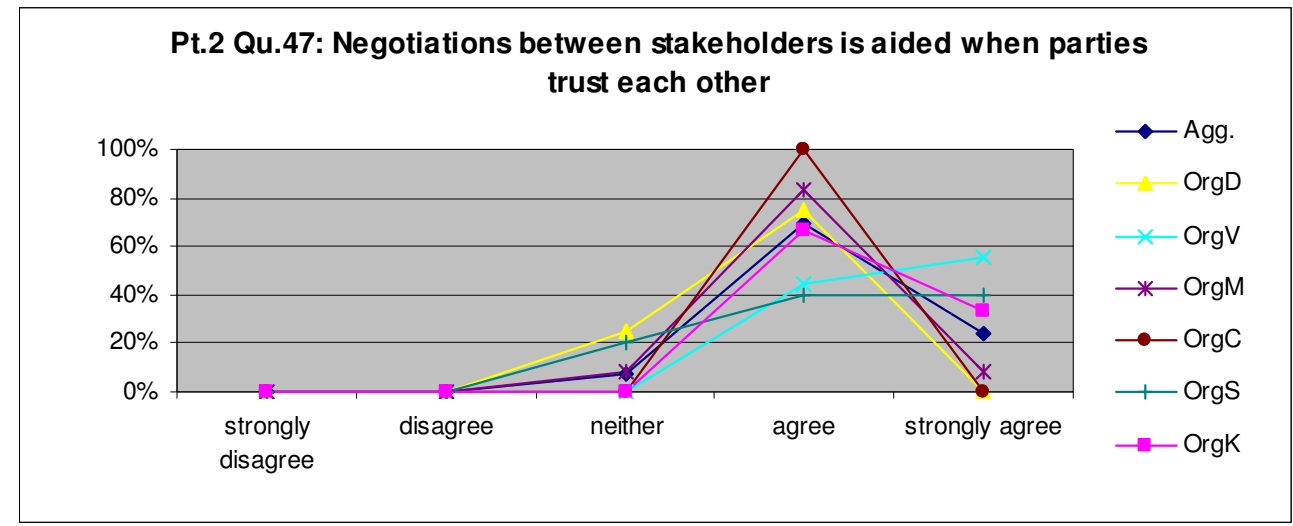

Figure 7-32: Pt.2 Qu.47: Negotiations between stakeholders is aided when parties trust each other

The responses to the statements that incentives are central to negotiations (Pt.2 Qu.45) and that OCTs hamper the negotiations process with stakeholders (Pt.2 Qu.46) are spread across the scale. More than half of the respondents $(52 \%)$ tend to support the first of these statements, while there is a stronger tendency towards a neutral response for the latter statement. The findings in this section do not allow for further extrapolation of the results. 


\subsubsection{PART TWO, Section Seven: Incentives}

This section reviewed the use of Incentives, such as time or money, in the PME.

Table 7-17: Incentives

\begin{tabular}{|c|c|c|c|c|c|c|c|c|}
\hline \multirow[t]{2}{*}{$\begin{array}{l}48(121) \text {. Incentives are a } \\
\text { prerequisite to sharing information }\end{array}$} & $\underset{n=42}{\text { Agg. }}$ & $\underset{n=4}{\operatorname{OrgD}}$ & $\underset{n=9}{\operatorname{OrgV}}$ & $\underset{n=I 2}{\operatorname{OrgM}}$ & $\underset{n=6}{\operatorname{OrgC}}$ & $\underset{n=5}{\operatorname{OrgS}}$ & $\underset{n=6}{\operatorname{OrgK}}$ & \multirow[t]{2}{*}{ Comment } \\
\hline & \multicolumn{7}{|c|}{ Case responses \% } & \\
\hline strongly disagree & 5 & 0 & 0 & 0 & 0 & 40 & 0 & \multirow{5}{*}{$\begin{array}{l}\text { Responses are spread across the } \\
\text { scale in respect to the statement that } \\
\text { incentives are a prerequisite to } \\
\text { sharing information. Half of the } \\
\text { respondents 'disagree' to 'strongly } \\
\text { disagree' with this statement. }\end{array}$} \\
\hline disagree & 45 & 0 & 67 & 33 & 83 & 40 & 33 & \\
\hline neither & 29 & 75 & 22 & 33 & 17 & 0 & 33 & \\
\hline agree & 19 & 25 & 11 & 33 & 0 & 20 & 17 & \\
\hline strongly agree & 2 & 0 & 0 & 0 & 0 & 0 & 17 & \\
\hline $\begin{array}{l}49(122) \text {. OCT reduce the need for } \\
\text { incentives in the project } \\
\text { environment }\end{array}$ & Agg. & OrgD & OrgV & OrgM & OrgC & OrgS & OrgK & Comment \\
\hline strongly disagree & $\mathbf{0}$ & 0 & 0 & 0 & 0 & 0 & 0 & \multirow{5}{*}{$\begin{array}{l}\text { Respondents equally rated ( } 43 \%) \\
\text { 'neither' and 'disagree' in respect to } \\
\text { the statement that the OCT reduces } \\
\text { the need for incentives in the project } \\
\text { environment. This statement was } \\
\text { worded to elicit a negative response. }\end{array}$} \\
\hline disagree & 43 & 0 & 56 & 33 & 67 & 60 & 33 & \\
\hline neither & 43 & 100 & 33 & 42 & 33 & 40 & 33 & \\
\hline agree & 12 & 0 & 11 & 25 & 0 & 0 & 17 & \\
\hline strongly agree & 2 & 0 & 0 & 0 & 0 & 0 & 17 & \\
\hline $\begin{array}{l}50 \text { (123).Without incentives, } \\
\text { information sharing would not occur }\end{array}$ & Agg. & OrgD & OrgV & OrgM & OrgC & OrgS & OrgK & Comment \\
\hline strongly disagree & 12 & 0 & 22 & 8 & 0 & 40 & 0 & \multirow{5}{*}{$\begin{array}{l}\text { Responses are spread across the } \\
\text { scale in respect to the statement that } \\
\text { without incentives, information } \\
\text { would not occur. More than half } \\
(60 \%) \text { 'disagree' to 'strongly } \\
\text { disagree' with this statement. This } \\
\text { statement was worded to elicit a } \\
\text { negative response. }\end{array}$} \\
\hline disagree & 48 & 0 & 56 & 50 & 67 & 40 & 50 & \\
\hline neither & 31 & 75 & 22 & 33 & 33 & 0 & 33 & \\
\hline agree & 10 & 25 & 0 & 8 & 0 & 20 & 17 & \\
\hline strongly agree & $\mathbf{0}$ & 0 & 0 & 0 & 0 & 0 & 0 & \\
\hline
\end{tabular}

\section{Summary}

Responses to whether incentives are a prerequisite to sharing information (Pt.2 Qu.48), if the OCT reduces the need for incentives (Pt.2 Qu.49), and whether without them, information sharing would not occur (Pt.2 Qu.50) are spread across the scale. Of interest in these findings is that Organisation D (the State Government Org) was predominantly neutral in its response to this section. This is consistent with the comments made by the OrgD PM1 where he noted that the project was unique in government circles because it is a project that will never fail due mostly to the strong political nature of the project and the fact that it must be delivered on time. Given this, the project provides little incentives (as understood by this research) to assist with the completion and quality controls of the project.

Responses to Pt.2 Qu.48 indicate support for the notion that incentives are not a prerequisite to sharing information, with Organisations V, C and S disagreeing with this statement. The responses reflect a neutrality across the cases in respect to the role of the OCT in the issue of incentives. Respondents indicate the lack of incentives do not inhibit the capacity for team 
members to share information or for information sharing to occur. The role of the OCT in respect to incentives within the PME would also appear to be generally supportive, with less than $15 \%$ disagreeing with the statement that the OCT reduces the need for incentives in the project environment (Pt.2 Qu.49), however there is a large minority of responses that are neutral in respect to this statement. The findings in this section do not allow for further extrapolation of the results.

\subsubsection{PART TWO, Summary}

The approach to the second part of the Likert instrument was similar to the first. The seven subsections of Part Two of Section 7.2 discussed the use of the OCT against the seven elements of collaboration, drawing on both the findings from Part Two of the Likert instrument, and from the interviews. The discussion was also presented in a cross-case fashion, presenting all the findings together and providing commentary or analysis drawn from these sources where appropriate.

In reviewing the use of the OCTs against the collaboration elements, the research is able to summarise the role and context that the collaborative elements play in the use of the OCTs within the PMEs of the case organisations. These collaborative elements are also mapped against the Collaboration scale as in Part One, in order to provide a consistent framework for analysis. In doing so, it provides additional material with which to address the second sub-research question and it associated proposition.

Research Question Two: $\quad H o w$ are Online Collaborative Toolsets used in the Project Management Environment?

Proposition 2: $\quad$ Online Collaborative Toolsets in the Project Management Environment are used for cooperation, and coordination, and to a lesser extent collaboration'

The discussion noted that the notion of trust is strongly supported by the project teams, and that they require a level of trust between each other in order to operate successfully. The findings in relation to the element of Trust are widely consistent across the cases, suggesting that it is an element that is well understood by the PME. Of interest was that the OCT is not seen to 
necessarily facilitate trust amongst team members (Pt.2 Qu 11). Given the degree of support to the element of Trust however, this element is seen to assist with all three collaboration functions within the PME.

There was also high support for the element of Communication, with project team members consistently indicating strong support for its place in the PME. Communication assists in the management of stakeholders and not surprisingly team members. Of interest is that the use of the OCT does not reduce the need for communication, even though it has the capacity to enhance its effectiveness. However the strong support shown for communication does not always translate to effective communication.

'The organisation doesn't necessarily talk about the important details, and they assume that everyone knows what is happening, but in reality no one is sharing information about the important details' (OrgD PM1).

However given the strength of the support for the element, Communication was seen to assist with all three collaboration functions within the PME.

Responses to the element of Equality vary across the cases. However respondents on the whole note that they do not need to feel equal in order to contribute to the PME, nor was equality demonstrated by team members sharing information. This would suggest that the element does not necessarily play a central role in the PME, regardless of its role in collaboration. Given this, the element is seen to assist with cooperation.

'So there are pockets within the organisation that are basically keeping secrets from everyone else' (OrgS PM1.

In managing Strategic Alliances in the PME, respondents note that a suite of management tools facilitates this including effective knowledge sharing, the presence of trust and open communication. These findings are consistent across the cases, supporting the premise that the management of strategic alliances is a project management knowledge area, one that requires specific processes and skills. Of interest in these findings is that this management function does not necessarily benefit from the use of the OCT. This is reinforced by previous findings where the use of the OCT is minimally used by project stakeholders (OrgS PM1), or as is the case in Organisation M (Government Construction project) that management of the Executive team was 
expressly kept outside of the OCT (OrgM PM1). This element is therefore seen to assist with cooperation and coordination.

Project Knowledge distribution is considered very important in the PME, with all cases showing strong support for this element. The OCT encourages information sharing amongst team members, and it is this centralisation of information which is supported, even though knowledge management is considered to be more than pushing information to a central online repository. Of interest in this area is that respondents do not necessarily agree that the project manager should solely manage knowledge distribution, even though they may have responsibility for ensuring project information is uploaded. Rather it suggests that this information distribution has a presence in many other project roles, some of which could feed into the OCT. Given this broad appeal to the element, and the general support for the OCT, it is seen to assist all three functions of cooperation, coordination and collaboration.

Negotiation plays a large role in the management of stakeholders, requiring communication and the presence of trust. However it is not clear what role the OCTs play in the negotiation process within the PME, with most of the cases neutral on this area. This is becoming a consistent theme across the findings, in that although the OCTs are used for information sharing and communication across the project team, this does not necessarily flow through to managing or negotiating with stakeholders. As such, this element is seen to assist with cooperation functions of the Collaboration scale.

Incentives are also seen to be central to negotiations, as well as a prerequisite to sharing information. This provides an opportunity for the OCT to manage these functions, however given the discussion about the role of the OCTs in managing stakeholders, it is not clear whether the use of the OCTs in the cases either reduce the need for incentives or facilitate this function. Given this, the element is also seen to assist with cooperative functions.

This discussion is presented here in Table 7-18 with a short comment on each feature, and its rating against the Collaboration scale. 
Table 7-18: Cross-case summary against Collaboration scale

\begin{tabular}{|l|l|c|c|c|}
\hline OCT feature & Cross case Usage Summary/Comment & \multicolumn{2}{|l|}{ Cross Case Collaboration Scale } \\
\hline & & Cooperation & Coordination & Collaboration \\
\hline Trust & Strong notion of support for trust within the PME. & $\checkmark$ & $\checkmark$ & $\checkmark$ \\
\hline Communication & $\begin{array}{l}\text { High support for the role effective communication } \\
\text { plays in delivering benefits to project } \\
\text { management. }\end{array}$ & $\checkmark$ & $\checkmark$ & $\checkmark$ \\
\hline Equality & $\begin{array}{l}\text { Not necessarily seen as essential in order to } \\
\text { contribute or share information. }\end{array}$ & $\checkmark$ & & $\checkmark$ \\
\hline Strategic Alliances & $\begin{array}{l}\text { Knowledge sharing, trust and communication are } \\
\text { essential when managing and maintaining } \\
\text { strategic alliances. }\end{array}$ & $\checkmark$ & & \\
\hline $\begin{array}{l}\text { (Project) Knowledge } \\
\text { Distribution }\end{array}$ & $\begin{array}{l}\text { High support for the notion that the distribution of } \\
\text { project knowledge is important in the PME. }\end{array}$ & $\checkmark$ & $\checkmark$ & $\checkmark$ \\
\hline Negotiation & $\begin{array}{l}\text { High support for the importance of negotiations } \\
\text { when dealing with stakeholders, but use of OCT } \\
\text { questioned. }\end{array}$ & $\checkmark$ & & $\checkmark$ \\
\hline Incentives & $\begin{array}{l}\text { Moderate support for the role that incentives play } \\
\text { in the PME. }\end{array}$ & $\checkmark$ & & \\
\hline
\end{tabular}




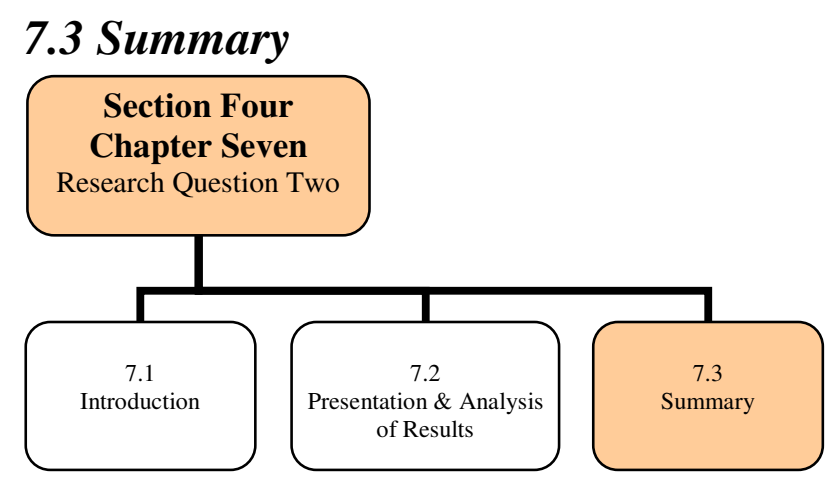

This chapter presented 14 sets of tabulated data and numerous figures in order to provide individual commentary on each result of the Likert questionnaire. This approach allowed for summaries of the data to be applied to each of the sections, whilst incorporating material from the interviews to assist with further understanding the responses provided. The presentation of results followed the layout of the Likert instrument, dealing with the seven general areas of OCTs first, and then the seven elements of collaboration. Each section was also rated against the Collaboration scale to chart the usage of the OCTs in the PME, and against the theories of collaboration developed in the research.

In undertaking the task in this way, the research was able to segment the analysis in accordance with the research approach, namely applying an understanding of the features of the OCT to the PME in order to gauge their relevance to the application and presence of collaboration within this environment.

The Literature Review noted that an organisation can be structured according to the way it is to deliver the project, and that the culture of the organisation will subsequently have direct influence on the project (PMI, 2004).

As Deal and Kennedy (1982) propose, the culture of the lead organisation will determine not only the choice of OCT, but the organisation/management structure. The type of project also determines the choice of the OCT.

'The alliance delivery method was chosen due to the complexity of the project' (OrgK PM1). 
The three construction projects used construction orientated OCTs which had strong document management capabilities, whilst the two government projects used an OCT that was prescribed by the I.C.T. environment of their respective departments. The use of a social networking OCT was selected by the continuous improvement project, whose focus was on socially connecting and networking its members.

The level of risk and complexity of the project was not reflected in the use of the tool, but moreso in the choice of the tool. For example, Organisation C (Commercial Construction project), which was predominantly an in-house project, selected AutoCad Buzzsaw to manage the drawings of the project, rather than to manage the project team. This feature was central to its approval for use by the management of Organisation $\mathrm{C}$, despite noting that the project was dominated by administrative and contractual processes (a characteristic that was common across all the construction projects). Of note is that the three construction projects had interorganisational project environments, and approached the OCTs in a similar manner, which involved managing the document repository feature successfully and linking in with contract procurement and quality assurance processes (OrgK PM1). The tool also greatly reduced printing and courier costs as a result of drawings being updated (OrgM SE1).

The OCTs are not necessarily used to manage the range of project stakeholders however, with communication to the business owner or client often expressly kept outside the OCT. In this sense, the OCTs are used to streamline the preparation required for reporting to stakeholders, rather than actually reporting to stakeholders, whilst also being used to manage scheduling activities.

As was discussed in Chapter Three on the PME, there is a distinction between traditional and contemporary project management, where the latter focuses on managing the work process through collaborative strategies (Romano et al., 2002). The tools for collaboration appear to be present within the cases, however the methodology is not necessarily aligned or designed towards a collaborative environment. The use of the OCTs focuses on information sharing and centrally stored documents, but as Romano et al (2002) notes, this on its own, it is not enough. This research noted that much of the use of the OCTs was within the cooperative and coordination scale of collaboration, even though there was relatively strong support for the collaboration elements of trust, communication and project/knowledge distribution. 
This finding is reinforced through the interviews and represents an emergent theme for this research; that the OCTs are used within the PME in order to facilitate cooperation and coordinating functions, and that collaborative activity is not identified within the OCTs or the PMEs.

'I wouldn't say it is collaborative, but it does coordinate a lot of work' (OrgS PM1).

The research was not able to identify if any of the case particulars significantly impact on, or determine the use of the OCTs. Moreover, the PME itself is not altered by the selection of the tool, but determines the extent to which its features will be used. This was supported by interviews where the strategic use of the OCT was often relegated to a particular team member (PM or equivalent) with other team members becoming recipients of these messages (as distinct from active co-contributors).

This finding is supported by O'Brien (2000) who notes that even in some of the most collaborative teams, traditional communication patterns will prevail, limiting access to information and communication. This would appear to be occurring in the case organisations reviewed, regardless that all deployed OCTs for their project environments.

The OCTs in the cases are used in an asynchronous fashion, making them the electronic project office, rather than a virtual project team. The synchronous feature, so strongly linked to the promise of online collaboration, is not utilised by the cases, nor presented or promoted as a dominant feature in the OCT itself.

The deployment of the OCT is not associated with a project management methodology, and as such is just one of the many tools used by the project manager and team to manage the project. The OCT is part of a set of processes with related functions that are consolidated into a functioning, unified whole (PMI, 2004).

'There is not a standard project management methodology . . but there are checks in place to ensure requirements are being met' (OrgC PM1)

'The methodology is used, however there is not a strict adherence to it . . . (it is) more about documentation than about methodology' (OrgM PM1) 
Lastly, the research did not uncover any activities to support the premise that the use of the OCT was specifically for collaboration. The findings indicate that although there is strong support for collaboration across the cases, the use of the OCT was not aligned to this use, but to the cooperative or coordinative aspects.

In presenting and analysing the data in this chapter, the research has addressed the second of the research questions:

How are Online Collaborative Toolsets used in the Project Management Environment?

The analysis can now also affirm the associated proposition:

Online Collaborative Toolsets in the Project Management Environment are used for cooperation and coordination, and to a lesser extent collaboration.

The following chapter will address the third and final question of the research, which seeks to review the role and extent to which collaboration exists within the PME. It will undertake this task through applying different tests to the data, and in doing so will provide further analysis on the manner in which OCTs are used, and the role that collaboration plays in this application. In making these comments the third and final research question and associated proposition is resolved highlighting implications for further research and theory. 


\section{SECTION FOUR}

\section{CHAPTER EIGHT - What is the Level of Collaboration when using Online Collaborative Toolsets in the Project Management Environment?}

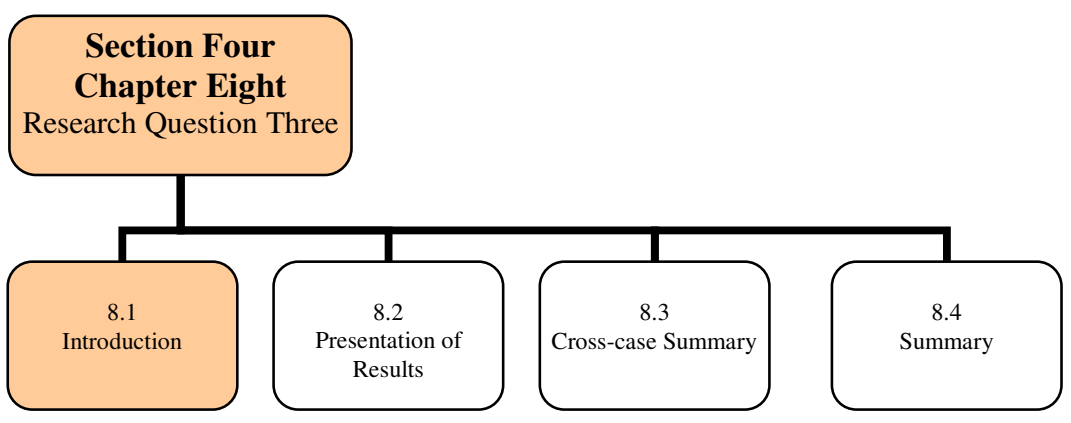

\subsection{Introduction}

This chapter continues the work introduced in Chapter Four, where collaboration was discussed. In this chapter, cooperation, coordination and collaboration were introduced as belonging to scales of collaboration, serving to highlight the variation in the way that collaboration can be understood and applied within the project management environment (PME). This lead to the introduction of the third and final research question:

What is the level of collaboration when using Online Collaborative Toolsets in the Project Management Environment?

This research question will be approached by reviewing the use of each OCT against the three scales of collaboration. This will assist to develop an understanding of the operational usage of the OCT within the context of the Collaboration scale, and in doing so provide a clearer understanding of the prerequisites required and the benefits offered through the use of an OCT within the PME. In answering this research question, an associated proposition emerges:

Collaboration can be modelled as a scale ranging from cooperation through coordination to collaboration. 
This chapter has four main sections, including this introduction in Section One. Section Two will present the six individual cases against the Collaboration scale, while Section Three will provide the cross-case summary to these findings. The fourth section will provide a conclusion to the chapter.

\subsection{Presentation of Results: Collaboration Scale}

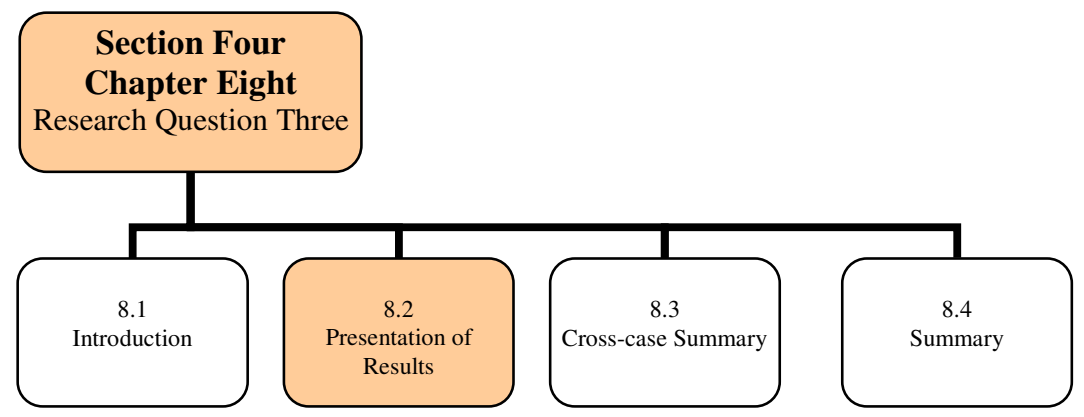

The following section will review the use of the individual OCTs within their PME or organisational context, using the Collaboration scale outlined in Chapter Four, s4.5. The application of this scale to the data enables the OCT to be reviewed against elements that have been identified as contributing to the presence of cooperation, coordination and collaboration. In approaching the analysis this way, the research focuses on the research question at hand, and contributes to the development of an understanding of the effectiveness of the tool within a specific operating environment. The results presented in these next two sections of the chapter will first concentrate on each specific case, and then summarise and analyse these findings across all six cases.

Each case will be discussed individually, providing a short summary of the use of the tool drawing from the analysis undertaken in the previous chapter. The Likert data will then be presented against the collaboration scale, detailing each organisation's use of the OCT as it applies to the seven elements of collaboration (as defined by the Collaboration scale developed in this research). To reiterate, the seven elements of the Collaboration scale are:

1. Resources

2. Task/scheduling

3. Communication

4. Information Sharing

5. Relationships

6. Rewards

7. Negotiation 
As noted in Chapter Five, the use of multiple approaches by which to analyse and triangulate the data provides alternate methods from which to understand the findings, and this presentation of the data using the Collaboration scale will add to the analysis of the data, in measuring the level of collaboration when using the OCTs within each organisation. The structure of the tables used to present the data for each organisation includes the Likert section reference point, question number, Likert statement, Collaboration scale ID, Tally, Percent of total in case and Rating. Statements in red have had their results reversed for consistency. A mean value for each of the seven collaboration scale elements is also included in the tables.

A summary of each of these elements as they relate to the organisation is then provided, including a mean value for each Collaboration scale. This value will be used to plot the results onto a graph for each case and in doing so highlights the variation in use by each organisation of the OCT. The results for each organisation are also presented alongside the Aggregate results to serve as a comparison.

\subsubsection{Organisation D (State Government Organisation)}

IBM notes the key benefits of QuickPlace to include anywhere/anytime access to information, asynchronous collaboration processes, facilitation of the formation of working teams, and centralised data for team members.

The description presented through the general summaries of the quantitative and qualitative data gathering processes for Organisation D indicates that while these claims may be an accurate description of the product, the application or implementation of all benefits do not necessarily follow through to the PME or its use of the OCT. The case study of Organisation D suggests that the anywhere/anytime capability of the product is appreciated by the team members, although as the project is not distributed outside a government network, this functionality is not exploited fully, as it is assumed that most access occurs onsite. Organisation D uses the product against departmental guidelines, using it more for document management and centralised document storage, than for collaboration practices.

Table 8-1 provides the results of the use of the IBM QuickPlace OCT within Organisation D against the Collaboration scale. 
Table 8-1: Organisation D sorted against Collaboration scale

\begin{tabular}{|c|c|c|c|c|c|c|}
\hline $\begin{array}{l}\text { Likert } \\
\text { Section }\end{array}$ & $\begin{array}{l}\text { Qu. } \\
\text { No. }\end{array}$ & Likert Statement & $\begin{array}{l}\text { Cb } \\
\text { Scale } \\
\text { ID }\end{array}$ & Tally & Percent & Rating \\
\hline 1.2 & 16 & detracts from organisational planning & 1 & 14 & $70 \%$ & mod-high \\
\hline 1.4 & 43 & increases difficulty in managing resources across the project & 1 & 14 & $70 \%$ & mod-high \\
\hline 1.5 & 49 & assists with monitoring and controlling risk in the project environment & 1 & 13 & $65 \%$ & mod-high \\
\hline 1.5 & 50 & provides greater control of resources planning & 1 & 13 & $65 \%$ & mod-high \\
\hline 1.6 & 60 & decreases the ability to manage and control risk & 1 & 13 & $65 \%$ & mod-high \\
\hline 1.7 & 69 & creates an online space which the team uses as a project meeting space & 1 & 13 & $65 \%$ & mod-high \\
\hline 1.7 & 73 & complicates managing staff and resources & 1 & 13 & $65 \%$ & mod-high \\
\hline 1.3 & 29 & assists with project planning & 1 & 12 & $60 \%$ & moderate \\
\hline 1.6 & 54 & manages time more effectively & 1 & 12 & $60 \%$ & moderate \\
\hline 1.6 & 55 & does not replace the number of meetings required & 1 & 12 & $60 \%$ & moderate \\
\hline 1.7 & 70 & increases the amount of time it takes to do things & 1 & 12 & $60 \%$ & moderate \\
\hline 1.4 & 31 & reduces the number of users accessing files & 1 & 11 & $55 \%$ & moderate \\
\hline 1.4 & 36 & increases the effort required to monitor and control risk & 1 & 11 & $55 \%$ & moderate \\
\hline 2.5 & 115 & Knowledge distribution should be managed by the project manager & 1 & 11 & $55 \%$ & moderate \\
\hline \multirow[t]{2}{*}{1.6} & 61 & replaces the need to meet physically & 1 & 10 & $50 \%$ & moderate \\
\hline & & Mean Value Collaboration Scale One & & & $61 \%$ & mod-high \\
\hline 1.1 & 1 & increases chances of meeting project schedules & 2 & 14 & $70 \%$ & mod-high \\
\hline 1.1 & 2 & improves planning activities & 2 & 14 & $70 \%$ & mod-high \\
\hline 1.1 & 3 & improves prioritising tasks & 2 & 14 & $70 \%$ & mod-high \\
\hline 1.1 & 5 & improves delivery of activities in a timely manner & 2 & 14 & $70 \%$ & mod-high \\
\hline 1.4 & 39 & increases the time and effort required to manage documents & 2 & 14 & $70 \%$ & mod-high \\
\hline 1.4 & 40 & decreases the quality controls of the document & 2 & 14 & $70 \%$ & mod-high \\
\hline 1.5 & 53 & assists with the execution of the project plan & 2 & 14 & $70 \%$ & mod-high \\
\hline 1.1 & 4 & complicates coordinating activities across the project environment & 2 & 13 & $65 \%$ & mod-high \\
\hline 1.5 & 48 & Contributes to controlling the project schedule & 2 & 13 & $65 \%$ & mod-high \\
\hline 1.7 & 71 & assists with managing scope issues & 2 & 13 & $65 \%$ & mod-high \\
\hline 1.7 & 72 & does not improve quality control & 2 & 13 & $65 \%$ & mod-high \\
\hline 1.5 & 52 & increases the capacity to manage risk & 2 & 12 & $60 \%$ & moderate \\
\hline 1.6 & 57 & enables more effective control over schedule and project issues & 2 & 12 & $60 \%$ & moderate \\
\hline 1.3 & 23 & risks quality control within the project & 2 & 10 & $50 \%$ & moderate \\
\hline \multirow[t]{2}{*}{1.7} & 65 & increases the amount of administration for the project & 2 & 10 & $50 \%$ & moderate \\
\hline & & Mean Value Collaboration Scale Two & & & $65 \%$ & mod-high \\
\hline 2.2 & 94 & communication is essential in achieving project objectives / deliverables & 3 & 18 & $90 \%$ & high \\
\hline 2.2 & 85 & effective communication benefits project management & 3 & 17 & $85 \%$ & High \\
\hline 2.2 & 87 & stakeholder management relies on communication & 3 & 17 & $85 \%$ & High \\
\hline 2.2 & 89 & managing team members requires communication & 3 & 17 & $85 \%$ & High \\
\hline 2.2 & 90 & communication is not important when using an OCT & 3 & 17 & $85 \%$ & High \\
\hline 2.3 & 101 & communication assists relationship management of project teams & 3 & 17 & $85 \%$ & High \\
\hline 1.1 & 7 & communicates the availability of team members and resources & 3 & 16 & $80 \%$ & mod-high \\
\hline 2.6 & 117 & Negotiation requires communication amongst stakeholders & 3 & 16 & $80 \%$ & mod-high \\
\hline 1.4 & 34 & discourages communication across the project team & 3 & 15 & $75 \%$ & mod-high \\
\hline 2.4 & 105 & strategic alliances are managed by open communication & 3 & 15 & $75 \%$ & mod-high \\
\hline 1.7 & 67 & Streamlines communication to the project teams & 3 & 14 & $70 \%$ & mod-high \\
\hline 1.2 & 19 & hampers communication across the project team & 3 & 13 & $65 \%$ & mod-high \\
\hline 1.6 & 58 & enhances communication across the project team & 3 & 13 & $65 \%$ & mod-high \\
\hline 2.2 & 92 & Team members communicate more effectively when using OCT & 3 & 13 & $65 \%$ & mod-high \\
\hline 2.2 & 95 & communication is not clearer when using OCT & 3 & 13 & $65 \%$ & mod-high \\
\hline 2.2 & 96 & communication across the project environment does not benefit from using OCT & 3 & 13 & $65 \%$ & mod-high \\
\hline 1.3 & 24 & improves communication regarding essential information & 3 & 12 & $60 \%$ & Moderate \\
\hline 1.5 & 44 & manages the use of email more efficiently & 3 & 12 & $60 \%$ & Moderate \\
\hline 1.5 & 47 & is ineffective when communicating to the project team & 3 & 12 & $60 \%$ & Moderate \\
\hline 2.2 & 86 & communication is not enhanced by technology & 3 & 12 & $60 \%$ & Moderate \\
\hline \multirow[t]{2}{*}{2.2} & 93 & online technology does not assist with communication in the project environment & 3 & 12 & $60 \%$ & Moderate \\
\hline & & Mean Value Collaboration Scale Three & & & $72 \%$ & mod-high \\
\hline 2.5 & 113 & Knowledge distribution is more than having a central repository of documents in an OCT & 4 & 16 & $80 \%$ & mod-high \\
\hline 1.2 & 15 & centralises reporting of data & 4 & 15 & $75 \%$ & mod-high \\
\hline 1.4 & 30 & enables easy access to all documents in the central repository & 4 & 15 & $75 \%$ & mod-high \\
\hline 1.4 & 33 & increases ease of retrieving documents & 4 & 15 & $75 \%$ & mod-high \\
\hline 1.4 & 35 & provides an incentive to share information amongst team members & 4 & 15 & $75 \%$ & mod-high \\
\hline 2.2 & 88 & sharing knowledge can be enhanced using online technology & 4 & 15 & $75 \%$ & mod-high \\
\hline 2.4 & 103 & Knowledge sharing is a critical component of managing alliances & 4 & 15 & $75 \%$ & mod-high \\
\hline 2.5 & 108 & the distribution of knowledge regarding the project is important to team members & 4 & 15 & $75 \%$ & mod-high \\
\hline 2.5 & 109 & OCT encourage sharing information amongst team members & 4 & 15 & $75 \%$ & mod-high \\
\hline 2.5 & 114 & Announcement boards in OCT assist in the distribution of important information & 4 & 15 & $75 \%$ & mod-high \\
\hline 1.2 & 12 & decreases confidence in the data & 4 & 14 & $70 \%$ & mod-high \\
\hline 1.5 & 51 & creates difficulty in distributing information across the project & 4 & 14 & $70 \%$ & mod-high \\
\hline 1.7 & 64 & ensures all documents are easily found & 4 & 14 & $70 \%$ & mod-high \\
\hline 1.7 & 66 & ensures all project related information is kept up to date and in one place & 4 & 14 & $70 \%$ & mod-high \\
\hline
\end{tabular}




\begin{tabular}{|c|c|c|c|c|c|c|}
\hline $\begin{array}{l}\text { Likert } \\
\text { Section }\end{array}$ & $\begin{array}{l}\text { Qu. } \\
\text { No. }\end{array}$ & Likert Statement & $\begin{array}{l}\mathrm{Cb} \\
\text { Scale } \\
\text { ID } \\
\end{array}$ & Tally & Percent & Rating \\
\hline 2.1 & 81 & documents can be shared in the project team without trust & 4 & 14 & $70 \%$ & mod-high \\
\hline 2.3 & 98 & knowledge distribution is not important for team members & 4 & 14 & $70 \%$ & mod-high \\
\hline 2.3 & 99 & equality is demonstrated by sharing information between team members & 4 & 14 & $70 \%$ & mod-high \\
\hline 2.5 & 111 & knowledge distribution should be on an ad hoc basis & 4 & 14 & $70 \%$ & mod-high \\
\hline 2.5 & 112 & knowledge should not be distributed from a central location & 4 & 14 & $70 \%$ & mod-high \\
\hline 1.2 & 10 & improves the quality of data in the database & 4 & 13 & $65 \%$ & mod-high \\
\hline 1.2 & 11 & manages data from a central environment & 4 & 13 & $65 \%$ & mod-high \\
\hline 1.2 & 14 & decreases the time it takes to undertake tasks & 4 & 13 & $65 \%$ & mod-high \\
\hline 1.3 & 27 & assists in managing change controls in the project & 4 & 13 & $65 \%$ & mod-high \\
\hline 1.4 & 38 & increases difficulty in accessing files remotely & 4 & 13 & $65 \%$ & mod-high \\
\hline 2.2 & 91 & OCT improve information sharing & 4 & 13 & $65 \%$ & mod-high \\
\hline 1.2 & 13 & increases possibility of data corruption & 4 & 12 & $60 \%$ & Moderate \\
\hline 1.3 & 21 & increases efficiencies in distribution of documents & 4 & 12 & $60 \%$ & Moderate \\
\hline 1.3 & 25 & produces inefficiencies in retrieval of information & 4 & 12 & $60 \%$ & Moderate \\
\hline 1.4 & 41 & enhances contract management processes & 4 & 12 & $60 \%$ & Moderate \\
\hline 1.7 & 63 & is the most effective tool for distributing information to the project team & 4 & 12 & $60 \%$ & Moderate \\
\hline 1.2 & 17 & reduces the complexity of maintaining data & 4 & 11 & $55 \%$ & Moderate \\
\hline 1.3 & 20 & increases the number of versions of documents & 4 & 11 & $55 \%$ & Moderate \\
\hline 1.7 & 68 & increases the amount of paperwork in managing projects & 4 & 11 & $55 \%$ & Moderate \\
\hline \multirow[t]{2}{*}{1.3} & 28 & adds time and cost to managing the shared documents & 4 & 10 & $50 \%$ & Moderate \\
\hline & & Mean Value Collaboration Scale Four & & & $67 \%$ & mod-high \\
\hline 1.2 & 18 & requires a level of trust between team members & 5 & 16 & $80 \%$ & mod-high \\
\hline 1.3 & 22 & requires a level of trust between team members & 5 & 16 & $80 \%$ & mod-high \\
\hline 2.1 & 74 & I trust my team members & 5 & 16 & $80 \%$ & mod-high \\
\hline 2.1 & 75 & my team members trust me & 5 & 16 & $80 \%$ & mod-high \\
\hline 2.1 & 76 & the project team requires a level of trust in order to successfully operate & 5 & 16 & $80 \%$ & mod-high \\
\hline 2.1 & 80 & trust is required between stakeholders in order to achieve project objectives / deliverables & 5 & 16 & $80 \%$ & mod-high \\
\hline 1.1 & 6 & assists with the development of trust across the project team & 5 & 15 & $75 \%$ & mod-high \\
\hline 2.1 & 78 & negotiations depend on the presence of trust & 5 & 15 & $75 \%$ & mod-high \\
\hline 2.1 & 79 & trust is important when sharing knowledge across the project areas & 5 & 15 & $75 \%$ & mod-high \\
\hline 2.4 & 104 & trust is not essential to developing and maintaining Strategic Alliances & 5 & 15 & $75 \%$ & mod-high \\
\hline 2.5 & 110 & the distribution of knowledge amongst team members is central to trust & 5 & 15 & $75 \%$ & mod-high \\
\hline 1.1 & 9 & detracts from managing Strategic alliances within the project team & 5 & 14 & $70 \%$ & mod-high \\
\hline 1.4 & 32 & develops trust between team members & 5 & 14 & $70 \%$ & mod-high \\
\hline 1.4 & 42 & assists with negotiations within the project management environment & 5 & 14 & $70 \%$ & mod-high \\
\hline 1.5 & 46 & requires team members to trust each other & 5 & 14 & $70 \%$ & mod-high \\
\hline 2.1 & 82 & trust is not required in the project management environment & 5 & 14 & $70 \%$ & mod-high \\
\hline 1.1 & 8 & supports equality amongst team members & 5 & 13 & $65 \%$ & mod-high \\
\hline 1.3 & 26 & develops an equality amongst the team members & 5 & 13 & $65 \%$ & mod-high \\
\hline 1.5 & 45 & develops relationships with team members & 5 & 13 & $65 \%$ & mod-high \\
\hline 2.1 & 77 & trust is not important in stakeholder management & 5 & 13 & $65 \%$ & mod-high \\
\hline 2.3 & 97 & members of the project team need to feel equal & 5 & 13 & $65 \%$ & mod-high \\
\hline 2.4 & 102 & Strategic alliances can be strengthened using the OCT & 5 & 13 & $65 \%$ & mod-high \\
\hline 2.4 & 106 & Stakeholder management is not improved when using OCT & 5 & 13 & $65 \%$ & mod-high \\
\hline 1.4 & 37 & reduces the need for alliances/relationships across the project environment & 5 & 12 & $60 \%$ & Moderate \\
\hline 2.1 & 84 & OCT facilitates trust amongst team members & 5 & 12 & $60 \%$ & Moderate \\
\hline 2.3 & 100 & team members do not need to feel equal in order to contribute & 5 & 12 & $60 \%$ & Moderate \\
\hline 2.4 & 107 & OCT delivers the incentives needed to manage Strategic Alliances & 5 & 12 & $60 \%$ & Moderate \\
\hline 1.6 & 62 & develops relationships with team members & 5 & 11 & $55 \%$ & Moderate \\
\hline 2.1 & 83 & collaboration can be achieved without trust & 5 & 11 & $55 \%$ & Moderate \\
\hline \multirow[t]{2}{*}{1.6} & 56 & makes it hard to establish trust between team members & 5 & 10 & $50 \%$ & Moderate \\
\hline & & Mean Value Collaboration Scale Five & & & $69 \%$ & mod-high \\
\hline 1.6 & 59 & discourages innovation and learning across the team & 6 & 12 & $60 \%$ & Moderate \\
\hline 2.6 & 118 & incentives are central to negotiations & 6 & 12 & $60 \%$ & Moderate \\
\hline 2.7 & 122 & OCT reduce the need for incentives in the project environment & 6 & 12 & $60 \%$ & Moderate \\
\hline 2.7 & 121 & incentives are a prerequisite to sharing information & 6 & 11 & $55 \%$ & Moderate \\
\hline \multirow[t]{2}{*}{2.7} & 123 & without incentives, information sharing would not occur & 6 & 11 & $55 \%$ & Moderate \\
\hline & & Mean Value Collaboration Scale Six & & & $\mathbf{5 8 \%}$ & mod \\
\hline 2.6 & 116 & negotiation is an integral part of managing stakeholders & 7 & 16 & $80 \%$ & mod-high \\
\hline 2.6 & 120 & negotiations between stakeholders is aided when parties trust each other & 7 & 15 & $75 \%$ & mod-high \\
\hline \multirow[t]{2}{*}{2.6} & 119 & OCT hamper the negotiation process with stakeholders & 7 & 13 & $65 \%$ & mod-high \\
\hline & & Mean Value Collaboration Scale Seven & & & $73 \%$ & mod-high \\
\hline
\end{tabular}




\section{General Comments on the Findings against the Collaboration Scale Resources}

Respondents in Organisation D rate the use of the OCT in the PME as moderate-high in assisting with resources issues. It assists in organisational planning and managing staff and resources across the project environment, and with monitoring and controlling risk. The OCT does not necessarily reduce the effort required to manage the risk. Responses rate as moderate the use of the OCT for project planning, time management, and the type and number of meetings required.

\section{Task/scheduling}

Respondents in Organisation D are consistently moderate-highly supportive of the use of the OCT in the task/scheduling category. The OCT assists and improves delivery in meeting project schedules, planning activities and prioritising tasks within the PME. It assists in quality controls, and managing scope issues and documentation, including the project plan. These responses are supported through a mixture of direct and negatively posed questions.

\section{Communication}

Respondents are supportive of the role that communication plays in the PME with high support for statements regarding the role of effective communication to achieve project objectives and deliverables, and to manage staff, stakeholders and relationships. The OCT assists in communicating across the project team and with negotiations. Respondents are moderately supportive on whether the use of the OCT reduces the use of email, and whether it is best used to communicate essential information. This is in contrast to the Project Manager's comments that he had problems with the email notification program of QuickPlace. These responses are supported through a mixture of direct and negatively posed questions.

\section{Information Sharing}

Respondents are strongly supportive of the role of knowledge sharing and information distribution across the PME, strongly agreeing with the statement that 'knowledge distribution is more than having a central repository of documents in an OCT'. The OCT assists to centralise data, and enables easy access to information and increases the ease of retrieving documents. It provides a mechanism and incentive to share information across the PME, which is considered important to the team members. Announcement Boards are supported as a feature for distributing 
information, whilst respondents are supportive of the capacity of the OCT to improve confidence in data quality, ensuring information is centralised and coordinated. Knowledge sharing and trust are linked, as was an equality amongst team members when sharing information. The OCT assists in managing and accessing files from a distributed or remote environment. Information sharing in the OCT is seen to add to the complexity of managing documentation including version control, with respondents moderately supportive on whether it reduces the amount of paperwork, time and cost of managing documents. Respondents similarly note that the OCT increases efficiencies in the distribution of documents, whilst also producing inefficiencies in the retrieval of documents.

\section{Relationships}

The use of the OCT requires a level of trust between team members, with the presence of trust supported as an integral part of the PME. Trust is important when sharing knowledge across project areas, and is essential to developing and maintaining strategic alliances. The distribution of knowledge amongst team members is also central to trust. Relationships within the PME are aided by the OCT as it assists with negotiations and strategic alliances, and the development of team relationships including the facilitation of trust. Responses are moderate on whether team members need to feel equal in order to contribute, and whether the OCT delivers the incentives needed to manage strategic alliances. Virtual conference capabilities did not necessarily contribute to the establishment of trust between team members. These responses are supported through a mixture of direct and negatively posed questions.

\section{Rewards}

Respondents are moderately supportive of the role of rewards in the PME, and whether the OCT encourages innovation and learning across the team. The OCT does not reduce the need for incentives to occur, nor are incentives a trigger for information sharing.

\section{Negotiation}

Respondents are highly supportive of the statement that negotiations play an integral part in managing stakeholders, and that it is aided when stakeholder parties trust each other. OCTs do not hamper these negotiations. 
The findings for the last two elements, when viewed in association with the interviews, may indicate that the attainment and management of rewards and negotiation fall outside the functional and operational capacities of the OCT. This comment can be applied across all cases.

\section{Summary of Organisation D}

Figure 8-1 portrays Organisation D as having moderate to high support in the use of the OCT for Communication, Information Sharing and Negotiation elements of the Collaboration scale, suggesting that for this organisation (State Government organisation), the tool is used for cooperation and coordination functions. This is consistent with other findings where the organisation notes that its use of the tool is more for administrative functions, than it is for collaboration. The findings for Organisation D are generally higher than the results for the Aggregate, but indicates a consistent response across the seven elements.

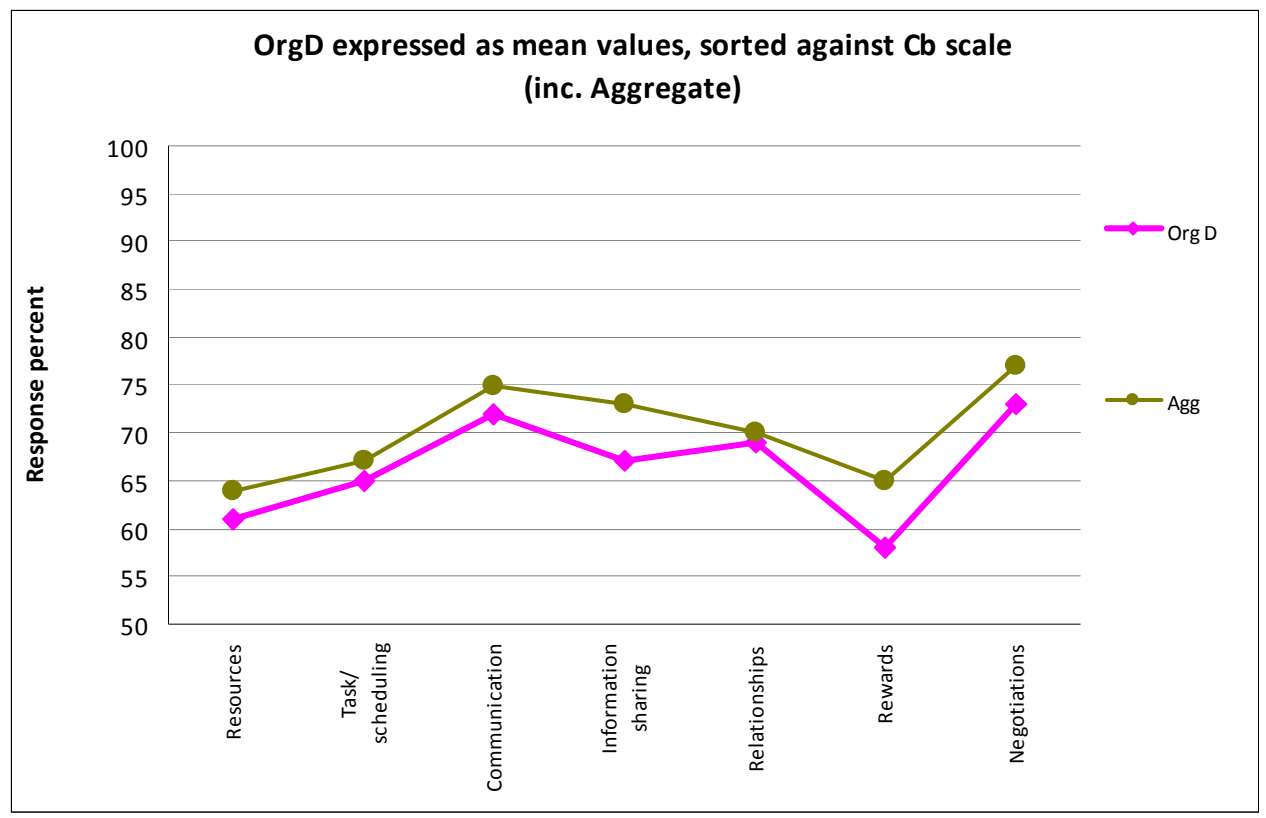

Figure 8-1: OrgD responses to Likert expressed as mean values, sorted against Collaboration scale 


\subsubsection{Organisation V (Continuous Improvement Organisation)}

The vendors of WordPress position the product as a blogging tool which is ultimately customisable to the needs of the environment. Therefore, it is difficult to compare the developer's/distributor's proposed use of the tool against that of Organisation V.

The membership of Organisation V comprises people spread across government whose primary point of contact with each other and the project manager is through the WordPress OCT. The OCT is not hosted in a secure environment, but on the public internet which differentiates it from all the other OCTs and cases reviewed as part of this research. The open environment in which the tool operates has not, in the eyes of the project manager, adversely affected the way in which the tool is used either by him or the membership (OrgV PM1). He notes that the open internet environment has most likely created more freedom for the group as it does not attempt to selfcensor or check its comments inside a government controlled electronic space.

Organisation V uses the tool to push out information to its members, so the publishing function is very well utilised by OrgV PM1. The blog receives responses from the membership, which is mainly in the manner of a response to a posted article by the project manager. The OCT assists with project planning and managing time more effectively and in managing resources across the project. This is a key feature for the OCT, given that a core function for the project manager is to coordinate activities and events, and manage resources across the CIN. The role of communication and information transmittal is therefore important for Organisation V.

Table 8-2 provides the results of the use of the WordPress OCT within Organisation V against the Collaboration scale. 
Table 8-2: Organisation V sorted against Collaboration scale

\begin{tabular}{|c|c|c|c|c|c|c|}
\hline $\begin{array}{c}\text { Likert } \\
\text { Section }\end{array}$ & $\begin{array}{l}\text { Qu. } \\
\text { No. }\end{array}$ & Likert Statement & $\begin{array}{c}\text { Cb } \\
\text { Scale } \\
\text { ID } \\
\end{array}$ & Tally & Percent & Rating \\
\hline 1.7 & 70 & increases the amount of time it takes to do things & 1 & 37 & $82 \%$ & high \\
\hline 1.3 & 29 & assists with project planning & 1 & 36 & $80 \%$ & mod-high \\
\hline 1.6 & 54 & manages time more effectively & 1 & 36 & $80 \%$ & mod-high \\
\hline 1.4 & 43 & increases difficulty in managing resources across the project & 1 & 35 & $78 \%$ & mod-high \\
\hline 1.6 & 60 & decreases the ability to manage and control risk & 1 & 35 & $78 \%$ & mod-high \\
\hline 1.2 & 16 & detracts from organisational planning & 1 & 34 & $76 \%$ & mod-high \\
\hline 1.7 & 73 & complicates managing staff and resources & 1 & 34 & $76 \%$ & mod-high \\
\hline 1.7 & 69 & creates an online space which the team uses as a project meeting space & 1 & 33 & $73 \%$ & mod-high \\
\hline 1.5 & 49 & assists with monitoring and controlling risk in the project environment & 1 & 30 & $67 \%$ & mod-high \\
\hline 1.4 & 36 & increases the effort required to monitor and control risk & 1 & 29 & $64 \%$ & mod-high \\
\hline 1.5 & 50 & provides greater control of resources planning & 1 & 29 & $64 \%$ & mod-high \\
\hline 1.6 & 55 & does not replace the number of meetings required & 1 & 29 & $64 \%$ & mod-high \\
\hline 2.5 & 115 & knowledge distribution should be managed by the project manager & 1 & 27 & $60 \%$ & moderate \\
\hline 1.4 & 31 & reduces the number of users accessing files & 1 & 23 & $51 \%$ & moderate \\
\hline \multirow[t]{2}{*}{1.6} & 61 & replaces the need to meet physically & 1 & 15 & $33 \%$ & low-mod \\
\hline & & Mean Value Collaboration Scale One & & & $68 \%$ & mod-high \\
\hline 1.1 & 2 & improves planning activities & 2 & 38 & $84 \%$ & high \\
\hline 1.1 & 4 & complicates coordinating activities across the project environment & 2 & 38 & $84 \%$ & high \\
\hline 1.1 & 1 & increases chances of meeting project schedules & 2 & 36 & $80 \%$ & mod-high \\
\hline 1.1 & 3 & improves prioritising tasks & 2 & 36 & $80 \%$ & mod-high \\
\hline 1.7 & 71 & assists with managing scope issues & 2 & 35 & $78 \%$ & mod-high \\
\hline 1.1 & 7 & communicates the availability of team members and resources & 3 & 35 & $78 \%$ & mod-high \\
\hline 1.1 & 5 & improves delivery of activities in a timely manner & 2 & 34 & $76 \%$ & mod-high \\
\hline 1.4 & 39 & increases the time and effort required to manage documents & 2 & 33 & $73 \%$ & mod-high \\
\hline 1.5 & 48 & contributes to controlling the project schedule & 2 & 33 & $73 \%$ & mod-high \\
\hline 1.5 & 53 & assists with the execution of the project plan & 2 & 32 & $71 \%$ & mod-high \\
\hline 1.4 & 40 & decreases the quality controls of the document & 2 & 31 & $69 \%$ & mod-high \\
\hline 1.7 & 65 & increases the amount of administration for the project & 2 & 31 & $69 \%$ & mod-high \\
\hline 1.5 & 52 & increases the capacity to manage risk & 2 & 30 & $67 \%$ & mod-high \\
\hline 1.3 & 23 & risks quality control within the project & 2 & 29 & $64 \%$ & mod-high \\
\hline 1.7 & 72 & does not improve quality control & 2 & 29 & $64 \%$ & mod-high \\
\hline \multirow[t]{2}{*}{1.6} & 57 & enables more effective control over schedule and project issues & 2 & 28 & $62 \%$ & mod-high \\
\hline & & Mean Value Collaboration Scale Two & & & 73\% & mod-high \\
\hline 2.2 & 85 & effective communication benefits project management & 3 & 43 & $96 \%$ & high \\
\hline 2.2 & 90 & communication is not important when using an OCT & 3 & 42 & $93 \%$ & high \\
\hline 2.3 & 101 & communication assists relationship management of project teams & 3 & 41 & $91 \%$ & high \\
\hline 2.2 & 89 & managing team members requires communication & 3 & 40 & $89 \%$ & high \\
\hline 2.2 & 94 & communication is essential in achieving project objectives / deliverables & 3 & 40 & $89 \%$ & high \\
\hline 2.6 & 117 & negotiation requires communication amongst stakeholders & 3 & 39 & $87 \%$ & high \\
\hline 2.2 & 87 & stakeholder management relies on communication & 3 & 38 & $84 \%$ & high \\
\hline 1.3 & 24 & improves communication regarding essential information & 3 & 36 & $80 \%$ & mod-high \\
\hline 2.2 & 93 & online technology does not assist with communication in the project environment & 3 & 36 & $80 \%$ & mod-high \\
\hline 1.5 & 44 & manages the use of email more efficiently & 3 & 35 & $78 \%$ & mod-high \\
\hline 1.6 & 58 & enhances communication across the project team & 3 & 35 & $78 \%$ & mod-high \\
\hline 2.4 & 105 & strategic alliances are managed by open communication & 3 & 35 & $78 \%$ & mod-high \\
\hline 1.4 & 34 & discourages communication across the project team & 3 & 34 & $76 \%$ & mod-high \\
\hline 1.7 & 67 & streamlines communication to the project teams & 3 & 34 & $76 \%$ & mod-high \\
\hline 2.2 & 96 & communication across the project environment does not benefit from using OCT & 3 & 34 & $76 \%$ & mod-high \\
\hline 1.2 & 19 & hampers communication across the project team & 3 & 33 & $73 \%$ & mod-high \\
\hline 2.2 & 86 & communication is not enhanced by technology & 3 & 33 & $73 \%$ & mod-high \\
\hline 2.2 & 95 & communication is not clearer when using OCT & 3 & 32 & $71 \%$ & mod-high \\
\hline 1.5 & 47 & is ineffective when communicating to the project team & 3 & 31 & $69 \%$ & mod-high \\
\hline \multirow[t]{2}{*}{2.2} & 92 & team members communicate more effectively when using OCT & 3 & 31 & $69 \%$ & mod-high \\
\hline & & Mean Value Collaboration Scale Three & & & $80 \%$ & mod-high \\
\hline 2.5 & 113 & knowledge distribution is more than having a central repository of documents in an OCT & 4 & 41 & $91 \%$ & high \\
\hline 1.4 & 30 & enables easy access to all documents in the central repository & 4 & 40 & $89 \%$ & high \\
\hline 2.3 & 98 & knowledge distribution is not important for team members & 4 & 39 & $87 \%$ & High \\
\hline 2.4 & 103 & knowledge sharing is a critical component of managing alliances & 4 & 39 & $87 \%$ & High \\
\hline 2.5 & 108 & the distribution of knowledge regarding the project is important to team members & 4 & 39 & $87 \%$ & High \\
\hline 1.3 & 21 & increases efficiencies in distribution of documents & 4 & 38 & $84 \%$ & high \\
\hline 2.2 & 88 & sharing knowledge can be enhanced using online technology & 4 & 38 & $84 \%$ & high \\
\hline 2.2 & 91 & OCT improve information sharing & 4 & 38 & $84 \%$ & high \\
\hline 1.4 & 33 & increases ease of retrieving documents & 4 & 37 & $82 \%$ & high \\
\hline 1.5 & 51 & creates difficulty in distributing information across the project & 4 & 37 & $82 \%$ & high \\
\hline 2.5 & 109 & OCT encourage sharing information amongst team members & 4 & 36 & $80 \%$ & mod-high \\
\hline 2.5 & 111 & knowledge distribution should be on an ad hoc basis & 4 & 36 & $80 \%$ & mod-high \\
\hline 1.2 & 15 & centralises reporting of data & 4 & 35 & $78 \%$ & mod-high \\
\hline 2.5 & 114 & Announcement boards in OCT assist in the distribution of important information & 4 & 35 & $78 \%$ & mod-high \\
\hline
\end{tabular}




\begin{tabular}{|c|c|c|c|c|c|c|}
\hline $\begin{array}{l}\text { Likert } \\
\text { Section }\end{array}$ & $\begin{array}{l}\text { Qu. } \\
\text { No. }\end{array}$ & Likert Statement & $\begin{array}{c}\text { Cb } \\
\text { Scale } \\
\text { ID }\end{array}$ & Tally & Percent & Rating \\
\hline 1.2 & 11 & manages data from a central environment & 4 & 34 & $76 \%$ & mod-high \\
\hline 1.2 & 12 & decreases confidence in the data & 4 & 33 & $73 \%$ & mod-high \\
\hline 1.3 & 25 & produces inefficiencies in retrieval of information & 4 & 33 & $73 \%$ & mod-high \\
\hline 2.1 & 81 & documents can be shared in the project team without trust & 4 & 33 & $73 \%$ & mod-high \\
\hline 1.4 & 35 & provides an incentive to share information amongst team members & 4 & 32 & $71 \%$ & mod-high \\
\hline 1.4 & 41 & enhances contract management processes & 4 & 32 & $71 \%$ & mod-high \\
\hline 1.7 & 68 & increases the amount of paperwork in managing projects & 4 & 32 & $71 \%$ & mod-high \\
\hline 2.3 & 99 & equality is demonstrated by sharing information between team members & 4 & 32 & $71 \%$ & mod-high \\
\hline 1.2 & 14 & decreases the time it takes to undertake tasks & 4 & 31 & $69 \%$ & mod-high \\
\hline 1.3 & 27 & assists in managing change controls in the project & 4 & 31 & $69 \%$ & mod-high \\
\hline 1.3 & 28 & adds time and cost to managing the shared documents & 4 & 31 & $69 \%$ & mod-high \\
\hline 2.5 & 112 & knowledge should not be distributed from a central location & 4 & 31 & $69 \%$ & mod-high \\
\hline 1.3 & 20 & increases the number of versions of documents & 4 & 30 & $67 \%$ & mod-high \\
\hline 1.7 & 63 & is the most effective tool for distributing information to the project team & 4 & 30 & $67 \%$ & mod-high \\
\hline 1.7 & 64 & ensures all documents are easily found & 4 & 30 & $67 \%$ & mod-high \\
\hline 1.7 & 66 & ensures all project related information is kept up to date and in one place & 4 & 30 & $67 \%$ & mod-high \\
\hline 1.4 & 38 & increases difficulty in accessing files remotely & 4 & 29 & $64 \%$ & mod-high \\
\hline 1.2 & 13 & increases possibility of data corruption & 4 & 28 & $62 \%$ & mod-high \\
\hline 1.2 & 17 & reduces the complexity of maintaining data & 4 & 27 & $60 \%$ & Moderate \\
\hline \multirow[t]{2}{*}{1.2} & 10 & improves the quality of data in the database & 4 & 24 & $53 \%$ & Moderate \\
\hline & & Mean Value Collaboration Scale Four & & & $75 \%$ & mod-high \\
\hline 2.1 & 76 & the project team requires a level of trust in order to successfully operate & 5 & 42 & $93 \%$ & high \\
\hline 2.1 & 77 & trust is not important in stakeholder management & 5 & 42 & $93 \%$ & high \\
\hline 2.1 & 79 & trust is important when sharing knowledge across the project areas & 5 & 41 & $91 \%$ & high \\
\hline 2.1 & 78 & negotiations depend on the presence of trust & 5 & 40 & $89 \%$ & high \\
\hline 2.1 & 82 & trust is not required in the project management environment & 5 & 40 & $89 \%$ & high \\
\hline 2.4 & 104 & trust is not essential to developing and maintaining Strategic Alliances & 5 & 38 & $84 \%$ & high \\
\hline 1.4 & 37 & reduces the need for alliances/relationships across the project environment & 5 & 37 & $82 \%$ & high \\
\hline 1.3 & 22 & requires a level of trust between team members & 5 & 36 & $80 \%$ & mod-high \\
\hline 2.1 & 74 & I trust my team members & 5 & 36 & $80 \%$ & mod-high \\
\hline 2.1 & 80 & trust is required between stakeholders in order to achieve project objectives / deliverables & 5 & 36 & $80 \%$ & mod-high \\
\hline 2.4 & 102 & strategic alliances can be strengthened using the OCT & 5 & 36 & $80 \%$ & mod-high \\
\hline 2.5 & 110 & the distribution of knowledge amongst team members is central to trust & 5 & 36 & $80 \%$ & mod-high \\
\hline 1.1 & 9 & detracts from managing Strategic alliances within the project team & 5 & 35 & $78 \%$ & mod-high \\
\hline 1.2 & 18 & requires a level of trust between team members & 5 & 35 & $78 \%$ & mod-high \\
\hline 2.1 & 75 & my team members trust me & 5 & 35 & $78 \%$ & mod-high \\
\hline 1.1 & 6 & assists with the development of trust across the project team & 5 & 33 & $73 \%$ & mod-high \\
\hline 1.4 & 42 & assists with negotiations within the project management environment & 5 & 33 & $73 \%$ & mod-high \\
\hline 2.3 & 97 & members of the project team need to feel equal & 5 & 33 & $73 \%$ & mod-high \\
\hline 1.6 & 62 & develops relationships with team members & 5 & 32 & $71 \%$ & mod-high \\
\hline 2.4 & 106 & stakeholder management is not improved when using OCT & 5 & 32 & $71 \%$ & mod-high \\
\hline 1.3 & 26 & develops an equality amongst the team members & 5 & 31 & $69 \%$ & mod-high \\
\hline 1.4 & 32 & develops trust between team members & 5 & 31 & $69 \%$ & mod-high \\
\hline 2.1 & 84 & OCT facilitates trust amongst team members & 5 & 31 & $69 \%$ & mod-high \\
\hline 1.5 & 45 & develops relationships with team members & 5 & 30 & $67 \%$ & mod-high \\
\hline 1.6 & 56 & makes it hard to establish trust between team members & 5 & 29 & $64 \%$ & mod-high \\
\hline 1.1 & 8 & supports equality amongst team members & 5 & 28 & $62 \%$ & mod-high \\
\hline 2.4 & 107 & OCT delivers the incentives needed to manage Strategic Alliances & 5 & 28 & $62 \%$ & mod-high \\
\hline 1.5 & 46 & requires team members to trust each other & 5 & 26 & $58 \%$ & Moderate \\
\hline 2.3 & 100 & team members do not need to feel equal in order to contribute & 5 & 25 & $56 \%$ & Moderate \\
\hline \multirow[t]{2}{*}{2.1} & 83 & collaboration can be achieved without trust & 5 & 15 & $33 \%$ & low-mod \\
\hline & & Mean Value Collaboration Scale Five & & & $\mathbf{7 4 \%}$ & mod-high \\
\hline 2.7 & 123 & without incentives, information sharing would not occur & 6 & 36 & $80 \%$ & mod-high \\
\hline 1.6 & 59 & discourages innovation and learning across the team & 6 & 35 & $78 \%$ & mod-high \\
\hline 2.6 & 118 & incentives are central to negotiations & 6 & 31 & $69 \%$ & mod-high \\
\hline 2.7 & 122 & OCT reduce the need for incentives in the project environment & 6 & 31 & $69 \%$ & mod-high \\
\hline \multirow[t]{2}{*}{2.7} & 121 & incentives are a prerequisite to sharing information & 6 & 22 & $49 \%$ & Moderate \\
\hline & & Mean Value Collaboration Scale Six & & & $69 \%$ & mod-high \\
\hline 2.6 & 120 & negotiations between stakeholders is aided when parties trust each other & 7 & 41 & $91 \%$ & high \\
\hline 2.6 & 116 & negotiation is an integral part of managing stakeholders & 7 & 39 & $87 \%$ & high \\
\hline \multirow[t]{2}{*}{2.6} & 119 & OCT hamper the negotiation process with stakeholders & 7 & 33 & $73 \%$ & mod-high \\
\hline & & Mean Value Collaboration Scale Seven & & & $84 \%$ & high \\
\hline
\end{tabular}




\section{General Comments on the Findings against the Collaboration Scale Resources}

Respondents in Organisation V highly support the statement that the OCT decreases the amount of time it takes to do tasks. The OCT assists with project planning and managing time more effectively as well as managing resources across the project. The OCT assists to manage and control risk, organisational planning and in the management of staff. Respondents do not support the statement that the use of an OCT replaces the need to meet physically.

\section{Task/scheduling}

Respondents in Organisation V highly support the statement that the OCT improves planning activities and reduces the complexities of coordinating activities across the project environment. Respondents are consistently moderate-highly supportive of the use of the OCT in the task/scheduling category. The OCT assists to meet project schedules, prioritising tasks, managing scope issues, communicating the availability of team members and resources, and improving the delivery of activities in a timely manner. This is consistent with information on core tasks provided by the project manager in the interview. These responses are supported through a mixture of direct and negatively posed questions.

\section{Communication}

Respondents are almost unanimous in their strong support for the statement that effective communication benefits project management. They also have strong support for the statement that communication is important when using an OCT, and communication assists in relationship management of project teams. Respondents are consistently supportive of the role of communication in the PME, and of the role that technology and the OCT play in this environment. These findings are consistent with an organisation that has a functional basis in continuous improvement. The responses are supported through a mixture of direct and negatively posed questions.

\section{Information Sharing}

Respondents are consistent in their strong support for the statement that knowledge distribution is more than having a central repository of documents in an OCT. The OCT enables easy access to all documents in the central repository, whilst also contributing to information sharing. 
Knowledge distribution and information sharing are strongly supported by the respondents, the former acknowledged as a critical component for managing alliances. The OCT increases the ease with which documents are retrieved, and contributes to sharing knowledge and managing data from a central environment. Respondents moderate-highly support the statement that equality is demonstrated by sharing information between team members, and that documents could not be shared in the project team without trust. These responses are supported through a mixture of direct and negatively posed questions.

\section{Relationships}

Respondents highly support the statement that 'the project team requires a level of trust in order to successfully operate'. Trust is seen as important in stakeholder management, as well as for sharing knowledge across the project areas. Negotiations require trust, which is seen as being required in the PME, and essential to developing and maintaining strategic alliances. The presence of trust does not reduce the need for alliances across the project environment.

Respondents provide low-moderate support for the statement that collaboration can be achieved without trust. The OCT assists with managing strategic alliances whilst also contributing to the development of trust within the project team. The OCT also assists with negotiations within the PME.

\section{Rewards}

Respondents moderately support the statement that without incentives, information sharing would not occur, and that OCTs encourage innovation and learning across the team. The OCT does not reduce the need for incentives in the PME, whilst incentives are not necessarily seen as a prerequisite to sharing information.

\section{Negotiation}

Respondents are highly supportive that negotiations between stakeholders are aided when the parties trust each other and that these negotiations play an integral part in managing stakeholders. The OCT does not hamper the negotiation process with the stakeholders. 


\section{Summary of Organisation V}

Figure 8-2 portrays Organisation $\mathrm{V}$ as having moderate to high support in the use of the OCT for Communication, Information Sharing and Negotiation elements of the Collaboration scale, suggesting that for this organisation (Continuous Improvement organisation), the tool is used for cooperation and coordination functions. This is consistent with other findings where the project manager noted that the use of the tool was more for coordination functions and activities across the membership, than it was for collaboration. This interpretation is also understood by the relatively low support for the Resources element. Of interest is that for an organisation based on Continuous Improvement, the use of the OCT for managing Rewards did not figure highly. The findings for Organisation V are generally higher than the results for the Aggregate, but indicates a consistent response variation across the seven elements.

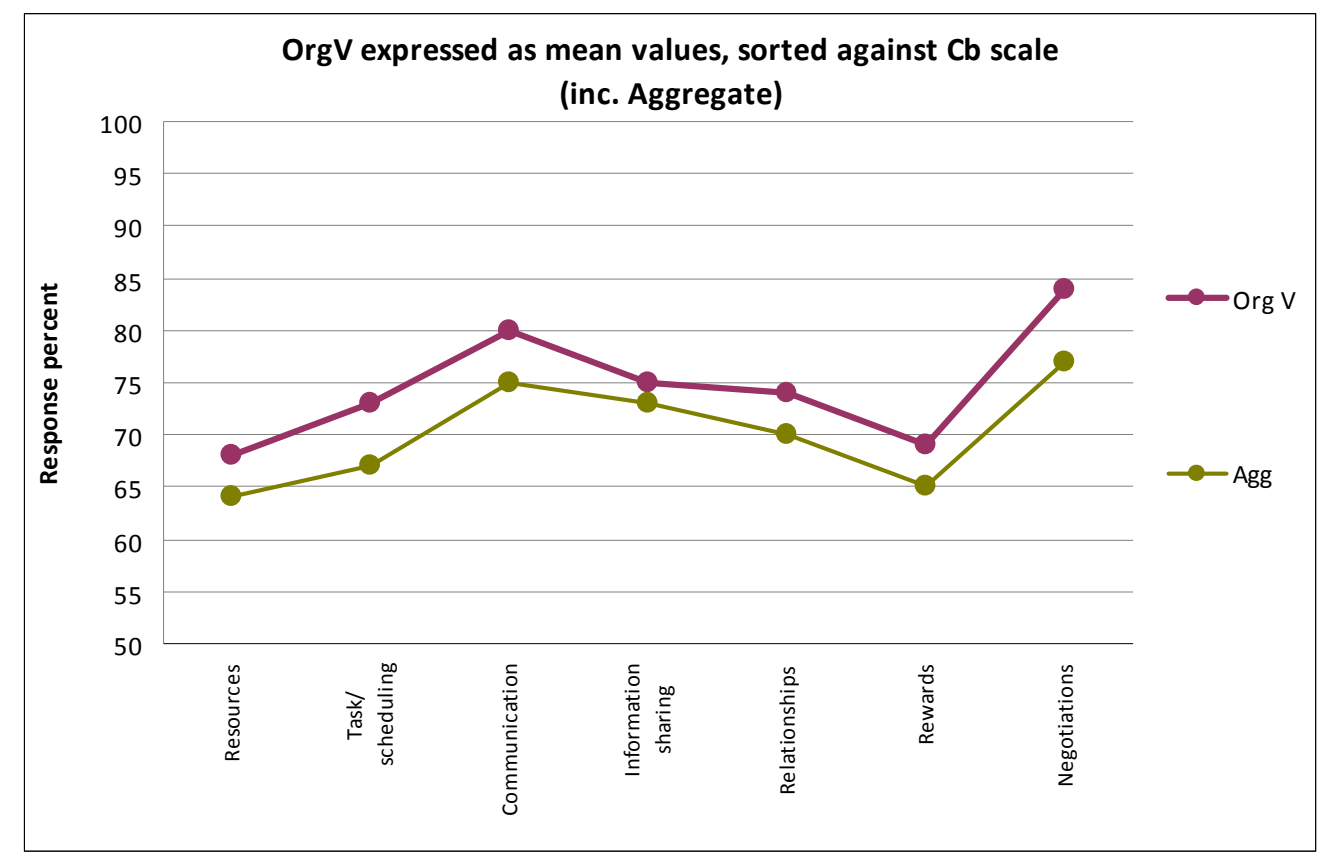

Figure 8-2: OrgV responses to Likert expressed as mean values, sorted against Collaboration scale 


\subsubsection{Organisation M (Government Construction Organisation)}

The vendors of ACONEX target users through four key capabilities: increasing control through management of documentation; increasing productivity though staff efficiencies and increasing communication; reducing costs through a reduction in printing jobs and associated couriers; and reducing risk by having data securely managed.

The description presented through the general summaries of the quantitative and qualitative data gathering processes for Organisation $\mathrm{M}$ indicates that the core features of the tool are being used as intended. The organisation is using the product to centrally manage and control the project documentation, whilst also using it to disseminate and manage the flow of information out to the project teams through its centralised repository. Organisation M uses the OCT to reduce the frequency of expensive printing jobs, whilst also exploiting its data security options. The benefit of the tool therefore lies in its ability to assist the project environment in the way that projectrelated documentation and procedures can be managed and distributed to the team members.

However there is a real risk that the email notification function of the tool will negatively impact on the way that the OCT is used by members of the team, or by certain groups within the team. This is especially the case where members do not see the desktop as a central business item for managing project-related information (OrgM SE1). Given the strong use of the tool for these communication and information dissemination tasks, it is conceivable that the use of the tool may also extend to mobile devises in the future as both the OCT product and mobile technology become more mature.

Table 8-3 provides the results of the use of the ACONEX OCT within Organisation M against the Collaboration scale. 
Table 8-3: Organisation $M$ sorted against Collaboration scale

\begin{tabular}{|c|c|c|c|c|c|c|}
\hline $\begin{array}{l}\text { Likert } \\
\text { Section }\end{array}$ & $\begin{array}{l}\text { Qu. } \\
\text { No. }\end{array}$ & Likert Statement & $\begin{array}{c}\text { Cb } \\
\text { Scale } \\
\text { ID }\end{array}$ & Tally & Percent & Rating \\
\hline 1.2 & 16 & detracts from organisational planning & $\mathbf{1}$ & 41 & $68 \%$ & mod-high \\
\hline 1.3 & 29 & assists with project planning & 1 & 41 & $68 \%$ & mod-high \\
\hline 1.7 & 73 & complicates managing staff and resources & 1 & 40 & $67 \%$ & mod-high \\
\hline 1.5 & 49 & assists with monitoring and controlling risk in the project environment & 1 & 39 & $65 \%$ & mod-high \\
\hline 1.6 & 54 & manages time more effectively & 1 & 37 & $62 \%$ & mod-high \\
\hline 1.6 & 60 & decreases the ability to manage and control risk & 1 & 37 & $62 \%$ & mod-high \\
\hline 1.6 & 61 & replaces the need to meet physically & 1 & 37 & $62 \%$ & mod-high \\
\hline 1.7 & 70 & increases the amount of time it takes to do things & 1 & 37 & $62 \%$ & mod-high \\
\hline 1.4 & 36 & increases the effort required to monitor and control risk & 1 & 36 & $60 \%$ & moderate \\
\hline 1.4 & 43 & increases difficulty in managing resources across the project & 1 & 36 & $60 \%$ & moderate \\
\hline 2.5 & 115 & knowledge distribution should be managed by the project manager & 1 & 36 & $60 \%$ & moderate \\
\hline 1.5 & 50 & provides greater control of resources planning & 1 & 35 & $58 \%$ & moderate \\
\hline 1.7 & 69 & creates an online space which the team uses as a project meeting space & 1 & 35 & $58 \%$ & moderate \\
\hline 1.4 & 31 & reduces the number of users accessing files & 1 & 34 & $57 \%$ & moderate \\
\hline \multirow[t]{2}{*}{1.6} & 55 & does not replace the number of meetings required & 1 & 29 & $48 \%$ & moderate \\
\hline & & Mean Value Collaboration Scale One & & & $61 \%$ & mod-high \\
\hline 1.4 & 40 & decreases the quality controls of the document & 2 & 46 & $77 \%$ & mod-high \\
\hline 1.1 & 2 & improves planning activities & 2 & 43 & $72 \%$ & mod-high \\
\hline 1.1 & 5 & improves delivery of activities in a timely manner & 2 & 43 & $72 \%$ & mod-high \\
\hline 1.1 & 3 & improves prioritising tasks & 2 & 42 & $70 \%$ & mod-high \\
\hline 1.5 & 53 & assists with the execution of the project plan & 2 & 42 & $70 \%$ & mod-high \\
\hline 1.7 & 72 & does not improve quality control & 2 & 42 & $70 \%$ & mod-high \\
\hline 1.1 & 1 & increases chances of meeting project schedules & 2 & 41 & $68 \%$ & mod-high \\
\hline 1.1 & 4 & complicates coordinating activities across the project environment & 2 & 41 & $68 \%$ & mod-high \\
\hline 1.3 & 23 & risks quality control within the project & 2 & 41 & $68 \%$ & mod-high \\
\hline 1.7 & 71 & assists with managing scope issues & 2 & 39 & $65 \%$ & mod-high \\
\hline 1.5 & 48 & contributes to controlling the project schedule & 2 & 38 & $63 \%$ & mod-high \\
\hline 1.6 & 57 & enables more effective control over schedule and project issues & 2 & 36 & $60 \%$ & moderate \\
\hline 1.5 & 52 & increases the capacity to manage risk & 2 & 35 & $58 \%$ & moderate \\
\hline 1.4 & 39 & increases the time and effort required to manage documents & 2 & 32 & $53 \%$ & moderate \\
\hline \multirow[t]{2}{*}{1.7} & 65 & increases the amount of administration for the project & 2 & 31 & $52 \%$ & moderate \\
\hline & & Mean Value Collaboration Scale Two & & & $66 \%$ & mod-high \\
\hline 2.2 & 85 & effective communication benefits project management & 3 & 55 & $92 \%$ & high \\
\hline 2.2 & 89 & managing team members requires communication & 3 & 54 & $90 \%$ & high \\
\hline 2.2 & 94 & communication is essential in achieving project objectives / deliverables & 3 & 54 & $90 \%$ & high \\
\hline 2.3 & 101 & communication assists relationship management of project teams & 3 & 51 & $85 \%$ & high \\
\hline 2.6 & 117 & negotiation requires communication amongst stakeholders & 3 & 50 & $83 \%$ & high \\
\hline 2.2 & 87 & stakeholder management relies on communication & 3 & 49 & $82 \%$ & high \\
\hline 2.2 & 90 & communication is not important when using an OCT & 3 & 47 & $78 \%$ & mod-high \\
\hline 2.4 & 105 & strategic alliances are managed by open communication & 3 & 47 & $78 \%$ & mod-high \\
\hline 1.3 & 24 & improves communication regarding essential information & 3 & 46 & $77 \%$ & mod-high \\
\hline 1.7 & 67 & streamlines communication to the project teams & 3 & 46 & $77 \%$ & mod-high \\
\hline 2.2 & 86 & communication is not enhanced by technology & 3 & 45 & $75 \%$ & mod-high \\
\hline 2.2 & 96 & communication across the project environment does not benefit from using OCT & 3 & 45 & $75 \%$ & mod-high \\
\hline 1.2 & 19 & hampers communication across the project team & 3 & 42 & $70 \%$ & mod-high \\
\hline 2.2 & 93 & online technology does not assist with communication in the project environment & 3 & 42 & $70 \%$ & mod-high \\
\hline 1.1 & 7 & communicates the availability of team members and resources & 3 & 40 & $67 \%$ & mod-high \\
\hline 1.4 & 34 & discourages communication across the project team & 3 & 38 & $63 \%$ & mod-high \\
\hline 1.5 & 44 & manages the use of email more efficiently & 3 & 37 & $62 \%$ & mod-high \\
\hline 2.2 & 95 & communication is not clearer when using OCT & 3 & 37 & $62 \%$ & mod-high \\
\hline 1.5 & 47 & is ineffective when communicating to the project team & 3 & 36 & $60 \%$ & moderate \\
\hline 1.6 & 58 & enhances communication across the project team & 3 & 36 & $60 \%$ & moderate \\
\hline \multirow[t]{2}{*}{2.2} & 92 & team members communicate more effectively when using OCT & 3 & 36 & $60 \%$ & moderate \\
\hline & & Mean Value Collaboration Scale Three & & & $74 \%$ & mod-high \\
\hline 1.7 & 66 & ensures all project related information is kept up to date and in one place & 4 & 51 & $85 \%$ & high \\
\hline 2.2 & 88 & sharing knowledge can be enhanced using online technology & 4 & 51 & $85 \%$ & high \\
\hline 2.5 & 108 & the distribution of knowledge regarding the project is important to team members & 4 & 50 & $83 \%$ & high \\
\hline 1.2 & 11 & manages data from a central environment & 4 & 49 & $82 \%$ & high \\
\hline 1.2 & 15 & centralises reporting of data & 4 & 49 & $82 \%$ & high \\
\hline 1.7 & 63 & is the most effective tool for distributing information to the project team & 4 & 49 & $82 \%$ & high \\
\hline 2.5 & 113 & knowledge distribution is more than having a central repository of documents in an OCT & 4 & 49 & $82 \%$ & high \\
\hline 1.4 & 30 & enables easy access to all documents in the central repository & 4 & 48 & $80 \%$ & mod-high \\
\hline 1.4 & 33 & increases ease of retrieving documents & 4 & 47 & $78 \%$ & mod-high \\
\hline 1.7 & 64 & ensures all documents are easily found & 4 & 47 & $78 \%$ & mod-high \\
\hline 2.2 & 91 & OCT improve information sharing & 4 & 47 & $78 \%$ & mod-high \\
\hline 2.4 & 103 & knowledge sharing is a critical component of managing alliances & 4 & 47 & $78 \%$ & mod-high \\
\hline 2.5 & 109 & OCT encourage sharing information amongst team members & 4 & 47 & $78 \%$ & mod-high \\
\hline
\end{tabular}




\begin{tabular}{|c|c|c|c|c|c|c|}
\hline $\begin{array}{c}\text { Likert } \\
\text { Section }\end{array}$ & $\begin{array}{l}\text { Qu. } \\
\text { No. }\end{array}$ & Likert Statement & $\begin{array}{c}\text { Cb } \\
\text { Scale } \\
\text { ID } \\
\end{array}$ & Tally & Percent & Rating \\
\hline 1.3 & 21 & increases efficiencies in distribution of documents & 4 & 46 & $77 \%$ & mod-high \\
\hline 1.2 & 12 & decreases confidence in the data & 4 & 44 & $73 \%$ & mod-high \\
\hline 1.4 & 41 & enhances contract management processes & 4 & 44 & $73 \%$ & mod-high \\
\hline 1.3 & 27 & assists in managing change controls in the project & 4 & 43 & $72 \%$ & mod-high \\
\hline 1.4 & 35 & provides an incentive to share information amongst team members & 4 & 43 & $72 \%$ & mod-high \\
\hline 2.1 & 81 & documents can be shared in the project team without trust & 4 & 43 & $72 \%$ & mod-high \\
\hline 2.3 & 98 & knowledge distribution is not important for team members & 4 & 43 & $72 \%$ & mod-high \\
\hline 2.3 & 99 & equality is demonstrated by sharing information between team members & 4 & 43 & $72 \%$ & mod-high \\
\hline 2.5 & 111 & knowledge distribution should be on an ad hoc basis & 4 & 42 & $70 \%$ & mod-high \\
\hline 2.5 & 112 & knowledge should not be distributed from a central location & 4 & 42 & $70 \%$ & mod-high \\
\hline 1.2 & 13 & increases possibility of data corruption & 4 & 41 & $68 \%$ & mod-high \\
\hline 1.4 & 38 & increases difficulty in accessing files remotely & 4 & 41 & $68 \%$ & mod-high \\
\hline 2.5 & 114 & Announcement boards in OCT assist in the distribution of important information & 4 & 41 & $68 \%$ & mod-high \\
\hline 1.2 & 10 & improves the quality of data in the database & 4 & 40 & $67 \%$ & mod-high \\
\hline 1.5 & 51 & creates difficulty in distributing information across the project & 4 & 39 & $65 \%$ & mod-high \\
\hline 1.3 & 25 & produces inefficiencies in retrieval of information & 4 & 38 & $63 \%$ & mod-high \\
\hline 1.2 & 17 & reduces the complexity of maintaining data & 4 & 37 & $62 \%$ & mod-high \\
\hline 1.7 & 68 & increases the amount of paperwork in managing projects & 4 & 35 & $58 \%$ & Moderate \\
\hline 1.2 & 14 & decreases the time it takes to undertake tasks & 4 & 34 & $57 \%$ & Moderate \\
\hline 1.3 & 28 & adds time and cost to managing the shared documents & 4 & 30 & $50 \%$ & Moderate \\
\hline \multirow[t]{2}{*}{1.3} & 20 & increases the number of versions of documents & 4 & 27 & $45 \%$ & Moderate \\
\hline & & Mean Value Collaboration Scale Four & & & $72 \%$ & mod-high \\
\hline 2.1 & 76 & the project team requires a level of trust in order to successfully operate & 5 & 52 & $87 \%$ & High \\
\hline 2.1 & 78 & negotiations depend on the presence of trust & 5 & 50 & $83 \%$ & High \\
\hline 2.1 & 79 & trust is important when sharing knowledge across the project areas & 5 & 50 & $83 \%$ & High \\
\hline 2.1 & 80 & trust is required between stakeholders in order to achieve project objectives / deliverables & 5 & 49 & $82 \%$ & High \\
\hline 2.1 & 74 & I trust my team members & 5 & 48 & $80 \%$ & mod-high \\
\hline 2.1 & 75 & my team members trust me & 5 & 48 & $80 \%$ & mod-high \\
\hline 2.1 & 77 & trust is not important in stakeholder management & 5 & 48 & $80 \%$ & mod-high \\
\hline 2.4 & 104 & trust is not essential to developing and maintaining Strategic Alliances & 5 & 44 & $73 \%$ & mod-high \\
\hline 2.5 & 110 & the distribution of knowledge amongst team members is central to trust & 5 & 44 & $73 \%$ & mod-high \\
\hline 2.1 & 82 & trust is not required in the project management environment & 5 & 43 & $72 \%$ & mod-high \\
\hline 2.3 & 97 & members of the project team need to feel equal & 5 & 43 & $72 \%$ & mod-high \\
\hline 2.4 & 106 & stakeholder management is not improved when using OCT & 5 & 43 & $72 \%$ & mod-high \\
\hline 1.2 & 18 & requires a level of trust between team members & 5 & 41 & $68 \%$ & mod-high \\
\hline 1.4 & 32 & develops trust between team members & 5 & 41 & $68 \%$ & mod-high \\
\hline 1.3 & 22 & requires a level of trust between team members & 5 & 40 & $67 \%$ & mod-high \\
\hline 2.4 & 102 & strategic alliances can be strengthened using the OCT & 5 & 40 & $67 \%$ & mod-high \\
\hline 1.1 & 6 & assists with the development of trust across the project team & 5 & 39 & $65 \%$ & mod-high \\
\hline 1.1 & 8 & supports equality amongst team members & 5 & 39 & $65 \%$ & mod-high \\
\hline 1.3 & 26 & develops an equality amongst the team members & 5 & 39 & $65 \%$ & mod-high \\
\hline 2.4 & 107 & OCT delivers the incentives needed to manage Strategic Alliances & 5 & 39 & $65 \%$ & mod-high \\
\hline 1.4 & 42 & assists with negotiations within the project management environment & 5 & 38 & $63 \%$ & mod-high \\
\hline 1.4 & 37 & reduces the need for alliances/relationships across the project environment & 5 & 37 & $62 \%$ & mod-high \\
\hline 1.1 & 9 & detracts from managing Strategic alliances within the project team & 5 & 36 & $60 \%$ & Moderate \\
\hline 1.5 & 46 & requires team members to trust each other & 5 & 36 & $60 \%$ & Moderate \\
\hline 1.6 & 56 & makes it hard to establish trust between team members & 5 & 35 & $58 \%$ & Moderate \\
\hline 1.6 & 62 & develops relationships with team members & 5 & 34 & $57 \%$ & Moderate \\
\hline 2.3 & 100 & team members do not need to feel equal in order to contribute & 5 & 34 & $57 \%$ & Moderate \\
\hline 1.5 & 45 & develops relationships with team members & 5 & 33 & $55 \%$ & Moderate \\
\hline 2.1 & 84 & OCT facilitates trust amongst team members & 5 & 33 & $55 \%$ & Moderate \\
\hline \multirow[t]{2}{*}{2.1} & 83 & collaboration can be achieved without trust & 5 & 24 & $40 \%$ & low-mod \\
\hline & & Mean Value Collaboration Scale Five & & & $68 \%$ & mod-high \\
\hline 2.6 & 118 & incentives are central to negotiations & 6 & 44 & $73 \%$ & mod-high \\
\hline 2.7 & 123 & without incentives, information sharing would not occur & 6 & 43 & $72 \%$ & mod-high \\
\hline 2.7 & 122 & OCT reduce the need for incentives in the project environment & 6 & 37 & $62 \%$ & mod-high \\
\hline 1.6 & 59 & discourages innovation and learning across the team & 6 & 36 & $60 \%$ & Moderate \\
\hline \multirow[t]{2}{*}{2.7} & 121 & incentives are a prerequisite to sharing information & 6 & 36 & $60 \%$ & Moderate \\
\hline & & Mean Value Collaboration Scale Six & & & $65 \%$ & mod-high \\
\hline 2.6 & 116 & negotiation is an integral part of managing stakeholders & 7 & 48 & $80 \%$ & mod-high \\
\hline 2.6 & 120 & negotiations between stakeholders is aided when parties trust each other & 7 & 48 & $80 \%$ & mod-high \\
\hline \multirow[t]{2}{*}{2.6} & 119 & OCT hamper the negotiation process with stakeholders & 7 & 38 & $63 \%$ & mod-high \\
\hline & & Mean Value Collaboration Scale Seven & & & $74 \%$ & mod-high \\
\hline
\end{tabular}




\section{General Comments on the Findings against the Collaboration Scale Resources}

Respondents in Organisation M give moderate to high support for the use of the OCT for assisting with both organisational and project planning. The OCT assists with managing staff and resources and with monitoring and controlling risk within the PME, however respondents are moderately supportive on the effort required to do this. The OCT assists to manage time effectively. Respondents are moderately supportive on whether the OCT provides greater control of resource planning, reduces the number of users accessing files, and if the use of an OCT replaced the number of meetings required, or replaced the need for onsite meetings.

\section{Task/scheduling}

Respondents in Organisation M are consistently moderately supportive of the use of the OCT in the task/scheduling category. The OCT increases the quality controls of documents, improves planning and delivery of activities in a timely manner, improves prioritising tasks and assists with the execution of the project plan. The OCT assists to meet project schedules and with managing scope issues. Respondents were moderately supportive of the capacity of the OCT to manage risk and whether it reduced the amount of time spent on administration or managing documents. These responses are supported through a mixture of direct and negatively posed questions.

\section{Communication}

Respondents are very supportive of the role that communication plays in the PME with high support for statements regarding the role of effective communication to achieve project objectives and deliverables, and to manage staff, stakeholders and relationships. The highest response was in support for the statement that 'effective communication benefits project management'. Subsequently respondents from Organisation M are generally supportive of all areas of the communication elements, noting that communication is enhanced by technology and remains important when using an OCT. The OCT assists to streamline communication and improves the flow of essential information across the PME. It is moderately effective in managing the use of email more effectively, and communicates the availability of resources to the PME. This finding can also be seen in contrast to comments made by OrgM SE1 about what he considers to be an excessive volume of emails received through the OCT, and the role a 
document controller may have in managing this on behalf of the PME. These responses are supported through a mixture of direct and negatively posed questions.

\section{Information Sharing}

Respondents are strongly supportive of the role of knowledge sharing and information distribution across the PME, highly supporting the statement that the use of the OCT 'ensures all project-related information is kept up-to-date and in one place'. Online technology contributes to sharing knowledge, and the distribution of project-related information is important to team members. The OCT is the most effective tool for doing this. The OCT enables easy access to all documents in a central repository, ensuring documents can be easily located and shared across the PME. The OCT improves information sharing and increases the efficiencies in doing so amongst team members. Trust is considered important when sharing documents. Respondents are supportive of the role that the OCT plays in knowledge distribution and support the statement that it should occur 'from a central location'. Respondents are moderately supportive on whether the OCT reduces the amount of time and cost in managing shared documents, as well as the number of versions of documents. These responses are supported through a mixture of direct and negatively posed questions.

\section{Relationships}

Respondents highly support the statement that 'the project team requires a level of trust in order to successfully operate'. Respondents trust each other, and consider trust important when sharing knowledge across the project areas and in dealings with stakeholders to achieve project objectives/deliverables. The OCT assists with the development of trust across the project team, whilst also delivering incentives needed to manage strategic alliances and stakeholder management. Respondents are moderately supportive of the OCT developing relationships with team members and whether it requires team members to trust each other. Respondents have lowmoderate support for the statement that 'collaboration can be achieved without trust'.

\section{Rewards}

Respondents support the statement that incentives are central to negotiations, and that without them, information sharing would not occur. The OCT does not reduce the need for incentives in the PME. Respondents are moderately supportive of whether the OCT discourages innovation and learning across the team. 


\section{Negotiation}

Respondents are highly supportive that negotiations play an integral part in managing stakeholders, and that it is aided when stakeholder parties trust each other. OCTs do not hamper these negotiations.

\section{Summary of Organisation M}

Figure 8-3 portrays Organisation $\mathrm{M}$ as having moderate to high support in the use of the OCT for Communication, Information Sharing, Relationships and Negotiation elements of the Collaboration scale, suggesting that for this organisation (Government Construction project), the tool is used for cooperation and coordination functions. This is consistent with other findings where the organisation noted that its use of the tool was more for managing documentation and communication, especially through the various types of transmittals offered by the OCT. The use of the tool is not used to manage the strategic alliances of the project, even though the Communication element rates highly. The findings for Organisation $\mathrm{M}$ are very close to those results for the Aggregate.

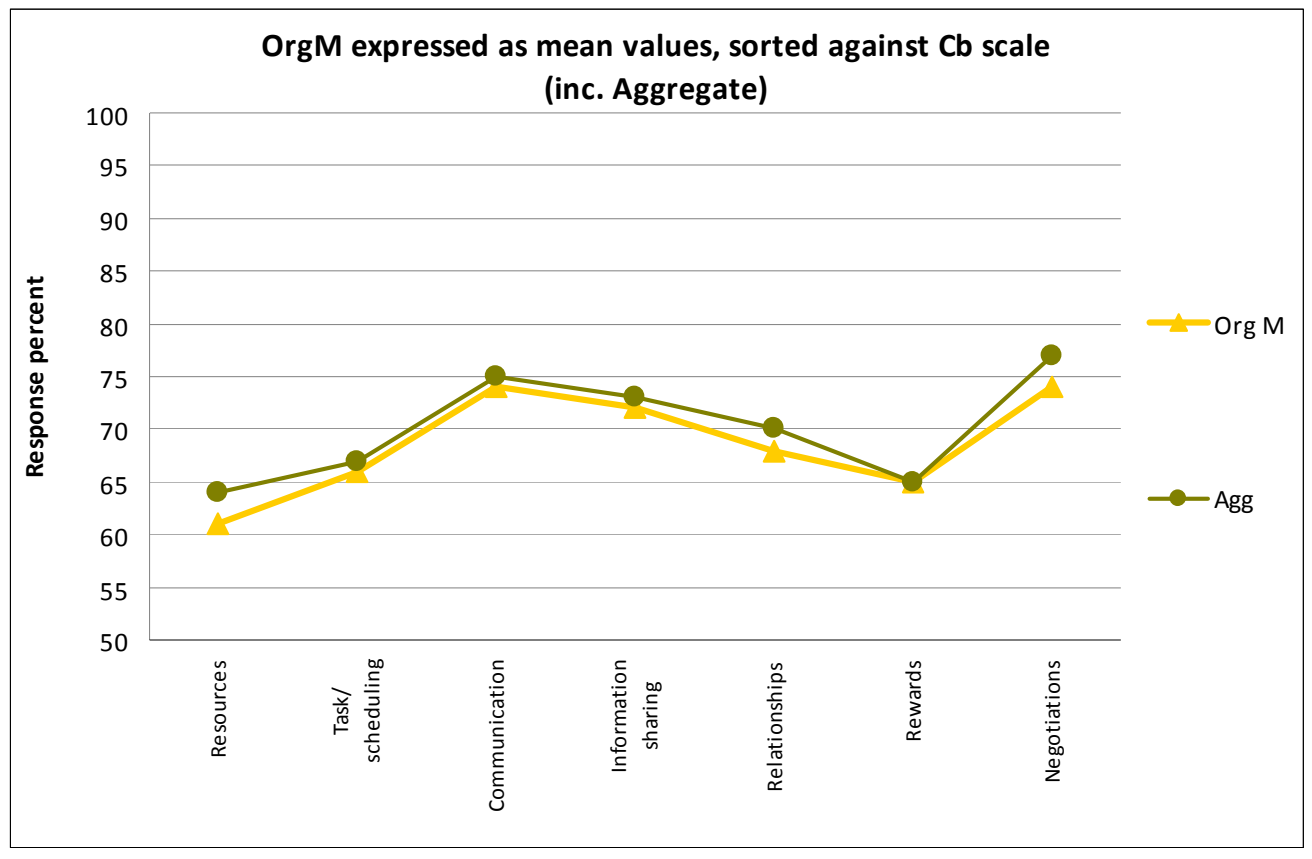

Figure 8-3: OrgM responses to Likert expressed as mean values, sorted against Collaboration scale 


\subsubsection{Organisation C (Commercial Construction Project)}

The vendors of AutoCAD Buzzsaw promote the value of the deployment of the tool against several core areas - simplification of tasks, centralising project documentation, and the simplification of communication, whilst noting that the use of the tool will streamline collaboration.

The information presented through the data analysis and interviews supports these core value areas to a limited extent, with the analysis not readily showing the organisation's project environment being significantly altered through the use of the OCT. In the instance of this case study, the use of the tool can be described as rudimentary and simplistic, yet catering for the organisation's needs. These benefits are primarily characterised by the value the various project teams place on the capacity of the OCT to manage centralised information and associated project documentation including AutoCAD formatted drawings.

The manner in which the OCT manages the AutoCAD drawing component was considered essential for the project, and was linked to the decision to use the tool (OrgC PM2). This is further drawn out by a strong pre-existing governance structure of Organisation C, and the fact that this was the first time the organisation had used an OCT for an in-house project. To that end, much of the work when using the OCT centred around managing and distributing the technical drawings, and developing procedures.

Table 8-4 provides the results of the use of the Autodesk Buzzsaw OCT within Organisation C against the Collaboration scale. 
Table 8-4: Organisation C sorted against Collaboration scale

\begin{tabular}{|c|c|c|c|c|c|c|}
\hline $\begin{array}{c}\text { Likert } \\
\text { Section }\end{array}$ & $\begin{array}{l}\text { Qu. } \\
\text { No. }\end{array}$ & Likert Statement & $\begin{array}{c}\text { Cb } \\
\text { Scale } \\
\text { ID } \\
\end{array}$ & Tally & Percent & Rating \\
\hline 1.7 & 73 & complicates managing staff and resources & 1 & 22 & $73 \%$ & mod-high \\
\hline 1.3 & 29 & assists with project planning & 1 & 21 & $70 \%$ & mod-high \\
\hline 1.2 & 16 & detracts from organisational planning & 1 & 20 & $67 \%$ & mod-high \\
\hline 1.4 & 43 & increases difficulty in managing resources across the project & 1 & 20 & $67 \%$ & mod-high \\
\hline 1.6 & 60 & decreases the ability to manage and control risk & 1 & 19 & $63 \%$ & mod-high \\
\hline 1.6 & 55 & does not replace the number of meetings required & 1 & 18 & $60 \%$ & $\bmod$ \\
\hline 1.7 & 70 & increases the amount of time it takes to do things & 1 & 18 & $60 \%$ & mod \\
\hline 2.5 & 115 & knowledge distribution should be managed by the project manager & 1 & 18 & $60 \%$ & mod \\
\hline 1.4 & 31 & reduces the number of users accessing files & 1 & 17 & $57 \%$ & mod \\
\hline 1.4 & 36 & increases the effort required to monitor and control risk & 1 & 17 & $57 \%$ & mod \\
\hline 1.5 & 49 & assists with monitoring and controlling risk in the project environment & 1 & 17 & $57 \%$ & mod \\
\hline 1.6 & 54 & manages time more effectively & 1 & 17 & $57 \%$ & mod \\
\hline 1.6 & 61 & replaces the need to meet physically & 1 & 17 & $57 \%$ & mod \\
\hline 1.5 & 50 & provides greater control of resources planning & 1 & 16 & $53 \%$ & mod \\
\hline \multirow[t]{2}{*}{1.7} & 69 & creates an online space which the team uses as a project meeting space & 1 & 16 & $53 \%$ & $\bmod$ \\
\hline & & Mean Value Collaboration Scale One & & & $61 \%$ & mod-high \\
\hline 1.3 & 23 & risks quality control within the project & 2 & 23 & $77 \%$ & mod-high \\
\hline 1.4 & 40 & decreases the quality controls of the document & 2 & 23 & $77 \%$ & mod-high \\
\hline 1.7 & 72 & does not improve quality control & 2 & 22 & $73 \%$ & mod-high \\
\hline 1.1 & 2 & improves planning activities & 2 & 21 & $70 \%$ & mod-high \\
\hline 1.1 & 3 & improves prioritising tasks & 2 & 21 & $70 \%$ & mod-high \\
\hline 1.1 & 4 & complicates coordinating activities across the project environment & 2 & 20 & $67 \%$ & mod-high \\
\hline 1.1 & 5 & improves delivery of activities in a timely manner & 2 & 20 & $67 \%$ & mod-high \\
\hline 1.5 & 48 & contributes to controlling the project schedule & 2 & 20 & $67 \%$ & mod-high \\
\hline 1.5 & 53 & assists with the execution of the project plan & 2 & 20 & $67 \%$ & mod-high \\
\hline 1.1 & 1 & increases chances of meeting project schedules & 2 & 19 & $63 \%$ & mod-high \\
\hline 1.5 & 52 & increases the capacity to manage risk & 2 & 19 & $63 \%$ & mod-high \\
\hline 1.6 & 57 & enables more effective control over schedule and project issues & 2 & 19 & $63 \%$ & mod-high \\
\hline 1.7 & 71 & assists with managing scope issues & 2 & 18 & $60 \%$ & $\bmod$ \\
\hline 1.7 & 65 & increases the amount of administration for the project & 2 & 17 & $57 \%$ & mod \\
\hline \multirow{2}{*}{1.4} & 39 & increases the time and effort required to manage documents & 2 & 16 & $53 \%$ & mod \\
\hline & & Mean Value Collaboration Scale Two & & & $66 \%$ & mod-high \\
\hline 2.2 & 89 & managing team members requires communication & 3 & 27 & $90 \%$ & high \\
\hline 2.2 & 94 & communication is essential in achieving project objectives / deliverables & 3 & 27 & $90 \%$ & high \\
\hline 2.2 & 85 & effective communication benefits project management & 3 & 26 & $87 \%$ & high \\
\hline 2.2 & 90 & communication is not important when using an OCT & 3 & 26 & $87 \%$ & high \\
\hline 2.2 & 87 & stakeholder management relies on communication & 3 & 24 & $80 \%$ & mod-high \\
\hline 2.3 & 101 & communication assists relationship management of project teams & 3 & 24 & $80 \%$ & mod-high \\
\hline 2.6 & 117 & negotiation requires communication amongst stakeholders & 3 & 24 & $80 \%$ & mod-high \\
\hline 1.7 & 67 & streamlines communication to the project teams & 3 & 23 & $77 \%$ & mod-high \\
\hline 2.2 & 86 & communication is not enhanced by technology & 3 & 23 & $77 \%$ & mod-high \\
\hline 2.2 & 93 & online technology does not assist with communication in the project environment & 3 & 23 & $77 \%$ & mod-high \\
\hline 2.4 & 105 & strategic alliances are managed by open communication & 3 & 23 & $77 \%$ & mod-high \\
\hline 1.2 & 19 & hampers communication across the project team & 3 & 22 & $73 \%$ & mod-high \\
\hline 1.4 & 34 & discourages communication across the project team & 3 & 22 & $73 \%$ & mod-high \\
\hline 2.2 & 95 & communication is not clearer when using OCT & 3 & 22 & $73 \%$ & mod-high \\
\hline 1.3 & 24 & improves communication regarding essential information & 3 & 21 & $70 \%$ & mod-high \\
\hline 2.2 & 96 & communication across the project environment does not benefit from using OCT & 3 & 21 & $70 \%$ & mod-high \\
\hline 1.1 & 7 & communicates the availability of team members and resources & 3 & 20 & $67 \%$ & mod-high \\
\hline 1.5 & 47 & is ineffective when communicating to the project team & 3 & 19 & $63 \%$ & mod-high \\
\hline 1.6 & 58 & enhances communication across the project team & 3 & 18 & $60 \%$ & mod \\
\hline 1.5 & 44 & manages the use of email more efficiently & 3 & 17 & $57 \%$ & mod \\
\hline \multirow{2}{*}{2.2} & 92 & team members communicate more effectively when using OCT & 3 & 16 & $53 \%$ & mod \\
\hline & & Mean Value Collaboration Scale Three & & & $74 \%$ & mod-high \\
\hline 2.5 & 113 & knowledge distribution is more than having a central repository of documents in an OCT & 4 & 27 & $90 \%$ & high \\
\hline 1.2 & 11 & manages data from a central environment & 4 & 25 & $83 \%$ & high \\
\hline 1.7 & 64 & ensures all documents are easily found & 4 & 25 & $83 \%$ & high \\
\hline 2.2 & 88 & sharing knowledge can be enhanced using online technology & 4 & 25 & $83 \%$ & high \\
\hline 2.3 & 98 & knowledge distribution is not important for team members & 4 & 25 & $83 \%$ & high \\
\hline 2.5 & 108 & the distribution of knowledge regarding the project is important to team members & 4 & 25 & $83 \%$ & high \\
\hline 1.2 & 15 & centralises reporting of data & 4 & 24 & $80 \%$ & mod-high \\
\hline 1.3 & 25 & produces inefficiencies in retrieval of information & 4 & 24 & $80 \%$ & mod-high \\
\hline 1.4 & 30 & enables easy access to all documents in the central repository & 4 & 24 & $80 \%$ & mod-high \\
\hline 2.4 & 103 & knowledge sharing is a critical component of managing alliances & 4 & 24 & $80 \%$ & mod-high \\
\hline 1.2 & 12 & decreases confidence in the data & 4 & 23 & $77 \%$ & mod-high \\
\hline 1.7 & 68 & increases the amount of paperwork in managing projects & 4 & 23 & $77 \%$ & mod-high \\
\hline 2.2 & 91 & OCT improve information sharing & 4 & 23 & $77 \%$ & mod-high \\
\hline 2.5 & 109 & OCT encourage sharing information amongst team members & 4 & 23 & $77 \%$ & mod-high \\
\hline
\end{tabular}




\begin{tabular}{|c|c|c|c|c|c|c|}
\hline $\begin{array}{l}\text { Likert } \\
\text { Section }\end{array}$ & $\begin{array}{l}\text { Qu. } \\
\text { No. }\end{array}$ & Likert Statement & $\begin{array}{c}\text { Cb } \\
\text { Scale } \\
\text { ID }\end{array}$ & Tally & Percent & Rating \\
\hline 1.2 & 13 & increases possibility of data corruption & 4 & 22 & $73 \%$ & mod-high \\
\hline 1.3 & 20 & increases the number of versions of documents & 4 & 22 & $73 \%$ & mod-high \\
\hline 1.3 & 21 & increases efficiencies in distribution of documents & 4 & 22 & $73 \%$ & mod-high \\
\hline 1.3 & 27 & assists in managing change controls in the project & 4 & 22 & $73 \%$ & mod-high \\
\hline 1.4 & 33 & increases ease of retrieving documents & 4 & 22 & $73 \%$ & mod-high \\
\hline 1.4 & 41 & enhances contract management processes & 4 & 22 & $73 \%$ & mod-high \\
\hline 1.7 & 63 & is the most effective tool for distributing information to the project team & 4 & 22 & $73 \%$ & mod-high \\
\hline 1.2 & 17 & reduces the complexity of maintaining data & 4 & 21 & $70 \%$ & mod-high \\
\hline 1.7 & 66 & ensures all project related information is kept up to date and in one place & 4 & 21 & $70 \%$ & mod-high \\
\hline 2.5 & 114 & Announcement boards in OCT assist in the distribution of important information & 4 & 21 & $70 \%$ & mod-high \\
\hline 1.2 & 14 & decreases the time it takes to undertake tasks & 4 & 20 & $67 \%$ & mod-high \\
\hline 1.4 & 38 & increases difficulty in accessing files remotely & 4 & 20 & $67 \%$ & mod-high \\
\hline 1.3 & 28 & adds time and cost to managing the shared documents & 4 & 19 & $63 \%$ & mod-high \\
\hline 1.2 & 10 & improves the quality of data in the database & 4 & 18 & $60 \%$ & $\bmod$ \\
\hline 1.5 & 51 & creates difficulty in distributing information across the project & 4 & 18 & $60 \%$ & $\bmod$ \\
\hline 2.1 & 81 & documents can be shared in the project team without trust & 4 & 18 & $60 \%$ & $\bmod$ \\
\hline 2.5 & 112 & knowledge should not be distributed from a central location & 4 & 18 & $60 \%$ & mod \\
\hline 1.4 & 35 & provides an incentive to share information amongst team members & 4 & 17 & $57 \%$ & $\bmod$ \\
\hline 2.3 & 99 & equality is demonstrated by sharing information between team members & 4 & 17 & $57 \%$ & mod \\
\hline \multirow[t]{2}{*}{2.5} & 111 & knowledge distribution should be on an ad hoc basis & 4 & 15 & $50 \%$ & $\bmod$ \\
\hline & & Mean Value Collaboration Scale Four & & & $73 \%$ & mod-high \\
\hline 2.1 & 77 & trust is not important in stakeholder management & 5 & 25 & $83 \%$ & high \\
\hline 2.1 & 76 & the project team requires a level of trust in order to successfully operate & 5 & 24 & $80 \%$ & mod-high \\
\hline 2.1 & 79 & trust is important when sharing knowledge across the project areas & 5 & 24 & $80 \%$ & mod-high \\
\hline 2.1 & 75 & my team members trust me & 5 & 23 & $77 \%$ & mod-high \\
\hline 2.1 & 80 & trust is required between stakeholders in order to achieve project objectives / deliverables & 5 & 23 & $77 \%$ & mod-high \\
\hline 2.4 & 104 & trust is not essential to developing and maintaining Strategic Alliances & 5 & 23 & $77 \%$ & mod-high \\
\hline 1.2 & 18 & requires a level of trust between team members & 5 & 22 & $73 \%$ & mod-high \\
\hline 2.1 & 74 & I trust my team members & 5 & 22 & $73 \%$ & mod-high \\
\hline 2.1 & 78 & negotiations depend on the presence of trust & 5 & 22 & $73 \%$ & mod-high \\
\hline 1.3 & 22 & requires a level of trust between team members & 5 & 21 & $70 \%$ & mod-high \\
\hline 2.1 & 82 & trust is not required in the project management environment & 5 & 21 & $70 \%$ & mod-high \\
\hline 2.5 & 110 & the distribution of knowledge amongst team members is central to trust & 5 & 21 & $70 \%$ & mod-high \\
\hline 1.1 & 6 & assists with the development of trust across the project team & 5 & 20 & $67 \%$ & mod-high \\
\hline 1.4 & 37 & reduces the need for alliances/relationships across the project environment & 5 & 20 & $67 \%$ & mod-high \\
\hline 2.4 & 102 & strategic alliances can be strengthened using the OCT & 5 & 20 & $67 \%$ & mod-high \\
\hline 2.4 & 106 & stakeholder management is not improved when using OCT & 5 & 20 & $67 \%$ & mod-high \\
\hline 1.1 & 9 & detracts from managing Strategic alliances within the project team & 5 & 19 & $63 \%$ & mod-high \\
\hline 1.3 & 26 & develops an equality amongst the team members & 5 & 19 & $63 \%$ & mod-high \\
\hline 1.5 & 46 & requires team members to trust each other & 5 & 19 & $63 \%$ & mod-high \\
\hline 1.6 & 56 & makes it hard to establish trust between team members & 5 & 19 & $63 \%$ & mod-high \\
\hline 2.1 & 83 & collaboration can be achieved without trust & 5 & 19 & $63 \%$ & mod-high \\
\hline 2.3 & 97 & members of the project team need to feel equal & 5 & 19 & $63 \%$ & mod-high \\
\hline 1.1 & 8 & supports equality amongst team members & 5 & 18 & $60 \%$ & $\bmod$ \\
\hline 1.4 & 32 & develops trust between team members & 5 & 18 & $60 \%$ & mod \\
\hline 1.6 & 62 & develops relationships with team members & 5 & 18 & $60 \%$ & $\bmod$ \\
\hline 2.4 & 107 & OCT delivers the incentives needed to manage Strategic Alliances & 5 & 18 & $60 \%$ & mod \\
\hline 1.4 & 42 & assists with negotiations within the project management environment & 5 & 17 & $57 \%$ & $\bmod$ \\
\hline 2.1 & 84 & OCT facilitates trust amongst team members & 5 & 17 & $57 \%$ & $\bmod$ \\
\hline 2.3 & 100 & team members do not need to feel equal in order to contribute & 5 & 17 & $57 \%$ & $\bmod$ \\
\hline \multirow[t]{2}{*}{1.5} & 45 & develops relationships with team members & 5 & 15 & $50 \%$ & $\bmod$ \\
\hline & & Mean Value Collaboration Scale Five & & & $67 \%$ & mod-high \\
\hline 2.7 & 122 & OCT reduce the need for incentives in the project environment & 6 & 22 & $73 \%$ & mod-high \\
\hline 2.7 & 123 & without incentives, information sharing would not occur & 6 & 22 & $73 \%$ & mod-high \\
\hline 1.6 & 59 & discourages innovation and learning across the team & 6 & 19 & $63 \%$ & mod-high \\
\hline 2.6 & 118 & incentives are central to negotiations & 6 & 19 & $63 \%$ & mod-high \\
\hline \multirow[t]{2}{*}{2.7} & 121 & incentives are a prerequisite to sharing information & 6 & 13 & $43 \%$ & $\bmod$ \\
\hline & & Mean Value Collaboration Scale Six & & & $63 \%$ & mod-high \\
\hline 2.6 & 120 & negotiations between stakeholders is aided when parties trust each other & 7 & 24 & $80 \%$ & mod-high \\
\hline 2.6 & 116 & negotiation is an integral part of managing stakeholders & 7 & 22 & $73 \%$ & mod-high \\
\hline \multirow[t]{2}{*}{2.6} & 119 & OCT hamper the negotiation process with stakeholders & 7 & 19 & $63 \%$ & mod-high \\
\hline & & Mean Value Collaboration Scale Seven & & & $72 \%$ & mod-high \\
\hline
\end{tabular}




\section{General Comments on the Findings against the Collaboration Scale Resources}

Respondents in Organisation C are moderately- highly supportive of the use of the OCT to assist with the element of Resources. Responses indicate that the OCT enables the management of staff and resources across the project, assists in controlling risk and having a positive impact on the amount of time it takes to do things. It also contributes to organisational and project planning. The responses are moderately supportive of the role of the Announcement Board or the use of Virtual Conferencing capabilities in controlling risk, resources planning and contributing to the effective use of time.

\section{Task/scheduling}

Respondents in Organisation C are moderately - highly supportive of the use of the OCT to assist with the element of Tasks and Scheduling. Responses indicate that the OCT assists with managing risk and quality controls of the project, improves planning and prioritising tasks, contributes to coordinating activities across the PME and assists in the delivery of project schedules and associated tasks. Respondents are generally consistent in their positive support of Autodesk Buzzsaw to contribute to the task and scheduling activities required within the project environment with most responses providing moderate-high support. This is consistent with information discovered through the interviews.

\section{Communication}

Respondents are strongly supportive of the role of communication within the PME, and note that this needed to be carried through to the use of the OCT. Respondents support communication as useful in managing and negotiating with stakeholders, project teams and other relationships including strategic alliances. Respondents consider that the use of the OCT encourages and assists with communication and is effective in dealing with project teams and resources. Responses are moderately supportive on whether communication by team members was more effective when using the OCT, and whether it assisted in controlling the use of email. This finding is supported by comments made in the interviews, and may be especially pertinent given the distributed nature of the project team. 


\section{Information Sharing}

Respondents are strongly supportive of the role of knowledge sharing and distribution across the PME, and note that it is important for team members. The use of the OCT in the PME is effective in centralising data, reducing inefficiencies in the retrieval of data, and contributes to an increase in the ease with which information can be shared and distributed. Respondents also note that information sharing is a component of managing relationships and improving the quality of data within the PME, including managing change controls, retrieving documents and the contract management process. Responses are moderately supportive regarding the ability of the OCT to provide an incentive to share information, regardless of its capacity to do so, or whether documents can be distributed without trust. This comment shows the high regard in which it is held to manage and centralise file types and in the project team's support for sharing information.

\section{Relationships}

Respondents are moderate-highly supportive of the role and effectiveness of the OCT in managing relationships within the PME. Respondents note that trust is important when managing stakeholders and that the project team requires a level of trust to operate successfully. Respondents trust their team members and consider that their team members trust them. The need for strategic alliances is not weakened by the use of the OCT and there is support that the OCT assists with managing trust across the project team and with the broader stakeholder and relationship management functions. However, respondents are moderately supportive on whether the OCT assists in developing or facilitating trust or relationships within the PME or its team members.

\section{Rewards}

Respondents were moderate-highly supportive of the role of rewards in the PME, and note that the OCT does not reduce the need for incentives to occur, or discourage innovation and learning across teams.

\section{Negotiation}

Respondents are supportive of the statement that negotiations with stakeholders are assisted when parties trust each other, and that these negotiations can play an integral part in managing stakeholders. OCTs do not hamper these negotiations. 


\section{Summary of Organisation C}

Figure 8-4 portrays Organisation $\mathrm{C}$ in a very similar way to the previous organisation (OrgM), in that it has moderate to high support in the use of the OCT for Communication, Information Sharing, Relationships, and Negotiation elements of the Collaboration scale. Of interest in this comment is that both organisations are construction projects with a strong requirement for managing drawings and procedures. As with the previous organisation, these findings suggest that for this organisation (commercial construction project), the tool is used for cooperation and coordination functions, and not for collaboration. The findings for Organisation $\mathrm{C}$ are very close to those results for the Aggregate.

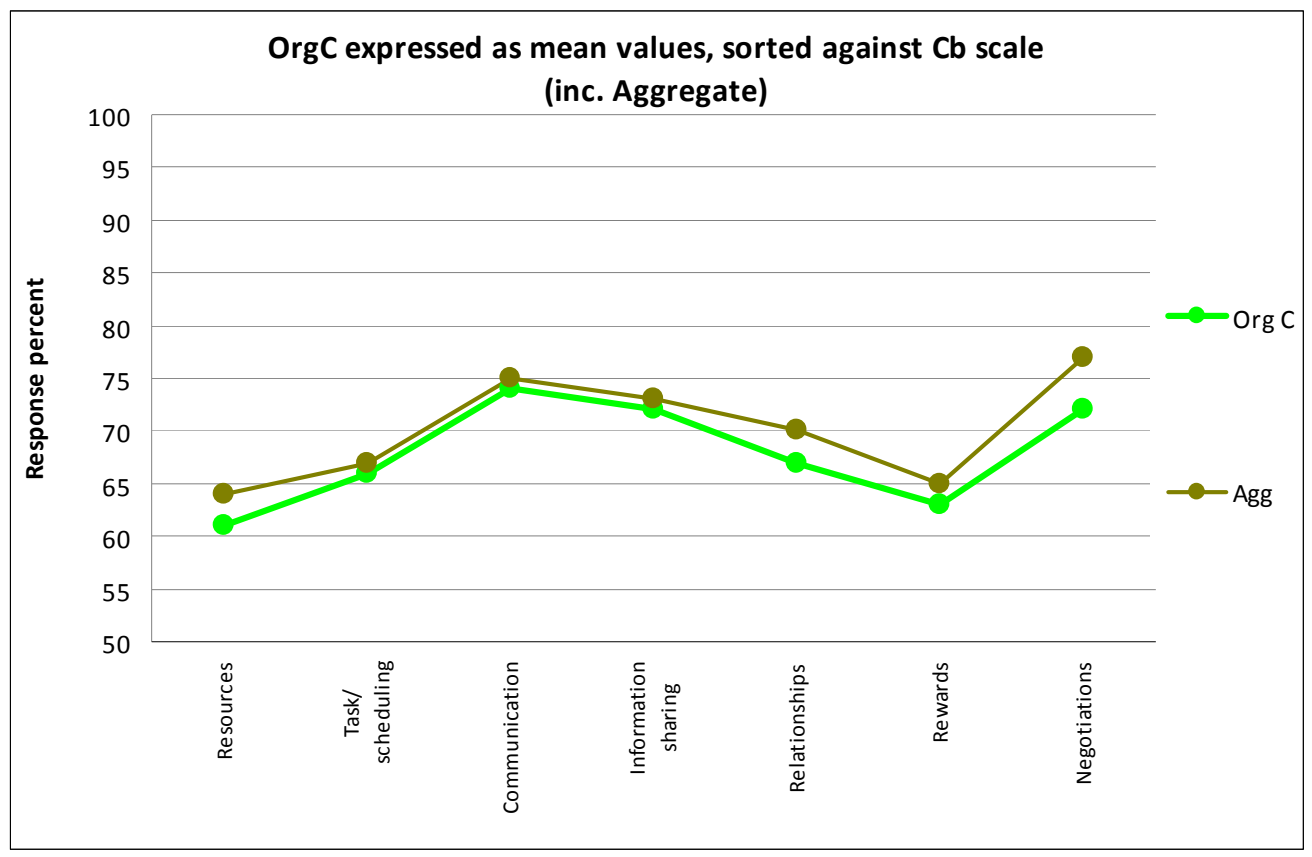

Figure 8-4: OrgC responses to Likert expressed as mean values, sorted against Collaboration scale 


\subsubsection{Organisation S (Government Authority)}

As previously mentioned, the key benefits of QuickPlace include anywhere/anytime access to information, asynchronous collaboration processes, facilitation of the formation of working teams, and centralised data for team members.

Organisation $\mathrm{S}$ has strong support for the OCT where it assists project planning and managing resources across the project, and in managing risk. Given the nature of the organisation environment, in that it was an internal project with several sub-project teams and outsourced contractors, the OCT was used to complement a focus on a robust governance mechanism. Communication within the project team and reporting up through to the Executive team (and other government relationships) was an integral part of the project, with the use of the OCT closely linked to the preparation of these functions.

Table 8-5 provides the results of the use of IBM QuickPlace OCT within Organisation S against the Collaboration scale. 
Table 8-5: Organisation $S$ sorted against Collaboration scale

\begin{tabular}{|c|c|c|c|c|c|c|}
\hline $\begin{array}{c}\text { Likert } \\
\text { Section } \\
\end{array}$ & $\begin{array}{l}\text { Qu. } \\
\text { No. }\end{array}$ & Likert Statement & $\begin{array}{c}\text { Cb } \\
\text { Scale } \\
\text { ID }\end{array}$ & Tally & Percent & Rating \\
\hline 1.3 & 29 & assists with project planning & 1 & 19 & $76 \%$ & mod-high \\
\hline 1.4 & 43 & increases difficulty in managing resources across the project & 1 & 19 & $76 \%$ & mod-high \\
\hline 1.6 & 60 & decreases the ability to manage and control risk & 1 & 18 & $72 \%$ & mod-high \\
\hline 1.7 & 69 & creates an online space which the team uses as a project meeting space & 1 & 18 & $72 \%$ & mod-high \\
\hline 1.5 & 49 & assists with monitoring and controlling risk in the project environment & 1 & 17 & $68 \%$ & mod-high \\
\hline 1.5 & 50 & provides greater control of resources planning & 1 & 17 & $68 \%$ & mod-high \\
\hline 1.6 & 54 & manages time more effectively & 1 & 17 & $68 \%$ & mod-high \\
\hline 1.2 & 16 & detracts from organisational planning & 1 & 16 & $64 \%$ & mod-high \\
\hline 1.4 & 36 & increases the effort required to monitor and control risk & 1 & 16 & $64 \%$ & mod-high \\
\hline 1.7 & 70 & increases the amount of time it takes to do things & 1 & 16 & $64 \%$ & mod-high \\
\hline 1.7 & 73 & complicates managing staff and resources & 1 & 16 & $64 \%$ & mod-high \\
\hline 2.5 & 115 & knowledge distribution should be managed by the project manager & 1 & 16 & $64 \%$ & mod-high \\
\hline 1.4 & 31 & reduces the number of users accessing files & 1 & 15 & $60 \%$ & moderate \\
\hline 1.6 & 55 & does not replace the number of meetings required & 1 & 13 & $52 \%$ & moderate \\
\hline \multirow[t]{2}{*}{1.6} & 61 & replaces the need to meet physically & 1 & 10 & $40 \%$ & low-mod \\
\hline & & Mean Value Collaboration Scale One & & & $65 \%$ & mod-high \\
\hline 1.1 & 1 & increases chances of meeting project schedules & 2 & 19 & $76 \%$ & mod-high \\
\hline 1.1 & 2 & improves planning activities & 2 & 19 & $76 \%$ & mod-high \\
\hline 1.1 & 4 & complicates coordinating activities across the project environment & 2 & 19 & $76 \%$ & mod-high \\
\hline 1.1 & 5 & improves delivery of activities in a timely manner & 2 & 18 & $72 \%$ & mod-high \\
\hline 1.5 & 52 & increases the capacity to manage risk & 2 & 18 & $72 \%$ & mod-high \\
\hline 1.4 & 40 & decreases the quality controls of the document & 2 & 17 & $68 \%$ & mod-high \\
\hline 1.5 & 53 & assists with the execution of the project plan & 2 & 17 & $68 \%$ & mod-high \\
\hline 1.1 & 3 & improves prioritising tasks & 2 & 16 & $64 \%$ & mod-high \\
\hline 1.3 & 23 & risks quality control within the project & 2 & 16 & $64 \%$ & mod-high \\
\hline 1.5 & 48 & contributes to controlling the project schedule & 2 & 16 & $64 \%$ & mod-high \\
\hline 1.6 & 57 & enables more effective control over schedule and project issues & 2 & 16 & $64 \%$ & mod-high \\
\hline 1.7 & 72 & does not improve quality control & 2 & 16 & $64 \%$ & mod-high \\
\hline 1.4 & 39 & increases the time and effort required to manage documents & 2 & 14 & $56 \%$ & moderate \\
\hline 1.7 & 65 & increases the amount of administration for the project & 2 & 14 & $56 \%$ & moderate \\
\hline \multirow[t]{2}{*}{1.7} & 71 & assists with managing scope issues & 2 & 14 & $56 \%$ & moderate \\
\hline & & Mean Value Collaboration Scale Two & & & $66 \%$ & mod-high \\
\hline 2.2 & 90 & communication is not important when using an OCT & 3 & 22 & $88 \%$ & high \\
\hline 2.6 & 117 & negotiation requires communication amongst stakeholders & 3 & 22 & $88 \%$ & high \\
\hline 2.2 & 93 & online technology does not assist with communication in the project environment & 3 & 21 & $84 \%$ & high \\
\hline 2.4 & 105 & strategic alliances are managed by open communication & 3 & 21 & $84 \%$ & high \\
\hline 1.1 & 7 & communicates the availability of team members and resources & 3 & 20 & $80 \%$ & mod-high \\
\hline 1.2 & 19 & hampers communication across the project team & 3 & 20 & $80 \%$ & mod-high \\
\hline 1.6 & 58 & enhances communication across the project team & 3 & 20 & $80 \%$ & mod-high \\
\hline 2.2 & 89 & Managing team members requires communication & 3 & 20 & $80 \%$ & mod-high \\
\hline 2.2 & 96 & communication across the project environment does not benefit from using OCT & 3 & 20 & $80 \%$ & mod-high \\
\hline 2.3 & 101 & communication assists relationship management of project teams & 3 & 20 & $80 \%$ & mod-high \\
\hline 1.3 & 24 & improves communication regarding essential information & 3 & 19 & $76 \%$ & mod-high \\
\hline 2.2 & 85 & effective communication benefits project management & 3 & 19 & $76 \%$ & mod-high \\
\hline 2.2 & 87 & stakeholder management relies on communication & 3 & 19 & $76 \%$ & mod-high \\
\hline 2.2 & 94 & communication is essential in achieving project objectives / deliverables & 3 & 19 & $76 \%$ & mod-high \\
\hline 2.2 & 95 & communication is not clearer when using OCT & 3 & 19 & $76 \%$ & mod-high \\
\hline 1.7 & 67 & streamlines communication to the project teams & 3 & 18 & $72 \%$ & mod-high \\
\hline 2.2 & 86 & communication is not enhanced by technology & 3 & 18 & $72 \%$ & mod-high \\
\hline 1.5 & 44 & manages the use of email more efficiently & 3 & 17 & $68 \%$ & mod-high \\
\hline 1.5 & 47 & is ineffective when communicating to the project team & 3 & 16 & $64 \%$ & mod-high \\
\hline 1.4 & 34 & discourages communication across the project team & 3 & 15 & $60 \%$ & moderate \\
\hline \multirow[t]{2}{*}{2.2} & 92 & team members communicate more effectively when using OCT & 3 & 14 & $56 \%$ & moderate \\
\hline & & Mean Value Collaboration Scale Three & & & $76 \%$ & mod-high \\
\hline 1.2 & 11 & manages data from a central environment & 4 & 23 & $92 \%$ & high \\
\hline 1.4 & 30 & enables easy access to all documents in the central repository & 4 & 23 & $92 \%$ & high \\
\hline 2.5 & 108 & the distribution of knowledge regarding the project is important to team members & 4 & 23 & $92 \%$ & high \\
\hline 2.5 & 113 & knowledge distribution is more than having a central repository of documents in an OCT & 4 & 23 & $92 \%$ & high \\
\hline 1.7 & 64 & ensures all documents are easily found & 4 & 22 & $88 \%$ & high \\
\hline 1.2 & 15 & centralises reporting of data & 4 & 21 & $84 \%$ & high \\
\hline 1.3 & 27 & assists in managing change controls in the project & 4 & 21 & $84 \%$ & high \\
\hline 2.5 & 111 & knowledge distribution should be on an ad hoc basis & 4 & 21 & $84 \%$ & high \\
\hline 1.3 & 21 & increases efficiencies in distribution of documents & 4 & 20 & $80 \%$ & mod-high \\
\hline 1.3 & 25 & produces inefficiencies in retrieval of information & 4 & 20 & $80 \%$ & mod-high \\
\hline 1.4 & 33 & increases ease of retrieving documents & 4 & 20 & $80 \%$ & mod-high \\
\hline 1.7 & 66 & ensures all project related information is kept up to date and in one place & 4 & 20 & $80 \%$ & mod-high \\
\hline 2.2 & 91 & OCT improve information sharing & 4 & 20 & $80 \%$ & mod-high \\
\hline
\end{tabular}




\begin{tabular}{|c|c|c|c|c|c|c|}
\hline $\begin{array}{l}\text { Likert } \\
\text { Section }\end{array}$ & $\begin{array}{l}\text { Qu. } \\
\text { No. }\end{array}$ & Likert Statement & $\begin{array}{c}\text { Cb } \\
\text { Scale } \\
\text { ID }\end{array}$ & Tally & Percent & Rating \\
\hline 1.2 & 13 & increases possibility of data corruption & 4 & 19 & $76 \%$ & mod-high \\
\hline 2.2 & 88 & sharing knowledge can be enhanced using online technology & 4 & 19 & $76 \%$ & mod-high \\
\hline 2.3 & 98 & knowledge distribution is not important for team members & 4 & 19 & $76 \%$ & mod-high \\
\hline 2.5 & 109 & OCT encourage sharing information amongst team members & 4 & 19 & $76 \%$ & mod-high \\
\hline 2.5 & 114 & Announcement boards in OCT assist in the distribution of important information & 4 & 19 & $76 \%$ & mod-high \\
\hline 1.2 & 17 & reduces the complexity of maintaining data & 4 & 18 & $72 \%$ & mod-high \\
\hline 1.3 & 28 & adds time and cost to managing the shared documents & 4 & 18 & $72 \%$ & mod-high \\
\hline 1.7 & 63 & is the most effective tool for distributing information to the project team & 4 & 18 & $72 \%$ & mod-high \\
\hline 2.4 & 103 & knowledge sharing is a critical component of managing alliances & 4 & 18 & $72 \%$ & mod-high \\
\hline 1.2 & 12 & decreases confidence in the data & 4 & 17 & $68 \%$ & mod-high \\
\hline 1.4 & 35 & provides an incentive to share information amongst team members & 4 & 17 & $68 \%$ & mod-high \\
\hline 1.4 & 41 & enhances contract management processes & 4 & 17 & $68 \%$ & mod-high \\
\hline 1.5 & 51 & creates difficulty in distributing information across the project & 4 & 17 & $68 \%$ & mod-high \\
\hline 1.7 & 68 & increases the amount of paperwork in managing projects & 4 & 17 & $68 \%$ & mod-high \\
\hline 2.5 & 112 & knowledge should not be distributed from a central location & 4 & 17 & $68 \%$ & mod-high \\
\hline 1.2 & 10 & improves the quality of data in the database & 4 & 16 & $64 \%$ & mod-high \\
\hline 1.4 & 38 & increases difficulty in accessing files remotely & 4 & 16 & $64 \%$ & mod-high \\
\hline 2.3 & 99 & equality is demonstrated by sharing information between team members & 4 & 16 & $64 \%$ & mod-high \\
\hline 1.3 & 20 & increases the number of versions of documents & 4 & 14 & $56 \%$ & moderate \\
\hline 1.2 & 14 & decreases the time it takes to undertake tasks & 4 & 13 & $52 \%$ & moderate \\
\hline \multirow[t]{2}{*}{2.1} & 81 & documents can be shared in the project team without trust & 4 & 13 & $52 \%$ & moderate \\
\hline & & Mean Value Collaboration Scale Four & & & $75 \%$ & mod-high \\
\hline 2.1 & 77 & trust is not important in stakeholder management & 5 & 22 & $88 \%$ & high \\
\hline 2.1 & 76 & the project team requires a level of trust in order to successfully operate & 5 & 21 & $84 \%$ & high \\
\hline 2.1 & 79 & trust is important when sharing knowledge across the project areas & 5 & 21 & $84 \%$ & high \\
\hline 2.1 & 82 & trust is not required in the project management environment & 5 & 21 & $84 \%$ & high \\
\hline 1.3 & 22 & requires a level of trust between team members & 5 & 20 & $80 \%$ & mod-high \\
\hline 2.1 & 74 & I trust my team members & 5 & 20 & $80 \%$ & mod-high \\
\hline 2.1 & 75 & my team members trust me & 5 & 20 & $80 \%$ & mod-high \\
\hline 1.2 & 18 & requires a level of trust between team members & 5 & 19 & $76 \%$ & mod-high \\
\hline 1.4 & 37 & reduces the need for alliances/relationships across the project environment & 5 & 19 & $76 \%$ & mod-high \\
\hline 1.6 & 62 & develops relationships with team members & 5 & 19 & $76 \%$ & mod-high \\
\hline 2.1 & 80 & trust is required between stakeholders in order to achieve project objectives / deliverables & 5 & 19 & $76 \%$ & mod-high \\
\hline 2.4 & 104 & trust is not essential to developing and maintaining Strategic Alliances & 5 & 19 & $76 \%$ & mod-high \\
\hline 2.4 & 106 & stakeholder management is not improved when using OCT & 5 & 19 & $76 \%$ & mod-high \\
\hline 2.5 & 110 & the distribution of knowledge amongst team members is central to trust & 5 & 19 & $76 \%$ & mod-high \\
\hline 1.1 & 9 & detracts from managing Strategic alliances within the project team & 5 & 18 & $72 \%$ & mod-high \\
\hline 1.6 & 56 & makes it hard to establish trust between team members & 5 & 18 & $72 \%$ & mod-high \\
\hline 2.1 & 78 & negotiations depend on the presence of trust & 5 & 18 & $72 \%$ & mod-high \\
\hline 1.3 & 26 & develops an equality amongst the team members & 5 & 17 & $68 \%$ & mod-high \\
\hline 1.1 & 6 & assists with the development of trust across the project team & 5 & 16 & $64 \%$ & mod-high \\
\hline 1.5 & 45 & develops relationships with team members & 5 & 16 & $64 \%$ & mod-high \\
\hline 2.4 & 102 & strategic alliances can be strengthened using the OCT & 5 & 16 & $64 \%$ & mod-high \\
\hline 1.1 & 8 & supports equality amongst team members & 5 & 15 & $60 \%$ & moderate \\
\hline 1.4 & 32 & develops trust between team members & 5 & 15 & $60 \%$ & moderate \\
\hline 1.4 & 42 & assists with negotiations within the project management environment & 5 & 15 & $60 \%$ & moderate \\
\hline 1.5 & 46 & requires team members to trust each other & 5 & 15 & $60 \%$ & moderate \\
\hline 2.3 & 97 & members of the project team need to feel equal & 5 & 14 & $56 \%$ & moderate \\
\hline 2.4 & 107 & OCT delivers the incentives needed to manage Strategic Alliances & 5 & 14 & $56 \%$ & moderate \\
\hline 2.1 & 84 & OCT facilitates trust amongst team members & 5 & 12 & $48 \%$ & moderate \\
\hline 2.3 & 100 & team members do not need to feel equal in order to contribute & 5 & 12 & $48 \%$ & moderate \\
\hline \multirow[t]{2}{*}{2.1} & 83 & collaboration can be achieved without trust & 5 & 9 & $36 \%$ & low-mod \\
\hline & & Mean Value Collaboration Scale Five & & & $69 \%$ & mod-high \\
\hline 2.7 & 123 & without incentives, information sharing would not occur & 6 & 20 & $80 \%$ & mod-high \\
\hline 1.6 & 59 & discourages innovation and learning across the team & 6 & 19 & $76 \%$ & mod-high \\
\hline 2.7 & 122 & OCT reduce the need for incentives in the project environment & 6 & 18 & $72 \%$ & mod-high \\
\hline 2.6 & 118 & incentives are central to negotiations & 6 & 16 & $64 \%$ & mod-high \\
\hline \multirow[t]{2}{*}{2.7} & 121 & incentives are a prerequisite to sharing information & 6 & 10 & $40 \%$ & low-mod \\
\hline & & Mean Value Collaboration Scale Six & & & $66 \%$ & mod-high \\
\hline 2.6 & 116 & negotiation is an integral part of managing stakeholders & 7 & 22 & $88 \%$ & high \\
\hline 2.6 & 120 & negotiations between stakeholders is aided when parties trust each other & 7 & 21 & $84 \%$ & high \\
\hline \multirow[t]{2}{*}{2.6} & 119 & OCT hamper the negotiation process with stakeholders & 7 & 19 & $76 \%$ & mod-high \\
\hline & & Mean Value Collaboration Scale Seven & & & $83 \%$ & high \\
\hline
\end{tabular}




\section{General Comments on the Findings against the Collaboration Scale Resources}

Respondents in Organisation S are moderate-highly supportive of the use of the OCT for resources within the PME. The OCT assists with project planning and in managing staff and resources across the project. It contributes to managing and controlling risk and in creating an online space for the project team. Respondents are low-moderately supportive of the statement that the use of an OCT replaces the need to meet physically. These responses are supported through a mixture of direct and negatively posed questions.

\section{Task/scheduling}

Respondents in Organisation S moderate-highly support the use of the OCT for task and scheduling functions. The OCT assists in planning and coordinating activities across the PME, and in meeting project schedules. The OCT improves delivery of activities in a timely manner and respondents were consistent in that the OCT assists in managing risk. Quality controls are aided by the use of the tool, which also contributes to the execution of the project plan. Respondents are moderately supportive of whether the OCT reduces the amount of time it takes to manage documents and in the management of scope issues.

\section{Communication}

Respondents strongly support the statement that communication is important when using an OCT and that negotiation requires communication amongst stakeholders. Online technology assists with communication in the PME and strategic alliances are managed by open communication. The OCT enhances communication and assists with relationship management of project teams, stakeholders and the dissemination of essential information. This is consistent with the strong governance focus of the Project Director, where mechanism are required to report and communicate the project at different stages. These responses are supported through a mixture of direct and negatively posed questions.

\section{Information Sharing}

Respondents are consistent in their strong support that the OCT manages data from a central environment, and enables easy access to all documents in the central repository. Knowledge distribution is important for team members, but is more than having a central repository available. The use of the OCT ensures that all documents are easily found, whilst centralising 
reporting functions and assisting in managing change controls. The OCT increases efficiencies in the distribution of documents, increasing the ease with which they can be retrieved, and ensuring that all project-related information is kept up-to-date and in one place. Knowledge distribution is considered important to project members and the OCT is the most effective tool for distributing information to them.

Respondents are moderately supportive of the statement that documents can not be shared in the project team without trust, and whether the OCT decreases the number of versions of documents. These responses are supported through a mixture of direct and negatively posed questions.

\section{Relationships}

Respondents highly support the statement that trust is important in stakeholder management and is required in order for the project team to operate successfully. Trust is important when sharing knowledge across project areas and across the PME. The use of the OCT requires a level of trust between team members and assists to develop relationships amongst each other. Trust is essential to developing and maintaining strategic alliances, with the OCT contributing to the task of stakeholder management.

Respondents are moderately supportive of whether the OCT supports equality amongst team members, and whether team members need to feel equal in order to contribute. Respondents provide low-moderate support for the statement that collaboration can be achieved without trust.

\section{Rewards}

Respondents are moderate-highly supportive of the statement that without incentives, information sharing would not occur, and that the OCT encourages innovation and learning across the team. The OCT does not reduce the need for incentives in the PME, which are central to negotiations, and are a prerequisite to sharing information.

\section{Negotiation}

Respondents are highly supportive that negotiating is an integral part in managing stakeholders, and is aided when the parties trust each other. The OCT does not hamper the negotiation process with the stakeholders. 


\section{Summary of Organisation S}

Figure 8-5 portrays Organisation $\mathrm{S}$ as having high support in the use of the OCT for Negotiation, and moderate to high support for Communication and Information Sharing elements of the Collaboration scale. Organisation S (State Authority) place a large emphasis on governance and processes related functions, seeing the OCT as playing a central role the management and administration of these processes and functions. Given this, it is not surprising that their use of the OCT returns a high level of support for negotiation, as it is used to manage the documentation and governance material required for the various internal project stakeholders. However this use also suggests that the organisation uses the tool for cooperation and coordination functions and not collaboration. This is consistent with other findings where the organisation notes that the project environment is not collaborative, but that it does coordinate significant bodies of material whilst also suffering from a 'silo mentality' from its team members. The findings for Organisation S are very closely aligned with the results for the Aggregate, except in the instance of the Negotiation element.

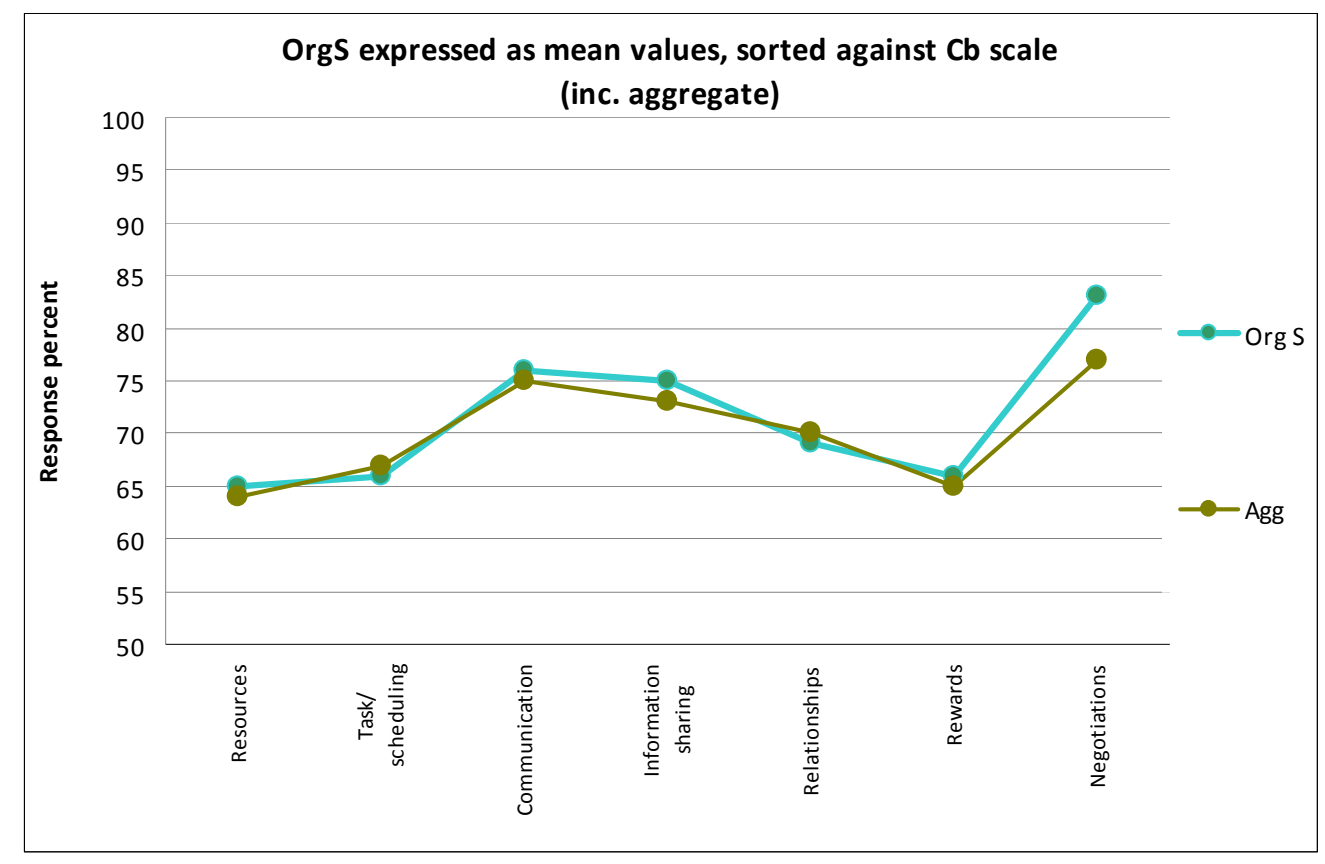

Figure 8-5: OrgS responses to Likert expressed as mean values, sorted against Collaboration scale 


\subsubsection{Organisation K (Alliance Project)}

INCITE is developed for business owners to structure communications within the PME and to integrate internal business processes. It is provided in five modules that combine to assist in information management through key areas of project management. These modules include design management, correspondence, variation and approval, instruction and reporting.

Organisation $\mathrm{K}$ has deployed four of the five modules of the INCITE product (with the fifth and final to be implemented at the construction phase). Respondents highly support elements around communication, trust, stakeholder management, and alliances, which is consistent with its organisation structure. The tool enables the distribution of documents and procedures across multiple teams drawn from partner organisations, and in doing so assists with managing the multiple stakeholders and relationships from within the organisation. The INCITE tool is used to manage the quality assurance of project-related documentation and to control specific workflows internal to the PME. This finding is also to be anticipated given the role of those interviewed for the case study are from a quality assurance background.

The input of information into INCITE is managed by the Document Controller in the organisation, and as such, access to information in the OCT is read only. This is an interesting distinction in the use of the OCT by this organisation, as it directly controls the material that can be introduced onto the OCT, rather than allowing team members to upload materials as required. The organisations control of the OCT, at first seems at odds with the intention of the tool and its capability to provide anytime/anywhere access to material. It may however be as a result of the alliance PME (and its associated complexity of the project) that project-related information is centralised by a document controller role. It is also interesting to note that this role was suggested by OrgM SE1 as a way to further streamline the use of its OCT (ACONEX) and minimise the effort it took to retrieve documents.

Table 8-6 provides the results of the use of the INCITE OCT within Organisation K against the Collaboration scale. 
Table 8-6: Organisation K sorted against Collaboration scale

\begin{tabular}{|c|c|c|c|c|c|c|}
\hline $\begin{array}{c}\text { Likert } \\
\text { Section } \\
\end{array}$ & $\begin{array}{l}\text { Qu. } \\
\text { No. }\end{array}$ & Likert Statement & $\begin{array}{c}\text { Cb } \\
\text { Scale } \\
\text { ID } \\
\end{array}$ & Tally & Percent & Rating \\
\hline 1.3 & 29 & assists with project planning & 1 & 24 & $80 \%$ & mod-high \\
\hline 1.6 & 54 & manages time more effectively & 1 & 22 & $73 \%$ & mod-high \\
\hline 1.7 & 70 & increases the amount of time it takes to do things & 1 & 22 & $73 \%$ & mod-high \\
\hline 1.7 & 73 & complicates managing staff and resources & 1 & 22 & $73 \%$ & mod-high \\
\hline 1.4 & 43 & increases difficulty in managing resources across the project & 1 & 21 & $70 \%$ & mod-high \\
\hline 1.7 & 69 & creates an online space which the team uses as a project meeting space & 1 & 20 & $67 \%$ & mod-high \\
\hline 1.6 & 60 & decreases the ability to manage and control risk & 1 & 20 & $67 \%$ & mod-high \\
\hline 1.5 & 49 & assists with monitoring and controlling risk in the project environment & 1 & 19 & $63 \%$ & mod-high \\
\hline 1.2 & 16 & detracts from organisational planning & 1 & 19 & $63 \%$ & mod-high \\
\hline 1.4 & 36 & increases the effort required to monitor and control risk & 1 & 19 & $63 \%$ & mod-high \\
\hline 1.6 & 55 & does not replace the number of meetings required & 1 & 17 & $57 \%$ & moderate \\
\hline 1.4 & 31 & reduces the number of users accessing files & 1 & 17 & $57 \%$ & moderate \\
\hline 1.5 & 50 & provides greater control of resources planning & 1 & 17 & $57 \%$ & moderate \\
\hline 2.5 & 115 & knowledge distribution should be managed by the project manager & 1 & 17 & $57 \%$ & moderate \\
\hline \multirow[t]{2}{*}{1.6} & 61 & replaces the need to meet physically & 1 & 16 & $53 \%$ & moderate \\
\hline & & Mean Value Collaboration Scale One & & & 65\% & mod-high \\
\hline 1.1 & 2 & improves planning activities & 2 & 27 & $90 \%$ & high \\
\hline 1.1 & 1 & increases chances of meeting project schedules & 2 & 23 & $77 \%$ & mod-high \\
\hline 1.1 & 4 & complicates coordinating activities across the project environment & 2 & 23 & $77 \%$ & mod-high \\
\hline 1.4 & 40 & decreases the quality controls of the document & 2 & 23 & $77 \%$ & mod-high \\
\hline 1.7 & 72 & does not improve quality control & 2 & 23 & $77 \%$ & mod-high \\
\hline 1.1 & 3 & improves prioritising tasks & 2 & 22 & $73 \%$ & mod-high \\
\hline 1.1 & 5 & improves delivery of activities in a timely manner & 2 & 21 & $70 \%$ & mod-high \\
\hline 1.5 & 53 & assists with the execution of the project plan & 2 & 20 & $67 \%$ & mod-high \\
\hline 1.5 & 48 & contributes to controlling the project schedule & 2 & 18 & $60 \%$ & moderate \\
\hline 1.5 & 52 & increases the capacity to manage risk & 2 & 18 & $60 \%$ & moderate \\
\hline 1.4 & 39 & increases the time and effort required to manage documents & 2 & 17 & $57 \%$ & moderate \\
\hline 1.6 & 57 & enables more effective control over schedule and project issues & 2 & 17 & $57 \%$ & moderate \\
\hline 1.7 & 71 & assists with managing scope issues & 2 & 17 & $57 \%$ & moderate \\
\hline 1.3 & 23 & risks quality control within the project & 2 & 15 & $50 \%$ & moderate \\
\hline \multirow{2}{*}{1.7} & 65 & increases the amount of administration for the project & 2 & 14 & $47 \%$ & moderate \\
\hline & & Mean Value Collaboration Scale Two & & & $66 \%$ & mod-high \\
\hline 2.2 & 85 & effective communication benefits project management & 3 & 29 & $97 \%$ & high \\
\hline 2.2 & 89 & managing team members requires communication & 3 & 29 & $97 \%$ & high \\
\hline 2.3 & 101 & communication assists relationship management of project teams & 3 & 28 & $93 \%$ & high \\
\hline 2.4 & 105 & strategic alliances are managed by open communication & 3 & 25 & $83 \%$ & high \\
\hline 2.6 & 117 & negotiation requires communication amongst stakeholders & 3 & 25 & $83 \%$ & high \\
\hline 2.2 & 90 & communication is not important when using an OCT & 3 & 25 & $83 \%$ & high \\
\hline 1.1 & 7 & communicates the availability of team members and resources & 3 & 24 & $80 \%$ & mod-high \\
\hline 2.2 & 87 & stakeholder management relies on communication & 3 & 24 & $80 \%$ & mod-high \\
\hline 1.3 & 24 & improves communication regarding essential information & 3 & 23 & $77 \%$ & mod-high \\
\hline 2.2 & 94 & communication is essential in achieving project objectives / deliverables & 3 & 23 & $77 \%$ & mod-high \\
\hline 1.2 & 19 & hampers communication across the project team & 3 & 23 & $77 \%$ & mod-high \\
\hline 2.2 & 93 & online technology does not assist with communication in the project environment & 3 & 23 & $77 \%$ & mod-high \\
\hline 1.7 & 67 & streamlines communication to the project teams & 3 & 22 & $73 \%$ & mod-high \\
\hline 2.2 & 86 & communication is not enhanced by technology & 3 & 22 & $73 \%$ & mod-high \\
\hline 1.5 & 47 & is ineffective when communicating to the project team & 3 & 21 & $70 \%$ & mod-high \\
\hline 2.2 & 92 & team members communicate more effectively when using OCT & 3 & 20 & $67 \%$ & mod-high \\
\hline 1.4 & 34 & discourages communication across the project team & 3 & 20 & $67 \%$ & mod-high \\
\hline 2.2 & 96 & communication across the project environment does not benefit from using OCT & 3 & 20 & $67 \%$ & mod-high \\
\hline 2.2 & 95 & communication is not clearer when using OCT & 3 & 18 & $60 \%$ & moderate \\
\hline 1.6 & 58 & enhances communication across the project team & 3 & 17 & $57 \%$ & moderate \\
\hline \multirow[t]{2}{*}{1.5} & 44 & manages the use of email more efficiently & 3 & 16 & $53 \%$ & moderate \\
\hline & & Mean Value Collaboration Scale Three & & & $76 \%$ & mod-high \\
\hline 1.2 & 11 & manages data from a central environment & 4 & 27 & $90 \%$ & high \\
\hline 1.4 & 30 & enables easy access to all documents in the central repository & 4 & 26 & $87 \%$ & high \\
\hline 2.3 & 98 & knowledge distribution is not important for team members & 4 & 26 & $87 \%$ & high \\
\hline 1.7 & 64 & ensures all documents are easily found & 4 & 25 & $83 \%$ & high \\
\hline 2.2 & 88 & sharing knowledge can be enhanced using online technology & 4 & 25 & $83 \%$ & high \\
\hline 2.5 & 108 & the distribution of knowledge regarding the project is important to team members & 4 & 25 & $83 \%$ & high \\
\hline 1.2 & 17 & reduces the complexity of maintaining data & 4 & 24 & $80 \%$ & mod-high \\
\hline 1.3 & 21 & increases efficiencies in distribution of documents & 4 & 24 & $80 \%$ & mod-high \\
\hline 1.7 & 66 & ensures all project related information is kept up to date and in one place & 4 & 24 & $80 \%$ & mod-high \\
\hline 2.2 & 91 & OCT improve information sharing & 4 & 24 & $80 \%$ & mod-high \\
\hline 2.5 & 103 & knowledge sharing is a critical component of managing alliances & 4 & 24 & $80 \%$ & mod-high \\
\hline 2.5 & 109 & OCT encourage sharing information amongst team members & 4 & 24 & $80 \%$ & mod-high \\
\hline 2.5 & 113 & knowledge distribution is more than having a central repository of documents in an OCT & 4 & 24 & $80 \%$ & mod-high \\
\hline 1.5 & 51 & creates difficulty in distributing information across the project & 4 & 24 & $80 \%$ & mod-high \\
\hline
\end{tabular}




\begin{tabular}{|c|c|c|c|c|c|c|}
\hline $\begin{array}{r}\text { Likert } \\
\text { Section } \\
\end{array}$ & $\begin{array}{l}\text { Qu. } \\
\text { No. }\end{array}$ & Likert Statement & $\begin{array}{c}\text { Cb } \\
\text { Scale } \\
\text { ID } \\
\end{array}$ & Tally & Percent & Rating \\
\hline 1.2 & 10 & improves the quality of data in the database & 4 & 23 & $77 \%$ & mod-high \\
\hline 1.2 & 15 & centralises reporting of data & 4 & 23 & $77 \%$ & mod-high \\
\hline 1.4 & 33 & increases ease of retrieving documents & 4 & 23 & $77 \%$ & mod-high \\
\hline 1.4 & 41 & enhances contract management processes & 4 & 23 & $77 \%$ & mod-high \\
\hline 1.2 & 13 & increases possibility of data corruption & 4 & 23 & $77 \%$ & mod-high \\
\hline 2.1 & 81 & documents can be shared in the project team without trust & 4 & 23 & $77 \%$ & mod-high \\
\hline 2.6 & 111 & knowledge distribution should be on an ad hoc basis & 4 & 23 & $77 \%$ & mod-high \\
\hline 1.2 & 14 & decreases the time it takes to undertake tasks & 4 & 22 & $73 \%$ & mod-high \\
\hline 1.3 & 27 & assists in managing change controls in the project & 4 & 22 & $73 \%$ & mod-high \\
\hline 1.4 & 35 & provides an incentive to share information amongst team members & 4 & 22 & $73 \%$ & mod-high \\
\hline 1.7 & 63 & is the most effective tool for distributing information to the project team & 4 & 22 & $73 \%$ & mod-high \\
\hline 2.5 & 114 & Announcement boards in OCT assist in the distribution of important information & 4 & 22 & $73 \%$ & mod-high \\
\hline 1.3 & 25 & produces inefficiencies in retrieval of information & 4 & 22 & $73 \%$ & mod-high \\
\hline 2.3 & 99 & equality is demonstrated by sharing information between team members & 4 & 21 & $70 \%$ & mod-high \\
\hline 1.7 & 68 & increases the amount of paperwork in managing projects & 4 & 21 & $70 \%$ & mod-high \\
\hline 2.5 & 112 & knowledge should not be distributed from a central location & 4 & 21 & $70 \%$ & mod-high \\
\hline 1.3 & 28 & adds time and cost to managing the shared documents & 4 & 20 & $67 \%$ & mod-high \\
\hline 1.4 & 38 & increases difficulty in accessing files remotely & 4 & 20 & $67 \%$ & mod-high \\
\hline 1.2 & 20 & increases the number of versions of documents & 4 & 19 & $63 \%$ & mod-high \\
\hline \multirow[t]{2}{*}{2.1} & 12 & decreases confidence in the data & 4 & 18 & $60 \%$ & Moderate \\
\hline & & Mean Value Collaboration Scale Four & & & $76 \%$ & mod-high \\
\hline 2.1 & 77 & trust is not important in stakeholder management & 5 & 27 & $90 \%$ & high \\
\hline 2.1 & 82 & trust is not required in the project management environment & 5 & 27 & $90 \%$ & high \\
\hline 2.1 & 104 & trust is not essential to developing and maintaining Strategic Alliances & 5 & 27 & $90 \%$ & high \\
\hline 2.4 & 18 & requires a level of trust between team members & 5 & 26 & $87 \%$ & high \\
\hline 1.2 & 22 & requires a level of trust between team members & 5 & 26 & $87 \%$ & high \\
\hline 1.3 & 76 & the project team requires a level of trust in order to successfully operate & 5 & 26 & $87 \%$ & high \\
\hline 2.1 & 79 & trust is important when sharing knowledge across the project areas & 5 & 24 & $80 \%$ & mod-high \\
\hline 2.1 & 80 & trust is required between stakeholders in order to achieve project objectives / deliverables & 5 & 24 & $80 \%$ & mod-high \\
\hline 2.1 & 74 & I trust my team members & 5 & 23 & $77 \%$ & mod-high \\
\hline 2.1 & 75 & my team members trust me & 5 & 23 & $77 \%$ & mod-high \\
\hline 2.1 & 78 & negotiations depend on the presence of trust & 5 & 23 & $77 \%$ & mod-high \\
\hline 2.1 & 110 & the distribution of knowledge amongst team members is central to trust & 5 & 23 & $77 \%$ & mod-high \\
\hline 2.5 & 37 & reduces the need for alliances/relationships across the project environment & 5 & 23 & $77 \%$ & mod-high \\
\hline 1.4 & 106 & stakeholder management is not improved when using OCT & 5 & 23 & $77 \%$ & mod-high \\
\hline 2.4 & 102 & strategic alliances can be strengthened using the OCT & 5 & 22 & $73 \%$ & mod-high \\
\hline 2.4 & 9 & detracts from managing Strategic alliances within the project team & 5 & 22 & $73 \%$ & mod-high \\
\hline 1.1 & 6 & assists with the development of trust across the project team & 5 & 21 & $70 \%$ & mod-high \\
\hline 1.1 & 97 & members of the project team need to feel equal & 5 & 21 & $70 \%$ & mod-high \\
\hline 2.3 & 32 & develops trust between team members & 5 & 20 & $67 \%$ & mod-high \\
\hline 1.4 & 45 & develops relationships with team members & 5 & 20 & $67 \%$ & mod-high \\
\hline 1.5 & 84 & OCT facilitates trust amongst team members & 5 & 20 & $67 \%$ & mod-high \\
\hline 2.1 & 26 & develops an equality amongst the team members & 5 & 19 & $63 \%$ & mod-high \\
\hline 1.3 & 8 & supports equality amongst team members & 5 & 18 & $60 \%$ & moderate \\
\hline 1.1 & 42 & assists with negotiations within the project management environment & 5 & 18 & $60 \%$ & moderate \\
\hline 1.4 & 56 & makes it hard to establish trust between team members & 5 & 18 & $60 \%$ & moderate \\
\hline 1.6 & 100 & team members do not need to feel equal in order to contribute & 5 & 18 & $60 \%$ & moderate \\
\hline 2.3 & 46 & requires team members to trust each other & 5 & 17 & $57 \%$ & moderate \\
\hline 1.5 & 62 & develops relationships with team members & 5 & 17 & $57 \%$ & moderate \\
\hline 1.6 & 107 & OCT delivers the incentives needed to manage Strategic Alliances & 5 & 17 & $57 \%$ & moderate \\
\hline \multirow[t]{2}{*}{2.4} & 83 & collaboration can be achieved without trust & 5 & 9 & $30 \%$ & low-mod \\
\hline & & Mean Value Collaboration Scale Five & & & $71 \%$ & mod-high \\
\hline 2.6 & 118 & incentives are central to negotiations & 6 & 22 & $73 \%$ & mod-high \\
\hline 1.6 & 59 & discourages innovation and learning across the team & 6 & 21 & $70 \%$ & mod-high \\
\hline 2.7 & 123 & without incentives, information sharing would not occur & 6 & 20 & $67 \%$ & mod-high \\
\hline 2.7 & 121 & incentives are a prerequisite to sharing information & 6 & 19 & $63 \%$ & mod-high \\
\hline \multirow[t]{2}{*}{2.7} & 122 & OCT reduce the need for incentives in the project environment & 6 & 17 & $57 \%$ & Moderate \\
\hline & & Mean Value Collaboration Scale Six & & & $66 \%$ & mod-high \\
\hline 2.6 & 120 & negotiations between stakeholders is aided when parties trust each other & 7 & 26 & $87 \%$ & high \\
\hline 2.6 & 116 & negotiation is an integral part of managing stakeholders & 7 & 22 & $73 \%$ & mod-high \\
\hline \multirow[t]{2}{*}{2.6} & 119 & OCT hamper the negotiation process with stakeholders & 7 & 21 & $70 \%$ & mod-high \\
\hline & & Mean Value Collaboration Scale Seven & & & $77 \%$ & mod-high \\
\hline
\end{tabular}




\section{General Comments on the Findings against the Collaboration Scale Resources}

Respondents in Organisation K are moderate to highly supportive of using the OCT for resources within the PME. The OCT assists with project planning and in managing time, resources and staff. The OCT assists in managing and controlling risk and is used as an online meeting space. Respondents are less supportive of the statement that the use of an OCT replaces the need to meet physically. These responses are supported through a mixture of direct and negatively posed questions.

\section{Task/scheduling}

Respondents in Organisation $\mathrm{K}$ are moderate-highly supportive of the use of the OCT for task and scheduling functions. The OCT assists in planning activities and in meeting project schedules. It contributes to managing quality controls in the PME, prioritising tasks, and assisting with the delivery of the project plan. Respondents are moderately supportive of whether the OCT reduces the amount of time it takes to manage documents and in the management of scope issues.

\section{Communication}

Respondents are almost unanimous in their strong support for the statement that effective communication benefits project management, and that managing team members requires communication. Communication is also seen as important when using an OCT. The OCT communicates the availability of team members, and improves communication of essential information across the project team. Respondents are consistently supportive of the role of communication in the PME, and of the role that technology and the OCT play in this environment. These responses are supported through a mixture of direct and negatively posed questions.

\section{Information Sharing}

Respondents are consistent in their strong support that the OCT manages data from a central location, and enables easy access to all documents in the central repository. Knowledge distribution is important for team members. The OCT improves information sharing and increases efficiencies in the distribution of documents, and ensures all project information is kept 
up-to-date and in one place. The OCT enhances contract management processes, assists in managing change controls in the project, and improves the quality of data in the database.

Respondents are moderate-highly supportive of the statement that documents could not be shared in the project team without trust, and that the OCT reduces the chance of data corruption. These responses are supported through a mixture of direct and negatively posed questions. The majority of responses to this element are moderate-high and above.

\section{Relationships}

Respondents highly support the statement that trust is important in stakeholder management and is required in the PME. Trust is integral to the PME and between team members, and is required in order for the project team to operate successfully. Trust is important when sharing knowledge across project areas.

The OCT facilitates trust and develops relationships amongst the team members, but respondents are moderately supportive of whether the OCT delivers the incentives needed to manage strategic alliances. The OCT develops and supports equality amongst team members and strengthens relationships with strategic alliances, a finding that is consistent with an Alliance structured organisation. Respondents provide low-moderate support for the statement that collaboration can be achieved without trust.

\section{Rewards}

Respondents are moderate-highly supportive of the statement that incentives are central to negotiations and the OCT encourages innovation and learning across the team. Without incentives, information sharing would not occur, and as such, are a prerequisite to sharing information.

\section{Negotiation}

Respondents are highly supportive that negotiations between stakeholders are aided when the parties trust each other and that these negotiations play an integral part in managing stakeholders. The OCT does not hamper the negotiation process with the stakeholders. 


\section{Summary of Organisation K}

Figure 8-6 portrays Organisation $\mathrm{K}$ as having moderate to high support in the use of the OCT for Communication, Information Sharing and Negotiation elements of the Collaboration scale. This finding is somewhat surprising given the intensive task related and scheduling activity of the project. Higher levels for the Resources, Task Scheduling and Relationships elements could have been anticipated for this organisation. The findings are however consistent with an organisation that uses the tool to manage document libraries and perceives the OCT more as a very large database (OrgK PM2), than it does a collaborative tool. Of interest is that this organisation has implemented (or intends to implement) the full suite of the product, but only seems to use certain components of these modules. This use of the tool by Organisation $\mathrm{K}$ is consistent with the cooperative and coordinating functions, than it is for collaboration. The findings for Organisation $\mathrm{K}$ were generally consistent with the results for the Aggregate, except for Information sharing and Relationships elements.

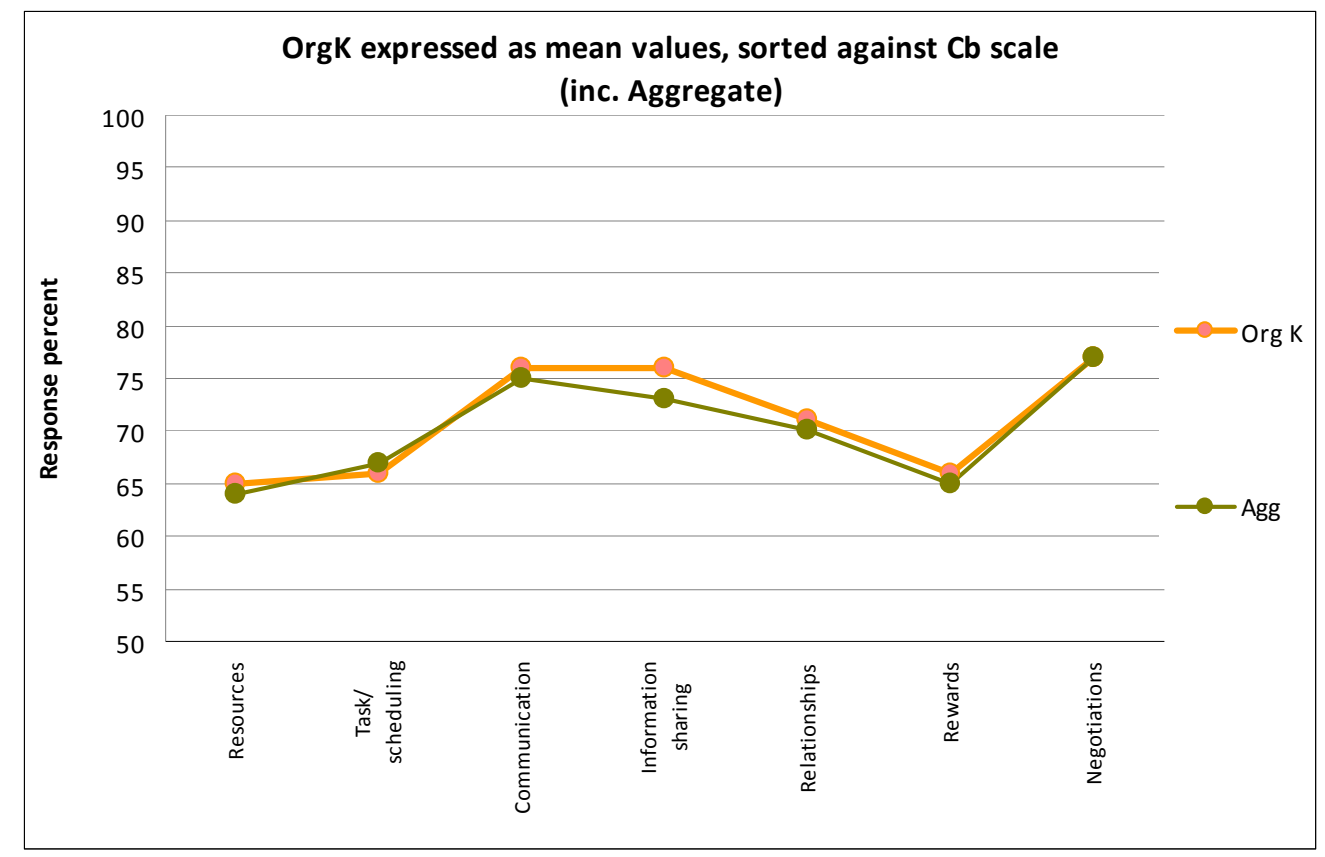

Figure 8-6: OrgK responses to Likert expressed as mean values, sorted against Collaboration scale 


\subsection{Cross-Case Summary}

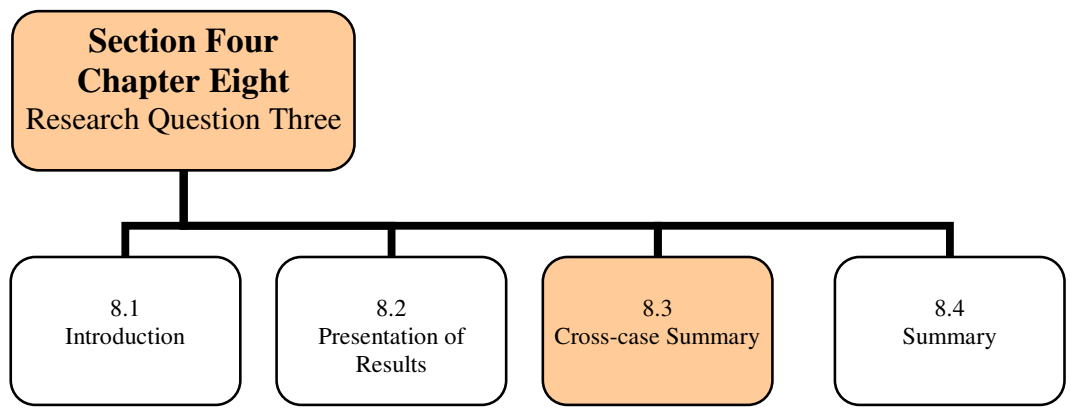

This section of Chapter 8 summarises the findings discussed in the previous section and attempts to combine the analysis of the individual cases to develop a cross-case analysis of the results. In approaching the findings this way, this research is able to understand the use of the OCTs from an individual case perspective, and from a cross-case perspective, whilst answering the third research question:

What is the level of Collaboration when using Online Collaborative Toolsets in the PME?

When posing this question, an associated proposition was also introduced, one that proposed:

Collaboration can be modelled as a scale ranging from cooperation, through coordination, to collaboration.

In order to answer this question and associated proposition, the research used the Collaboration scale developed in Chapter Four. In restating this scale, Collaboration is understood as ranging from cooperation through coordination to collaboration. Each of the seven key elements of resources, tasks, communications, information sharing, relationship and rewards are rated according to this scale to provide an indication of the level of collaboration occurring in the PME. As such, the Collaboration scale is designed so that the collaborative activity can be plotted across the cases. In posing this scale, this research argues that although collaborative elements are found within the PME, it is the level of each of the seven elements that determines the degree to which collaboration is occurring. Cooperation is viewed on the first scale and has the lowest response rate to the scale's elements. Coordination is placed on the second scale and has a middle response rate to the scale's elements, while collaboration is the third scale, and is indicated with the highest response rate to the seven key elements. 
This scale has been applied and discussed in relation to each of the six cases, and will now be used to discuss the findings across the six cases. This discussion will draw on results in the form of tables and figures already presented in Section 8.2, however, for the sake of clarity, will represent these tables and figures also in a summary format, labelled here as Table 8-7 and Figure 8-7. The full set of aggregate figures across all six cases can be found in Appendix 14.

Table 8-7: Summary of Mean Case values against Collaboration scale

\begin{tabular}{|l|c|c|c|c|c|c|c|}
\hline & \multicolumn{7}{|c|}{ Collaboration scale Elements } \\
\cline { 2 - 8 } & Resources & $\begin{array}{c}\text { Task/ } \\
\text { scheduling }\end{array}$ & Communication & $\begin{array}{c}\text { Information } \\
\text { sharing }\end{array}$ & Relationships & Rewards & Negotiations \\
\hline $\begin{array}{l}\text { Org D } \\
\text { (State Gov) }\end{array}$ & 61 & 65 & 72 & 67 & 69 & 58 & 73 \\
\hline $\begin{array}{l}\text { Org V } \\
\text { (Cont. Imp.) }\end{array}$ & 68 & 73 & 80 & 75 & 74 & 69 & 84 \\
\hline $\begin{array}{l}\text { Org M } \\
\text { (Gov. Cons) }\end{array}$ & 61 & 66 & 74 & 72 & 68 & 65 & 74 \\
\hline $\begin{array}{l}\text { Org C } \\
\text { (Comm. Cons) }\end{array}$ & 61 & 66 & 74 & 73 & 67 & 63 & 72 \\
\hline $\begin{array}{l}\text { Org S } \\
\text { (Gov Auth) }\end{array}$ & 65 & 66 & 76 & 75 & 69 & 66 & 83 \\
\hline $\begin{array}{l}\text { Org K } \\
\text { (Alliance) }\end{array}$ & 65 & 66 & 76 & 76 & 71 & 66 & 77 \\
\hline Aggregate & 64 & 67 & 75 & 73 & 70 & 65 & 77 \\
\hline
\end{tabular}

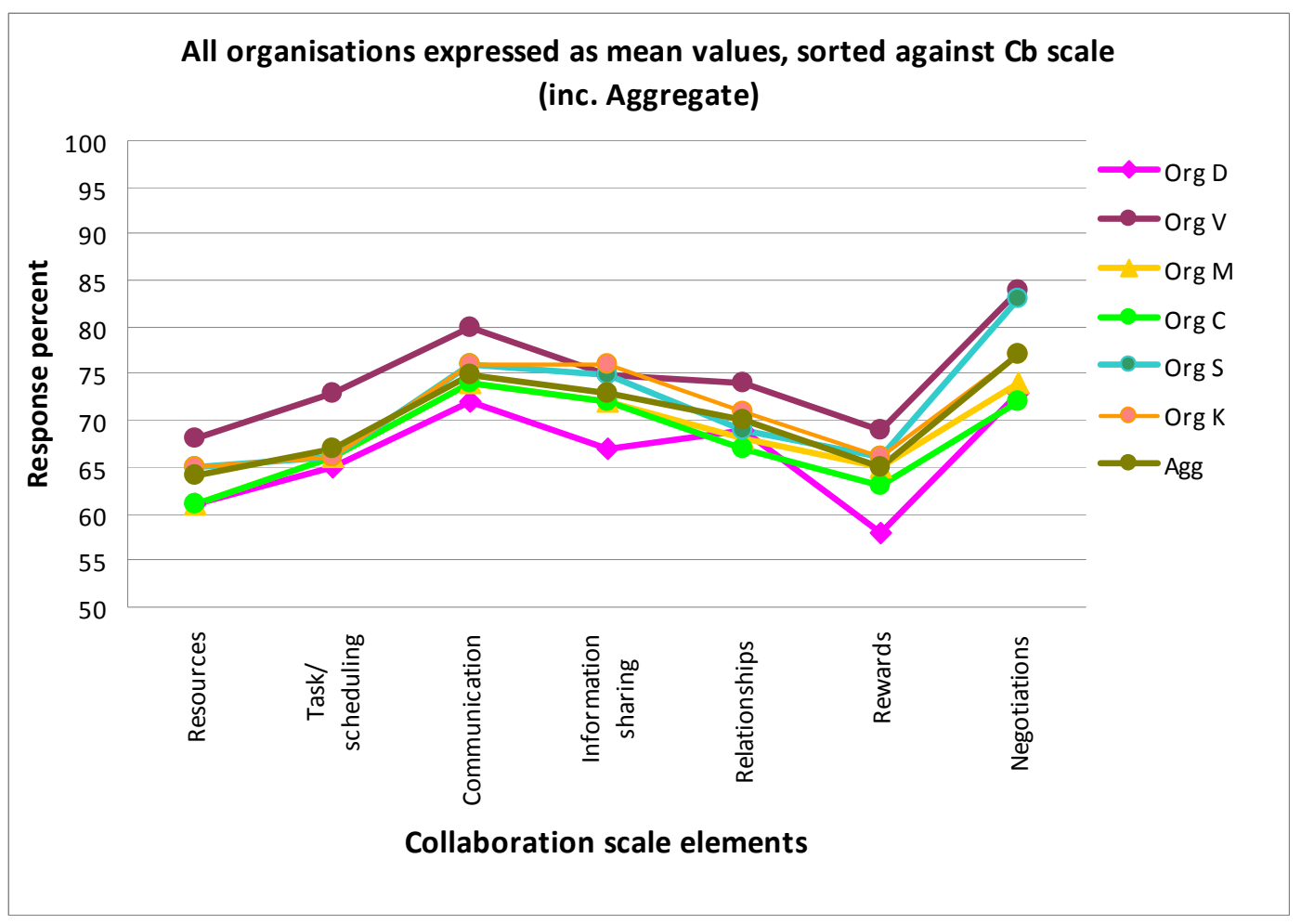

Figure 8-7: All organisations responses to Likert expressed as mean values, sorted against Collaboration scale (inc. Aggregate) 
As shown in Figure 8-7, the data highlights a consistent approach to the use of the OCTs across all six cases. The pattern across the cases is also consistent with the Aggregate results (shown here in Agg - dark green), suggesting that an analysis of the cases as a group is warranted.

In reviewing Figure 8-7 it can be noted that all of the results fall within the $55-85 \%$ range. This level provides the research with an answer to the research question at hand, and suggests that at an elementary level, the application of the Collaboration scale indicates a medium level of collaboration occurring across the cases. Furthermore, the Collaboration scale allows a response to the associated proposition, allowing this research to propose that this level of collaboration correlates to the coordination (or middle) scale of collaboration.

These conclusions to the third research question and proposition are also consistent with the previous analysis throughout Section 8.2 and with the general findings detailed in the previous Section 7.2. In these sections, the findings indicated that collaboration was not achieved throughout the PME, but that much of the activity related to coordinating materials across the team, often for governance, legal and procedural reasons. The central nature of the communication function of the OCTs, provided access to documents, and allowed the project manager and team members to manipulate and distribute messages from a central location. These functions of the OCT were most often supported as key components of the OCT regardless of the focus of the project or the make-up of the PME. Furthermore, Figure 8-7 presents a picture to suggest that regardless of the PME, the use of the OCT is consistent across the cases, each of which had variations in the core project dimensions as outlined in Table 5-9 such as size, risk, cost, complexity, organisation and management structure.

These findings also demonstrate support for use of the Collaboration scale in assessing each case's use of the OCT within its PME. The application of the Collaboration scale against the six cases indicates not only a variation of support by the PME for the different elements across the collaboration scale, but a consistent pattern relative to the individual placement or ratings of each element within the case(s). Put another way, the Resources element in the Collaboration scale consistently rates lower than the Communication element in both the individual cases reviewed, and across all cases. The same comment can be made for the Task/Scheduling element, which consistently rates above Resources and below the Communication element across all cases. The 
Information Sharing element also always rates under the Communication element, but is consistently higher than the Rewards element.

It is the consistency of the findings that demonstrates that each element in the cases is therefore not equal when using OCTs in the PME, and which subsequently supports the premise of the Collaboration scale developed in this research. In doing so, the use of the OCTs within the PMEs can be rated against the Collaboration scale (and for these six cases it is at the coordination level), and as such supports the proposition that collaboration can be modelled as a scale ranging from cooperation, through coordination, to collaboration.

\subsection{Summary}

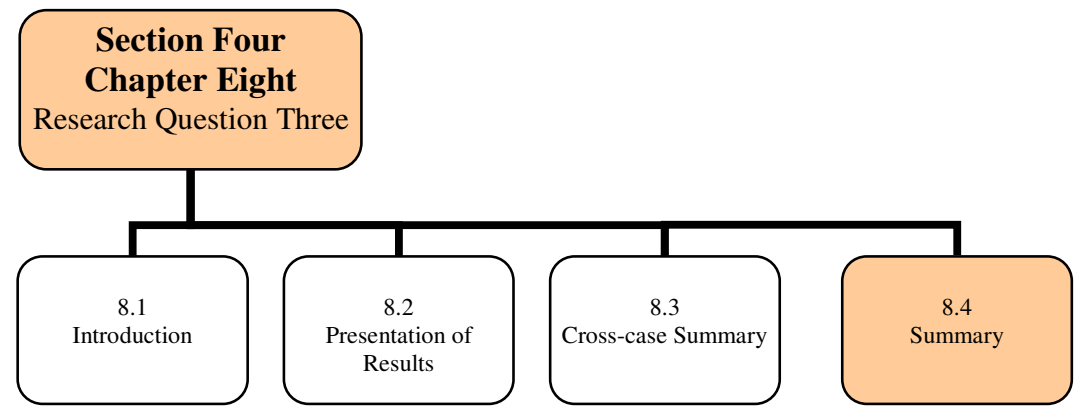

This chapter presented an analysis of each individual case's use of the OCT by applying the Collaboration scale developed in Chapter Five. This scale provided another interpretation of the findings and sought specifically to measure the level of collaboration occurring within each case's use of the OCT within their PME. This approach was taken in order to answer the third research question:

What is the level of collaboration when using Online Collaborative Toolsets in the Project Management Environment?

In addressing this research question, the chapter also sought to respond to the associated proposition:

Collaboration can be modelled as a scale ranging from cooperation, through coordination, to collaboration. 
The approach of the chapter was undertaken to detail the response to each of the collaboration characteristics on an individual case basis, and then to plot these findings to develop a cross-case comparison of the case's collaboration level.

The Collaboration scale is used to respond to the third research question and associated proposition. It was developed as a mechanism to measure the level or degree of collaboration present within the case's use of OCTS in the PME. As outlined in this and previous chapters, this thesis has argued that although the OCTs have a capacity to facilitate collaboration, the PME dynamic in each case has prescribed a non-collaborative approach.

'While the organisation wants to be collaborative, it isn't yet' (OrgD PM1)

The Collaboration scale applied in this research (and described in detail in Chapter Five) presents collaboration not as a single entity, but as a scale ranging from low to high across seven elements. To recap, these elements include Resources, Tasks/scheduling, Communication, Information Sharing, Relationships, Rewards and Negotiations. The low end of the scale of collaboration is referred to as cooperation. The second or middle point on the scale is coordination, where increased cooperative activity is achieved and interrelationships become more complex. The third and highest point on the scale is collaboration itself. Central to this theory, is that for collaboration to be said to exist, ALL elements must rate highly against the scale. The Collaboration scale is designed to be able to plot the collaborative activity within an organisation or PME. In posing this scale in the earlier chapters, the research argued that although all collaborative elements are found within a PME, it is the level of each element that determines the degree to which collaboration is occurring. This approach does not assume that it is simply a matter of observing a response and concluding that a project is therefore cooperating, coordinating or collaborating. However, in combination with other data sources (including interviews), the scale provides an interpretative device by which to understand the use of the tool.

It is from this theoretical underpinning that the third and final research question and associated proposition was presented and discussed. Section 8.2 of this chapter presented the findings of each organisation individually against the Collaboration scale, including presenting data in table format, and then plotting this data on a graph. This graph also included the result for the Aggregate as a comparison point. The cross-case summary presented in section 8.3 (and in Table 8-7 and Figure 8-7) provided the final data presentations of the chapter. Table 8-7 provided a 
summary of the mean values for each case across each of the Collaboration scale elements. Figure 8-7 plotted these mean values across the six cases (including the aggregate) to provide a graphical summary of each case, against each element in the Collaboration scale. Both the table and the figure subsequently provided a comparative (cross-case) summary of the mean responses across the six case study environments. This summary noted a consistency in the use of the OCTs within the PMEs.

The consistency in these findings supports the proposition that collaboration can be modelled as a scale ranging from cooperation, through coordination to collaboration. It shows that, across the cases, the use of the OCTs is moderately effective in managing the Resources element of collaboration, whilst the Task/Scheduling element rates only marginally higher. The Communication and Information Sharing element is well served by the OCT, a finding that is supported by the interviews. Relationships and Rewards each rated consistently lower than Communication and Information Sharing, whilst Negotiations rated consistently higher. And while the data associated with each element is a mean value, a pattern across all six cases has emerged.

Given this consistency, the research can extrapolate from this model that the presence of collaboration within the PME lies more within the cooperative and coordinative functions than with the collaborative.

These results support the pattern across the cases, and suggest not only that the Collaboration scale is valid in understanding collaboration within projects, but that these findings point more to general priorities within contemporary projects. That is to say, in the context of the use of OCTs, collaboration is not occurring within projects, however consistently high levels of cooperation and coordination are observed.

'I wouldn't say its collaborative, but it does coordinate a lot of work '(OrgS PM1)

'While the organisation wants to be collaborative it isn't there yet' (OrgD PM1)

'The culture is starting to share but it is dependent on the project and personnel' (OrgM PM1)

'The CIN culture is like a gas' (OrgV PM1) 
In summarising the different cases in Chapter 5 (Table 5-9) and again in chapter 7 (Table 7-1), this research itemised almost a dozen different aspects to the project, which not only differentiate these projects from each other, but highlighted the variety and breadth in their PMEs. These aspects included project type, risk, complexity, organisation, management structure and environment size, process, OCT stakeholders and cost.

The findings presented in Table 8-7 and Figure 8-1 however, show a set of organisations very closely related to each other in their use of OCTs (in context to the Collaboration scale). Organisation V (Continuous Improvement organisation) returns the highest support for the use of the OCT across the scale, and whilst this may not be a surprising result given its charter, the difference between it and the lowest rated organisation is less than 10 percentage points. Some elements such as Resources and Communication are less than this, while the Aggregate results were found to be within the range of the cases.

These results present an interpretation of collaboration as being consistent across the cases. It would appear that regardless of the type of project, or level of risk, the use of the tool is consistent. Organisational structure and environment also appeared not to play a role in the results, nor size, where some projects had 400 people actively involved in the OCT and others had 10 - in these situations, the PMEs all tended to review the collaborative elements in very similar ways.

'The methodology is used, however there is not a strict adherence to it. . it is more about documentation than about methodology.' (OrgM PM1)

The collaboration elements that returned a smaller data spread included Task/scheduling, Communication and Relationships, suggesting perhaps that these elements are central to the use of the OCTs. This finding is supported through the interviews and questionnaires, even though some features (including email notification) provided some administrative congestion.

Lastly, Figure 8-7 clearly shows the spread of cases across a range is firmly located within the middle zone of the scales. However, this range is not consistent across all elements, but rather fluctuating across the elements, within the range of $55-80$, or between moderate to moderatehigh. At no time do any elements peak into the high zones of the scale, or drop to the lowmoderate and low zones. These findings add further support to the notion that the presence of 
collaboration within the PME lies more within the cooperative and coordinative functions than with the collaborative.

In conclusion, the findings presented in this chapter argue that the level of collaboration (across the cases) when using OCTs in the PME is at the moderate, or coordination level. In making this assessment, it can also support the associated proposition, one that suggests that collaboration can be modelled as a scale ranging from cooperation, through coordination, to collaboration.

In making these comments the third and final research question and associated proposition is resolved highlighting implications for further research and theory. This concludes this chapter and Section Four of the thesis. The following chapter will draw the research to conclusion, and present the final commentary on the research as a whole. 


\section{SECTION FIVE}

\section{CHAPTER NINE - Conclusion}

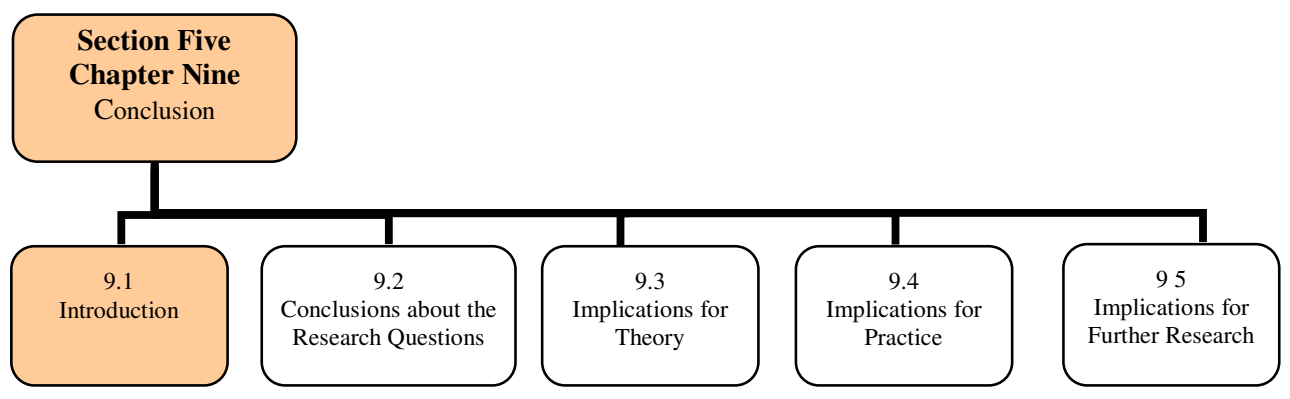

\subsection{Introduction}

This final chapter provides conclusions regarding the research problem, questions and propositions, discusses the implications for theory, policy and practice as a result of the research undertaken, and provides a commentary on implications for future research. This chapter draws out the main points from the research and concludes the discussion.

\subsection{Conclusions about the Research Question and Propositions}

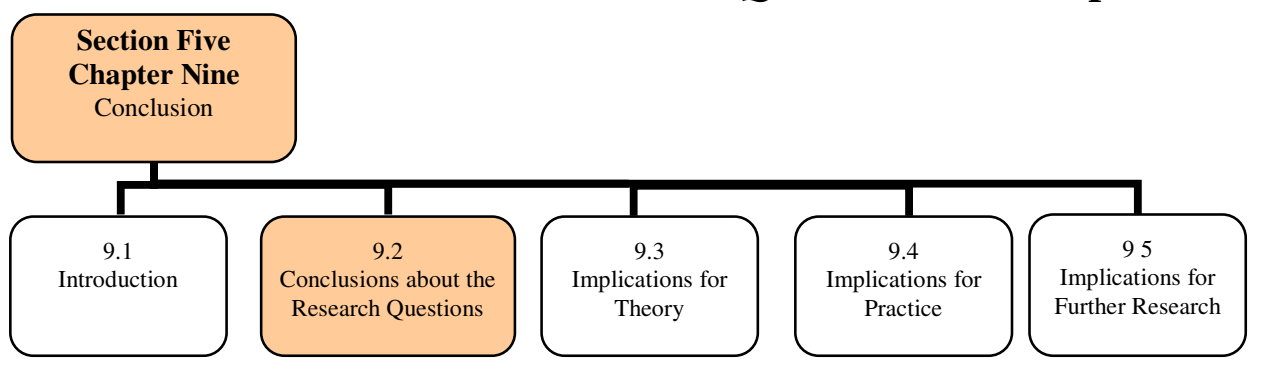

This section provides a conclusion for each of the three research questions posed and ends with a conclusion on the main Research Question. Table 9-1 details the three research questions and associated propositions, while Table 9-2 presents the details of the six cases as a reminder of the context for this final discussion.

Table 9-1: Research questions and propositions

\begin{tabular}{l|l} 
Research Question & Proposition \\
$\begin{array}{l}\text { What are the features of Online Collaborative } \\
\text { Toolsets? }\end{array}$ & $\begin{array}{l}\text { Online Collaborative Toolsets contain features that facilitate } \\
\text { cooperation, coordination, and collaboration. }\end{array}$ \\
$\begin{array}{l}\text { How are Online Collaborative Toolsets used } \\
\text { in the Project Management Environment? }\end{array}$ & $\begin{array}{l}\text { Online Collaborative Toolsets in the Project Management } \\
\text { Environment are used for cooperation and coordination, and } \\
\text { to a lesser extent collaboration. }\end{array}$ \\
$\begin{array}{l}\text { What is the level of collaboration when using } \\
\text { Online Collaborative Toolsets in the Project } \\
\text { Management Environment? }\end{array}$ & $\begin{array}{l}\text { Collaboration can be modelled as a scale ranging from } \\
\text { cooperation, through coordination, to collaboration. }\end{array}$ \\
\hline
\end{tabular}


Table 9-2: Case study details comparatively summarised (represented from Table 5-9)

\begin{tabular}{|c|c|c|c|c|c|c|}
\hline $\begin{array}{l}\text { Case } \\
\text { Particulars }\end{array}$ & $\begin{array}{l}\text { Case Study } \\
\text { Details } \\
\text { Org D }\end{array}$ & $\begin{array}{c}\text { Case Study } \\
\text { Details } \\
\text { Org V }\end{array}$ & $\begin{array}{c}\text { Case Study Details } \\
\text { Org M }\end{array}$ & $\begin{array}{c}\text { Case Study Details } \\
\text { Org C }\end{array}$ & $\begin{array}{c}\text { Case Study } \\
\text { Details } \\
\text { Org S }\end{array}$ & $\begin{array}{c}\text { Case Study Details } \\
\text { Org K }\end{array}$ \\
\hline Type & $\begin{array}{l}\text { State } \\
\text { Government }\end{array}$ & $\begin{array}{l}\text { Continuous } \\
\text { Improvement }\end{array}$ & $\begin{array}{l}\text { Government } \\
\text { Construction } \\
\end{array}$ & $\begin{array}{l}\text { Commercial } \\
\text { Construction } \\
\end{array}$ & $\begin{array}{l}\text { Government } \\
\text { Authority }\end{array}$ & $\begin{array}{l}\text { Alliance } \\
\text { Construction }\end{array}$ \\
\hline Risk & High & Medium & Low - medium & Medium & Low & High \\
\hline Complexity & $\begin{array}{l}\text { Medium - due } \\
\text { to logistic of } \\
\text { coordinating } \\
\text { many authors } \\
\text { across multiple } \\
\text { sites } \\
\end{array}$ & $\begin{array}{l}\text { Low - use of } \\
\text { established } \\
\text { technology }\end{array}$ & $\begin{array}{l}\text { High - dual clients, } \\
\text { varying scope }\end{array}$ & $\begin{array}{l}\text { Low - use of } \\
\text { established } \\
\text { technology }\end{array}$ & $\begin{array}{l}\text { Low - use of } \\
\text { established } \\
\text { technology }\end{array}$ & $\begin{array}{l}\text { Medium to high - } \\
\text { ethane pipeline }\end{array}$ \\
\hline Organisation & $\begin{array}{l}\text { Government } \\
\text { department } \\
\text { managing the } \\
\text { project }\end{array}$ & $\begin{array}{l}\text { Government } \\
\text { department } \\
\text { managing the } \\
\text { project }\end{array}$ & $\begin{array}{l}\text { Government } \\
\text { organisation } \\
\text { managing the } \\
\text { project }\end{array}$ & $\begin{array}{l}\text { Commercial } \\
\text { organisation } \\
\text { managing the } \\
\text { project }\end{array}$ & Internal project & $\begin{array}{l}\text { Alliance } \\
\text { organisation } \\
\text { managing the } \\
\text { project }\end{array}$ \\
\hline $\begin{array}{l}\text { Management } \\
\text { Structure }\end{array}$ & $\begin{array}{l}\text { Balanced Matrix } \\
\text { Structure }\end{array}$ & $\begin{array}{l}\text { Weak Matrix } \\
\text { Structure }\end{array}$ & $\begin{array}{l}\text { Balanced Matrix } \\
\text { Structure }\end{array}$ & $\begin{array}{l}\text { Balanced Matrix } \\
\text { Structure }\end{array}$ & $\begin{array}{l}\text { Balanced Matrix } \\
\text { Structure }\end{array}$ & Projectised \\
\hline Environment & Distributed & Distributed & Interorganisational & Interorganisational & Traditional & Interorganisational \\
\hline Size & $\begin{array}{l}100 \text { people in } \\
\text { total: distributed } \\
\text { teams }\end{array}$ & $\begin{array}{l}2000 \text { people in } \\
\text { total: } 7-8 \text { sub- } \\
\text { project teams }\end{array}$ & $\begin{array}{l}400+\text { people: approx } \\
15 \text { teams }\end{array}$ & $\begin{array}{l}100 \text { people in total: } \\
10 \text { teams }\end{array}$ & $\begin{array}{l}\text { Approximately } \\
10 \text { people in } \\
\text { total: } 3 \text { sub- } \\
\text { projects }\end{array}$ & $\begin{array}{l}150 \text { people in total: } \\
8 \text { functional areas }\end{array}$ \\
\hline Process & $\begin{array}{l}\text { Departmental } \\
\text { Project } \\
\text { Management } \\
\text { Methodology }\end{array}$ & $\begin{array}{l}\text { Information } \\
\text { distribution }\end{array}$ & $\begin{array}{l}\text { Administrative and } \\
\text { contractual }\end{array}$ & $\begin{array}{l}\text { Administrative and } \\
\text { contractual }\end{array}$ & $\begin{array}{l}\text { Administrative } \\
\text { and corporate }\end{array}$ & $\begin{array}{l}\text { Administrative and } \\
\text { contractual }\end{array}$ \\
\hline OCT & $\begin{array}{l}\text { IBM Lotus } \\
\text { Notes } \\
\text { QuickPlace }\end{array}$ & WordPress & ACONEX & Autodesk Buzzsaw & $\begin{array}{l}\text { IBM Lotus } \\
\text { Notes } \\
\text { QuickPlace }\end{array}$ & $\begin{array}{l}\text { Nexus Point } \\
\text { INCITE }\end{array}$ \\
\hline Stakeholders & $\begin{array}{l}\text { Varied - } \\
\text { Government } \\
\text { Ministers, } \\
\text { Private Offices } \\
\text { of Ministers, } \\
\text { Departmental } \\
\text { Executive, } \\
\text { media }\end{array}$ & $\begin{array}{l}\text { SC\&MC, } \\
\text { membership }\end{array}$ & $\begin{array}{l}\text { Complex including } \\
\text { two main clients, } \\
\text { two Government } \\
\text { Ministers, associated } \\
\text { technical and user } \\
\text { groups }\end{array}$ & $\begin{array}{l}\text { Varied - Board of } \\
\text { Directors, } \\
\text { shareholders, State } \\
\text { Government }\end{array}$ & $\begin{array}{l}\text { Varied - } \\
\text { Executive, State } \\
\text { Government, } \\
\text { target audiences }\end{array}$ & $\begin{array}{l}\text { Varied - Board of } \\
\text { Directors, } \\
\text { shareholders, State } \\
\text { Government }\end{array}$ \\
\hline Cost & $\begin{array}{l}\text { Approximately } \\
\$ 200,000 \\
(\$ 0.2 \mathrm{~m}) \text { plus in- } \\
\text { kind }\end{array}$ & $\begin{array}{l}\text { Approximately } \\
\$ 70,000 \\
(\$ 0.07 \mathrm{~m})\end{array}$ & $\begin{array}{l}\$ 122,000,000 \\
(\$ 122 \mathrm{~m})\end{array}$ & $\begin{array}{l}\text { Approximately } \\
\$ 73,000,000 \\
(\$ 73 \mathrm{~m})\end{array}$ & $\begin{array}{l}\$ 70,000 \\
(\$ 0.07 \mathrm{~m})\end{array}$ & $\begin{array}{l}\$ 500,000,000 \\
(\$ 500 \mathrm{~m})\end{array}$ \\
\hline
\end{tabular}

\subsubsection{Research Question One}

Research Question One: What are the features of Online Collaborative Toolsets?

Proposition One:

Online Collaborative Toolsets contain features that facilitate cooperation, coordination, and collaboration.

The features of the OCTs are many and varied. A review of 32 OCTs detailed more than 30 different functional elements, all of which were gathered together to showcase and compare this feature list against the OCTs used within the six case studies. In undertaking this task, the research provides ample response to the research question, further noting that the findings support the premise that there is not one 'suite' of features common across all the OCTs, but rather there are features which are common to most. Given this, the final make-up of any feature 
list for an OCT will be drawn from what is available from the OCT vendor, as well as what is dictated by client requirements. This appears obvious, however not all OCTs are suitable or designed for all purposes, and the feature list of the OCTs presented in this research highlights this variety, and the different applications for these products.

In Table 9-3 (over) re-presented from Chapter Six, it becomes apparent that the features can facilitate a level of collaboration in most instances. For example, the first feature, Central File Repository (document management) requires a degree of cooperation and coordination to be successful, but not necessarily collaboration. The same can be said for the Task and Project List feature in that it requires parties to cooperate and coordinate their efforts in order for these lists to be generated. The Discussion/Bulletin Board or Blog feature is developed specifically to embrace collaborative elements and therefore can be present across all three scales. Although not exhaustive, Table 9-3 correlates the features of the five OCTs with the three elements of collaboration, highlighting both the commonality of elements and the collaborative capacity of each OCT.

Given the variety of OCTs reviewed, the research is able to demonstrate the most common features of the OCTs, and in doing so, provide a response to Research Question One. The list of features available from the OCTs clearly demonstrates on the one hand a vast array of functionality that is suited to many different types of project requirements, from CAD integration, to workflow, data export/import, reporting and shared calendars. In providing these options, the OCTs can provide both a level of functionality that allows for complex management and administrative activities functions, whilst also enabling the different project environments to 'mix and match' their requirements in order to either select the most suitable OCT, or to find one that can be customised to their needs. On the other hand, reviewing the number of OCTs on the market and their suite of functional features available, the desk research demonstrates that almost one half of the features are common to all. This suggests a core feature list that is required to make the OCT either commercially successful or attractive to the prospective PME. 
Table 9-3: Feature list of OCTs rated against Cases and 3Cs (represented from Table 6-3)

\begin{tabular}{|c|c|c|c|c|c|c|c|c|c|}
\hline & & $\begin{array}{l}\text { Org } \\
\mathbf{D}, \mathbf{S}\end{array}$ & $\begin{array}{c}\text { Org } \\
\text { V }\end{array}$ & $\begin{array}{c}\text { Org } \\
\text { M }\end{array}$ & $\begin{array}{c}\text { Org } \\
\text { C }\end{array}$ & $\begin{array}{c}\text { Org } \\
\mathbf{K}\end{array}$ & & & \\
\hline Feature & $\begin{array}{l}\text { ALL } \\
\text { (32) } \\
\text { OCTs } \\
\text { (that } \\
\text { offer } \\
\text { these } \\
\text { features) }\end{array}$ & 竞 & 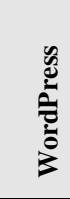 & 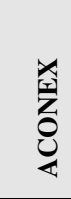 & 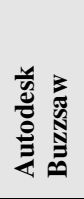 & 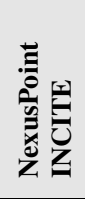 & 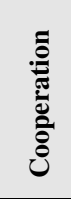 & 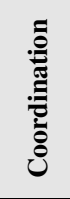 & 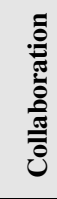 \\
\hline $\begin{array}{l}\text { central file repository } \\
\text { (document management) }\end{array}$ & $78 \%$ & $\checkmark$ & & $\checkmark$ & $\checkmark$ & $\checkmark$ & $\checkmark$ & $\checkmark$ & \\
\hline $\begin{array}{l}\text { task and project list } \\
\text { (project management) }\end{array}$ & $75 \%$ & $\checkmark$ & & $\checkmark$ & $\checkmark$ & $\checkmark$ & $\checkmark$ & $\checkmark$ & \\
\hline $\begin{array}{l}\text { discussions / bulletin boards / } \\
\text { blogs }\end{array}$ & $66 \%$ & $\checkmark$ & $\checkmark$ & $\checkmark$ & $\checkmark$ & & $\checkmark$ & $\checkmark$ & $\checkmark$ \\
\hline calendar and schedule & $59 \%$ & $\checkmark$ & & & & $\checkmark$ & $\checkmark$ & $\checkmark$ & \\
\hline email notification & $56 \%$ & $\checkmark$ & $\checkmark$ & $\checkmark$ & $\checkmark$ & $\checkmark$ & $\checkmark$ & $\checkmark$ & \\
\hline messages & $50 \%$ & $\checkmark$ & $\checkmark$ & $\checkmark$ & & $\checkmark$ & & $\checkmark$ & \\
\hline project dashboard & $44 \%$ & & $\checkmark$ & $\checkmark$ & $\checkmark$ & & $\checkmark$ & $\checkmark$ & \\
\hline security and access rights & $44 \%$ & $\checkmark$ & $\checkmark$ & $\checkmark$ & $\checkmark$ & $\checkmark$ & $\checkmark$ & $\checkmark$ & $\checkmark$ \\
\hline customised forms and templates & $38 \%$ & & $\checkmark$ & $\checkmark$ & $\checkmark$ & $\checkmark$ & $\checkmark$ & $\checkmark$ & \\
\hline task manager & $31 \%$ & $\checkmark$ & & & $\checkmark$ & & $\checkmark$ & & \\
\hline address book & $31 \%$ & $\checkmark$ & & & & $\checkmark$ & $\checkmark$ & & \\
\hline search & $31 \%$ & $\checkmark$ & $\checkmark$ & $\checkmark$ & $\checkmark$ & $\checkmark$ & $\checkmark$ & $\checkmark$ & \\
\hline Gantt chart & $28 \%$ & $\checkmark$ & & & & & $\checkmark$ & $\checkmark$ & \\
\hline library & $28 \%$ & $\checkmark$ & & $\checkmark$ & & $\checkmark$ & $\checkmark$ & & \\
\hline data export/import & $28 \%$ & & $\checkmark$ & $\checkmark$ & & $\checkmark$ & $\checkmark$ & & \\
\hline $\begin{array}{l}\text { collaboration space / central ideas } \\
\text { area / wiki }\end{array}$ & $25 \%$ & & & $\checkmark$ & & & $\checkmark$ & $\checkmark$ & $\checkmark$ \\
\hline reports & $25 \%$ & & & $\checkmark$ & $\checkmark$ & $\checkmark$ & $\checkmark$ & & \\
\hline chat & $19 \%$ & $\checkmark$ & & & & & $\checkmark$ & $\checkmark$ & $\checkmark$ \\
\hline file to task attachments & $19 \%$ & $\checkmark$ & & $\checkmark$ & & $\checkmark$ & & $\checkmark$ & \\
\hline RSS & $16 \%$ & & $\checkmark$ & & & & & $\checkmark$ & $\checkmark$ \\
\hline time sheets & $13 \%$ & & & & & & $\checkmark$ & & \\
\hline workflow & $13 \%$ & & $\checkmark$ & $\checkmark$ & $\checkmark$ & $\checkmark$ & $\checkmark$ & $\checkmark$ & \\
\hline workload report & $9 \%$ & & & & $\checkmark$ & & $\checkmark$ & $\checkmark$ & \\
\hline change tracking & $9 \%$ & & & & $\checkmark$ & $\checkmark$ & & $\checkmark$ & \\
\hline issue tracking & $9 \%$ & & & & & & & $\checkmark$ & \\
\hline event registration and calendar & $9 \%$ & & & & & & & $\checkmark$ & \\
\hline user manager & $6 \%$ & & & & $\checkmark$ & & & $\checkmark$ & \\
\hline user specification & $6 \%$ & $\checkmark$ & & & & & & $\checkmark$ & \\
\hline newsletters & $6 \%$ & & $\checkmark$ & & & & & $\checkmark$ & $\checkmark$ \\
\hline CAD integration & $6 \%$ & & & & $\checkmark$ & $\checkmark$ & $\checkmark$ & $\checkmark$ & \\
\hline virtual conference & $6 \%$ & & & $\checkmark$ & & $\checkmark$ & & & $\checkmark$ \\
\hline eCommerce & $3 \%$ & & & & & & & $\checkmark$ & \\
\hline database & $3 \%$ & & & & & & $\checkmark$ & & \\
\hline SMS & $3 \%$ & & & & & & & $\checkmark$ & \\
\hline
\end{tabular}


From this feature list, the research can also address the first proposition of the research, that states that OCTs contain features that facilitate cooperation, coordination and collaboration (3Cs). Table 9-3 also provides the necessary summary information to respond to this proposition. The desk research noted that all of these features were able to be mapped against the $3 \mathrm{Cs}$, and in doing so provided a picture of the OCTs against these elements. The table shows that while all of the features could be mapped against one or more of the $3 \mathrm{Cs}$, most could be mapped to the element of cooperation and coordination, with some elements being mapped to both. Of interest for this research however is that very few features (seven in total) were mapped to collaboration. These features included:

- discussion/bulletin boards/blogs;

- security and access rights;

- collaboration space/central ideas area/wiki;

- chat;

- RSS;

- Newsletters; and

- Virtual Conferencing.

The importance of this finding is that only the first two of these features were part of the top ten on the feature list, and not all OCTs had the same amount of collaborative features. What this may mean for the use of the OCT or for the level of collaboration within the PME was addressed in Chapters Eight and Nine and will be reviewed later in sections 9.2.2 and 9.2.3 of this chapter. However of note for this section is that the finding has supported the proposition that the feature list of OCTs details a functional capacity to facilitate cooperation, coordination, and collaboration.

The Discussion/Bulletin Boards/Blogs is in the top ten of the feature list, and is present in all the OCTs except for the INCITE product (used by Organisation K). This finding is supported by the fact that OrgK PM2 described the OCT as 'a very large database', where information was managed by a Document Controller role who would control the flow of all information into the OCT. These activities and approach to the OCT (and in particular this feature) can be described as cooperative and coordinative, but not one that engenders collaboration, which is perhaps why the Discussion/Bulletin Boards/Blogs feature was not required for that PME.

Security and Access Rights was the other feature in the top ten feature list, and was the only feature to be present in all OCTs. This finding can be seen to support the distributed nature of the 
OCTs, and the varying roles and positions that are in place across the teams. This is also not a surprising finding when viewed against the project details, where some projects had more than 400 people accessing material on the OCT, were financially significant (two projects individually costed at $\$ 122 \mathrm{~m}$ and $\$ 500 \mathrm{~m}$ ), and where political pressure was often prevalent. Case organisations clearly wanted to manage who accessed the OCT, and what material would be available to them.

The only other two features common to all OCTs were Email Notification and the Search feature, both rating as facilitating cooperation and coordination. The Email Notification received mixed responses from the research, and indicates that although the concept may be supported, the implementation and use of this feature is often fraught with technical issues, or seen as adding to email congestion. The Search feature, by virtue of being linked with the centralised functionality of the OCT, was well supported by the PMEs.

\subsubsection{Research Question Two}

Research Question Two: $\quad H o w$ are Online Collaborative Toolsets used in the Project Management Environment?

Proposition Two: $\quad$ Online Collaborative Toolsets in the Project Management Environment are used for cooperation, and coordination, and to a lesser extent collaboration.

In the previous Section 9.2.1 the features of the OCTs were identified and compared across the case organisations. This comparison also included a mapping of the features against the collaboration elements and concluded that most of the OCT features could be mapped to the elements of cooperation and coordination, with some elements being mapped to both. Very few features however were mapped to collaboration. This section builds from this point and reviews the way in which the OCTs are used in the PME, especially as they relate to the $3 \mathrm{Cs}$. In doing so, this section will draw from discussions of previous chapters and address the second research question and its associated proposition.

Not all features of the OCTs are used to the same level, nor, as has been discussed, do all OCTs share the same feature list. However, the research has demonstrated that there is uniformity in 
the use of the OCTs. That is to say, that the OCTs provide similar benefits to the organisations regardless of their feature list, even though some features are rated higher by the different PMEs.

Generally, OCTs are seen to assist in the planning and coordinating of activities and in communicating the availability of team members. They are important due to their functional ability to manage and report on data from a central location, whilst the ability to share and store documents not only increases the efficiencies in their distribution, but provides access to these materials in an asynchronous environment. In all, the variety of uses of the OCT reflects general support, especially where they can assist in managing and distributing information to the project team.

These findings are to be expected for an online tool designed for use in the project environment; however, the support for these tools is not overwhelming. The cases's support for the OCTs are more moderate and targeted towards the functions or activities that benefit from automation or electronic facilitation, such as a central storage area for procedures and manuals. The use of the tool by the six cases is supported through the findings from the Likert questionnaire, the interviews and the desk research. It is also verified and supported by the mapping exercise of the feature list to the $3 \mathrm{Cs}$.

In this exercise, the features could only be mapped against cooperation and coordination functions. This finding resonates with comments from the project managers that noted none of the organisations specifically considered itself to be operating in a collaborative environment. As such, the project managers saw the focus of the PME to encourage at best, coordination rather than collaborative activities.

The collaboration characteristics and their role in the OCT were also tested on the six cases, with the result that although there appeared to be an appreciation for the term collaboration, this did not eventuate in the individual PME. Responses to the questionnaire showed that the elements of Trust, Communication and Project/Knowledge distribution were all strongly held across the cases. The remaining elements of Equality, Negotiation, Incentives and Strategic Alliances were however not as strongly supported. As such projects were being managed drawing from some, but not all of the collaboration characteristics. 
This interpretation is consistent with previous comments regarding the use of the OCT, in that the elements which attracted support - trust, communication and information distribution - are also consistent with the use of the OCT which favoured features that shared, stored and distributed project-related material to the project team members.

Table 9-4 re-presents the tables from Chapter Seven (Tables 7-10 and 7-18) in support of this discussion, highlighting the relationship between the feature list of the OCT, its use within the PME and the Collaboration scale.

In re-presenting these tables as a combined table, it becomes clear that the use of the OCTs can support cooperation and coordination activities, but that collaboration is all but absent from this environment. This is not necessarily a failure by the cases however, but an acceptance founded in pragmatism and operational efficiencies. That is, the use of the OCTs are aligned with the business requirements of the PMEs, none of which include collaboration as a central pillar or goal for the organisation, even though there is support for the term and its perceived values and elements. 
Table 9-4: Re-presented from Chapter 7, Tables 7-10 and 7-18

\begin{tabular}{|c|c|c|c|c|}
\hline \multirow[t]{2}{*}{ OCT feature } & \multirow[t]{2}{*}{ Cross-case Usage Summary/Comment } & \multicolumn{3}{|c|}{ Cross-Case Collaboration Scale } \\
\hline & & Cooperation & Coordination & Collaboration \\
\hline $\begin{array}{l}\text { Use of Shared } \\
\text { Calendars }\end{array}$ & $\begin{array}{l}\text { General support across all cases, where it assisted } \\
\text { with planning and coordinating activities, and } \\
\text { assisted to communicate the availability of team } \\
\text { members. }\end{array}$ & $\checkmark$ & $\checkmark$ & \\
\hline Central Database & $\begin{array}{l}\text { General support across all cases, especially in } \\
\text { being able to manage and report on data from a } \\
\text { central location. }\end{array}$ & $\checkmark$ & $\checkmark$ & \\
\hline Shared Documents & $\begin{array}{l}\text { General support across all cases to increase } \\
\text { efficiencies in distribution of documents and } \\
\text { communicating. }\end{array}$ & $\checkmark$ & $\checkmark$ & \\
\hline Store Documents & $\begin{array}{l}\text { Strong support for the capacity of the OCT to } \\
\text { provide (asynchronous) access to material from a } \\
\text { central location regardless of the physical location } \\
\text { of the team member. }\end{array}$ & $\checkmark$ & $\checkmark$ & \\
\hline $\begin{array}{l}\text { Announcement } \\
\text { Boards }\end{array}$ & $\begin{array}{l}\text { Moderate support for the functionality, although } \\
\text { the findings suggest it is not effective in } \\
\text { disseminating information across the PME. }\end{array}$ & $\checkmark$ & $\checkmark$ & \\
\hline Virtual Conferencing & $\begin{array}{l}\text { Moderate support for this feature where it assists } \\
\text { to manage and control risk and time. }\end{array}$ & $\checkmark$ & $\checkmark$ & \\
\hline General use of OCTs & $\begin{array}{l}\text { Moderate support of the general use of the OCT in } \\
\text { particular for distributing information to the } \\
\text { project team. }\end{array}$ & $\checkmark$ & $\checkmark$ & \\
\hline Trust & $\begin{array}{l}\text { This sub-section indicated the presence of a strong } \\
\text { notion of support for trust within the PME. }\end{array}$ & $\checkmark$ & $\checkmark$ & $\checkmark$ \\
\hline Communication & $\begin{array}{l}\text { High support for the role effective communication } \\
\text { plays in delivering benefits to project management }\end{array}$ & $\checkmark$ & $\checkmark$ & $\checkmark$ \\
\hline Equality & $\begin{array}{l}\text { Not necessarily seen as essential in order to } \\
\text { contribute or share information. }\end{array}$ & $\checkmark$ & & \\
\hline Strategic Alliances & $\begin{array}{l}\text { Knowledge sharing, trust and communication are } \\
\text { essential when managing and maintaining } \\
\text { strategic alliances. }\end{array}$ & $\checkmark$ & $\checkmark$ & \\
\hline $\begin{array}{l}\text { (Project) Knowledge } \\
\text { Distribution }\end{array}$ & $\begin{array}{l}\text { High support for the notion that the distribution of } \\
\text { project knowledge is important in the PME }\end{array}$ & $\checkmark$ & $\checkmark$ & $\checkmark$ \\
\hline Negotiation & $\begin{array}{l}\text { High support for the importance of negotiations } \\
\text { when dealing with stakeholders, but use of OCT } \\
\text { questioned. }\end{array}$ & $\checkmark$ & & \\
\hline Incentives & $\begin{array}{l}\text { Moderate support for the role that incentives play } \\
\text { in the PME. }\end{array}$ & $\checkmark$ & & \\
\hline
\end{tabular}

As such, the analysis indicates that the OCTs across the cases contain features that can facilitate cooperation, coordination and collaboration, and that the use of the OCTs relates more to cooperation and coordination activities than it does to collaboration (as described by the Collaboration scale developed in this research). Given this, the final question to be concluded for this research, is measuring or determining the level of collaboration present in the PME when using the OCTs. This will be the focus of the next Section 9.2.3. 


\subsubsection{Research Question Three}

Research Question Three: What is the level of collaboration when using Online Collaborative Toolsets in the Project Management Environment?

Proposition Three: $\quad$ Collaboration can be modelled as a scale ranging from cooperation, through coordination, to collaboration.

A summary of each case's use of its particular OCT will serve as a roadmap to discuss the third and final research question and associated proposition.

\section{Cases and their OCTs}

The manner in which Organisation D uses the QuickPlace is against departmental guidelines, in that it uses it more for document management and centralised document storage, than for collaboration practices. It is a strong user of the asynchronous functionality and the document library, however found the tool to be lacking for managing stakeholders. In this sense the use of the tool relates to the communication, information and to a lesser extent the relationship elements of the Collaboration scale.

Given the focus of the project, Organisation $\mathrm{V}$ is a strong user of the publishing function of WordPress. The OCT contributes to effective project planning and managing time and resources across the project. The role of communication and information transmittal is very important for Organisation V and its membership; a finding that was reinforced by the organisation's approach to the communication and information element in the Collaboration scale.

The use of ACONEX by Organisation M involves managing and controlling project documentation, and disseminating and managing the flow of information. ACONEX is used to reduce the frequency of expensive printing jobs, whilst also exploiting its data security options. As such, the benefits of the use of the tool subsequently relates to the communication and information elements of the Collaboration scale.

The project environment of Organisation $\mathrm{C}$ is not significantly altered through the use of AutoCAD Buzzsaw. The use of the OCT is rudimentary and simplistic, with the organisation using the tool to manage information and associated project documentation (including AutoCAD 
formatted drawings). These benefits relate strongly to the communication and information elements of the Collaboration scale.

Organisation S uses QuickPlace for project planning and managing resources and risk. The QuickPlace is used for communicating with the project team and outsourced contractors. It is also used to complement the governance mechanism including reporting up through to the Executive team and other government relationships. As such, the tool relates strongly to the communication, information and relationship management elements of the Collaboration scale.

Organisation K uses INCITE for the distribution of documents and procedures across multiple teams and organisations, in order to manage its multiple stakeholders and relationships. INCITE is used to manage the quality assurance of project-related documentation and to control specific workflows and documents. Given this, the tool relates strongly to the communication, information and relationship management elements of the Collaboration scale.

\section{Collaboration scale}

The Collaboration scale is used to offer a response to the third research question and associated proposition, as it was developed as a means by which to understand if collaboration was present in the use of OCTS in the PME. This section therefore is structured around responding to the scale, and not the full concept of collaboration. As outlined in the discussion over the past two research questions, this thesis has argued that although the OCTs have a capacity to facilitate collaboration, the PME dynamic in each case has prescribed a non-collaborative approach.

'While the organisation wants to be collaborative, it isn't yet' (OrgD PM1)

The Collaboration scale applied in this research (and described in detail in Chapter Five) presents collaboration not as a single entity, but as a scale ranging from low to high across seven elements. Central to this theory is that for collaboration to exist, all elements must rate highly against the scale. The Collaboration scale is designed to be able to plot the collaborative activity within an organisation or PME. In posing this scale in the earlier chapters, the research argued that although all collaborative elements are found within a PME, it is the level of each element that 
determines the degree to which collaboration is occurring. The scale from Chapter Four (Table 4-9) is re-presented here in Table 9-5.

Table 9-5: Collaboration scale re-presented from Chapter Four, Table 4-9

\begin{tabular}{|l|l|c|c|c|}
\hline & Element & Cooperation & Coordination & Collaboration \\
\hline 1 & Resources & low & moderate & high \\
\hline 2 & Tasks / Activities/ Scheduling & low & moderate & high \\
\hline 3 & Communication & low & moderate & high \\
\hline 4 & Information Sharing (including K.D.) & low & moderate & high \\
\hline 5 & Relationships (including Trust, S.A.) & low & moderate & high \\
\hline 6 & Rewards (including Incentives) & low & moderate & high \\
\hline 7 & Negotiations & low & moderate & high \\
\hline
\end{tabular}

It is from this theoretical underpinning that a conclusion for the third and final research question and associated proposition is presented.

Table 9-6 and Figure 9-1 present a pattern or trend across the six cases and shows that the use of the OCTs is moderate-high across the majority of the elements. It also shows that the elements rate at different levels, with the Task/Scheduling element rating marginally higher than the Resources element. The Communication and Information Sharing element are well served by the OCT, a finding that is supported by the interviews. Relationships and Rewards each rate consistently lower than Communication and Information Sharing, whilst Negotiations rate consistently high.

Table 9-6: Summary of mean case values against Collaboration scale

\begin{tabular}{|l|c|c|c|c|c|c|c|}
\hline & \multicolumn{7}{|c|}{ Collaboration scale elements } \\
\cline { 2 - 9 } & Resources & $\begin{array}{c}\text { Task/ } \\
\text { scheduling }\end{array}$ & Communication & $\begin{array}{c}\text { Information } \\
\text { sharing }\end{array}$ & Relationships & Rewards & Negotiations \\
\hline $\begin{array}{l}\text { Org D } \\
\text { (State Gov) }\end{array}$ & 61 & 65 & 72 & 67 & 69 & 58 & 73 \\
\hline $\begin{array}{l}\text { Org V } \\
\text { (Cont. Imp.) }\end{array}$ & 68 & 73 & 80 & 75 & 74 & 69 & 84 \\
\hline $\begin{array}{l}\text { Org M } \\
\text { (Gov. Cons) }\end{array}$ & 61 & 66 & 74 & 72 & 68 & 65 & 74 \\
\hline $\begin{array}{l}\text { Org C } \\
\text { (Comm. Cons) }\end{array}$ & 61 & 66 & 74 & 73 & 67 & 63 & 72 \\
\hline $\begin{array}{l}\text { Org S } \\
\text { (Gov Auth) }\end{array}$ & 65 & 66 & 76 & 75 & 69 & 66 & 83 \\
\hline $\begin{array}{l}\text { Org K } \\
\text { (Alliance) }\end{array}$ & 65 & 66 & 76 & 76 & 71 & 66 & 77 \\
\hline & 64 & 67 & 75 & 73 & 70 & 65 & 77 \\
\hline Aggregate
\end{tabular}




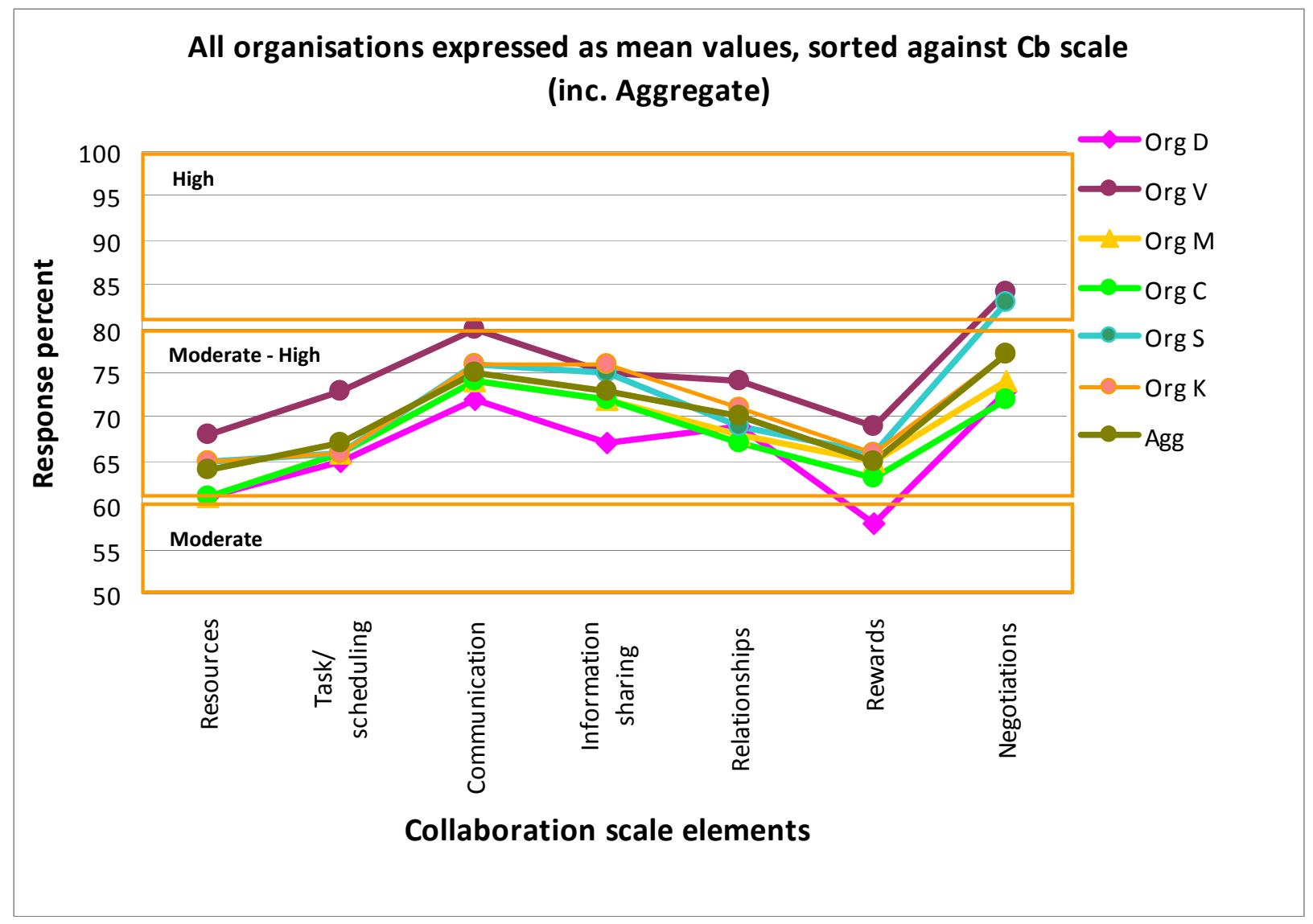

Figure 9-1: All Organisations expressed as mean values, sorted against Collaboration scale

These findings also support the proposition that collaboration can be modelled as a scale ranging from cooperation, through coordination to collaboration, in that the elements are not consistently applied across each case, but rather show peaks associated with different elements. These peaks relate to the different levels on the Collaboration scale, indicating for example that Resources is used for cooperative and coordination activities, while Communication is aligned with coordination. Importantly for this research, these peaks are similar across the cases, suggesting a usage pattern across the cases, as well as further supporting the Collaboration scale.

This provides an answer to the third research question, and also provides support to its associated proposition. As such, the research can extrapolate from these findings that the presence of collaboration within the PME lies more within the cooperative and coordinative functions than with the collaborative, and this supports the premise that collaboration can be modelled as a scale ranging from a low of cooperation, through coordination to a high of collaboration. Figure 9-1 clearly shows the results in the moderate to high grade of the Collaboration scale, indicating a level of coordination. 
The Collaboration scale can also be used to argue that this collaboration level will be defined by the importance the PME places on each of the collaboration elements, and their interconnectedness within the operating environment. This interpretation is supported by the pattern across the cases, and suggests not only that the Collaboration scale is valid in understanding collaboration within projects, but that these findings point more to general priorities within contemporary projects. That is to say, in the context of the use of OCTs, collaboration is not occurring within projects, however high levels of cooperation and coordination are observed.

In making these comments the third and final research question and associated proposition is resolved highlighting implications for further research and theory.

\subsubsection{Conclusion about Research Question}

The main Research Question, as expressed in Chapter One is:

Does collaboration occur through the use of Online Collaborative Toolsets in the Project Management Environment?

The research question sought to review a series of project environments, each possessing different project credentials, operating environments and scale of works, in order to understand how OCTs are used within the individual project environments. The research sought to address this problem by investigating the use of OCTs within the PME with a view to understanding the role that collaboration plays in this use.

In undertaking this research, the findings suggest that collaboration does not necessarily occur, nor is it required when using OCTs in the PME.

The research is able to respond to the research question in this way due to the development of the Collaboration scale, and its subsequent capacity to interpret and understand collaboration in terms of a scale, ranging from cooperation, through coordination to collaboration. Further conclusions that can be drawn out of the research, and which apply to the research question include the following: 
- OCTs can contain a variety of features, several of which are common amongst all. The research reviewed 32 OCTs to develop a feature list which identified common features across the suite of OCTs. Although this list is not exhaustive, the research identified common requirements and usage of the OCTs within the PME.

- Although OCTs are capable of facilitating a high level of collaboration, projects do not use them for these tasks. The research did not discover any attempts by the individual cases for the PME to be collaborative, or for the use of the OCTs to assist with collaborative exercises.

- $\quad$ OCTs are used predominantly for cooperation and coordinating activities within the PME. Given Point 2 above, the research showed ample examples where the OCTs are used to undertake tasks that can be described as cooperative or coordinating in nature. These tasks form the bulk of the activities of the OCT by the PME or project managers.

- To understand collaboration in the PMEs reviewed, is to recognise that it exists in degrees, at times being identified with cooperative functions, whilst at other times the coordinating functions take a dominant role. The Collaboration scale developed the degrees of collaboration which subsequently identifies the nature of the collaborative environment existing within the PME.

- The findings demonstrate a pattern in collaboration, which is consistent across all cases. In particular Figure 8-7 in the previous chapter highlights the consistency with which this pattern can be viewed. Although the result is from a limited study, it identifies a variation in the collaborative elements across the PME, and indicates a priority that may exist in regard to how these elements are prescribed within the actual project environment.

- On the strength of these conclusions, a statement can be drafted about the use of OCTs in the PME:

The use of online collaborative toolsets assists to negotiate the communication and information sharing functions of the project management environment in order to manage strategic relationships and coordinate related documentation. Furthermore, the use of these tools are effective in supporting the cooperative and coordinating functions of project management. 


\subsection{Implications for Theory}

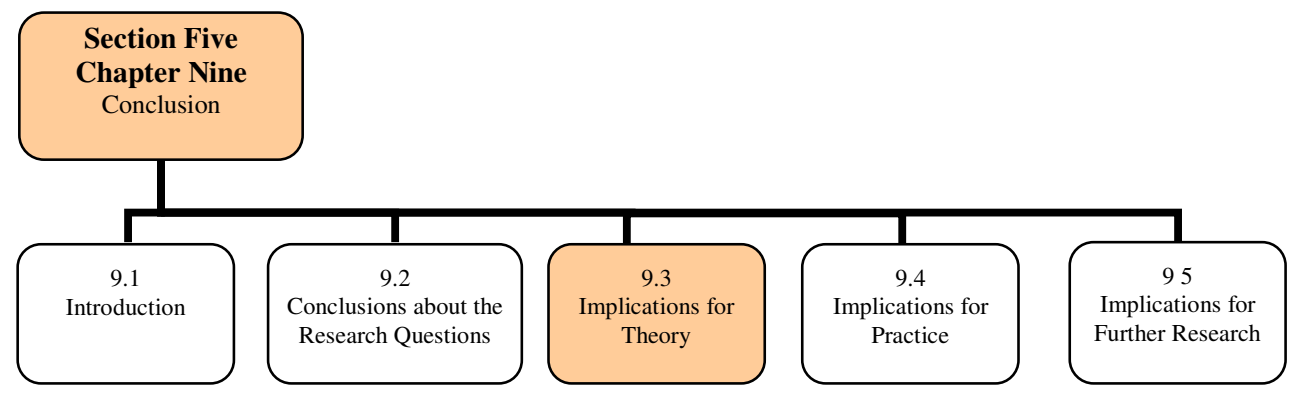

The research attempted to gain a greater understanding of the way in which OCTS are used within the contemporary PME. These toolsets, whilst now verging on the ubiquitous, and susceptible to hyperbolic predictions as to their importance, nonetheless offer hope that they will return great benefits to the environment in which they are deployed.

This research sought to understand these benefits, by reviewing six project environments, all of which utilised an OCT in a central position to its project management approach (as distinct from its methodology). As the literature search did not uncover material which informed this use, the research sought to review the project environment of each project, linking its project particulars with its choice and use of the OCT. It also attempted to assess the role or presence of collaboration within this usage, with a view to understanding more about the collaborative elements in the project environment.

Collaboration is written about as a positive aspect of the project environment, however this research was not able to find literature that quantified or substantiated this view by citing practical examples. Nor was the literature able to articulate the role that collaboration can play in project management, as distinct from its importance in a project team that uses collaboration to develop products. The distinction seems obvious to the research, but proved more difficult to substantiate. To this end, the research offers several items that may impact on the way in which this subject can be referenced in the future.

- In understanding the Collaboration scale, it is important to note that it is an interpretation of the context of contemporary projects, and as such its own theoretical proposition is distilled from the many and varied interpretations of collaboration identified in the literature. 
- The trend of the Collaboration scale showed collaboration in projects to comprise, in order of importance, the elements of Negotiations, Communications, Information sharing, Relationships, Tasks/scheduling, Rewards and Resources. This was a consistent result for the research, however as the research was only able to review six of the eleven cases it initially approached, the theory will profit from an extended data base.

- Collaboration in projects can best be understood in terms of the level of cooperative and coordinating activities (as outlined in the Collaboration scale) that are undertaken, rather than on a single notion of collaboration. This distinction is a central theme - and links back to the initial question of the study and which this research has sought to challenge; that when collaboration is generally referred to in literature, it is considered in a single or quantifiable entity.

- It is not confirmed through this research whether collaboration is indeed required within the PME, however it can be noted that it is not found to be a pre-requisite for utilising OCTs. This is demonstrated by the cases reviewed within this study, all of which did not consider themselves collaborative in nature or consider collaboration necessarily critical to either the use of the OCT or to the successful functioning of the broader PME. This conclusion resonates with the previous point, and reinforces the relevance of the nature of the research question, and subsequently the research itself.

- The application of the Collaboration scale for the elements of Rewards and Negotiations is however restricted within the test applied, and does not provide a firm basis on which to conclude the full extent of the role and presence of these two characteristics within a complex project environment. As previously noted, the Collaboration scale would benefit from the development of additional instruments on which to test its validity. 


\subsection{Implications for Practice}

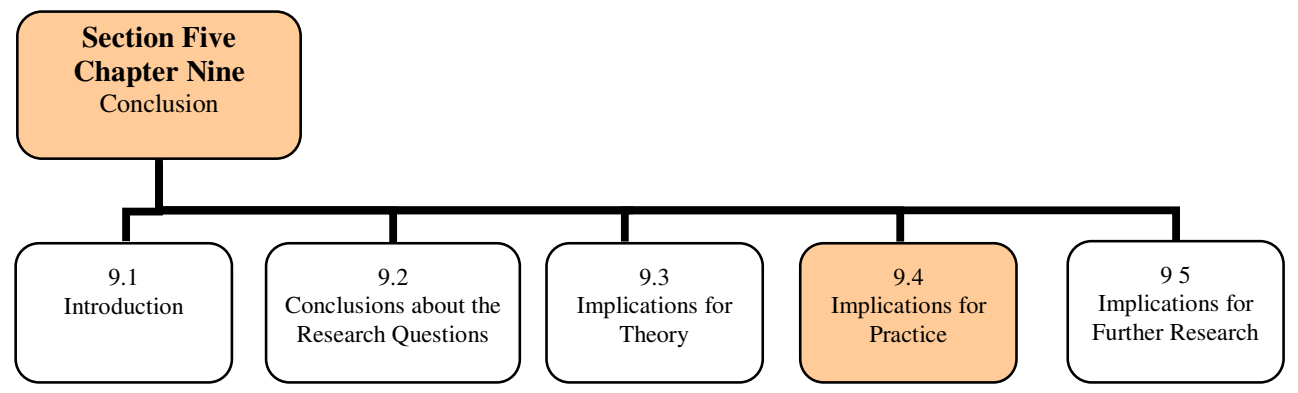

This study applied a research methodology that sought to test the use of the OCT within a specific environment, that of project management. In drawing its conclusions, the research has the implication that the theories underlying the use of the OCTs and the presence of collaboration itself, could be applied to any / all environments that use OCTs. In doing so, the research highlights several implications for practice that could form part of any implementation of an OCT regardless of the operating environment.

The implications include:

- The status of the organisation managing the project and any of its operational relationships or stakeholders. Of importance is whether the primary organisation considers itself (and its partners) collaborative in their operations prior to incorporating an OCT into the project.

- The role of collaboration within the project is important to understand at the outset. Questions for the management team to address would include whether the organisation has collaboration specifically as a driver of the project, or a pre-requisite for its outcomes. Of interest here will also be how the organisation will describe or define collaboration.

- The metrics applied to the term collaboration is important, as it will determine how the organisation intends to measure collaboration within the workforce or project environment. This will link strongly to the Collaboration scale, noting that all cases in the research related more to the cooperative and coordination roles of the OCT, than to the collaborative elements. In undertaking this task, the organisation will be in a stronger position to understand the requirements of the project, rather than the features of an OCT. 
- Many organisations do not measure their activity or work effort, so are unable to accurately measure whether one operating methodology (in this instance the use of collaboration for example) against another. Without a quantifiable tool or instrument at hand, it is difficult to effectively measure or understand an organisation's or project's work output, or to make a determination if one methodology is better suited to the project than another.

- Following on from point 4 (above), it is important to develop a shared understanding within the PME from which to design the methodology and governance structure that will manage the project. These processes will inform the requirements for documentation and as such the workflow, approval processes and underlying communication strategies of the OCT.

- The culture and dynamics of the team will impact on procedural compliance and should be considered and well understood. There are several factors that will impact on the use of the OCT to ensure take-up and adoption, including whether the project teams are experienced in using OCTs, will they co-locate if required, is the PME to be geographically dispersed, is the project team open to the introduction of a new PM tool, does the organisation prioritise training, and will it be necessary to mandate the use of the OCT.

- Although specifically excluded as an area to be investigated as part of this research, the cost of undertaking projects is however central to many administrative considerations of the contemporary PME. The use of the OCT to off-set costs or to deliver project outcomes under a new cost structure provides opportunities for the modern project manager and their organisations. Inextricably linked to having a cost benchmark on which to measure areas where savings could be delivered (as per point 4 above), the use of new technology, especially the online environment, has far reaching implications for the way that projects will be managed in the future. The research provided a snapshot of six projects, significantly varying in size, complexity and effort, with all providing support for aspects of the OCT. The advantages and benefits that the OCTs can bring to the contemporary PME are yet to be mapped in a way that enables business managers to make informed decisions about their best application. 
- Following on from this discussion of cost and the seemingly ever-growing ubiquity of the OCTs, is the issue of computer platform and devices on which the OCT is experienced. This research recorded all OCTs on PCs and laptops, most of which were hard-wired into the organisation's I.T. infrastructure even though the OCT itself was externally hosted. The fastdeveloping mobile device market will undoubtedly develop new mobile products that can increasingly manage complex web tools, and in doing so, provide even greater access for project professionals to project-related information, documentation and material. This increased access could see the likes of construction managers and foremen using mobile telephony onsite, as an on-the-job quality assurance and communications device, with the capacity to send and receive current project specifications and drawings as required.

These are but some of the implications to be considered when embarking on the use of an OCT. These items can be expanded to suit the circumstances, and identify several core issues pertaining to the notion of collaboration within the PME. These issues include the role or expectation of the type of behaviour of the PME (that is, is it to be cooperative, coordinative or collaborative however these terms are to be understood by the organisation and PME), and the actual methodological application or use of the tool on-site. Alternately, as has been noted by this research, the OCT may simply be used as a means to centrally control and distribute project related material in an online environment to as many team members as required, at any time it is required.

\subsection{Implications for Further Research}

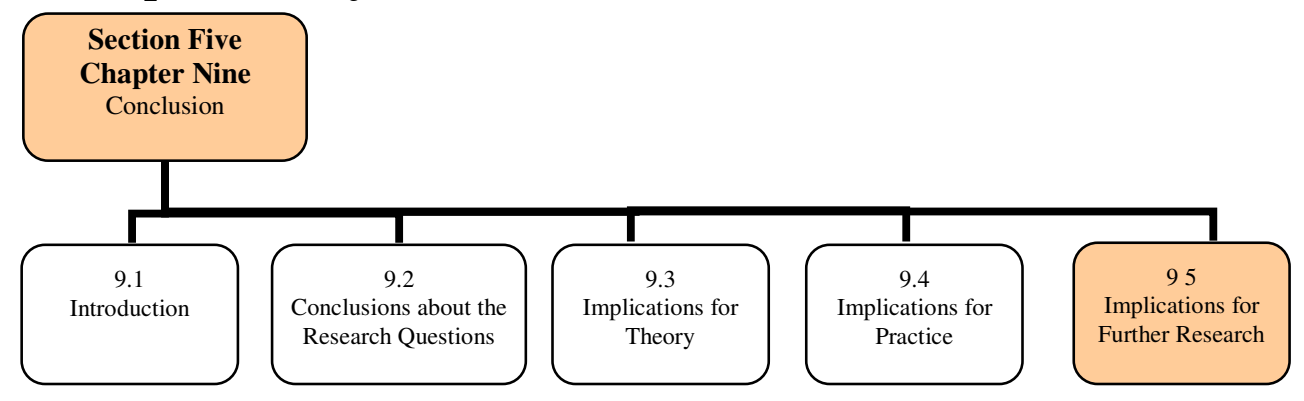

Whilst this research identifies and discusses the considerations under which OCTs are applied in the PME, the outcome of this work can be applied elsewhere. As such the research has the implication that the theories underlying the Collaboration scale, and the use of the OCTs within the PME could be applied to other environments. These environments need not be confined to the project environment, but rather extend to all environments that utilise the toolsets. 
Higher-education networks and scientific or research focussed environments would be particularly fertile fields on which to base continued investigation into the use of the OCTs, given a perceived closer fit for their collaboration methodologies. Of note, is that a research-focussed university project was approached to be included in the study, but was later withdrawn due to poor responses to the questionnaire.

Areas where the research could be developed include the following:

- A review into a cohort of significantly similar projects using different OCTs, or significantly similar environments using the same OCT, would provide further understanding not only of the use of the tool, but of the Collaboration scale itself. These options provide future opportunities for the study of this area; albeit one that requires an increase in the support of such an endeavour by the host organisation(s).

- The development of more precise work study measurement of project management effort is required in order to develop firm metrics for the (cost) effectiveness of the use of the OCT (or to support a decision to use or not use the tool). Access to suitable projects, and the opportunity to incorporate a control group, can also provide tighter data sets on the operational-usability of the OCTs within the PME.

- Further clarification of the Collaboration scale, especially in the areas of incentives, negotiation and resources in an effort to create more detailed tests for these elements.

- Further testing of the elements of the Collaboration scale in varying circumstances and PMEs to further refine its use as a measure of collaboration.

- Further development of additional tests to be applied to the Collaboration scale, especially where accurate metrics of OCTs can be accessed and analysed.

- Additional research work can be developed in the use of mobile technology (especially mobile telephony) as a front line or onsite receiver of project related information. 
- Further analysis of the project environment to better understand and clarify the project management-related activities that have a direct bearing on the use of the online technology, especially as it relates to synchronous (real-time) communication and the identification of project management assets, such as procedures and process manuals, governance, risk and legal materials. The synchronous feature of the OCT was all but ignored by the cases reviewed, however the timeliness of accurate and current information still poses the greatest challenge for many people working in the project/knowledge areas.

- This research has questioned whether collaboration occurs through the use of OCTs in the PME and subsequently concluded that it does not; noting however the existence of cooperation and coordination functions. Further research into the actual role of collaboration in project management is therefore warranted. This research would test whether collaboration is indeed a goal that should be sought after and nurtured in contemporary project management disciple, or whether it should be exercised as part of a project-related activity. This activity would subsequently feed into the project schedule as any other component or sub-task of the project, such as completion of drawings, technical specifications, consultation reports or design briefs to name a few. 


\section{REFERENCES}

ABS, 2008a, 4102.0 Australian Social Trends, 2008, Australian Government, 11 December 2008, http://www.abs.gov.au/AUSSTATS/abs@.nsf/Lookup/4102.0Chapter10002008.

ABS, 2008b, 8129.0 - Business Use of Information Technology, 2005-06 Australian Government, 11 December, 2008, http://www.abs.gov.au/Ausstats/abs@.nsf/mf/8129.0.

ABS, 2008c, 8153.0 Internet Activity, Australia Jine 2008, Australian Government, 11 December, 2008, http://www.abs.gov.au/ausstats/abs@.nsf/mf/8153.0/.

ABS, 2008d, 8166.0 - Summary of IT Use and Innovation in Australian Business, 2006-07 Australian Government, 11 December 2008, http://www.abs.gov.au/AUSSTATS/abs@.nsf/Latestproducts/A6A4AF58AECFF0C2CA257473 00120F51?opendocument.

AceProject, 2006, AceProject: The best online solution to manage your projects, Ace Project, 25 July 2006, http://www.aceproject.com.

ACONEX 2007 Collaboration in Construction. Melbourne, ACONEX.

Aitken, M., Dewar, R., Di Tomaso, N., Hage, J. \& Zeitz, G. 1975 Coordinating Human Services, San Francisco, USA, Jossey-Bass.

Argyle, M. 1991 Cooperation - The Basis of Sociability, London, Routledge.

Aschenbrenner, A. \& Miksch, S. 2005 Blog mining in a corporate environment. Austria, Research Studios Austria.

Austin, J. 2000 The Collaboration Challenge: How Nonprofits and Businesses Succeed Through Strategic Alliances, Jossey-Bass Publishers.

Autodesk, 2005, Autodesk Buzzsaw, Autodesk, 23 August 2005, http://usa.autodesk.com/adsk/servlet/index?siteID=123112\&id=2407898.

Bar-Llan, J. 2005 Information hub blogs. Journal of Information Science, 31, (4), 297 - 307.

Barnes, T. A., Pashby, I. R. \& Gibbons, A. M. 2000, 'Collaborative R\&D projects: a framework for effective management'. IEEE International Conference on Management of Innovation and Technology, Singapore, 12-15 November, 2000.

Barua, A., Ravindran, S. \& Whinston, A. B. 1997 Effective intra-organisational information exchange. Journal of Information Science, 23, (3), 239-248.

Batt, P. \& Purchase, S. 2004 Managing collaboration within networks and relationships. Industrial Marketing Management, 33, 169-174. 
Bharadwaj, V., Reddy, Y. V. R., Kankanahalli, S., Reddy, S., Selliah, S. \& Yu, J. 2004, 'Evaluating adaptability in frameworks that support morphing collaboration patterns'. 13th IEEE International Workshops on Enabling Technologies: Infrastructure for Collaborative Enterprises (WET ICE 2004). University of Modena, Italy, 14-16 June, 2004.

Binz-Scharf, M., C 2005, 'Collaboration, communication and control: the effects of ICT enabled innovation projects on informal organisational structures'. 38th Hawaii International Conference on System Sciences, Hawaii, USA, 3-6 January 2005.

Black, L., Creswell, A., Pardo, T., Thompson, F., Canestraro, D., Cook, M., Luna, L., Martinez, I., Anderson, D. \& Richardson, G. 2002, 'A dynamic theory of collaboration: a structural approach to facilitating intergovernmental use of information technology'. 36th Hawaii International Conference on System Sciences, Hawaii, USA, 2002.

Booch, G. \& Brown, A. 2002 Collaborative development environments. Rational Software Corporation.

Breite, R. \& Vanharanta, H. 2003 Evaluating Collaboration and Core Competence in Virtual Enterprise. Psychology Journal, 1, (4), 391-399.

Bryman, A. 2001 Social Research Methods, Great Britain, Oxford University Press.

Bryman, A. \& Burgess, R. (Eds.) 1994 Analysing Qualitative Data, London, Routledge.

Burton, J. 2001 Peer to peer computing. New York Times. New York, USA.

Cavana, R., Delahaye, B. \& Sekaran, U. 2001 Applied Business Research: Qualitative and Quantitative Methods, Australia, John Wiley \& Sons.

CeNTIE: Centre for Networking Technologies for the Information Economy, 2004, CSIRO Australia, 6 March 2006, http://www.ict.csiro.au/page.php?cid=22.

Chen, C.-H., Ling, S. F. \& Chen, W. 2002 Project scheduling for collaborative product development using DSM. International Journal of Project Management, 21, 291-299.

Chen, C.-J. 2003 The effects of environment and partner characteristics on the choice of allianceforms. International Journal of Project Management, 21, 115-124.

Christopher, T. 2007 Tools for teams: beyond the email bottleneck. Project Connections. Silicon Valley, USA, Digital Places.

Coleman, D. \& Antila, D., 2004, Enterprise Collaboration: Creating Value Through Content, Context and Process, Collaborative Strategies, viewed 13 July 2005, http://www.collaborate.com/.

CommunityCrossings, 2006, What is a Collaboration Gateway?, Community Crossings, http://www.communitycrossings.com/gateway.asp. 
Creswell, J. 1998 Qualitative inquiry and research design: choosing among five traditions, Thousand Oaks, USA, Sage.

Curtis, D. \& Lawson, M. 2001 Exploring collaborative online learning. Journal of Asynchronous Learning Networks (JALN), 5, (1), 21-34.

Dai, C. \& Wells, W. 2004 An exploration of project management office features and their relationship to project performance. International Journal of Project Management, 22, 523-532.

Davenport, S., Davies, J. \& Grimes, C. 1998 Collaborative research programmes: building trust from difference. Technovation, 19, 31-40.

de Vaus, D. 1995 Surveys in Social Research - Fourth Edition, Sydney, Australia., Allen \& Unwin.

Deal, T. \& Kennedy, A. 1982 Corporate Cultures: The Rites and Rituals of Corporate Life, Reading, USA, Addison-Wesley.

Denzin, N. 1989 The Research Act (Second Edition), Chicago, USA., Aldine.

Drezner, D. \& Farrell, H. 2004, 'The Power and Politics of Blogs'. 2004 American Political Science Association, Washington, USA, 2004.

Driver, E. 2006 Collaboration Trends 2006 to 2007. Forrester Group.

EasyProjects, 2007, Easy Projects - Product Information - Features, Logic Software Inc, http://www.easyprojects.net/features.asp/.

EdNa: Education Network of Australia, 2004, education.au Ltd, 10 March 2006, http://www.edna.edu.au/edna/page1.html.

Eisenhardt, K. 1989 Building theories from case study research. Academy of Management Review, 14, (4), 532- 550.

Enzer, M., 2006, Glossary of Internet Terms, http://www.matisse.net/files/glossary.html.

Evaristo, R. \& van Fenema, P. C. 1999 A typology of project management: emergence and evolution of new forms. International Journal of Project Management, 17, (5), 275-281.

Fingar, P. \& Aronica, R. 2001 The Death of e and the Birth of the Real New Economy: Business Models, Technology and Strategies for the 21st century, USA, Meghan-Kiffer Press.

Fisher, D. \& Dourish, P. 2004, 'Social and temporal structures in everyday collaboration'. CHI 2004: Conference on Human Factors and Computing Systems, Vienna Austria, 24 April 2004.

Fitzek, F. \& Katz, M. (Eds.) 2006 Cooperation in Wireless Networks: Principles and Applications - Real Egoistic Behaviour is to Cooperate, Dordrecht, The Netherlands, Springer.

Flick, U. 2002 An Introduction to Qualitative Research - Second Edition, London, Sage. 
Flinders, D. 1992 In search of ethical guidance: constructing a basis for dialogue. International Journal of Qualitative Studies in Education, 5, (2), 101-106.

Fontana, A. \& Frey, J. H. 2000 The interview: from structured questions to negotiated text. IN Denzin, N. \& Lincoln, Y. (Eds.) The Handbook of Qualitative Research. 2nd edition ed. California, USA., Sage.

ForakerDesign, 2007, Usability First: Groupware Applications, Foraker Design, 17 October 2007, http://www.usabilityfirst.com/.

Garson, G., 2008, Statnotes: Topics in Multivariate Analysis, North Carolina State University, 11 April 2008, http://www2.chass.ncsu.edu/garson/pA765/statnote.htm.

Goncalves, M. 2007 Implementing the Virtual Project Management Office: Proven Strategies for Success, USA, McGraw HIll.

Gray, C. \& Larson, E. 2000 Project Management: The Managerial Process, USA, McGraw Hill.

Gutwin, C. \& Greenberg, S. 2000, 'The mechanics of collaboration: developing low cost usability evaluation methods for shared workspaces'. IEEE 9th International Workshops on Enabling Technologies: Infrastructure for Collaborative Enterprises (WET ICE'00), Maryland, USA, June 2000 .

Halme, M. 2001 Learning for sustainable development in tourism networks. Business Strategy and the Environment, 10, (2), 100-114.

Hammersley, M. \& Atkinson, P. 1983 Ethnography: Principles in practice, London, Tavistock.

Harley, J. 2005, Online Collaboration in the Victorian Regional Gallery Network. School of Property Construction and Project Management, Melbourne, Royal Melbourne Institute of Technology, MAppSc (by Research) Thesis.

Hartman, F. \& Romahn, E. 1999, 'Trust: A New Tool for Project Managers'. Project Management Institute 1999 Seminars \& Symposium, Philadelphia, USA, 10 - 16 October 1999.

Health Share, 2004, HealthShare eHealth Network, 4 December 2004, http://www.healthshare.com.au/intro.html.

Herzog, V. 2001 Trust building on corporate collaborative project teams. Project Management Journal, 32, (1), 28-37.

Homan, R. 1991 The Ethics of Social Research, UK., Longman.

Hutchins, D. 2003 May the Salesforce be with you. Information Week Australia, (July), 34-37.

IKE, 2006, Features of IKE Office, IKE, 25 July 2006, http://www.ike.com/iKE/productFeatures.html. 
Internet.com, 2007, Webopedia, Jupiter Media Corporation, 26 October 2007, http://www.webopedia.com/.

Kadefors, A. 2004 Trust in project relationships - inside the black box. International Journal of Project Management, 22, 175-182.

Katzy, B., Evaristo, R. \& Zigurs, I. 2000, 'Knowledge management in virtual projects: a research agenda'. 33rd Annual Hawaii International Conference on System Sciences, Hawaii, USA, 4-7 January, 2000.

Kellahear, A. 1989 Ethics and social research. IN Perry, J. (Ed.) Doing Fieldwork: Eight Personal Accounts of Social Research. Australia., Deakin University Press.

Kontzer, T. 2002 Portals transform into a strategic collaboration asset. Information Week Australia, 18, (880), 86-87.

Krill, P., 2007, Social networking likely to grow in enterprises, InfoWorld, 8 November 2007, http://www.infoworld.com/article/07/11/02/mobile-mashup_1.html.

Larson, E. 1997 Partnering on construction projects: a study of the relationship between partnering activities and project success. Engineering Management, IEEE Transactions on, 44, (2), 188-195.

Lendrum, T. 1998 Strategic Partnering Handbook, Sydney, McGraw Hill.

Lynch, C. G., 2007, Why You Should Collaborate, CIO, 14 September 2007, http://www.cio.com/article/print/107253.

Mack, R., Ravin, Y. \& Byrd, R. 2001 Knowledge portals and the emerging digital knowledge workplace. IBM Systems Journal, 40, (4), 924-956.

Mason, J. 1996 Qualitative Researching, London, Sage.

Mattessich, P., Murray-Close, M. \& Monsey, B. R. 2001 Collaboration: What Makes it Work, Minnesota, USA, Wilder Publishing Centre.

Maxwell, J. 1992 Understanding and Validity in Qualitative Research. Harvard Educational Review, 62, (3), 279-300.

May, P. 2000 The Business of eCommerce: From Corporate Strategy to Technology, USA, Cambridge University Press in assoc with SIGS Books.

McDonald, D. W. 2003, 'Recommending collaboration with social networks: a comparative evaluation'. CHI 2003: Conference on Human Factors in Computing Systems, Fort Lauderdale, Florida USA, 5 -10 April 2003.

McFadzean, E. \& McKenzie, J. 2001 Facilitating virtual learning. The Journal of Management Development, 20, (5/6), 470-495. 
Microsoft Australia Small Business Centre, 2004, The power of collaboration: five steps, Ninemsn, 6 October 2004, http://smallbusiness.ninemsn.com.au/article.aspx? $\mathrm{id}=18927$.

Miles, M. \& Huberman, A. 1994 Qualitative Data Analysis, Second Edition, Thousand Oaks, USA, Sage Publications.

Monge, P., Fulk, J., Kalman, M., Flanigan, A., Parnassa C \& Rumsey, S. 1998 Production of collective action in alliance-based interorganisational communication and information systems. Organization Science, 9, (3), 411-433.

Near-Time, 2006, Near-Time, Near-time Inc, 25 July 2006, http//:www.neart-time.com/.

NECTAR, 2007, Network for Effective Collaboration Through Advanced Research, Nectar, 16 October 2007, http://www.nectar-research.net/about-nectar.php.

Netcraft, 2008, November 2008 web server survey, Netcraft, December 2008, http://news.netcraft.com/archives/web_server_survey.html.

O'Brien, W. J. 2000 Implementation issues in project websites: a practitioner's viewpoint. Journal of Management in Engineering, 16, (3), 34-39.

O'Connell, P. 2003 Online Diary - Can Johnny Blogg? New York Times, G3.

Onna, v. M., Hendriks, B. \& Schraven, G. 2000 The Little Prince 2: Project Management Methodology for Small and Medium Sized Projects, Netherlands, Pink Elephant / Ten Hagen Stam Publishers.

Palmer, N. 2003 Portals and Collaborations. E-Doc, Silver Spring 17, (1, Jan/Feb), 12-14.

Perry, C. 1998 A structured approach for presenting theses. Australian Marketing Journal, 6, (1), $63-85$.

Peterson, S. \& Stohr, V., 2008, Management Assistance Programs for Non-profits, 27 February 2008, http://www.managementhelp.org/grp_skll/virtual/virtual.htm\#anchor709243.

Phillips, N., Hardy, C. \& Lawrence, T. B. 1998 Interorganisational collaboration and the dynamics of institutional fields.(working paper in Human Resource Management and Industrial Relations). Melbourne, University of Melbourne.

PMI 2004 A Guide to the Project Management Body of Knowledge (PMBOK Guide), Pennsylvania, Project Management Institute Inc.

Pringle, J., 2006, Forum One Communication - Project Spaces, Forum One Communications, 25 July 2006, http://www.forumone.com/section/services/projectspaces/.

ProjectPlace, 2006, Product Overview, Project Place, July 2006, http://www.projectplace.com. 
Qureshi, S., Liu, M. \& Vogel, D. 2005, 'A grounded theory analysis of e-collaboration effects for distributed project management'. 38th Annual Hawaii International Conference on System Sciences, Hawaii, USA, 3-6 January, 2005.

Raygan, R. E. \& Green, D. G. 2002, 'Internet collaboration: TWiki'. IEEE SoutheastCon, 2002, Columbia, USA, 5-7 April, 2002.

Richardson, W., 2003, Weblogg-ed - Using Weblogs and RSS in Education, weblogg-ed, March 2006, http://www.weblogg-ed.com/.

Rogers, D. \& Whetten, D. (Eds.) 1982 Interorganisational Coordination - Theory, Research and Implementation, Iowa, USA, Iowa State University Press.

Romano, N. C., Jr., Chen, F. \& Nunamaker, J. F., Jr. 2002, 'Collaborative project management software'. 35th Annual Hawaii International Conference on System Sciences, 2002. HICSS, Hawaii, USA, 7-10 January, 2002.

Savas, E. 2000 Privatization and Public-Private Partnerships, New York, USA., Chatham House.

Schermerhorn, J. 1975 Determinants of interorganisational cooperation. Academy of Management Journal, 18, 846-856.

Sclater, N., Grierson, H., Ion, W. \& MacGregor, S. 2001 Online collaborative design projects: overcoming barriers to communication. International Journal of Engineering Education, 17, (2), 189-196.

Scoble, R. \& Israel, S. 2006 Naked Conversations, New Jersey, USA, John Wiley \& Sons.

Silverman, D. 2005 Doing Qualitative Research - Second Edition, London, Sage.

Tapscott, D. \& Williams, A., D 2006 Wikinomics: How Mass Collaboration Changes Everything, New York, USA, Portfolio (Penguin Group).

Teamspace, 2004, Teamspace: Let's Work Together, July 2006, http://www.teamspace.com.

TechTarget, 2007, What.Is, TechTarget, 17 October 2007, http://whatis.techtarget.com/.

Theony, P., 2005, TWiki - An Enterprise Collaboration Platform, Peter Theony, 28 May 2006, http://www.twiki.org/.

Thompson, J. 1967 Organisations in Action, New York, McGraw-Hill.

TLF: The Learning Federation, 2004, Curriculum Corporation and education.au, 8 March 2006, http://www.thelearningfederation.edu.au/tlf2/.

Turner, J. R. 1999 The Handbook of Project-based Management: Improving the Processes for Achieving Strategic Objectives, England, McGraw Hill. 
Udell, J. 1999 Practical Internet Groupware, Sebastapol, CA, USA, O'Reilly \& Associates Inc.

van Donk, P. D. \& Reizebos, J. 2005 Exploring the knowledge inventory in project-based organisations: a case study. International Journal of Project Management, 23, 75-83.

Vangen, S. \& Huxham, C. 2003, 'Building trust in interorganizational collaboration'. EURAM (European Academy of Management) 2003, Freie Universitat, Berlin, 3-5 April, 2003.

Walker, K. 2003, 'Collaborative power: collaboration processes and the semantic emergence of power'. 3rd International Conference on Critical Management Studies, Lancaster University, UK, 2003.

Walter, M. (Ed.) 2002 Social Research Methods: an Australian perspective, Melbourne, Australia, Oxford University Press.

Warkentin, M., Bapna, R. \& Suguman, V. 2001 E-Knowledge networks for inter-organizational collaborative e-business. Logistics Information International, 145, (1/2).

WebEx, 2006, WebEx WebOffice Workgroup, WebEx, 25 July 2006, http://www.weboffice.com/EN/Services/Workgroup.

WebScribbleSolutions, 2007, WebNetwork, Web Scribble Solutions, 31 October 2007, http://www.webscribble.com/products/webnetwork/index.shtml.

White, P. 1968 Myth and reality in interorganisational behaviour: a study of competition between two national voluntary health agencies. American Journal of Public Health, 58, 289-304.

Woolley, D., 2007, Collaborative Work Environments, Thinkofit, 17 October 2007, http://www.thinkofit.com/webconf/workspaces.htm.

WordPress, 2007, WordPress, WordPress, 1 March 2007, http://www.wordpress.org/.

Yin, R. 2003 Case Study Research: Design and Methods, Third Edition, California, USA., Sage.

Yoshino, M. \& Rangan, U. 1995 Strategic Alliances: an entrepreneurial approach to globalisation, USA, Harvard Business School. 


\section{APPENDICES}

\section{A1. Key Knowledge Areas}

Table 11-1: Key Knowledge Area

\begin{tabular}{|l|l|}
\hline $\begin{array}{l}\text { Key Knowledge } \\
\text { Area }\end{array}$ & Outline of knowledge area, process or activity \\
\hline $\begin{array}{l}\text { Project } \\
\text { organisation }\end{array}$ & $\begin{array}{l}\text { May include: contract negotiation, assigning roles and responsibilities, adopting reporting } \\
\text { structure, developing project charter, developing preliminary project scope statement, developing } \\
\text { project plans, directing and managing project execution, monitoring and controlling project work, } \\
\text { preparation of a project management framework, implementing a methodology and associated } \\
\text { PM processes, integrated change control, close project documentation, and an understanding of } \\
\text { the organisational culture. }\end{array}$
\end{tabular}

Description: The Project Organisation knowledge area includes those activities and processes that assist the project manager to identify, define and coordinate the many processes and project management activities occurring within the project management environment. This knowledge area includes an understanding of those characteristics that are central to managing customer and stakeholder requirements and expectations, including reporting and documentation systems and protocols. This area is key to understanding the factors that will influence the successful completion of the project.

\begin{tabular}{|c|c|}
\hline Scope & $\begin{array}{l}\text { May include: managing the project through a work breakdown structure (WBS), being results } \\
\text { focussed, balancing objectives and levels of ambition through scope definition, scope } \\
\text { verification, scope planning and control, and resource allocation methods. } \\
\text { Description: The Project Scope management area entails defining, identifying and subsequently } \\
\text { controlling those items and processes that are needed to ensure that the project has all the work } \\
\text { required to complete the project successfully. This knowledge area would include activities such } \\
\text { as defining the scope and constructing the work breakdown structure (WBS). }\end{array}$ \\
\hline Time & $\begin{array}{l}\text { May include: activity definition, activity sequencing, activity resource estimating, activity } \\
\text { duration estimating, schedule development and control. } \\
\text { Description: The Project Time Management knowledge area includes those processes required to } \\
\text { accomplish the project in a timely manner. It entails defining the activities that are required to be } \\
\text { undertaken in order to produce the required deliverables, and the subsequent identification and } \\
\text { documentation of any dependencies that may exist between those activities or tasks. Activity } \\
\text { resource and duration estimation entail estimating the range of resources and their work periods } \\
\text { that will be required for each of the scheduled activities. Each one of the processes interacts with } \\
\text { each other and with other knowledge areas, and may involve one or several project team } \\
\text { members across many or all of the project phases. This knowledge area also contributes to the } \\
\text { overall project plan in the Project organisation area. }\end{array}$ \\
\hline Cost & $\begin{array}{l}\text { May include: providing a measure to control costs, assessing project viability, obtaining funding, } \\
\text { managing cash flows, allocating resources, estimating durations, preparing tenders, and } \\
\text { budgeting. } \\
\text { Description: The Project Cost knowledge area involves those activities related to the planning, } \\
\text { estimating and controlling of costs that have been detailed in the project budget. This knowledge } \\
\text { area is primarily concerned with the cost of resources that are required to complete the identified } \\
\text { and scheduled activities. It may also involve life-cycle costing, where factors such as usage, } \\
\text { maintenance and support of the product are taken into consideration to improve quality and } \\
\text { performance of the overall project deliverable. As with the time knowledge area, sections of the } \\
\text { cost knowledge area interact with each other, and with other processes within the project } \\
\text { environment. }\end{array}$ \\
\hline
\end{tabular}




\begin{tabular}{|c|c|}
\hline $\begin{array}{l}\text { Key Knowledge } \\
\text { Area }\end{array}$ & Outline of knowledge area, process or activity \\
\hline Quality & $\begin{array}{l}\text { May include: meeting specifications, being fit for purpose, meeting requirements, satisfying the } \\
\text { customer, quality planning, quality assurance and quality control. } \\
\text { Description: The Project Quality knowledge area includes all those activities that determine } \\
\text { quality policies, objectives and responsibilities in order that the project satisfies the stated needs } \\
\text { for which it is intended. It implements the quality management system through the application of } \\
\text { policy, procedures and processes across the areas of planning, control and quality assurance. This } \\
\text { knowledge area is also linked to monitoring and managing customer satisfaction processes and } \\
\text { continuous improvement. }\end{array}$ \\
\hline $\begin{array}{l}\text { Human resources } \\
\text { (HR) }\end{array}$ & $\begin{array}{l}\text { May include: HR planning, acquiring the project team, developing project team, managing and } \\
\text { structuring the project team, ethics and project management, understanding organisational factors } \\
\text { and work cultures. } \\
\text { Description: The Human Resources (HR) knowledge area includes all those processes that } \\
\text { contribute to the management and organisation of the project team. This includes HR planning } \\
\text { and acquiring, developing and managing the project team to ensure that it has the competencies } \\
\text { and skills to deliver and enhance the project, whilst tracking the performance of its members and } \\
\text { of the team as a unit. Given this, it may be active in monitoring the functions and operations of } \\
\text { the larger (parent) organisation, and taking 'health checks' of its processes and work culture. }\end{array}$ \\
\hline Communications & $\begin{array}{l}\text { May include: communications planning, information distribution, performance reporting, } \\
\text { managing stakeholders and customer relations, social network building, knowledge and } \\
\text { information sharing, implementation of virtual teams and building authority. } \\
\text { Description: The Project Communications knowledge area is responsible for the processes that } \\
\text { are used to ensure that project information is collected, distributed, stored and retrieved in a } \\
\text { timely fashion. It involves determining the information that is required for the project as well as } \\
\text { the timeframes in which it is to be made available. A key area is the collection and distribution } \\
\text { of information related to project performance including status reporting, progress reports and } \\
\text { forecasting. It will also necessarily involve the application of a suite of communication tools to } \\
\text { manage stakeholders from across the project environment. }\end{array}$ \\
\hline Risk & $\begin{array}{l}\text { May include: identification of risks, assessing individual and joint impact of risks, developing } \\
\text { strategies for risk, monitoring and controlling risk and the associated strategies, risk management } \\
\text { planning, qualitative risk analysis, quantitative risk analysis, risk response planning, establishing } \\
\text { contingency reserves, and risk reward trade-offs. } \\
\text { Description: Project Risk is an uncertain event or condition that, if it occurs, has a positive or } \\
\text { negative effect on at least one project objective, such as time, cost, scope or quality (PMI, 2004). } \\
\text { A risk can also be caused by more than one factor, and subsequently impact more than one area. } \\
\text { Therefore, the project risk knowledge area includes those processes that are concerned with } \\
\text { conducting risk management planning, determining which risks could impact on the project and } \\
\text { analysing the effect a risk may have on a project. It will also develop scenarios that may reduce } \\
\text { the threat of risks and introduce processes whereby risks can be monitored and/or controlled on } \\
\text { the project. As the project progresses through its lifecycle, most of these processes will require } \\
\text { updating. }\end{array}$ \\
\hline Procurement & $\begin{array}{l}\text { May include: planning purchases and acquisitions, contracting, requesting seller response (RFI, } \\
\text { RFQ, RFT), selecting sellers, contract administration and measurement against key performance } \\
\text { indicators and contract closure. } \\
\text { Description: The Procurement knowledge area includes those processes that assist in the } \\
\text { procurement or purchasing of external products, goods or services that are required by the project } \\
\text { team to undertake the project work. It may involve the release of a Request for Information } \\
\text { (RFI), Request for Quotation (RFQ), or a Request for Tender (RFT). Given this, this knowledge } \\
\text { area includes activities related to contract management and change control processes that are } \\
\text { necessary for the administration and performance evaluation of third party contracts. }\end{array}$ \\
\hline
\end{tabular}




\section{A2. Likert Questionnaire}

Table 11-2: Likert Questionnaire

\begin{tabular}{|c|c|c|c|c|c|}
\hline PART ONE & 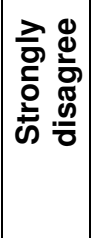 & 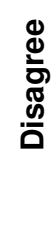 & 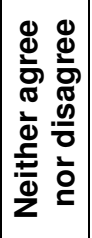 & 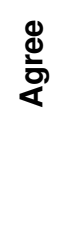 & 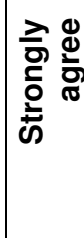 \\
\hline \multicolumn{6}{|l|}{ The use of SHARED CALENDARS in the Online Collaborative Toolsets (OCT): } \\
\hline - increases chances of meeting project schedules & 1 & 2 & 3 & 4 & 5 \\
\hline - improves planning activities & 1 & 2 & 3 & 4 & 5 \\
\hline - improves prioritising tasks & 1 & 2 & 3 & 4 & 5 \\
\hline - complicates coordinating activities across the project environment & 1 & 2 & 3 & 4 & 5 \\
\hline - improves delivery of activities in a timely manner & 1 & 2 & 3 & 4 & 5 \\
\hline - assists with the development of trust across the project team & 1 & 2 & 3 & 4 & 5 \\
\hline - communicates the availability of team members and resources & 1 & 2 & 3 & 4 & 5 \\
\hline - supports equality amongst team members & 1 & 2 & 3 & 4 & 5 \\
\hline - detracts from managing strategic alliances within the project team & 1 & 2 & 3 & 4 & 5 \\
\hline \multicolumn{6}{|l|}{ The use of a CENTRAL DATABASE in the OCT: } \\
\hline - improves the quality of data in the database & 1 & 2 & 3 & 4 & 5 \\
\hline - manages data from a central environment & 1 & 2 & 3 & 4 & 5 \\
\hline - decreases confidence in the data & 1 & 2 & 3 & 4 & 5 \\
\hline - increases possibility of data corruption & 1 & 2 & 3 & 4 & 5 \\
\hline - decreases the time it takes to undertake tasks & 1 & 2 & 3 & 4 & 5 \\
\hline - centralises reporting of data & 1 & 2 & 3 & 4 & 5 \\
\hline - detracts from organisational planning & 1 & 2 & 3 & 4 & 5 \\
\hline - reduces the complexity of maintaining data & 1 & 2 & 3 & 4 & 5 \\
\hline - requires a level of trust between team members & 1 & 2 & 3 & 4 & 5 \\
\hline - hampers communication across the project team & 1 & 2 & 3 & 4 & 5 \\
\hline \multicolumn{6}{|l|}{ The capacity to SHARE DOCUMENTS in the OCT: } \\
\hline - increases the number of versions of documents & 1 & 2 & 3 & 4 & 5 \\
\hline - increases efficiencies in distribution of documents & 1 & 2 & 3 & 4 & 5 \\
\hline - requires a level of trust between team members & 1 & 2 & 3 & 4 & 5 \\
\hline - $\quad$ risks quality control within the project & 1 & 2 & 3 & 4 & 5 \\
\hline - improves communication regarding essential information & 1 & 2 & 3 & 4 & 5 \\
\hline - $\quad$ produces inefficiencies in retrieval of information & 1 & 2 & 3 & 4 & 5 \\
\hline - develops an equality amongst the team members & 1 & 2 & 3 & 4 & 5 \\
\hline - assists in managing change controls in the project & 1 & 2 & 3 & 4 & 5 \\
\hline - adds time and cost to managing the shared documents & 1 & 2 & 3 & 4 & 5 \\
\hline - $\quad$ assists with project planning & 1 & 2 & 3 & 4 & 5 \\
\hline \multicolumn{6}{|l|}{ The capacity to STORE DOCUMENTS in the OCT: } \\
\hline - enables easy access to all documents in the central repository & 1 & 2 & 3 & 4 & 5 \\
\hline - reduces the number of users accessing files & 1 & 2 & 3 & 4 & 5 \\
\hline - develops trust between team members & 1 & 2 & 3 & 4 & 5 \\
\hline - increases ease of retrieving documents & 1 & 2 & 3 & 4 & 5 \\
\hline - discourages communication across the project team & 1 & 2 & 3 & 4 & 5 \\
\hline - $\quad$ provides an incentive to share information amongst team members & 1 & 2 & 3 & 4 & 5 \\
\hline - increases the effort required to monitor and control risk & 1 & 2 & 3 & 4 & 5 \\
\hline $\begin{array}{l}\text { - reduces the need for alliances/relationships across the project } \\
\text { environment }\end{array}$ & 1 & 2 & 3 & 4 & 5 \\
\hline - increases difficulty in accessing files remotely & 1 & 2 & 3 & 4 & 5 \\
\hline - increases the time and effort required to manage documents & 1 & 2 & 3 & 4 & 5 \\
\hline - decreases the quality controls of the document & 1 & 2 & 3 & 4 & 5 \\
\hline - enhances contract management processes & 1 & 2 & 3 & 4 & 5 \\
\hline - assists with negotiations within the project management environment & 1 & 2 & 3 & 4 & 5 \\
\hline - increases difficulty in managing resources across the project & 1 & 2 & 3 & 4 & 5 \\
\hline
\end{tabular}




\begin{tabular}{|c|c|c|c|c|c|}
\hline PART ONE & 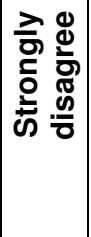 & 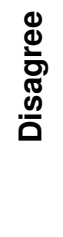 & 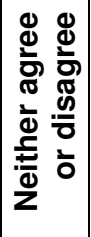 & ఖ & 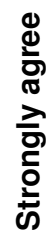 \\
\hline \multicolumn{6}{|l|}{ The use of an ANNOUNCEMENT BOARD in the OCT } \\
\hline - $\quad$ manages the use of email more efficiently & 1 & 2 & 3 & 4 & 5 \\
\hline - $\quad$ develops relationships with team members & 1 & 2 & 3 & 4 & 5 \\
\hline - $\quad$ requires team members to trust each other & 1 & 2 & 3 & 4 & 5 \\
\hline - $\quad$ is ineffective when communicating to the project team & 1 & 2 & 3 & 4 & 5 \\
\hline - $\quad$ contributes to controlling the project schedule & 1 & 2 & 3 & 4 & 5 \\
\hline - $\quad$ assists with monitoring and controlling risk in the project environment & 1 & 2 & 3 & 4 & 5 \\
\hline - $\quad$ provides greater control of resources planning & 1 & 2 & 3 & 4 & 5 \\
\hline - $\quad$ creates difficulty in distributing information across the project & 1 & 2 & 3 & 4 & 5 \\
\hline - $\quad$ increases the capacity to manage risk & 1 & 2 & 3 & 4 & 5 \\
\hline - $\quad$ assists with the execution of the project plan & 1 & 2 & 3 & 4 & 5 \\
\hline \multicolumn{6}{|l|}{ The use of VIRTUAL CONFERENCING in the OCT } \\
\hline - $\quad$ manages time more effectively & 1 & 2 & 3 & 4 & 5 \\
\hline - $\quad$ does not replace the number of meetings required & 1 & 2 & 3 & 4 & 5 \\
\hline - $\quad$ makes it hard to establish trust between team members & 1 & 2 & 3 & 4 & 5 \\
\hline - $\quad$ enables more effective control over schedule and project issues & 1 & 2 & 3 & 4 & 5 \\
\hline - $\quad$ enhances communication across the project team & 1 & 2 & 3 & 4 & 5 \\
\hline - $\quad$ discourages innovation and learning across the team & 1 & 2 & 3 & 4 & 5 \\
\hline - $\quad$ decreases the ability to manage and control risk & 1 & 2 & 3 & 4 & 5 \\
\hline - $\quad$ replaces the need to meet physically & 1 & 2 & 3 & 4 & 5 \\
\hline - develops relationships with team members & 1 & 2 & 3 & 4 & 5 \\
\hline \multicolumn{6}{|l|}{ The use of OCT in general } \\
\hline - $\quad$ is the most effective tool for distributing information to the project team & 1 & 2 & 3 & 4 & 5 \\
\hline - $\quad$ ensures all documents are easily found & 1 & 2 & 3 & 4 & 5 \\
\hline - $\quad$ increases the amount of administration for the project & 1 & 2 & 3 & 4 & 5 \\
\hline - $\quad$ ensures all project related information is kept up to date and in one place & 1 & 2 & 3 & 4 & 5 \\
\hline - $\quad$ streamlines communication to the project teams & 1 & 2 & 3 & 4 & 5 \\
\hline - $\quad$ increases the amount of paperwork in managing projects & 1 & 2 & 3 & 4 & 5 \\
\hline - $\quad$ creates an online space which the team uses as a project meeting space & 1 & 2 & 3 & 4 & 5 \\
\hline - $\quad$ increases the amount of time it takes to do things & 1 & 2 & 3 & 4 & 5 \\
\hline - $\quad$ assists with managing scope issues & 1 & 2 & 3 & 4 & 5 \\
\hline - $\quad$ does not improve quality control & 1 & 2 & 3 & 4 & 5 \\
\hline - $\quad$ complicates managing staff and resources & 1 & 2 & 3 & 4 & 5 \\
\hline
\end{tabular}




\begin{tabular}{|c|c|c|c|c|c|}
\hline PART TWO & 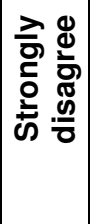 & 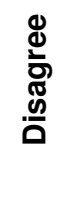 & 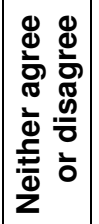 & ఖ & 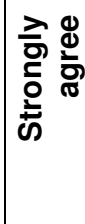 \\
\hline \multicolumn{6}{|l|}{ Trust } \\
\hline - I trust my team members & 1 & 2 & 3 & 4 & 5 \\
\hline - My team members trust me & 1 & 2 & 3 & 4 & 5 \\
\hline - The project team requires a level of trust in order to successfully operate & 1 & 2 & 3 & 4 & 5 \\
\hline - Trust is not important in stakeholder management & 1 & 2 & 3 & 4 & 5 \\
\hline - Negotiations depend on the presence of trust & 1 & 2 & 3 & 4 & 5 \\
\hline - Trust is important when sharing knowledge across the project areas & 1 & 2 & 3 & 4 & 5 \\
\hline $\begin{array}{l}\text { - Trust is required between stakeholders in order to achieve project } \\
\text { objectives / deliverables }\end{array}$ & 1 & 2 & 3 & 4 & 5 \\
\hline - Documents can be shared in the project team without trust & 1 & 2 & 3 & 4 & 5 \\
\hline - Trust is not required in the project management environment & 1 & 2 & 3 & 4 & 5 \\
\hline - Collaboration can be achieved without trust & 1 & 2 & 3 & 4 & 5 \\
\hline $\begin{array}{ll} & \text { OCT facilitates trust amongst team members } \\
\end{array}$ & 1 & 2 & 3 & 4 & 5 \\
\hline \multicolumn{6}{|l|}{ Communication } \\
\hline - Effective communication benefits project management & 1 & 2 & 3 & 4 & 5 \\
\hline - Communication is not enhanced by technology & 1 & 2 & 3 & 4 & 5 \\
\hline - Stakeholder management relies on communication & 1 & 2 & 3 & 4 & 5 \\
\hline - Sharing knowledge can be enhanced using online technology & 1 & 2 & 3 & 4 & 5 \\
\hline - Managing team members requires communication & 1 & 2 & 3 & 4 & 5 \\
\hline - Communication is not important when using an OCT & 1 & 2 & 3 & 4 & 5 \\
\hline - OCT improve information sharing & 1 & 2 & 3 & 4 & 5 \\
\hline - Team members communicate more effectively when using OCT & 1 & 2 & 3 & 4 & 5 \\
\hline $\begin{array}{l}\text { - Online technology does not assist with communication in the project } \\
\text { environment }\end{array}$ & 1 & 2 & 3 & 4 & 5 \\
\hline - Communication is essential in achieving project objectives / deliverables & 1 & 2 & 3 & 4 & 5 \\
\hline - $\quad$ Communication is not clearer when using OCT & 1 & 2 & 3 & 4 & 5 \\
\hline $\begin{array}{l}\text { - Communication across the project environment does not benefit from } \\
\text { using OCT }\end{array}$ & 1 & 2 & 3 & 4 & 5 \\
\hline \multicolumn{6}{|l|}{ Equality } \\
\hline - Members of the project team need to feel equal & 1 & 2 & 3 & 4 & 5 \\
\hline - Knowledge distribution is not important for team members & 1 & 2 & 3 & 4 & 5 \\
\hline - Equality is demonstrated by sharing information between team members & 1 & 2 & 3 & 4 & 5 \\
\hline - Team members do not need to feel equal in order to contribute & 1 & 2 & 3 & 4 & 5 \\
\hline - Communication assists relationship management of project teams & 1 & 2 & 3 & 4 & 5 \\
\hline \multicolumn{6}{|l|}{ Strategic alliances } \\
\hline - Strategic alliances can be strengthened using the OCT & 1 & 2 & 3 & 4 & 5 \\
\hline - Knowledge sharing is a critical component of managing alliances & 1 & 2 & 3 & 4 & 5 \\
\hline - Trust is not essential to developing and maintaining strategic alliances & 1 & 2 & 3 & 4 & 5 \\
\hline - Strategic alliances are managed by open communication & 1 & 2 & 3 & 4 & 5 \\
\hline - Stakeholder management is not improved when using OCT & 1 & 2 & 3 & 4 & 5 \\
\hline - OCT delivers the incentives needed to manage strategic alliances & 1 & 2 & 3 & 4 & 5 \\
\hline
\end{tabular}




\begin{tabular}{|c|c|c|c|c|c|}
\hline PART TWO & 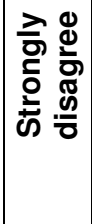 & 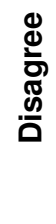 & 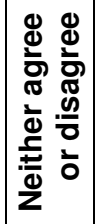 & 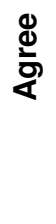 & 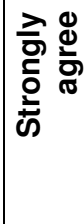 \\
\hline \multicolumn{6}{|l|}{ (Project) Knowledge distribution } \\
\hline $\begin{array}{l}\text { - The distribution of knowledge regarding the project is important to team } \\
\text { members }\end{array}$ & 1 & 2 & 3 & 4 & 5 \\
\hline - OCT encourage sharing information amongst team members & 1 & 2 & 3 & 4 & 5 \\
\hline - The distribution of knowledge amongst team members is central to trust & 1 & 2 & 3 & 4 & 5 \\
\hline - Knowledge distribution should be on an ad hoc basis & 1 & 2 & 3 & 4 & 5 \\
\hline - Knowledge should not be distributed from a central location & 1 & 2 & 3 & 4 & 5 \\
\hline $\begin{array}{l}\text { - Knowledge distribution is more than having a central repository of } \\
\text { documents in an OCT }\end{array}$ & 1 & 2 & 3 & 4 & 5 \\
\hline $\begin{array}{l}\text { - Announcement boards in OCT assist in the distribution of important } \\
\text { information }\end{array}$ & 1 & 2 & 3 & 4 & 5 \\
\hline - Knowledge distribution should be managed by the project manager & 1 & 2 & 3 & 4 & 5 \\
\hline \multicolumn{6}{|l|}{ Negotiation } \\
\hline - Negotiation is an integral part of managing stakeholders & 1 & 2 & 3 & 4 & 5 \\
\hline - Negotiation requires communication amongst stakeholders & 1 & 2 & 3 & 4 & 5 \\
\hline - Incentives are central to negotiations & 1 & 2 & 3 & 4 & 5 \\
\hline - $\quad$ OCT hamper the negotiation process with stakeholders & 1 & 2 & 3 & 4 & 5 \\
\hline - Negotiations between stakeholders is aided when parties trust each other & 1 & 2 & 3 & 4 & 5 \\
\hline \multicolumn{6}{|l|}{ Incentives (such as time, money, or something of value) } \\
\hline - Incentives are a prerequisite to sharing information & 1 & 2 & 3 & 4 & 5 \\
\hline - $\quad$ OCT reduce the need for incentives in the project environment & 1 & 2 & 3 & 4 & 5 \\
\hline - Without incentives, information sharing would not occur & 1 & 2 & 3 & 4 & 5 \\
\hline
\end{tabular}

Information on respondents.

Please provide some basic details about yourself and your project management experience.

\begin{tabular}{|l|c|c|c|}
\hline Age & Under 30 years & $31-50$ years & Over 51 years \\
\hline Sex & \multicolumn{1}{|c|}{ Female } & Male \\
\hline Years in project management & Under 5 years & $6-15$ years & Over 16 years \\
\hline $\begin{array}{l}\text { Position in project - what is your } \\
\text { main role in the project team? }\end{array}$ & \multicolumn{3}{|l}{} \\
\hline
\end{tabular}




\section{A3. Part One Statements set against the PME Knowledge Areas and Collaboration Characteristics}

Table 11-3: Part One Statements set against PME Knowledge Areas and Collaboration Characteristics

\begin{tabular}{|c|c|c|c|c|c|c|c|c|c|c|c|c|c|c|}
\hline Likert statement & \multicolumn{7}{|c|}{ Project knowledge areas } & \multicolumn{7}{|c|}{ Collaboration characteristics } \\
\hline & 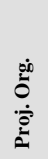 & 言 & $\stackrel{\mathscr{E}}{\Xi}$ & $\overrightarrow{3}$ & $\bar{\Xi}$ & 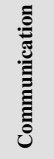 & $\stackrel{\frac{L}{\underline{m}}}{\dddot{2}}$ & $\stackrel{\overrightarrow{\underline{z}}}{E}$ & 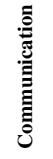 & 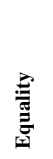 & 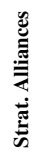 & 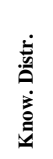 & 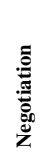 & 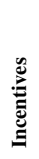 \\
\hline \multicolumn{15}{|l|}{ PART ONE - use of OCTs } \\
\hline \multicolumn{15}{|l|}{ The use of SHARED CALENDARS in the Online Collaborative Toolsets (OCT): } \\
\hline 1. increases chances of meeting project schedules & & & $\checkmark$ & & & & & & & & & & & \\
\hline 2. $\quad$ improves planning activities & $\checkmark$ & & & & & & & & & & & & & \\
\hline 3. improves prioritising tasks & $\checkmark$ & & & & & & & & & & & & & \\
\hline 4. complicates coordinating activities across the project environment & $\checkmark$ & & & & & & & & & & & & & \\
\hline 5. improves delivery of activities in a timely manner & $\checkmark$ & & & & & & & & & & & & & \\
\hline 6. assists with the development of trust across the project team & & $\checkmark$ & & & & & & $\checkmark$ & & & & & & \\
\hline 7. communicates the availability of team members and resources & & & & & & $\checkmark$ & & & $\checkmark$ & & & & & \\
\hline 8. $\quad$ supports equality amongst team members & & & & & & & & & & $\checkmark$ & & & & \\
\hline 9. detracts from managing Strategic alliances within the project team & & & & & & & & & & & $\checkmark$ & & & \\
\hline \multicolumn{15}{|l|}{ The use of a CENTRAL DATABASE in the OCT: } \\
\hline 10. improves the quality of data in the database & & & & & $\checkmark$ & & & & & & & & & \\
\hline 11. manages data from a central environment & $\checkmark$ & & & & & & & & & & & & & \\
\hline 12. decreases confidence in the data & & & & & $\checkmark$ & & & & & & & & & \\
\hline 13. increases possibility of data corruption & & & & & $\checkmark$ & & & & & & & & & \\
\hline 14. decreases the time it takes to undertake tasks & & & $\checkmark$ & & & & & & & & & & & \\
\hline 15. centralises reporting of data & $\checkmark$ & & & & & & & & & & & & & \\
\hline 16. detracts from organisational planning & $\checkmark$ & & & & & & & & & & & & & \\
\hline 17. reduces the complexity of maintaining data & $\checkmark$ & & & & & & & & & & & & & \\
\hline 18. requires a level of trust between team members & & & & & & & & $\checkmark$ & & & & & & \\
\hline 19. hampers communication across the project team & & & & & & & & & $\checkmark$ & & & & & \\
\hline \multicolumn{15}{|l|}{ The capacity to SHARE DOCUMENTS in the OCT: } \\
\hline 20. increases the number of versions of documents & $\checkmark$ & & & & & & & & & & & & & \\
\hline 21. increases efficiencies in distribution of documents & & & $\checkmark$ & & & & & & & & & & & \\
\hline 22. requires a level of trust between team members & & & & & & & & $\checkmark$ & & & & & & \\
\hline 23. risks quality control within the project & & & & & & & $\checkmark$ & & & & & & & \\
\hline 24. improves communication regarding essential information & & & & & & $\checkmark$ & & & $\checkmark$ & & & & & \\
\hline 25. produces inefficiencies in retrieval of information & & & & & $\checkmark$ & & & & & & & & & \\
\hline 26. develops an equality amongst the team members & & & & & & & & & & $\checkmark$ & & & & \\
\hline 27. assists in managing change controls in the project & $\checkmark$ & & & & & & & & & & & & & \\
\hline 28. adds time and cost to managing the shared documents & & & & $\checkmark$ & & & & & & & & & & \\
\hline 29. assists with project planning & $\checkmark$ & & & & & & & & & & & & & \\
\hline
\end{tabular}




\begin{tabular}{|c|c|c|c|c|c|c|c|c|c|c|c|c|c|c|}
\hline \multirow[t]{2}{*}{ Likert statement } & \multicolumn{7}{|c|}{ Project knowledge areas } & \multicolumn{7}{|c|}{ Collaboration characteristics } \\
\hline & 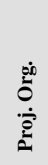 & 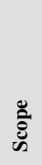 & $\stackrel{\mathscr{E}}{\Xi}$ & $\vec{s}$ & 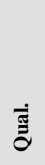 & 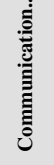 & $\frac{\breve{c}}{\underline{\underline{x}}}$ & $\overrightarrow{\underline{v}}$ & 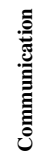 & 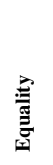 & 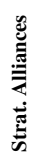 & 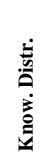 & 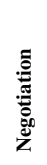 & : \\
\hline \multicolumn{15}{|l|}{ The capacity to STORE DOCUMENTS in the OCT: } \\
\hline 30. enables easy access to all documents in the central repository & & & $\checkmark$ & & & & & & & & & & & \\
\hline 31. reduces the number of users accessing files & & & & $\checkmark$ & & & & & & & & & & \\
\hline 32. develops trust between team members & & & & & & & & $\checkmark$ & & & & & & \\
\hline 33. increases ease of retrieving documents & $\checkmark$ & & & & & & & & & & & & & \\
\hline 34. discourages communication across the project team & & & & & & $\checkmark$ & & & $\checkmark$ & & & & & \\
\hline 35. provides an incentive to share information amongst team members & & & & & & $\checkmark$ & & & & & & & & $\checkmark$ \\
\hline 36. increases the effort required to monitor and control risk & & & & & & & $\checkmark$ & & & & $\checkmark$ & & & \\
\hline 37. reduces the need for alliances/relationships across the project environment & & & & & & $\checkmark$ & & & & & & & & \\
\hline 38. increases difficulty in accessing files remotely & & $\checkmark$ & & & & & & & & & & & & \\
\hline 39. increases the time and effort required to manage documents & & & $\checkmark$ & & & & & & & & & & & \\
\hline 40. decreases the quality controls of the document & & & & & $\checkmark$ & & & & & & & & & \\
\hline 41. enhances contract management processes & $\checkmark$ & & & & & & & & & & & & & \\
\hline 42. assists with negotiations within the project management environment & $\checkmark$ & & & & & & & & & & & & $\checkmark$ & \\
\hline 43. increases difficulty in managing resources across the project & & & & $\checkmark$ & & & & & & & & & & \\
\hline \multicolumn{15}{|l|}{ The use of an ANNOUNCEMENT BOARD in the OCT } \\
\hline 44. manages the use of email more efficiently & $\checkmark$ & & & $\checkmark$ & & & & & & & & & & \\
\hline 45. develops relationships with team members & & & & & & $\checkmark$ & & & & & & & & \\
\hline 46. requires team members to trust each other & & & & & & & & $\checkmark$ & & & & & & \\
\hline 47. is ineffective when communicating to the project team & & & & & & $\checkmark$ & & & $\checkmark$ & & & & & \\
\hline 48. contributes to controlling the project schedule & & $\checkmark$ & & & & & & & & & & & & \\
\hline 49. assists with monitoring and controlling risk in the project environment & & $\checkmark$ & & & & & & & & & & & & \\
\hline 50. provides greater control of resources planning & & $\checkmark$ & & & & & & & & & & & & \\
\hline 51. creates difficulty in distributing information across the project & & & & & & $\checkmark$ & & & & & & $\checkmark$ & & \\
\hline 52. increases the capacity to manage risk & & & & & & & $\checkmark$ & & & & & & & \\
\hline 53. assists with the execution of the project plan & $\checkmark$ & & & & & & & & & & & & & \\
\hline \multicolumn{15}{|l|}{ The use of VIRTUAL CONFERENCING in the OCT } \\
\hline 54. manages time more effectively & & & $\checkmark$ & & & & & & & & & & & \\
\hline 55. does not replace the number of meetings required & & & & & & $\checkmark$ & & & & & & & & \\
\hline 56. makes it hard to establish trust between team members & & & & & & & & $\checkmark$ & & & & & & \\
\hline 57. enables more effective control over schedule and project issues & & $\checkmark$ & & & & & & & & & & & & \\
\hline 58. enhances communication across the project team & & & & & & $\checkmark$ & & & $\checkmark$ & & & & & \\
\hline 59. discourages innovation and learning across the team & & & & & $\checkmark$ & & & & & & & & & \\
\hline 60. decreases the ability to manage and control risk & & & & & & & $\checkmark$ & & & & & & & \\
\hline 61. replaces the need to meet physically & & & & & & $\checkmark$ & & & & & & & & \\
\hline 62. develops relationships with team members & & & & & & $\checkmark$ & & & & & & & & \\
\hline
\end{tabular}




\begin{tabular}{|c|c|c|c|c|c|c|c|c|c|c|c|c|c|c|}
\hline Likert statement & \multicolumn{7}{|c|}{ Project knowledge areas } & \multicolumn{7}{|c|}{ Collaboration characteristics } \\
\hline & 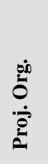 & :ँّ̆ & $\stackrel{\mathscr{\Xi}}{\Xi}$ & $\vec{z}$ & పٓ & 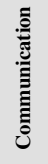 & $\frac{\ddot{x}}{\underline{x}}$ & $\overrightarrow{\underline{\underline{E}}}$ & 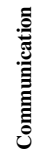 & 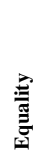 & 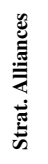 & 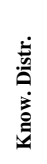 & 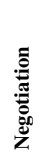 & 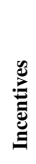 \\
\hline \multicolumn{15}{|l|}{ The use of OCT in general } \\
\hline 63. is the most effective tool for distributing information to the project team & & & & & & $\checkmark$ & & & & & & & & \\
\hline 64. ensures all documents are easily found & $\checkmark$ & & & & & & & & & & & & & \\
\hline 65. increases the amount of administration for the project & $\checkmark$ & & & & & & & & & & & & & \\
\hline 66. ensures all project related information is kept up to date and in one place & & & & & $\checkmark$ & & & & & & & & & \\
\hline 67. streamlines communication to the project teams & & & & & & $\checkmark$ & & & & & & & & \\
\hline 68. increases the amount of paperwork in managing projects & $\checkmark$ & & & & & & & & & & & & & \\
\hline 69. creates an online space which the team uses as a project meeting space & & & $\checkmark$ & & & & & & & & & & & \\
\hline 70. increases the amount of time it takes to do things & & & $\checkmark$ & & & & & & & & & & & \\
\hline 71. assists with managing scope issues & & $\checkmark$ & & & & & & & & & & & & \\
\hline 72. does not improve quality control & & & & & $\checkmark$ & & & & & & & & & \\
\hline 73. complicates managing staff and resources & & & & $\checkmark$ & & & & & & & & & & \\
\hline
\end{tabular}

HR and Procurement were not tested. 


\section{A4. Likert Statements set against Collaboration scale and Collaboration Characteristics}

Table 11-4: Likert Statements set against Collaboration scale and Collaboration Characteristics

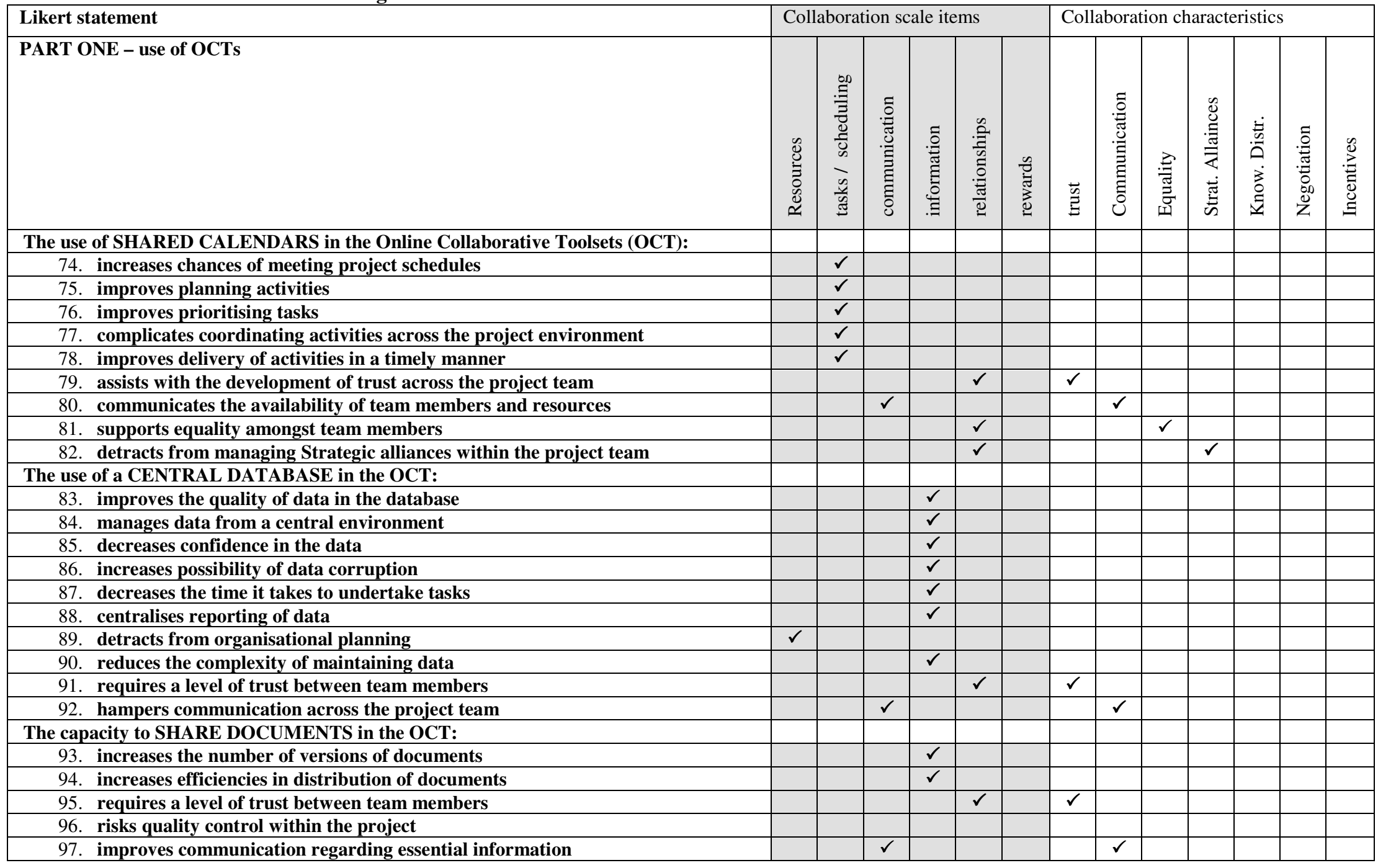


98. produces inefficiencies in retrieval of information

99. develops an equality amongst the team members

100. assists in managing change controls in the project

101. adds time and cost to managing the shared documents

102. assists with project planning

The capacity to STORE DOCUMENTS in the OCT:

103. enables easy access to all documents in the central repository

104. reduces the number of users accessing files

105. develops trust between team members

106. increases ease of retrieving documents

107. discourages communication across the project team

108. provides an incentive to share information amongst team members

109. increases the effort required to monitor and control risk

110. reduces the need for alliances/relationships across the project environment

111. increases difficulty in accessing files remotely

112. increases the time and effort required to manage documents

113. decreases the quality controls of the document

114. enhances contract management processes

115. assists with negotiations within the project management environment

116. increases difficulty in managing resources across the project

The use of an ANNOUNCEMENT BOARD in the OCT

117. manages the use of email more efficiently

118. develops relationships with team members

119. requires team members to trust each other

120. is ineffective when communicating to the project team

121. contributes to controlling the project schedule

122. assists with monitoring and controlling risk in the project environment

123. provides greater control of resources planning

124. creates difficulty in distributing information across the project

125. increases the capacity to manage risk

126. assists with the execution of the project plan

\begin{tabular}{|c|c|c|c|c|c|c|c|c|c|c|c|c|}
\hline $\begin{array}{l}0 \\
0 \\
0 \\
0 \\
0 \\
\mathscr{D} \\
\simeq\end{array}$ & 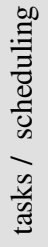 & 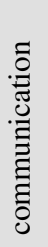 & 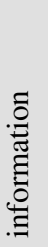 & 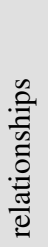 & 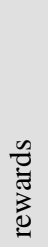 & $\overrightarrow{\vec{z}}$ & 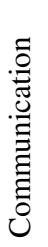 & 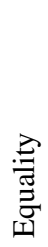 & 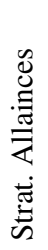 & 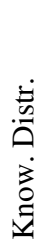 & 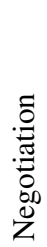 & 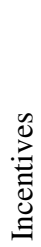 \\
\hline & & & $\checkmark$ & & & & & & & & & \\
\hline & & & & $\checkmark$ & & & & $\checkmark$ & & & & \\
\hline & & & $\checkmark$ & & & & & & & & & \\
\hline & & & $\checkmark$ & & & & & & & & & \\
\hline$\checkmark$ & & & & & & & & & & & & \\
\hline & & & & & & & & & & & & \\
\hline & & & $\checkmark$ & & & & & & & & & \\
\hline$\checkmark$ & & & & & & & & & & & & \\
\hline & & & & $\checkmark$ & & $\checkmark$ & & & & & & \\
\hline & & & $\checkmark$ & & & & & & & & & \\
\hline & & $\checkmark$ & & & & & $\checkmark$ & & & & & \\
\hline & & & $\checkmark$ & & & & & & & & & $\checkmark$ \\
\hline$\checkmark$ & & & & & & & & & $\checkmark$ & & & \\
\hline & & & & $\checkmark$ & & & & & & & & \\
\hline & & & $\checkmark$ & & & & & & & & & \\
\hline & $\checkmark$ & & & & & & & & & & & \\
\hline & $\checkmark$ & & & & & & & & & & & \\
\hline & & & $\checkmark$ & & & & & & & & & \\
\hline & & & & $\checkmark$ & & & & & & & $\checkmark$ & \\
\hline$\checkmark$ & & & & & & & & & & & & \\
\hline & & & & & & & & & & & & \\
\hline & & $\checkmark$ & & & & & & & & & & \\
\hline & & & & $\checkmark$ & & & & & & & & \\
\hline & & & & $\checkmark$ & & $\checkmark$ & & & & & & \\
\hline & & $\checkmark$ & & & & & $\checkmark$ & & & & & \\
\hline & $\checkmark$ & & & & & & & & & & & \\
\hline$\checkmark$ & & & & & & & & & & & & \\
\hline$\checkmark$ & & & & & & & & & & & & \\
\hline & & & $\checkmark$ & & & & & & & $\checkmark$ & & \\
\hline & $\checkmark$ & & & & & & & & & & & \\
\hline & $\checkmark$ & & & & & & & & & & & \\
\hline
\end{tabular}




\begin{tabular}{|c|c|c|c|c|c|c|c|c|c|c|c|c|c|}
\hline & 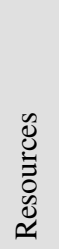 & 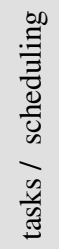 & 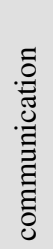 & 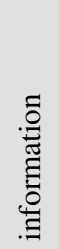 & 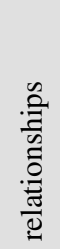 & $\begin{array}{l}\tilde{z} \\
\bar{z} \\
3 \\
0 \\
0\end{array}$ & $\overrightarrow{\underline{E}}$ & 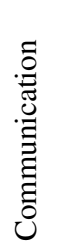 & 尔 & 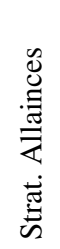 & $\begin{array}{l}\dot{\Delta} \\
\ddot{0} \\
\dot{a} \\
\dot{z} \\
\dot{\Xi}\end{array}$ & 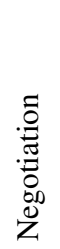 & : \\
\hline \multicolumn{14}{|l|}{ The use of VIRTUAL CONFERENCING in the OCT } \\
\hline 127. manages time more effectively & $\checkmark$ & & & & & & & & & & & & \\
\hline 128. does not replace the number of meetings required & $\checkmark$ & & & & & & & & & & & & \\
\hline 129. makes it hard to establish trust between team members & & & & & $\checkmark$ & & $\checkmark$ & & & & & & \\
\hline 130. enables more effective control over schedule and project issues & & $\checkmark$ & & & & & & & & & & & \\
\hline 131. enhances communication across the project team & & & $\checkmark$ & & & & & $\checkmark$ & & & & & \\
\hline 132. discourages innovation and learning across the team & & & & & & $\checkmark$ & & & & & & & \\
\hline 133. decreases the ability to manage and control risk & $\checkmark$ & & & & & & & & & & & & \\
\hline 134. replaces the need to meet physically & $\checkmark$ & & & & & & & & & & & & \\
\hline 135. develops relationships with team members & & & & & $\checkmark$ & & & & & & & & \\
\hline \multicolumn{14}{|l|}{ The use of OCT in general } \\
\hline 136. is the most effective tool for distributing information to the project team & & & & $\checkmark$ & & & & & & & & & \\
\hline 137. ensures all documents are easily found & & & & $\checkmark$ & & & & & & & & & \\
\hline 138. increases the amount of administration for the project & & $\checkmark$ & & & & & & & & & & & \\
\hline 139. ensures all project related information is kept up to date and in one place & & & & $\checkmark$ & & & & & & & & & \\
\hline 140. streamlines communication to the project teams & & & $\checkmark$ & & & & & & & & & & \\
\hline 141. increases the amount of paperwork in managing projects & & & & $\checkmark$ & & & & & & & & & \\
\hline 142. creates an online space which the team uses as a project meeting space & $\checkmark$ & & & & & & & & & & & & \\
\hline 143. increases the amount of time it takes to do things & $\checkmark$ & & & & & & & & & & & & \\
\hline 144. assists with managing scope issues & & $\checkmark$ & & & & & & & & & & & \\
\hline 145. does not improve quality control & & $\checkmark$ & & & & & & & & & & & \\
\hline 146. complicates managing staff and resources & $\checkmark$ & & & & & & & & & & & & \\
\hline
\end{tabular}




\begin{tabular}{|c|c|c|c|c|c|c|c|c|c|c|c|c|c|}
\hline Part Two - Collaboration & 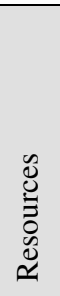 & 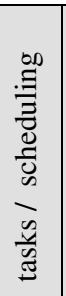 & 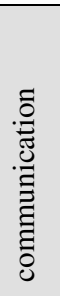 & 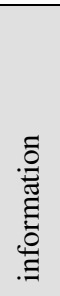 & 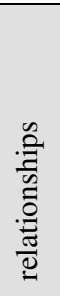 & \begin{tabular}{l}
$\tilde{Z}$ \\
\multirow{Z}{*}{} \\
0 \\
0
\end{tabular} & $\stackrel{\vec{E}}{E}$ & 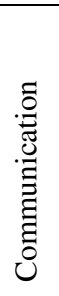 & 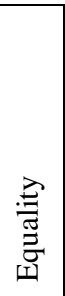 & 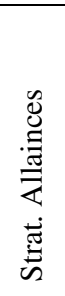 & $\begin{array}{l}\dot{E} \\
\dot{0} \\
\dot{0} \\
\dot{3} \\
\dot{0}\end{array}$ & 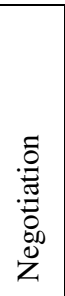 & 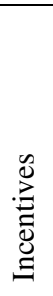 \\
\hline \multicolumn{14}{|l|}{ Trust } \\
\hline 1. I trust my team members & & & & & $\checkmark$ & & $\checkmark$ & & & & & & \\
\hline 2. My team members trust me & & & & & $\checkmark$ & & $\checkmark$ & & & & & & \\
\hline 3. The project team requires a level of trust in order to successfully operate & & & & & $\checkmark$ & & $\checkmark$ & & & & & & \\
\hline 4. Trust is not important in stakeholder management & & & & & $\checkmark$ & & $\checkmark$ & & & & & & \\
\hline 5. Negotiations depend on the presence of trust & & & & & $\checkmark$ & & $\checkmark$ & & & & & & \\
\hline 6. Trust is important when sharing knowledge across the project areas & & & & & $\checkmark$ & & $\checkmark$ & & & & & & \\
\hline $\begin{array}{l}\text { 7. Trust is required between stakeholders in order to achieve project objectives / } \\
\text { deliverables }\end{array}$ & & & & & $\checkmark$ & & $\checkmark$ & & & & & & \\
\hline 8. Documents can be shared in the project team without trust & & & & $\checkmark$ & & & $\checkmark$ & & & & & & \\
\hline 9. Trust is not required in the project management environment & & & & & $\checkmark$ & & $\checkmark$ & & & & & & \\
\hline 10. Collaboration can be achieved without trust & & & & & $\checkmark$ & & $\checkmark$ & & & & & & \\
\hline 11. OCT facilitates trust amongst team members & & & & & $\checkmark$ & & $\checkmark$ & & & & & & \\
\hline \multicolumn{14}{|l|}{ Communication } \\
\hline 12. Effective communication benefits project management & & & $\checkmark$ & & & & & $\checkmark$ & & & & & \\
\hline 13. Communication is not enhanced by technology & & & $\checkmark$ & & & & & $\checkmark$ & & & & & \\
\hline 14. Stakeholder management relies on communication & & & $\checkmark$ & & & & & $\checkmark$ & & & & & \\
\hline 15. Sharing knowledge can be enhanced using online technology & & & & $\checkmark$ & & & & & & & & & \\
\hline 16. Managing team members requires communication & & & $\checkmark$ & & & & & $\checkmark$ & & & & & \\
\hline 17. Communication is not important when using an OCT & & & $\checkmark$ & & & & & $\checkmark$ & & & & & \\
\hline 18. OCT improve information sharing & & & & $\checkmark$ & & & & & & & & & \\
\hline 19. Team members communicate more effectively when using OCT & & & $\checkmark$ & & & & & $\checkmark$ & & & & & \\
\hline 20. Online technology does not assist with communication in the project environment & & & $\checkmark$ & & & & & $\checkmark$ & & & & & \\
\hline 21. Communication is essential in achieving project objectives / deliverables & & & $\checkmark$ & & & & & $\checkmark$ & & & & & \\
\hline 22. Communication is not clearer when using OCT & & & $\checkmark$ & & & & & $\checkmark$ & & & & & \\
\hline 23. Communication across the project environment does not benefit from using OCT & & & $\checkmark$ & & & & & $\checkmark$ & & & & & \\
\hline \multicolumn{14}{|l|}{ Equality } \\
\hline 24. Members of the project team need to feel equal & & & & & $\checkmark$ & & & & $\checkmark$ & & & & \\
\hline 25. Knowledge distribution is not important for team members & & & & $\checkmark$ & & & & & $\checkmark$ & & & & \\
\hline 26. Equality is demonstrated by sharing information between team members & & & & $\checkmark$ & & & & & $\checkmark$ & & & & \\
\hline 27. Team members do not need to feel equal in order to contribute & & & & & $\checkmark$ & & & & $\checkmark$ & & & & \\
\hline 28. Communication assists relationship management of project teams & & & $\checkmark$ & & & & & & $\checkmark$ & & & & \\
\hline
\end{tabular}




\begin{tabular}{|c|c|c|c|c|c|c|c|c|c|c|c|c|c|}
\hline Part Two - Collaboration & 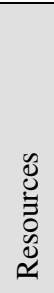 & 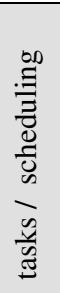 & 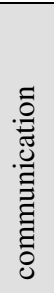 & 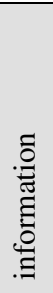 & 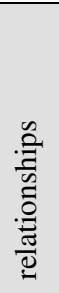 & 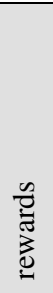 & $\stackrel{\vec{D}}{\Xi}$ & 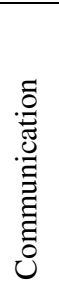 & 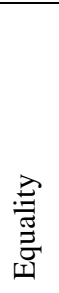 & 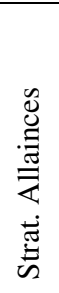 & 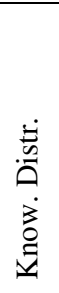 & 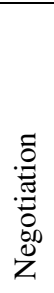 & 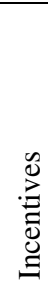 \\
\hline \multicolumn{14}{|l|}{ Strategic alliances } \\
\hline 29. Strategic alliances can be strengthened using the OCT & & & & & $\checkmark$ & & & & & $\checkmark$ & & & \\
\hline 30. Knowledge sharing is a critical component of managing alliances & & & & $\checkmark$ & & & & & & $\checkmark$ & & & \\
\hline 31. Trust is not essential to developing and maintaining Strategic Alliances & & & & & $\checkmark$ & & $\checkmark$ & & & $\checkmark$ & & & \\
\hline 32. Strategic alliances are managed by open communication & & & & $\checkmark$ & & & & & & $\checkmark$ & & & \\
\hline 33. Stakeholder management is not improved when using OCT & & & & & $\checkmark$ & & & & & $\checkmark$ & & & \\
\hline 34. OCT delivers the incentives needed to manage Strategic Alliances & & & & & $\checkmark$ & & & & & $\checkmark$ & & & \\
\hline \multicolumn{14}{|l|}{ (Project) Knowledge distribution } \\
\hline 35. The distribution of knowledge regarding the project is important to team members & & & & $\checkmark$ & & & & & & & $\checkmark$ & & \\
\hline 36. OCT encourage sharing information amongst team members & & & & $\checkmark$ & & & & & & & $\checkmark$ & & \\
\hline 37. The distribution of knowledge amongst team members is central to trust & & & & & $\checkmark$ & & $\checkmark$ & & & & & & \\
\hline 38. Knowledge distribution should be on an ad hoc basis & & & & $\checkmark$ & & & & & & & $\checkmark$ & & \\
\hline 39. Knowledge should not be distributed from a central location & & & & $\checkmark$ & & & & & & & $\checkmark$ & & \\
\hline $\begin{array}{l}\text { 40. Knowledge distribution is more than having a central repository of documents in an } \\
\text { OCT }\end{array}$ & & & & $\checkmark$ & & & & & & & $\checkmark$ & & \\
\hline 41. Announcement boards in OCT assist in the distribution of important information & & & & $\checkmark$ & & & & & & & $\checkmark$ & & \\
\hline 42. Knowledge distribution should be managed by the project manager & $\checkmark$ & & & & & & & & & & $\checkmark$ & & \\
\hline \multicolumn{14}{|l|}{ Negotiation } \\
\hline 43. Negotiation is an integral part of managing stakeholders & & & & & & & & & & & & $\checkmark$ & \\
\hline 44. Negotiation requires communication amongst stakeholders & & & $\checkmark$ & & & & & & & & & $\checkmark$ & \\
\hline 45. Incentives are central to negotiations & & & & & & $\checkmark$ & & & & & & $\checkmark$ & \\
\hline 46. OCT hamper the negotiation process with stakeholders & & & & & & & & & & & & $\checkmark$ & \\
\hline 47. Negotiations between stakeholders is aided when parties trust each other & & & & & & & & & & & & $\checkmark$ & \\
\hline \multicolumn{14}{|l|}{ Incentives (such as time, money, or something of value) } \\
\hline 48. Incentives are a prerequisite to sharing information & & & & & & $\checkmark$ & & & & & & & $\checkmark$ \\
\hline 49. OCT reduce the need for incentives in the project environment & & & & & & $\checkmark$ & & & & & & & $\checkmark$ \\
\hline 50. Without incentives, information sharing would not occur & & & & & & $\checkmark$ & & & & & & & $\checkmark$ \\
\hline
\end{tabular}




\section{A5. Likert questionnaire coded for the Collaboration scale}

Table 11-4: Likert questionnaire coded for the Collaboration scale

\begin{tabular}{|c|c|c|c|}
\hline $\begin{array}{l}\mathrm{Pt} \\
\text { No. }\end{array}$ & & PART ONE & $\begin{array}{c}\text { Cn Scale } \\
\text { CODE }\end{array}$ \\
\hline & & The use of SHARED CALENDARS in the Online Collaborative Toolsets (OCT): & \\
\hline 1.1 & 1 & increases chances of meeting project schedules & 2 \\
\hline 1.1 & 2 & improves planning activities & 2 \\
\hline 1.1 & 3 & improves prioritising tasks & 2 \\
\hline 1.1 & 4 & complicates coordinating activities across the project environment & 2 \\
\hline 1.1 & 5 & improves delivery of activities in a timely manner & 2 \\
\hline 1.1 & 6 & assists with the development of trust across the project team & 5 \\
\hline 1.1 & 7 & communicates the availability of team members and resources & 3 \\
\hline 1.1 & 8 & supports equality amongst team members & 5 \\
\hline \multirow[t]{2}{*}{1.1} & 9 & detracts from managing Strategic alliances within the project team & 5 \\
\hline & & The use of a CENTRAL DATABASE in the OCT: & \\
\hline 1.2 & 10 & improves the quality of data in the database & 4 \\
\hline 1.2 & 11 & manages data from a central environment & 4 \\
\hline 1.2 & 12 & decreases confidence in the data & 4 \\
\hline 1.2 & 13 & increases possibility of data corruption & 4 \\
\hline 1.2 & 14 & decreases the time it takes to undertake tasks & 4 \\
\hline 1.2 & 15 & centralises reporting of data & 4 \\
\hline 1.2 & 16 & detracts from organisational planning & 1 \\
\hline 1.2 & 17 & reduces the complexity of maintaining data & 4 \\
\hline 1.2 & 18 & requires a level of trust between team members & 5 \\
\hline \multirow[t]{2}{*}{1.2} & 19 & hampers communication across the project team & 3 \\
\hline & & The capacity to SHARE DOCUMENTS in the OCT: & \\
\hline 1.3 & 20 & increases the number of versions of documents & 4 \\
\hline 1.3 & 21 & increases efficiencies in distribution of documents & 4 \\
\hline 1.3 & 22 & requires a level of trust between team members & 5 \\
\hline 1.3 & 23 & risks quality control within the project & 2 \\
\hline 1.3 & 24 & improves communication regarding essential information & 3 \\
\hline 1.3 & 25 & produces inefficiencies in retrieval of information & 4 \\
\hline 1.3 & 26 & develops an equality amongst the team members & 5 \\
\hline 1.3 & 27 & assists in managing change controls in the project & 4 \\
\hline 1.3 & 28 & adds time and cost to managing the shared documents & 4 \\
\hline \multirow[t]{2}{*}{1.3} & 29 & assists with project planning & 1 \\
\hline & & The capacity to STORE DOCUMENTS in the OCT: & \\
\hline 1.4 & 30 & enables easy access to all documents in the central repository & 4 \\
\hline 1.4 & 31 & reduces the number of users accessing files & 1 \\
\hline 1.4 & 32 & develops trust between team members & 5 \\
\hline 1.4 & 33 & increases ease of retrieving documents & 4 \\
\hline 1.4 & 34 & discourages communication across the project team & 3 \\
\hline 1.4 & 35 & provides an incentive to share information amongst team members & 4 \\
\hline 1.4 & 36 & increases the effort required to monitor and control risk & 1 \\
\hline 1.4 & 37 & reduces the need for alliances/relationships across the project environment & 5 \\
\hline 1.4 & 38 & increases difficulty in accessing files remotely & 4 \\
\hline 1.4 & 39 & increases the time and effort required to manage documents & 2 \\
\hline 1.4 & 40 & decreases the quality controls of the document & 2 \\
\hline 1.4 & 41 & enhances contract management processes & 4 \\
\hline 1.4 & 42 & assists with negotiations within the project management environment & 5 \\
\hline 1.4 & 43 & increases difficulty in managing resources across the project & 1 \\
\hline
\end{tabular}




\begin{tabular}{|c|c|c|c|}
\hline & & The use of an ANNOUNCEMENT BOARD in the OCT & \\
\hline 1.5 & 44 & manages the use of email more efficiently & 3 \\
\hline 1.5 & 45 & develops relationships with team members & 5 \\
\hline 1.5 & 46 & requires team members to trust each other & 5 \\
\hline 1.5 & 47 & is ineffective when communicating to the project team & 3 \\
\hline 1.5 & 48 & contributes to controlling the project schedule & 2 \\
\hline 1.5 & 49 & assists with monitoring and controlling risk in the project environment & 1 \\
\hline 1.5 & 50 & provides greater control of resources planning & 1 \\
\hline 1.5 & 51 & creates difficulty in distributing information across the project & 4 \\
\hline 1.5 & 52 & increases the capacity to manage risk & 2 \\
\hline \multirow[t]{2}{*}{1.5} & 53 & assists with the execution of the project plan & 2 \\
\hline & & The use of VIRTUAL CONFERENCING in the OCT & \\
\hline 1.6 & 54 & manages time more effectively & 1 \\
\hline 1.6 & 55 & does not replace the number of meetings required & 1 \\
\hline 1.6 & 56 & makes it hard to establish trust between team members & 5 \\
\hline 1.6 & 57 & enables more effective control over schedule and project issues & 2 \\
\hline 1.6 & 58 & enhances communication across the project team & 3 \\
\hline 1.6 & 59 & discourages innovation and learning across the team & 6 \\
\hline 1.6 & 60 & decreases the ability to manage and control risk & 1 \\
\hline 1.6 & 61 & replaces the need to meet physically & 1 \\
\hline \multirow[t]{2}{*}{1.6} & 62 & develops relationships with team members & 5 \\
\hline & & The use of OCT in general & \\
\hline 1.7 & 63 & is the most effective tool for distributing information to the project team & 4 \\
\hline 1.7 & 64 & ensures all documents are easily found & 4 \\
\hline 1.7 & 65 & increases the amount of administration for the project & 2 \\
\hline 1.7 & 66 & ensures all project related information is kept up to date and in one place & 4 \\
\hline 1.7 & 67 & streamlines communication to the project teams & 3 \\
\hline 1.7 & 68 & increases the amount of paperwork in managing projects & 4 \\
\hline 1.7 & 69 & creates an online space which the team uses as a project meeting space & 1 \\
\hline 1.7 & 70 & increases the amount of time it takes to do things & 1 \\
\hline 1.7 & 71 & assists with managing scope issues & 2 \\
\hline 1.7 & 72 & does not improve quality control & 2 \\
\hline \multirow[t]{3}{*}{1.7} & 73 & complicates managing staff and resources & 1 \\
\hline & & PART TWO & \\
\hline & & Trust & \\
\hline 2.1 & 74 & I trust my team members & 5 \\
\hline 2.1 & 75 & My team members trust me & 5 \\
\hline 2.1 & 76 & The project team requires a level of trust in order to successfully operate & 5 \\
\hline 2.1 & 77 & Trust is not important in stakeholder management & 5 \\
\hline 2.1 & 78 & Negotiations depend on the presence of trust & 5 \\
\hline 2.1 & 79 & Trust is important when sharing knowledge across the project areas & 5 \\
\hline 2.1 & 80 & $\begin{array}{l}\text { Trust is required between stakeholders in order to achieve project objectives / } \\
\text { deliverables }\end{array}$ & 5 \\
\hline 2.1 & 81 & Documents can be shared in the project team without trust & 4 \\
\hline 2.1 & 82 & Trust is not required in the project management environment & 5 \\
\hline 2.1 & 83 & Collaboration can be achieved without trust & 5 \\
\hline \multirow[t]{2}{*}{2.1} & 84 & OCT facilitates trust amongst team members & 5 \\
\hline & & Communication & \\
\hline 2.2 & 85 & Effective communication benefits project management & 3 \\
\hline 2.2 & 86 & Communication is not enhanced by technology & 3 \\
\hline 2.2 & 87 & Stakeholder management relies on communication & 3 \\
\hline
\end{tabular}




\begin{tabular}{|c|c|c|c|}
\hline 2.2 & 88 & Sharing knowledge can be enhanced using online technology & 4 \\
\hline 2.2 & 89 & Managing team members requires communication & 3 \\
\hline 2.2 & 90 & Communication is not important when using an OCT & 3 \\
\hline 2.2 & 91 & OCT improve information sharing & 4 \\
\hline 2.2 & 92 & Team members communicate more effectively when using OCT & 3 \\
\hline 2.2 & 93 & Online technology does not assist with communication in the project environment & 3 \\
\hline 2.2 & 94 & Communication is essential in achieving project objectives / deliverables & 3 \\
\hline 2.2 & 95 & Communication is not clearer when using OCT & 3 \\
\hline \multirow[t]{2}{*}{2.2} & 96 & Communication across the project environment does not benefit from using OCT & 3 \\
\hline & & Equality & \\
\hline 2.3 & 97 & Members of the project team need to feel equal & 5 \\
\hline 2.3 & 98 & Knowledge distribution is not important for team members & 4 \\
\hline 2.3 & 99 & Equality is demonstrated by sharing information between team members & 4 \\
\hline 2.3 & 100 & Team members do not need to feel equal in order to contribute & 5 \\
\hline \multirow[t]{2}{*}{2.3} & 101 & Communication assists relationship management of project teams & 3 \\
\hline & & Strategic alliances & \\
\hline 2.4 & 102 & Strategic alliances can be strengthened using the OCT & 5 \\
\hline 2.4 & 103 & Knowledge sharing is a critical component of managing alliances & 4 \\
\hline 2.4 & 104 & Trust is not essential to developing and maintaining Strategic Alliances & 5 \\
\hline 2.4 & 105 & Strategic alliances are managed by open communication & 3 \\
\hline 2.4 & 106 & Stakeholder management is not improved when using OCT & 5 \\
\hline \multirow[t]{2}{*}{2.4} & 107 & OCT delivers the incentives needed to manage Strategic Alliances & 5 \\
\hline & & (Project) Knowledge distribution & \\
\hline 2.5 & 108 & The distribution of knowledge regarding the project is important to team members & 4 \\
\hline 2.5 & 109 & OCT encourage sharing information amongst team members & 4 \\
\hline 2.5 & 110 & The distribution of knowledge amongst team members is central to trust & 5 \\
\hline 2.5 & 111 & Knowledge distribution should be on an ad hoc basis & 4 \\
\hline 2.5 & 112 & Knowledge should not be distributed from a central location & 4 \\
\hline 2.5 & 113 & Knowledge distribution is more than having a central repository of documents in an OCT & 4 \\
\hline 2.5 & 114 & Announcement boards in OCT assist in the distribution of important information & 4 \\
\hline \multirow[t]{2}{*}{2.5} & 115 & Knowledge distribution should be managed by the project manager & 1 \\
\hline & & Negotiation & \\
\hline 2.6 & 116 & Negotiation is an integral part of managing stakeholders & 7 \\
\hline 2.6 & 117 & Negotiation requires communication amongst stakeholders & 3 \\
\hline 2.6 & 118 & Incentives are central to negotiations & 6 \\
\hline 2.6 & 119 & OCT hamper the negotiation process with stakeholders & 7 \\
\hline \multirow[t]{2}{*}{2.6} & 120 & Negotiations between stakeholders is aided when parties trust each other & 7 \\
\hline & & Incentives (such as time, money, or something of value) & \\
\hline 2.7 & 121 & Incentives are a prerequisite to sharing information & 6 \\
\hline 2.7 & 122 & OCT reduce the need for incentives in the project environment & 6 \\
\hline 2.7 & 123 & Without incentives, information sharing would not occur & 6 \\
\hline
\end{tabular}




\section{A6. Interview Questions}

Asked of the Project Manager or Project Leader

Table 11-5: Interview Questions

\begin{tabular}{|c|c|c|}
\hline & Type & \\
\hline 1 & What is the type of project? & $\begin{array}{l}\text { Administrative, research, } \\
\text { construction (civic, } \\
\text { government, PPP), other }\end{array}$ \\
\hline 2 & What are the project timeframes? & Free text \\
\hline 3 & What are the project's main deliverables? & Free text \\
\hline 4 & What is the estimated cost of the project? & Free text \\
\hline \multirow[t]{2}{*}{5} & Describe the level of complexity of the project & Free text \\
\hline & $\begin{array}{l}\text { Prompt: number of tasks, number of contractors, technical } \\
\text { difficulty, specific physical environment in which project } \\
\text { is undertaken, logistically }\end{array}$ & \\
\hline \multirow[t]{3}{*}{6} & Describe the level of risk of the project & Free text \\
\hline & Prompt: financial, legal, technical, commercial & \\
\hline & Organisation & \\
\hline 7 & What type of client organisation is managing the project? & $\begin{array}{l}\text { Government, commercial, } \\
\text { private, PPP, corporate, } \\
\text { other }\end{array}$ \\
\hline 8 & $\begin{array}{l}\text { How is the organisation structured to manage the project? } \\
\text { - this should include org chart to show relationships to } \\
\text { parent companies and sub-management organisations }\end{array}$ & Free text \\
\hline 9 & Does the project sub contract / outsource teams? & Free text \\
\hline \multirow[t]{2}{*}{10} & How does the organisation share information? & Free text \\
\hline & Prompt: methodology, tools, culture, the OCT & \\
\hline \multirow[t]{3}{*}{11} & How does the project environment share information? & Free text \\
\hline & $\begin{array}{l}\text { Prompt: methodology and behaviour, tools, culture, } \\
\text { Project Manager specific behaviour, expectations of } \\
\text { teams, the OCT }\end{array}$ & \\
\hline & Management structure & \\
\hline 12 & Describe the management structure of the project? & Free text \\
\hline 13 & $\begin{array}{l}\text { What are the responsibilities of the Project Manager? } \\
\text { (including roles and areas of responsibilities) }\end{array}$ & Free text \\
\hline 14 & Are there individual team leaders for sub-project teams? & Free text \\
\hline \multirow[t]{2}{*}{15} & How are sub-project teams managed? & Open ended \\
\hline & Environment & \\
\hline \multirow[t]{2}{*}{16} & Describe the culture of the organisation & Free Text \\
\hline & $\begin{array}{l}\text { Prompt: corporate vision, behaviour, enunciated visions or } \\
\text { emphasis on R\&D skills or organisational learning etc }\end{array}$ & \\
\hline \multirow[t]{2}{*}{17} & Is it collaborative by nature? & Free Text \\
\hline & $\begin{array}{l}\text { Prompt: collaboration characteristics include } \\
\text { trust, communication, equality, strategic alliances, } \\
\text { knowledge distribution, negotiations and incentives }\end{array}$ & \\
\hline 18 & $\begin{array}{l}\text { Does the organisation have a history of successfully } \\
\text { deploying collaborative strategies? }\end{array}$ & Yes / No - comment \\
\hline
\end{tabular}




\begin{tabular}{|c|c|c|}
\hline & Size & \\
\hline 19 & How many people work on the project? & Scale (tbd) \\
\hline 20 & How many project teams are there? & Scale (tbd) \\
\hline 21 & $\begin{array}{l}\text { How many different contractors are working on the } \\
\text { project? }\end{array}$ & Scale (tbd) \\
\hline 22 & Where are the project teams based? & Free text \\
\hline 23 & Are they located close to each other? & Yes / No - open ended \\
\hline \multirow[t]{2}{*}{24} & $\begin{array}{l}\text { What processes are in place to manage the spread of } \\
\text { project teams, or members? }\end{array}$ & Open ended \\
\hline & Process & \\
\hline 25 & $\begin{array}{l}\text { Are there mandated processes for the Project } \\
\text { environment? }\end{array}$ & Yes / No \\
\hline 26 & $\begin{array}{l}\text { If yes, what does this entail? Methodology, software, } \\
\text { reporting etc }\end{array}$ & $\begin{array}{l}\text { Open ended - but pick up } \\
\text { on OCT characteristics? }\end{array}$ \\
\hline 27 & Describe the theoretical use of the online tool & Process map / model \\
\hline \multirow[t]{2}{*}{28} & Describe the practical flow of information & Process map / model \\
\hline & Software & \\
\hline 29 & What software is used to manage the Project? & Free text \\
\hline 30 & What software is used to manage the project teams? & Free text \\
\hline 31 & Is this software mandated? & Yes / No \\
\hline 32 & Who decided the use of the software? & Free text \\
\hline 33 & $\begin{array}{l}\text { Are there circumstances that determined the use of the } \\
\text { software: i.e. I.T. support requirements, network } \\
\text { capabilities, pre-existing supplier scenarios as examples. }\end{array}$ & Open ended \\
\hline \multirow[t]{2}{*}{34} & What type of Online Tool is used? & Free text \\
\hline & Stakeholders & \\
\hline 35 & Who are the stakeholders of the project? & $\begin{array}{l}\text { Free text - relational } \\
\text { map? }\end{array}$ \\
\hline 36 & What role do they play in the management of the project? & Free text \\
\hline 37 & $\begin{array}{l}\text { How are the stakeholders managed by the Project } \\
\text { Manager? }\end{array}$ & Free text \\
\hline 38 & What processes are in place for managing stakeholders? & Open ended \\
\hline
\end{tabular}




\section{A7. Plain Language Statement}

Building 8, Level 8

Design and Social Context Portfolio

Australia

School of Property Construction and Project Management.

My name is James Harley

I am undertaking a Doctorate of Philosophy at RMIT University. The title of my research is Online collaborative toolsets in the project management environment.
GPO Box 2476V

Melbourne VIC 3001

Australia

Tel. +61399252230

Fax +61399251939

- www.rmit.edu.au

The research will take a comparative case study approach in that it will seek to investigate, in some detail, the circumstances around the use of online collaborative toolsets in managing projects, in a variety of project environments. The research seeks to develop a broad understanding of this use, whilst using a series of metrics with which to measure the application of OCT and identify any benefits that may flow out of their use.

The definition of OCT is intentionally loose, and encompasses the use of any internet enabled tools, like email, online tracking or workflow systems, programs like lotus Notes Quick Place, the internet or a portal, to name a few.

At the heart of the study lies the fundamental question, "How and why does the application of online collaborative toolsets benefit the project management environment?" In answering this question, I will also attempt to flesh out some general concepts of collaboration, the use of OCTs, project management frameworks and the part all this plays in delivering project outcomes.

As part of the information collecting process, and because of your role in the project management environment, I am writing to invite you to participate in a one-to-one interview.

The interview will take no longer than one hour and will be conducted at your place of work, or a mutually convenient site chosen by you. I seek your permission to audiotape the interview for accuracy and later analysis and transcription purposes if necessary. Your comments will not be directly attributable to you or your organisation. You may withdraw from the interview at any time, and any unprocessed data may also be withdrawn at your request. The research seeks to interview approximately 24 people involved in project management roles across a variety of sectors.

If you are willing to consent to being interviewed for this research, can you please complete and retain the attached consent form for collection at the time of interview. Please contact me directly, or my supervisor at RMIT on telephone: 9925 2230, if you require any further information.

Yours sincerely

James Harley, M.App. Sc (PCPM), M.App.Sc (Mus Studs), Grad Dip (Mus Studs), BA $\mathrm{PhD}$ - Candidate 0438854988
Nick Blismas, Ph.D. MCIOB

Property, Construction and Project Management Senior Supervisor

99252230

Any complaints about your participation in this project may be directed to the Secretary, RMIT Human Research Ethics Committee, University Secretariat, RMIT, GPO Box 2476V, Melbourne, 3001. The telephone number is (03) 99251745.

Details of the complaints procedure are available from: www.rmit.edu.au/council/hrec 


\section{A8. Consent Form}

\section{RMIT HUMAN RESEARCH ETHICS COMMITTEE}

Prescribed Consent Form For Persons Participating In Research Projects Involving Interviews, Questionnaires, Focus Groups or Disclosure of Personal Information

\section{PORTFOLIO OF \\ SCHOOL/CENTRE OF \\ Name of participant:}

Project Title:

Name(s) of investigators:

\begin{tabular}{l} 
Design and Social Context \\
\hline Property Construction and Project Management \\
\hline \multicolumn{2}{l}{ Online collaborative toolsets in the project management environment. } \\
\hline James Harley $\quad$ Phone: $\mathbf{0 4 3 8} 854988$ \\
\hline
\end{tabular}

1. I have received a statement explaining the interview/questionnaire involved in this project.

2. I consent to participate in the above project, the particulars of which - including details of the interviews or questionnaires - have been explained to me.

3. I authorise the investigator or his or her assistant to administer a questionnaire.

4. $\quad$ I give my permission for my name or identity to be used $\square$ Yes $\square$ No

5. I acknowledge that:

(a) Having read the Plain Language Statement, I agree to the general purpose, methods and demands of the study.

(b) I have been informed that I am free to withdraw from the project at any time and to withdraw any unprocessed data previously supplied.

(c) If I am representing a company, I have sought their permission to participate.

(d) The project is for the purpose of research and/or teaching. It may not be of direct benefit to me.

(e) The privacy of the information I provide will be safeguarded. However should information of a private nature need to be disclosed for moral, clinical or legal reasons, I will be given an opportunity to negotiate the terms of this disclosure.

(f) The security of the research data is assured during and after completion of the study. The data collected during the study may be published, and a report of the project outcomes will be provided to RMIT in the form of a thesis, possible journal publications and conference presentations. Any information which may be used to identify me will not be used unless I have given my permission (see point 4).

\section{Participant's Consent}

Name:

Date:

$$
\text { (Participant) }
$$

Name:

$$
\text { (Witness to signature) }
$$

Date:

\section{Where participant is under 18 years of age:}

I consent to the participation of in the above project.

Signature:

(1)

(2)

Date:

(Signatures of parents or guardians)

Name:

Date:
(Witness to signature)

Participants should be given a photocopy of this consent form after it has been signed.

Any complaints about your participation in this project may be directed to the Secretary, RMIT Human Research Ethics Committee, University Secretariat, RMIT, GPO Box 2476V, Melbourne, 3001. The telephone number is (03) 99251745.

Details of the complaints procedure are available from : www.rmit.edu.au/council/hre 


\section{A9. Case One Organisation D}

\section{Organisation Details}

The business unit in which the project manager is located is also responsible for managing and coordinating the project. The business unit uses a responsibility matrix to delineate responsibility across the departments and to describe the structure of the project. This document identifies the core project item, the business unit to which it has been allocated, the name of the responsible Executive officer and any support names, and the details of any reference teams required. This document provides a meaningful and contextual summary of the core items or products of the project.

The organisation does not normally engage contractors for the project; instead, members of contributing teams are drawn from across each department and/or agency of the state government. As such it is primarily an in-house departmental project, albeit one that has a very high profile within the government list of projects.

\section{Management}

The management structure of the project is formal, with the Project Manager responsible for direct reports from five areas. These areas constitute the functional areas of the project and include Financial, Presentation, Editing and Quality Assurance, Production and Communication. The Project Manager reports to the Steering committee, and both the Steering Committee and Project Manager report to the Treasurer. The Senior Executive team has overall responsibility for the project, and through its Ad hoc Group, manages the Steering committee. The Project Manager also has reports from Chapter Leaders, who are responsible for each chapter of the document. The project management structure of the project has the features of a balanced matrix organisation and is represented in Figure 11-1. 


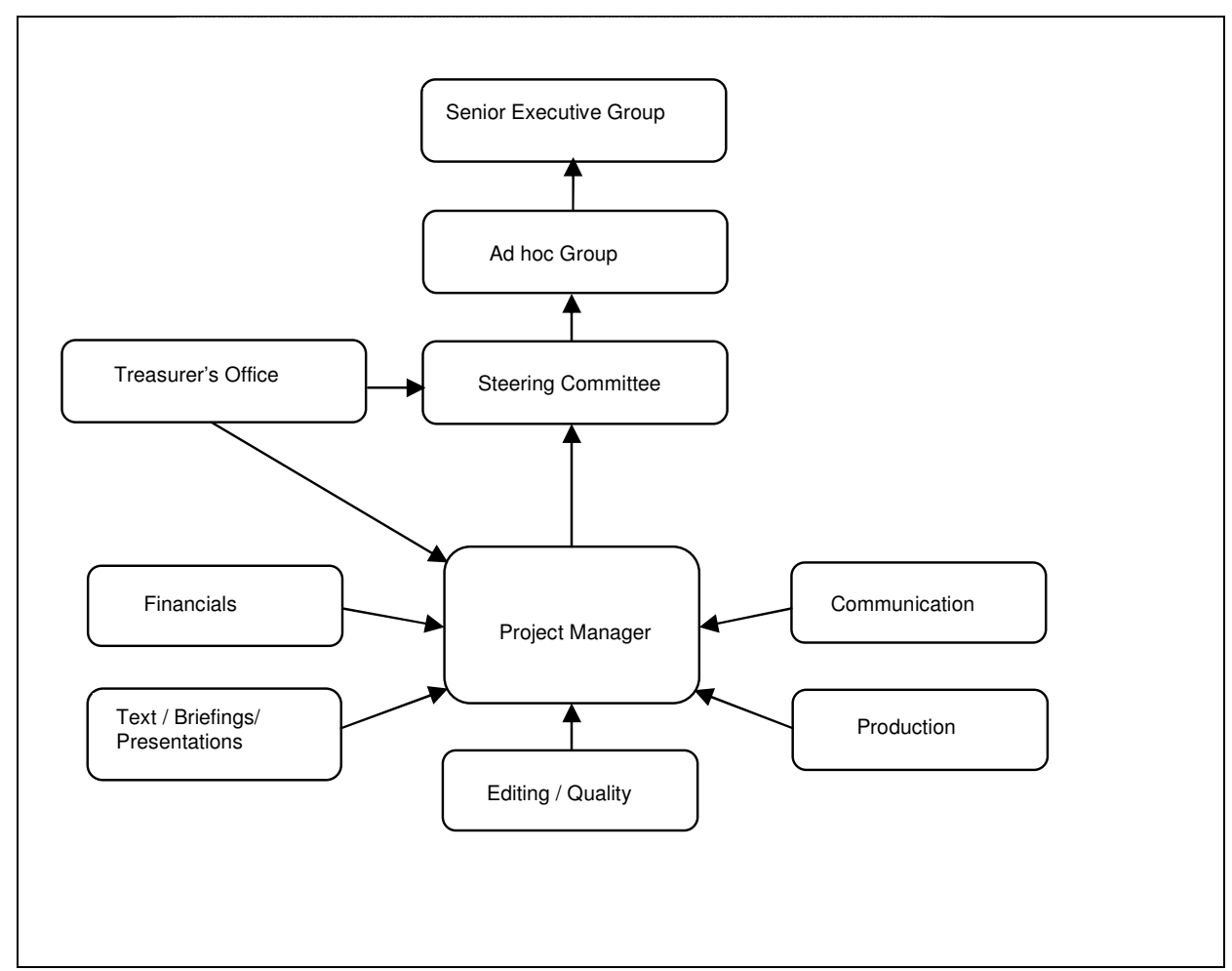

Figure 11-1: Organisation D governance structure

Given the nature of the project, and the environment in which it exists, the project has a variety of stakeholders. These stakeholders include the Premier, Treasurer and Minister for Finance and their associated private offices, other Government Ministers, all government departments, including the Auditor-General's Office, media and special interest groups and several divisions with the department coordinating the project. As the project environment references the Prince2 methodology, the Treasurer and Minister for Finance are considered the main customers of the project.

Within the department, the list of stakeholders increases to include the:

- Departmental Secretary;

- Project Issue Reference Group - comprising the Secretary and two Deputy Secretaries;

- Financial Reporting Process Steering Committee - comprising 15 assorted Department Directors and Assistant Directors. This group is the closest thing to a Project Board for the project manager (OrgD PM1). The Output Manager is normally the Chairperson of this group and this allows the project manager the opportunity to have a central audit and sign-off mechanism for his work. It also provides a quality assurance process and risk mitigation mechanism, ensuring that the project manager has the ongoing support and operational approval at regular and key stages of the project (OrgD PM1);

- Other Departments and Agencies. 


\section{Environment}

'While the organisation wants to be collaborative, it isn't just yet.' (OrgD PM1)

The project shares information by bringing together key stakeholders from across the department into a committee. This committee is considered more an information dissemination group than a steering committee, with about 15 key people meeting weekly (OrgD PM1). The project environment hasn't focussed on collaboration specifically, but on the attitudinal and behavioural areas of the project team (OrgD PM1). This is consistent with the approach the project environment has taken to information sharing, which is not formalised either. However, a strong push from the leadership group has assisted the project team to become more collaborative. The project manager sees the application of collaboration within the project environment normally breaking down as a result of someone not wanting to keep it going.

\section{Size}

The project involves approximately 60 people who spend about $80 \%$ of their time focussed on it in a full time capacity, even though this number may increase at various times of the project. The project manager coordinates the project in a series of smaller groups, which are distinguished by the two primary outputs - publication and financial input.

The Publication output includes four separate groups ranging from $4-25$ people comprising:

- Four key Directors - meet on a frequent basis;

- Six key Directors - meet on a less frequent basis;

- 12 Assistance Directors - meet regularly;

- 25 Chapters coordinators - meet regularly.

The Financial output includes five separate groups ranging in size from 4 - 50 people comprising:

- Ten analysts;

- Four database systems analysts;

- Six communications officers;

- Ten economics analysts;

- Up to 50 budget analysts who also undertake much of the relationship management out to the other Departments and Agencies.

Of interest in describing this scenario is the extent to which the process is centralised, in contrast with the extent to which the different parts of the document drafting is dispersed and distributed across State Government. To counter this, the use of the OCT is mandated in order to be the central source of information for project team members (OrgD PM1). 


\section{Process}

The Department has its own Project Management Methodology (PMM) that is based on the Prince 2 methodology. The PMM has been simplified from the Prince 2 methodology, as the Department considered the Prince2 methodology overwhelming for the majority of

prospective users within the department. As the PMM was developed to be a streamlined and simplified methodology, not all components of Prince2 methodology are present. Most noticeable is the way in which the PMM combines the Prince2 processes of Controlling a stage, Managing Product Delivery and Managing the Stage Boundary, into a single Project Implementation section.

Appendix A16 provides a comparative overview of the Prince2 and Departmental Project Management Methodology.

The project uses product descriptions (later called Chapter descriptions) to detail the contents of each chapter. This methodology serves two purposes - the first is to outline the components that are to be included in the documents, and the second in assisting with knowledge management for new starters. The use of the product structures in documentation also assists to describe the project process. The use of the PMM is mandated across the Department, including this project, and as noted previously, so is the use of the OCT.

\section{A10. Case Two Organisation V}

\section{Organisation Details}

'The CIN takes a common sense approach to the use of the CIN and the blog.' (OrgV PM1)

Organisation V is managed from within a government department; however, it is not owned or controlled by that department. The coordinator is an employee of the department sponsoring the organisation. The organisation is managed through a committee that comprises representatives from each department and as such is considered to be an interorganisational project type. This committee is a formal decision-making committee, and reports to the Departmental Secretary, who subsequently reports to one of the most high-level councils within government, the State Coordination and Management Council (SC\&MC). This ensures the project has sufficient executive endorsement, but also greatly increases the political stakes of the network. The coordinator is the convenor of the committee and is the primary conduit to the membership. 
Organisation V uses contractors and consultants widely and whenever possible due to the limited human resources of the CIN. Contractors are used for subject matter expert workshops and any form of consulting required to deliver a specific service or program to the CIN. The organisation's raison d'être is to share information across its membership, and it does this through the blog, which it has found to be very effective (OrgV PM). The medium is also used to disseminate a bi-monthly electronic newsletter. The organisation does not use a formal methodology to undertake its project work, but rather adopts a 'common sense approach' to the use of the blog and the network (OrgV PM). The coordinator's skill set and competencies - knowledge management and public relations - drives the use of the blog and of the CIN, with the two key pillars of the CIN being knowledge sharing and collaboration (OrgV PM).

The project poses a medium level of risk in several areas. The first area of risk is that the organisation may fail and the project is discontinued, resulting in a lack of strategic continuous improvement initiatives across the government environment. The second area of risk is that it succeeds, and people may start to think differently with the working environment - this can lead to some tension in the funding model if it can be shown that behaviours are changing to the dissatisfaction of the financially supporting departments. The third area of risk is that the media report some of the programs in an unsympathetic light, or with an anti$\mathrm{CI}$ bias (OrgV PM). The final risk highlights the quasi-political nature of the project and notes factors that may influence how its progress is perceived by the stakeholders.

\section{Management}

'The committee is a bit dysfunctional and difficult to work with at the moment.' (OrgV PMI)

The Chair of the organisation has control over much of what happens to the CIN, with the operational committee, formed as part of the governance mechanism, being described as 'verging on dysfunctional' (OrgV PM). Given this and the nature of the organisation's objectives, the coordinator has a fair degree of autonomy with his tasks and direction (OrgV PM). Consequently, the project management structure of the project has the features of a weak matrix organisation and is represented in Figure 11-2 below, with the project manager and membership highlighted. 


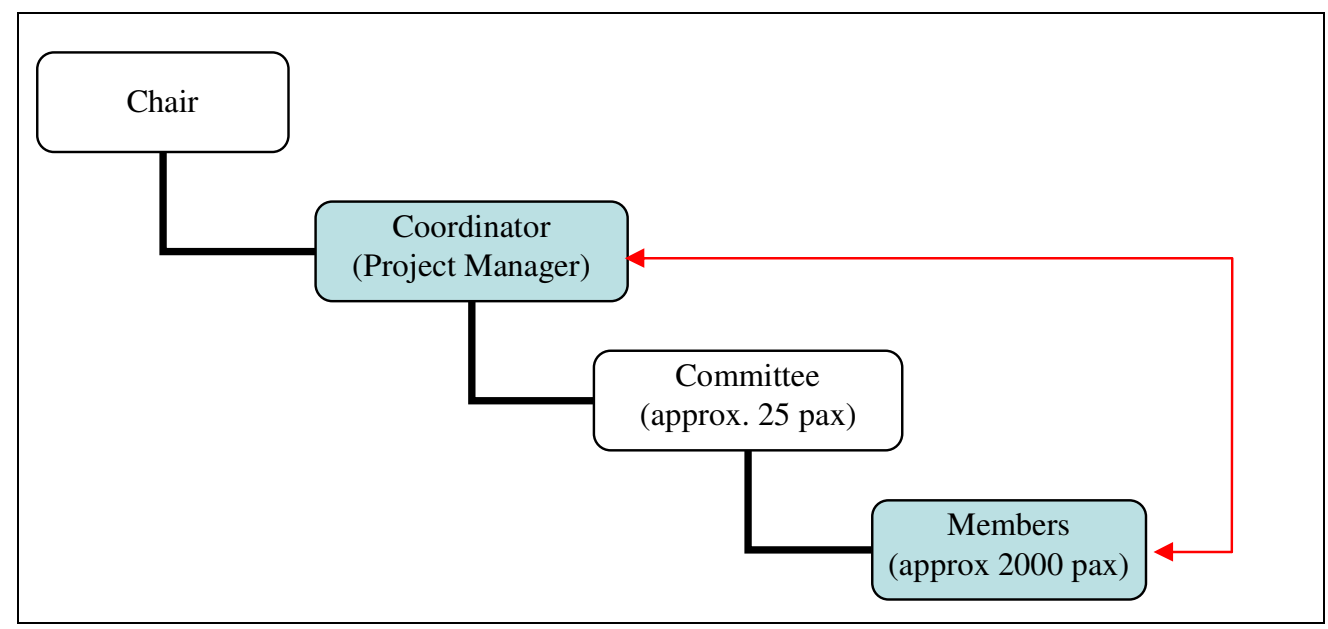

Figure 11-2: Organisation structure

The responsibilities of the coordinator include being the primary liaison point for the membership and the CIN, running events, workshops and seminars and/or to coordinate the facilitation of these events. The coordinator has a strong professional network and draws on this regularly to manage the current and proposed suite of activities and sub-projects (OrgV $\mathrm{PM})$. The coordinator manages all the information distribution from the CIN out to members and liaises with other departments where required, using the blog as the primary vehicle.

The members of the CIN have expressed a view that it wishes the organisation to remain independent of any one government department, to ensure that the network takes a whole-ofgovernment approach to issues and matters relating to continuous improvement (OrgV PM). This causes repercussions in that departments do not acknowledge the CIN from their own websites, nor is it acknowledged through the whole-of-government portal (OrgV PM), further reinforcing the role of the blog as the main information dissemination mechanism.

There are varying degrees of sub-projects within the CIN, often referred to as pilot projects (OrgV PM). These projects can often be tailored specifically for one business unit or a government department, with the coordinator being able to refine the particulars depending on the requested requirements (OrgV PM). His role on these pilot projects will also be determined based on other competing pressures and the availability of in-kind assistance of specific funding from the business.

The primary stakeholders of the project are the State Coordination and Management Council (SC\&MC) of the government, given that it will be their determination if the project continues into the future (OrgV PM). This group also functions to authorise the activity and operating environment of the organisation, whilst the committee provides an opportunity for ongoing 
development of the CIN. In response to seeming dysfunctionality of the committee, the coordinator has embarked on engaging the committee with the development of a strategic plan, as a mechanism to engender sharing and group/collaborative efforts (OrgV PM).

\section{Environment}

'The CIN culture is like a gas.' (OrgV PM1)

'The CIN culture is like a gas' (OrgV PM), in that it is difficult for the coordinator to discuss in concrete terms (OrgV PM). The coordinator believes the culture to be progressive and forward thinking. It is his opinion that members are passionate about and determined to change the government-working environment; as such they are a positive force, which is in contrast to what the coordinator sees as an otherwise general lack of focus towards continuous improvement initiatives within government (OrgV PM).

The CIN however is not collaborative, nor is significantly established to have a collaborative history, even though it has collaboration as one of its strategic pillars. The sub-groups normally work in silos, primarily because people have a tendency to work within their own organisation. This is borne out by the situation that when continuous improvement activities do occur within individual departments, these will take precedence and priority over CIN activities (OrgV PM).

\section{Size}

The total number of members in the CIN is 2000 at time of interview, with this number steadily increasing. There are at any one time approximately seven to eight project teams operating, with each having times frames and particulars peculiar to their individual requirements (OrgV PM). There are only a couple of contractors working on sub-projects at any one time, with each sub-project normally based within the specific department of metropolitan centres.

\section{Process}

'The blog was used because ... it did not require strong technical expertise to operate.' (OrgV PM1)

Organisation $\mathrm{V}$ does not have a mandated process in place to manage the membership, opting instead to treat the blog as its main corporate communication mechanism. The blog is developed from WordPress open source software, is externally hosted, and has been 
customised for the organisation. The blog approach is used to manage as much of the process requirements for the organisation as possible. The blog was selected because it was considered easy to use and had extended functional features, it did not require a strong technical expert role, and this was important as the coordinator does not possess sophisticated technical knowledge.

The blog is used to deal with the immediacy of the subjects and issues discussed within the CIN. It was also selected by the coordinator as the most effective and technically simplistic mechanism for the membership to be able to publish and distribute comments amongst themselves through the website. The technical constraints applied by the host organisation also prohibited the installation of internet sharing technology inside its firewall; a restriction that further supported the decision to use an externally hosted blog application. The moderator role was instigated to protect potentially difficult, 'inflammatory or libellous material from bring published over the blog' (OrgV PM).

The blog encourages all members to contribute, and after these comments have passed through the moderator, they are publically available over the blog ( OrgV PM). It is noteworthy that the blog does not reside inside a protected internet space, for example an intranet or virtual private network, but rather in the public internet domain. This results in all discussions and published material being accessible and potentially viewed by anyone with internet access, regardless of membership status.

\section{A11. Case Three Organisation M}

\section{Organisation Details}

'The methodology is used, however there is not a strict adherence to it ... (it is) more about documentation than about methodology.' (OrgM PM1)

Organisation $\mathrm{M}$ is a unit within a State Government department, and in this position, manages the project on behalf of the clients - as such, it performs a coordination function within the project, with the project manager seeing the organisation's main role as the facilitator of the contract and its outcomes (OrgM PM1). It is a Design \& Construct contract with a guaranteed maximum price. The project commenced with the appointment of the architects, who came on board first and defined the product. The construction company provided a response to this documentation in the form of a Request for Tender (RFT). This approach is used by government as a method to facilitate a higher degree of knowledge about the end product 
(facility) and the efforts and costs associated with it. The government has "an open and transparent relationship" (OrgM PM1) with the construction firm.

There are many sub-contractors on the project, and depending on their area of (technical) expertise will be coordinated by the State Government, the architectural firm, or the construction firm. The architectural firm coordinated the sub-contractors prior to the construction firm being appointed. Organisation $\mathrm{M}$ has a project management framework, however 'there is not a strict adherence to it... as it is more about documentation than it is about methodology' (OrgM PM1). An outline of the Project Management Framework is in Appendix A17.

At the request of the architectural firm who had previous experience with the tool, the project uses ACONEX (the OCT) to share information. Given this preference by the architectural firm, Organisation $\mathrm{M}$ has mandated that all communications from the team (including Organisation M, architectural firm, construction firm and subcontractors where appropriate) go through ACONEX, with the exception of the Project Control Group, who are expressly excluded from the OCT. Communications and associated management for this group is through email and is undertaken solely by Organisation M. Given the expert nature of the many of the subcontractors, the project manager noted that many consultants take a silo approach to information sharing, in that they do not review anything outside of their area (OrgM PM1).

\section{Management}

The management environment of the project is hierarchical, which is consistent with many government project environments. The internal project governance structure follows a simple chain of command framework, as expressed in Figure 11-3 below.

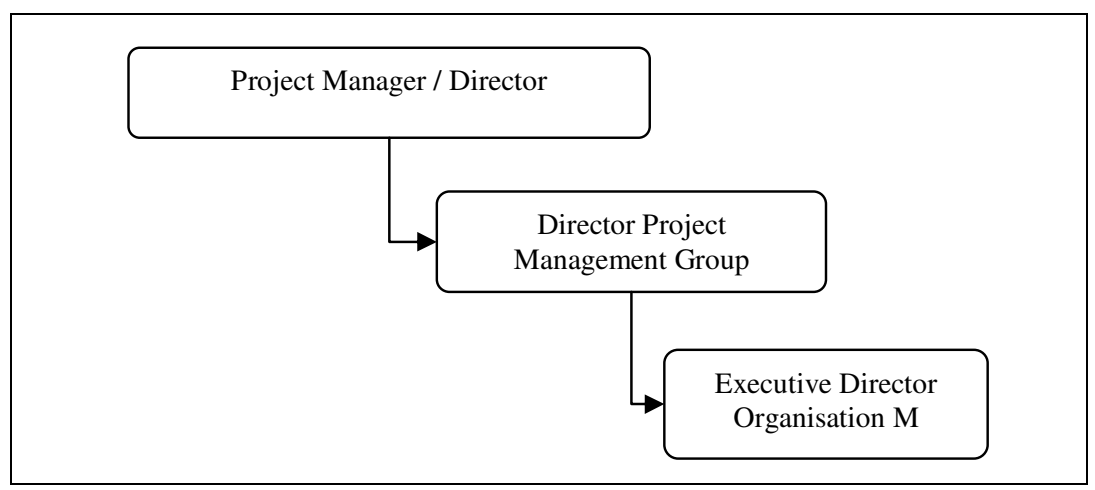

Figure 11-3: Organisation $M$ internal project governance structure 
The project manager manages the day-to-day operations of the project (as it relates to the government role), as well as managing the stakeholder relationships across the project landscape to ensure that the relevant networks within government are aware of the status of the project and its associated milestones. There are about 20 sub-project teams, set up primarily in disciplines. The project management structure has the features of a balanced matrix organisation, with the high level relationships represented in Figure 11-4 over page.

The primary stakeholders on the project include the following:

Client 1: $\quad$ The project is funded by, and developed for, the government client (Client 1). The State has assigned the capital expenditure within their portfolio.

Organisation M: $\quad$ The Governor in Council appoints this government department (Organisation $\mathrm{M}$ ) as the Agency responsible to procure and project manage the delivery of the Project. The nomination of this project under the Project Development and Construction Management Act (PDCM Act) specifies the Minister for Major Projects (Minister B) as the Minister responsible for the Project.

Company 1 Board: $\quad$ Appointed by the Minister of the client organisation (Minister A) to represent the future user and operator of the facility.

Client 2: $\quad$ Client 2 is party to the Funding and Development Deed which transfers ownership of the land to the State. The title for the footprint of the facility will be transferred back to the Client 2 upon Commercial Acceptance.

Company 2 Board: $\quad$ Appointed by the Client 2 to represent the future user and operator of the facility (OrgM PM1).

The broader stakeholder list includes:

- The Secretary of the Department of Premier and Cabinet;

- Industry reference groups;

- Artistic advisers;

- Technical advisers;

- Government departments and their respective ministers;

- Federal Minister for Education;
- Design consultants;

- Planning authorities;

- Statutory authorities;

- Location Neighbours (i.e. those organisations that share boundaries of vicinity with the development);

- Head contractor; and

- General public (OrgM PM1). 


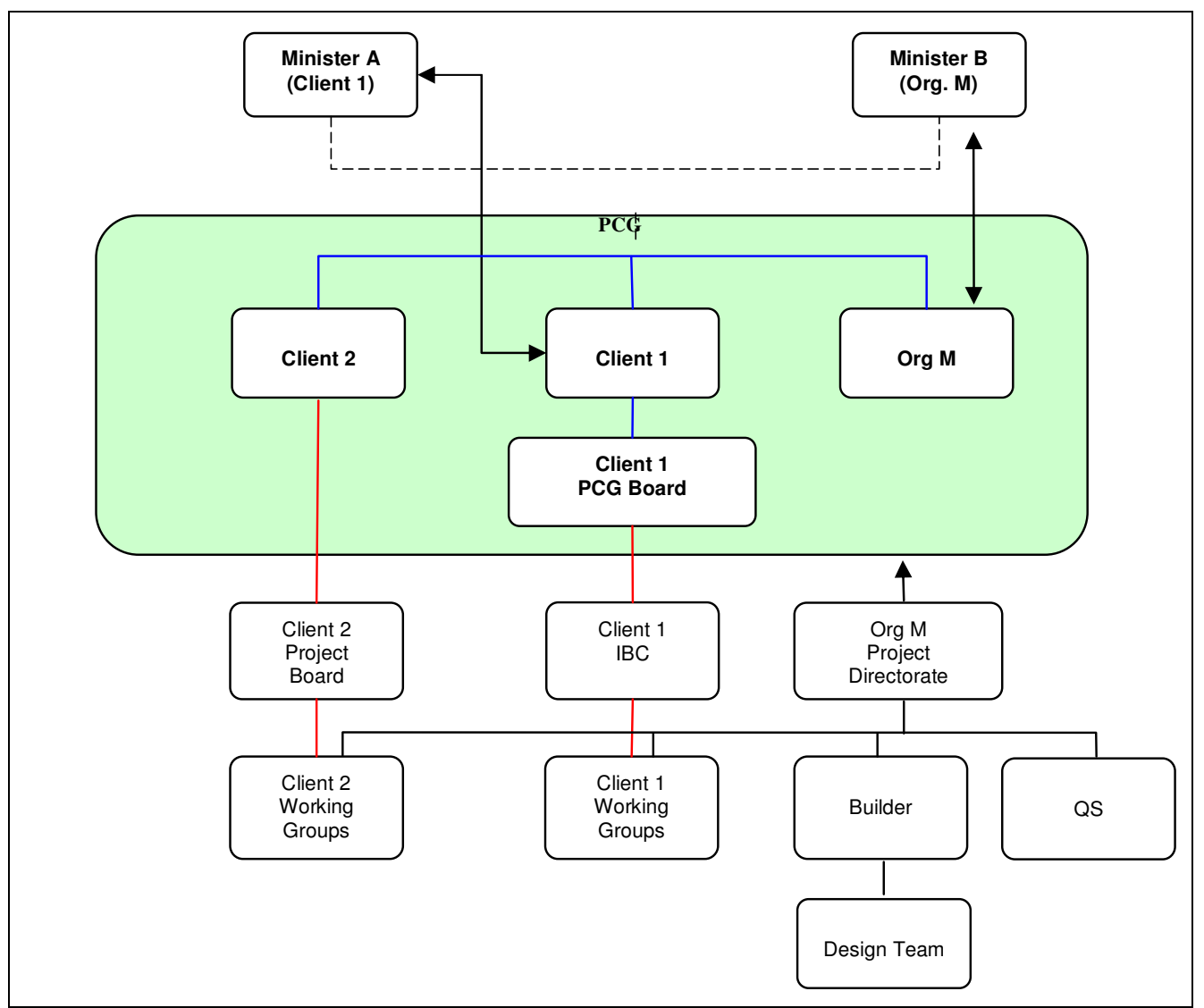

Figure 11-4: Organisation M project governance structure

\section{Environment}

'The culture is starting to share but it is dependent on the project and personnel.' (OrgM PM1)

In Organisation $\mathrm{M}$, there are two distinct functional elements. The first element comprises the corporate whilst the second element includes the operational or project-based. The corporate elements relate to the bureaucratic or business of government (including the management of stakeholders) whilst the second element relates to the project specific details of construction and delivery of the outcomes. Each project undertaken by the organisation is separate to others undertaken, with no overlap or corporate sharing of information; however, there is a project based library being developed. The culture of the organisation is one that is starting to share, but the degree to which this occurs is dependent on the project and the personnel involved. The organisation is managed from the top down and this has resulted in some improvements in the flow of information (OrgM PM1). The organisation is not considered collaborative, even though it has a history of collaboration, but it does not have a strategy to support or encourage collaboration, whilst staff and business units operate on a silo basis (OrgM PM1), that is, one where there is minimal sharing of information or expertise across the different disciplines or business units. 


\section{Size}

There are about 427 people working on the project, comprising about 15 teams in all - these teams including Organisation M, involve:

- Architects;

- Engineers;

- Acoustians - drawn from three different companies spread across local, state and international cities;

- Theatre planners;
- Services consultants;

- Client Organisations;

- Traffic consultants;

- Surveyors; and

- Variety of expert subcontractors including wind and landscape.

These project teams are primarily based in the metropolitan district, but a few live in other states and one or two are in the United Kingdom. The majority of these teams use ACONEX, which facilitates all management related information and ensures this material is centrally located and accessible by all those that require it.

\section{Process}

There are no mandated process within Organisation M, except for the use of ACONEX on this specific project. The organisation uses its Project Management Framework to guide the development and management of project-related documentation, which also covers some process components. This document, in conjunction with the Project Plan and Procurement Strategy, provide a level of structure for Organisation M to coordinate the project management environment. These documents follow a familiar outline as detailed by the PMBOK. An outline of these two documents in the form of a table of contents was provided by Organisation M and can be found in Appendices A17 and A18 respectively. A communication strategy is also developed by Organisation $M$ to guide the flow of information between stakeholders, especially through the Ministerial networks. A copy of this was not provided. 


\section{A12. Case Four Organisation C}

\section{Organisation Details}

Organisation $\mathrm{C}$ undertakes the management organisation component for the project. In this instance, Organisation $\mathrm{C}$ is both client and owner, and has two main project managers - one for construction and one for materials. There is also an external project manager who reports to the client/owner organisation. There are site meetings every week.

The project governance includes the establishment of a project team (which may include a representative from the Board), that has oversight for the project. A steering committee, which also reports to the Executive team, is also established to undertake the functional aspects of the project. This is the standard governance structure in use across Organisation C.

Organisation $\mathrm{C}$ does not mandate a standard project management methodology for its construction projects, but rather in its place, requires that specific checks and balances are followed to ensure essential requirements are being met. This work is undertaken by an outsourced architectural firm fulfilling the role of Head Consultant, and is contracted to provide guidance on processes and procedures for the construction components of the project (OrgC PM2), and to coordinate and manage the consultation processes (OrgC PM1). As this was a large project with government stakeholders, the project also required approval from the State Government before it could proceed.

\section{Management}

The management environment within Organisation $\mathrm{C}$ is congenial which flows through to the operational aspects of the project. The Project Manager's responsibilities include the administration of both construction projects, supporting the Project Director, administering the OCT utilised for the project, and setting up procedures, as well as managing smaller projects (OrgC PM1).

Consequently, the project management structure of the project has the features of a balanced matrix organisation and is represented as follows (Figure 11-5, Figure 11-6). 


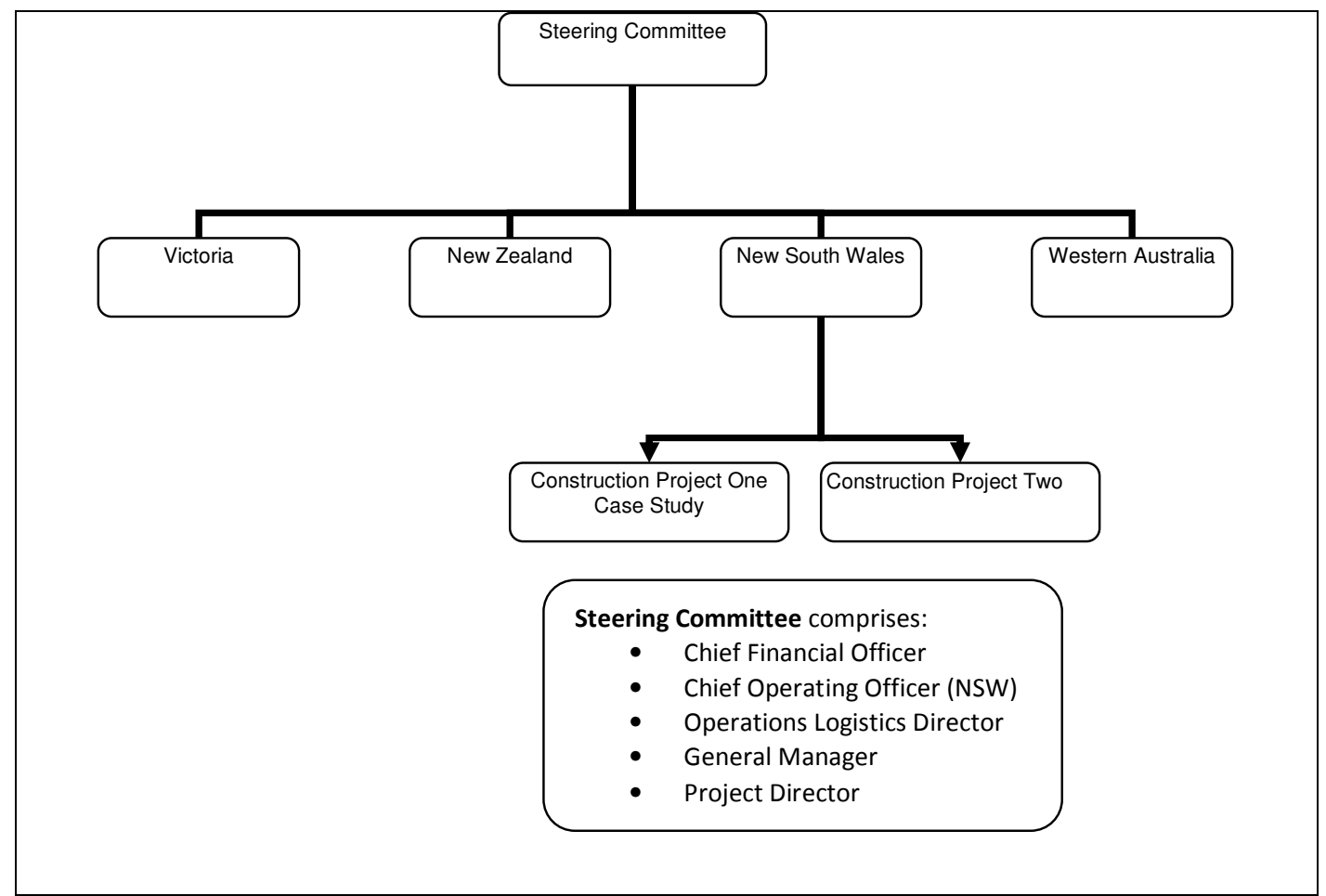

Figure 11-5: Organisation C governance structure

The Project Team (comprises the following people)

- Finance Manager

- Building Works Project Manager - - - - - - - - - - - - -

- Materials Handling Equipment Manager - Project One (NM)

- Materials Handling Equipment Manager - Project Two (EC)

- Information Services

- Project Coordinator

Building Works Project Manager

(has the following people reporting to him)

- Building Superintendent

- Project Engineers (

- Government Liaison staff

- Contractor

- Design Consultants

- MNIA

Figure 11-6: Organisation C Project management structure 


\section{Environment}

Organisation $\mathrm{C}$ is considered a sharing organisation (OrgC PM1), but it does not have a history of successfully deploying collaborative strategies. The use of the OCT in the project was the first time it has been deployed within the organisation, and to date the Project Director has been 'quite comfortable with the tool' (OrgC PM1). The organisation has an added advantage in that it can draw from the intelligence and capabilities of its international business if and when required.

\section{Size}

The project is the largest warehouse infrastructure project for the organisation in Australia. The project has about 65 consultants working within 10 teams, across three Australian states (Western Australia, NSW and Victoria) with approximately 100 people on the project in total. The majority of the team members are based in Sydney. Eight of the ten teams use the OCT, and the OCT is used effectively to distribute information across these groups (OrgC PM1).

\section{Process}

Organisation $\mathrm{C}$ has mandated processes to manage the project management environment. These processes are not project management methodologies, but more contract driven activities set in place in order to dictate procedures (OrgC PM1). The legal and occupational health and safety business groups within the organisation prevail (Org PM1), which ensures that the project has approval milestones at key points of its operations (OrgC PM1) and an appropriate and safe work environment.

There is a strong governance regime within Organisation $\mathrm{C}$, which is used as the primary mechanism through which project activity is reported. The Project Manager reports to the Project Steering committee on the project status including financials. The Project Director and the Finance Manager both report to the Chief Financial Officer on a monthly basis, which pre-empts the Steering Committee Meeting. 


\section{A13. Case Five Organisation S}

\section{Organisation Details}

'... so there are pockets within the organisation that are basically keeping secrets from everyone else.' (OrgS PM1)

Organisation $\mathrm{S}$ is an independent state government authority and as such is responsible for managing the entire project. The Executive appointed a Communications Reference Group responsibility for the project. The Reference group is chaired by a member of the Executive team who reports to the Executive team on a regular basis. The Reference group structure includes a Project Director, a Project Manger and various business representatives who bring subject matter expertise to the project. The design and construction of the website is outsourced to consultants, who report through the Project Manager to the Reference group. The Authority's third party Information Technology Service Group hosts the end product (OrgS PM1).

Due to the relatively small staff size of Organisation S, it outsources many non-core related functions, including this project. In this instance, Organisation $\mathrm{S}$ uses expert consultants outsourced from a panel of Government suppliers, to develop individual components of the project including:

- the initial review of the website and the associated business case;

- development of the new design and associated functionality; and

- building/developing the site.

The Project Manager was also sourced from outside the Organisation to provide expert capabilities to the project. The organisation did not have a preferred project management methodology, however opted to use a simplistic version of the Prince 2 methodology at the suggestion of the Project Manager (OrgS PM1).

The organisation is relatively young in its formation, having been set up eight months prior to the review commencing. Given this, many business groups were newly formed and the organisation 'hadn't gelled yet' (OrgS PM1), but it was the wish of the Executive team that the project develop strong corporate knowledge banks (OrgS PM1). The complexity of the project however came from the status of much of the work of the organisation, which was often Cabinet-in-Confidence and therefore could not be widely shared across the organisation (OrgS PM1). This has led to the creation of pockets within the organisation that are 
"basically keeping secrets from everyone else" (OrgS PM1). The organisation has a shared drive structure on its I.T. network, however as the organisation is an amalgam of pre-existing government departments, the electronic drives are only accessible to those staff in each unit. This 'locking down' of drives is also a requirement for those units undertaking confidential reviews, where material cannot be widely distributed even to other parts of the organisation (OrgS PM1). There is a common drive for all staff that is used for generic information and procedures.

\section{Management}

The management environment of Organisation $\mathrm{S}$ follows a standard government hierarchy, with a CEO and an Executive team, each responsible for their individual work units. The project Reference group was designed to have representatives from each business unit, as it was hoped that this would streamline communication across the organisation, whilst also creating an inclusive and contributing project environment.

Consequently, the project management structure of the project has the features of a balanced matrix organisation and is represented in Figure 11-7, with shaded areas representing project team members. A representation of the project structure is also included at Figure 11-8.

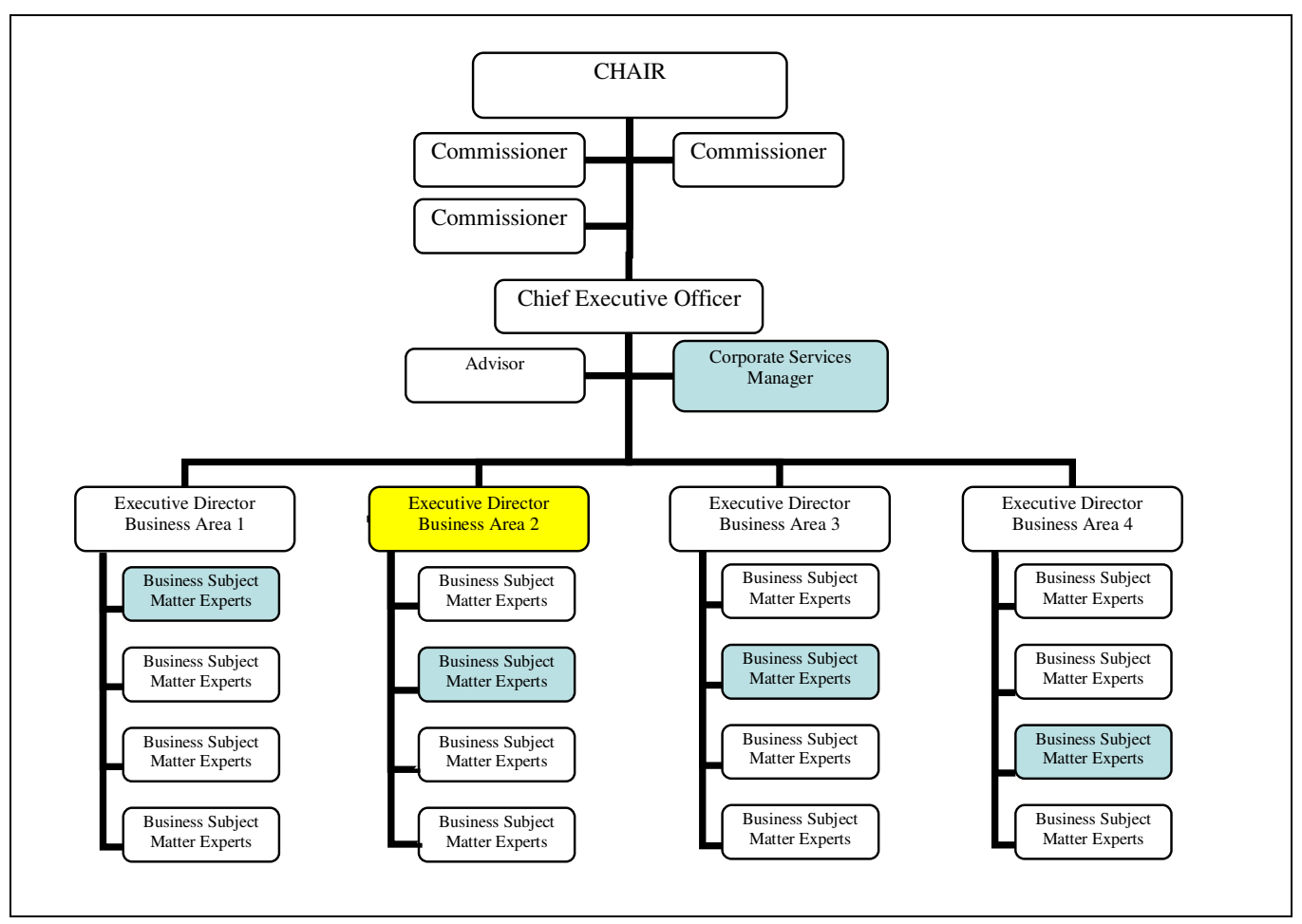

Figure 11-7: Organisation S management structure 
The Project Manager is responsible for managing and coordinating all aspects of the project, including ensuring that all appropriate documentation is available for viewing and that the Executive team are informed as required. As there is an Executive Director chairing the committee, the Project Manager is excused from briefing the Executive team directly, a function that is undertaken by the Chair.

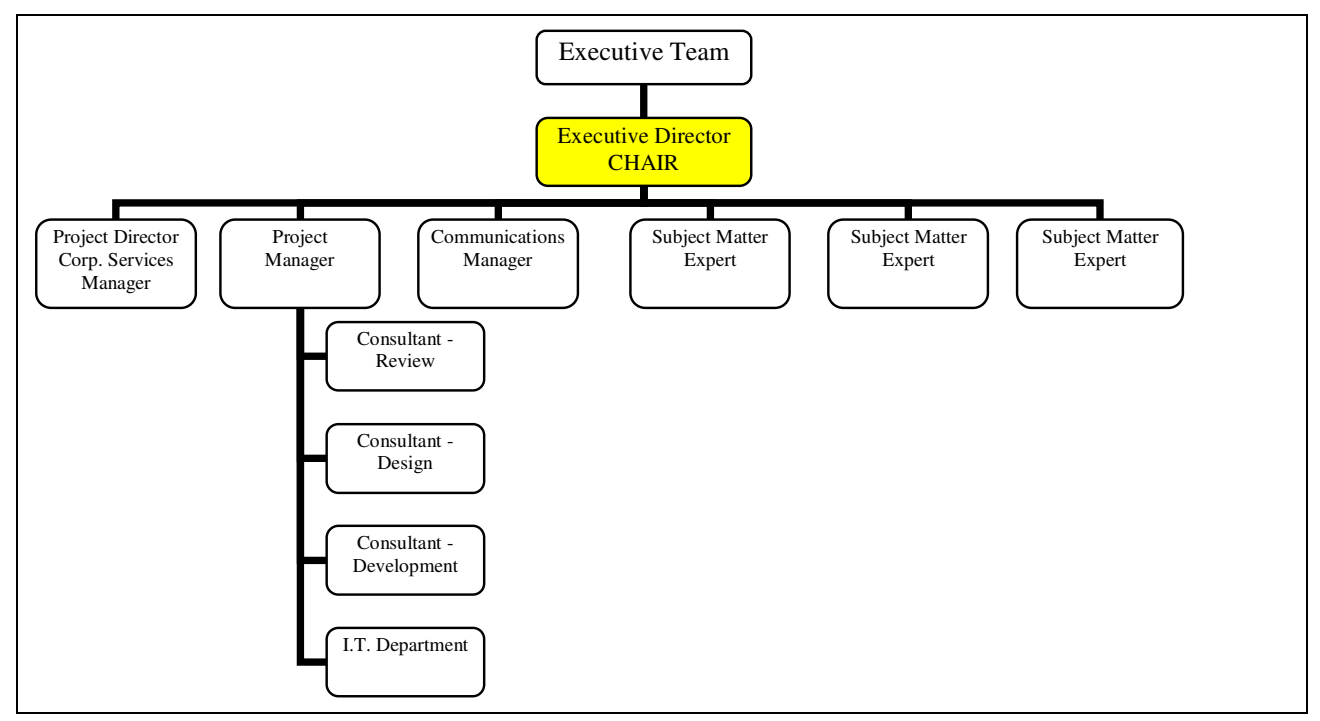

Figure 11-8: Organisation $S$ project Reference group structure

The stakeholders of the project include the Executive team and users of the website. The former group provide governance and quality assurance where required and are managed through both formal and informal briefing procedures as directed by the Executive Director acting as Chair.

\section{Environment}

'I wouldn't say it is collaborative, but it does coordinate a lot of work....' (OrgS PM1)

Organisation $S$ is still relatively young and so has not yet developed a culture shared by all its staff (OrgS PM1). As it is an amalgam of two separate organisations plus a business unit of a central government department, it is attempting to clarify its role and create a unified corporate bond amongst its staff (OrgS PM1). Given this setting, the organisation is "not collaborative, but does coordinate a lot of work in its reviews, and sometimes this involves calling on different people across the organisation to be seconded onto projects" (OrgS PM1). The organisation generally operates vertically across the silos of its functional areas with little impetus to share information or staff resources (OrgS PM1). 


\section{Size}

On the project Reference group, there are six core staff, with this number growing depending on the amount of consultation required (OrgS PM1). There are three main sub-project streams occurring throughout the project lifecycle, all of which report to the Reference group. As previously noted, there are outsourced contractors/consultants brought in for each of the different sub-projects. All these contractors are locally sourced and are subsequently managed by the Project Manager, who feeds through issues and reports to the Reference group. There are no processes in place to manage the spread of teams or members, but the simplified Prince 2 methodology is closely followed, and the OCT is used wherever possible to communicate issues and core project information to the Reference group and consultants.

\section{Process}

'It is the job of the Project Manager to ensure that all members are appropriately informed on project related information'. (OrgS PM1)

Organisation $\mathrm{S}$ has formal governance processes in place to manage the project management environment. These processes are not formal project management methodologies, but more a series of prompts and procedures informed by 'a couple of methodologies' including the Prince 2 methodology and has been designed to ensure that appropriate authority, resources and commitments are provided to the project (OrgS PM1). As a Government Authority, Organisation S must ensure appropriated decision trails and audit requirements have been satisfied, and that it can be shown to be a leader to other government departments and authorities in this area (OrgS PM1).

Given this, the Project Manager is responsible for ensuring all governance documentation is current and closely followed. Appendix A18 outlines the process to be undertaken for all I.T. projects within Organisation $\mathrm{S}$ and details a suite of eight mandatory processes and associated templates. These processes follow a generic I.T. project lifecycle process, with key milestones identified for documentation completion and business approval.

The role of the OCT is to provide an electronic distributed central file repository for all appropriate project-related material, with editor access provided to team members, contractors and consultants as required (OrgS PM1). The Project Manager is the administrator of the OCT and has the highest level access to the OCT controls. The use of the tool is not specifically part of the formal governance processes noted above, but rather is an implicit component of the project-related process. 


\section{A14. Case Six Organisation K}

\section{Organisation Details}

'The alliance delivery method was chosen due to the complexity of the project.' (OrgK PM1)

The client of the project is the state owned corporation responsible for delivering public transport construction projects with an emphasis on commuter rail. The client oversees the process of planning, design, regulatory approval, construction, environmental management and community liaison for its projects that are designed and constructed by private sector companies. The organisation managing the construction is a composite of several project partners, and is an Alliance structure. The project partner list cannot be presented here due to anonymity of participants, but a breakdown of its areas of responsibility or delivery can be detailed (Table 11-6).

Table 11-6: Organisation K project partner table

\begin{tabular}{|l|l|}
\hline Project contributors & Area of responsibility \\
\hline Client corporation & Delivery of infrastructure \\
\hline Partner One & Design - clearways \\
\hline Partner Two & Design \\
\hline Partner Three & Construction \\
\hline Partner Four & Track construction \\
\hline Partner Five & Overhead wiring \\
\hline
\end{tabular}

The Alliance delivery method was chosen due to the complexity of the project. The project is multifaceted with significant community, environmental and engineering issues to be taken into consideration.

'An alliance organisation structure allows the contractors the scope to be able to address these issues as a whole, whilst also having the capacity to be rewarded for innovation and breakthrough performance.' (OrgK PMI).

The Alliance has a set of values and principals that it expects it members to uphold and work towards - it is in essence its cultural pledge for working on the project. These are listed in Appendix A20.

The organisation has introduced eight functional areas to oversee the project. Each area is allocated a dedicated manager and each manager is a member of the Alliance Management Team (AMT). The AMT reports to the Alliance Leadership Team (ALT), which has a 
representative from each partner organisation. An Alliance Manager is the conduit between the AMT and the ALT, however there are also some instances where line managers report to their functional managers as well as participate in the AMT, as is the case for OrgK PM1 (Figure 11-9).

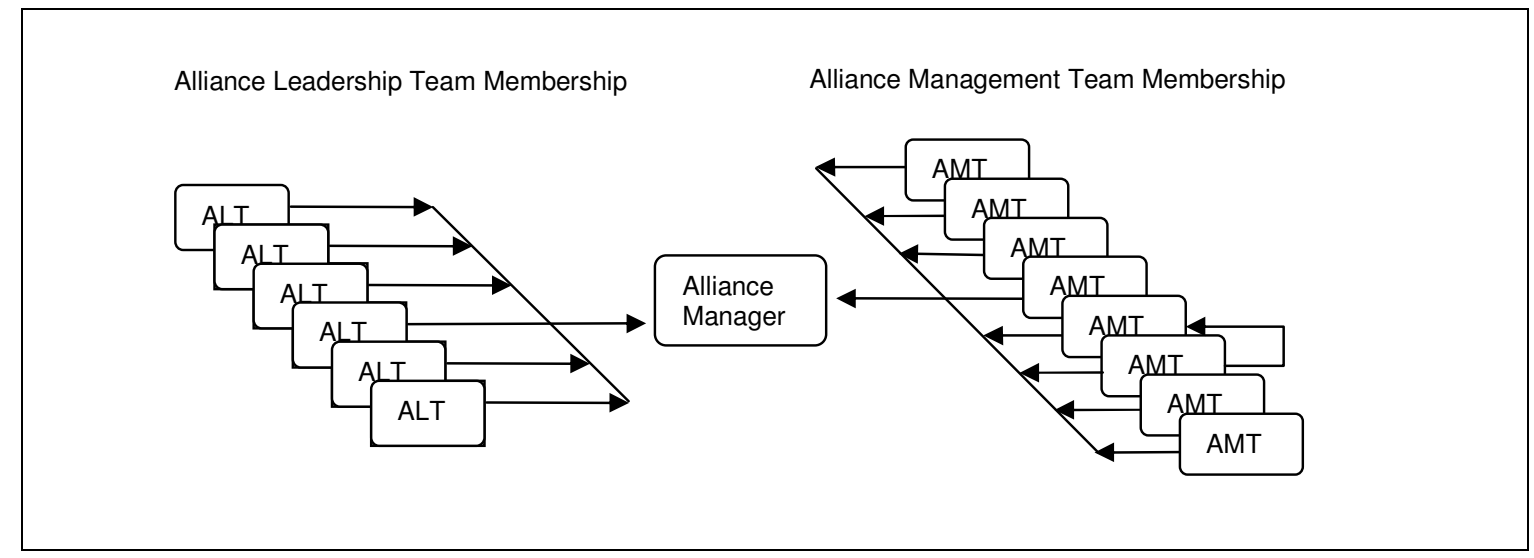

Figure 11-9: Alliance Leadership Team

The Alliance method is closely aligned to the Composite matrix organisation approach in that it is essentially the creation of a special project team to handle a critical or unique project. The team has many characteristics of a project team to be found in a projectised organisation, in that it includes full time staff from different functional departments, develops its own set of operating procedures, and operates outside the standard, formalised reporting structure of a single project organisation. It does this through adherence to the Alliance values and principles and the governance structures demanded through the Alliance Leadership Team (ALT) and the Alliance Management Team (AMT). The distinction in the Alliance structure however, is that the staff are seconded or dedicated to the project environment from the partner organisations, and do not engage in other external project initiatives (OrgK PM1).

The project is itself a composite of contractors, 'so ultimately, everyone is brought in due to their expertise' (OrgK PM1). The project environment is an amalgam of resources and skills based on the Just-In-Time (JIT) methodology. As an exception to this rule, the construction team will be brought in as required and will not have a more formal or permanent place within the organisation structure of the project (OrgK PM1).

The manner in which the organisation shares information is based on an intranet tool owned and managed by the construction partner (Partner Three) - for the sake of this discussion, this tool will be referred to as $\mathrm{P} 3$ eResource. 
The P3 eResource is a product that is used by Partner Three company to provide process and governance information to all of its projects. As a result, Organisation $\mathrm{K}$, as an alliance, uses both the P3 eResource and the dedicated OCT to manage information within the PME. The dedicated OCT in use is INCITE, a product developed by the Australian company Nexus Point Solutions, however the introduction of this tool into the PME is not as straight forward as has been the situation in other cases.

The use of the P3 eResource is however restricted within the Organisation project environment due to the Alliance structure, which subsequently does not follow any one partner organisation methodology over another. As such, the use of the tool is dependent upon the value that the Alliance perceives it to have to the Alliance PME (OrgK PM1). Given this, the Alliance uses the P3 eResource to mine its store of system templates, procedures, plans and governance documentation - documentation that is not available to the Alliance, and which therefore can be used in the project's quality assurance process. As the Alliance does not have such project documentation, it draws from the P3 eResource document repository and re-formats them to fit its own purposes, and then places these into the INCITE OCT product. The documents from the P3 eResource are not accessible from INCITE except when completed and then only as 'read only'. In summary, the Alliance uses INCITE as its repository for its completed project specific documentation and associated record repository, drawing the empty files or templates from P3 eResource. This strategy facilitates the sharing of best-available project documentation across the PME, through a centralised online environment.

The INCITE tool is used to share information across the PME and all team members are trained in its features as well as being encouraged to use the tool for all project-related activity. However the use of this product does not restrict team members from using other electronic products such as MS Office or the P3 eResource. Hiccups with the INCITE system support and the navigation structure of the P3 eResource, in association with the fact that the Alliance was in its infancy, contributed to a lower than anticipated use of the tools and subsequent sharing of information (OrgK PM1). 


\section{Management}

The Alliance Leadership and Management Teams (ALT \& AMT) formalise governance, communication and procedural mechanisms within the PME whilst also assisting with stakeholder relationships (OrgK PM1). Of interest in the project structure is that as an Alliance, the associated hierarchies of the partner organisations do not play a formal role in the structure of the project. The Alliance subsequently sets its own mechanism for management, as expressed through the two governance bodies of the ALT and AMT (OrgK PM1).

OrgK PM1 has a set of key performance indicators and result areas that must be met, including reporting through the AMT to the ALT and associated Steering Committees. OrgK PM1 notes however that the communication and informational processes 'are fairly streamlined' through these two groups (OrgK PM1).

The organisation chart is presented in Figure 11-10, with the eight functional areas and positions that have a role in the AMT highlighted in blue; OrgK PM1 is shown with a red border. From this representation, it is not immediately apparent how the partner organisations are broken down or distributed across the alliance PME, although as the PME draws expertise from the partner organisation (OrgK PM1) it is assumed that these members would be assigned a position in the PME according to their discipline or subject matter expertise.

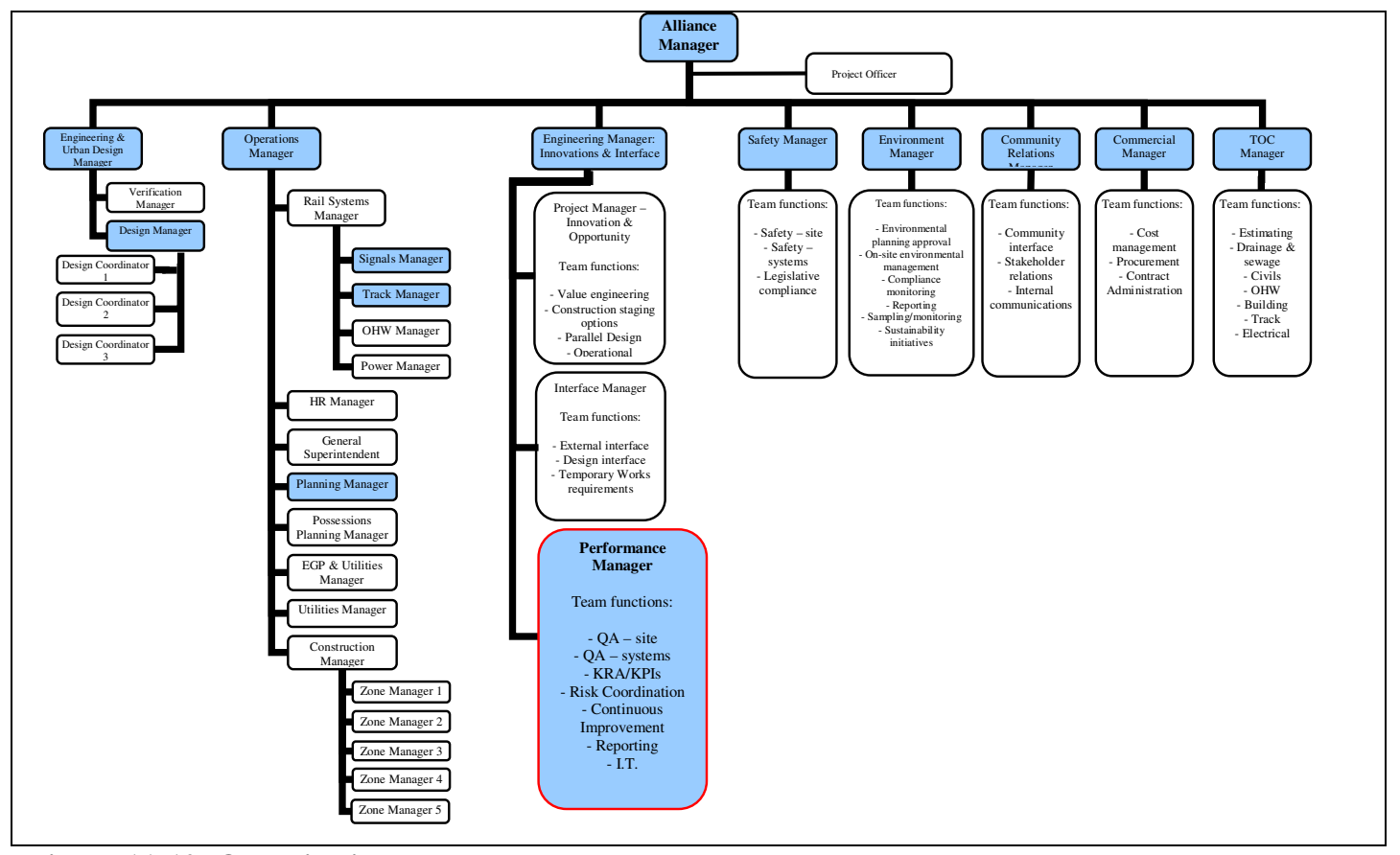

Figure 11-10: Organisation K management structure 
The major stakeholders of the project are included in the Alliance organisation structure. The stakeholders are managed through the interrelationships of the Alliance Leadership Team and the Alliance Management Team, with the exception of the major rail stakeholder. The client organisation has two members on the ALT as well as a project liaison officer who is the single point of contact for the client. Communication between the stakeholders is facilitated through the ALT and AMT structures, and as these groups form part of the formal Alliance organisation structure, partners/stakeholders can be managed on a day-to-day basis without need for any additional processes (OrgK PM1).

\section{Environment}

'The organisation is an amalgam of six different companies with six different cultures.' (OrgK PM1)

The organisation is an amalgam of six different companies with six different cultures (OrgK PM1) and in this sense, the bringing together of these disparate entities into a single operating culture represents the nature of an alliance model. Team members are encouraged to discard their parent/partner company culture and philosophy, and follow the values and principles of the Alliance as defined by the ALT (OrgK PM1). As expressed by OrgK PM1, 'you need to forget about past allegiances and concentrate on the current project - I am an Organisation K person - I go with the project, delivering for the project' (OrgK PM1).

Communication between team members and across Organisation $\mathrm{K}$ is facilitated through colocation. Most team members are placed in the same building as much as is practicable (OrgK PM1). The sharing of information and the culture of the Organisation is guided by the ALT and in this case, supports the use of a single PM tool to achieve this. The use of the INCITE tool was stipulated in the contract and as such is the mandated OCT for the PME. This places the INCITE OCT as the corporate device, but its use is weakened through the application of the P3 eResource. The latter tool is favoured by some members of the ALT, and is used by the OrgK PM1 because as stated previously, it affords him access to considerable procedural documentation and governance material.

\section{'It is more an exchange of email (than collaboration).' (OrgK PM1)}

Most alliance members are in the same building however the organisation does not collaborate well (OrgK PM1). The INCITE tool provides the capabilities to allow work flow and processes to be built into the application so that certain steps are undertaken in a 
coordinated fashion. In the place of collaboration, OrgK PM1 notes that the nature of the Alliance PME is 'definitely cooperative and coordinative' rather than collaborative, especially given its shared understanding of delivering project objectives. As the organisation is relatively new it does not have a history of collaboration, however the use of the alliance 'removes the "them" and "us" mentality of traditional project management dynamics' (OrgK PM1).

The major rail stakeholder declined to be incorporated into the alliance, which OrgK PM1 notes is unfortunate as it is a key stakeholder of the project and controls the maintenance days available to undertake the actual onsite construction. Given this, its inclusion in the AMT would remove the client / organisation dynamic and increase communication around a project that has an exceptional scheduling constraint.

\section{Size}

The project has approximately 150 individuals working on the project over two sites, which will grow to six sites during the busy time of the project. There is one main administrative site or headquarters and the project is structured to have only one core project team; however, there are eight sub-speciality teams operating from this set. The construction component is considered separate to this group brought in when needed over the duration of the project and on key identified maintenance days.

\section{Process}

Organisation $\mathrm{K}$ uses a series of processes and procedures outlined in assorted documentation in the P3 eResource, but as the project is not being driven by Partner Three, the documents are not mandated. However for quality assurance processes, the P3 eResources is followed as it provides a robust procedural and methodological framework on which to manage the project. Of note is that the mandated OCT is not used to assist with key procedural or governance activities.

The P3 eResource has a significant knowledge database that can be tailored to each of its projects. The project management related topics are broken down into three main areas: Overview, Delivering Work, and Supporting Work (Table 11-7, Figure 11-11) 
Table 11-7: P3 eResource Knowledge Areas

\begin{tabular}{|l|l|}
\hline Knowledge Area & Item \\
\hline Overview & \\
\hline & \\
\hline Deliver product & description \\
\hline & objectives and targets \\
\hline & govern project \\
\hline & start project \\
\hline & design \\
\hline & procure \\
\hline & construct \\
\hline & commission and complete \\
\hline & close project \\
\hline & \\
\hline & safety and health \\
\hline & environment \\
\hline & quality \\
\hline & stakeholder and community \\
\hline & industrial relations \\
\hline & risk and opportunity management \\
\hline & human resources \\
\hline & planning and programming \\
\hline & cost management \\
\hline & commercial \\
\hline & document management \\
\hline & administration \\
\hline & crisis management \\
\hline & systems management \\
\hline & \\
\hline &
\end{tabular}

\section{Source P3 eResource interface}

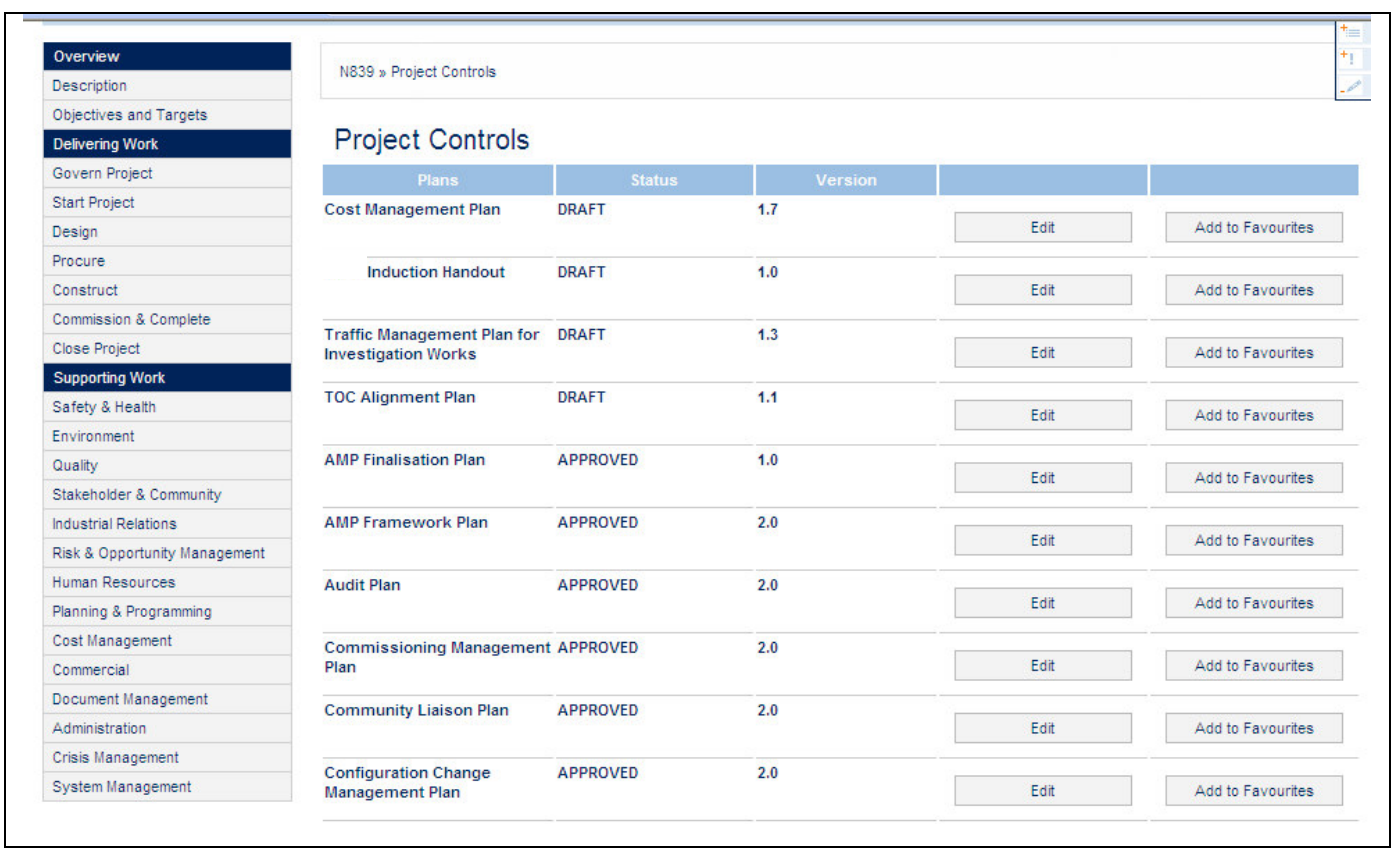

Figure 11-11: P3 eResource knowledge areas - interface 
A15. Cross-case summary of total aggregate sorted against Collaboration scale

Table 11-8: Cross-case summary of total aggregate sorted against Collaboration scale

\begin{tabular}{|c|c|c|c|c|c|c|c|c|c|c|}
\hline $\begin{array}{l}\text { Likert } \\
\text { Section }\end{array}$ & $\begin{array}{l}\text { Qu. } \\
\text { No. }\end{array}$ & Statement & $\begin{array}{l}\text { Cb Scale } \\
\text { CODE }\end{array}$ & $\underset{n=6}{\mathbf{D}}$ & $\underset{n=9}{\mathbf{V}}$ & $\underset{n=12}{\mathbf{M}}$ & $\underset{n=6}{\mathbf{C}}$ & $\underset{n=5}{\mathbf{S}}$ & $\underset{n=6}{\mathbf{K}}$ & $\begin{array}{c}\text { Agg } \\
\text { sorted } \\
n=42\end{array}$ \\
\hline 1.3 & 29 & assists with project planning & 1 & $60 \%$ & $80 \%$ & $68 \%$ & $70 \%$ & $76 \%$ & $80 \%$ & $72 \%$ \\
\hline 1.4 & 43 & increases difficulty in managing resources across the project & 1 & $70 \%$ & $78 \%$ & $60 \%$ & $67 \%$ & $76 \%$ & $70 \%$ & $70 \%$ \\
\hline 1.7 & 73 & complicates managing staff and resources & 1 & $65 \%$ & $76 \%$ & $67 \%$ & $73 \%$ & $64 \%$ & $73 \%$ & $70 \%$ \\
\hline 1.2 & 16 & detracts from organisational planning & 1 & $70 \%$ & $76 \%$ & $68 \%$ & $67 \%$ & $64 \%$ & $63 \%$ & $68 \%$ \\
\hline 1.6 & 60 & decreases the ability to manage and control risk & 1 & $65 \%$ & $78 \%$ & $62 \%$ & $63 \%$ & $72 \%$ & $67 \%$ & $68 \%$ \\
\hline 1.7 & 70 & increases the amount of time it takes to do things & 1 & $60 \%$ & $82 \%$ & $62 \%$ & $60 \%$ & $64 \%$ & $73 \%$ & $67 \%$ \\
\hline 1.6 & 54 & manages time more effectively & 1 & $60 \%$ & $80 \%$ & $62 \%$ & $57 \%$ & $68 \%$ & $73 \%$ & $67 \%$ \\
\hline 1.7 & 69 & creates an online space which the team uses as a project meeting space & 1 & $65 \%$ & $73 \%$ & $58 \%$ & $53 \%$ & $72 \%$ & $67 \%$ & $65 \%$ \\
\hline 1.5 & 49 & assists with monitoring and controlling risk in the project environment & 1 & $65 \%$ & $67 \%$ & $65 \%$ & $57 \%$ & $68 \%$ & $63 \%$ & $64 \%$ \\
\hline 1.5 & 50 & provides greater control of resources planning & 1 & $65 \%$ & $64 \%$ & $58 \%$ & $53 \%$ & $68 \%$ & $57 \%$ & $61 \%$ \\
\hline 1.4 & 36 & increases the effort required to monitor and control risk & 1 & $55 \%$ & $64 \%$ & $60 \%$ & $57 \%$ & $64 \%$ & $63 \%$ & $61 \%$ \\
\hline 2.5 & 115 & knowledge distribution should be managed by the project manager & 1 & $55 \%$ & $60 \%$ & $60 \%$ & $60 \%$ & $64 \%$ & $57 \%$ & $59 \%$ \\
\hline 1.6 & 55 & does not replace the number of meetings required & 1 & $60 \%$ & $64 \%$ & $48 \%$ & $60 \%$ & $52 \%$ & $57 \%$ & $57 \%$ \\
\hline 1.4 & 31 & reduces the number of users accessing files & 1 & $55 \%$ & $51 \%$ & $57 \%$ & $57 \%$ & $60 \%$ & $57 \%$ & $56 \%$ \\
\hline \multirow[t]{2}{*}{1.6} & 61 & replaces the need to meet physically & 1 & $50 \%$ & $33 \%$ & $62 \%$ & $57 \%$ & $40 \%$ & $53 \%$ & $49 \%$ \\
\hline & & Mean value $\mathrm{Cb}$ Scale One & & $61 \%$ & $68 \%$ & $61 \%$ & $61 \%$ & $65 \%$ & $65 \%$ & $64 \%$ \\
\hline 1.1 & 2 & improves planning activities & 2 & $70 \%$ & $84 \%$ & $72 \%$ & $70 \%$ & $76 \%$ & $90 \%$ & $77 \%$ \\
\hline 1.1 & 4 & complicates coordinating activities across the project environment & 2 & $65 \%$ & $84 \%$ & $68 \%$ & $67 \%$ & $76 \%$ & $77 \%$ & $73 \%$ \\
\hline 1.4 & 40 & decreases the quality controls of the document & 2 & $70 \%$ & $69 \%$ & $77 \%$ & $77 \%$ & $68 \%$ & $77 \%$ & $73 \%$ \\
\hline 1.1 & 1 & increases chances of meeting project schedules & 2 & $70 \%$ & $80 \%$ & $68 \%$ & $63 \%$ & $76 \%$ & $77 \%$ & $72 \%$ \\
\hline 1.1 & 3 & improves prioritising tasks & 2 & $70 \%$ & $80 \%$ & $70 \%$ & $70 \%$ & $64 \%$ & $73 \%$ & $71 \%$ \\
\hline 1.1 & 5 & improves delivery of activities in a timely manner & 2 & $70 \%$ & $76 \%$ & $72 \%$ & $67 \%$ & $72 \%$ & $70 \%$ & $71 \%$ \\
\hline 1.7 & 72 & does not improve quality control & 2 & $65 \%$ & $64 \%$ & $70 \%$ & $73 \%$ & $64 \%$ & $77 \%$ & $69 \%$ \\
\hline 1.5 & 53 & assists with the execution of the project plan & 2 & $70 \%$ & $71 \%$ & $70 \%$ & $67 \%$ & $68 \%$ & $67 \%$ & $69 \%$ \\
\hline 1.5 & 48 & contributes to controlling the project schedule & 2 & $65 \%$ & $73 \%$ & $63 \%$ & $67 \%$ & $64 \%$ & $60 \%$ & $65 \%$ \\
\hline 1.7 & 71 & assists with managing scope issues & 2 & $65 \%$ & $78 \%$ & $65 \%$ & $60 \%$ & $56 \%$ & $57 \%$ & $63 \%$ \\
\hline 1.5 & 52 & increases the capacity to manage risk & 2 & $60 \%$ & $67 \%$ & $58 \%$ & $63 \%$ & $72 \%$ & $60 \%$ & $63 \%$ \\
\hline 1.3 & 23 & risks quality control within the project & 2 & $50 \%$ & $64 \%$ & $68 \%$ & $77 \%$ & $64 \%$ & $50 \%$ & $62 \%$ \\
\hline 1.6 & 57 & enables more effective control over schedule and project issues & 2 & $60 \%$ & $62 \%$ & $60 \%$ & $63 \%$ & $64 \%$ & $57 \%$ & $61 \%$ \\
\hline 1.4 & 39 & increases the time and effort required to manage documents & 2 & $70 \%$ & $73 \%$ & $53 \%$ & $53 \%$ & $56 \%$ & $57 \%$ & $60 \%$ \\
\hline \multirow[t]{2}{*}{1.7} & 65 & increases the amount of administration for the project & 2 & $50 \%$ & $69 \%$ & $52 \%$ & $57 \%$ & $56 \%$ & $47 \%$ & $55 \%$ \\
\hline & & Mean value $\mathrm{Cb}$ Scale Two & & $65 \%$ & $73 \%$ & $66 \%$ & $66 \%$ & $66 \%$ & $66 \%$ & $67 \%$ \\
\hline 2.2 & 85 & effective communication benefits project management & 3 & $85 \%$ & $96 \%$ & $92 \%$ & $87 \%$ & $76 \%$ & $97 \%$ & $89 \%$ \\
\hline 2.2 & 89 & managing team members requires communication & 3 & $85 \%$ & $89 \%$ & $90 \%$ & $90 \%$ & $80 \%$ & $97 \%$ & $88 \%$ \\
\hline 2.2 & 90 & communication is not important when using an OCT & 3 & $85 \%$ & $93 \%$ & $78 \%$ & $87 \%$ & $88 \%$ & $83 \%$ & $86 \%$ \\
\hline 2.3 & 101 & communication assists relationship management of project teams & 3 & $85 \%$ & $91 \%$ & $85 \%$ & $80 \%$ & $80 \%$ & $93 \%$ & $86 \%$ \\
\hline 2.2 & 94 & communication is essential in achieving project objectives / deliverables & 3 & $90 \%$ & $89 \%$ & $90 \%$ & $90 \%$ & $76 \%$ & $77 \%$ & $85 \%$ \\
\hline 2.6 & 117 & negotiation requires communication amongst stakeholders & 3 & $80 \%$ & $87 \%$ & $83 \%$ & $80 \%$ & $88 \%$ & $83 \%$ & $84 \%$ \\
\hline 2.2 & 87 & stakeholder management relies on communication & 3 & $85 \%$ & $84 \%$ & $82 \%$ & $80 \%$ & $76 \%$ & $80 \%$ & $81 \%$ \\
\hline 2.4 & 105 & strategic alliances are managed by open communication & 3 & $75 \%$ & $78 \%$ & $78 \%$ & $77 \%$ & $84 \%$ & $83 \%$ & $79 \%$ \\
\hline 1.1 & 7 & communicates the availability of team members and resources & 3 & $80 \%$ & $78 \%$ & $67 \%$ & $67 \%$ & $80 \%$ & $80 \%$ & $75 \%$ \\
\hline 2.2 & 93 & online technology does not assist with communication in the project environment & 3 & $60 \%$ & $80 \%$ & $70 \%$ & $77 \%$ & $84 \%$ & $77 \%$ & $75 \%$ \\
\hline 1.7 & 67 & streamlines communication to the project teams & 3 & $70 \%$ & $76 \%$ & $77 \%$ & $77 \%$ & $72 \%$ & $73 \%$ & $74 \%$ \\
\hline 1.3 & 24 & improves communication regarding essential information & 3 & $60 \%$ & $80 \%$ & $77 \%$ & $70 \%$ & $76 \%$ & $77 \%$ & $73 \%$ \\
\hline
\end{tabular}




\begin{tabular}{|c|c|c|c|c|c|c|c|c|c|c|}
\hline $\begin{array}{l}\text { Likert } \\
\text { Section }\end{array}$ & $\begin{array}{l}\text { Qu. } \\
\text { No. }\end{array}$ & Statement & $\begin{array}{l}\text { Cb Scale } \\
\text { CODE }\end{array}$ & $\underset{n=6}{\mathbf{D}}$ & $\underset{n=9}{\mathbf{V}}$ & $\underset{n=12}{\mathbf{M}}$ & $\underset{n=6}{\mathbf{C}}$ & $\underset{n=5}{\mathbf{S}}$ & $\underset{n=6}{\mathbf{K}}$ & $\begin{array}{c}\text { Agg } \\
\text { sorted } \\
n=42\end{array}$ \\
\hline 1.2 & 19 & hampers communication across the project team & 3 & $65 \%$ & $73 \%$ & $70 \%$ & $73 \%$ & $80 \%$ & $77 \%$ & $73 \%$ \\
\hline 2.2 & 96 & communication across the project environment does not benefit from using OCT & 3 & $65 \%$ & $76 \%$ & $75 \%$ & $70 \%$ & $80 \%$ & $67 \%$ & $72 \%$ \\
\hline 2.2 & 86 & communication is not enhanced by technology & 3 & $60 \%$ & $73 \%$ & $75 \%$ & $77 \%$ & $72 \%$ & $73 \%$ & $72 \%$ \\
\hline 1.4 & 34 & discourages communication across the project team & 3 & $75 \%$ & $76 \%$ & $63 \%$ & $73 \%$ & $60 \%$ & $67 \%$ & $69 \%$ \\
\hline 2.2 & 95 & communication is not clearer when using OCT & 3 & $65 \%$ & $71 \%$ & $62 \%$ & $73 \%$ & $76 \%$ & $60 \%$ & $68 \%$ \\
\hline 1.6 & 58 & enhances communication across the project team & 3 & $65 \%$ & $78 \%$ & $60 \%$ & $60 \%$ & $80 \%$ & $57 \%$ & $67 \%$ \\
\hline 1.5 & 47 & Is ineffective when communicating to the project team & 3 & $60 \%$ & $69 \%$ & $60 \%$ & $63 \%$ & $64 \%$ & $70 \%$ & $64 \%$ \\
\hline 1.5 & 44 & manages the use of email more efficiently & 3 & $60 \%$ & $78 \%$ & $62 \%$ & $57 \%$ & $68 \%$ & $53 \%$ & $63 \%$ \\
\hline \multirow[t]{2}{*}{2.0} & 92 & team members communicate more effectively when using OCT & 3 & $65 \%$ & $69 \%$ & $60 \%$ & $53 \%$ & $56 \%$ & $67 \%$ & $62 \%$ \\
\hline & & Mean value $\mathrm{Cb}$ Scale Three & & $72 \%$ & $80 \%$ & $74 \%$ & $74 \%$ & $76 \%$ & $76 \%$ & $75 \%$ \\
\hline 2.5 & 113 & $\begin{array}{l}\text { knowledge distribution is more than having a central repository of documents in an } \\
\text { OCT }\end{array}$ & 4 & $80 \%$ & $91 \%$ & $82 \%$ & $90 \%$ & $92 \%$ & $80 \%$ & $86 \%$ \\
\hline 2.5 & 108 & the distribution of knowledge regarding the project is important to team members & 4 & $75 \%$ & $87 \%$ & $83 \%$ & $83 \%$ & $92 \%$ & $83 \%$ & $84 \%$ \\
\hline 1.4 & 30 & enables easy access to all documents in the central repository & 4 & $75 \%$ & $89 \%$ & $80 \%$ & $80 \%$ & $92 \%$ & $87 \%$ & $84 \%$ \\
\hline 1.2 & 11 & manages data from a central environment & 4 & $65 \%$ & $76 \%$ & $82 \%$ & $83 \%$ & $92 \%$ & $90 \%$ & $81 \%$ \\
\hline 2.2 & 88 & sharing knowledge can be enhanced using online technology & 4 & $75 \%$ & $84 \%$ & $85 \%$ & $83 \%$ & $76 \%$ & $83 \%$ & $81 \%$ \\
\hline 1.2 & 15 & centralises reporting of data & 4 & $75 \%$ & $78 \%$ & $82 \%$ & $80 \%$ & $84 \%$ & $77 \%$ & $79 \%$ \\
\hline 2.3 & 98 & knowledge distribution is not important for team members & 4 & $70 \%$ & $87 \%$ & $72 \%$ & $83 \%$ & $76 \%$ & $87 \%$ & $79 \%$ \\
\hline 2.4 & 103 & knowledge sharing is a critical component of managing alliances & 4 & $75 \%$ & $87 \%$ & $78 \%$ & $80 \%$ & $72 \%$ & $80 \%$ & $79 \%$ \\
\hline 1.7 & 64 & ensures all documents are easily found & 4 & $70 \%$ & $67 \%$ & $78 \%$ & $83 \%$ & $88 \%$ & $83 \%$ & $78 \%$ \\
\hline 2.5 & 109 & OCT encourage sharing information amongst team members & 4 & $75 \%$ & $80 \%$ & $78 \%$ & $77 \%$ & $76 \%$ & $80 \%$ & $78 \%$ \\
\hline 1.4 & 33 & increases ease of retrieving documents & 4 & $75 \%$ & $82 \%$ & $78 \%$ & $73 \%$ & $80 \%$ & $77 \%$ & $78 \%$ \\
\hline 2.2 & 91 & OCT improve information sharing & 4 & $65 \%$ & $84 \%$ & $78 \%$ & $77 \%$ & $80 \%$ & $80 \%$ & $77 \%$ \\
\hline 1.3 & 21 & increases efficiencies in distribution of documents & 4 & $60 \%$ & $84 \%$ & $77 \%$ & $73 \%$ & $80 \%$ & $80 \%$ & $76 \%$ \\
\hline 1.7 & 66 & ensures all project related information is kept up to date and in one place & 4 & $70 \%$ & $67 \%$ & $85 \%$ & $70 \%$ & $80 \%$ & $80 \%$ & $75 \%$ \\
\hline 2.5 & 111 & knowledge distribution should be on an ad hoc basis & 4 & $70 \%$ & $80 \%$ & $70 \%$ & $70 \%$ & $84 \%$ & $77 \%$ & $75 \%$ \\
\hline 2.5 & 114 & Announcement boards in OCT assist in the distribution of important information & 4 & $75 \%$ & $78 \%$ & $68 \%$ & $70 \%$ & $76 \%$ & $73 \%$ & $73 \%$ \\
\hline 1.3 & 27 & assists in managing change controls in the project & 4 & $65 \%$ & $69 \%$ & $72 \%$ & $73 \%$ & $84 \%$ & $73 \%$ & $73 \%$ \\
\hline 1.3 & 25 & produces inefficiencies in retrieval of information & 4 & $60 \%$ & $73 \%$ & $63 \%$ & $80 \%$ & $80 \%$ & $73 \%$ & $72 \%$ \\
\hline 1.7 & 63 & Is the most effective tool for distributing information to the project team & 4 & $60 \%$ & $67 \%$ & $82 \%$ & $73 \%$ & $72 \%$ & $73 \%$ & $71 \%$ \\
\hline 1.5 & 51 & creates difficulty in distributing information across the project & 4 & $70 \%$ & $82 \%$ & $65 \%$ & $60 \%$ & $68 \%$ & $80 \%$ & $71 \%$ \\
\hline 1.4 & 41 & enhances contract management processes & 4 & $60 \%$ & $71 \%$ & $73 \%$ & $73 \%$ & $68 \%$ & $77 \%$ & $70 \%$ \\
\hline 1.2 & 12 & decreases confidence in the data & 4 & $70 \%$ & $73 \%$ & $73 \%$ & $77 \%$ & $68 \%$ & $60 \%$ & $70 \%$ \\
\hline 1.2 & 13 & increases possibility of data corruption & 4 & $60 \%$ & $62 \%$ & $68 \%$ & $73 \%$ & $76 \%$ & $77 \%$ & $69 \%$ \\
\hline 1.4 & 35 & provides an incentive to share information amongst team members & 4 & $75 \%$ & $71 \%$ & $72 \%$ & $57 \%$ & $68 \%$ & $73 \%$ & $69 \%$ \\
\hline 2.5 & 112 & knowledge should not be distributed from a central location & 4 & $70 \%$ & $69 \%$ & $70 \%$ & $60 \%$ & $68 \%$ & $70 \%$ & $68 \%$ \\
\hline 2.1 & 81 & documents can be shared in the project team without trust & 4 & $70 \%$ & $73 \%$ & $72 \%$ & $60 \%$ & $52 \%$ & $77 \%$ & $67 \%$ \\
\hline 2.3 & 99 & equality is demonstrated by sharing information between team members & 4 & $70 \%$ & $71 \%$ & $72 \%$ & $57 \%$ & $64 \%$ & $70 \%$ & $67 \%$ \\
\hline 1.7 & 68 & increases the amount of paperwork in managing projects & 4 & $55 \%$ & $71 \%$ & $58 \%$ & $77 \%$ & $68 \%$ & $70 \%$ & $67 \%$ \\
\hline 1.2 & 17 & reduces the complexity of maintaining data & 4 & $55 \%$ & $60 \%$ & $62 \%$ & $70 \%$ & $72 \%$ & $80 \%$ & $66 \%$ \\
\hline 1.4 & 38 & increases difficulty in accessing files remotely & 4 & $65 \%$ & $64 \%$ & $68 \%$ & $67 \%$ & $64 \%$ & $67 \%$ & $66 \%$ \\
\hline 1.2 & 10 & improves the quality of data in the database & 4 & $65 \%$ & $53 \%$ & $67 \%$ & $60 \%$ & $64 \%$ & $77 \%$ & $64 \%$ \\
\hline 1.2 & 14 & decreases the time it takes to undertake tasks & 4 & $65 \%$ & $69 \%$ & $57 \%$ & $67 \%$ & $52 \%$ & $73 \%$ & $64 \%$ \\
\hline 1.3 & 28 & adds time and cost to managing the shared documents & 4 & $50 \%$ & $69 \%$ & $50 \%$ & $63 \%$ & $72 \%$ & $67 \%$ & $62 \%$ \\
\hline \multirow[t]{2}{*}{1.3} & 20 & increases the number of versions of documents & 4 & $55 \%$ & $67 \%$ & $45 \%$ & $73 \%$ & $56 \%$ & $63 \%$ & $60 \%$ \\
\hline & & Mean value $\mathrm{Cb}$ Scale Four & & $67 \%$ & $75 \%$ & $72 \%$ & $73 \%$ & $75 \%$ & $76 \%$ & $73 \%$ \\
\hline 2.1 & 76 & the project team requires a level of trust in order to successfully operate & 5 & $80 \%$ & $93 \%$ & $87 \%$ & $80 \%$ & $84 \%$ & $87 \%$ & $85 \%$ \\
\hline 2.1 & 77 & trust is not important in stakeholder management & 5 & $65 \%$ & $93 \%$ & $80 \%$ & $83 \%$ & $88 \%$ & $90 \%$ & $83 \%$ \\
\hline
\end{tabular}




\begin{tabular}{|c|c|c|c|c|c|c|c|c|c|c|}
\hline $\begin{array}{l}\text { Likert } \\
\text { Section }\end{array}$ & $\begin{array}{l}\text { Qu. } \\
\text { No. }\end{array}$ & Statement & $\begin{array}{l}\text { Cb Scale } \\
\text { CODE }\end{array}$ & $\underset{n=6}{\mathbf{D}}$ & $\underset{n=9}{\mathbf{V}}$ & $\underset{n=12}{\mathbf{M}}$ & $\underset{n=6}{\mathbf{C}}$ & $\underset{n=5}{\mathbf{S}}$ & $\underset{n=6}{\mathbf{K}}$ & $\begin{array}{c}\text { Agg } \\
\text { sorted } \\
n=42\end{array}$ \\
\hline 2.1 & 79 & trust is important when sharing knowledge across the project areas & 5 & $75 \%$ & $91 \%$ & $83 \%$ & $80 \%$ & $84 \%$ & $80 \%$ & $82 \%$ \\
\hline 2.4 & 104 & trust is not essential to developing and maintaining Strategic Alliances & 5 & $75 \%$ & $84 \%$ & $73 \%$ & $77 \%$ & $76 \%$ & $90 \%$ & $79 \%$ \\
\hline 2.1 & 82 & trust is not required in the project management environment & 5 & $70 \%$ & $89 \%$ & $72 \%$ & $70 \%$ & $84 \%$ & $90 \%$ & $79 \%$ \\
\hline 2.1 & 80 & $\begin{array}{l}\text { trust is required between stakeholders in order to achieve project objectives / } \\
\text { deliverables }\end{array}$ & 5 & $80 \%$ & $80 \%$ & $82 \%$ & $77 \%$ & $76 \%$ & $80 \%$ & $79 \%$ \\
\hline 2.1 & 75 & my team members trust me & 5 & $80 \%$ & $78 \%$ & $80 \%$ & $77 \%$ & $80 \%$ & $77 \%$ & $79 \%$ \\
\hline 2.1 & 74 & I trust my team members & 5 & $80 \%$ & $80 \%$ & $80 \%$ & $73 \%$ & $80 \%$ & $77 \%$ & $78 \%$ \\
\hline 2.1 & 78 & negotiations depend on the presence of trust & 5 & $75 \%$ & $89 \%$ & $83 \%$ & $73 \%$ & $72 \%$ & $77 \%$ & $78 \%$ \\
\hline 1.3 & 22 & requires a level of trust between team members & 5 & $80 \%$ & $80 \%$ & $67 \%$ & $70 \%$ & $80 \%$ & $87 \%$ & $77 \%$ \\
\hline 1.2 & 18 & requires a level of trust between team members & 5 & $80 \%$ & $78 \%$ & $68 \%$ & $73 \%$ & $76 \%$ & $87 \%$ & $77 \%$ \\
\hline 2.5 & 110 & the distribution of knowledge amongst team members is central to trust & 5 & $75 \%$ & $80 \%$ & $73 \%$ & $70 \%$ & $76 \%$ & $77 \%$ & $75 \%$ \\
\hline 2.4 & 106 & stakeholder management is not improved when using OCT & 5 & $65 \%$ & $71 \%$ & $72 \%$ & $67 \%$ & $76 \%$ & $77 \%$ & $71 \%$ \\
\hline 1.4 & 37 & reduces the need for alliances/relationships across the project environment & 5 & $60 \%$ & $82 \%$ & $62 \%$ & $67 \%$ & $76 \%$ & $77 \%$ & $71 \%$ \\
\hline 1.1 & 9 & detracts from managing Strategic alliances within the project team & 5 & $70 \%$ & $78 \%$ & $60 \%$ & $63 \%$ & $72 \%$ & $73 \%$ & $69 \%$ \\
\hline 2.4 & 102 & strategic alliances can be strengthened using the OCT & 5 & $65 \%$ & $80 \%$ & $67 \%$ & $67 \%$ & $64 \%$ & $73 \%$ & $69 \%$ \\
\hline 1.1 & 6 & assists with the development of trust across the project team & 5 & $75 \%$ & $73 \%$ & $65 \%$ & $67 \%$ & $64 \%$ & $70 \%$ & $69 \%$ \\
\hline 2.3 & 97 & members of the project team need to feel equal & 5 & $65 \%$ & $73 \%$ & $72 \%$ & $63 \%$ & $56 \%$ & $70 \%$ & $67 \%$ \\
\hline 1.4 & 32 & develops trust between team members & 5 & $70 \%$ & $69 \%$ & $68 \%$ & $60 \%$ & $60 \%$ & $67 \%$ & $66 \%$ \\
\hline 1.3 & 26 & develops an equality amongst the team members & 5 & $65 \%$ & $69 \%$ & $65 \%$ & $63 \%$ & $68 \%$ & $63 \%$ & $66 \%$ \\
\hline 1.4 & 42 & assists with negotiations within the project management environment & 5 & $70 \%$ & $73 \%$ & $63 \%$ & $57 \%$ & $60 \%$ & $60 \%$ & $64 \%$ \\
\hline 1.6 & 62 & develops relationships with team members & 5 & $55 \%$ & $71 \%$ & $57 \%$ & $60 \%$ & $76 \%$ & $57 \%$ & $63 \%$ \\
\hline 1.1 & 8 & supports equality amongst team members & 5 & $65 \%$ & $62 \%$ & $65 \%$ & $60 \%$ & $60 \%$ & $60 \%$ & $62 \%$ \\
\hline 1.6 & 56 & makes it hard to establish trust between team members & 5 & $50 \%$ & $64 \%$ & $58 \%$ & $63 \%$ & $72 \%$ & $60 \%$ & $61 \%$ \\
\hline 1.5 & 46 & requires team members to trust each other & 5 & $70 \%$ & $58 \%$ & $60 \%$ & $63 \%$ & $60 \%$ & $57 \%$ & $61 \%$ \\
\hline 1.5 & 45 & develops relationships with team members & 5 & $65 \%$ & $67 \%$ & $55 \%$ & $50 \%$ & $64 \%$ & $67 \%$ & $61 \%$ \\
\hline 2.4 & 107 & OCT delivers the incentives needed to manage Strategic Alliances & 5 & $60 \%$ & $62 \%$ & $65 \%$ & $60 \%$ & $56 \%$ & $57 \%$ & $60 \%$ \\
\hline 2.1 & 84 & OCT facilitates trust amongst team members & 5 & $60 \%$ & $69 \%$ & $55 \%$ & $57 \%$ & $48 \%$ & $67 \%$ & $59 \%$ \\
\hline 2.3 & 100 & team members do not need to feel equal in order to contribute & 5 & $60 \%$ & $56 \%$ & $57 \%$ & $57 \%$ & $48 \%$ & $60 \%$ & $56 \%$ \\
\hline \multirow{2}{*}{2.1} & 83 & collaboration can be achieved without trust & 5 & $55 \%$ & $33 \%$ & $40 \%$ & $63 \%$ & $36 \%$ & $30 \%$ & $43 \%$ \\
\hline & & Mean value $\mathrm{Cb}$ Scale Five & & $69 \%$ & $74 \%$ & $68 \%$ & $67 \%$ & $69 \%$ & $71 \%$ & $70 \%$ \\
\hline 2.7 & 123 & without incentives, information sharing would not occur & 6 & $55 \%$ & $80 \%$ & $72 \%$ & $73 \%$ & $80 \%$ & $67 \%$ & $71 \%$ \\
\hline 1.6 & 59 & discourages innovation and learning across the team & 6 & $60 \%$ & $78 \%$ & $60 \%$ & $63 \%$ & $76 \%$ & $70 \%$ & $68 \%$ \\
\hline 2.6 & 118 & incentives are central to negotiations & 6 & $60 \%$ & $69 \%$ & $73 \%$ & $63 \%$ & $64 \%$ & $73 \%$ & $67 \%$ \\
\hline 2.7 & 122 & OCT reduce the need for incentives in the project environment & 6 & $60 \%$ & $69 \%$ & $62 \%$ & $73 \%$ & $72 \%$ & $57 \%$ & $65 \%$ \\
\hline \multirow[t]{2}{*}{2.7} & 121 & incentives are a prerequisite to sharing information & 6 & $55 \%$ & $49 \%$ & $60 \%$ & $43 \%$ & $40 \%$ & $63 \%$ & $52 \%$ \\
\hline & & Mean value $\mathrm{Cb}$ Scale Six & & $58 \%$ & $69 \%$ & $65 \%$ & $63 \%$ & $66 \%$ & $66 \%$ & $65 \%$ \\
\hline 2.6 & 120 & negotiations between stakeholders is aided when parties trust each other & 7 & $75 \%$ & $91 \%$ & $80 \%$ & $80 \%$ & $84 \%$ & $87 \%$ & $83 \%$ \\
\hline 2.6 & 116 & negotiation is an integral part of managing stakeholders & 7 & $80 \%$ & $87 \%$ & $80 \%$ & $73 \%$ & $88 \%$ & $73 \%$ & $80 \%$ \\
\hline \multirow[t]{2}{*}{2.6} & 119 & OCT hamper the negotiation process with stakeholders & 7 & $65 \%$ & $73 \%$ & $63 \%$ & $63 \%$ & $76 \%$ & $70 \%$ & $69 \%$ \\
\hline & & Mean value Cb Scale Seven & & $73 \%$ & $84 \%$ & $74 \%$ & $72 \%$ & $83 \%$ & $77 \%$ & $77 \%$ \\
\hline
\end{tabular}




\section{A16. Organisation D comparative overview of the Prince2 and Departmental Project Management Methodology}

Table 11-9: Organisation D comparative overview of the Prince2 and Departmental Project Management Methodology

\begin{tabular}{|c|c|c|c|}
\hline Prince2 & Description & Departmental PMM & Description \\
\hline $\begin{array}{l}\text { Process 1: Starting up a } \\
\text { project }\end{array}$ & $\begin{array}{l}\text { This phase describes the work to be completed before the project should } \\
\text { commence. It should include an idea or request that identifies the project, } \\
\text { which triggers the creation of a Project Manager who reports to a Project } \\
\text { Board. The terms of reference for the project are set and a project brief } \\
\text { drafted which contains amongst other things, the justification for the project. }\end{array}$ & Project Conception & $\begin{array}{l}\text { This section introduces the concept of the Project Mandate document and } \\
\text { Project sizing including a brief mention of scope. }\end{array}$ \\
\hline $\begin{array}{l}\text { Process 2: Initiating the } \\
\text { Project }\end{array}$ & $\begin{array}{l}\text { This phase describes the activities that need to be carried out by the project } \\
\text { manager after the initial request (in the previous phase) has been approved. } \\
\text { The project brief is now developed into the Project Initiation Document } \\
\text { which acts as the commencement of the business case for the project, and } \\
\text { includes preliminary planning schedule and risk evaluation. The Project } \\
\text { initiation Document (PID) also specifies the products which are to be } \\
\text { delivered and the quality measures around these. The PID is a mechanism to } \\
\text { draft a project agreement between the Project Manager and Project Board. }\end{array}$ & Project Preparation & $\begin{array}{l}\text { This section addresses two key areas including Project Start-up and Project } \\
\text { Initiation. } \\
\text { Project Start-Up includes project organisation, stakeholder analysis, } \\
\text { preparing documentation including the Project Brief, Business Case, Project } \\
\text { Approach and Risk Log. } \\
\text { Project Initiation includes preparation of a Quality Plan, Project Definition, } \\
\text { Project Plan and Communication Plan. It also includes defining the project } \\
\text { controls and preparing a Stage Plan. It is in this section that Logs are } \\
\text { commenced including Quality Logs, Issue Logs and the Lessons Learned } \\
\text { Log. }\end{array}$ \\
\hline $\begin{array}{l}\text { Process 3: Controlling a } \\
\text { stage }\end{array}$ & $\begin{array}{l}\text { This phase describes the everyday work of the Project Manager and details } \\
\text { those components that monitor quality, project changes and monitoring } \\
\text { progress. }\end{array}$ & \multirow[t]{2}{*}{ Project Implementation } & $\begin{array}{l}\text { The Project Implementation section addresses three main areas including } \\
\text { Controlling a Stage, Managing Product Delivery and Managing Stage } \\
\text { Boundaries. }\end{array}$ \\
\hline $\begin{array}{l}\text { Process 4: Managing } \\
\text { Product Delivery }\end{array}$ & $\begin{array}{l}\text { This phase covers those tasks and products that are undertaken by Project } \\
\text { staff. The product is a component of the Prince } 2 \text { methodology where the } \\
\text { product descriptions define the deliverables of the project. There are three } \\
\text { main types of products including Specialist products, Management products } \\
\text { and Quality products. Specialist products are the intermediate products that } \\
\text { are generated by the project for the host organisation such as specifications, } \\
\text { software modules, a contract or a manual. Management products are those } \\
\text { products which are created to support the project management process, such } \\
\text { as the project brief, PID and initiation document. The Quality products are } \\
\text { those that manage the quality assurance components of the project. }\end{array}$ & & $\begin{array}{l}\text { Controlling a Stage includes reviewing the stage status of the project and } \\
\text { managing risk, issues and quality concerns of the project. This area also } \\
\text { includes preparation of the Highlight and Checkpoint Report, and managing } \\
\text { any change that has been introduced into the project (which might necessitate } \\
\text { an Exception Report). } \\
\text { Managing Product Delivery includes creating, executing and completing } \\
\text { defined pieces of work called work packages and which is related to the } \\
\text { delivery of one or more products. } \\
\text { Managing Stage Boundaries identifies and signifies the closing of one stage } \\
\text { of the project and the commencement of another. This area includes the } \\
\text { review of documentation for the project, reporting on the end of a stage of the } \\
\text { project, and producing an Exception Plan if required. }\end{array}$ \\
\hline
\end{tabular}




\begin{tabular}{|c|c|c|c|}
\hline Prince2 & Description & Departmental PMM & Description \\
\hline $\begin{array}{l}\text { Process 5: Managing the } \\
\text { Stage Boundary }\end{array}$ & $\begin{array}{l}\text { This phase of the process entails the Project Board providing information at } \\
\text { key decision points i.e. the beginning and end of a stage of work. This focus } \\
\text { on the boundaries of activities enables reporting to be undertaken on the } \\
\text { current state of the project, which may include an assessment of the business } \\
\text { case, the project's risks and overall status of the project. It is at this time that } \\
\text { the Project Board may also want to review the continuation of the project. }\end{array}$ & & \\
\hline $\begin{array}{l}\text { Process 6: Closing the } \\
\text { Project }\end{array}$ & $\begin{array}{l}\text { This process ensures that there is a structured conclusion of the project and } \\
\text { that there is a formal handover of the final products to the users and the } \\
\text { organisation. This is also the time when reports are drafted that detail lessons } \\
\text { learnt on the project and recommendations for follow-up activities. }\end{array}$ & Project Closure & $\begin{array}{l}\text { This section covers the work that the Project Manager needs to complete in } \\
\text { order to finish the project. It includes formal acceptance by the customer of } \\
\text { the project deliverables, and the preparation of several plans including a Post } \\
\text { Project Review Plan, Follow on Actions, Lessons Learned Report and the } \\
\text { End Project Report. }\end{array}$ \\
\hline Process 7: Planning & $\begin{array}{l}\text { This process is used by the other processes to formulate the delivery and } \\
\text { outline the project plan. }\end{array}$ & Project Planning & $\begin{array}{l}\text { The Planning section provides for the project plan to be broken down into } \\
\text { lower level plans which contain more details, but which all relate to the } \\
\text { original planned requirements of the project. The Departmental PMM guide } \\
\text { approach is that the lower the plan level, the shorter the plan's timeframe and } \\
\text { the more specific detail it contains. There are three levels of plan - the } \\
\text { Project Plan, the Stage Plan and the Team Plan. } \\
\text { This section covers designing the plan required; defining the products that } \\
\text { will match the plans; identifying activities and dependences of the sequence } \\
\text { of products to be delivered; estimating resources and time for each activity; } \\
\text { and creating the project schedule to ensure the project objectives are achieved } \\
\text { on time, to the budget available, and to the required quality. }\end{array}$ \\
\hline $\begin{array}{l}\text { Process 8: Directing the } \\
\text { Project }\end{array}$ & $\begin{array}{l}\text { This process describes the role of the Project Board, which has several } \\
\text { functions including authorisation of the initial Project and subsequent stages } \\
\text { of the project, providing timely advice, and providing guidance to the project } \\
\text { management regarding the extent to which the role may act independently } \\
\text { from the Project Board. }\end{array}$ & Project Direction & $\begin{array}{l}\text { This section addresses the roles and responsibilities of senior management } \\
\text { within the project environment and therefore covers off issues such as the } \\
\text { operation of the project board, authorisation of the initiation of the project } \\
\text { process and the subsequent project, providing ad hoc advise, authorising the } \\
\text { next stages and confirming when the project closure processes. }\end{array}$ \\
\hline
\end{tabular}




\section{A17. Organisation M Project Management Framework}

1. Introduction

a. Purpose and Objectives

b. Guidelines for Use and Review

c. Glossary of Terms

d. Documentation and Information Management

e. Library

2. Organisational and Operational Parameters

a. Org M Governance Framework

b. Org M Organisational Structure

c. WOG Systems \& Reporting

i. Ministerial Briefing and Correspondence

ii. Cabinet Submissions

d. DoI Services and Interface

e. Approval Processes and Delegations

i. Gateway Review Process

ii. PRC Process

3. Project Initiation \& Feasibility

a. Introduction

b. Clients \& Stakeholders

i. Client \& Stakeholder Identification

ii. Client Management

iii. Stakeholder Management

c. Project Governance Development

i. Factors for Success

ii. Typical Governance Structure

iii. Roles \& Responsibilities

iv. Memorandums of Understanding

d. Project Definition

i. Setting Project Objectives

ii. Developing the Project Brief

e. Project Feasibility

i. Master Plan

ii. Business Case

iii. Design Concepts

iv. Cost Plan

4. Project Planning

v. Consultant Investigation Reports

a. Client Functional Brief

b. Engagement of Project Consultants

i. MPV Panel

c. Project Management Plan

d. Project Procurement Strategy

e. Project Orders

f. Project Cost Planning \& Control

g. Risk Management

h. Resource Management

i. Time Management

j. OH \& S Guidelines

k. Quality Management

1. Statutory Planning Requirements \& Government Policy

m. ESD

n. Probity Plan

o. Stakeholder/ User Management

p. Communications Plan

q. Industrial Relations 
5. Design \& Documentation Management

a. Engagement of Design Professionals

i. List of Potential Consultants

ii. Control, Coordination, Reviewing \& Verifying Sub-consultant Works

b. Design Phases

i. Design Operations Continuum

ii. Master Planning \& Concept Development (covered in more detail in section 2)

iii. Schematic Design

iv. Design Development

v. Construction Documentation

c. Design Management Tools

i. Development Application

ii. Schedules of Accommodation

iii. User Consultation Process \& Management

iv. Room Data Sheets

v. Value Management Reviews/ Design Reviews/ Peer Reviews

vi. Constructability Reviews

vii. Authorities/ Standards (Federal/ State/ Local)

viii. Building Certification

ix. OH \& S Reviews

$\mathrm{x}$. Accessibility

xi. ESD

xii. Quality Assurance

xiii. Reporting \& Meetings

xiv. Design Change Process/ Requests for Change

xv. Community Consultation

xvi. Whole of Life/ Recurrent Costs

6. Tender Process
a. Introduction
b. Pre-Qualification of Tenderers
c. Preparation and Review of the Tender Documentation
d. Tender Preparation
e. Tender Evaluation and Clarification
f. Preparation and Approval of the Tender Evaluation Procedures
g. Selection of the Preferred Tenderer
h. Proceeding to Contract
i. De-briefing unsuccessful tenderers
j. The Independent Probity Auditor's role in the process
k. The output from the Tender Process
a. Law In Australia - overview
i. Origins of Australian Law - Common Law/Legislation
ii. Australian Legal System - State/Federal Courts
iii. Court Actions/Commercial Arbitration/Alternative Dispute Resolution
b. Contract Principles
i. The elements of a Contract
1. General -5 elements to a Contract
ii. Formation Of the Contract
1. Types of Contracts
a. Standard Form Contracts
b. Fixed-Price Contracts/Cost-Plus Contracts
c. Consultant Contracts
iii. Risk Allocation
d. Supply Contracts
iv. The Department's Policy on Contracting
c. Rules of Construction
d. Contract Administration Phase - Scope of Services
e. Contract Administration Management Systems
i. Affinitext

7. Contract Management \& Administration 
ii. Aconex

iii. Other Time \& Cost Systems to assist Contract Management \& Contract Administration

1. Cost Management

a. Timberline

b. Prolog

c. Other

2. Time Management
a. MS Project
b. Primavera
c. Other

3. Documentation Management

a. Project Wise

b. Other

4. Defects Management
a. Blueprint

b. Other

f. The Major Standard Form Contract Terms

i. The Contract Sum

1. Contingencies

ii. Contract Documents

1. Prepared by the Principal

a. Formal Instrument of Agreement

b. The Contract

c. Construction Documentation, Specs \& Schedules

d. Bill of Quantities, Schedule of Rates

2. Prepared by the Contractor

a. Shop Drawings

b. As Built Drawings

c. Operation \& Maintenance Manuals

iii. Roles, Responsibilities \& Obligations

1. Principal \& Principal's Representative

2. Contractor \& Contractor's Representative

3. Superintendent \& Contractor's Representative

4. Dual Role of the Superintendent

5. Certifier

6. Clerk of Works

iv. The Site

1. Date for Possession

2. Extent of "The Site" \& Setting Out

3. Site Conditions

4. Latent Conditions

v. Statutory Notices \& Fees

vi. Time and Performance

1. The Contractor's Program \& Methods

2. Counting of Days

3. Extensions of Time

4. Delay \& Cost of Delay

5. Acceleration \& Cost of Acceleration

6. Liquidated Damages

vii. Material \& Workmanship

1. Warranties

2. Defects

3. Defect Liability Period

4. Rectification Costs

5. Inspection \& Testing

viii. Subcontracting \& Assignment

1. Nominated Subcontractors \& Suppliers

2. Selected Subcontractors \& Suppliers

ix. Indemnities \& Insurance 
1. Care of the Works

2. Care of the Surroundings

3. Workcover

x. Adjustment of the Contract Sum

1. Provisional Allowances

2. Rise and Fall

3. Errors in Bills \& Schedules

xi. Variations

1. Contract Variations

2. Valuation

3. Power to order variations

4. Instruction for Variations

5. Recovery without written orders

6. Additional works and omissions

xii. Security \& Retention

xiii. Certificates \& Payment

1. Security of Payments Act

2. Progress Claims

3. Payment Schedules

4. Final Payment Schedule

xiv. Completion

1. Practical Completion

2. Occupation Prior to Practical Completion

3. Final Completion

4. Settlement of Disputes

g. Key Contract Administration Issues

i. Role of the Superintendent

ii. Time

iii. Payment

iv. Quality

v. Misrepresentation

vi. Mistake

vii. Duress/Unconscionable Contract

viii. Default/Termination

h. Non-Contract Remedies

i. Negligence

ii. Misleading and Deceptive Conduct/Trade Practices Act

iii. Restitution

iv. Estoppel/Quantum Meruit

i. Contract Communication Plan

8. Project Reporting

a. Client Reporting

b. Programme Reporting

c. Financial Reporting

d. Contractor's Reports

e. Consultant's Reports

f. Government Reporting

9. Project Completion \& Handover

a. Project Close Out

b. Project Finalisation Plan

i. Building Commissioning

ii. Handover to Client

iii. Defects Liability Period

iv. Final Completion

c. Operational Commissioning

d. Records Disposal / Transfer

e. Knowledge Transfer Process

i. After Action Reviews

f. Post-Occupancy Reviews 


\section{A18. Organisation M Project Plan and Procurement Strategy}

Project Plan and Procurement Strategy

TABLE OF CONTENTS

1.0 INTRODUCTION

1.1 Purpose of this document

2.0 PROJECT SCOPE AND DESCRIPTION OF THE WORKS

2.1 Client One

2.2 Client One - business and operational planning.

2.3 Client Two

2.4 Client Two - business and operational planning

2.5 Benchmarking

\subsection{PROJECT INTEGRATION AND MANAGEMENT}

3.1 Project Responsibility

3.2 Responsible Minister

3.3 Project Client

3.4 Project Operator / End User Client One

3.5 Project Operator / End User Client Two

3.6 Project Organisational Chart

\subsection{PROJECT LIFE CYCLE}

5.0 ROLES AND RESPONSIBILITIES OF CLIENTS AND MANAGERS

5.1 Project Control Group 1 (PCG) Chaired by Organisation M

5.2 Project Control Group 2 (PCG) Chaired by Organisation M

5.3 Role of Client / Operator / End User

5.4 Role of Client / Operator / End User

5.5 Role of the funding agent

5.6 Role of Organisation M

5.7 Role of Specialist Consultants

\subsection{PROJECT COST MANAGEMENT}

6.1 Project funding

6.2 Cost control

\subsection{PROJECT PROGRAMME AND TIME MANAGEMENT}

7.1 Time Management

7.2 Project Programme

8.0 PROCUREMENT STRATEGY - DESIGN AND CONSTRUCTION

8.1 Procurement Strategy - Design

8.2 Procurement Strategy - Construction

8.3 Preferred Procurement Strategy - Construction

8.4 Project status

8.5 Design Development and Contract Documentation

8.6 Tendering

8.7 Construction and fitout

9.0 PROJECT QUALITY MANAGEMENT

10.0 PROJECT HUMAN RESOURCE MANAGEMENT

11.0 PROJECT RISK MANAGEMENT

12.0 PROJECT COMMUNICATION MANAGEMENT

13.0 PROJECT DOCUMENT MANAGEMENT

14.0 APPENDICES 


\section{A19. Organisation S I.T. Project Lifecycle}

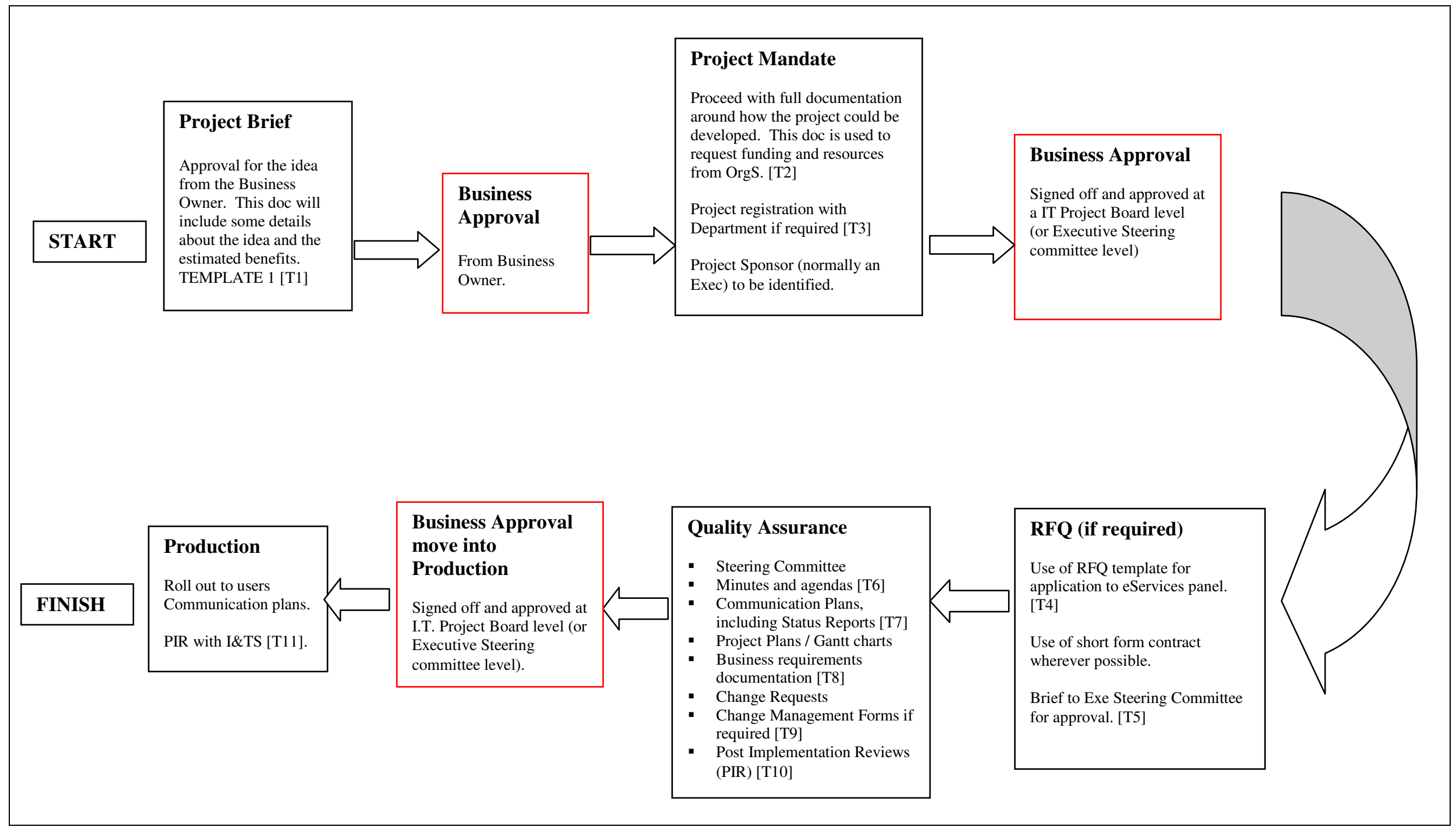

Figure 11-12: Organisation S I.T. Project Lifecycle 


\section{A20. Organisation K Values and Principles.}

The alliance values are expressed as follows:

- we will uphold ethical standards, maintain respect for ourselves, each other and our surroundings

- we will strive to improve our physical \& psychological well-being

- we will preserve and protect the health and safety of all those that come into contact with the project

- we will strive to instil a passion within our work that drives the project to success

- our collective effort will drive excellence so that we can be as good as we can be

- we all have a right to a quality of life and appropriate work-life balance.

The Alliance also has a list of principles that guide the management of the environment. These principles are expressed as follows:

- to be consistent with the Alliance Values

- a primary focus on satisfying project objectives and delivering outstanding outcomes

- all Alliance participants win, or all Alliance participants lose, depending on project outcomes actually achieved

- all decisions will be made on a 'best for project' basis

- a commitment to innovative thinking and continuous improvement

- clear responsibilities exist, within a 'no blame \& no surprises' culture and the confidence to act

- open, straight and honest communication, mindful of other people's perspectives

- all transactions are fully open book. 